Tesis de doctorado en Historia

LA REFORMA UNIVERSITARIA DESDE SUS GRUPOS Y REVISTAS

UNA RECONSTRUCCIÓN DE LOS PROYECTOS Y LAS DISPUTAS DEL MOVIMIENTO ESTUDIANTIL PORTEÑO DE LAS PRIMERAS DÉCADAS DEL SIGLO XX (1914-1928)

Doctoranda: Natalia Bustelo Director: Horacio Tarcus Co-directora: Alejandra Mailhe Buenos Aires, noviembre de 2014 


\section{LA REFORMA UNIVERSITARIA DESDE SUS GRUPOS Y REVISTAS UNA RECONSTRUCCIÓN DE LOS PROYECTOS Y LAS DISPUTAS DEL MOVIMIENTO ESTUDIANTIL PORTEÑO DE LAS PRIMERAS DÉCADAS DEL SIGLO XX (1914-1928)}

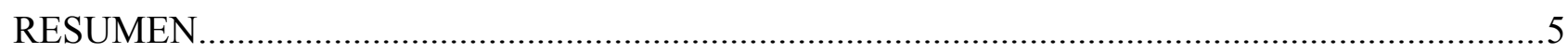

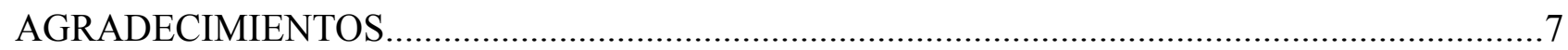

INTRODUCCIÓN

La Reforma Universitaria como movimiento político-cultural................................................. 8

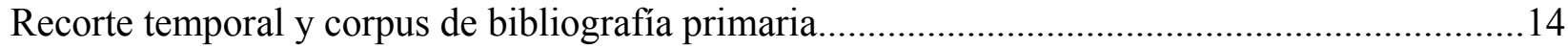

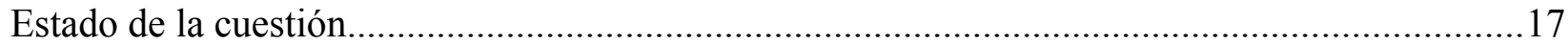

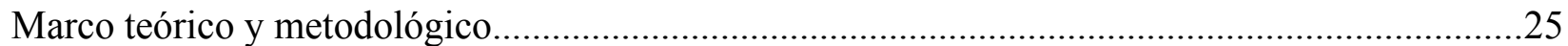

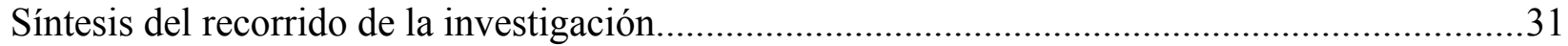

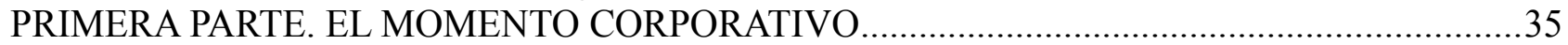

CAPÍTULO 1. La construcción de una "familia estudiantil"............................................................36

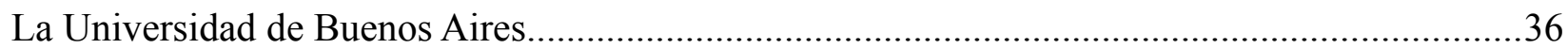

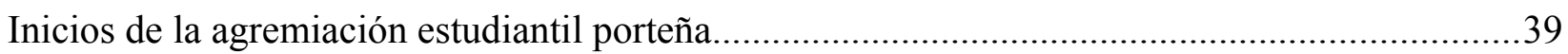

La agremiación estudiantil argentina, uruguaya y americana................................................42

La identidad de los universitarios porteños: ¿socialistas científicos, idealistas estéticos o católicos

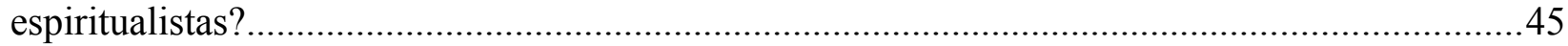

Las primeras revistas culturales de los estudiantes porteños.................................................49

1914. El despuntar del estudiante como un tipo de intelectual...............................................51

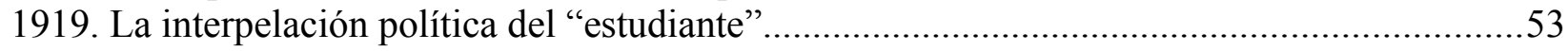

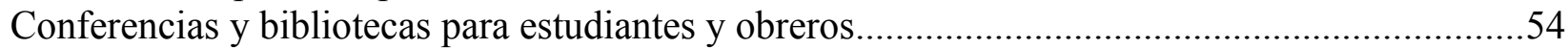

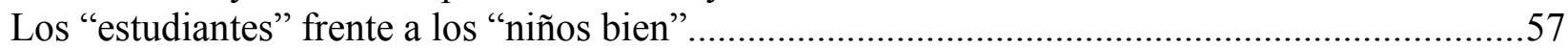

Capítulo 2. Los "revisteros descontentadizos" de Buenos Aires......................................................62

José Enrique Rodó, "maestro de la juventud americana".........................................................62

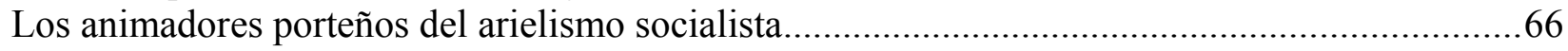

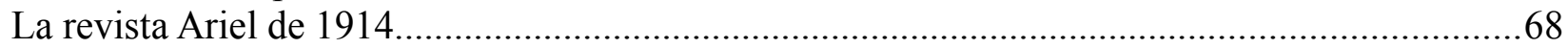

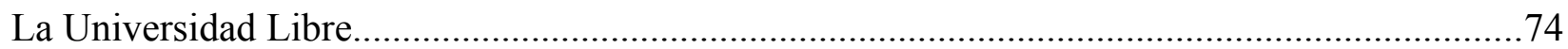

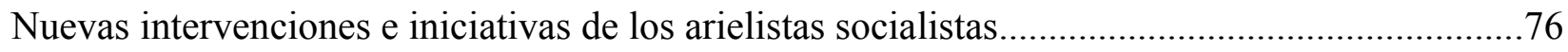

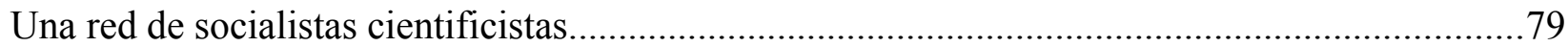

El Ateneo de Estudiantes Universitarios de Buenos Aires (1914-1920)....................................80

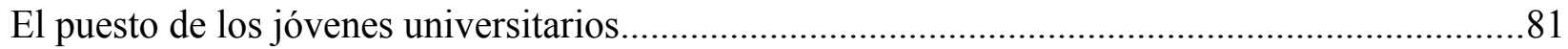

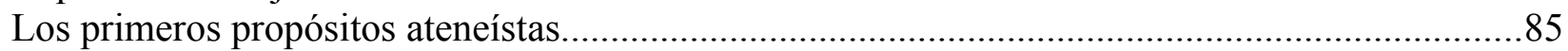

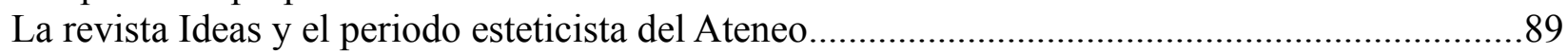

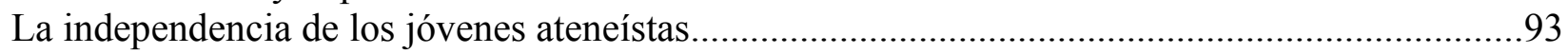

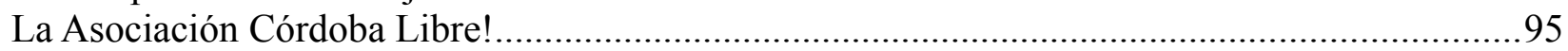

Ideas, la armadora de la primera red de revistas estudiantiles.................................................. 98

Capítulo 3. Naves españolas en el puerto de la Reforma Universitaria.......................................101

La Renovación Española en la cultura universitaria porteña.................................................102

El periodismo político del semanario España y sus hermanas menores americanas....................105

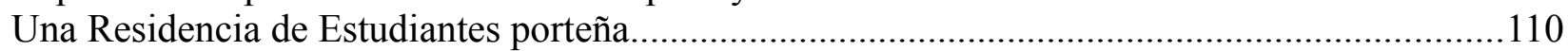

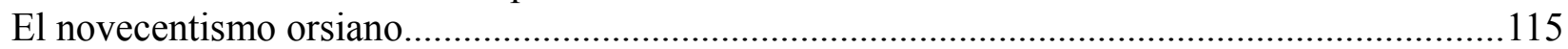

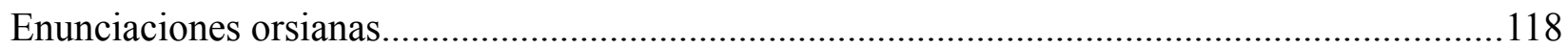

Los orsianos porteños (1917-1923) .................................................................................. 121

Capítulo 4. La fillosofía, ¿aliada de la ciencia o de la literatura? Debates sobre la racionalidad y el compromiso político en el proceso de profesionalización de los estudios filosóficos....................125

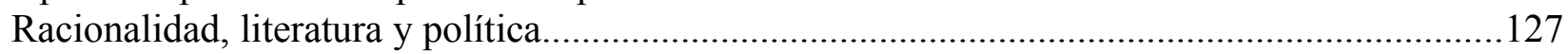

La “desinteresada” Facultad de Filosofía y Letras de Buenos Aires.........................................129

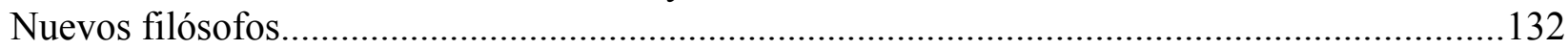


Verbum y la disputa por la resonancia social de la filosofía ...................................................135

El arielismo socialista en el Centro de Estudiantes de Filosofía y Letras.................................144

Filosofía novecentista y expresión poética............................................................................151

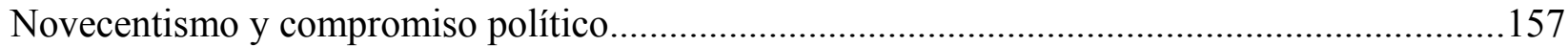

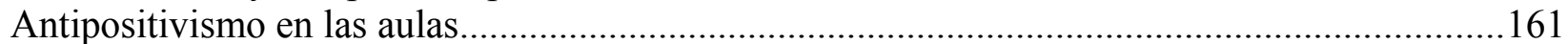

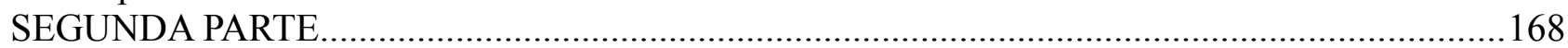

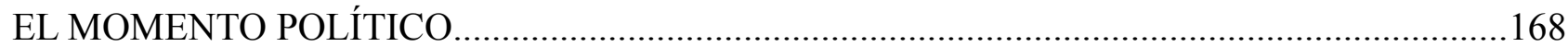

Capítulo 5. La revolución universitaria de 1918, o la inscripción de la sociabilidad estudiantil en

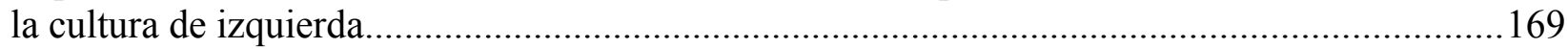

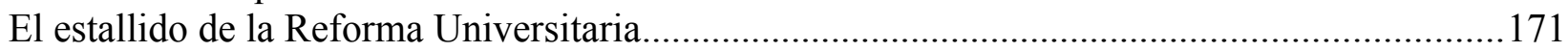

1918 y la primera articulación de los estudiantes revolucionarios.............................................179

Los ateneístas y los novecentistas porteños frente a la política...............................................197

Themis (1918-1919), la revista izquierdista de los estudiantes de Derecho ............................209

Capítulo 6. Los ladrillos de la gran casa del porvenir social. Los periódicos internacionalistas de

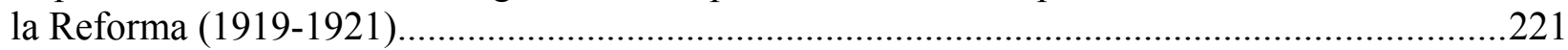

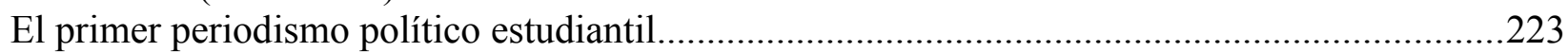

Clarín, o el arribo al Ateneo de la "pérfida política"............................................................226

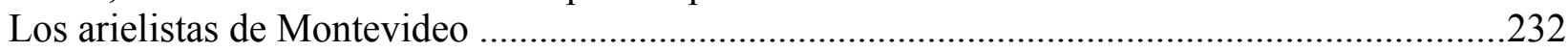

Ariel, aliada del ala radicalizada de la Reforma.....................................................................236

Bases, la primer tribuna de la juventud revolucionaria porteña.............................................241

El llamado a la juventud porteña a aliarse al movimiento obrero.............................................246

Insurrexit y Hoy, o las primeras tensiones estudiantiles entre comunistas y socialistas.............250

La apuesta por una federación estudiantil revolucionaria...................................................25

CAPÍTULO 7. Fragmentos de la construcción de una universidad científica y social (1918-1923)

La dimensión institucional de la Reforma Universitaria........................................................263

Eugenio d'Ors, el filósofo de la reacción antipositivista.......................................................271

Eugenio d'Ors, el filósofo de la revolución universitaria......................................................28

Georg Nicolai y Alfons Goldschmidt, los maestros cientificistas y revolucionarios..................283

La Facultad porteña de Derecho y la Reforma Universitaria..................................................297

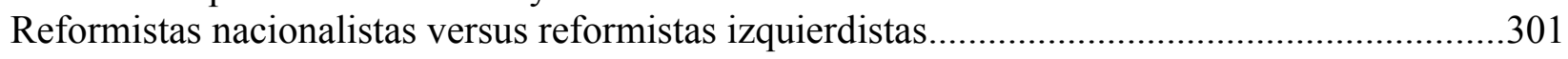

La llegada del reformismo a la gestión de la Facultad de Derecho.............................................310

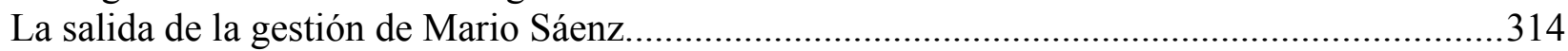

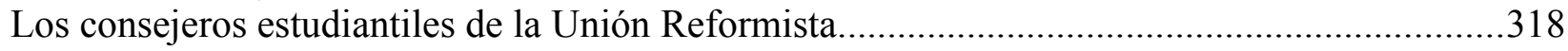

Cambios institucionales, cambios de fuerzas políticas.........................................................321

CAPÍTULO 8. La Reforma Universitaria como identidad antiimperialista latinoamericana (1923-

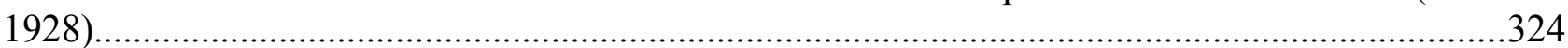

Los primeros intentos de proyectar políticamente el movimiento reformista argentino..............326

La identidad reformista en disputa: ¿vanguardismo estético-político, reacción antipositivista o

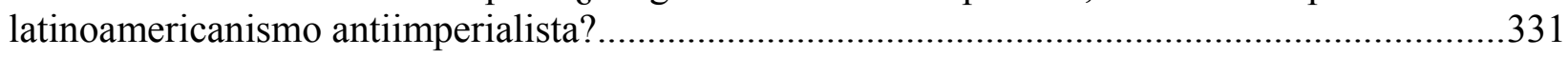

De la hora americana al antiimperialismo latinoamericano: el Primer Congreso Internacional de

Estudiantes, la revista Claridad de Lima y la gira sudamericana de Vasconcelos.......................337

El primer tramado de una red intergeneracional porteña de latinoamericanismo antiimperialista

Sagitario, la revista estudiantil de cultura de la Unión Latino-Americana..................................353

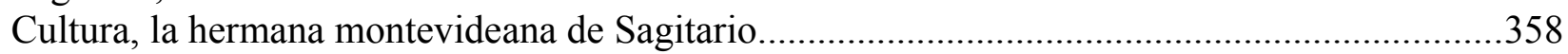

El Partido Unión Reformista Centro-Izquierda, la Asociación Cultural Universitaria y la

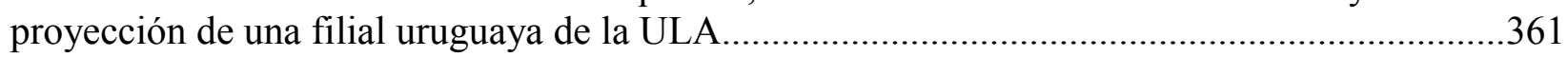

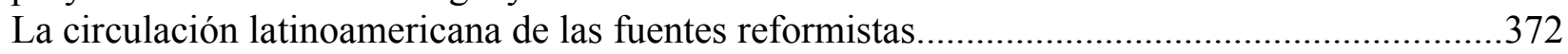

1928. El balance de los primeros diez años de la Reforma Universitaria..................................376

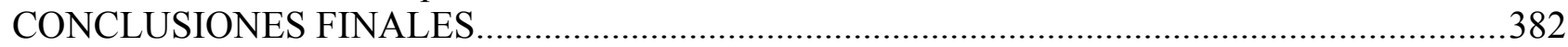

Las publicaciones estudiantiles como campo de estudio del movimiento estudiantil......................382 
ABREVIATURAS.

BIBLIOGRAFÍA.

388

Nosotros. Revista mensual de letras, arte, historia, filosofía y ciencias sociales (1907-1934), Buenos

Aires. 


\section{LA REFORMA UNIVERSITARIA DESDE SUS GRUPOS Y REVISTAS UNA RECONSTRUCCIÓN DE LOS PROYECTOS Y LAS DISPUTAS DEL MOVIMIENTO ESTUDIANTIL PORTEÑO DE LAS PRIMERAS DÉCADAS DEL SIGLO XX (1914-1928)}

\section{RESUMEN}

La presente investigación se propone recuperar la densidad ideológica y material del movimiento político-cultural que se gestó en la ciudad de Buenos Aires en el marco de la Reforma Universitaria (1914-1930), y se ocupa de precisar las conexiones que ese movimiento tramó con las expresiones registradas en las ciudades de Córdoba, La Plata, Montevideo, Rosario y Santa Fe. Para ello son colocados en el centro del análisis los grupos estudiantiles y sus publicaciones periódicas. A su vez, la investigación se propone iluminar el itinerario intelectual de varios líderes estudiantiles y reconstruye la recepción de las tres figuras extranjeras que llegaron a la Argentina convocadas por los reformistas, a saber, el filósofo catalán Eugenio d'Ors, el fisiólogo judeoalemán Georg Nicolai y el economista, también judeoalemán, Alfons Goldschmidt.

Si bien la investigación se apoya en los estudios previos sobre la Reforma Universitaria, la mayoría de los grupos, revistas y visitas aquí analizados permanecían muy poco explorados. Así, es fundamentalmente a través de un exhaustivo rastreo y análisis de las revistas, de los archivos personales y de la correspondencia de los protagonistas del movimiento estudiantil que la tesis busca iluminar todo un conjunto de prácticas, ideas y redes que terminaron conformando al estudiante como un nuevo actor de la sociedad moderna y a la Reforma Universitaria como un movimiento político-cultural de duradera proyección continental.

Los distintos capítulos de la tesis exploran las iniciativas de los estudiantes universitarios porteños desde la fundación, durante la primera década del siglo XX, de centros de estudiantes y revistas que expresaron reclamos estudiantiles de carácter gremial hasta la aparición de grupos y publicaciones estudiantiles que construyeron una identidad socialista o nacionalista de la juventud universitaria, pasando por agrupaciones de carácter fundamentalmente cultural. Si bien el foco está puesto en la construcción del movimiento político-cultural de la Reforma, también es analizado el debate en torno del positivismo que atraviesa el proceso de configuración reformista.

La primera parte de la tesis se concentra en la reconstrucción y el análisis de la sociabilidad e intervención propuestas por los tres grupos porteños que, en los años anteriores al estallido de la Reforma, más se empeñaron en la construcción de una identidad estudiantil que excediera los reclamos gremiales. Esos grupos son: el Centro Ariel y su revista Ariel; el Ateneo de Estudiantes Universitarios y su revista Ideas; y el Colegio Novecentista y sus Cuadernos. La segunda parte de la tesis se detiene en las estrategias culturales que desplegaron los grupos estudiantiles una vez que, 
hacia mediados de 1918, la Reforma y la coyuntura nacional e internacional instalaron entre los estudiantes una fuerte preocupación política. Si bien hacia 1928 quedó configurado un movimiento político-cultural reformista que, durante décadas, ligó al estudiante a una identidad latinoamericanista y antiimperialista, esta parte de la investigación muestra que en los diez años anteriores tuvieron lugar diversas empresas reformistas que propusieron asociar la figura del estudiante a identidades políticas tan diversas como el nacionalismo de resonancias católicas o el socialismo bolchevique. Entre esas olvidadas empresas, la presente tesis se detiene en la reconstrucción de la Federación de Asociación Culturales, de la Unión Reformista y de la Federación de Estudiantes Revolucionarios, así como de las revistas Clarín, Revista Nacional, Bases, Insurrexit y Hoy.

\section{PALABRAS CLAVE}

Reforma Universitaria - Revistas estudiantiles - Formaciones culturales estudiantiles - Historia intelectual y política 


\section{AGRADECIMIENTOS}

Esta investigación fue financiada por una beca doctoral del CONICET y es el punto de llegada del pasaje que fui realizando desde mi formación de grado en filosofía hacia la historia intelectual y la historia de los intelectuales. El inicio de ese pasaje fueron centrales Horacio Banega, quien con entusiasmo me dio su aval para inscribirme en la Maestría en Sociología de la Cultura, y a María Marta Quintana, una gran amiga que, con su certeza de que hay que hacerle hablar a la filosofía de problemáticas sociales, me convenció de iniciar juntas esta nueva etapa. Asimismo, quiero agradecer a Horacio Tarcus, quien, también con entusiasmo, me orientó en mi tesis de maestría y dirigió la presente investigación, ayudándome a precisar varias líneas y señalándome insistentemente la importancia de los archivos y las revistas. Además, me sumó al Seminario de Historia Intelectual y Recepción de Ideas, que dirige en el CeDInCI.

En las reuniones mensuales de ese seminario y las del Proyecto PICT "Publicaciones periódicas y proyectos editoriales de las formaciones intelectuales nacionales-populares y de izquierda en Argentina (1910-1980)" pude discutir cuestiones teórico-metodológicas y también varios capítulos de mi tesis. Agradezco entonces a mis compañeros de esas instancias, quienes con su lectura atenta e inquisidora me motivaron a tomar varias decisiones, y especialmente a la directora del PICT, Alejandra Mailhe, quien además co-dirigió esta investigación ofreciéndome incondicionalmente su tiempo y su aguda mirada, pero también un espacio de discusión y producción académica en el Proyecto de Investigación "Pensar al otro/Pensar la nación" que dirige en la UNLP.

Esta investigación está basada en una serie de fuentes primarias desperdigadas en distintas bibliotecas, archivos y colecciones personales. La reunión de esos materiales no hubiera sido posible sin la generosa disposición de Karina Vásquez, Ada y Herminia Solari, Hugo Biagini y Verónica Delgado, gracias a quienes accedí a revistas centrales en esta tesis. Asimismo, fue fundamental la amable disposición para orientarme en la búsqueda bibliográfica que me brindó el personal del Museo de la Histórico de la Universidad del Litoral, de la Casa de la Reforma Universitaria de la Universidad Nacional de Córdoba, de la Biblioteca de la Facultad de Derecho de la Universidad del Litoral y, en especial, del CeDInCI, donde consulté la mayor parte de las fuentes.

Además de Martita, Cecilia Guerín, María Castel, Elina Ibarra, Karina Jannello, Jazmín Centeno y Malena Costa me ofrecieron su amistad para compartir las angustias y alegrías de la investigación y, sobre todo, de la vida. Mis padres, Manolo y Elida, la tía Sara y mis hermanas Julieta y Griselda sumaron los conflictos y el afecto de la familia. Y Adrián Celentano, además de alentar y problematizar cada punto de esta investigación, me acompañó durante estos años en los que, junto a Juana y Dante, compartimos una divertida cotidianidad. 


\title{
LA REFORMA UNIVERSITARIA DESDE SUS GRUPOS Y REVISTAS
}

\section{UNA RECONSTRUCCIÓN DE LOS PROYECTOS Y LAS DISPUTAS DEL MOVIMIENTO ESTUDIANTIL PORTEÑO DE LAS PRIMERAS DÉCADAS DEL SIGLO XX (1914-1928)}

\begin{abstract}
En la gestación de una revista de cultura siempre hay algo de designio histórico, de "astucia de la razón”. Algo así como una fuerza inmanente que nos impulsa a plasmar cosas que roen nuestro interior y que tenemos urgente necesidad de objetivar. No es por ello desacertado buscar en las revistas el desarrollo del espíritu público de un país, la formación, separación o unificación de sus capas de intelectuales. Puesto que al margen de lo anecdótico, toda revista es siempre la expresión de un grupo de hombres que tiende a manifestar una voluntad compartida, una posición común frente a la realidad. Expresa, en otras palabras, el vehemente deseo de elaborar en forma crítica lo que se es, lo que se ha llegado a ser, a través del largo y difícil proceso histórico que caracteriza la formación de todo intelectual. José Aricó, "Pasado y presente", 1963.
\end{abstract}

\section{INTRODUCCIÓN}

\section{La Reforma Universitaria como movimiento político-cultural}

A mediados de 1918, durante los fuertes conflictos que mantenían los estudiantes cordobeses con las autoridades de la Universidad Nacional de Córdoba (UNC), la recién fundada Federación Universitaria de Córdoba (FUC) puso a circular el "Manifiesto liminar". En ese célebre texto, redactado por el egresado en Derecho Deodoro Roca a pedido de la FUC, los estudiantes federados les anunciaban "a los hombres libres de Sud América" que acababan de romper "la última cadena que en pleno siglo XX nos ataba a la antigua dominación monárquica y monástica" y, luego de relatar la primera batalla ganada a favor de una universidad laica y democrática, llamaban a esos hombres libres a "recoger la lección" y "colaborar en la obra de libertad que se inicia" (del Mazo, 1927, t.I: 13). El ciclo de protestas al que el manifiesto le dio sustento ideológico, así como la rápida articulación de otras iniciativas que recogieron ese llamado, convirtieron al texto en el indiscutido inicio simbólico del movimiento latinoamericano de la Reforma Universitaria.

A diferencia del caso peruano y el cubano, los impulsores argentinos de la Reforma no lograron precisar una ideología política ni fundar un partido de alcance nacional. Pero ello no quita que la Reforma haya sido significativa para la cultura política argentina, pues en ese episodio de masas protagonizado por las clases medias se conformó una persistente identidad política juvenil, que en un principio simpatizó con el socialismo bolchevique y desde mediados de la década del veinte se ligó fuertemente al antiimperialismo latinoamericano. Más precisamente, siguiendo a Juan Carlos Portantiero (1976), en Argentina la Reforma operó durante décadas como la "escuela 
ideológica de los líderes de la contraelite cultural y política". Y, como subrayaron Cattáneo y Rodríguez (2000), esa contraelite moldeó un nuevo y perdurable sujeto político colectivo: la juventud en tanto agente privilegiado del cambio social.

Disputada por la Unión Cívica Radical (UCR), el Partido Socialista (PS) y el Partido Comunista (PC), la cultura reformista argentina fue el marco en el que muchos jóvenes de clase media hicieron sus primeras experiencias políticas. Y sería dentro de esa cultura que, a comienzos de los sesenta, se gestaría su sucesora/superadora, la "nueva izquierda argentina". En efecto, no es difícil mostrar que esta izquierda -que renovó tanto las reflexiones sobre el marxismo y la experiencia comunista como la relación entre izquierda y peronismo- hizo su primera formación político-cultural en la Reforma para luego señalar su ocaso desde publicaciones y colecciones editoriales, hoy célebres, como Contorno, La rosa blindada, Pasado y Presente y Los Libros.

En el estallido y la pervivencia del conflicto del año 1918, sin duda, jugaron un papel decisivo la llegada de los hijos de los sectores medios a la universidad y la conquista del poder estatal que logró en 1916 el partido aglutinante de esos sectores, la UCR. También se contaron entre las condiciones de posibilidad de la Reforma factores de orden ideológico como, por un lado, el aristocratismo del pensamiento y el juvenilismo que recorrían a las elites intelectuales y, por el otro, el clima de crisis espiritual y de bancarrota del liberalismo con que eran interpretados los dos acontecimientos que abrían el siglo XX: la Gran Guerra y la Revolución Rusa, a los que se sumaba la Revolución Mexicana. Pero, como señalaron Bergel y Martínez Mazzola (2010), la confluencia de esos factores hubiera sido imposible sin la organización que se dieron los estudiantes en una serie de grupos y revistas, y sin los contactos epistolares y los viajes realizados por figuras nacionales, latinoamericanas y europeas. A pesar del significativo papel que jugaron esas distintas instancias organizativas en la construcción del estudiante como un actor social y un tipo de intelectual, así como en la pervivencia de la Reforma, la bibliografía crítica se ha ocupado muy poco de ellas.

Específicamente, nuestra investigación busca en los grupos y en las revistas estudiantiles los "hilos" en que se tramó el movimiento porteño de la Reforma Universitaria. Junto a ello busca iluminar el itinerario intelectual de algunos de esos estudiantes y la recepción que los grupos y revistas realizaron de los tres intelectuales extranjeros -partícipes de la izquierda europea- que fueron convocados como "maestros de la Reforma", a saber, el filósofo antipositivista catalán Eugenio d'Ors, el fisiólogo judeoalemán Georg Nicolai y el economista marxista, también judeoalemán, Alfons Goldschmidt. A través del análisis de los grupos, revistas y visitantes, la investigación recupera la densidad ideológica y material del movimiento político-cultural que se gestó en la ciudad de Buenos Aires en el marco de la Reforma Universitaria, y se preocupa especialmente por precisar el modo en que ese movimiento se inscribió y renovó el campo de las 
izquierdas. Si bien la mayoría de las iniciativas que analizamos no lograron prolongarse en el tiempo, veremos que esa brevedad no impidió que ellas pusieran en circulación nuevas prácticas e ideas, ni que se alentaran debates a través de los que se tramó una primera red estudiantil nacional y se instaló la figura del estudiante como un nuevo actor cultural y político de la sociedad moderna. Más específicamente, sostendremos que esas breves iniciativas reformistas hicieron emerger al estudiante como un tipo de intelectual con ideas y prácticas de intervención pública distintivas respecto del escritor, el científico y el profesor, pero también con ideas y prácticas que se fueron renovando y que permanecieron fuertemente disputadas por los distintos grupos estudiantiles.

La Reforma Universitaria es uno de los pocos acontecimientos políticos argentinos que sin surgir en Buenos Aires traspasó las fronteras nacionales hasta conseguir una dimensión continental. Iniciado en Córdoba, en junio de 1918, con una revuelta estudiantil que reclamaba la renovación de una planta docente marcada por la cultura católica y por la pertenencia a un círculo social cerrado, ese reclamo rápidamente fue recogido por los estudiantes de universidades laicas $\mathrm{y}$ predominantemente cientificistas, como la de Buenos Aires y la de La Plata. La disímil impronta educativa no le impidió a los estudiantes porteños y platenses retomar y amplificar el reclamo de una reforma de los estatutos universitarios. Éstos fundamentalmente debían introducir cátedras libres, asistencia libre, autonomía universitaria y participación de los estudiantes en el gobierno universitario. Pero la Reforma no sólo tuvo una dimensión institucional, sino que, desde su inicio, estuvo ligada a otras dos dimensiones: la política -desde la que se vinculó a una reforma social- y la dimensión cultural -asociada a la "reacción antipositivista"-. Y si, a diferencia de otros acontecimientos políticos, en un comienzo "todos" se reconocieron reformistas, ello implicó no tanto el acuerdo en torno de un proyecto, sino más bien la decisión de participar en la disputa por el peso y la definición de las tres dimensiones mencionadas.

Como sugerimos al inicio de este apartado, ya en su primera victoria institucional, los reformistas cordobeses ligaron sus reclamos a una dimensión política, específicamente a una "hora americana" y a una democratización que tendía a exceder la esfera universitaria. En torno de ese llamado, una serie de grupos estudiantiles argentinos -y luego de otros puntos del continente-, que nunca dejaron de ser minoritarios respecto de la matrícula universitaria, se politizaron y comenzaron a precisar el perfil intelectual del estudiante, o bien propusieron que los "jóvenes que estudiaban en la universidad" se reconocieran como "estudiantes" en tanto actores del campo de la cultura y de la política con ideas y prácticas culturales características. Entre esas ideas se encontraron el juvenilismo, la democratización de la universidad, el nacionalismo y la igualdad social ligada al socialismo; entre las prácticas, se destacaron la edición de revistas y el despliegue en ellas de polémicas, la redacción de manifiestos, los ciclos de conferencias y los actos de 
solidaridad. Las dos disputas más álgidas que recorrieron al estudiante en tanto figura intelectual fueron, por un lado, su inscripción en distintos filones de la izquierda o bien en el incipiente nacionalismo político; y, por el otro, la identificación de la Reforma con cambios exclusivamente institucionales o con una reforma que implicara un orden social más igualitario y se ligara a las fracciones de izquierda.

Como puede esperarse, la confluencia y el solapamiento de la dimensión institucional de la Reforma, que impulsaba la democratización de las casas de estudio, y la dimensión política, que construía al estudiante como un actor político-cultural con reivindicaciones sociales, fue intensamente discutida por los primeros reformistas. Entre quienes ligaron la Reforma a los reclamos y prácticas de la izquierda, se destacó Deodoro Roca y su reiteradas declaraciones de que "el universitario puro es una cosa monstruosa" y que la Reforma es un "enlace vital de lo universitario con lo político, camino y peripecia dramática de la juventud continental, que conducen a un nuevo orden social" (Portantiero, 1978 [1936]: 432). Una interpretación que también difundieron Alejandro Korn, José Ingenieros, Saúl Taborda, Gregorio Bermann, Gabriel del Mazo, entre otros líderes argentinos, y que a escala latinoamericana encontró importante eco en José Carlos Mariátegui, Víctor Haya de la Torre y Julio Antonio Mella, entre otros.

Un líder reformista menos recordado, Isidoro Ódena (1906-1977), ofrece una interesante síntesis de esa tensión entre la dimensión institucional de la Reforma y la dimensión política de izquierda. En una nota de combate, este joven comunista, que entonces lideraba el Partido Reformista Centro-Izquierda de la Facultad de Derecho, tomaba un claro partido a favor de la dimensión política de la Reforma, y para ello sostenía:

[...] el objetivo más alto y perdurable del movimiento reformista [es] el de que éste sirva como simple instrumento técnico, para la educación revolucionaria de la nueva generación. Fue esta directiva, impresa desde las jornadas de Córdoba, la única que pudo mantener la vitalidad y coherencia de la acción; la Reforma podrá vivir sólo de ese contenido histórico que la sustenta. Cuando él sea abandonado y los estudiantes se detengan en la doméstica labor de mejorar sus institutos y de corregir las fallas de sus maestros, el espíritu trascendente de la Reforma habrá muerto y todo lo que se haga será sólo una pura sombra de aquel movimiento que sintió al nacer que estaba pisando sobre una Revolución "viviendo una hora americana" (Isidoro J. Odena, "Acerca de las próximas elecciones universitarias. La crisis de la Reforma en Buenos Aires", Renovación. Órgano de la Unión Latino-Americana, mayo a julio de 1929, p. 1).

Esta tensión entre la dimensión política y la institucional de la Reforma no sólo se advierte en las "fuentes" que dejaron los líderes reformistas sino también en los abordajes y diagnósticos disímiles realizados por investigaciones críticas como las de Portantiero (1978), Graciano (2008) y Biagini (2012) frente a las de Halperín Donghi (1962), Buchbinder (2005; 2008) y Rimoldi (2010). El primero se preocupa por reconstruir los conflictos del 1918 en Córdoba y su expansión para mostrar 
la productividad político-cultural que, a diferencia del caso argentino, tuvo la Reforma en la construcción del APRA, el primer partido político de las clases medias del Perú, y en la formación del PC cubano. Por su parte, Graciano se concentra en el caso argentino para marcar zonas en las que el movimiento reformista local tuvo una importante incidencia político-cultural. A partir de una minuciosa reconstrucción del itinerario de un conjunto de intelectuales reformistas platenses, señala los proyectos ligados a la Reforma que emprendieron distintos universitarios desde 1918 hasta la caída del peronismo. Biagini también analiza el caso platense e ilumina la trayectoria de algunos grupos porteños, sobre todo para recuperar la importante recepción de ideas españolas y francesas que realizaron esos grupos. Trazando una genealogía de la "contracultura juvenil", el trabajo de Biagini también se ocupa de los vínculos continentales del movimiento reformista. En cambio, Halperín Donghi y Buchbinder y Rimoldi se concentran en la dimensión institucional: el último precisa la existencia en la Universidad de La Plata de muchas de las demandas institucionales reclamadas por los estudiantes de Córdoba y Buenos Aires, mientras que los otros dos autores muestran las escasas repercusiones que consiguió la Reforma en su prédica democratizadora y renovadora de las casas de estudio.

En cuanto a lo cultural, el desarrollo del movimiento reformista coincidió con el despliegue de la llamada "reacción antipositivista" y la profesionalización de los estudios filosóficos. Según veremos, varias figuras, grupos y revistas propusieron una convergencia entre el movimiento reformista y el antipositivismo. A los nombres de Alejandro Korn, Saúl Taborda y Carlos Astrada se sumaron: el grupo cordobés Córdoba Libre! y su revista La Montaña (1918), el grupo platense Renovación y su revista Valoraciones (1923-1928) y la revista porteña Inicial (1923-1927). Pero también se registraron figuras, grupos y revistas que se reconocieron decididamente reformistas y que establecieron una relación sumamente tensa con el antipositivismo. Dos ejemplos contrastantes son el Colegio Novecentista de Buenos Aires (1917-1923) y la Unión Latino-Americana (ULA; 1924-1930). Jóvenes del primer grupo, como Adolfo Korn Villafañe, Tomás Casares y Jorge Max Rohde, impulsaron una reacción antipositivista filiada a una versión de la Reforma que se distanciaba del "caos" maximalista para asumir un nacionalismo aristocratizante y una renovación de los contenidos académicos que no cuestionaban las jerarquías sociales. En cambio, los miembros de la ULA -y antes José Ingenieros, Gregorio Bermann, Alberto Palcos, entre otros- tendieron a permanecer distantes del antipositivismo, simpatizaron con la Revolución Rusa y ligaron la Reforma tanto a una renovación institucional que construyera una universidad social y científica como a una identidad estudiantil antiimperialista y latinoamericana. Es que junto a la discusión sobre el antipositivismo los reformistas debatieron intensamente la cuestión social -especialmente, el vínculo entre Derecho y sociedad moderna-, las nuevas corrientes pedagógicas y la certeza de una evolución de la humanidad ligada a la ciencia. 
Para terminar de precisar el proceso estudiantil que analizamos y cerrar el presente apartado, volvamos sobre ese proceso desde una perspectiva diacrónica. En la primera década del siglo XX, crecía fuertemente la matrícula universitaria de la Universidad de Buenos Aires (UBA) y aparecían las primeras instancias organizativas preocupadas por los reclamos estudiantiles de carácter gremial (Chiroleu, 2000; Buchbinder, 2008). A los centros de estudiantes con personería jurídica que se inauguraban en cada facultad y a la Federación Universitaria de Buenos Aires (FUBA), que desde 1908 reunía a los representantes de esos centros, se sumó a mediados de la década del diez un nuevo tipo de organización estudiantil: los ateneos y las revistas. A través de éstos, algunos jóvenes provenientes de las emergentes clases medias cosntruyeron la figura del estudiante como un tipo de intelectual. Definido y redefinido por distintos grupos, revistas y viajeros, esa figura forzó, sobre todo entre 1918 y 1921, que la politización también llegara a las instancias gremiales de los centros de estudiantes y a las federaciones universitarias. En cuanto a esta politización, una de las tesis que buscamos introducir en los estudios sobre la Reforma es la existencia de un período en el que algunos grupos estudiantiles radicalizados, en lugar de identificarse con el latinoamericanismo antiimperialista, promovieron un "socialismo bolchevique", esto es, un socialismo que, entusiasmado con el horizonte político abierto por la Revolución Rusa, se alejaba de la estrategia parlamentaria y gradualista hacia el socialismo diseñada en el plano local por Juan B. Justo para bregar por una estrategia insurreccional ligada al movimiento obrero.

Junto a lo que en términos gramscianos podemos identificar como el pasaje de un "momento corporativo" de las agrupaciones estudiantiles -en el que predominaron los reclamos gremiales- a un "momento político" -en el que se buscó una organización que disputara al Estado su hegemonía político-cultural-, se producía otro proceso de carácter cultural, la "reacción antipositivista". Esta reacción propiciaba el pasaje de una formación universitaria ligada al cientificismo a otra identificada con un culturalismo neokantiano, en el que gravitaban sobre todo la producción intelectual de Henri Bergson, Benedetto Croce y Wilhelm Dilthey, y que tenía como embajadores a los filósofos españoles José Ortega y Gasset, que visitó la Argentina en 1916 y en 1928, y Eugenio d'Ors, quien llegó al país a fines de 1921. Como sugerimos, la compleja inscripción del movimiento antipositivista en la dimensión cultural de la Reforma es clara cuando se atiende a que varios grupos

y líderes reformistas, entre los que se destacó Ingenieros, cuestionaron el antipositivismo sin sentirse por ello menos partícipes de la Reforma, al tiempo que se registraron defensores del antipositivismo ligados al nacionalismo aristocratizante, como Korn Villafañe y Carlos Cossio, pero también otros identificados con un "socialismo ético", como Alejandro Korn.

\section{Recorte temporal y corpus de bibliografía primaria}

La bibliografía sobre la Reforma acuerda en recortar un ciclo entre 1918 y 1930 con tres 
subperiodos demarcados según los avances o retrocesos en la implementación institucional de los reclamos reformistas (Portantiero, 1976; Buchbinder, 1990; Caldelari y Funes, 1999; Graciano, 2008; Vásquez, 2000). El primero subperiodo abarca los años 1918-1922, año en que el movimiento reformista tuvo el apoyo del presidente nacional, Hipólito Yrigoyen, y consiguió que se aplicaran en las universidades argentinas muchas de sus reivindicaciones institucionales (cogobierno estudiantil, instancias de extensión universitaria, enseñanza y asistencia libre, eliminación de los cupos de inscripción y aprobación de exámenes). El segundo subperíodo coincide con la llegada de Marcelo Torcuato de Alvear a la presidencia nacional: durante esos años se produjo una "contrarreforma", pues el gobierno nacional intervino las universidades y eliminó la mayoría de las modificaciones estatutarias. Finalmente, entre 1928 y 1930, cuando Yrigoyen retornó a la presidencia, los estudiantes reinstalaron varias de sus reivindicaciones hasta que el golpe de Estado volvió a intervenir las universidades.

Ahora bien, si la mirada se traslada de lo que llamamos la dimensión institucional de la Reforma a la dimensión político-cultural, las iniciativas promovidas por los grupos, revistas y viajeros nos sugieren ciertas modificaciones en la periodización. En principio, a partir del trabajo de fuentes que realizamos, parece más adecuado comenzar la periodización en 1914, pues ese año algunos estudiantes porteños fundaron dos grupos que emprendieron una persistente labor cultural orientada a organizar a la comunidad estudiantil más allá de las cuestiones gremiales. Esos grupos fueron el Centro Ariel (1914-1915) y su revista Ariel (1914-1915), por un lado, y el Ateneo de Estudiantes Universitarios (1914-1920) e Ideas (1915-1919), por el otro. En segundo lugar, como señala Rodríguez (1999), el ciclo ideológico tendió a cerrarse hacia 1928, pues entonces dejaron de editarse las tres revistas estudiantiles más importantes del período (Valoraciones, Sagitario e Inicial), pero además en 1928 ya estaba claramente bosquejada la identidad latinoamericanista y antiimperialista con la que durante décadas se asociaría la Reforma, sobre todo entre quienes, en el caso argentino, pretenderían ligarla al PS, al PC o a la UCR.

Así, el movimiento político-cultural de la Reforma que nos interesa investigar se acuñó entre 1914 y 1928 y tuvo como rasgo común la irrupción y disolución de numerosas formaciones culturales y revistas que, respondiendo al llamado del célebre ensayo Ariel de José Enrique Rodó, se proponían constituir a la juventud estudiosa como una élite cultural y moral, que debía vincularse a través de la "extensión universitaria". Ese legado arielista sufrió durante el proceso reformista fuertes reformulaciones, pues los distintos emprendimientos estudiantiles se "apropiaron" -de modo diverso y desde repertorios culturales sumamente disímiles- del llamado de Rodó. A modo introductorio mencionemos que mientras el Centro Ariel, que surgía en Buenos Aires en 1914, proponía incorporar al arielismo un igualitarismo y cientificismo de matriz socialista, el Ateneo de Estudiantes Universitarios y el Colegio Novecentista (1917-1922) combinaron el arielismo con el 
antipositivismo y una cultura estética que rivalizaba con la científica. Por otra parte, desde 1920 el Centro de Estudiantes Ariel y su revista Ariel (1917-1920) de Montevideo ligaron el arielismo al socialismo bolchevique; en cambio, el grupo de la revista Inicial (1923-1927) tendió a asociarlo al vanguardismo estético-político.

En cuanto a la subperiodización, los estudios sobre la cultura política de la Reforma suelen concentrarse en la construcción de una sensibilidad latinoamericana (Bergel y Martínez Mazzola, 2010; Biagini, 2012; Pita González, 2009; Cattáneo y Rodríguez, 2000). Sin desconocer que esa sensibilidad recorre desde sus orígenes a la Reforma, la presente investigación propone distinguir un subperíodo que se inicia hacia 1919 y se prolonga hasta 1922, en el que entre los grupos estudiantiles porteños no primó el latinoamericanismo sino un internacionalismo ligado a la Revolución Rusa, y particularmente al llamado de Henri Barbusse a una "Revolución en los Espíritus" y una "Internacional del Pensamiento". Hacia 1923 se abriría un nuevo subperíodo en el que esos grupos radicalizados tendieron a disolverse y aparecieron otros que construyeron la sensibilidad latinoamericanista y antiimperialista de la Reforma sobre la que la bibliografía citada ha realizado agudos análisis.

En definitiva, las revistas, memorias y cartas que analizamos nos siguieren que, según las distintas estrategias que primaron en los grupos y revistas, el movimiento político-cultural desplegado por los estudiantes entre 1914 y 1928 debe dividirse en tres subperíodos. Entre 1914 y 1918 se recortaría un primer subperíodo en el que, con distinto éxito, una serie de agrupaciones estudiantiles configuraron, por primera vez, una identidad estudiantil que excedía las inquietudes gremiales universitarias para reconocer en el estudiante no una figura de tránsito hacia la inserción profesional sino un actor social y cultural con inquietudes propias.

En el trazado de esa configuración, algunas agrupaciones optaron por el socialismo científico mientras que otras lo hicieron por la cultura estética o por la cultura católica. Por su longevidad y constancia, la revista Ideas. Órgano del Ateneo de Estudiantes Universitarios (19151919) será nuestro mirador privilegiado, pero también componen este primer corpus: Ariel. Revista mensual de ciencias, letras y artes (1914-1915), los números editados entre 1916 y 1918 de Verbum. Órgano del Centro de Estudiantes de Filosofía y Letras de Buenos Aires (1912-1948), los Cuadernos del Colegio Novecentista (1917-1919), la Tribuna Universitaria. Revista de los Centros Católicos de Estudiantes (1917-1920) y el Boletín de la Federación Universitaria de Buenos Aires (1917-1918).

Con el estallido de la Reforma y el ciclo de protestas obreras ligado al "trienio rojo" (19191921), ${ }^{1}$ se instalaría en el movimiento estudiantil un "momento político". Durante esos años, ya se 
pueden reconocer los rasgos de una "juventud estudiosa" en la que pasó a un segundo plano la rivalidad entre la adopción de una cultura científica, una estética o una católica, para comenzar a primar la discusión en torno del tipo de vínculo que el movimiento estudiantil debía promover con el movimiento obrero. El parteaguas en esa discusión tendió a trazarse en torno al compromiso con la mencionada "Internacional del Pensamiento" de Barbusse o con un nacionalismo aristocratizante. Forman el segundo corpus: Themis. Revista del Centro de Estudiantes de la Derecho y Ciencias Sociales (1918-1920), la Revista Nacional (1918-1920), Clarín. Periódico del Ateneo de estudiantes Universitarios (1919-1920), La Cureta (1918-1925), Claridad. Revista quincenal de crítica, literatura y arte (1919-1920), Bases. Tribuna de la juventud (1919-1920), Insurrexit. Revista Universitaria (1920-1921), Hoy (1921) y el Boletín de la Federación Universitaria Argentina (1920-1922). También incluimos aquí una revista no editada en Buenos Aires, la montevideana Ariel. Revista del Centro de Estudiantes (1918-1930), pues ella mantuvo una estrecha relación con algunas de las publicaciones porteñas estudiadas.

Finalmente, hacia 1922, cuando la economía argentina se recuperó de la crisis producida por la Primera Guerra Mundial y declinó el ciclo de protestas obreras, el movimiento estudiantil no pudo evitar nuevas intervenciones nacionales de las universidades que dieran marcha atrás a las reivindicaciones reformistas, y en estas nuevas condiciones varios grupos y revistas se convencían de que la política y el intento de incidir en la opinión pública ya no debían estar en el centro de sus proyectos. Mientras el grupo Renovación (1919-1928) de la ciudad de La Plata volvía a interesarse por una identidad estudiantil ligada a la cultura estética, y especialmente a las filosofías antipositivistas, otros se propusieron formar una vanguardia estética y política, y una tercera fracción señaló al latinoamericanismo antiimperialista como la identidad estudiantil, opción que se complejizó hacia 1927 con la aparición de las ligas antiimperialistas comunistas y que terminó instalándose como la cultura política de la Reforma. En este corpus se encuentran: Renovación. Boletín de ideas, libros y revistas de la América Latina (1923-1930), Inicial. Revista de la nueva generación (1923-1927), Acción Universitaria (1924-1925) y 1918. Órgano de la nueva generación sudamericana (1925-1926). Dada su estrecha vinculación con estas publicaciones, incluimos aquí las revistas platenses Valoraciones. Humanidades, crítica y polémica (1923-1928), Sagitario. Revista de Humanidades (1925-1927), Estudiantina. Letras, critica y arte (1925-1926) y Don Segundo Sombra (1928) y la publicación montevideana Cultura. Órgano de la Asociación Cultural Universitaria (1924-1926).

Los tres corpus de revistas mencionados se completan con otras publicaciones periódicas que no abordaremos de modo sistemático sino en lo relativo a los vínculos que tramaron con los estudiantes: Revista de Derecho, Historia y Letras (1898-1923), Nosotros (1907-1948), Revista 
Argentina de Ciencias Políticas (1910-1928) y Revista de Filosofía, Ciencia, Educación y Cultura (1915-1929). Asimismo, son parte fundamental de nuestro corpus primario otros dos tipos de fuentes: por un lado, las memorias elaboradas por figuras vinculadas a la Reforma (del Mazo, 1976; Gabriel, 1943; González, 1931, Irazusta, 1975; Monner Sans, 1930 y 1976; Nalé Roxlo, 1978; Noé, 1993; Sánchez Viamonte, 1971) y, por el otro, las cartas editadas (Sanguinetti, 2002; Mariátegui, 1984) y las que se conservan en los fondos personales de José Ingenieros, Florentino Sanguinetti (ambos depositados en el CeDInCI), Gregorio Bermann (disponible en la Casa de la Reforma Universitaria, UNC), Pablo Vrillaud (del Museo Histórico, Universidad del Litoral) y Eugenio d'Ors (del Arxiu Nacional de Catalunya). Finalmente, también contamos con algunos de los folletos difundidos por el Partido Unión Reformista y otras agrupaciones de la Facultad de Derecho de Buenos Aires, que se conservan en el Fondo personal Florentino Sanguinetti del CeDInCI.

Estas diversas fuentes, prácticamente inexploradas por la bibliografía crítica, nos permitirán conocer más sobre las diversas formaciones estudiantiles que participaron desde la ciudad de Buenos Aires en la construcción de una cultura política reformista, específicamente sobre las ideas que recepcionaron, las formas de sociabilidad que adoptaron, las redes de contactos intelectuales que establecieron y las relaciones que tendieron con los partidos políticos y el Estado. Junto a ello el análisis del corpus pondrá de manifiesto el espesor histórico del proceso ideológico de la Reforma, del que el ideario latinoamericanista y antiimperialista aparece como el punto de llegada. Y ello tanto porque varias de las revistas aparecidas entre 1919 y 1921 sugieren que por entonces primó en el espacio porteño una identidad ligada al socialismo bolchevique y que ella rivalizó con un nacionalismo jerarquizante, como porque las revistas editadas en los años posteriores muestran distintas versiones del ideario latinoamericanista y tensiones entre ese ideario y el nacionalista.

\section{Estado de la cuestión}

Como venimos desarrollando, en torno de la Reforma Universitaria confluyen tres iniciativas: la democratización de la universidad, la reacción antipositivista y el trazado de una identidad política de los estudiantes. Si bien nuestra atención no estará puesta en la reconstrucción de los distintos procesos institucionales desencadenados por la Reforma, recuperamos las documentadas investigaciones sobre ello realizadas por Buchbinder (1997, 2000 y 2005), Chiroleu (2000) y Halperín Donghi (1962), y prestamos suma atención al llamado formulado por Funes y Caldelari (1996) a historizar los reclamos realizados por los estudiantes reformistas de las distintas universidades. Esta biblografía es fundamental en el capítulo siete, dedicado al cruce entre la dimensión institucional y la política que hizo posible, por un lado, la llegada de los intelectuales europeos d'Ors, Goldschmidt y Nicolai y, por otro, la breve gestión de Mario Sáenz en la Facultad porteña de Derecho. 
En lo relativo a la reacción antipositivista porteña, nos resulta fundamental el estudio de Dotti (1990), en el que se reconstruye la recepción del kantismo emprendida por los intelectuales y grupos argentinos, desde la generación del '37 hasta 1930. Además, son importantes los análisis propuestos por el mismo autor sobre el peculiar positivismo que desplegaron intelectuales argentinos como Justo e Ingenieros. En efecto, la tensión casi irreconciliable que Dotti (1992) subraya entre la matriz determinista de la filosofía positivista -en la que no hay lugar para la libertad humana-, por un lado, y la formulación de una ética socialista -que asume la condición libre del hombre y la posibilidad de acciones orientadas a la consecución de un orden social más justo-, por el otro, no sólo la reencontraremos en la intervención de varios reformistas, sino que además nos ofrece un importante punto de contraste con las propuestas antipositivistas de los jóvenes que animaron el Colegio Novecentista. Por otra parte, los señalamientos de Terán (1986b y 2008b) sobre la producción de Ingenieros y de otros miembros de la elite intelectual también nos aportan claves significativas para pensar la relación preponderante, durante las primeras décadas del siglo $\mathrm{XX}$, entre intelectuales y política, y en particular entre filosofía y política. A ello debemos sumar los análisis de Vásquez (2003 y 2005) sobre la gravitación argentina de Ortega y Gasset y específicamente la productividad de ese "archivo ideológico" entre los primeros reformistas y las revistas culturales de la época.

En cuanto a la tercera iniciativa que converge en la Reforma, esto es, la formación de una cultura política, varios textos provenientes de líderes reformistas realizaron análisis sistemáticos y extensos que cumplían con los parámetros científicos de la época y que -a pesar de la defensa que proponen de determinadas iniciativas- continúan esbozando importantes claves de lectura. En ese sentido, optamos por clasificar las obras de los siguientes autores no como fuentes primarias sino como los primeros estudios sobre el movimiento político-cultual de la Reforma: Julio V. González (1922, 1927 y 1931), Carlos Cossio (1927), Gabriel del Mazo (1955; 1956), Juan Lazarte (1935) y Gregorio Bermann (1946).

En distintos escritos, González enfatizó la conexión del movimiento reformista con las inquietudes generadas por la época. Valiéndose del archivo orteguiano, sostuvo que con la Reforma nacía una "Nueva Generación” marcada por la Gran Guerra, la Revolución Rusa y el radicalismo. Sostuvo en una de esas formulaciones:

Nosotros, para quienes la guerra fue un espectáculo apocalíptico donde se hundía el mundo capitalista; la revolución rusa, una gran esperanza de redención para los hombres; la causa aliada, el epílogo de un período de endeudamiento a los intereses extranjeros que enajenaban el alma nacional; el advenimiento popular, un aluvión multitudinario de iniciación democrática que liquidaba el pasado político argentino; nosotros, que naciéramos en medio de esta suerte de caos genésico, no podíamos, por nuestra parte, sino traducirlo en la enorme blasfemia de la Reforma Universitaria y en la 
vasta promesa de la Nueva Generación (González, 1931: 44).

Tomando como referencia implícita su propio itinerario político, González trazó un particular ciclo político de la Reforma. Éste iría desde una revuelta indefinida hasta el socialismo pasando por el americanismo.

En 1918, un reformista era un estudiante sublevado contra sus maestros; en 1921, el americano de la nueva generación que declaraba su divorcio con el pasado y su disconformidad con el estado de cosas y sistema de ideas por el que se regía la comunidad de América; en 1925, un hombre entregado a un ideal reconstructivo tocado de un fuerte sentido socialista (González, 1927: 11).

Esta periodización, en la que se reconoce, además del itinerario de González, el de varios de los reformistas platenses estudiados recientemente por Graciano (2008), fue tempranamente cuestionada. En La Reforma Universitaria o la Nueva Generación, Carlos Cossio (1927), quien terminó sus estudios en Derecho en 1923 y en las décadas siguientes se convirtió en un destacado jurista, criticó la posición "extrauniversitaria” de González y de otros ideólogos de la Reforma. En consonancia con la propuesta de la agrupación Unión Universitaria y de su líder Korn Villafañe, Cossio identificó a la nueva generación con una renovación de los estudios jurídicos y filosóficos guiada por el kantismo y por la instalación de un idealismo de entonaciones aristocratizantes y nacionalistas.

Por su parte, del Mazo, al igual que González, asoció su figura político-intelectual a la de los "hombres de la Reforma", pero mientras éste adscribió desde los treinta al PS, aquel lo hizo a las filas del radicalismo yrigoyenista y a las expresiones apristas argentinas, al tiempo que se convertía en el más importante compilador de los documentos de la Reforma. Entre 1926 y 1927 del Mazo publicó la primera compilación, cuyos seis tomos -de casi doscientas páginas cada uno- circularon inmediatamente por el continente participando de la identificación del reformismo con el latinoamericano y antiimperialismo. ${ }^{2}$ En 1941 preparó otra compilación más breve, a partir de una selección de los textos de la primera y del agregado de documentos redactados entre 1927 y 1940, una edición que -respondiendo a la afinidad de del Mazo con el aprismo- fue también reimpresa en Lima. $^{3}$

\footnotetext{
${ }^{2}$ Los títulos de cada uno de los seis tomos de la primera edición proponen una rápida idea del criterio bajo el cual del Mazo volvió a poner a circular los documentos reformistas: I. Juicio de hombres de la nueva generación acerca de su significado y alcances (1918-1926); II. Documentos relativos al movimiento estudiantil en las universidades de Córdoba y Buenos Aires (1918); III. El primer Congreso Nacional de Estudiantes Universitarios, Córdoba, 1918 ; IV. Documentos relativos al movimiento estudiantil en La Plata (1919-1920); V. Documentos complementarios que se refieren a la acción directamente social del Movimiento Estudiantil Argentino (1918-1921), con un apéndice relativo a la campaña contra la limitación del ingreso a las universidades (1926); VI. Documentos relativos a la propagación del movimiento en América Latina (1918-1927). Los tomos fueron editados por el Centro de Estudiantes de Medicina de Buenos Aires.

${ }^{3}$ La edición argentina fue publicada por el Centro de Estudiantes de la Facultad de Ingeniería de La Plata, en la que del
} 
A distancia de González, para del Mazo el acontecimiento que gravitaba en el surgimiento de la Reforma no era la Gran Guerra ni la Revolución Rusa -ni ese kantismo que reclamaba Cossio-, sino la experiencia democrática local. Retomando la posición que expresó en numerosos discursos y que sistematizó en su estudio sobre el radicalismo (del Mazo, 1955), proponía en sus memorias:

\begin{abstract}
¿Hubiera sido posible barrer con estas anomalías [universitarias] si no hubiese comenzado a operar en el país la profunda transformación que permitió que por primera vez el pueblo de la Nación eligiera su gobierno? ¿Sin la democratización que se realizaba en el gobierno nacional?. ¿Hubiera podido lograrse la aireación, la democratización, que se reclamaba para toda la universidad? (del Mazo, 1976: 79).
\end{abstract}

En los discursos y escritos de del Mazo, la Reforma aparece como una reacción juvenil ante una institución que, a diferencia del escenario político, permanecía liderada por "un pasado que se resistía a morir", esto es, por "oligarquías mercantiles y extranjerizantes" que habían perdido el control del Estado pero intentaban perpetuar su poder y privilegio social (del Mazo, 1956[1938]: 7). En el plano ideológico, la reacción reformista habría iniciado una "conciencia de emancipación en desarrollo" cuya expresión más clara e interesante habría sido el APRA. Es que luego de las primeras luchas de carácter cultural, los estudiantes habrían descubierto que había

un enlace ineludible entre los problemas de la educación y los que dimanaban de un sistema estatal apócrifo y lesivo de lo auténtico. El problema de la Reforma se refiere a un conjunto de cultura y de poder. [...] Los estudiantes difundieron el planteamiento de fondo del problema social. Fueron la primera fuerza que denunció nuestra sujeción al imperialismo mundial, motor de nuestra fragmentación continental y de nuestras guerras fratricidas, y promotor de nuestras dictaduras, sus órganos, cuya injerencia condiciona poderosamente nuestra vida cultural (del Mazo, 1956: 10-11).

Desde esa denuncia, Haya de la Torre habría sido el primero en superar la Reforma, pues construyó un partido político que pasó del movimiento educativo a una política económica y social, pasaje que del Mazo y otros se propusieron realizar en la Argentina de los treinta con la Fuerza de Orientación Radical de la Joven Argentina (FORJA) y en la de los cuarenta con el Movimiento de Intransigencia y Renovación.

Sea para inscribirla en los logros del yrigoyenismo o en la lucha socialista, la Reforma quedó ligada, en las obras de del Mazo y de González, a la construcción de una identidad latinoamericana y antiimperialista, apuesta que, según veremos, tendió a borrar de la historia de la Reforma la unión obrero-estudiantil de tinte bolchevique que alentaron diversos grupos argentinos entre 1918 y 1922 y que el mismo del Mazo se había encargado de documentar en uno de los tomos

Mazo era profesor; en 1943 sería vicepresidente de la UNLP. Los títulos de cada tomo fueron: I. El Movimiento Argentino; II. Propagación americana, III. Ensayos Críticos. 
de su compilación de $1927 .^{4}$

Un análisis muy distinto a los hasta aquí reseñados fue ofrecido en 1935 por el médico anarquista Juan Lazarte, quien había participado de la fundación de la FUC y en 1920 dirigió su órgano, La Gaceta Universitaria. En sus Líneas y trayectorias de la Reforma Universitaria, libro que buscó legitimar la lucha antifascista iniciada en 1934 por los sectores comunistas y anarquistas del movimiento estudiantil y obrero, Lazarte insiste en que entre 1919 y 1923 la mayoría estudiantil que aspiraba a reducir la Reforma a las cuestiones pedagógicas sufrió el persistente cuestionamiento de una minoría revolucionara, a la que señala como lo más fecundo que dio el movimiento. ${ }^{5}$ Para probar la existencia de esa minoría -de la que hasta la actualidad sólo Tarcus (1997 y 2004) ha recuperado a uno de sus grupos, Insurrexit-, Lazarte trascribe fragmentos de los manifiestos y refiere algunas iniciativas. Esas referencias, sumadas a los periódicos que hemos rescatado, son centrales para colocar a la identidad latinoamericanista y antimperialista de la Reforma como el punto de llegada en el proceso de construcción y disputa de una cultura política estudiantil.

Finalmente, al igual que Lazarte, Bermann se opuso, primero en algunos artículos, y luego en una obra sistemática, La juventud de América (1946), tanto a la interpretación generacionista de la Reforma, promovida por del Mazo y, sobre todo, por González, como a la reducción de la Reforma a la renovación académica que alentaba Cossio. Pero, a diferencia de Lazarte, Bermann cuestionó a la "minoría revolucionaria" por haber sostenido una posición exclusivamente obrerista y rescató el "socialismo dialéctico" que habrían formulado Mella, Mariátegui y Aníbal Ponce. Siguiendo algunas claves del materialismo dialéctico, Bermann propuso que la Reforma y sus prolongaciones continentales debían inscribirse en el ciclo histórico abierto en 1848 por los movimientos juveniles europeos y latinoamericanos que acompañaron las irrupciones proletarias de las revoluciones republicanas y democráticas.

Seguramente, el mayor aporte de esta obra sea la sistematización de las "Interpretaciones y corrientes de la Reforma Universitaria” ofrecida por el capítulo once. Allí Bermann presenta y evalúa las seis expresiones reformistas registradas en Argentina y en el continente. La primera de ellas habría sido la "teoría de la nueva generación americana", que tuvo en González a su expositor más autorizado y que falló, según Bermann, por el carácter idealista con que abordó el devenir histórico. En polémica con esa teoría se habrían registrado: las interpretaciones idealistas y aristocratizantes de Adolfo Korn Villafañe, Cossio y Homero Gugliemini; la limitación de la

\footnotetext{
${ }^{4}$ En efecto, los documentos estudiantiles redactados sobre "la acción directamente social del Movimiento Estudiantil Argentino" (1918-1921) que reúne el tomo V dan cuenta de la constante vinculación que intentaron los reformistas con el activo movimiento obrero, desde expresiones izquierdistas que se referenciaban no en la identidad americanista sino en el revolucionarismo bolchevique.

${ }^{5}$ Este señalamiento también se encuentra, formulado en clave marxista, en los artículos sobre la Reforma publicados por el intelectual trotskista y protagonista de la Reforma Liborio Justo. Éste considera que el revolucionarismo despertó las inquietudes políticas de una generación que no logró pasar de sus vacilaciones pequeño-burguesas. Véase Liborio Justo, “Autopsia y funeral de la Reforma Universitaria”, Claridad, n 326-327, junio-julio de 1938 y Justo (2006).
} 
Reforma a los aspectos docentes y culturales -identificable, entre otros, en los planteos disímiles de Sebastián Soler, Germán Arciniegas y Saúl Taborda-; el "sectarismo de la izquierda" alentado por el primer grupo Insurrexit y ubicado en las antípodas de la línea anterior, en tanto no habría asignado ninguna importancia a los reclamos estudiantiles por considerar que sólo mediante una "revolución nacional liberadora" encabezada por el proletariado podían obtenerse aquellas reivindicaciones. Otra interpretación la habría ofrecido el aprismo, con su convocatoria a las clases medias a luchar contra el imperialismo y a favor de un liberalismo honesto y resonante. En último término, Bermann presenta la "interpretación dialéctica”. Esta sería la más virtuosa, pues evitaría tanto el elemento idealista de la posición de González como el sectarismo de la izquierda. En esta interpretación, el nacimiento de la nueva generación aparecería como el resultado de la búsqueda, por parte de las clases medias, de un profundo y pleno conocimiento de la realidad americana, desde la que debería continuarse la construcción de una filosofía que fuera el arma intelectual del proletariado. ${ }^{6}$

Los iniciales análisis de la Reforma realizados por González, Cossio, del Mazo, Lazarte y Bermann pudieron contar con una temprana sistematización de las fuentes primarias de la Reforma, que, como mencionamos, fue realizada por del Mazo entre 1926 y 1927. A partir de estos documentos, que originariamente habían aparecido en revistas y que expresaban la posición de grupos estudiantiles y que comenzaban a aparecer en compilaciones y a expresar el movimiento político-cultural de la Reforma, tendió a configurarse el primer campo de estudio de la Reforma Universitaria.

En 1966 Alberto Ciria y Horacio Sanguinetti publicaron otra obra importante para nuestra investigación. Valiéndose de las compilaciones de del Mazo, de los rasgos señalados por algunas de las obras arriba mencionadas y, sobre todo, del archivo personal del líder reformista Florentino Sanguinetti, los autores elaboraron el primer estudio de las trayectorias políticas de los líderes reformistas argentinos. Por otra parte, en 1978 Juan Carlos Portantiero preparó para la editorial Siglo XXI una compilación de documentos de la Reforma, que contó con un ensayo que hoy se ha convertido en un clásico de los estudios sobre la Reforma y es un antecedente fundamental de la investigación que emprendemos. Si bien Portantiero analiza un espacio más amplio (estudia el devenir del movimiento estudiantil desde Córdoba hasta la Revolución Cubana pasando por Lima), veremos en el apartado siguiente que, en su intento de mostrar que la Reforma debe ser pensada como el inicio de la politización de algunas fracciones de las clases medias, propone

\footnotetext{
${ }^{6}$ Como ha subrayado Kohan (2000), llama la atención que Bermann no señale la línea en la que participó su amigo y compañero de empresas reformistas Deodoro Roca -ni en la que se inscribió el mismo Bermann, podríamos agregar-. Kohan propone que la ausencia de Roca se debe a que su interpretación fue tan completa que recuperó transversalmente elementos de cada una de las señaladas -y ello también podría explicar que Bermann no recuerde su entusiasta participación en una versión izquierdista e ilustrada de la Reforma-.
} 


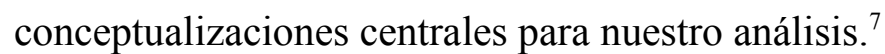

Un propósito similar al de Portantiero recorre la reconstrucción que llevó a cabo Kohan (2000). En este caso, la atención está puesta no en los procesos político-sociales, sino en el pensamiento y en las iniciativas de intelectuales reformistas y de izquierda, en su mayoría argentinos. Allí se arroja una lograda sistematización de muchas de las vertientes ideológicas socialistas del siglo XX que tomaremos como referencia.

Por otra parte, en los últimos años se han realizado algunas investigaciones que, siguiendo las preocupaciones de la historia intelectual de las que aquí partimos, analizaron importantes cuestiones. Específicamente, Terán (1998a) propuso un análisis de las condiciones de recepción de las ideas orteguianas. Vásquez (2000) y Cattáneo y Rodríguez (2000) formularon agudas reconstrucciones de las ideas y prácticas de las que se valieron los primeros reformistas para elaborar una intervención política que los distinguiera de la generación anterior. Tarcus (2001) rastreó la animada circulación de Mariátegui en el campo intelectual y en el campo político porteños de los años veinte, trayendo nuevas fuentes que prueban que la correspondencia, el envío de libros, las revistas de cultura y los grupos -entre los que se destacaban los reformistascompusieron "un campo intelectual sumamente politizado y movilizado, en plena efervescencia y cuyos enlaces latinoamericanos eran numerosos y significativos" (Tarcus, 2001: 22).

Por su parte, Graciano (2008), en una extensa investigación doctoral, se detuvo en la productiva y prolongada sociabilidad que tramó la generación reformista platense. En otra investigación extensa, Pita González (2009) reconstruyó la red político-cultural que a partir de 1923 consiguió desplegar Ingenieros en torno de la ULA y su boletín Renovación, y que, mediante sus vínculos con el APRA y su polémica con la Alianza Continental y la Liga Antiimperialista, se prolongó hasta 1930. Bergel y Martínez Mazzola (2010) introdujeron la pregunta por las prácticas "trasnacionales" -cartas, viajes y revistas, fundamentalmente- que acompañaron e incluso posibilitaron la construcción de la idea latinoamericanista de la Reforma y propusieron una primera reconstrucción.

Tanto el estudio de Portantiero como el de Ciria y Sanguinetti y las citadas investigaciones recientes nos ofrecen distintos análisis del movimiento político-cultural de la Reforma que son fundamentales para la presente investigación. Más precisamente, a los rasgos ideológicos del movimiento reformista argentino trazados por esos estudios buscamos aportar un análisis que complejice la periodización de la Reforma y el conocimiento de sus diversas empresas estudiantiles. Para ello incorporamos dos tipos de fuentes primarias aún muy poco trabajadas: las revistas

\footnotetext{
${ }^{7}$ Al igual que la compilación preparada por Dardo Cúneo (1978) para la Biblioteca Ayacucho, Portantiero seleccionó sus textos de los tomos editados por del Mazo en 1941. Por otra parte, la primera versión del ensayo de Portantiero fue redactada en 1969, cuando preparó una selección de textos más acotada para publicar en Milán en 1971 por la editorial comunista Il Saggiatore. Para un breve estudio comparativo de las dos versiones del ensayo, véase Bustelo y Celentano (2012).
} 
estudiantiles y las correspondencias. A ello sumamos la atención a los tres visitantes porteños convocados por la Reforma: Eugenio d'Ors, Georg Nicolai y Alfons Goldschmidt. Los estudios suelen señalar la visita que realizó Ortega y Gasset a la Argentina en 1916 y la de José Vasconcelos en 1922 como los dos hitos en la estructuración del archivo ideológico de la Reforma. Si bien no ponemos en duda la importancia de esas figuras, veremos que también fueron productivas las ideas y prácticas asociadas a d'Ors, Nicolai y Goldschmidt, quienes, además de haber estado ligados a una clara y polémica impronta izquierdista del movimiento estudiantil, fueron las únicas tres figuras que arribaron por la iniciativa del ala radicalizada de la Reforma, la FUC.

Las revistas que analizamos forman parte tanto de la historia de las industrias culturales argentinas como del proceso de especialización de los lectores y de las publicaciones. Ellas surgían en el mismo período en que aparecía una prensa moderna, sometida al mercado, que ensayaba nuevas ecuaciones comerciales y dejaba de buscar la conformación de la opinión politica de las elites para priorizar la información de los sectores medios y populares (Saítta, 1998; Girbal-Blacha y Quatrocchi-Woisson, 1999). Las publicaciones periódicas estudiantiles se dirigieron a los sectores medios -y algunas buscaron incorporar lectores pertenecientes a grupos obreros- pero, a diferencia de la prensa moderna, se mantuvieron alejadas del mercado e hicieron primar la formación de opinión. Como hemos sugerido, se propusieron como la herramienta de difusión, e incluso de formación, de la identidad cultural y/o política colectiva de una fracción de los sectores medios, la que accedía a la universidad y advertía que le faltaba aún una cultura política desde la cual intervenir.

Sobre todo las revistas estudiantiles aparecidas entre 1919 y 1921 participaron de la construcción de una prensa argentina de izquierda y en ese sentido deben incorporarse al mapa que trazaron Doeswijk (1024), Lobato (2009), Suriano (2004) y Tarcus (2007) a partir del estudio de distintos períodicos y familias políticas. Al respecto mencionemos que mientras que en las primeras dos décadas del siglo XX la prensa de izquierda (anarquista y socialista) competía, por sus lectores obreros, con la prensa comercial de masas y la gremial, la prensa político-ideológica estudiantil parece haber sufrido la competencia con las revistas vanguardistas argentinas, analizadas agudamente por Sarlo (1983) y Romano (1984). En ambos tipos de publicaciones primó un proyecto intelectual frente a los mandatos del mercado -e Inicial es la muestra de la posible convergencia entre vanguardismo estético-político y Reforma Universitaria-, pero en general la inscripción de las revistas estudiantiles en un proyecto democratizador de la universidad -y en muchos casos de la sociedad- tuvo un peso tal que no hizo lugar al desafío, característico de las revistas vanguardistas, de instalar nuevos cánones estéticos.

Trazados estos contrastes y similitudes entre los distintos tipos de publicaciones periódicas, mencionemos brevemente los análisis existentes de las revistas que componen nuestro corpus. 
Sobre varias de ellas el índice bibliográfico de Lafleur, Lorenzano y Alonso (2006) ofrece una primera aproximación, enriquecida en los últimos años por agudos análisis. Específicamente, aún no se ha realizado un estudio centrado en las siguientes revistas: Ariel de Montevideo, Revista Nacional, La Cureta, Clarín, Bases, Hoy, Claridad, Boletín de la Federación Universitaria de Buenos Aires, Boletín de la Federación Universitaria Argentina, Acción Universitaria, 1918, Cultura y Diógenes. Pero sí han merecido importantes análisis las siguientes: Cuadernos del Colegio Novecentista (Eujanian, 2001; Vásquez, 2002), Insurrexit (Tarcus, 1997 y 2004), Inicial (Alterman, 2003; Rodríguez, 2005), Renovación (Pita González, 2009), Valoraciones, Sagitario y Estudiantina (Rodríguez y Vásquez, 2002). A ellos hemos aportado nuestro estudio de Ideas (Bustelo, 2013), Ariel de Buenos Aires y los Cuaderno (Bustelo, 2012).

Estos distintos trabajos son fundamentales para alcanzar una mirada sistemática de las numerosas revistas estudiantiles aparecidas en Buenos Aires entre 1914 y 1928 y con ello de la cultura política que fueron tramitando los grupos estudiantiles. En ese sentido, merece ser recuperado, además del señalamiento de Aricó que transcribimos como epígrafe de la investigación, el realizado hace más de medio siglo por uno de los revisteros de la Reforma. En un artículo publicado por primera vez en 1950, Guillermo Korn, quien había sido secretario de Valoraciones y fundador de la Libertad Creadora (1943), proponía que el ciclo del "pensamiento político de la Reforma" se había desarrollado a través de las revistas. Más precisamente, sostenía que Ideas y los Cuadernos habían abierto ese ciclo al presentar los primeros "focos de política difusa" de la Reforma; esa política se desarrolló en diversas publicaciones hasta que Valoraciones cerró el ciclo en 1928. Recuperando esos diversos llamados a estudiar la Reforma desde las revistas, nuestra investigación ofrece una complejización del mapa trazado por Korn, pues incorpora otras publicaciones que, a pesar de que han sido olvidadas por los estudios sobre la Reforma, emergen como las herramientas privilegiadas de la construcción y disputa de una cultura política reformista.

\section{Marco teórico y metodológico}

La presente investigación es realizada desde el enfoque teórico de la historia intelectual centrada en los procesos de producción, recepción y discusión de ideas. Siguiendo las propuestas de Jay (2007, 1993), Altamirano (2007) Collini (2007) y Tarcus (2007), entendemos por "historia intelectual" un campo que retoma abordajes característicos de disciplinas como la historia social y política, la sociología de la cultura y el análisis del discurso, con el propósito de analizar e interpretar tanto las representaciones simbólicas difundidas por los intelectuales como los modos en que ellas se inscribieron en la realidad social. En ese sentido, se trata de un enfoque que parte del postulado de que las representaciones simbólicas no son el mero reflejo ideológico de una realidad preexistente, sino que tienen efectos modeladores sobre ella, así como condiciones de posibilidad dictadas por 
esa realidad. Asimismo, el enfoque adoptado se distancia de la "historia de las ideas" para proponer una disciplina que se preocupe, además de las ideas, de la historia social y política de los actores de la cultura y de sus prácticas culturales.

Sobre ese vínculo entre "ideas" y "aquello que no lo es", seguimos las advertencias de Bourdieu (2009), Palti (2007) y Tarcus (2007) relativas al carácter activo de todo proceso de recepción de ideas, o bien a la condición de que las ideas viajan sin sus contextos y que, por ello, toda recepción es una "apropiación"; lo relevante entonces no es medir el grado de fidelidad a las ideas originales sino recomponer, por un lado, los canales materiales (en nuestro caso, los grupos, revistas y cátedras, fundamentalmente) que posibilitaron esa apropiación y, por otro, el modo en que ella se articuló con el sistema de ideas previo y con la realidad a la que se propuso modelar. Asimismo, retomando a Angenot (2010), procuramos identificar el modo en que las ideas fueron agrupadas hasta constituir "matrices culturales" dentro del horizonte de lo "decible" en el discurso social del período estudiado.

Esta atención a la compleja y disímil circulación de las ideas nos conduce a ocuparnos no sólo de las figuras centrales en el espacio intelectual, sino también de otras marginales y de breve intervención, a las que nos acercaremos ayudados por las herramientas de la microhistoria y de la sociobiografía -especialmente, del estudio modélico que ofrece Williams (1982) sobre el grupo Bloomsbury-. Sobre la importancia de atender a las prácticas de un movimiento político-cultural como el de la Reforma que termina por inscribirse y reformular el campo de las izquierdas argentinas, así como sobre el rescate de las figuras marginales o de breve intervención, traigamos algunas de las preguntas que formulaba Tarcus (2007a) a la historiografía argentina cuando justificaba la necesidad de un diccionario biográfico de la izquierda argentina. Alentando el armado de prosopografías posibles a partir de una perseverante búsqueda en archivos personales y fuentes que solían considerarse menores, se interroga Tarcus:

¿Como estudiar las grandes corrientes de pensamiento de la izquierda sin saber qué sujetos singulares las recibierons, se las apropiaron y las difundieron?, ¿sin examinar quiénes intentaron implantarlas en los gremios, en los partidos políticos, en los centros de estudiantes o en la prensa? ¿cómo analizaron los grandes acontecimientos históricos sin saber cómo se orientaron ante ellos los sujetos singulares que los impulsaron, o los resistieron? [...] ¿Quienes dieron vida, concretamente, a instituciones como el Socorro Rojo, la Unión Latinoamericana, la AIAPE o el FAS? ¿Es suficiente conocer el porgrama y los pronunciamientos públicos de estos nucleamientos, o para comprenderlos en profundidad es necesario identificar los sujetos singulares que se comprometieron en darles vida? (Tarcus, 2007a: XIV).

Es teniendo en cuenta las certezas historiográficas que sugieren esas preguntas y sumando a ello la advertencia de Altamirano (2005: 15-16) sobre las elites intelectuales como actores significativos no 
sólo en lo relativo a la cultura (el dominio de las ideas, el arte o la literatura), sino también en la historia política que nos orientamos, dentro del amplio campo de la historia intelectual y de los debates implicados en su construcción disciplinar, hacia la historia de los intelectuales. En otros términos, retomando la advertencia sobre las elite intelectuales y las citadas preguntas sobre la historia de las izquierdas argentinas, nos proponemos contribuir a la elaboración de una historia de los intelectuales argentinos y de la cultura de izquierdas a través de una investigación que se instala en el cruce entre la lectura interna del discurso producido por un grupo o un intelectual y su lectura externa, esto es, el análisis de las repercusiones que ese discurso tuvo entre los pares intelectuales y la relación con la sociedad de la que emergió. En conexión con ello, esta investigación reconoce en las revistas una fructífera vía para recuperar la construcción de una cultura política estudiantil.

Presentada la propuesta, detengámonos en una cuestión metodológica, el corpus de las revistas, y dos cuestiones conceptuales, una relativa al concepto de cultura política y otra al de estudiante. En cuanto a las revistas, la importancia de su análisis para la historia intelectual ha sido señalado de modo particular por Sarlo (1992) y Pluet-Despatin (1999), entre otros autores. La primera autora ha subrayado que las revistas culturales son un laboratorio de ideas que debe ser analizado como una práctica de producción y circulación cultural marcada por la temporalidad presente, pues, a diferencia de los libros, las revistas tienden a conformar un grupo cuya finalidad principal es la voluntad de intervenir públicamente en la coyuntura. Esa intervención se expresaría en una "sintaxis", o bien en la disposición asignada por cada revista a sus textos y temas. El análisis de esa sintaxis permitiría recuperar las problemáticas del campo intelectual del período, el modo en que fueron leídos los textos, los límites ideológicos y estéticos de la coyuntura, la "política" de cada revista (esto es, el campo de lo deseable y lo posible de cada proyecto) y la "geografía" de cada revista (esto es, el espacio de circulación y el espacio imaginario en el que se ubica idealmente el proyecto).

Por su parte, Pluet-Despatin propone una serie de ejes de análisis que tienden a coincidir con los de Sarlo. Utilizando ejemplos del campo francés y una conceptualización diversa, aquella también destaca que las revistas deben ser abordadas teniendo en cuenta que allí se reúne bajo una misma afinidad un grupo que construye una sociabilidad y unas relaciones de poder, que su intervención privilegia el presente y que la línea editorial se advierte en la disposición de los textos y no sólo en las declaraciones editoriales. Seguramente, los señalamientos más interesantes de este texto en relación con el de Sarlo sean, por un lado, la advertencia sobre la posibilidad de que las revistas, en términos de Bourdieu, logren institucionalizar un conjunto de reglas que establezcan un campo autónomo; y, por otro, el llamado a recuperar tanto la "cocina" de las revistas como las actividades e instituciones que estuvieron ligadas a ella.

En consonancia con este tipo de abordaje de las revistas, Fernando Rodríguez ha propuesto 
que las editadas por los reformistas fueron un "laboratorio de la militancia moderna" de los años veinte $\mathrm{y}$, en diversos trabajos, ha mostrado la productividad de esa clave (Rodríguez, 1999; Cattáneo y Rodríguez, 2000; Vásquez y Rodríguez, 2002; Rodríguez, 2004).

Respecto de las conceptualizaciones que estructuran la presente investigación, en las páginas anteriores nos hemos referido a la "cultura política" de la Reforma. Con ello retomamos, haciendo una importante salvedad, la formulación que propuso Berstein (1999). Éste introdujo la noción de cultura política para incorporar, en los estudios centrados casi exclusivamente en las líneas políticas asumidas por las conducciones partidarias, el análisis de las ideas, las prácticas y el modo en que ambas fueron retomadas y reformuladas por quienes adhirieron a las líneas partidarias. La utilización de "cultura política" en el estudio de la Reforma nos permite analizar las ideas y prácticas desde las que diferentes animadores, ubicados no siempre en espacios reconocidos, tramaron una sociabilidad común y una identidad estudiantil prolongada.

Pero, a diferencia de las grandes corrientes políticas que toma como referencia Berstein, el movimiento político-cultural de la Reforma no dejó de estar recorrido por fuertes disputas en cuanto a sus ideas y prácticas definitorias, y con ello no alcanzó una visión del mundo sistemática -incluso puede aplicársele el diagnóstico que hacía Real de Azúa (1986) sobre el modernismo y su carencia de una estricta ideología-. En ese sentido, estudiaremos las ideas y prácticas compartidas por la cultura política reformista, pero también las que permanecieron en disputa y desde esa condición se inscribieron en la cultura política reformista.

Específicamente, el movimiento de la Reforma definió algunas prácticas (como la redacción de manifiestos y la organización de grupos y de revistas) e ideas (el juvenilismo o arielismo a través del que los estudiantes se reconocieron llamados a intervenir en la sociedad y la democratización de la universidad) asociables a una cultura política. Pero, a distancia de la precisión y sistematicidad de los partidos políticos, esa cultura estuvo recorrida por fuertes disputas en torno de otras ideas y prácticas, sobre todo en cuanto a la adhesión al cientificismo o al antipositivismo, el tipo de relación de los estudiantes con las organizaciones obreras, el deslumbramiento y solidaridad con la Revolución Rusa, el nacionalismo y el antiimperialismo.

Respecto del deslinde del estudiante como un tipo de intelectual, es conocida la falta de acuerdo sobre la noción de intelectual. Siguiendo el mapa propuesto por Altamirano (2007), esa noción ha sido asociada a la configuración de sociedades de carácter moderno y a la formación de un campo intelectual, pero las diferencias comienzan cuando se intentan precisar sus rasgos definitorios. A la discusión en torno de un enfoque normativo que analice a los intelectuales siguiendo una definición previa, o bien un enfoque descriptivo que atienda a la autopercepción de los sujetos en cuestión, se suman la cuestión de la vinculación entre el intelectual y la dimensión pública y moral, el interés público y la asociación de las ideas a la verdad. Más que interesarnos en 
precisar una noción de intelectual, procuramos aquí un enfoque descriptivo desde el que reconstruir las distintas figuras de intelectual con las que los grupos y revistas estudiantiles argentinas de comienzos del siglo XX construyeron una identidad política del estudiante, o bien lograron que los jóvenes que estudiaban en la universidad se reconocieran como un tipo de actor social y político con prácticas y plataformas de intervención particulares. Desde esas prácticas y plataformas, la juventud universitaria se vinculó y diferenció de otras figuras de intelectual -fundamentalmente, del escritor, el científico, el profesor y el artista-, pero además participó de una primera instancia de aprendizaje político-cultural que se revelaría como fuente de reconocimiento en el itinerario posterior, esto es, cuando esos estudiantes devinieron científico, profesores, escritores o artistas con una pretensión de intervención pública.

Los lineamientos conceptuales más significativos de esa juventud universitaria y del movimiento continental de la Reforma, sin duda, fueron formulados por el mencionado ensayo de Portantiero (1976). Guiado por una matriz gramsciana, aquel identificó al movimiento reformista con una situación de Kulturkampf ${ }^{8}$ y lo enmarca conceptualmente en la posibilidad que advierte Gramsci cuando, en uno de sus Cuadernos de la Cárcel, reflexiona sobre la "cuestión de los jóvenes". La única cita textual de Gramsci que realiza Portatiero es la siguiente: "La burguesía no consigue educar a sus jóvenes (lucha de generaciones) y los jóvenes se dejan arrastrar culturalmente por los obreros y al mismo tiempo hacen o tratan de convertirse en jefes (deseo 'inconsciente' de realizar la hegemonía de su propia clase sobre el pueblo) pero con las crisis históricas vuelven al redil" (Portantiero, 1978: 84). Los estudiantes reformistas latinoamericanos formarían parte de esa fracción de la burguesía que rompió con la generación anterior para aliarse a los obreros y enfrentarse a las oligarquías. Para entender la "vuelta al redil" Portantiero retoma la distinción gramsciana relativa a las organizaciones sociales: los grupos estudiantiles transitarían por un "momento corporativo", en el que sus reivindicaciones giran en torno de intereses gremiales, o por un "momento político", en el que cuestionan al Estado y participan de la construcción de una fuerza cultural y política que disputa la hegemonía acumulada por áquel.

En esas teorizaciones gramscianas, Portantiero encuentra la posibilidad tanto de realizar un giro marxista en la doctrina de las generaciones con que se solía explicar la Reforma como de evitar la apelación exclusiva a cuestiones económicas. Si los alicientes externos de una organización estudiantil que reclama la democratización de la universidad y de la sociedad en su conjunto deben buscarse en las noticias de la Revolución Rusa y el activo ciclo de protestas obreras de varios países latinoamericanos, los alicientes internos residen en la modernización de las sociedades y en el

\footnotetext{
${ }^{8}$ Una de las notas en las que Gramsci realiza esa caracterización fue publicada en Los intelectuales y la organización de la cultura. Allí se lee: "En general, se puede decir que en estas regiones americanas existe una situación Kulturkampf (lucha cultural) y de proceso Dreyfus, es decir, una situación en la que el elemento laico y burgués no ha alcanzado la etapa de la subordinación de los intereses de la influencia clerical y militar a la política laica del estado moderno" (Gramsci, 1975: 27).
} 
surgimiento de una clase media que asiste a la universidad y pugna por incorporarse a la vida política; el similar grado de desarrollo del capitalismo en América Latina sería un factor interno decisivo -pero no el único- para explicar la emergencia de la Reforma, su expansión continental y su absorción por el Estado.

Esa explicación no puede olvidar que el conflicto se produce porque el movimiento de las estructuras sociales libera fuerzas, las clases medias reunidas en la universidad, que intentan ser frenadas por las oligarquías. Desde comienzo de siglo y hasta algunas décadas después de la Reforma, según Portantiero, la universidad funcionó como un reducto político de las clases medias, "quienes, relegadas del poder, tendieron a construir en la universidad reformista un espacio de autoafirmación social y política" (Portantiero, 1978: 22). De las filas de esas clases medias, pertenecientes a distintas urbes capitalistas del continente, emergió a partir de 1918 la Nueva Generación, o bien un grupo de jóvenes que desbordó los horizontes de su clase para proyectar reivindicaciones políticas que dependieron de alianzas interclases y se articularon desde una relativa estabilidad ideológica de izquierda.

La movilización de los conceptos del marxismo gramsciano le permite a Portantiero ordenar y valorar los distintos proyectos reformistas, pues el auténtico movimiento de la Reforma "supone en su origen una intención de cambio social, que va más allá de modificar la ordenación de las casas de estudio" (Portantiero, 1978: 13), o bien la intención de que la organización estudiantil pase de un momento corporativo a uno político. En ese sentido, el sector reformista "avanzado" sería el que buscó reconducir los reclamos desde la cuestión estudiantil hacia el delineamiento de una ideología que, durante la década del veinte, se articuló en torno del "humanismo utópico, el socialismo liberal y el nacionalismo" (Portantiero, 1978: 29). Ese sector habría reconocido rápidamente que el movimiento tenía como "límite infranqueable" su confinación a las aulas. Portantiero es sumamente claro al respecto: "La reforma en las aulas no puede ser absorbida por las poco permeables clases dominantes. O es un capítulo de la reforma social o termina triturada por los intereses de los poderosos. En ambos casos la estructuración de la respuesta debe ser global, política, extrauniversitaria" (Portantiero, 1978: 62).

Por un lado, de la caracterización de la Reforma citada Portantiero extrae el tipo de abordaje: dado el carácter extrauniversitario de la Reforma, "todo análisis que intente acercarse a sus raíces deberá detenerse en el aislamiento de variables más específicas para cada país, más particulares en cuanto indicadoras del grado de desarrollo económico, social y político de las distintas sociedades latinoamericanas" (Portantiero, 1978: 13). Esas sociedades comparten una similar estructura económico-social (en la que se registra la existencia de vastos sectores sociales que buscan conquistar mayor participación social, política y cultural) que opera como condición de posibilidad de la expansión de la Reforma y cuya especificidad nacional es analizada en los casos de Argentina, 
Perú y Cuba. Por el otro, de la reconstrucción de esos procesos ideológicos concluye que en torno de la Reforma se conformó "la mayor escuela ideológica para los sectores avanzados de la pequeña burguesía, el más frecuente espacio de reclutamiento de las contraélites que enfrentaron a las oligarquías y de [las que] surgieron la mayoría de los líderes civiles latinoamericanos" (Portantiero, 1978: 14). Esa “escuela ideológica" habría producido dos tipos de egresados cuya profunda desconexión entre sí tendría efectos sumamente negativos para la izquierda latinoamericana: el socialismo internacionalista e ilustrado, del que Mariátegui sería su figura más destacada, habría ido por un lado, mientras que el movimiento antitimperialista y populista, liderado por Haya de la Torre, marchó por el otro.

Una preocupación central de la presente tesis es precisar las peculiares "escuelas ideológicas" que propusieron los jóvenes argentinos de las clases medias. Retomando los análisis sobre el específico desarrollo social, económico y político de la Argentina en la que se desarrolló el movimiento reformista, analizamos los distintos grupos y revistas que entre 1914 y 1928 buscaron que los estudiantes se reunieran no sólo para delinear sus intereses gremiales comunes (como el cupo de alumnos aprobados en los exámenes, la asistencia libre y el costo de los aranceles universitarios), sino también una mirada y un tipo de intervención políticas. En ese análisis, atendemos a las preocupaciones de una historia de los intelectuales atenta a la microhistoria y la sociobiografía, incorporamos nuevas fuentes, reinscribimos los documentos de la Reforma en las revistas y los grupos a los que estuvieron originariamente asociados, y nos guiamos por dos conceptualizaciones propuestas por Portantiero: la estrecha vinculación de la Reforma con una reforma social y el pasaje del movimiento estudiantil de un momento corporativo a uno político. A pesar de algunos intentos que analizaremos, en la Argentina el momento político no se enmarcó en un partido político, sino en grupos, revistas, manifiestos, ensayos, cargos públicos, cátedra, conferencias, bibliotecas y huelgas. En muy pocas situaciones esas iniciativas se inscribieron de modo prolongado en un frente que disputaba la hegemonía del Estado, pero ellas sin duda lograron acuñar "cultura política" recorrida por ideas y prácticas que moldearon la intervención estudiantil.

\section{Síntesis del recorrido de la investigación}

La investigación ha sido dividida en ocho capítulo agrupados en dos partes. La organización en esas partes fue decidida por la hipótesis de que, hacia 1918, el estallido de la Reforma Universitaria en Córdoba, junto con la fuerte protesta obrera a nivel nacional y con las noticias de la Revolución Rusa, motivó la politización de una identidad estudiantil que, desde algunos años antes, venían construyendo los grupos estudiantiles porteños. A partir de entonces habría sido más claro y entusiasta el figura de un estudiantes que se sumaba a la construcción de una hegemonía cultural y política en disputa con la concentrada por el Estado. Los capítulos que conforman la primera parte 
se concentran en el análisis de las agrupaciones y revistas estudiantiles que comenzaron a precisar una imagen colectiva. Siguiendo la terminología gramsciana, proponemos que esas agrupaciones y revistas estructuraron el "momento corporativo" de la organización estudiantil.

Específicamente, el primer capítulo tiene como objetivo presentar los rasgos generales de las agrupaciones estudiantiles que intervinieron en las dos primeras décadas del siglo XX. Para ello comienza por recuperar, a partir de la bibliografía crítica y de las memorias de algunos protagonistas, el tipo de sociabilidad y tareas de los Centros de Estudiantes, esto es, de las primeras agrupaciones que se dieron los jóvenes universitarios porteños. Luego el capítulo se detiene en los grupos culturales fundados por estudiantes en la década del diez, para subrayar que éstos no sólo decidieron editar revistas culturales desde las que precisaron y difundieron un tipo de identidad estudiantil, sino que además optaron por tres matrices culturales diversas en torno de las que, hasta 1918, se definió esa identidad estudiantil: el cientificismo socialista comprometido con la difusión del conocimiento entre los obreros, la cultura estética ligada a los valores éticos y estéticos grecolatinos y la cultura católica asociada a la encíclica Rerum novarum.

El segundo capítulo analiza la figura de estudiante propuesta por el Centro Ariel y su revista Ariel, por un lado, y el Ateneo de Estudiantes Universitarios e Ideas, por el otro. La importancia de estos dos grupos reside en que hemos descubierto que fueron los que entre 1914 y 1918 más se empeñaron en que los estudiantes porteños dejaran de preocuparse exclusivamente por su trayectoria académica para reconocerse como actores con una específica función en la sociedad.

El tercer capítulo recupera la gravitación en la cultura universitaria de lo que entonces se entendía como la "Renovación Española", y específicamente se detiene en la auspiciosa difusión del proyecto de la Residencia Española de Madrid que emprendió el mencionado Ateneo y la recepción, también intensa, del proyecto de renovación cultural ligado al filósofo catalán Eugenio d'Ors, una recepción animada especialmente por los jóvenes antipositivistas que, a mediados de 1917, fundaron el Colegio Novecentista y su publicación Cuadernos.

El objetivo del cuarto capítulo es analizar las proyecciones estudiantiles del debate de la década del diez sobre la validez de la matriz científica para pensar la cultura, y específicamente sobre el lugar asignado a la racionalidad científica y a la vinculación entre filosofía y política. Los dos grupos estudiantiles aquí estudiados intervinieron en la FFyL de Buenos Aires y se reunieron, uno en torno de la revista Verbum y del proyecto cientificista de la Revista de Filosofía de José Ingenieros, y otro en torno del antipositivismo orsiano y los mencionados Cuadernos del Colegio Novecentista.

Los capítulos de la segunda parte analizan la sociabilidad y las iniciativas tramadas por los grupos porteños una vez que el movimiento estudiantil se instaló en un "momento político". El objetivo general de esta parte de la investigación es mostrar que, si bien hacia 1928 quedó 
configurada en Argentina una cultura reformista que, durante décadas, ligó al estudiante a una identidad latinoamericana y antiimperialista y fue disputada por el PS, el PC y fracciones de la UCR, en los diez años anteriores habían tenido lugar diversas empresas reformistas que asociaron la figura del estudiante a identidades políticas tan diversas como el nacionalismo de resonancias católicas y el socialismo bolchevique. El capítulo que abre esta segunda parte repasa el modo en que se reconfiguró el mapa de agrupaciones y revistas estudiantiles porteñas ante el conflicto que protagonizaron los estudiantes de la FUC. Para ello recupera la intervención de la olvidada Federación de Asociaciones Culturales y reconstruye la disímil posición política por la que optaron el Ateneo y el Colegio, dos grupos hermanados por su definición antipositivista en el debate sobre el cientificismo, pero desde fines de 1918 distanciados por la reivindicación del socialismo del primero y del nacionalismo católico del segundo. El capítulo se cierra con el análisis de dos revistas estudiantiles surgidas en 1918 que se dirigieron a los estudiantes de Derecho y de Filosofía y Letras y rivalizaron entre sí: Themis, asociada al Ateneo y al socialismo, y la Revista Nacional, ligada al Colegio y al nacionalismo de resonancias católicas.

El capítulo sexto muestra la emergencia del primer periodismo político estudiantil. Se recupera allí el tipo de posicionamientos y proyectos estudiantiles de las revistas izquierdistas que entre 1919 y 1922 editaron el Ateneo, el Centro de Estudios Ariel de Montevideo, el grupo de Juan Antonio Solari y el grupo Insurrexit.

El siguiente capítulo analiza tres eventos institucionales ligados a la construcción de una cultura política universitaria de izquierda: la invitación que realizó la UNC -y que saludó la Federación Universitaria Argentina (FUA) y los grupos reformistas radicalizados- a Eugenio d'Ors; la contratación de dos profesores judeoalemanes reconocidos, al igual que d'Ors, por sus posiciones izquierdistas, Alfons Goldschmidt y Georg Nicolai; y la llegada de la Reforma a la aristocrática Facultad de Derecho de Buenos Aires. Si bien desde 1923 la facultad recuperó su impronta antirreformista, el análisis del período reformista tiene especial importancia porque, al calor de la resistencia a la Reforma que ofrecieron los profesores de Derecho, surgió el grupo que, en vinculación con la ULA y otras agrupaciones, tramó la sensibilidad latinoamericana y antiimperialista del estudiante que terminó por ligarse a la Reforma.

El capítulo octavo examina el tipo de intervención que propuso la fracción de reformistas que hacia 1923 acentuó el tramado de una cultura política reformista ligada al latinoamericanismo antiimperialista. En esos años, en los que el retroceso tanto del ciclo nacional de protestas obreras como de las insurrecciones europeas instaló nuevamente la primacía de la cultura sobre la política en la intervención estudiantil, se registraron tres grupos y revistas ligados a proyectos reformistas rivales: la revista Inicial que difundió un vanguardismo estético y político, la revista Valoraciones que retomó el antipositivismo del Colegio Novecentista para ligarlo no al nacionalismo sino a lo 
que Alejandro Korn había definido como un "socialismo ético" y la revista Sagitario que, en tanto publicación cultural de la ULA, enlazó el reformismo a un antiimperialismo izquierdista.

La investigación se cierra con un apartado de "Conclusiones finales" en el que se sistematizan los principales rasgos de los grupos y revistas analizados y con ello de la cultura política acuñada por la Reforma Universitaria. 
PRIMERA PARTE. EL MOMENTO CORPORATIVO 


\section{CAPÍTULO 1. La construcción de una "familia estudiantil"}

El presente capítulo se propone esbozar el perfil de los jóvenes que estudiaban en la UBA durante las primeras décadas del siglo XX. A partir de la revisión de la bibliografía crítica, de las memorias y de las revistas estudiantiles, reconstruimos tanto la inicial sociabilidad estudiantil tramada en torno de los Centros de Estudiantes como la que se conformó hacia la década del diez cuando aparecieron grupos estudiantiles que se erigieron en una suerte de ateneos culturales y proyectaron empresas editoriales.

\section{La Universidad de Buenos Aires}

A comienzos del siglo XX, las ciudades capitales de ambos márgenes del Río de la Plata registraron un acelerado proceso de inserción en el mercado internacional, proceso que sería acompañado de una creciente instalación del conflicto obrero y de una, menos acelerada, modernización cultural. Dejando atrás la "gran aldea" de trescientos mil habitantes que retratara Lucio Vicente López en su novela de 1884, el censo de 1914 revelaba una Buenos Aires de un millón seiscientos mil habitantes, y un crecimiento similar -aunque de menor escala- se registraba en la población de Montevideo, donde la cifra de habitantes se elevó de ciento cincuenta mil a más de trescientos mil.

Ese crecimiento poblacional también alcanzó a las universidades, las que desde fines de la década del diez atravesarían una importante modernización impulsada por los estudiantes y, específicamente, por el movimiento de alcance continental que se identificaría como la Reforma Universitaria. Durante las primeras décadas del siglo XX, tanto la UBA (fundada en 1821 en competencia con la Universidad de Córdoba, UNC) como la Universidad de la República (creada en 1849 y, durante muchas décadas, la única casa de estudios superiores estatal del Uruguay) abrieron nuevas carreras e incrementaron fuertemente su matrícula (Halperín Donghi, 1962; Buchbinder, 2005; Odonne y Paris de Odonne, 2010). A ellas se sumaba en 1906 la Universidad Nacional de La Plata (UNLP), fundada, en principio, para proveer a la provincia de Buenos Aires de profesores secundarios, profesionales de la administración pública y de la salud, y expertos de la industria agraria (Castiñeira, 1940; Palacios, 1925). ${ }^{9}$

Las universidades perdían por entonces parte de su condición de espacio de sociabilidad de las elites económicas y políticas, pues el crecimiento de la matrícula universitaria era producido por el ingreso de los hijos de una emergente clase media. Ésta lograba una estabilidad económica que le permitía solventar los estudios superiores de sus jóvenes. Y como la high society no fundó instituciones propias, sus hijos varones comenzaron a convivir con los jóvenes que ingresaban a la

\footnotetext{
9 En cuanto a la disímil matrícula de las tres universidades nacionales existentes antes de la Reforma, consigna Buchbinder (2005: 75) que para 1916 la UBA contaba con cinco mil cuatrocientos estudiantes mientras que la UNLP tenía algo más de mil y la UNC sólo setecientos. Cifras que serán importantes para entender la preocupación de los estudiantes federados por que la FUBA adhiera a las reivindicaciones de la FUA y movilice a los estudiantes.
} 
Universidad no para obtener la formación y sociabilidad que los reafirmara en su condición de elite dirigente, sino un título de médico o abogado que les asegurara el ascenso social y económico (Losada, 2008: 106-109). ${ }^{10}$ Asimismo, los varones de la alta sociedad y de las clases medias que optaban por la Facultad de Medicina comenzaron a compartir las aulas con unas pocas mujeres. A partir de la fundación, en las última década del siglo XIX, de las primeras escuelas normales, las mujeres pudieron obtener un título de maestra y con ello ejercer una profesión estrechamente ligada a las que serían sus tareas "naturales" de cuidado. Desde entonces presionaron para estudiar en la universidad, y algunas de ellas, luego de presentar recursos judiciales y esperar varios meses, conseguían ingresar a carreras también ligadas a esas tareas "naturales", esto es, enfermería, farmacéutica y obstetricia. Por otra parte, con la fundación de la FFyL en 1896 las mujeres contaron con una facultad que, a diferencia del resto, aceptaba automáticamente el título de las escuelas normales. ${ }^{11}$

Seguramente, el primero que, sin ocuparse de las mujeres, haya reflexionado de modo sistemático sobre el proceso democratizador que se desplegaba en el Uruguay fue el filósofo Carlos Vaz Ferreira (1872-1958). Sostenía en 1908 en su Moral para intelectuales:

Las profesiones liberales tienen entre nosotros una muy caracterizada y profunda significación democrática [...] No hay absolutamente ninguna otra profesión, sea la que sea, comercio, industria, la que ustedes quieran, que permita como aquéllas al que está dotado de talento y voluntad elevarse legítimamente en menos tiempo, sin apoyo de ningún género, sin protectores, sin amigos, sin recomendaciones, sin padres y sin herencias. [...] Hasta desde el punto de vista puramente social, esa significación democrática de las profesiones liberales, entre nosotros, se manifiesta manteniendo, diremos, una especie de ósmosis continua de las clases, e impidiendo la formación de aristocracias en el mal sentido del término, sean aristocracias de nombre, sean aristocracias de dinero, menos dignas todavía. [...] el ascenso, por esas profesiones, se produce con tanta facilidad que, repito, no se necesita siquiera la vida de una generación; bastan unos cuantos años: los de carrera de un estudiante... (Vaz Ferreira, 1978: 214-215; destacado del autor).

Si bien la obtención de un título universitario tendía a desdibujar las jerarquías socioculturales, la observación de Vaz Ferreira también tenía una alta carga prescriptiva, pues los reclamos reformistas

\footnotetext{
${ }^{10}$ Hasta las primeras década del siglo XX, los hijos de la elite político-económica argentina tendieron a seguir el siguiente recorrido intelectual: luego de terminar los estudios secundarios en el Colegio Nacional Buenos Aires, cursaban la carrera de Derecho y coronaban esos estudios con la asistencia a cursos de especialización en Europa (Losada, 2008). Recordemos que el Colegio Nacional y el Instituto Libre de Estudios Superiores eran los únicos institutos que el Estado reconocía automáticamente para ingresar en la universidad, mientras que los egresados de otros institutos tenían que rendir un examen.

${ }^{11}$ Para atraer a un mayor número de estudiantes, la FFyL decidió, además de dictar los cursos en horario vespertino, la habilitación de las mujeres. La formación universitaria de las mujeres en esta universidad era menos cuestionada porque, a diferencia de las otras facultades, FFyL brindaba un saber "desinteresado", esto es, una formación que otorgaba un título de doctor y no una matrícula que regulaba una profesión liberal. De todos modos, una vez que la facultad contó con casi un tercio de mujeres entre su alumnado, se reclamó -y en algunos breves periodos se logró- un título que habilitara a la enseñanza secundaria. Sobre el ingreso de las mujeres a la UBA, véase Denot (2007), Barrancos (2007) y García (2006).
} 
que asumieron desde 1918 distintos grupos rioplatenses muestran que el paso por la universidad mantuvo rasgos que consolidaban como profesores y autoridades a los miembros de la elite política y que dificultaban la permanencia de los estudiantes de clase media.

Durante la primera década del siglo XX, tanto en la ciudad de Montevideo como en la de Buenos Aires y de La Plata, una parte de esos estudiantes de clase media fundaron grupos y revistas desde los que, por un lado, saludaron el crecimiento de la matrícula ${ }^{12}$ y, por otro, reclamaron condiciones que agilizaran y democratizaran las carreras (específicamente, la baja de los aranceles de los exámenes, la ampliación de los cupos de aprobados y la validez de los exámenes de marzo) ${ }^{13}$ $\mathrm{y}$, finalmente, buscaron democratizar la conformación de la planta docente y el gobierno universitaria.

Y si el crecimiento de la matrícula posibilitaba que los reclamos estudiantiles adquirieran una importante visibilidad en la ciudad, la nueva proveniencia social fue central para que esos reclamos trascendieran las cuestiones gremiales e hicieran emerger a la juventud estudiosa como un nuevo actor de la escena política (Buchbinder, 2005; Chiroleu, 2000; Graciano, 2008; Portantiero, 1978). Juventud que, por otra parte, no sólo estuvo durante décadas constituida exclusivamente por varones sino que además no tuvo entre sus reivindicaciones centrales la incorporación de las mujeres en el sistema universitario. ${ }^{14}$

En términos de uno de los historiadores que analizó la emergencia de la juventud en el espacio político-social porteño:

La democratización de nuestro régimen de gobierno creó, sin embargo, una fuente nueva de tensión, originada en los grupos desplazados del poder político, que si no podían expresarse bajo la forma de protesta tumultuosa, encontraban otros modos de manifestación a la larga no menos eficaces. [...] Ese tono de vida nacional no puede no encontrar algo más que un eco en el plano universitario: también en él resulta

\footnotetext{
${ }^{12}$ Un ejemplo de ese saludo lo ofrece el primer número de Ideas (septiembre de 1915: 84), en el que se subraya que la FUBA reunía a nada menos que cinco mil estudiantes. Cuatro años después, cuando ya había estallado la Reforma, los distintos números de Bases (1919-1920) alentaron la participación en la misma federación anunciando a los estudiantes que allí "10.000 compañeros los esperan entusiastas y fraternalmente, para la obra común de impedir que el futuro de nuestro país se escriba en libros de caja". Por otra parte, el órgano de la FUC exageraba la cifra para declarar que no estaba sola porque "45.000 estudiantes", representados por la FUA, los acompañaban (Suplemento de La Gaceta Universitaria, $\mathrm{n}^{\circ} 8,10 / 06 / 1918, \mathrm{~s} / \mathrm{d}$.).

${ }_{13}$ Aclaremos aquí que ni la gratuidad ni la eliminación de los exámenes de ingreso (dos núcleos centrales del movimiento estudiantil de mediados del siglo XX) formaron parte de las reivindicaciones estudiantiles iniciales. Es que en las primeras décadas del siglo los grupos estudiantiles tendían a considerar, por un lado, a las casas de estudio como una institución demasiado onerosa y exclusiva como para que fuera financiada por la sociedad en su conjunto y, por el otro, a los exámenes como una garantía del nivel académico.

${ }^{14}$ Cuando surgen los primeros grupos, ya había numerosas estudiantes mujeres -sobre todo en la Facultad de Medicina y en la de Filosofía y Letras-, pero recién en los años veinte algunas participarían de agrupaciones estudiantiles de carácter gremial, cultural o político. Según veremos, a fines de los diez, sólo unas pocas voces, entre las que se destacan las de Mercedes Gauna y Herminia Brumana, reclamaron desde grupos estudiantiles la incorporación de las mujeres en la universidad. De todos, por fuera de esos grupos sí se registraron iniciativas que reclamaban la igualdad de las mujeres, como la Asociación Universitarias Argentinas y el Congreso Feminista Internacional de la República Argentina de 1910 (Asociación Universitarias Argentinas, 2010). Sobre los grupos feministas anarquistas de las primeras décadas del siglo XX y sus discusiones, véase Fernández Cordero (2014). Sobre los grupos socialistas, véase Barrancos (2007) y Becerra (2009).
} 
determinante, y permite entender mejor las vicisitudes, a primera vista desconcertantes, de la institución universitaria en los años que van hasta 1930 (Halperín Donghi, 1962: 106-107).

Entre las universidades mencionadas, el crecimiento de la UBA fue sin duda el más notable. A las facultades de Derecho, Medicina, Ciencias Exactas, Físicas y Naturales se agregaron: en 1896 la de Filosofía y Letras, en 1909 la de Agronomía y Veterinaria y en 1913 la de Económicas. Asimismo, entre 1880 y 1910 la matrícula estudiantil pasó de mil a cinco mil estudiantes (Chiroleu, 2000; Buchbinder, 2005). Esa cifra prácticamente se duplicaría en 1918, lo que -como veremos en el quinto capítulo- convenció a los estudiantes cordobeses de que el apoyo de esos estudiantes era central para que sus reclamos iniciaran un movimiento político-cultural como el de la Reforma.

La renovación cultural que vivió Buenos Aires a comienzos del siglo XX -retratada tempranamente por Manuel Gálvez en su exitosa novela El Mal Metafísico (1916)- tuvo su centro de irradiación en espacios extrauniversitarios como las tertulias de café y la prensa. Pero, según el análisis del presente capítulo, parte de esa renovación también fue irradiada por las universidades, espacio en el que, como anhelaba Vaz Ferreira, tendían a disolverse las aristocracias y a democratizarse la alta cultura.

\section{Inicios de la agremiación estudiantil porteña}

A fines de febrero de 1903 vine de la estancia, en la que estaba veraneando, para dar examen de alguna materia complementaria. [...] Llegamos a la calle Moreno aquella mañana y encontramos la puerta de rejas trabada con cadena y candado y un gran cartón adosado a la verja con un letrero que decía CERRADO POR FALTA DE AUTORIDAD MORAL[...] ahí nomás quedé convertido en huelguista. Adolfo Bioy, Años de mocedad, 1963.

Las primeras apariciones de la juventud universitaria de Buenos Aires como un actor con voz propia se produjeron en torno de reclamos por cuestiones gremiales. Desde marzo de 1903 y por casi dos años, los estudiantes de la Facultad porteña de Derecho protagonizaron una huelga contra una disposición del Consejo Académico de esa facultad relativa a los plazos y aranceles de los exámenes. La huelga se inició porque el Consejo desoía el pedido de que los exámenes de marzo dejaran de ser complementarios. Pero, según el recuerdo de uno de esos huelguistas -y miembro de la high society-, el entonces estudiante de Derecho Adolfo Bioy (1882-1962), ${ }^{15}$ esa falta de

\footnotetext{
${ }^{15}$ Ya recibido de abogado, Bioy sería jefe del gabinete del ministerio de Relaciones Exteriores y de Culto entre 1911 y 1913, participaría de los gabinetes del gobierno de Uriburu y Justo y presidiría la Sociedad Rural a comienzos de la década del cuarenta.
} 
consideración de las autoridades condujo a los estudiantes a no tener "duda de que la autoridad moral de aquellos viejos y, hasta entonces, respetados maestros, estaba relajada" (Bioy, 1963: 88). ${ }^{16}$

El relato de Bioy es bastante extenso y conviene citar varios tramos porque es uno de los pocos documentos que nos permite recuperar el tipo de sociabilidad estudiantil que comenzaba a gestarse entre los jóvenes universitarios porteños. Sobre la organización que acompañaba a la certera falta moral de los profesores, declara Bioy:

[...] fueron días de cabildeos; nos reuníamos, en grupos, en las proximidades de la Facultad y en otros sitios, en casas de amigos, como lo de Dávila, lo de Mantilla en la calle Perú, lo de Larco en la calle Cangallo. Planeábamos la acción que debía de ser violenta [...] como la de penetrar subrepticiamente en casas vecinas de la Facultad y, bien armados, acantonarnos en las azoteas contiguas y, en el momento oportuno, hacer fuego contra las autoridades y contra la policía. Sabíamos que habíase dispuesto asegurar la toma de exámenes con una custodia policial en la casa y eso nos había producido indignación. ¡La casa de estudios ocupada por la policía! (Bioy, 1963: 88).

Luego de narrar el plan que finalmente idearon para interrumpir la mesa examinadora y reiniciar la huelga, Bioy describe la que probablemente haya sido la primera manifestación callejera de los universitarios porteños:

El entusiasmo continuó en la calle; un grupo considerable se formó en manifestación, llevando algunos un trofeo que otro, un puntero de pizarrón o cosas así; el estudiante Di Diego (que nunca supe si efectivamente lo era) de quien se decía que era anarquista, como igualmente de [Alfredo] Bianchi, llevaba a guisa de capa la carpeta de felpa encarnada que cubría la mesa del decano. Todos profiriendo gritos, cruzamos la plaza de la Victoria; llegamos a la, de rigor, calle Florida y en ella, en una esquina, Zavalía Guzmán subió a una victoria de plaza que cruzaba y, de pie en el pescante, nos arengó [...]. Lo aplaudimos con entusiasmo. Por cansancio nos disolvimos después, para continuar al día siguiente y al otro y al otro durante un mes, dos meses, tres y más (Bioy, 1963: 90).

Unos párrafos después, el antiguo huelguista expone las múltiples tareas que debieron realizar en esos meses. Ofrecemos la última cita extensa de esas memorias:

Hubo compañeros que defeccionaron en el correr del largo tiempo de disturbios, y hasta se dijo que algunos, según afirmaron otros, nos traicionaron. [...] en todo ese año 1903, la huelga se mantuvo latente y los huelguistas activos. Visitábamos a profesores para pedirles su renuncia, y más de uno renunció; visitábamos a senadores y diputados y éramos acogidos con bastante simpatía, hasta con apoyo a veces, siempre sin reproche. Visitábamos la redacción de los diarios y éramos bien recibidos en ellos. La Prensa nos consintió una reunión en el vasto hall de la calle Rivadavia, que se colmó de gente; allí habló Juan Solá, con elocuencia ciceroneana, habló un Gómez (creo que se llamaba Gustavo), correntino, de palabra cálida y conmovedora, que hizo un hermoso cuadro de

\footnotetext{
${ }^{16}$ Ciria y Sanguinetti (1968: 23) recuerdan que un primer reclamo estudiantil de ese tipo se dio en 1901, luego de que un estudiante se suicidara, y fue liderado por Estanislao Zeballos.
} 
los estudiantes pobres, que eran, según dijo con lágrimas en el rostro y haciendo correr otras en los nuestros, los héroes y las victimas. Llegamos en nuestras visitas hasta el ministro de Instrucción Pública, doctor Fernández, quien nos acogió de manera alentadora. [...] Una vez fuimos en grupo de quince o veinte [...] a la Facultad de Medicina, a invitar a los estudiantes a que nos acompañasen. [...] Grandjean pidió disculpas al profesor por nuestro atrevimiento, le dio las gracias y le dijo que no éramos sino unos estudiantes de Derecho, que habíamos ido allí para (y dirigió la mirada y la palabras a los estudiantes) invitar a nuestros compañeros de Medicina a que nos acompañen, a que se solidaricen con nosotros en nuestra justa protesta contra todos los profesores y todas las autoridades universitarias, cuyo prestigio había decaído, etc, etc (Bioy, 1963: 92-94).

Por su parte, el antiguo anarquista que menciona Bioy, Alfredo Bianchi (1882-1942), también dejó un breve recuerdo de esa militancia estudiantil. A diferencia de Bioy, Bianchi pertenecía a las clases medias en ascenso e incluso había nacido en el extranjero. En 1907, junto a Roberto Giusti (18871978), otro inmigrante que pasó por las aulas de Filosofía y Letras, Bianchi fundó Nosotros (la revista cultural argentina más influyente de las primeras décadas del siglo $\mathrm{XX})^{17}$ y a fines de la década del diez reemplazó su anarquismo por un socialismo simpatizante de la Revolución Rusa. Buscando expandir esas simpatías al interior del PS, dirigió la colección de folletos Adelante! en la que, ante el Congreso Extraordinario de enero de 1921 que se pronunciaría sobre la Revolución Rusa, se difundieron textos de autores nacionales que reivindicaban esa revolución.

En febrero de 1920, Bianchi polemizaba con Juan Emiliano Carulla (1888-1968, entonces un diputado que defendía las guardias civiles antiobreras de la Liga Patriótica), y ofrecía un esbozo de su pasada militancia estudiantil anarquista al recordar que Carulla era su "íntimo amigo, compañero inseparable de la lejana iniciación universitaria, él mismo fue nuestro jefe y nuestro guía en aquellos años de rebelión de 1904 y 1905, cuando íbamos a la Facultad de Letras con el folleto de Malatesta sobre La anarquía en el bolsillo y La Protesta en la mano". ${ }^{18}$

Por esos años, los jóvenes que difundían literatura anarquista participaron de la campaña de desprestigio de los profesores integrantes de las academias vitalicias de cada facultad porteña, campaña a la que en 1906 se sumaron los profesores de Medicina y líderes del PS Juan B. Justo y Nicolás Repetto, y los profesores Federico Texo y Samuel de Madrid. Si bien los cuatro fueron expulsados de la UBA, al año siguiente los estudiantes consiguieron una serie de reformas de la ley

\footnotetext{
${ }^{17}$ Esta revista mensual tuvo dos épocas, entre 1907 y 1934 aparecieron trescientos números; en 1936 volvió a aparecer hasta fines de 1943, período en el que se publicaron noventa números. Entre septiembre de 1920 y marzo de 1924 , Giusti dejó la dirección quedando a cargo el joven que desde 1913 ocupaba la secretaria, Julio Noé. Si bien volveremos sobre Nosotros, consignemos que dos importantes estudios centrados en su intervención literaria son los de Shumway (1999) y Delgado (2010), mientras que los trabajos de Prislei (1992, 1994, 199a y 1999b) exponen la relación de la revista con el campo político.

${ }^{18}$ Alfredo Bianchi, "Renegados", Claridad, no 2, 05/02/1920. A la asistencia a la FFyL solían sucederle las tertulias en los cafés. Sobre ellas realizó Gálvez una larga caracterización en El Mal Metafísico: "Anarquistas violentos, perseguidos más que por la policía por el hambre, que veneraban a Kropotkin, a Salvador y a Angiolillo y amenazaban destruir la sociedad a fuerza de bombas y pésima literatura [...]. Junto a algún anónimo y pontificial genio de café, vociferaban los literaloides, discutiendo sobre los méritos de media humanidad literaria, arrojándose tumultuosamente unos a otros, insultos y doctrinas, paradojas y citas" (Gálvez, 1916).
} 
Avellaneda, entre las que se encontraba la eliminación de las academias. ${ }^{19}$

El petitorio de reformas fue presentado al Congreso el 18 de junio de 1906 por dos estudiantes de Medicina: el futuro decano Julio Iribarne y el futuro dirigente de la UCR Intransigente J. Agustín Gatti. Allí se reclamaba la docencia libre, el examen de estado, la separación de la gestión administrativa y científica, la renovación periódica de los cuerpos dirigentes, la elección de la mayoría de las autoridades más importantes de la Universidad y la concesión de derechos electorales a los estudiantes. ${ }^{20}$ El petitorio consiguió eliminar los Consejos Académicos de cada facultad porteña para fundar Consejos Directivos, esto es, desde 1907 dejaron de existir en la UBA -pero no en Córdoba- los consejos formados por un número fijo de miembros vitalicios, elegidos por el mismo cuerpo y confirmados por el poder ejecutivo. En lugar de ellos se establecieron consejos renovables y compuestos por profesores elegidos en asamblea, a los que en 1918 se sumaron los representantes estudiantiles. ${ }^{21}$

En medio de esos cuestionamientos a la autoridad académica, los estudiantes porteños ensayaron las primeras instancias organizativas formales tanto al interior de cada facultad como a escala continental. En marzo de 1904 obtuvieron personería jurídica el Centro de Estudiantes (CE) de Medicina y el de Ingeniería; en julio de 1905 el de Derecho y en setiembre de 1909 el de Filosofía y Letras. $^{22}$ Asimismo, en 1908 los estudiantes fundaron la FUBA, un organismo compuesto por dos representantes de cada centro.

\section{La agremiación estudiantil argentina, uruguaya y americana}

En 1911 los estudiantes de la UNLP crearon la Federación Universitaria de La Plata (FULP, de actividad muy esporádica hasta 1917), mientras que la Federación Universitaria de Córdoba (FUC) surgiría en mayo de 1918, cuando se desató el conflicto en la ciudad. Un mes antes había sido

\footnotetext{
${ }^{19}$ Esta ley había sido sancionada en 1885 y reglamentaba las bases que debían seguir los estatutos que se promulgaran las dos universidades nacionales entonces existentes, la UBA y la UNC. Sobre la organización universitaria que se establece luego de esta ley, véase Halperín Donghi (1962) y Buchbinder (2000). Sobre la expulsión de los líderes socialistas, véase el folleto firmado por el Partido Socialista (1945).

${ }^{20}$ Sergio Bagú, "Cómo se gestó la Reforma Universitaria Argentina", 1938 (del Mazo, 1941 t.III: 472). Una pormenorizada historia de ese proceso de reclamos fue publicada, apenas estalló la Reforma, por Iribarne, bajo el título "El movimiento reformista universitario de 1905-1907", en la Revista del Circulo Médico y del Centro de Estudiantes de Medicina. Si bien el texto constituye actualmente un importante documento del conflicto estudiantil, a ello se le sumaba en 1918 otro propósito: Iribarne era profesor de la Facultad de Medicina y la difusión de su antigua militancia estudiantil fue uno de los materiales con los que construyó su perfil reformista -moderado- que lo llevaría a ser decano de la misma facultad.

${ }^{21}$ Sobre las consecuencias de esos cambios, el reformista y líder del PC Héctor Agosti emitió un juicio negativo tajante: los consejos directivos no habrían hecho más que reemplazar las camarillas académicas por unas nuevas camarillas de profesores. Éstas recién perderían algo de su peso con la reforma a la base de los estatutos establecidas por el poder ejecutivo en agosto de 1918, pues entonces se estipuló que los cuerpos directivos estuvieran integrados no sólo por profesores titulares sino también por profesores suplentes y por estudiantes de los últimos cursos o por graduados recientes. Cf. Héctor Agosti, "El surguimiento de la Reforma", Rosario, El Ateneo. Revista del Centro de Estudiantes de Ciencias Económicas, nº 2, 1931, Rosario (copia en el Fondo personal Héctor Agosti, CeDInCI).

${ }_{22}^{2}$ Para una breve referencia a la formación de los centros y especialmente el de Derecho, véase Gómez (1995: 18-25).
} 
fundada la FUA, conformada por dos representantes de esas federaciones más los enviados por los centros universitarios provinciales de Tucumán y de Santa Fe. Como recalca en La revolución estudiantil el segundo presidente de la FUA -y tal como veremos en el capítulo quinto-, la conformación de un organismo central como la FUA fue fundamental para la coordinación de los primeros reclamos del movimiento de la Reforma (González, 1922).

En cuanto a los estudiantes uruguayos, éstos permanecieron sumamente vinculados a los porteños. Fundaron sus instancias gremiales varios años antes que los estudiantes de la UBA, en 1893 surgió la Asociación de Estudiantes del Uruguay con una importante actividad gremial en la primera década del siglo XX, pero en la siguiente se disolvió. Durante la década del veinte, los estudiantes uruguayos se reunieron en torno del Centro de Estudios Ariel (1917-1931) y su revista Ariel (1919-1931), y en torno de la Asociación de los Estudiantes de Medicina (1919-1956) y El Estudiante Libre (1919-1956), y recién en abril de 1929, luego de la importante huelga de 1928 en reclamo de la autonomía universitaria y el cogobierno estudiantil, fundaron la vigente Federación de Estudiantes Universitarios del Uruguay (FEUU).

En 1908 la Asociación de Estudiantes del Uruguay organizó en Montevideo el Congreso Americano de Estudiantes. Dos años después, los grupos que habían participado conformaron la Liga de Estudiantes Americanos y organizaron un segundo encuentro en Buenos Aires. Este se desplegó en el marco de los festejos del Centenario de la Revolución de Mayo y las agrupaciones juveniles nacionalistas y antiobreras (Lvovich, 2003). El siguiente Congreso fue en 1912 en Lima y allí se eligió a Santiago de Chile como la nueva sede, pero el encuentro no pudo organizarse. ${ }^{23}$ Como ha señalado Biagini (2012), esas instancias fueron sumamente importantes porque allí los estudiantes -además de decidir su adhesión a la Federación Internacional de Estudiantes (FIDE) 'Corda Frates'- definieron varias de las reivindicaciones institucionales que luego impulsarían los reformistas. ${ }^{24}$ Pero, a distancia del carácter confrontativo que encontraremos en el movimiento de la

\footnotetext{
${ }^{23}$ Sobre la organización estudiantil chilena puede consultarse la detallada y aguda reconstrucción de Moraga Valle (2007). Allí se advierte que, a diferencia de los uruguayos, hasta comienzos de la década del veinte los estudiantes chilenos no mantuvieron vínculos cercanos con los jóvenes argentinos. Pero además se descubren interesantes diferencias entre la organización de los estudiantes chilenos y la de los argentinos, pues aquellos desplegaron iniciativas claramente políticas ya a comienzos de la década del diez, a pesar de que recién a fines de 1922 "estallara la Reforma", esto es, se registra una organización explícitamente hermanada con las reivindicaciones político-culturales de la fracción radicalizada del reformista argentino. Para un análisis de las revistas que entonces publicó la Federación Universitaria de Chile, puede consultarse también Biagini (2012: 101-107).

${ }^{24}$ En "Ecos del Congreso de Lima. Informes de la delegación de Buenos Aires", el joven Nerio A. Rojas (Verbum, $\mathrm{n}^{\circ} 21$, noviembre de 1912: 47-48) informa que los delegados estudiantiles porteños propusieron la moción -luego aprobada- de que la Liga de Estudiantes Americanos adhiriera a la FIDE 'Corda Frates'. Ésta había sido fundada en 1898 en Turín para promover la fraternidad estudiantil y no tuvo ninguna relación con la conocida agrupación de profesores católicos y antirreformistas cordobeses Corda Frates. La FIDE se reunió en 1913 en Ithaca, Nueva York. Como representantes de la Liga, sólo asistieron una delegación brasileña y una argentina. Según las memorias de uno de los delegados argentinos, la comisión se compuso del siguiente modo: presidente, Alberto Viñas, por la Facultad de Medicina de Buenos Aires; secretario, Arturo Capdevila, por la Facultad de Derecho de Córdoba; tesorero, Braulio Ipola, por la Facultad de Derecho de La Plata; vocales: Julio A. Cores y Diego Luis Molinari, de Ingeniería y Derecho, respectivamente (Capdevila, 1933: 7). Estas delegaciones consiguieron que la Liga fuera incorporada a la FIDE. Desde entonces, al menos, las revistas de los Centros de Estudiantes porteños comenzaron a exponer en su tapa el sello de la Federación.
} 
Reforma, los Congresos Americanos estuvieron ligados a la diplomacia nacional; y ello no sólo porque cada país erigió a los estudiantes enviados como sus embajadores nacionales, sino también porque ese mismo lugar les asignó el gobierno que los recibió (Biagini, 2012: 43-52; Vera de Flachs, s/d).

La primera articulación estudiantil argentina, uruguaya y americana que acabamos de describir contó con algunas publicaciones periódicas. Éstas oficiaron al mismo tiempo como toque de reunión de los estudiantes y medio de difusión de sus reivindicaciones gremiales. Cada centro se propuso reunir los recursos financieros y simbólicos para editar una revista, pero sin editorial ni secciones fijas, esas publicaciones no tendieron a alcanzar un perfil propio. Más allá de algún artículo seleccionado por su importancia científica, el resto de las páginas se limitaban a reproducir los textos que los estudiantes debían aprender para cada materia y las actas de las reuniones de los centros. De ahí que hayan sido descalificadas como meros "canastos de apuntes" por uno de los líderes de la Reforma que alentó el periodismo político estudiantil, el joven Gregorio Bermann $(1894-1972){ }^{25}$

Entrada la década del diez, esta primera organización marcada por el rechazo a la autoridad académica se vio modificada por la aparición de una nueva generación de estudiantes -perteneciente en su mayoría a las clases medias- que se propuso intervenir en sectores más amplios de la sociedad y tendió a asumirse como "arielista". Esto es, recogiendo el llamado que había realizado el escritor montevideano José Enrique Rodó en su Ariel (1900) a la juventud culta, se erigió en la difusora, desde cánones del "modernismo literario", de la cultura grecolatina y en la guía moral de las modernas sociedades latinoamericanas. Esa generación dio vida a una serie de formaciones culturales y revistas que buscaron conformar una "familia estudiantil" con una específica "misión social" y que hacia fines de la década del diez lograron que el juvenilismo arielista precisara su dimensión política.

Como mencionamos, en la irrupción de estos grupos y el camino que recorren puede identificarse lo que Gramsci calificó como el intento de pasar de un momento corporativo a otro político. Más precisamente, las fuentes que relevamos sugieren que, antes de que en 1918 el movimiento estudiantil se reconociera en un momento político, surgieron distintos emprendimientos estudiantiles que se diferenciaban de los centros de estudiantes para organizar tres espacios de sociabilidad en los que despuntaban intereses no sólo culturales sino también políticos. Aunque porosos entre sí, esos espacios se distinguieron por su adhesión a distintas matrices culturales: uno

\footnotetext{
${ }^{25} \mathrm{Si}$ bien volveremos sobre ello, traigamos aquí uno de los pasajes en los que ese estudiante de Medicina y de Filosofía crítica las revistas que sólo difunden la bibliografía de las cátedras: "Entre nosotros hay muchos Centros que gastan miles de pesos mensuales en su Revista, y es uno de los síntomas más simpáticos que podrían ofrecer observar que casi todo el tesoro de los estudiantes se vaya de esta manera. [...] Pero no basta que se publiquen gruesos volúmenes; con harta frecuencia las revistas languidecen al continuar una rutina monótona, carentes de otra finalidad que la muy pobre de servir de canasto de apuntes, de una utilización bien inmediata para los muchachos" (Bermann, Verbum $\mathrm{n}^{\mathrm{o}}$ 37-38, setiembre y octubre de 1917, p. 90).
} 
se ligó al socialismo cientificista, otro a la cultura estética correctora del cientificismo y el tercero al catolicismo.

\section{La identidad de los universitarios porteños: ¿socialistas científicos, idealistas estéticos o católicos espiritualistas?}

Hacia mediados de la década del diez, cuando los centros de estudiantes y la FUBA ya habían mostrado su eficacia para articular el malestar ante las autoridades académicas y aún no existía una organización estudiantil nacional, una nueva generación de estudiantes dio vida a las primeras formaciones intelectuales preocupadas por la cultura de la juventud estudiosa. Una rápida aproximación a las novedades que introdujeron las nuevas empresas estudiantiles la ofrece en 1916 el joven Gabriel del Mazo (1898-1965). El entonces estudiante de Ingeniería declaraba, en calidad de presidente del Ateneo de Estudiantes Universitarios, que

Relegada la Federación Universitaria a una situación de simple directora, en el sentido gubernativo, de las distintas corporaciones estudiantiles de la ciudad, había menester de una institución que ligara a los estudiantes universitarios por vínculos de familiaridad más acentuada, aumentando su propia aptitud para la vida en común y donde se estudiaran y debatieran los problemas sociales del momento (Gabriel del Mazo, "Discurso inaugural", Ideas, no 5, mayo de 1916, p. 91).

Si en los primeros años del siglo XX la FUBA había mostrado una importante capacidad para expresar las demandas gremiales, su consolidación le sugería a los jóvenes que era el momento de precisar una proyección social de la incipiente identidad estudiantil que se aleje de los grupos nacionalistas organizados durante el Centenario. El Ateneo de Estudiantes Universitarios, la nueva institución a la que hacía referencia del Mazo, debía dedicarse a la formación cultural y política de los universitarios, sobre todo de aquellos pertenecientes a esa clase media que no podía coronar su carrera con el viaje "iniciático" a Europa y que comprendía que le faltaba estudio y debate para intervenir en un sistema político que, luego de prolongados reclamos, comenzaba su apertura democrática.

Una colocación similar de los nuevos grupos la ofrece el líder del mismo Ateneo, José María Monner Sans (1896-1987). Éste publicaba en 1930 en la revista Nosotros las memorias del grupo y afirmaba:

Los 'centros' estudiantiles de entonces estaban encerrados dentro de su respectiva especialidad; la 'federación' que los congregaba planteábase sólo problemas gremiales, y a nosotros nos parecía ingenuamente que un estudiante universitario, en sus dilatados momentos de ocio, podía tener otras preocupaciones, ajenas, por ejemplo, a la anatomía del antebrazo, a la resistencia de materiales o al régimen inmobiliario tunecino. Además 
de esto, 'lo otro' también era lícito que nos interesara. Y entre 'lo otro', vago y múltiple, colocábamos los temas nacionales -incluso la pérfida política-, las manifestaciones del pensamiento filosófico contemporáneo, las producciones literarias y las actividades artísticas (Monner Sans, 1930: 5).

La llegada a la universidad de los jóvenes de los sectores medios parece haber sido clave en la aparición y permanencia de una "familia estudiantil" capaz de llenar sus "momentos de ocio con preocupaciones diversas". En la definición de esas preocupaciones, sin duda tuvieron una singular importancia las publicaciones periódicas y los proyectos editoriales de la inicial y agitada izquierda argentina, pues esas publicaciones y ediciones señalaban y ponían a circular, en ediciones económicas, los libros del pensamiento mundial y nacional, y con ello tendían a conformar distintas matrices culturales. ${ }^{26}$ Entre las editoriales, la Biblioteca Blanca de la editorial valenciana Sempere fue la más importarte, pues, como subraya Tarcus, editó centenares de títulos en ediciones populares que eran importadas regularmente por distribuidores y libreros argentinos, al punto que

constituyó la verdadera biblioteca obrera de principios de siglo XX, donde, junto a los textos de Engels y el resumen de El Capital de Deville, se publicaba a Büchner, Comte, Spencer y Haeckel; al lado de Vandervelde, Berstein, Jaunrès y Labriola se editaba a Sorel y a los 'sindicalistas', a Bakunin, Faure y Kropotkin, a Max Nodau y a Mazzini, a Gorki y Anatole France, a Tolstoy y a Zola, a Ibsen y D'Annunzio, a Haine y Max Stirner, a Wagner, Nietxsche y Schopenhauer (2007b: 332).

Uno de sus lectores, Juan Carulla, recuerda en sus memorias que, en cuando era estudiante del Colegio Nacional de Concepción del Uruguay, esas lecturas compartidas lo motivaron a fundar un club literario y la revista Principios, que se editó durante dos años (Carulla, 1964: 85-86). Pero antes precisa:

Maravilla el éxito que tuvieron las obras de aquella editorial aun en los más recónditos villoríos del continente y que atestaban los estantes de cuanto lector conocimos en la época. Estos libros ejercieron poderosa influencia en las inteligencias juveniles y en la masa popular. Ponían al alcance de cualquier bolsillo, pues eran ediciones económicas, las obras cumbres del pensamiento contemporáneo [...] ¿quién puede negar que mediante ellas quedó franqueado a todos el conocimiento de grandes filósofos, pensadores y políticos de las más diversas tendencias e idiomas? (Carulla, 1964: 83).

A mediados de la década del diez, se sumaban a esa circulación de libros mundiales las colecciones nacionales de José Ingenieros (1877-1925) y de Ricardo Rojas (1882-1957). Ambas se proponían definir las obras del pensamiento argentino. Para ello editaban y prologaban obras hasta entonces inaccesibles y pertenecientes, en el caso de la colección de Ingenieros, al ámbito histórico y, en el

\footnotetext{
${ }^{26}$ Sobre la conformación de un campo de izquierda en la Argentina, véase Tarcus (2007b). Para un listado y análisis de las publicaciones periódicas libertarias argentinas de las primeras décadas del siglo XX, véase Domínguez Rubio (2013).
} 
caso de Rojas, al literario. ${ }^{27}$ Valiéndose del imaginario iniciático característico de las memorias, refiere del Mazo:

Sucedió en mí, entonces, una situación crítica que tuvo una derivación, en definitiva, importante. Me dediqué a leer y a tomarle el gusto a temas culturales. [...] comencé a formar una pequeña biblioteca que pronto se enriqueció con la Biblioteca Argentina, que comenzó a publicar Ricardo Rojas, y con la Biblioteca de la Cultura Argentina, que comenzó a publicar José Ingenieros. Y esas lecturas me formaron y reafirmaron en lo principal, y me dieron lo que ya no la Facultad sino la Universidad entera, jamás hubieran podido darme. [...] Tres años después era Presidente del Centro de Estudiantes de Ingeniería y Presidente del Ateneo Universitario (del Mazo, 1976: 68-69).

Hacia 1917 el Ateneo se pobló de jóvenes que, como del Mazo, provenían de las clases medias y se interesaban por la cultura, sobre todo en la matriz identificada con el "esteticismo". Pero ese no fue el único grupo estudiantil de Buenos Aires. En su organización y difusión de esas "otras" preocupaciones, los jóvenes tendieron a recortar tres redes de sociabilidad y matrices culturales diversas. Específicamente, a partir de 1910 aparecieron varios Centros Católicos de Estudiantes en las ciudades más pobladas del país, que con diverso éxito asumieron como lema "Por la fe y por la ciencia católica" y se propusieron reemplazar la cultura laica, predominante en la UBA y en la UNLP, por una católica (Devoto, 2010). Su revista declaraba que esos Centros respondían a un "plan social cristiano" y buscaban "preparar a la juventud intelectual por medio del estudio y de la acción, al cumplimiento de sus deberes para con Dios y con la Patria". ${ }^{28}$ A esa iniciativa se sumaron en 1917 el Ateneo Social de la Juventud (antecedente del Ateneo de la Juventud de 1922) y en 1918 el Club Universitario de Buenos Aires (CUBA), vigente hasta la actualidad. ${ }^{29}$

En fuerte rivalidad con esa poco activa apuesta estudiantil, en 1914 un grupo de estudiantes judíos se separó de la revista Juventud (1913-1916) para asumir una identidad laica y ligarse al PS. Entre ellos se encontraban dos futuros líderes reformistas: Alberto Palcos y Gregorio Bermann, quienes propusieron un arielismo en el que gravitó el socialismo científico y la instrucción de los

\footnotetext{
${ }^{27}$ Para un estudio de ambos proyectos, atento a sus divergencias, véase De Giovanni (2007). En un comienzo, Rojas e Ingenieros proyectaron fundar juntos una colección pero rápidamente aparecieron desacuerdos, que suscitaron una breve polémica en las columnas del diario La Nación. Sobre esos desacuerdos traigamos la elocuente caracterización que Monner Sans proponía como explicación: “en los trasfondos de su espíritu [Rojas] confesábase dominado por aquel demonio interior de los antiguos que, al parecer, le dictaba estrofas y romances. Pero a la inspiración irrefrenable, añadía Rojas la incesante lectura de todo lo nuestro, la pesquisa en bibliotecas y archivos apenas visitados por los escritores de su misma promoción, la reflexión sobre cuanto concernía a nuestra nacionalidad, para descubrir las verdaderas huellas de lo autóctono en las marchas ya cumplidas y para que no nos extraviáramos en las que debíamos reemprender. [...] Había algo de arúspice en su prédica y mucho de sacerdote en su ademán. Más tales exterioridades, bastante hieráticas, se desvanecían en la rueda amistosa, caldeada por Rojas de sonriente cordialidad, de bien dosificada gracia irónica, de raudalosa fluencia verbal. [...] [y en esto se diferenciaba] del Ingenieros campechano, travieso, burlón, desconcertante, resuelto siempre a no darse importancia, de seguro para combatir el acartonamiento de muchos compatriotas que, sin tenerla, se la daban" (Monner Sans, "La Historia de la Literatura Argentina de Ricardo Rojas", Revista iberoamericana, $\mathrm{n}^{\circ}$ 46, julio-diciembre de 1958, pp. 268-269).

28 “Tribuna Universitaria”, Tribuna Universitaria, n 26, marzo de 1917.

29 Para una historia -de carácter apologético- de CUBA, véase Newton (1968).
} 
obreros. Como analizaremos, en torno de ese Centro comenzó a organizarse una suerte de red que se prolongó en los números de Verbum de los años 1916 y 1917 y en dos agrupamientos en los que los arielistas participaron junto a figuras de la generación anterior: la Universidad Libre (19151919) y la Federación de Asociaciones Culturales (1918-1919).

A su vez, en 1914 también era fundado el grupo que luego tomaría el mencionado Ateneo de Estudiantes Universitarios. Éste desplegó una activa red ligada a un idealismo estético corrector del cientificismo, que guardó una relación distante -aunque no de enfrentamiento- tanto con la intelectualidad católica como con los socialistas cientificistas. ${ }^{30}$ Como veremos, acompañaron al Ateneo en el tramado de esta red: la asociación cordobesa Córdoba Libre! (1916-1919), el Colegio Novecentista de Buenos Aires (1917-1924) y el grupo editor de la revista Themis (1918-1920).

La perdurabilidad que logró el Ateneo seguramente fue posible por la decisión de su líder de ligar las "preocupaciones diversas" a una formación cultural integral en la que no terminaba de precisarse la "función social" de la juventud. En efecto, el llamado político-cultural de los "arielistas socialistas" no conseguía reunir a un número importante de jóvenes y hacia 1915 era reformulado. En cambio, la impronta cultural y "desinteresada" que -a pesar de que su líder militaba en el PS- mantuvieron los ateneístas hasta 1919 congregó a trescientos socios y perduró hasta 1920.

Uno de los miembros del Ateneo, el futuro antropólogo Francisco de Aparicio (1892-1951), publicaba en 1917 en Verbum una nota que ofrece otro interesante testimonio de los rasgos que se adjudicaba la juventud porteña que animaría la Reforma Universitaria:

\begin{abstract}
Al lado de la juventud universitaria que no persigue otro ideal que la aprobación de sus materias, ajustándose estrictamente al programa, y que ha hecho del diez la suprema aspiración de su vida, existe otra categoría de estudiantes que, con mayor propiedad, podría llamarse simplemente estudiosos, que se siente inquietada por todos los problemas, que se presentan en la vida política, intelectual y económica de su sociedad. [...] La pequeña minoría que forma el segundo grupo, constituida por elementos dispersos, que brotan como lunares, en medio del utilitarismo del ambiente universitario, esterilizan sus esfuerzos en una acción individual, condenada casi siempre a fracasar por falta de ambiente y de cohesión (Francisco de Aparicio, "El Ateneo de Estudiantes Universitarios", Verbum, no 35-36, pp. 72-73).
\end{abstract}

Como adelantamos en la Introducción y analizaremos en el cuarto capítulo, con el estallido y articulación de la Reforma, se reconfigura el mapa de las "pequeñas minorías estudiosas" que acabamos de trazar. Además de aparecer nuevos grupos identificados con el socialismo bolchevique, la oposición entre la matriz científica y la estética pierde peso al punto de que el

\footnotetext{
${ }^{30}$ Siguiendo a Terán (2008), a partir del acentuado cuestionamiento al positivismo que se registró en la década del diez, las elites ilustradas argentinas tendieron a alinearse en dos amplios bloques. Uno de esos bloques estuvo conformado por los partidarios de la "cultura estética" y tuvo como máxima figura a Leopoldo Lugones y su búsqueda de modelos culturales inspirados en la civilización griega. En el otro bloque se ubicaban los partidarios de la "cultura científica", quienes tuvieron como principal referente a Ingenieros y su confianza en los avances científicos para resolver los problemas sociales.
} 
Ateneo rompe con el Colegio para ligarse a la Federación de Asociaciones Culturales y al Partido Socialista Internacional (que a fines de 1920 se convertiría en el PC). En cuanto a la matriz católica, si bien CUBA declaraba que sus fines eran estrictamente deportivos, en un momento de fuerte politización de los estudiantes esa convocatoria a congregarse en torno del deporte era encabezada por jóvenes partidarios de una cultura católica que, enfrentada a la identidad izquierdista del estudiante, consideraba las jerarquías sociales como la garantía del orden social.

\section{Las primeras revistas culturales de los estudiantes porteños}

En los años anteriores a la reconfiguración de 1918, los estudiantes que animaron la red cientificista, la red esteticista y la red católica crearon publicaciones periódicas y proyectaron colecciones editoriales, y con ello tramaron un modo específico -que en el caso de las dos últimas redes se politizaría en los años siguientes- de contacto y difusión de la cultura letrada. Sostiene Julio Noé (1893-1958), quien, además de haber sido secretario -y, por un breve período, director- de la revista Nosotros, fue uno de los dieciséis jóvenes que fundaron el Colegio Novecentista:

Hacer revista es, para los jóvenes escritores, una necesidad pareja a la de escribir versos. Es su doble manera de expresarse. Con el verso disciplinan su estilo; con la revista forman su juicio y extienden su acción. De los versos primigenios, publicados en cuidadas plaquetas y con títulos casi siempre ingenuos o estrafalarios, no tardan en arrepentirse. No así de las revistas que dirigen solos o con amigos. En los versos suelen poner bastante insinceridad y retórica, pero en las revistas se expande su juventud desbordada en afirmaciones tan absolutas como las negaciones equivalentes (Noé, 1992 [1962]: 118; destacado nuestro).

La revista con la que los jóvenes de la red del socialismo científico comenzaron a formar su juicio y extender su acción fue Ariel. Revista mensual de ciencias, letras y artes (1914-1915). Desaparecida ésta, algunos encontraron lugar en la longeva revista Nosotros. Revista mensual de Letras, Arte, Historia, Filosofía y Ciencias Sociales (1907-1934, primer época). Por su parte, los jóvenes ligados al "idealismo estético" fundaron Ideas. Órgano del Ateneo Universitario (1915-1919), los Cuadernos del Colegio Novecentista (1917-1919) y la cordobesa La Montaña. Publicación de “Córdoba Libre” (1918), al tiempo que reconfiguraron la mencionada revista del CE de Derecho, Themis (1918-1920). Finalmente, los difusores de la cultura católica editaron desde 1914 hasta 1920 -de manera interrumpida- Tribuna Universitaria. Revista de los Centros Católicos de Estudiantes.

Esta "juventud desbordada" daba a conocer en las revistas sus versos y artículos, pero también proyectó otras dos vías de formación y difusión, a saber: los ciclos de conferencias orientados a remediar la formación exclusivamente profesional que ofrecía la universidad y las empresas editoriales. Entre éstas se encontraron la accidentada experiencia de las "Publicaciones de 
la Universidad Libre", la prolífica "Cooperativa Editorial Nosotros" y las "Publicaciones del Colegio Novecentista”, en las que aparecieron obras tanto de novecentistas como de ateneístas. ${ }^{31}$

A través de estas experiencias $-\mathrm{y}$ de los proyectos que no superaron su carácter programático-, los jóvenes fueron construyendo un modo específico de contacto y difusión de la cultura letrada. En términos de Noé, esas experiencias habrían dado nacimiento al "revistero" estudiantil, una figura rival a la del "universitario" y que en las primeras décadas del siglo XX tendió a ser animada por jóvenes hijos de extranjeros o extranjeros de nacimiento. Afirma Noé en el texto ya citado:

El revistero, así sea de ciencia, de arte o de literatura, se nutre de lo fragmentario, casi siempre de lo nuevo y muchas veces de lo riesgoso, improvisado y poco sabido. El universitario -en teoría, por lo menos- parte de un saber presuntivamente alcanzado y puesto en orden con riguroso método. Acoge con precaucional reserva las tendencias renovadoras, y muchas veces con repudio franco las doctrinas revolucionarias. El revistero, por el contrario, se regodea con lo recién aparecido o diferente. El universitario se envanece de su saber aunque sea poco; el revistero de su información aunque sea inexacta. En fin, el buen revistero es por lo general más ágil y simpático que el buen universitario (Noé, 1992 [1962]: 118).

Ese "buen revistero" surgía en medio de un proceso que, motivado por la alfabetización de sectores hasta entonces desplazados de la cultura letrada, diversificaba tanto la oferta de lectura según los nuevos tipos de lectores como las posibilidades del incipiente mercado editorial. La literatura de folletín dirigida a los nuevos lectores comenzaba a convivir con las ediciones de libros baratos (Romero, 1995) y, además de los magazines de interés general, comercial y masivo, aparecían otros dirigidos a un público específico (mujeres, varones, niños) con una vocación pedagógica (Bontempo, 2012; Romano, 2004). A su vez, por entonces el diario Crítica modernizaba la prensa periódica, pues frente a los más de trescientos diarios ligados a grupos políticos, aquel proponía la primacía de la noticia sobre la opinión y se distinguía de la gran prensa (conformada fundamentalmente por La Nación y La Prensa) porque dejaba de interpelar a la elite política para ofrecer un periodismo popular urbano, que desplegaba estrategias comerciales como la seducción del público a partir de la oferta de servicios (Saítta, 1998).

En el marco de ese proceso de complejización de los lectores y las publicaciones, aparecían, por un lado, el primer periódico porteño que se proponía informar sobre la vida de los estudiantes y, por el otro, las revistas culturales de los jóvenes "revisteros". En efecto, en 1915 Armando B. Rillo

\footnotetext{
31 Las "Publicaciones de la Universidad Libre" parecen haber sacado un único volumen, el folleto Nuestro analfabetismo de Ernesto Nelson, en el que se reproduce una conferencia dictada por ese miembro de la Universidad Libre. Las "Publicaciones del Colegio Novecentista", en cambio, editaron cinco volúmenes: La otra arcadia de Teofilo de Sais (seudónimo de Benjamín Taborga), Cantos de Jorge Max Rohde, Impresiones de Alberto Britos Muñoz, El irredimido de Korn Villafañe y La Religión y el Estado de Tomás Casares. La colección anunció La historia secreta del novecentismo de Korn Villafañe, obra que aparentemente no fue publicada.
} 
y José B. Gill fundaban El universitario. Órgano de los estudiantes universitarios, un periódico de seis páginas, formato tabloide, papel de baja calidad y aparición trimensual que publicaba noticias sobre la vida universitaria del país y el continente, siguiendo el formato de lo que comenzaba a ser la prensa moderna, a saber, notas breves, informativas y sin firma. A través de los pocos números que se han conservado y de algunas referencias, sabemos que el periódico se editó al menos hasta 1923. Esos números muestran que, a pesar del primado de la información sobre la opinión, una vez que estalló la Reforma el periódico seleccionó las novedades que deslizaban un posicionamiento del lado del ala reformista más radicalizada, entre ellas una polémica entre el estudiante católico Juan Díaz Salazar y José Ingenieros. A mediados de 1917, aquél había publicado varias notas en las que bregaba por el ingreso de profesores católicos a la universidad e identificaba a la liberal UNLP como el máximo peligro para la moral y el orden. Meses después, cuando los estudiantes cordobeses prolongaban su huelga, Ingenieros, bajo el seudónimo de Julio Barreda Lynch, respondió a Díaz Salazar denunciando el clericalismo de la Corda Frates y apoyando a los estudiantes "liberales" cordobeses.

\section{El despuntar del estudiante como un tipo de intelectual}

Como mencionamos, las revistas estudiantiles participaron a su manera del proceso de complejización de los lectores y las publicaciones. Editadas de modo bimestral, aquellas contaban con más de sesenta páginas, nucleaban a las frágiles redes estudiantiles que esteticistas, cinetificistas o católicas y se diferenciaban de las revistas oficiales de los centros de estudiantes porque su propósito general era la difusión de la alta cultura entre la juventud. Para ello publicaban artículos y poemas de las figuras señeras de la generación anterior y los primeros textos de los jóvenes universitarios. Además editaban reseñas de los últimos libros y exposiciones de arte, y solían saludar el crecimiento de la matrícula universitaria.

Es que, al igual que El Universitario, este tipo de publicaciones se dirigía a los jóvenes de los sectores medios que habían conseguido ingresar a la universidad, pero, a distancia de aquel, ponían en el centro de sus inquietudes las cuestiones culturales que excedían la formación profesional. Y una de las críticas recurrentes que formulaban las revistas estudiantiles era la dirigida a los jóvenes que, en lugar de sumarse al movimiento reformista, sólo se interesaban por pasar los exámenes y obtener un título que les asegurara un buen pasar económico. Es más, en una entrevista que le realizaron en 1921 Florentino Sanguinetti, en su condición de líder del grupo reformista izquierdista de la Facultad de Derecho, declaraba que ese rasgo del estudiantado era justamente uno de los males que debía erradicar la Reforma: “A los jóvenes, dicho sea en verdad, no les interesa la ciencia por la ciencia misma les interesa principalmente la patente, con la cual el Estado autoriza un privilegio, acredita una idoneidad y ofrece un modo de vivir que cohonesta los los ocios de nuestro 
clásico arrivismo". ${ }^{32}$ Por su parte, un líder reformista montevideano con quien el grupo de Sanguinetti organizó actividades comunes, Oscar Cosco Montaldo, también denunciaba en un discurso de 1924 ese arribismo:

El tipo de reaccionario "a outrance" no había hecho irrupción en nuestra universidad, ni lo ha hecho hasta el presente; pero, en cambio, la indiferencia más desesperante aniquilaba los espíritus y sepultaba los intentos renovadores.

Los estudiantes aprovechaban de la gratuidad de la enseñanza, conquista alcanzada felizmente en nuestro país, para engrosar la caravana sin rumbo de los profesionalistas (del Mazo, 1927 [1924], t.V: 305).

Las revistas estudiantiles en las que aparecieron este tipo de críticas a la juventud culta son significativas no sólo porque se erigieron en una instancia de difusión de ideas, sino sobre todo porque modelaron al estudiante como un tipo de intelectual, al tiempo que buscaron tensar las primeras redes en las que ese estudiante estaba llamado a intervenir, sobre todo la red del latinoamericano antiimperialista en la que participaría activamente Cosco Montaldo.

Más precisamente, las publicaciones periódicas fueron clave en la invención de un "espacio" y una "figura" político-culturales. Mediante la fundación de grupos y la elaboración y puesta en circulación de una revista y una colección editorial, así como de la discusión política y cultural, la redacción de manifiestos, la organización de conferencias, los contactos intergeneracionales y la designación de corresponsales asentados en otras ciudades universitarias, se recortó un ámbito de sociabilidad, o bien un modo de contacto con la cultura letrada específico de los jóvenes que pertenecían a las clases medias e ingresaban a la universidad. Correlativamente, las prácticas características de ese espacio perfilaron al "revistero" estudiantil como una específica figura intelectual.

Una confirmación de que para 1923 las revistas estudiantiles habían logrado delinear a esa figura opuesta al "universitario" puede reconocerse en el modo en que el manifiesto inaugural de Inicial. Revista de la nueva generación (1923-1927) justificaba su aparición. Se lee allí:

Hemos fundado INICIAL porque hemos creído obedecer a un mandato imperioso de nuestras conciencias, el cual es el sincerarnos en una tribuna libre respecto a los problemas que preocupan al mundo, respecto a los valores, decadentes o estimables, de nuestro medio moral y artístico. Sabemos que existe una juventud que se ha puesto al ritmo vertiginoso de esta hora histórica, y esa juventud tiene muchas cosas que decir. [...] INICIAL será el hogar de toda esa juventud dispersa que vagabundea por las publicaciones y revistas más o menos desteñidas de nuestro ambiente, sin encontrar donde pueda elevar el tono de su acento a la altura de sus propias convicciones (Inicial, $\mathrm{n}^{\mathrm{o}} 1$, octubre de 1923, p. 3).

\footnotetext{
Florentino Sanguinetti, "Entrevista", s/d. Fondo personal Florentino Sanguinetti, CeDInCI.
} 
Los directores de la "vanguardista" Inicial no dudaban de que la "puesta en ritmo de la juventud" involucraba tanto los reclamos dirigidos a las autoridades académicas como la fundación de grupos y revistas político-culturales. Es que, a través de esas prácticas culturales, la "juventud dispersa" había comenzado a poner en circulación autores, citas y colaboraciones que, más allá de sus fuertes diferencias, coincidieron en definir al estudiante universitario como una figura intelectual que debía tener sus propias convicciones y construir plataformas desde las que hacer públicas esas convicciones.

\section{La interpelación política del "estudiante"}

Desde sus primeros esbozos, la figura intelectual del estudiante se presentó a distancia de los partidos políticos. Pero en los años de fuerte politización que conformarían el trienio rojo (19191921) difícilmente los grupos estudiantiles pudieron evitar un pronunciamiento sobre su relación con los sectores populares y la política, así como sobre su pertenencia o distancia ante las fracciones de izquierda que venían interviniendo en la ciudad de Buenos Aires. Una muestra de la conciencia de los cambios irreversibles que se producían en la organización estudiantil y en la identidad de los estudiantes la ofrece el joven porteño José Belbey (1894-1960). En una breve nota de 1921, este estudiante de medicina y director de la irreverente revista estudiantil La Cureta (1918-1925) se mostraba a favor de la politización extrapartidaria de los grupos estudiantiles, pero antes sintetizaba:

Se ha discutido, y se seguirá discutiendo, la posición de las asociaciones estudiantiles frente a la sociedad [...]. Algunos opinan que ellas no tienen para qué salirse de la esfera puramente estudiantil marcada en sus comienzos. Pretenden que su finalidad es sólo la de trabajar por el bien exclusivo de los estudiantes. Otros creen debe ser más amplio el miraje, más extenso su radio de acción. Que no debe serles indiferente la ideología social, ni sus inquietudes. Que no pueden permanecer enquistadas en el cuerpo colectivo. Que toda causa noble, justa, necesita de ellas su aplauso o su apoyo, cualquiera sea el plano en que ella se debata; y que, toda injusticia, todo mal merece de ellas el repudio (Belbey, "La misión social de la juventud estudiantil", Ariel, no 19-20, Montevideo, agosto de 1921, p. 16).

Para expresar ese apoyo o aplauso ante las causas nobles y el repudio a toda injusticia, algunas asociaciones estudiantiles rediseñaron los emprendimientos estudiantiles. Entre 1919 y 1920, grupos como el Ateneo, los editores de Bases, de Insurrexit, de La Gaceta Universitaria de Córdoba y de Ariel de Montevideo, el grupo Lux de Córdoba y el Centro Cultural Evolución de Rosario explicitaron en sus propósitos la unión de los estudiantes con los obreros y la lucha, de filiación bolchevique, por la emancipación de la humanidad.

Para alentar ambos propósitos algunos de esos grupos impulsaron la fundación de una Federación de Estudiantes Revolucionarios, al tiempo que reemplazaron la práctica de editar revistas de muchas páginas y aparición bimestral, dirigidas a los estudiantes y centradas en lo 
cultural, por el primer periodismo político estudiantil. En efecto, entre 1919 y 1922 circularon distintas revistas estudiantiles de diez o doce páginas y frecuencia semanal o quincenal, que pusieron el foco en la política local e internacional y fueron preparadas para llegar no sólo a los pares estudiantiles sino también a los obreros.

\section{Conferencias y bibliotecas para estudiantes y obreros}

Otras dos prácticas estudiantiles en las que puede identificarse la llegada de la política izquierdista entre 1919 y 1921 fueron: el nuevo carácter de los ciclos de conferencias y la fundación de bibliotecas populares. A distancia de las conferencias en las que la juventud universitaria se reunía para procurarse la "formación integral" que no ofrecía el profesionalismo universitario, a partir de 1918 distintos revisteros estudiantiles que simpatizaron con el obrerismo socialista y anarquista se convencieron de que la formación integral no podía ser tal si se realizaba a la sombra de los obreros. Si bien esos emprendimientos no tuvieron las dimensiones alcanzadas por las Universidades Populares peruanas, hacia 1919 fue frecuente que las nuevas publicaciones difundieran actividades como la anunciada por Bases:

\section{LA NUEVA UNIVERSIDAD \\ CONFERENCIA DE NUESTRO DIRECTOR}

Con este tema, y organizada por el "Ateneo Popular", Juan Antonio Solari dará una conferencia el día 10 de junio, a las 21, en el local de la Biblioteca "Carlos Darwin”, Belgrano 1946.

Quedan invitados los obreros y estudiantes. Entrada libre (Bases, $\mathrm{n}^{\circ}$ 8, junio de 1920, p. 8).

Iniciativas similares fueron publicitadas en Ariel de Montevideo, Insurrexit y Tribuna universitaria. Órgano oficial de la Federación Universitaria de Rosario. Esta última, en su número del 19 de mayo de 1922, reseñó elogiosamente el homenaje que había organizado la Federación al delegado de los estudiantes peruanos, Haya de la Torre y precisaba: esa "elocuente manifestación de confraternidad internacional" asumió "un carácter eminentemente popular, ya que el público que llenaba por completo el amplio salón de la Facultad estaba compuesto no solamente por estudiantes, sino también en gran parte por maestros, obreros y personas de todas las clases sociales". ${ }^{33}$ Además, ese número de la Tribuna Universitaria publicitó un próximo evento del mismo carácter, pero en este caso para financiar la experiencia de extensión universitaria a la que estaba ligada la federación rosarina: ${ }^{34}$

\footnotetext{
33 "Homenaje al delegado de los estudiantes del Perú", Tribuna Universitaria, 19/05/1922, p. 1.

${ }^{34}$ El 22 de mayo de 1921, el gobernador de Santa Fe dejó cesante a los maestros que mantenían una huelga en reclamo del pago del sueldo. En repudio a ese hecho, la Federación de Estudiantes de Rosario junto a algunos grupos ácratas y sindicatos fundaron entre 1922 y 1924, al menos, escuelas racionalistas de alfabetización. En la detenida investigación sobre las experiencias educativas anarquistas en la Argentina de Acri y Cácerez (2011), puede encontrarse una referencia a las escuelas "22 de mayo", pero están aún por reconstruir sus vínculos con la Federación Universitaria de
} 


\section{COMPAÑEROS}

EL 22 DEL CORRIENTE a las 21 horas EN EL "SOCIAL THEATRE" (Rioja 960) se realizará una velada a beneficio de las "ESCUELAS 22 DE MAYO" con el siguiente programa:

1. - La internacional por la orquesta.

2. - Palabras alusivas al acto de la compañera Ángela G. de Agüero.

3. - El gato, aires criollos, de R. Maffioli, ejecutado por el señor Mario Maurano. [...]

OBREROS Y ESTUDIANTES!

Es necesario que no faltéis a esta fiesta.

A su vez, los números conservados de Insurrexit muestran que las conferencias dirigidas a obreros y estudiantes fueron una actividad regular del grupo editor. A partir del segundo número se lee en Insurrexit:

El Grupo Universitario "INSURREXIT" Comunista antiparlamentario, da todos los Sábados a las 21 horas conferencias públicas en el local SUIPACHA 72, a las que incita especialmente a estudiantes y obreros.

Respecto de la dimensión política de la otra iniciativa estudiantil, la fundación de bibliotecas, hemos rastreado algunos entusiastas proyectos estudiantiles. Por un lado, poco después del estallido de la Reforma, los estudiantes federados cordobeses anunciaban la pronta inauguración de "la biblioteca pública de la Federación Universitaria”, solicitaban la donación de libros y bibliotecas y concluían incitando "a los que crean en la necesidad de instruir al pueblo, a que contribuyan con su esfuerzo a fin de que nuestra biblioteca pueda pronto abrir sus puertas, dotada de los textos y comodidades que requiere". 35

Ese tipo de iniciativas también sería alentada por los estudiantes santafesinos. En efecto, una de las pocas cartas conservadas del joven Pablo Vrillaud (1897-1925) nos anoticia de que, también en 1919, el CE de Derecho de la Universidad del Litoral fundaba en su local una "biblioteca popular". Y aquel, en calidad de presidente del Centro, se ocupaba de garantizar una de las condiciones para la pervivencia del proyecto: el tramado de una red de intelectuales y estudiantes con una sensibilidad política afín. Escribía Vrillaud:

Una biblioteca será siempre un nuevo surco que se abra; al fundar la nuestra pensamos en que la patria las necesita hoy más que nunca, laboratorios silenciosos que servirán para orientar las energías de la juventud. Las bibliotecas son los complementos de las escuelas y universidades, queremos que la nuestra sea también una proyección de la fábrica y del taller prestigiando así la concurrencia del obrero, para que se viva en la serenidad del estudio, esa anhelada confraternización de los espíritus que engendrarán las patrias del mañana (Fondo documental sobre la Reforma Universitaria, Museo y Archivo Histórico, Universidad Nacional del Litoral).

Rosario.

${ }^{35}$ La Gaceta Universitaria de Córdoba, no 14, 11/07/1919, p. 6. 
Ya desde fines del siglo XIX, las culturas socialista y anarquista asignaban un importante lugar a los libros y a la difusión de la cultura letrada, núcleos que serán recogidos por los grupos estudiantiles de mediados de la década del diez y por la cultura política que terminará por acuñar la Reforma. Esa impronta ilustrada -que en los treinta se revelará como el parteaguas entre el reformismo y el revisionismo histórico de derecha, y en los cuarenta entre aquel y el peronismo- llevó a varios animadores de la Reforma a proponerse como directores de las bibliotecas universitarias. Entre ellos, Vrillaud, luego de una intensa participación en las instancias representativas de los estudiantes, consiguió en 1924 la dirección de la Biblioteca de la Facultad de Ciencias Jurídicas y Sociales de la Universidad del Litoral. ${ }^{36}$ Por su parte, Arturo Orgaz, bajo la convicción de que "las bibliotecas deben ser fiel expresión de la capacidad y del empeño en que se vive”, reestructuró la Biblioteca de la Facultad de Derecho de la UNC y alentó la fundación de una sección de Librería y Publicaciones de esa facultad en la que, bajo la dirección del joven Carlos Astrada, se editaron obras de autores nacionales y europeos relativas a los problemas contemporáneos y a cuestiones filosóficas. En un temprano balance, Orgaz no dudaba en asociar la Reforma a la instalación de librerías en la ciudad y a la fundación de bibliotecas populares y centros culturales -trazando una contraposición entre cultura ilustrada y cultura popular que, con la llegada del peronismo, revelará su dramatismo político-. Se lee en ese balance:

Córdoba carece de bibliotecas populares valiosas; las muy pocas que hay son raquíticas; carece de centros culturales importantes; las exposiciones de arte son raras y a veces fracasan lamentablemente aquí; el teatro de ideas o de alta emoción carece de público nutrido que lo hay, en cambio, para llenar noche a noche, salas de espectáculos en donde no se sale del cocoliche, del tango suburbano, del cabaret y la puñalada del bajo fondo (Arturo Orgaz, "Lo que fue, lo que es y lo que debe ser nuestra facultad de derecho", Revista de la Universidad Nacional de Córdoba, no 8-9-10, 1922, p. 23).

Para superar esas carencias, Orgaz contó, entre otros, con la iniciativa de Gregorio Bermann, quien en 1922 llegó a Córdoba para ocupar tanto la cátedra de Medicina Legal y toxicología como la dirección de la Revista de la Universidad de Córdoba y de la Biblioteca Mayor de la UNC. Desde esta última, el joven porteño dispuso otra de las vías para el acercamiento entre obreros y estudiantes. Durante 1922, la Biblioteca Mayor fue publicitada del siguiente modo en La Gaceta Universitaria de Córdoba -publicación que por entonces buscaba circular tanto entre estudiantes

\footnotetext{
${ }^{36} \mathrm{Su}$ itinerario reformista ha sido reconstruido en el folleto Pablo Vrillaud. Huellas de un líder estudiantil (2009: $75-$ 78). Sobre ese itinerario destaquemos que Vrillaud ingresó en la carrera de Derecho en 1918 y ese año viajó a Córdoba como representante de los estudiantes de la Universidad Provincial de Santa Fe en el Primer Congreso Nacional; en 1921 formó parte de la comitiva estudiantil que viajó a México para participar del Primer Congreso Internacional de Estudiantes y desde allí partió a Europa en una gira financiada por el Estado mexicano para difundir las resoluciones del congreso. A su vuelta a la Argentina en 1922, presidió la FUA y hasta su muerte precoz en 1925 viajó por el país pronunciando conferencias y participando de actos que buscaban asentar el carácter izquierdista de la Reforma.
} 
como entre obreros-:

\section{Biblioteca de la Universidad Nacional de Córdoba}

Horario continuo-Abierta desde las 8 hasta las 23

Integra continuamente su caudal bibliográfico con obras recientes de Derecho, Medicina, Ingeniería, Filosofía, Literatura, Artes, etc.

Se halla suscrita y establece canje con las más importantes revistas del extranjero y del país.

Tienen acceso a la Biblioteca, estudiantes y público.

A través de la mención del amplio horario, de la incorporación de obras recientes y de un acceso que no se restringía a los estudiantes, la gestión de Bermann explicitaba su participación en un proyecto reformista identificado con la actualización de las disciplinas académicas pero también con la difusión de la alta cultura más allá de las clases altas y medias. Y la ampliación del horario de la biblioteca remite a otras dos marcas distintivas de las clases medias universitarias: su temprano ingreso en el mundo del trabajo y la ausencia de contactos que facilitaran la carrera universitaria.

\section{Los "estudiantes" frente a los "niños bien"}

Entre los jóvenes que, en la década del diez, comenzaban a animar grupos estudiantiles y revistas y que, en la década del veinte, se erigieron como líderes reformistas se encontraban hijos de la elite cultural, como Deodoro Roca, Julio V. González y Carlos Sánchez Viamonte, pero en esas instancias grupales primaban los hijos de inmigrantes o inmigrantes ellos mismos, como Monner Sans, José Gabriel y Pedro Verde Tello (Ciria y Sanguinetti, 1968: 24). ${ }^{37}$ Si bien -como destacaba Vaz Ferreira- el paso por la universidad disolvía las aristocracias, los revisteros llegaban a una universidad poblada de "pingüinos" o "niños bien", esto es, de hijos de la elite político-cultural que vestían trajes elegantes y que participaban de los Centros de Estudiantes con el fin de tener un espacio más de reconocimiento entre la familia y los profesores. Asimismo, en el momento de ser examinados, los hijos de la élite también podían exponer ante esos profesores "cartas de recomendación" que, en muchos casos, respondían a contactos familiares.

Algunos hechos ofrecen claros indicios de que la universidad estaba dejando de ser un espacio exclusivo de la elite. Entre ellos, el acceso a la presidencia del CE de Filosofía y Letras en 1917 de un hijo de inmigrantes judíos, filiado al socialismo, como Bermann, o la elección en 1920 de otro hijo de inmigrantes y socialista, José Belbey, como presidente del importante CE de Medicina y al año siguiente de un joven sin pertenencia a la elite, Jacinto Armando, en el CE de la facultad más aristocrática, la Facultad de Derecho. Sobre la representación del estudiante que

\footnotetext{
${ }^{37}$ Agreguemos a ello que muchos de esos hijos de inmigrantes eran de origen judío, como Gregorio Bermann, Simón Scheimberg, Emilio Biagosch y Alberto Palcos, y convivían con el desprecio antisemita.
} 
acompañaba a la presencia de este tipo de jóvenes en las instancias organizativas son ilustrativas las frecuentes denuncias que realizaban las revistas estudiantiles contra las cartas de recomendación. A ellas se suma una elocuente aclaración que, en carta privada, realizaba en 1921 el joven Florentino Sanguinetti a un profesor que había firmado una de esas cartas:

Decidido a combatir la clásica costumbre criolla de ascender por cuñas, he eliminado sistemáticamente en los últimos exámenes, a todos los jóvenes que llegaban a mi mesa, confiados en alguna recomendación. Justifico mi actitud con dos razones: primero porque nadie pide remolque si tiene su programa preparado, y en segundo términos porque entiendo que los reformistas criticamos los procedimientos clandestinos del viejo régimen y ahora tenemos el deber de suprimirlos sin reparos. [...] como caso excepcional y en homenaje a su amistad, olvidaré por esta vez el nombre del interesado, quien solo debe confiar en la rectitud del tribunal. Aconséjele que estudie mucho (Carta de Florentino Sanguinetti a (?) Perdomo, Buenos Aires, 14/12/1921, Buenos Aires. Fondo personal Florentino Sanguinetti, CeDInCI). ${ }^{38}$

Como mencionamos, la otra diferencia importante entre los revisteros estudiantiles y los "pingüinos" residió en que los primeros repartían su tiempo entre el estudio, la sociabilidad estudiantil y el trabajo en la prensa. En cuanto a la cotidianidad estudiantil, uno de los jóvenes que no necesitó trabajar, Julio Irazusta (1899-1982), recuerda que

Aunque hacía una vida de estudio bastante regular, ya había gustado las delicias de la bohemia literaria. Madrugaba y leía hasta la hora de almorzar, por la tarde iba a casa de las señoritas de Durán, donde viví mientras estuve en el bachillerato y había dejado mi biblioteca, en busca de los libros míos que necesitaba, para luego cenar en el centro. Las tertulias habituales de uno u otro grupo en los diversos restaurantes ofrecían l'embarras $d u$ choix, desde la hora del aperitivo hasta después de la cena. El medio literario era mucho más reducido que ahora, y quienes lo frecuentábamos nos veíamos a diario en una u otra peña (Irazusta, 1975: 67).

El futuro codirector de la revista filomaurrasiana La Nueva República (1927-1931) y referente de la derecha argentina pertenecía a una familia de medianos propietarios de Gualeguaychú y había llegado a Buenos Aires para cursar el bachillerato. En 1918 comenzó a estudiar Derecho y fundó, junto a su amigo Mario Jurado, la Revista Nacional (1918-1920). Según veremos, esta publicación estudiantil fue la rival más enérgica de la identidad izquierdista de la Reforma, sobre todo desde que a fines de 1919 se sumó a la Unión Universitaria.

Irazusta recuerda que en 1918 vivía en una habitación alquilada donde funcionaba la

\footnotetext{
${ }^{38}$ Esta carta respondía a la siguiente que transcribimos en su totalidad, pues su desafiante tono antirreformista es elocuente del malestar que causaban los nuevos grupos estudiantiles: "Estimado Sanguinetti: Hoy por su mesa y la de su colega Doctor Monner Sans hijo rendirá examen un muchacho amigo mío llamado Antonio Usama. Me permito recomendárselo, rogándole no se esfuerce en preguntarle lo que no sabe, desaprobable función a la que se dedican Uds. después que las 'virtudes' de la Reforma los llevaron a sendos sillones consejales. Y además mi buen amigo bien sabe Ud.: qué poco influye en la vida el aprobar un examen de filosofía! - agradeciéndole y rogándole excuse la molestia, me es grato saludarle affte" (Carta de Perdomo a Sanguinetti, Buenos Aires, 13/12/1921. Fondo personal Florentino Sanguinetti, CeDInCI).
} 
dirección, la redacción y la administración de la Revista Nacional. Un año después, comenzó a frecuentar la FFyL y ya vivía en dos departamentos que reunían su biblioteca y que compartía con su hermano, su amigo Mario Jurado y el hijo de la cocinera de sus padres, encargado de los servicios domésticos de los estudiantes. Poco tiempo después, Irazusta interrumpía definitivamente los estudios para realizar su primer viaje a Europa y asistir a varios cursos universitarios en los que quedaría entusiasmado con las ideas de Charles Maurras (Irazusta, 1975: 69-70).

Una similar holgura económica acompañó los estudios de Julio Noé, pues del siguiente modo recuerda su decisión de embarcarse junto a Ortega y Gasset hacia Madrid:

Por felices circunstancias tuve oportunidad de ver a Ortega con frecuencia. Egresado poco antes de la Facultad de Derecho, y con pocos quehaceres, solía encontrarme con él en los jardines de Palermo, donde al sol tibio de ese final de invierno conversábamos largamente. [...] una semana antes de su partida me preguntó qué pensaba hacer yo durante el verano. Cómo dudé en la respuesta, me instó a acompañarle en su viaje inminente.

El 2 de enero de 1917 nos embarcamos en un transatlántico español y dieciseis días después llegamos a Cádiz (Noé, 1993 [circa 1960]: 108-109).

Pero si el mundo del trabajo no estaba en el horizonte de los dos fundadores de la Revista Nacional ni del "encargado" del Colegio Novecentista, otro fue el caso de los cofundadores de ese Colegio y de los Cuadernos. Tanto Benjamín Taborga como José Gabriel pertenecían a la "malquerida" bohemia que, como contaba con muy pocos libros, solía visitar la Biblioteca Nacional, se ganaba la vida con el periodismo y, si visitaba Europa, lo hacía como reportera. ${ }^{39}$ Precisa Gabriel: "aparte de reporter y redactor de La Prensa, y de crítico de El Hogar y El Mundo Argentino, yo era alumno de Filosofía y Letras, donde ingresé en forma normal y honrosa". ${ }^{40}$ Justamente para atacar la "forma anormal y deshonrosa" con que ingresaban algunos de los hijos de las clases acomodadas, la revista Ideas diseñó en 1917 la sarcástica columna "Las memorias de un modesto estudiante", en la que “Aserrín" expuso las diversas y despreciables costumbres de los "pingüinos" y de sus distintos emuladores.

Al igual que Gabriel, Monner Sans (la pluma que se escondía tras el seudónimo que parodiaba al prestigioso escritor español Azorín y sus Confesiones de un pequeño filósofo) recuerda que fueron los trabajos en la prensa los que le permitieron financiar sus estudios. El principal animador del Ateneo confiesa que luego de haber sido echado de un estudio de abogados

[...] busqué acomodo en la revista ilustrada P.B.T. Su director, Emilio Dupuy de Lome,

\footnotetext{
${ }^{39}$ Sobre estos jóvenes recuerda Alfredo Bianchi en unas memorias de Nosotros: "el 25 de mayo de 1913 conocí a José Gabriel, y desde esa noche, con él y otros amigos, nos reunimos en el café Ideal, de Corrientes y Libertad. Poco después se agregó al grupo, el taciturno y profundo Benjamín Taborga" (Bianchi, 1932: 12).

40 José Gabriel, "Verdadera historia del Colegio Novecentista", Libertad Creadora, no 2, La Plata, abril-mayo-junio de 1943, p. 313.
} 
palió mi infortunio metálico encomendándome una sección fija y encargó los correspondientes 'monos' al pintor Oscar Soldati. Y cuando desapareció esa revista -tal vez contribuí yo a precipitar su eclipse-, me coló en Caras y Caretas y Plus Ultra. Después, en El Hogar y Mundo Argentino de la empresa Haynes.

En la década del veinte, algunos reformistas se incorporarían a la redacción de Crítica y en las décadas siguientes participarían de la industria editorial redactando manuales de textos para estudiantes primarios y secundarios.

En cuanto a esos días en los que se estaba gestando la "juventud universitaria", refiere Monner Sans, olvidando su militancia en el PS, que

en orden abierto resultaba bravita cada jornada: clases matutinas, de asistencia obligatoria, en Derecho, almuerzo a escape para salir rumbo a un estudio abogadil donde me "especialicé" en juicios ejecutivos, todos iguales, para, a la tardecita y trepando a un tranvía, recalar en las inmediaciones del susodicho islote [la FFyL]. Algunos días, juntarnos en el Ateneo Universitario con estudiantes de distintas facultades donde charlábamos preferentemente de política y de libros y, por supuesto como buenos descontentadizos-, arreglábamos de prisa orbe y sus arrabales, las letras y sus suburbios (Monner Sans, 1976: 135-136).

Guiados por este tipo de recuerdos, por las revistas estudiantiles y por la correspondencia, el objetivo de los siguientes capítulos es ofrecer una minuciosa reconstrucción de la trama material y simbólica que, entre 1914 y 1928, se fue tejiendo en las "charlas de política y libros", pues esa trama es la que motivó a muchos de los "revisteros descontentadizos" a confiar en que el movimiento de la Reforma Universitaria era la vía para probar una intervención intelectual que se prolongase más allá de la "clausura de los claustros", según la expresión que en 1917 comenzó a utilizar el futuro decano reformista Mario Sáenz.

Para concluir este primer trazado de la juventud universitaria, retomemos algunos de los rasgos que fuimos presentando en el presente capítulo y que encontrarán una mayor precisión en el abordaje de los distintos grupos que realizaremos en los capítulos siguientes. A las agrupaciones estudiantiles que desde comienzos del siglo XX reclamaban por asuntos académicos y que cuestionaban la autoridad moral de los profesores, se sumaron en la década del diez grupos y revistas animados por jóvenes provenientes de las clases medias. Éstos procuraron no sólo la agilización y democratización de los estudios, sino también una formación cultural que excediera el conocimiento profesional. Las actividades de esos grupos, entre las que se destacó la edición de revistas culturales, tramaron un espacio de sociabilidad y una primera identidad estudiantil que procuró que la juventud universitaria ampliara sus intereses más allá de las cuestiones de su profesión. Hasta 1918 esa identidad fue fundamentalmente cultural y se ligó a la "cultura integral". Asimismo, se dirigió de modo casi exclusivo a los estudiantes y permaneció tensionada por las 
definiciones propuestas por tres redes de sociabilidad recortadas a partir de la opción por diversas matrices culturales: la del idealismo estético, la del socialismo cientificista y la del catolicismo. Luego del estallido de la Reforma -al que lo antecedieron el malestar ante la prolongación de la Gran Guerra y las noticias de la Revolución Rusa-, la pregunta por la "misión social” comenzó a estar en el centro de los grupos que procuraban definir al estudiante. Desde entonces muchos jóvenes revisaron sus propósitos para fundar revistas, organizar conferencias y dirigir bibliotecas que otorgaron un importante peso a la definición política y al vínculo de los estudiantes con los obreros. 


\section{Capítulo 2. Los "revisteros descontentadizos" de Buenos Aires}

En 1914 surgen las dos asociaciones estudiantiles de la ciudad de Buenos Aires que buscaron más activamente que los estudiantes universitarios dejaran de preocuparse exclusivamente por su trayectoria académica para reconocerse como actores con una ineludible preocupación social. Esos grupos son el Centro de Estudios Ariel y el Ateneo de Estudiantes Universitarios. Las iniciativas y los vínculos tramados por estos dos grupos están en el centro del análisis del presente capítulo. Dado que en esa juventud universitaria circuló fuertemente el juvenilismo que Rodó había condensado en su Ariel, el capítulo comienza repasando ese llamado para luego dedicar distintos apartados a la caracterización de las iniciativas, los vínculos y las definiciones del Centro Ariel y del Ateneo.

\section{José Enrique Rodó, "maestro de la juventud americana”}

En 1900 el escritor y político montevideano José Enrique Rodó (1871-1917) publicaba Ariel, un "sermón laico" que pertenecía al emergente movimiento modernista (con el que las letras del continente lograrían independizarse de las reglas españolas), pero que retomaba el imaginario romántico aristocrático, de amplia circulación entre los letrados rioplatenses. Allí se le proponía a la juventud culta que se erigiera en la portadora de los valores grecolatinos y cristianos que remediarían la crisis moral del fin de siglo. ${ }^{41} \mathrm{Al}$ enviarle su libro a Unamuno precisaba Rodó:

Mi aspiración inmediata es despertar con mi prédica, y si puedo con mi ejemplo, un movimiento literario realmente serio correspondiente a cierta tendencia ideal, no limitado a vanos juegos de forma, en la juventud de mi querida América. [...] estoy convencido de que sin una ancha base de ideas y sin un objetivo humano, capaz de interesar profundamente, las escuelas literarias son cosa leve y fugaz (Carta de José Enrique Rodó a Miguel de Unamuno, cit. Benedetti, 1966: 166).

Esa "base de ideas" era desarrollada a partir de tres núcleos problemáticos. Ariel comienza con un llamado a la juventud a recomponer la situación de decadencia, así como a rechazar el utilitarismo y a superar la profesionalización. La tarea de la juventud culta sería la restauración del espíritu integral y del cultivo de la belleza. El segundo núcleo está marcado por la crítica a la "mesocracia" que produciría la democracia. Ante la posible nivelación alentada por el régimen político moderno, los jóvenes deberían

\footnotetext{
${ }^{41}$ Real de Azúa (1975) ha realizado dos importantes señalamientos sobre el texto. Por un lado, ha mostrado que el género al que pertenece no es el del ensayo sino el de los sermones laicos de fines del siglo XIX. Por el otro, puso en evidencia que sus tópicos retoman sobre todo las preocupaciones del ambiente cultural rioplatense, y que por ello su importante repercusión continental no se debe tanto a su originalidad cuanto a la lograda condensación de esos tópicos. Por su parte, Terán (1986a) ha identificado en el Ariel y sus resonancias la configuración de un primer antiimperialismo, marcado por una impronta no política sino cultural. Asimismo, en un texto más reciente ha analizado la relación que propuso Rodó entre modernismo literario y modernización político-económica (Terán, 2009). Sobre la misma cuestión, véase Ramos (2003).
} 
[...] insistir en la concepción de una democracia noble, justa; de una democracia dirigida por la noción y el sentimiento de las verdaderas superioridades humanas; de una democracia en la cual la supremacía de la inteligencia y de la virtud -únicos límites para la equivalencia meritoria de los hombres- reciba su autoridad y su prestigio de la libertad, y descienda sobre las multitudes en la efusión bienhechora del amor" (Rodó, 1967: 68).

Finalmente, el texto exalta la "cultura latina" frente a la "nordomanía". Rodó comienza por enumerar una serie de virtudes ligadas a los Estados Unidos como modelo de civilización (el imperio de la libertad, el culto al trabajo, el afán conquistador del pionero, el espíritu asociativo, la eficacia en la aplicación de la técnica y el instinto de curiosidad insaciable), pero enseguida afirma su célebre frase "aunque no les amo, les admiro" (1967: 76). Se pregunta el montevideano:

¿Realiza aquella sociedad, o tiende a realizar, por lo menos, la idea de la conducta racional que cumple a las legítimas exigencias del espíritu, a la dignidad intelectual y moral de nuestra civilización? ¿Es en ella donde hemos de señalar la más aproximada imagen de nuestra ciudad perfecta?" (Rodó, 1967: 77).

La respuesta sería decididamente negativa: frente al utilitarismo vacío, a la vaguedad cosmopolita y a la nivelación de la democracia bastarda que impulsaría la cultura estadounidense, debería exaltarse a América Latina como el espacio en el que florecerán los intereses del alma. Nuestro continente propondría un modelo de modernización que, a diferencia del norteamericano, sería capaz de conjugar la potencia material con los valores del espíritu.

Rodó se encargó de enviar su libro por correo a numerosos intelectuales de América Latina y Europa, pero esa primera edición no logró despertar en la juventud de su "querida América" la "tendencia ideal" que le subrayaba a Unamuno. Fue, en cambio, a partir de la edición de 1907 que varios grupos de veinteañeros y revistas estudiantiles se reconocieron "arielistas" y propusieron versiones diversas de esa base de ideas. Las propuestas fueron tales que, como señala Biagini, la visión de Rodó sobre la juventud "constituye una matriz germinal doctrinaria que se prolonga operativa y críticamente a su alcance cronológico y a su misma legitimación” (Biagini, 2012: 53). A ello podríamos agregar que la "constelación de revistas Ariel" será reemplazadas en las siguientes décadas del siglo XX por la "constelación de revistas Claridad”.

Si bien es difícil recuperar las breves iniciativas estudiantiles que comenzaron a identificarse como arielistas e iniciaron esa constelación, podemos mencionar algunas pioneras. En 1904 el joven dominicano Pedro Henríquez Ureña (1884-1946), quien luego de su participación cultural en la Revolución Mexicana se radicó en Buenos Aires convirtiéndose en un importante constructor cultural, publicaba en Veracruz sus laudatorias impresiones del texto de Rodó, al tiempo que le 
escribía a éste para que lo autorizara a realizar una edición cubana de ese texto "allí desconocido". La reedición finalmente aparecería en México en 1908, con prólogo de Henríquez Ureña y financiación de Bernardo Reyes, hermano mayor de Alfonso Reyes con quien entonces Henríquez Ureña mantenía una estrecha amistad intelectual. En Perú sería Francisco García Calderón (18831953) quien iniciaba la recepción crítica del texto (Quintanilla, 2008: 134-139; Real de Azúa, 2010).

Por esos años aparecían las primeras revistas Ariel. La pionera parece haber sido la fundada en 1901 en Maracaibo por el joven médico y periodista Jesús María Semprúm (1882-1931). Luego el escritor y editor Joaquín García Monge (1881-1958) publicaría mensualmente entre 1906 y 1917 , en San José de Costa Rica, una selección y traducción "de los buenos autores, antiguos y modernos" llamada Colección Ariel y compuesta de treinta páginas, aproximadamente. ${ }^{42}$ Otra revista Ariel fue fundada en París en 1912 por un veinteañero argentino, el escritor y periodista anarquista Alejandro Sux (seúd. de Alejandro José Maudet, 1888-1959). Esta Ariel llevó el subtítulo de "revista de arte libre" y sólo tuvo cuatro números, interrumpidos seguramente por la demanda judicial que debió afrontar Sux luego de publicar un texto de corte antimilitarista de Rubén Darío, sin la autorización de éste.

Dos años después surgieron en la ciudad de Buenos Aires dos grupos que recogieron y reformularon el llamado arielista a la juventud culta como conductora política y que son objeto de análisis del presente capítulo. A comienzos de 1914, una veintena de jóvenes rompían con la sociabilidad judía reunida en la revista Juventud para ligarse al PS y fundar el Centro de Estudios Ariel. En junio de ese año ponían a circular Ariel. Revista mensual de ciencias, letras y artes, de la que aparecieron cinco números (el último doble) de sesenta páginas cada uno y tapas que reproducían un grabado que evocaba el rostro de un joven mirando al porvenir. ${ }^{43}$ En mayo de ese año, otro grupo, liderado por el estudiante de Derecho José María Monner Sans, se conformó en la "Sección de Estudiantes Universitarios" del Ateneo Hispano-Americano de Buenos Aires estudiantil, rebautizada luego como el Ateneo de Estudiantes Universitarios. El grupo editó entre abril de 1915 y septiembre de 1919 veintidós números, de ciento veinte páginas, de la revista Ideas. Órgano del Ateneo de Estudiantes Universitarios (1915-1919), la que a partir de su número doce también contó con un grabado de reminiscencias juvenilistas para ilustrar su tapa. ${ }^{44}$

En su respuesta al llamado arielista, estos grupos no ensayaban la misma fórmula cultural.

\footnotetext{
${ }^{42}$ Con esa edición de bajo costo, a la que agregaba un amplio glosario que facilitaba la comprensión a los lectores poco familiarizados con esa literatura, Monge inauguraba su profusa labor democratizadora de la alta cultura. Y mencionemos, al menos, que, cuando estalla la Reforma, su revista Repertorio Americano (1919-1958) es central en el tramado de la red continental de los intelectuales reformistas (Devés Valdéz, 2011).

${ }^{43}$ Agradezco a Verónica Delgado el acceso a la colección completa de esta revista.

${ }^{44}$ Para simplificar la comprensión nos referiremos a este grupo como el Ateneo de Estudiantes Universitario, incluso cuando aludimos a su período inicial en el que tenían el nombre de Sección. Agradezco a Hugo Biagini el acceso a la colección completa de esta revista y el señalamiento de la importancia de su estudio.
} 
Desde 1913 el juvenilismo americanista tenía un nuevo "sermón laico": a distancia del esteticismo del ensayo de Rodó, José Ingenieros con su exitoso El hombre mediocre proponía una interpelación juvenil anclada en la certera evolución de la humanidad que aseguraba el cientificismo. Retomando este cientificismo, la veintena de jóvenes que participaban del Centro porteño Ariel conectaba la interpelación de Rodó con el desarrollo de una ciencia ligada al igualitarismo democrático de la cultura socialista, la organización de cursos de extensión para obreros y estudiantes y la edición de una revista en la que confluían los textos y poemas de los jóvenes con la producción de los intelectuales reconocidos filiados al socialismo. Por su parte, los ateneístas no se mostraron partidarios de la "matriz científica" sino de la "matriz estética", esto es, a través de conferencias, cursos, conciertos y la edición de una revista, buscaron que los estudiantes alcanzaran una formación en la tradición grecolatina que remediara el utilitarismo y profesionalismo denunciados por Rodó. Como mencionamos, si bien Monner Sans fue un entusiasta militante del PS, su grupo filió el juvenilismo arielista a una intensa labor cultural entre los estudiantes que hasta 1919 suspendió una definición política común. Por otra parte, a diferencia de Ariel, la revista editada por los ateneístas fue estrictamente juvenil: sus páginas informaron sobre las actividades del grupo y sólo pusieron a circular los textos (artículos, reseñas y poemas) redactados por los estudiantes.

Antes de concentrarnos en estos dos activos grupos porteños, listemos, al menos, las otras revistas que tomaron el nombre de "Ariel” y aparecieron en el Río de la Plata y en el continente durante las décadas inmediatas. En 1916 aparecieron dos efímeras Ariel rioplatenses preocupadas por la difusión de la cultura estética y moral: una editada en la La Plata y la otra en Treinta y Tres, Uruguay, (ésta fue el órgano de la Asociación de estudiantes secundarios Cervantes). En 1918 fueron fundadas otras dos, una en Santiago del Estero y otra en Río Cuarto. Al año siguiente un grupo de estudiantes secundarios de Buenos Aires, liderado por el futuro editor Samuel Glusberg, creaba otra Ariel. Por su parte, a mediados de 1919, el Centro de Estudios Ariel de Montevideo, que lideraba Carlos Quijano, ponía a circular el primer número de la revista Ariel que lograría prolongarse más en el tiempo. Como analizaremos en el capítulo sexto, la Ariel montevideana, al igual que la porteña de 1914, combinaba el juvenilismo rodoniano con el socialismo, e incluso se relacionaba con algunos de los que habían participado en la revista porteña. Pero el nuevo grupo surgía luego del estallido de la Reforma Universitaria y de la Revolución Rusa, dos acontecimientos que permitían reemplazar la impronta gradualista del socialismo cientificista de los porteños por un socialismo que simpatizaba con la vía revolucionaria y se referenciaba en la figura de Henri Barbusse.

Finalmente, en los años inmediatos fueron fundadas fuera de Buenos Aires otras revistas Ariel: en Santiago de Chile (1925), en Río Cuarto (1926), en Cosquín (1927), en Lima (1917 y 1928), en Río de Janeiro (1931-1936), en Cuba (1936-1937), en San José de Costa Rica (1937- 
1942) (Biagini, Introducción a Prieto, 2003). ${ }^{45}$

\section{Los animadores porteños del arielismo socialista}

Los jóvenes que a comienzos de 1914 fundaron el Centro de Estudios Ariel tenían, en su mayoría, veinte años, simpatizaban con el PS, estudiaban Medicina o Abogacía en la UBA y eran todos ellos varones judíos. Si bien algunas mujeres habían conseguido ingresar en la universidad (fundamentalmente, en la Facultad de Medicina y en la de Filosofía y Letras), las únicas jóvenes que parecen haber participado del grupo son las concertistas de piano y violoncello "srtas Alba Rosa y Sarah Ancell”, que ejecutaron junto al violinista Ennio Bolognini un concierto organizado por el Centro, una participación que sugiere que los arielistas no estaban exentos de la división de géneros de las labores intelectuales.

Entre los arielistas se encontraban tres figuras que se reconocían como entusiastas discípulos de "cientificista" Ingenieros: los estudiantes Alberto Palcos (1894-1965) y Gregorio Bermann (1894-1972), y el “Dr.” Enrique Mouchet (1886-1977), quien, antes de recibirse de médico en 1914, se había doctorado en 1910 en la FFyL de Buenos Aires. Por otra parte, Mouchet en 1923, mientras ejercía el cargo de concejal de la ciudad de Buenos Aires por el PS, asumiría el primer decanato reformista de la Facultad de Humanidades y Ciencias de la Educación de La Plata -en unas elecciones en las que el grupo estudiantil Renovación había apoyado la candidatura del "antipositivista" Alejandro Korn-.

En Ariel Mouchet fue parte del equipo de redacción y publicó varias notas. Por su parte, Bermann fue el responsable de la tesorería del grupo mientras que Palcos se encargó de la dirección de los cinco números de la revista. Para 1914 Bermann ya había participado de un grupo políticointelectual. Al iniciar sus estudios en Medicina, se asoció a la sección argentina de la Liga de Educación Racionalista, que dirigía el pedagogo anarquista Julio R. Barcos y en la que Leonilda Barrancos (1892-1954), una importante promotora del feminismo socialista y futura esposa de Bermann, dictaba el curso de extensión sobre Literatura Contemporánea. ${ }^{46}$ Esa Liga, que impulsaba la sindicalización docente y organizó la primera huelga docente argentina (Puiggrós, 2006), editaba La escuela popular. Revista mensual. Órgano de la Liga de Educación Racionalista (1912-1914). Allí Bermann publicó sus primeras notas. ${ }^{47}$ Éstas versaron sobre la importancia de que los estudiantes y los profesores mejoraran el nivel cultural de los obreros a través de cursos de "extensión universitaria", y veremos que se revelan como, por un lado, el inicio de una reflexión que se continuó en las notas aparecidas en Ariel y en las revistas que surgieron al calor de la

\footnotetext{
${ }^{45}$ Sobre el arielismo a nivel continental, véase Devés Valdés (2007) y Real de Azúa (2010).

${ }^{46}$ Sobre el itinerario político-intelectual de Barcos y de Barrancos, véase Tarcus (2007) y Pita González (2012).

${ }^{47}$ Las notas en cuestión son: "La psicología, ciencia natural", La escuela popular, no 17, pp. 12-18 y "Sobre extensión universitaria. El profesor y el alumno", La escuela popular, n 18, pp. 15-18. Para un estudio de las experiencias de extensión universitaria en Buenos Aires, véase Barrancos (1996). Sobre el itinerario de Bermann, véase Celentano (2006a) y Tarcus (2007).
} 
Reforma y, por el otro, como el sustento ideológico de las iniciativas del Centro Ariel, de la Universidad Libre y de la Biblioteca Mayor de la Universidad de Córdoba -como mencionamos, dirigida por Bermann entre 1922 y $1923-$.

Por su parte, Palcos no participó de la sociabilidad de la Liga pero sí de la del PS, al que se había afiliado en 1913, y de la del ateneo estudiantil. Su dirección de Ariel fue la primera de una serie que se extendió en los años inmediatamente posteriores: entre 1917 y 1918 dirigió la Revista Socialista, y entre 1919 y 1920 fue el director de La Internacional. Órgano del Partido Socialista Internacional. ${ }^{48}$ Estas dos empresas se inscribieron en la fracción "internacionalista" del socialismo porteño, esto es, se opusieron a la adhesión al bando aliado en la Primera Guerra Mundial que sostuvo hacia 1917, en sintonía con el movimiento internacional, el PS argentino. En 1918 esta fracción fundó el Partido Socialista Internacional (PSI), el que en 1920 cambió su nombre por el de PC y tiempo después consiguió ser reconocido como la única sección argentina de la Internacional Comunista (Campione, 2005).

Los números de Ariel consignan en su tapa que el secretario de redacción fue Simón Scheimberg (1894-1973), quien se inscribirá en la historia del comunismo argentino por editar junto a Aldo Pechini los Documentos del Progreso (1919-1921) -que abordaremos en el capítulo sexto-. ${ }^{49}$ A partir de los anuncios de Ariel, sabemos que los otros jóvenes que formaron la comisión directiva del centro fueron: Mario E. Massa como secretario general, Víctor Astrada como secretario de actas y G. Reck, Isaac Palcos, Arturo Blanco y J. Zimerman como vocales. Quienes acompañaron a Palcos y Scheimberg en el armado de Ariel fueron: Mouchet (el único del que se aclara que era doctor), R. A. Nocito, José G. Grosso y J. Zimerman como redactores y Graciano Reca como administrador. Al igual que Palcos, varias de estas olvidadas figuras participaron de la fracción internacionalista del socialismo argentino; asimismo, algunos de esos nombres formaron, entre 1915 y 1918, la comisión directiva de la Universidad Libre y en 1919 el comité ejecutivo del PSI.

Como mencionamos, el sermón de Rodó ya había sido invocado para fundar una revista con el nombre de “Ariel”. La particularidad de la Ariel de 1914 es su combinación del arielismo con el

\footnotetext{
${ }^{48}$ El itinerario político-intelectual de Palcos está aún por reconstruirse. Campione (2005) refiere la afiliación de Palcos al PS en 1913 y recuerda que fue miembro de la Academia Nacional de Historia y profesor de psicología en el Colegio Nacional de La Plata, en el que trabajaron varios de los reformistas de los que nos ocupamos. Palcos integró el primer comité ejecutivo del PSI pero luego volvió al PS. Por otra parte, a mediados de los veinte, en el marco de una de las renovaciones de profesores conseguidas por la FULP, ingresó como profesor en la UNLP y en el Colegio Nacional de La Plata, dos tribunas desde las que continuó defendiendo una filosofía y una psicología de matriz cientificista. Durante 1938 dirigió la colección "Grandes escritores argentinos" para la que preparó estudios -que continúan siendo de referencia fundamental- sobre obras clave del pensamiento nacional, como el Facundo o el Dogma Socialista.

${ }^{49}$ No hemos logrado reconstruir el itinerario político-intelectual de Pechini. En cuanto a Scheimberg, a partir de nuestra investigación, sabemos que se recibió de abogado y en 1920 fue candidato a concejal por el PS, después del IV Congreso fue expulsado e ingresó al PSI hasta fines de 1922, ese año coordinó la campaña comunista contra el hambre en Rusia pero fue expulsado junto al grupo editor de la revista Nuevo Orden por sus posiciones a favor de un frente único argentino. En 1926 fue el abogado defensor de Enrique Müller, un miembro de la fracción chispista -entonces expulsada del partido- al que se lo acusaba de haber asesinado a otro comunista, Modesto Fernández (Gilbert, 2003: 6880). En las décadas siguiente participó de los grupos antifascistas.
} 
compromiso socialista y científico. Sin la impronta cientificista, esa convergencia entre arielismo y socialismo también se reconoce en, al menos, otras tres revistas homónimas: la Ariel editada entre 1919 y 1931 en Montevideo por el grupo estudiantil que, en un comienzo, lideró el joven Carlos Quijano; la Ariel fundada en 1919 en Buenos Aires por Samuel Glusberg (1898-1987); y la que apareció en 1926 en Río Cuarto bajo la dirección de José P. Cardella y la administración de Antonio Sosa Avedaño. ${ }^{50}$

\section{La revista Ariel de 1914}

Sobre las motivaciones del grupo de 1914 Bermann dejó un brevísimo relato:

A comienzos de siglo, Paul Groussac, entonces una especie de dictador intelectual de la Argentina, nos contó en qué se resolvía todo aquel tumulto, que designó con un calificativo: civilización 'mamuth'. ¿Para qué el conocimiento directo? 'Del Plata al Niágara', hoy olvidado, fue el itinerario para los argentinos, que sin necesidad de tomarse el trabajo de verlo con sus propios ojos, deseaban tener una 'opinión' sobre el coloso del Norte. El mensaje de Rodó a la juventud continental afianzó la convicción de que estábamos en el justo camino frente a Cartago. Y nos lanzamos a fundar "Centros Ariel” para difundir nuestras idealidades (Bermann, 1946: 249).

Los cinco números de Ariel muestran que esa fundación condensaba una original apropiación del juvenilismo espiritualista de Rodó. Por un lado, la Cartago frente a la que los arielistas porteños trazaron el "justo camino" portaba un carácter más claramente "burgués" que la del intelectual uruguayo $\mathrm{y}$, por otro, las idealidades que las juventudes debían difundir para combatir el "filisteísmo cartaginés" no se identificaban con una cultura estética capaz de formar un espíritu selecto, sino con la ciencia socialista y su difusión entre los obreros. Y en ello es significativo que la revista se haya financiado no sólo con anuncios comerciales, sino también con anuncios de profesionales y líderes socialistas argentinos, algunos de los cuales, además, ofrecieron sus textos inéditos para construir el cuerpo doctrinal de la publicación. Entre los anuncios profesionales figuraron los de Enrique Del Valle Iberlucea, Mario Bravo, Alfredo Palacios, Antonio de Tomaso y José Ingenieros.

Este reconocido intelectual -que acababa de regresar de su autoexilio europeo- les cedió a los jóvenes dos de sus últimas producciones: "Los estudios filosóficos en el Renacimiento Cultural de Cataluña" abrió el segundo número de Ariel y "Un filósofo del año veinte. Juan M. Fernández Agüero" el número cuatro/cinco (de aparición doble). ${ }^{51}$ Otras figuras reconocidas ligadas al socialismo y al cientificismo que publicaron notas breves en la revista estudiantil fueron el diputado

\footnotetext{
${ }^{50}$ Sobre esta última, puede consultarse el análisis de Prieto (2003). Como mencionamos, la Ariel montevideana será estudiada en el sexto capítulo junto a las revistas porteñas a las que se vinculó.

${ }^{51}$ En 1916 ambos artículos son publicados, con algunas modificaciones, como parte del libro de Ingenieros La cultura filosófica en España. Sobre el itinerario político-intelectual de Ingenieros, Terán (1986) y Tarcus (2011).
} 
Antonio de Tomaso y los profesores de Psicología Experimental Rodolfo Senet y Carlos Rodríguez Etchart (entonces decano de la recién fundada Facultad de Ciencias Económicas de Buenos Aires).

En cuanto a la gravitación de Ingenieros, ésta no se redujo a la publicación de los mencionados artículos, pues el cruce entre arielismo y cientificismo socialista que inauguraron los jóvenes porteños se inscribe fácilmente en el "idealismo experimental" propiciado por El hombre mediocre, así como en la crítica al "idealismo antipositivista" por desviar su atención a entidades "casi místicas" como el espíritu y lo trascendental en lugar de preocuparse por los problemas sociales vigentes. ${ }^{52}$

Al retomar el "idealismo experimental" ingenieriano y su llamado a una ciencia y una filosofía encargadas de resolver los problemas sociales y de construir ideales morales, los jóvenes porteños proponían una traducción evolucionista y socialista del arielismo. La prueba más clara de ello seguramente la ofrezca el manifiesto con que Palcos inauguraba la revista. Se afirma allí:

El ideal, en efecto, es una fuerza de primer orden que impulsa constantemente a la especie humana a ascender en busca de las cumbres más excelsas de la vida humana, quien no acaricia ninguno es un ser detenido, retardado, en la evolución de la especie, un fósil, una hosca caricatura humana.

Para abrigar un ideal requiérese tener amplios horizontes mentales, contemplar el panorama de la vida con una mirada global y sintética, ser en una palabra, hombres y no un rodaje subalterno en la mecánica social (Alberto Palcos, "Los ideales de la juventud", Ariel, no 1, junio de 1914, p. 4).

Unos párrafos después el joven precisaba que el grupo se enfrentaba al criterio de autoridad y el imperio de las ideas que, además de aniquilar la originalidad, enseñoreaban el servilismo y el egoísmo: 'El 'Centro de Estudios Ariel' formado por jóvenes que conservan intactos la integridad de sus espíritus, propónese reaccionar contra tal estado de cosas por medio del estudio, de la acción, de la discusión, de la difusión de los conocimientos, del cultivo de la sociabilidad, de la ciencia y del arte" (Idem, 5).

Al manifiesto de Palcos le sucede "El nuevo Ariel", un breve texto que Rodó les envió a los jóvenes porteños y que Bermann rescatara para publicar en Verbum en 1917, luego de la muerte de aquel. ${ }^{53}$ Ofreciendo una síntesis de la labor cultural que su ensayo de 1900 le pedía a las juventudes cultas, declaraba Rodó:

El nombre de Ariel, significa en la evolución de las ideas que han preparado la actual orientación del pensamiento hispano-americano, la afirmación del sentido idealista de la vida contra las limitaciones del positivismo utilitario; el espíritu de calidad y selección,

\footnotetext{
${ }^{52}$ Sobre el dispositivo argumental propuesto por Ingenieros en El hombre mediocre, véase Mailhe (2013) y Pita y Bruno (2009).

${ }_{53}$ En la presentación del texto, Bermann aprovecha para homenajear tanto a Rodó como al grupo de arielistas cientificistas. Cf. José Enrique Rodó, “El nuevo Ariel”, Verbum, no 35-36, mayo-junio de 1917, p. 53.
} 
opuesto a la igualdad de la falsa democracia, y la reinvindicación del sentimiento de la raza, del abolengo histórico latino, como energía necesaria para salvar y mantener la personalidad de estos pueblos [...] Hoy, generaciones nuevas reconocen en Ariel la "melodía de ideas", el sentimiento de la vida que espontáneamente brotan de su propia conciencia. Toca a esas generaciones demostrar que nuestro ambiente americano no es incapaz de contener la ejecución de tal programa en la esfera de la realidad y de la acción (Rodó, “El nuevo Ariel”, Ariel, no 1, junio de 1914, pp. 9-10).

Los porteños acompañaron esa síntesis con importantes "correcciones". En efecto, el artícuo siguiente, "Ariel (Párrafos de una carta íntima escrita en septiembre de 1909)", ofrece el balance realizado por el abogado socialista Antonio de Tomaso luego de leer a el ensayo de Rodó. Allí el entonces diputado nacional por el PS repasa el llamado que Próspero formulaba a la juventud, para destacar que la ciencia y no la estética es la guía del género humano pues aquella concilia el espíritu de justicia y el de belleza. A esta corrección del "esteticismo" de Rodó le sigue una corrección más explícita con la que se intenta inscribir el ensayo uruguayo en la tradición igualitarista del socialismo:

Si yo hubiera formado parte del grupo que escuchaba la palabra del maestro, le hubiera recordado que el problema no debe plantearse porque democracia no significa nivelación absurda y antinatural, ni tampoco imperio del número sino imperio de la capacidad y de la conciencia. $\mathrm{Y}$ justamente lo que ella persigue es el desarrollo completo, lógico, sin obstáculos, del ser humano, obligado hoy a torcerse o a vivir apegado a la tierra como los gusanos, por la tiranía terrible de la miseria. A los que se mofan de la democracia porque se la imaginan el apagaluz de la espiritualidad y del idealismo, basta recordarles la odisea dolorosa de los que, abarcando todo una época, son hoy Berlioz, Beethoven y Wagner (Antonio de Tomaso, "Ariel (Párrafos de una carta íntima escrita en septiembre de 1909)”, Ariel, no 1, p. 23; destacado en el texto).

De Tomaso, y a través de él los arielistas porteños, no podían ser más claros en la corrección que formulaban al elitismo de Rodó: la "tiranía terrible de la miseria", y no la "tiranía de las masas", era la que debía preocupar a los arielistas. Una nueva formulación de esa corrección la ofrece el texto que los jóvenes publican a continuación. En "Aristocracia del talento”, Julio R. Barcos sentencia:

Acabaron para siempre todas las filosofías aristocráticas que aíslan, ensordecen y estilizan a los hombres de talento. La ciencia ha roto todos los dogmas y todos los ritualismos herméticos [...]. Ha muerto (teóricamente) en política [el privilegio], pero ha resucitado en los hechos reales de la existencia económica y pretende enseñorearse en el mundo intelectual. Pues bien, es preciso concluir con todas las aristocracias, inclusive la del talento, ya que de la intelectualización del pueblo provendrá como consecuencia lógica la desaparición de todas las castas privilegiadas inclusive las de los sabios y artistas (Julio R. Barcos, "Aristocracia del talento", Ariel, no 1, junio de 1914, p. 26).

Las dos tareas trazadas por Barcos también son formuladas en por el joven Scheimberg. En 
polémica con los revolucionarios (anarquistas) que desean cambiar violentamente el estado de cosas, el futuro editor de los textos bolcheviques glosa, sin citar, la sociología evolutiva de Ingenieros para proponer que "el ritmo de la vida" conduce a la llegada del "día en que cada uno se gobierne a sí mismo, en que desaparezcan todos los amos por inútiles”, y dado ese ritmo los arielistas deben ser metódicos en el camino que los lleva a alcanzar la profunda revolución (socialista): además de capacitarse individualmente, tienen que "educar constantemente a las multitudes". Es que:

Si una revolución bastara para modificar el orden de cosas existentes y colocarnos en el mejor de los mundos posibles, ninguno trepidaría en alistarse en las filas revolucionarias, pero el solo hecho de unirse a ellos, implica una capacitación superior que la gran masa no posee. Los revolucionarios constituirán siempre una pequeña minoría. Y aún en el caso hipotético que la revolución social, violenta, se llevara a cabo, [...] la enorme masa al siguiente día de producida la revolución social volvería a su vida de siempre: no se modifica en un día la manera de ser de un individuo y menos la de un pueblo (Simón Scheimberg, "El ritmo de la vida", Ariel, no 1, junio de 1914, pp. 19-20)

Esta declaración es interesante no sólo porque, junto a la de Barcos, explicita los núcleos ideológicos a partir de los que se reúnen los veinteañeros, sino también porque, al contrastarla con las afirmaciones probolcheviques que difunde Scheimbeg en 1919, ofrece una interesante prueba de la revisión de las posiciones políticas que introducieron tanto la Revolución Rusa como las revueltas estudiantiles y las huelgas obreras argentinas de 1919.

En cuanto a 1914, los arielistas comenzaron sin demoras las dos tareas trazadas por Barcos y Scheimberg. Por un lado, organizaron conferencias dirigidas a los socios universitarios, en las que discutieron las "filosofías aristocráticas" y, por el otro, emprendieron la educación cientificista de los trabajadores -tarea que ya venían realizando la Sociedad Luz, la Liga de Educación Racionalista y el Ateneo Popular, entre otros- ${ }^{54}$ La voluntad de que esas iniciativas se inscribieran en un sustrato arielista preexistente al que se le corregían sus aspectos elitistas es notoria cuando se atiende a que en la revista confluyeron poemas y prosa de literatos que señalaban a Rodó como un faro intelectual con artículos de reconocidos intelectuales cientificistas y socialistas.

En ese sentido, el segundo número contiene, además del mencionado texto de Ingenieros que elogia la filosofía cientificista española, dos breves textos inéditos del escritor y diplomático uruguayo Alberto Nin Frías: “Auto-confesión” y “Jonatán, el amigo ideal”. ${ }^{55}$ El primero explicita la búsqueda arielista de la perfección literaria y la belleza moral, el segundo es un elogio a la amistad

\footnotetext{
54 Para una abarcadora y aguda reconstrucción de los proyectos pedagógicos socialistas, véase Barrancos (1996)

${ }^{55}$ Ariel, $\mathrm{n}^{\circ}$ 2, agosto de 1914. pp. 69-78. Frías publica luego los textos en 1919 en su libro Un huerto de manzanas. Este escritor mantendrá una estrecha amistad, prolongada durante tres décadas, con Miguel de Unamuno, ver Unamuno y América, pp. 257-266.
} 
y la moral, y se propone como un ejemplo de aquella búsqueda arielista. ${ }^{56}$ Para el tercer número, Ariel cuenta con otra colaboración de un joven arielista uruguayo. Allí aparece el poema "Evangelio divino" de Julio Garet Mas, fechado en Montevideo 1914 y dedicado a Rodó. ${ }^{57}$ Estas intervenciones orientadas al gusto estético conviven con la difusión de tesis, enmarcadas en la psicología experimental, que declaran un evolucionismo social tendiente a la igualación económica de la sociedad.

Más muestras de la corrección socialista y científica del esteticismo arielista son ofrecidas por la nota del segundo número en la que se comentan las conferencias organizadas. Allí se sostiene que, además de "La Filosofía de Nietzsche" y "Estética", una tercera conferencia versó sobre la "Psicología Trascendental” y el señor A. Saravia "llegó a conclusiones francamente espiritualistas, siendo refutado contundentemente por varios concurrentes". Asimismo, la revista aclara que la discusión sobre "El Darwinismo Social” fue larga y amena y "en general, todos los que hablaron estuvieron concordes en admitir que el principio de la selección natural no rige la lucha por la existencia en la especie humana". ${ }^{58}$

Pero el grupo, como mencionamos, también procuró la "intelectualización del pueblo" que reclamaban Barcos y Scheimberg. Para ello inició cursos de extensión orientados a la formación científica de los obreros. Las notas "Extensión Universitaria" mencionan los distintos cursos populares que los arielistas habían comenzado a dictar: "Anatomía” a cargo de Bermann, "Fisiológica e Higiene" dictado por Ubaldo Isnardi (joven que en 1918 formará parte de la primera comisión directiva de la FUA), "Biología" por Mario E. Massa, "Historia” por Graciano Recca y "Economía Política" por Scheimberg. Los próximos cursos serían: "La población en relación con la Economía Política" por Isaac Palcos, "Instituciones del Progreso Social” por J. Piñero (hijo) y "Economía Política" por N. Martínez. ${ }^{59}$

Estos títulos permiten reconstruir una estrategia intelectual del grupo. Entre los universitarios sería necesario desenmascarar esos renovados "dogmas y ritualismos herméticos" referidos por Barcos: en Psicología equivalía a refutar las nuevas corrientes "trascendentales" o “neokantianas" y a promover una disciplina "experimental" fundada en el laboratorio; en Economía consistía en la compatibilización del marxismo con el evolucionismo. En cambio, entre los obreros directamente debían difundirse las verdades establecidas por las ciencias naturales y la economía

\footnotetext{
${ }^{56}$ Por otra parte, las "Notas" del mismo número informan que Frías, primer secretario de la legación uruguaya ante los gobiernos de Venezuela, Colombia y Panamá, lleva la representación de la revista a las repúblicas americanas del Pacífico. Asimismo, anuncia que el primer número de Ariel ha recibido múltiples elogios de la prensa tanto argentina como uruguaya.

${ }^{57}$ Ariel no 3, septiembre de 1914, pp. 130-131.

58 "Del Centro de estudios Ariel”, Ariel, n” 2, agosto de 1914, p. 102.

59 "Del Centro de estudios Ariel", Ariel, n' 2, agosto de 1914, p. 103; "Centro de estudios Ariel", Ariel, no 3, setiembre de 1914, p. 152
} 
política (con la que seguramente aludían a la versión marxista del socialismo).

El encargado de formular una nueva fundamentación teórica de la tarea de difusión cultural entre los obreros sería Bermann, quien firma en el tercer número de Ariel “"Cuestiones obreras' por Altamira". Ese número difunde un nuevo texto de Scheimberg, en el que se declara que el inicio de la Gran Guerra puso a la civilización ante "La bancarrota de un régimen". Asimismo, se publica allí una serie de "Moralículas de la dicha" del reconocido dramaturgo anarquista José González Castillo (padre de Cátulo Castillo). Hacia el final, se publica la reseña de Bermann a Cuestiones obreras, libro que acababa de editar el profesor español Rafael Altamira.

El joven porteño sostiene que la plataforma arielista se apoya en la "misión de cultura popular" que el grupo de Altamira, entonces ligado al Partido Socialista Obrero Español, llevaba a cabo en la Universidad de Oviedo. ${ }^{60}$ Precisa Bermann sobre el libro que "su contenido concreta aspiraciones que bullían en la mentalidad del medio ambiente [argentino]", que "ha servido de segura guía a realizaciones en germen, y que su contenido ha tenido notable influencia en la obra cultural que se está desplegando". Esta obra no sólo se dirigía a un destinatario preciso, sino que era el primer peldaño en la conquista de justicia económica que emprendía el socialismo: "Fuerzas inhibitorias de toda índole impiden a una inmensa mayoría -a los obreros, sobre todo- obtener lo que en justicia les corresponde, como seres superiores. Es necesario destruir esas fuerzas, y la difusión de la cultura es primordial para esta obra de idealismo". ${ }^{61}$

En el siguiente -y último- número, Palcos se encarga de equiparar la obra de idealismo con una versión economicista del socialismo. El director de Ariel toma partido en el debate sobre la doctrina socialista para mostrar la compatibilidad entre el discutido principio formulado por Marx de que "la estructura económica de la sociedad es la base sobre la que se levanta el edificio jurídico y social" y los últimos desarrollos de la sociología evolutiva. Al igual que en el manifiesto inaugural, Palcos equiparara aquí los ideales arielistas al evolucionismo socialista y al compromiso con su difusión, pero además menciona las obras de referencia locales: la compatibilidad entre la economía marxista y la moderna sociología estarían garantizadas por los desarrollos que ofrecieron Ingenieros en Sociología argentina y Juan B. Justo en El socialismo argentino. Palcos no concluye el artículo sin antes esbozar una esperanzada descripción de la sociedad que reemplazaría a la burguesa:

Cada hombre desarrollará por completo su personalidad y desaparecerá, con la abolición del vasallaje económico, la dependencia humillante de un hombre de otro hombre, de un pueblo de otro pueblo.

No se conocerán las guerras; se archivarán los mortíferos cañones; se extenderá la

\footnotetext{
60 Sobre la resonancia porteña de la experiencia de Oviedo puede consultarse una breve sistematización en Biagini (2012: 187-192).

${ }^{61}$ Gregorio Bermann, “'Cuestiones obreras’ por Altamira”, Ariel, nº 3, setiembre de 1914, pp. 97-100.
} 
cultura y brillarán soberanos el arte y la ciencia, enriquecidos por el aporte espontáneo del mayor número. [...] y por una paradoja extraña aquellos que sostienen que hoy gobiernan más las nobles elaboraciones del intelecto que el economismo, contribuyen, con su cómoda convicción, a prologar indefinidamente el imperio de las fuerzas económicas que tanto detestan, lejos de apresurar su evolución inevitable (Alberto Palcos, "El materialismo o economismo histórico", Ariel, no 4/5, diciembre de 1914, enero de 1915, p. 27).

Coincidiendo con otros proyectos pedagógicos alentados entonces por socialistas y anarquistas, la tarea de estos peculiares arielistas quedaba entonces tramada en la posibilidad de articular la ley de la inevitable evolución de la humanidad, probada por la ciencia, con una instrucción popular, que apresurara esa evolución.

El número doble 4-5 anunciaba una próxima aparición bimensual, en la que se publicarían algunos artículos de actualidad "como el comentario crítico de Juan Pedro Calou al 'Sayal de mi espíritu', de Morales; 'La Maestra Normal', de Gálvez; y 'Poemas de la Serenidad', de Guzmán (poeta chileno)". ${ }^{62}$ Pero ese número no aparecería y la revista dejaría de editarse sin aviso.

Estos arielistas cientificistas impulsaban dos núcleos que se revelarán centrales entre los estudiantes una vez que, a mediados de 1918, estalle la Reforma, a saber: la construcción de una identidad estudiantil enlazada a la cultura de izquierda, por un lado, y la vinculación de los estudiantes con los trabajadores a través de la extensión universitaria, por el otro. A diferencia de lo que ocurre en 1918, en 1914 estos núcleos no lograron demasiada repercusión estudiantil. Ello seguramente se ligue a que, para que prospere una identidad estudiantil marcada por el socialismo faltaba aún una mayor presencia de las clases medias en la universidad pero también eran necesarias las noticias de las Revolución Rusa, las revueltas estudiantiles cordobesas y las huelgas obreras. En efecto, el entusiasmo revolucionario o el miedo serían decisivos para que un número mayor de jóvenes porteños trasciendan sus preocupaciones exclusivamente gremiales, ligadas al reclamo por plazos y aranceles de los exámenes y organizadas a través de los Centros de Estudiantes de cada facultad, para esbozar un movimiento estudiantil.

En cuanto a los jóvenes arielistas que "tempranamente" trascendieron las preocupaciones gremiales, veremos que la revista y los centros, en muchos casos, funcionaron como la primera estación de una intervención en el campo socialista que se prolongó durante algunos años y que los descubrió como líderes del ala radicalizada de la Reforma.

\section{La Universidad Libre}

En setiembre de 1915, un grupo que recogiendo las iniciativas del librepensamiento se denominaba

"Universidad Libre" daba a conocer sus propósitos en las revistas culturales de la época. Siete de

\footnotetext{
${ }^{62}$ Ariel, $\mathrm{n}^{\mathrm{o}} 4-5$, p. 80.
} 
los trece miembros de su comisión directiva -compuesta exclusivamente por varones- provenían de la comisión del Centro y la revista Ariel: Isaac Palcos, Alberto Palcos, Bermann, Massa, Scheimberg, José F. Grosso y Arturo Blanco. ${ }^{63}$

En esta nueva experiencia, los estudiantes aparecían organizados en torno de una figura magisterial: mientras el primer presidente fue el diputado socialista -integrante de la fracción internacionalista hasta 1920- Augusto Bunge, en 1918 ese cargo lo ocupó Ingenieros y el vicepresidente fue Roberto Giusti, otro socialista que simpatizará con la Revolución Rusa. ${ }^{64} \mathrm{Si}$ bien este grupo no apeló explícitamente a Rodó, sus integrantes asumieron un llamado generacional similar al de los arielistas cientificistas, esto es, defendieron la cultura científica, la propusieron para solucionar los problemas sociales y la promocionaron entre las clases populares. Además, la formulación de propósitos no podía ser más similar a la del Centro Ariel. Allí se proclamó como primer objetivo "dedicarse a la investigación de los problemas científicos de interés social, refiriéndolos, en lo posible, a nuestro país", y como segundo objetivo "difundir entre el pueblo la mayor suma de conocimientos útiles a su elevación económica, intelectual, artística y moral". ${ }^{65} \mathrm{Si}$ bien la Universidad Libre se declaraba "ajena, por completo, a toda bandería política", los conocimientos a los que daba preferencia explicitaban una clara afinidad con el programa pedagógico socialista. Sostenía el manifiesto: "La higiene y la medicina social, la legislación social, la evolución del derecho, la sociología, la historia, la antropología, la biología, la psicología, la economía social y política son las disciplinas que más nos interesan hacer conocer al pueblo, al igual de las conclusiones prácticas de la leal interpretación de sus principios". ${ }^{66}$

La primera comisión directiva había designado a Scheimberg como "director de publicaciones", pero el grupo parece no haber conseguido editar una revista. Ante ello, sus integrantes tendieron a usar como tribuna de expresión dos prestigiosas revistas dirigidas por intelectuales centrales en esta suerte de "red de socialismo científico" que venimos reconstruyendo: la Revista de Filosofía. Cultura, Ciencia y Educación (1915-1929) de Ingenieros y Nosotros (19071934, primer época) de Giusti y Bianchi. A través de estas publicaciones sabemos que las actividades de la Universidad Libre consistieron en reuniones y conferencias a las que asistieron

\footnotetext{
${ }^{63}$ Los miembros y los cargos consignados en el manifiesto inaugural eran los siguientes: Augusto Bunge, presidente; I. Palcos, vice presidente; Alberto Palcos, secretario general; José F. Grosso y Carlos Manacorda, prosecretarios; Alfredo L. Spinetto, tesorero; Arturo Blanco, pro-tesorero; S. Scheimberg, director de publicaciones; Ángel A. Masciotra, director de biblioteca; Gregorio Bermann, Cristóbal R. Solari, Guido A. Cartey y Mario E. Massa, vocales

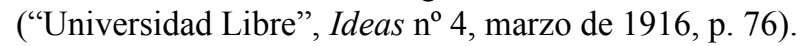

${ }^{64}$ El manifiesto que el grupo difundió a mediados de 1918 estaba firmado prácticamente por los mismo nombres que respaldaban el manifiesto fundacional de 1915. La lista de 1918 es las siguientes: presidente, doctor José Ingenieros; vicepresidente, doctor Roberto F. Giusti; secretario general, doctor Simón Scheimberg; secretario de actas, señor Gregorio Bermann; tesorero, doctor Samuel E. Bermann; vocales; señores Ernesto Nelson, Guido A. Cartey, Alberto Palcos, Juan C. del Giúdice, Alejandro Castiñeiras, ingenieros N. Ortiz, Luis Bontempi; suplentes, señores Juan Kern, A. Senillosa, Mario E. Massa, doctor Graciano Recca, Juan, J. S. Guestrino, Julio C. Savón, E. Belcaguy ("Universidad Libre. Propósitos", Themis, no 71, Buenos Aires, setiembre de 1918, pp. 74-76).

65 "Universidad Libre", Ideas n $\mathrm{n}^{\circ}$ 4, marzo de 1916, p. 74.

66 "Universidad Libre", Ideas no 4, marzo de 1916, p. 76.
} 
intelectuales y estudiantes. No hemos podido recuperar ninguna actividad de difusión científica entre los obreros, pero probablemente se hayan realizado, pues esa difusión no sólo se encontraba entre sus propósitos declarados, sino que una nota firmada por "Amelius" -seudónimo que seguramente escondiera la pluma de Bermann- y aparecida en La Gaceta Universitaria de Córdoba declara que la Universidad Libre formó parte, junto a la Sociedad Luz, la Liga de Educación Racionalista, los Ateneos y la Universidad Popular, de los "núcleos particulares de estudiosos [que] trabajaban seriamente en la divulgación del saber". Una labor seria que consistía en "bajar al pueblo" para asegurar la cultura de las "clases productoras", lo que "abarca desde lo elemental -educación primaria- hasta la superior incluyendo la enseñanza técnica". ${ }^{67}$

A partir de nuestro rastreo, sabemos que el grupo realizó, al menos, las siguientes actividades: a comienzos de 1917, el profesor Ernesto Nelson (director del Internado de estudiantes del Colegio Nacional de la Universidad de La Plata y vocal de la Universidad Libre, afín al georgismo $^{68}$ y aliado desde 1918 a distintos grupos reformistas a pesar del cuestionamiento que recibía el Internado) inauguró el curso de Eduardo Holmberg sobre la evolución; ${ }^{69}$ en noviembre se realizó una reunión en la que Giusti disertó sobre Roberto Payró; ese mismo año Nelson abordó la cuestión del analfabetismo; y en mayo de 1919 Paulina Luisi, la activista del feminismo socialista y primera médica uruguaya, se ocupó de la "trata de blancas" y del problema de una posible reglamentación. La conferencia de Nelson circuló en una edición de las "Publicaciones de la Universidad Libre", el único número que aparentemente logró editar Scheimberg desde la institución. $^{70}$

\section{Nuevas intervenciones e iniciativas de los arielistas socialistas}

Entre los más entusiastas arielistas socialistas se encontraba Palcos, quien, además de integrar la Universidad Libre y de editar por esos años sus primeros ensayos sobre psicología experimental, colaboró con Ideas -la revista del Ateneo de Estudiantes Universitarios que analizaremos en este capítulo- y estuvo a cargo de la sección "Filosofía y psicología" de la revista Nosotros. En esa sección publicó reseñas y artículos breves que difundieron una versión científica de ambos saberes, como fue el caso de su elogiosa reseña a las Proposiciones relativas al porvenir de la filosofía. Con

\footnotetext{
${ }^{67}$ Amelius, “Apuntes de extensión universitaria”, La Gaceta Universitaria de Córdoba, no 18, 11/08/1919, p. 4.

${ }^{68}$ Esta corriente política, surgida a fines del siglo XIX a partir de la obra del estadounidense Henry George, propuso una reorganización de la economía rival al socialismo. En Argentina, tuvo una importante y diversa recepción, pues -como veremos en el caso del grupo Córdoba Libre!- su principio de enfiteusis fue defendido por figuras y proyectos ligados al socialismo. Al respecto, véase De Lucía (2004 y 2012) y Grisendi (2014).

${ }^{69}$ El discurso de Nelson fue publicado como "Universidad Libre" en Verbum, no 34-35, mayo-junio de 1917 pp. $70-72$ (uno de los tres números dobles de esa revista que, como veremos, dirigió Bermann).

${ }^{70}$ Por su parte, la conferencia de Giusti fue compilada en Crítica y polémica. Segunda serie, Buenos Aires, Cooperativa editorial limitada, 1924. La conferencia de Luisi parece no haberse editado. Conocemos de su existencia por una referencia que ella realiza en el prólogo a Una vergüenza social. La reglamentación. Este folleto, editado en 1919 por la Asociación de Jóvenes Cristianos, recopila otra conferencia sobre el mismo tema que dictó Luisi en Buenos Aires y que se centró en los argumentos de la Federación Abolicionista Internacional.
} 
ello buscó resistir a la reacción antipositivista que pregonó José Ortega y Gasset en sus concurridas conferencias de 1916 y que comenzaba a nuclearse en torno del filósofo platense Alejandro Korn (1860-1936) y del Colegio Novecentista de Buenos Aires, un grupo que -según veremos en el capítulo cuarto- tuvo como objetivo inmediato contrarrestar el cientificismo socialista que entonces proponía Bermann en la FFyL.

Como ha señalado Rossi (1999), esa resistencia a un antipositivismo que propondría una reflexión abstracta, o incluso mística, y alejada de los problemas sociales fue una preocupación central de la Revista de Filosofía. Pero también es fácilmente advertible -pero poco recordada- en Nosotros. ${ }^{71}$ Como ha señalado Prislei, en su primera década la revista "al tiempo que propicia la búsqueda de una literatura argentina, exhibe un eclecticismo literario sesgado por el reconocimiento del magisterio del pensamiento francés y por al adscripción a un americanismo de origen rodoniano" (Prislei, 1994: 44). A ese eclecticismo Nosotros suma un decidido posicionamiento cientificista, en el que la sección "Filosofía y psicología" de Palcos no responde sólo a las afinidades filosóficas del joven, sino también a la línea editorial de la publicación. En efecto, si bien durante su visita Ortega pronunció una conferencia a beneficio de Nosotros, el filósofo inauguró su exposición aclarando que dejaba de lado "las múltiples divergencias" que lo separaban de la revista. Diferencias con las que aludía a la crítica de Palcos pero seguramente también a conversaciones mantenidas con Bianchi y Giusti, y al partido por las filosofías cientificistas que éstos deslizaba en la sección "Letras argentinas". Al respecto, recuerda Giusti en sus memorias que "la mayoría éramos positivistas, pero no tanto como para concederle crédito entero a los experimentos que se hacían con aparatos de dudosa precisión en el laboratorio anexo a la cátedra de Psicología del doctor Horacio Piñero" (Giusti, 1965: 312).

Tanto en el caso de Giusti como en el de varios arielistas, la defensa de la cultura científica estuvo acompañada de la participación en las fracciones del socialismo argentino que simpatizaron con la Revolución Rusa y que hasta 1921 tuvieron en el senador Enrique Del Valle Iberlucea (18771921) a su máximo referente. En efecto, al tiempo que Giusti pronunciaba conferencias en distintos centros socialistas de la provincia de Buenos Aires y participaba junto con Bermann y Scheimberg de la fracción bolchevique del PS, Palcos dirigió primero la Revista Socialista. Publicación mensual de doctrina y crítica socialista y cultura general y luego La Internacional. Órgano del Partido Socialista Internacional. A su vez, junto a otros arielistas figuró en la lista de concejales del PSI para las elecciones de octubre de 1918. Sobre este partido traigamos la breve y precisa

\footnotetext{
${ }^{71}$ El rol central que cumplió Nosotros en la constitución de un campo literario ha sido objeto de varios análisis. Entre ellos se destacan los citados de Delgado (2010) y Shuway (1999). En cambio, las posiciones políticas y culturales que, más allá de lo literario, eran asumidas por Nosotros sólo han merecido dos breves trabajos de Prislei (1992 y 1999), y ello a pesar de que un estudio sistemático y extenso permitiría conocer cuestiones clave de la historia de los intelectuales del periodo, como la que aquí trabajamos relativa a la vinculación entre la veneración a la ciencia y el compromiso socialista, o como el proyecto político-intelectual compartido con la Revista de Filosofía, que mencionaremos en otros capítulos.
} 
sostenían frente a la guerra un internacionalismo inspirado en la izquierda de Zimmerwald, una política de mayor implicación partidaria en el movimiento sindical y una crítica a la dedicación central a las reformas parlamentarias, a favor de un acompañamiento más estrecho de las luchas sociales y un ataque más radical al orden social burgués (Campione, 2007: 173).

Aclarando que "han merecido la separación del Partido Socialista por no claudicar del socialismo", la primera página de La Internacional $\mathrm{n}^{\mathrm{o}} 14$ publicitó la lista de candidatos a concejal, en la que entre otros figuraban los siguientes arielistas: Graciano Recca (caracterizado como abogado), José Grosso (maestro), Arturo Blanco (estudiante) y Alberto Palcos (periodista y estudiante). ${ }^{72}$ Asimismo, Isaac Palcos (contador) y Grosso, junto a Alberto Palcos, fueron parte de la veintena de jóvenes que formó durante 1919 el comité ejecutivo del PSI: el primero se encargó de la revisión de cuentas mientras que Grosso ocupó nada menos que el secretaría general del comité. ${ }^{73}$

Una vez que estalló la Reforma Universitaria, Palcos fue uno de los jóvenes que más insistentemente llamó, desde la prensa estudiantil, a que la lucha de clases y la vanguardia obrera se convirtieran en los ejes del reclamo estudiantil. Y, según veremos, Bermann fue el principal enlace de los reformistas cordobeses con los estudiantes porteños.

Otras publicaciones contaron por esos años con antiguos arielistas entre sus directores. Por un lado, entre abril de 1914 y julio 1915, José Grosso dirigió junto a Barcos y Barrancos Renovación. Revista de educación, letras y ciencias sociales, órgano de la Liga Nacional de Maestros. Por otro, entre agosto de 1919 y junio de 1921 Scheimberg junto a Aldo Pechini puso a circular los bolcheviques Documentos del progreso. Si bien volveremos sobre ello, adelantemos aquí que la perdurabilidad de esa publicación sugiere que una nueva figura de estudiante había conseguido esbozarse hacia 1919, pues distintos grupos estudiantiles se entusiasman con los bolcheviques y fundan revistas que saludan a los Documentos, dando origen a lo que sería el periodismo estudiantil de tipo político.

\footnotetext{
${ }^{72}$ La Internacional, $\mathrm{n}^{\mathrm{o}} 14,03 / 10 / 1918$, p. 1.

${ }^{73}$ La historia del PC argentino fue objeto de varias disputas, pues la historia oficial elaborada en la década del cuarenta modificó la lista de los miembros fundadores de ese partido y del PSI para otorgarle un rol protagónico a quienes eran los líderes partidarios contemporáneos. En su revisión de esa historia, Cobière (1984: 42-43) consigna como parte del primer comité ejecutivo del PSI a los siguientes: Juan Ferlini (668 votos), José Grosso (664 votos), Alberto Palcos (647 votos), Aldo Cantoni (629 votos), Guido Cartey (604 votos), Pedro Zibecchi (593 votos), Luis Emilio Recabarren (562 votos), Carlos Pascali (331 votos), José Alonso (304 votos), Emilio González (287) y Arturo Blanco (265 votos). Al año siguiente, el comité habría sufrido algunas modificaciones pues el folleto de 1919, que citamos en la nota anterior, publica la siguiente lista: secretario general: José F. Grosso. Secretario de actas: Nicolás De Palma. Tesorero: Victorio Codovilla. Vocales: Arturo Blanco, Aldo Cantoni, Pedro D. Zibecchi, Guido A. Carey, Atilio Medaglia, José Alonso, Emilio G. Mellén y M. Lorenzo Raño. Concejal de la Comuna de Buenos Aires: Juan Ferlini, órgano del Partido: "La Internacional". Director: Alberto Palcos. Administrador: Luis Koifman. Revisores de cuentas: Isaac Palcos, J. J. Suárez. Delegado al Congreso Internacional: José F. Penelón. El folleto también consigna dieciocho secretarías y centros en la Capital Federal, nueve en la provincia de Buenos Aires, tres en la de Córdoba, uno en San Juan, dos en Santa Fe, uno en Mendoza y uno en San Luis.
} 
A fines de 1920, encontramos a Scheimberg formando parte de los candidatos a concejales municipales del PS, en una lista que encabezaba Giusti e incluía a Mouchet. ${ }^{74}$ En cuanto al itinerario posterior de aquel, a diferencia de Palcos y Solari, quienes al poco tiempo abandonaron sus simpatías revolucionarias, Scheimberg, al igual que Bermann, será un compañero de ruta del PC y participará del grupo antifascista AIAPE. Por su parte, Bermann sería quien más perseverará en el proyecto trazado por los arielistas socialistas. Adelantemos aquí que, además de difundir en Nosotros una versión cientificista de la filosofía y la psicología, entre 1916 y 1917 concentró su acción en la FFyL de Buenos Aires, donde buscó formar un grupo de estudiantes que propiciara el reemplazo del clasicismo aristocrático de los estudios impartidos en esa casa por una formación cientificista y socialista. Iniciada la Reforma, se vinculó al líder cordobés Enrique Barros y fundó una federación que organizó el apoyo porteño a los reformistas cordobeses, la Federación de Asociaciones Culturales. En 1922 se radicó en Córdoba donde continuó participando de iniciativas reformistas y de la fracción de intelectuales socialistas y comunistas.

\section{Una red de socialistas cientificistas}

Como sugerimos, la aparición de la revista Ariel marca el inicio de una frágil red de intelectuales interesados por construir una identidad de los estudiantes ligada al socialismo científico, primero en torno de la revista Ariel y luego de la Universidad Libre. Propósitos similares se advierten en los tres números de Verbum. Órgano del Centro de Estudiantes de Filosofía y Letras dirigidos por Bermann y en las iniciativas del Centro entre junio de 1917 y abril de 1918, cuando fue presidido por el mismo joven.

A su vez, mencionamos que la matriz socialista científica que recorrió la revista Ariel encontró una importante plataforma de difusión en dos revistas fundamentales en la constitución del campo cultural argentino: la Revista de Filosofía y Nosotros. En cuanto a la primera, si bien estos jóvenes arielistas adherían al tratamiento positivista de los problemas filosóficos (ligados, sobre todo, a la pedagogía, la psicología experimental y la sociología) realizado por la mayoría de los artículos, veremos que la afinidad se estrechó hacia 1918, cuando, acompañando el creciente interés de Ingenieros por la intervención intelectual ligada a las izquierdas, la Revista de Filosofía comenzó a difundir con entusiasmo las reformas de la Revolución Rusa y buscó fortalecer el ala radicalizada de la Reforma a través de la publicación de sus manifiestos y noticias.

En cuanto a Nosotros, su politización es más explícita hacia 1919 pero sus saludos al socialismo científicos son claros durante 1916 en la mencionada sección de Palcos y en las reseñas de Giusti a las actividades del Ateneo y al Colegio Novecentista. Antes de analizar esas intervenciones con las que avanzamos en el recorrido temporal, cerremos este primer capítulo con

\footnotetext{
${ }^{74}$ Folleto, Fondo Roberto Giusti, CeDInCI.
} 
la presentación del otro grupo estudiantil surgido en 1914.

\section{El Ateneo de Estudiantes Universitarios de Buenos Aires (1914-1920)}

A diferencia del Centro Ariel, el Ateneo ha recibido alguna atención por parte de la bibliografía sobre la Reforma. En su investigación sobre los reformistas platenses, Graciano (2008) señala la importancia del grupo y reproduce uno de sus primeros manifiestos. También Navarro (2009) en su reconstrucción del grupo Córdoba Libre! refiere brevemente al grupo. Pero es Biagini (2012) quien, en su análisis de los movimientos contraculturales juveniles, dedica un capítulo al Ateneo centrado en la relación de éste con las instituciones españolas.

El Ateneo también ha sido recordado por los protagonistas de la Reforma en textos que constituyen fuentes primarias fundamentales para nuestra investigación. En 1930 su principal animador, José María Monner Sans, publicó en Nosotros unas informativas memorias del grupo. Por su parte, del Mazo -de quien ya mencionamos que fue un activo ateneísta e incluso presidió el grupo- publicó en 1941 una nueva versión de su compilación La Reforma Universitaria, con un breve apartado dedicado a los antecedentes inmediatos del movimiento reformista en el que señala al Ateneo y al Colegio como los grupos porteños más importantes en los años previos a la Reforma. $^{75}$

A estas dos referencias se sumó un artículo de Guillermo Korn, que, como referimos en la Introducción, a pesar de su interesante carácter programático, ha caído en el olvido. En 1968 este destacado animador de la fracción socialista de la Reforma Universitaria y tenaz revistero, emprendía la última de sus travesías en el mundo de las revistas: junto a su amigo reformista Luis Aznar fundaba los Cuadernos de La Plata ${ }^{76}$ Conocidos el itinerario intelectual y la sensibilidad política de ambos directores, no sorprende que el Cincuentenario de la Reforma Universitaria haya sido el suceso que dio vida a la nueva publicación. Y tampoco es del todo inesperado que, en el artículo dedicado a los "focos de política difusa" de los inicios de la Reforma, Korn haya declarado que esos focos debían ser pensados bajo el signo de las revistas.

Allí Korn propone que las publicaciones del Ateneo de Estudiantes Universitarios (1914-

\footnotetext{
${ }^{75}$ El primero de los tres tomos que componen esa edición se cierra con la sección “Antecedentes más inmediatos del movimiento del 18”. Allí se publica, además del primer manifiesto del Ateneo y el primero del Colegio Novecentista, las siguientes fuentes: el mencionado petitorio de reformas que habían enviado en 1907 los estudiantes de Medicina al Congreso, una crónica del grupo Córdoba Libre! -del que nos ocuparemos más adelante-, un breve escrito de la revista cordobesa Cultura y un artículo de Bagú que citamos en el primer capítulo de esta investigación (del Mazo, 1941: 468470).

${ }^{76}$ Los Cuadernos de La Plata fueron fundados por Korn y Aznar en Caracas, donde se habían radicado a mediados de los años cuarenta para enseñar en la Facultad de Humanidades y Educación de la Universidad Central de Venezuela, luego de haber renunciado a sus cargos en la UNLP por su oposición al gobierno peronista. Si bien Korn y Aznar editaron los dos primeros en Caracas, en su elaboración reactivaron la antigua sociabilidad ligada al PS y al reformismo platense y porteño. A partir del tercer cuaderno (aparecido en julio de 1970) y hasta el cierre (luego del séptimo cuaderno editado en noviembre de 1972), la dirección quedó a cargo de Eduardo C. Schaposnik, un joven socialista que transformó lo que había comenzado como una publicación cultural en una publicación orientada exclusivamente a la discusión de la coyuntura política, la muestra más clara de ello es que el sexto cuaderno estuvo dedicado a la crisis argentina y el séptimo al gobierno chileno de Allende.
} 
1919) y del Colegio Novecentista (1917-1922) esbozaron la primera e indefinida ideología reformista. Sostenía exactamente: "Desde la salida de Ideas [la revista del primer grupo], en 1915, se abre un ciclo del pensamiento argentino que se cierra con el último número de Valoraciones, órgano del grupo Renovación de La Plata que comenzó a publicarse en 1923 y duró hasta 1928". ${ }^{77}$ Dejando para los dos capítulos que siguen el análisis de la intervención del Colegio, en las páginas siguientes caracterizamos al Ateneo, el grupo porteño más numeroso y duradero de los que actuaron en los años que anteceden al estallido de la Reforma. En ese análisis retomamos las dos claves planteadas por Korn: por un lado, la afirmación de que el ciclo de pensamiento reformista fue tramitado a través de las revistas; por el otro, el señalamiento de que el Ateneo y el Colegio funcionaron como el semillero político en un conjunto de protagonistas de la Reforma que luego recorrieron itinerarios intelectuales sumamente disímiles.

\section{El puesto de los jóvenes universitarios}

[La juventud estudiosa] puede pasar horas de juventud cantadas por los poetas, entre el libro, la serena propaganda de patria y estas horas de sano esparcimiento en que se reúne para estrechar vínculos amistosos, para formar falange y para marchar recto hacia los puestos que le están reservados en el futuro.

Agustín de Vedia, "La comida del Ateneo", 1916.

El 8 de mayo de 1914, en presencia del ministro de Instrucción Pública, el joven estudiante de Derecho José María Monner Sans (1896-1987) pronunciaba el discurso con el que quedaba públicamente inaugurada la "Sección de Estudiantes Universitarios" del Ateneo HispanoAmericano de Buenos Aires. Dos años después, el grupo estudiantil se independizaba del ateneo y comenzaba a llamarse "Ateneo de Estudiantes Universitarios". Al poco tiempo se adhería al Museo Social Argentino y en 1919 -año en que varios integrantes habían dejado de ser estudiantes- volvía a modificar el nombre: hasta su desaparición a comienzos de la década del veinte, el grupo sería el “Ateneo Universitario". 78

En 1919 este grupo lanza un manifiesto en el que se declara "decididamente, de parte de las clases productoras en la lucha entre el capital y el trabajo que hoy divide el linaje humano" y se acerca al PSI, cuyo comité ejecutivo ya mencionamos que estaba conformado por varios jóvenes del Centro Ariel. Sin embargo, en su origen los ateneístas se distinguieron de aquellos no sólo porque priorizaron la reunión entre pares más allá de las inscripciones políticas -e incluso de la opción por

\footnotetext{
${ }^{77}$ Guillermo Korn, "Filiación ideológica europea de la Reforma Universitaria", Cuadernos de La Plata, n 1, La Plata, 1968, pp. 19. Bajo el seudónimo de Lautaro Wagner y el título "Política difusa", Korn había publicado una primera versión del texto en la revista socialista porteña Liberalis, $\mathrm{n}^{\circ} 9$ (septiembre/octubre, 1950) y $\mathrm{n}^{\circ} 10$ (noviembre/diciembre, 1950). Con algunas modificaciones, el artículo vuelve a aparecer en Unos pasos por el teatro, libro de Korn editado en 1972 en Caracas por la editorial Casuz.

${ }^{78}$ Para una caracterización del Museo Social, véase Girbal-Blacha y Ospital (1986) y Zimmermann (1994).
} 
una cultura laica o una católica-, sino además porque buscaron participar tanto de la sociabilidad de la elite intelectual porteña como de su diálogo con el poder político. Es que la fundación del grupo respondía a la iniciativa de Carlos Octavio Bunge (1975-1918), un miembro de la aristocracia porteña y prestigioso intelectual positivista que, como muchos positivistas criollos, se mostraba preocupado por establecer las ideas-fuerza que permitieran agrupar a una sociedad en la que la amalgama religiosa estaba en retirada. ${ }^{79}$

Durante uno de los cursos que impartía en la Facultad de Derecho, Bunge había conocido al estudiante Monner Sans. En 1914 el profesor ejercía la presidencia del Ateneo Hispano-Americano y desde ese cargo le proponía al joven crear la sección estudiantil del Ateneo. Al padrinazgo de Bunge se sumó otro hecho que seguramente facilitó el reconocimiento inicial del grupo: el joven líder era hijo de un destacado intelectual nacido en España. ${ }^{80}$

En sus inicios, los jóvenes también consiguieron cierto reconocimiento de la elite política. Como mencionamos, el ministro de Instrucción Pública estuvo presente en el acto inaugural del grupo y, a fines de 1915, el presidente de la nación les obsequió una serie de obras con las que sería fundada la biblioteca de la Sección. A diferencia de los arielistas socialistas, estos estudiantes buscaron en sus inicios inscribirse en la elite intelectual. Una muestra de ello la ofrece el primer discurso de Monner Sans. En 1915 sentenciaba el joven: “Olvidar que mañana, por la fuerza incontrastable de los hechos, hemos de dirigir el país, política, intelectual y moralmente, es traicionarnos". ${ }^{81}$ Otra muestra es la declaración que colocamos como epígrafe de este apartado: esa anhelada "marcha recta a los puestos reservados para el futuro" era parte del discurso pronunciado al inicio de una comida del grupo por el joven Agustín de Vedia, quien durante 1916 presidió la sección. ${ }^{82}$

Al igual que los arielistas porteños, los ateneístas reaccionaban contra el interés exclusivo de los estudiantes por la aprobación de los exámenes. Pero esa "reacción contra el profesionalismo", de clara resonancia rodoniana, no los conducía a participar decididamente de la sociabilidad del PS,

\footnotetext{
${ }^{79}$ Siguiendo a Terán (1998), puede sostenerse que la producción intelectual de Bunge está recorrida por un positivismo agnóstico que retoma tópicos de la cultura fin-de-siglo como el reemplazo del optimismo científico por el degeneracionismo y la preocupación por la disolución del lazo social que produciría la laicización. Con esos tópicos Bunge elaboraría una respuesta que, como en otros positivistas locales, permanece en la tensión entre el cientificismo y la voluntad ético-política. Más precisamente, sin dejar de inscribirse en el positivismo criollo, Bunge erige la psicología como la ciencia capaz de retotalizar el campo de los saberes, las "ideas-fuerza" de Fouillée como la amalgama del cuerpo social y el nacionalismo como el recurso para educar a las masas.

${ }^{80}$ Proveniente de Cataluña, Ricardo Monner Sans había llegado a la Argentina a fines del siglo XIX con una sólida formación en filología y gramática. Para 1910 esa formación y su preocupación por la pureza del castellano lo habían convertido en uno de los estudiosos de la lengua más importantes de nuestro país. A partir de una de sus obras, Biagini lo caracteriza como una figura conservadora que ataca "el racionalismo, el ateísmo, el utilitarismo, el igualitarismo y el estatismo pedagógicos, propiciando la llamada libertad de enseñanza, el primado de las humanidades sobre las postulaciones de Benoit, aunque refrendando algunos planteos krausistas como los de Altamira, Posada, González Serrano y Sales Ferré" (Biagini, 1995: 129-130).

${ }^{81}$ José María Monner Sans, "La función social de nuestra generación", Revista de Criminología, Psiquiatría y Medicina Legal II, Buenos Aires, 1915, p. 302.

82 "La comida del Ateneo", Ideas, n 7, Buenos Aires, setiembre de 1916, p. 106.
} 
sino a vincularse con fracciones de la elite intelectual que temían las consecuencias de la apertura del régimen político y habían construido instancias de reflexión y de prescripción de reformas. Entre las instancias construidas por la elite intelectual se destacan, además del mencionado Ateneo Hispano-Americano, la Revista de Derecho, Historia y Letras (1898-1923) de Estanislao Zeballos, la Revista Argentina de Ciencias Políticas (1910-1928) de Ricardo Rivarola y el semanario La Nota (1915-1917) del emir y cónsul argentino de la embajada de Turquía, Emín Arslán, publicaciones éstas que saludaron los primeros números de la revista del ateneo estudiantil. ${ }^{83}$

Aunque no se posicionaron de modo similar ante la Primera Guerra Mundial, las publicaciones de Zeballos, Rivarola y Arslán compartieron un mismo proyecto intelectual orientado a la formación de una nueva elite política y cultural surgida de las filas universitarias, particularmente de la Facultad de Derecho. La UBA debía ser rediseñada para que, además de centralizar la habilitación de las profesiones liberales, asegurara la existencia de una clase dirigente con aptitudes morales capaces de contener la "mesocracia” que habilitaba la Ley Sáenz Peña.

Entre 1914 y 1916, los jóvenes ateneístas se ligaron tanto a ese proyecto como al que sostenía Ingenieros con su llamado a construir partidos políticos representativos de las clases sociales. Este futuro "maestro de la juventud", que seguramente haya orientado con charlas personales la intervención tanto de estos arielistas científicos como de estos arielistas, aceptó impartir en 1915 una conferencia sobre Ramos Mejía para el nuevo grupo y publicitó en Ideas su colección editorial La Cultura Argentina. Sobre la orientación inicial ofreció Ingenieros al grupo de Monner Sans, el activo ateneísta Hiram Pozzo sostenía en un discurso -sobre el que volveremosque "las simpatías de Martínez Paz por aquellos que sienten el ansia entrañable de surgir, pudiera compararse al apoyo que constituía Ingenieros para el primitivo grupo estudiantil que fue creciendo al lado del Ateneo Hispano-Americano". ${ }^{84}$

Como veremos, cuando la Reforma obligó a precisar las posiciones políticas de los estudiantes, los jóvenes decidieron que los "puestos reservados para el futuro" debían tener rasgos democrátizadores intolerables para las revistas de Zeballos, Rivarola y Arslán y sumamente afines a los que alentaban, con entusiasmo creciente, la Revista de Filosofía y Nosotros. Más precisamente, Ingenieros y los directores de Nosotros sostuvieron que la nueva elite dirigente emergía del ala izquierda del movimiento estudiantil -de la que participó entusiastamente el Ateneo de Estudiantes Universitarios- y buscaron fortalecerla tanto desde sus revistas como desde el diseño de actos

\footnotetext{
${ }^{83}$ Estas publicaciones no sólo difundieron reseñas elogiosas de las primeras intervenciones del grupo estudiantil, sino que también reprodujeron algunas notas de los jóvenes. Para una caracterización de la revista de Zeballos, véase Galassi y López (2011); sobre la de Rivarola, Buchbinder (2006) y sobre La Nota, Delgado (2005).

${ }^{84}$ Hiram Pozzo, "Plática cordobesa", Ideas, n ${ }^{\circ}$ 7, septiembre de 1916, p. 96. En cuanto al anuncio de la colección La Cultura Argentina, los balances publicados en Ideas consignan el pago regular que realizó Ingenieros entre 1915 y 1917. Si bien ese anuncio -el único de carácter no comercial- no representó una suma decisiva para la edición de la revista, seguramente operaba como un importante aliciente, pues provenía de ese reconocido intelectual que había llamado a la juventud a superar a los "hombres mediocres".
} 
compartidos, discusiones personales y grupos como la ULA. ${ }^{85}$ En cambio, Zeballos desde su condición de decano de la Facultad de Derecho y Rivarola desde su condición de presidente de la UNLP, fueron ambos los intelectuales que encabezaron las fracciones que más rotundamente se opusieron al movimiento reformista, e incluso a reivindicaciones institucionales como la participación de los estudiantes en los consejos directivos. Sobre ese enfrentamiento recordemos una nota aparecida en el primer número del Boletín de la Federación Universitaria Argentina que pudieron leer los estudiantes de distintos puntos del país. El líder estudiantil platense Luis H. Sommariva citaba un fragmento de un artículo anónimo de La Nota que sostenía: "A Rivarola le sucede el mismo caso que a Zeballos. Este comenzó por atacar al ministro de Instrucción Pública, siguiendo con el director de la universidad, con el interventor de la facultad, con el secretario y con los estudiantes de la misma. Cuando ya no pudo acusar a nadie, ¿qué hizo? ¡Acusó a la policía!” ${ }^{86}$

Volviendo a los inicios del grupo estudiantil, sus diecisiete fundadores se organizaron siguiendo el modelo de los ateneos: a mediados de 1914 se reunieron en asamblea para darse unos estatutos que priorizaban la labor cultural y designaron a Monner Sans como el primer presidente anual y a otros ocho veinteañeros como miembros de la comisión directiva. Además, buscaron nuevos socios y dispusieron un ciclo anual de nada menos que veintitrés disertaciones. Entre los disertantes se encontraron intelectuales reconocidos, como Rivarola, Ingenieros y Mario Sáenz, y los jóvenes que entonces presidían los Centros de Estudiantes de algunas de las facultades de la UBA. Sobre ese elenco de figuras, confiesa Monner Sans en las mencionadas memorias, que no respondía exclusivamente a las afinidades intelectuales sino también a que la "densidad mayor o menor [de público] dependía del grado de vinculación social de los que intervenían en cada reunión” (Monner Sans, 1930: 9). Asimismo, en unas memorias posteriores Monner Sans refiere una de las frecuentes bromas que, antes de comenzar su conferencia, le realizó Ingenieros al joven que presidía el grupo. De allí sabemos que la conferencia de Ingenieros contó con una "concurrencia desbordada del salón en los locales linderos y en el rellano de la escalera, deseosa de escuchar al profesor famoso", pues "singular éxito editorial obtenía a la sazón su Hombre mediocre, cuyo contenido -discutido y discutible- escandalizaba a mucha gente porque una nota a pie de página individualizaba al modelo inspirador" (Monner Sans, 1976: 186).

En abril de 1915, cuando la Sección debía elegir a su segundo presidente, ya había

\footnotetext{
${ }^{85}$ Para una breve reconstrucción de la relación que en 1927 mantenía Nosotros con el movimiento reformista, véase Prislei (1992 y 1994).

${ }^{86}$ Luis H. Sommariva, "La reforma universitaria”, Boletín de la Federación Universitaria Argentina, n 1, agosto de 1920, p. 5. En cuanto a Zeballos, la cita alude a la denuncia judicial que emprendió contra tres estudiantes que encabezaban los reclamos estudiantiles y que determinó su renuncia como decano y una investigación universitaria realizada por Ernesto Quesada en calidad de decano interventor (Revista de la Universidad de Buenos Aires, año XVIII, tomo XLVII). En cuanto a Rivarola, éste pidió el ingreso de la policía a la UNLP para desalojar a los estudiantes que mantenían la "huelga grande" de 1920. Esta decisión dividió a los profesores más prestigiosos de esa universidad: mientras Rojas apoyó a Rivarola desde el diario La Nación, Korn sostuvo la legitimidad de los reclamos estudiantiles desde el diario platense El Argentino (Biagini, 2001).
} 
incorporado como socios a unos cien estudiantes de las distintas facultades de la UBA. La segunda presidencia fue encargada a Tomás Casares, un estudiante de Derecho y de Filosofía que, junto con Dell'Oro Maini, animaba los grupos laicos de cultura católica y que en las décadas siguientes se convertiría en uno de los referentes más importante de la cultura católica universitaria (Devoto, 2009). Los veinteañeros que ocuparon la presidencia del Ateneo fueron: en 1914 Monner Sans; en 1915 Casares; en 1916 del Mazo, reemplazado por Agustín de Vedia cuando aquel asumió la presidencia del CE de Ingeniería; en 1917 Casares, reemplazado por Gonzalo Muñoz Montoro cuando aquel renunció en desacuerdo con el posicionamiento a favor de la legalización del divorcio de Ideas; en 1918 de Aparicio, reemplazado por Horacio Pozzo cuando aquel asumió la dirección de Ideas; en 1919 Muñoz Montoro. Este año la vicepresidencia la ocupó, por primera vez, una mujer, la egresada de la FFyL Lidia Peradotto (1892-1951), quien entonces era la rectora reformista del Liceo de Señoritas de La Plata.

Por su parte, al dejar la presidencia del grupo en abril de 1915, Monner Sans empezó a planificar la publicación que Guillermo Korn mencionaba como la iniciadora del ciclo del pensamiento de la Reforma Universitaria: en septiembre de 1915 se puso a circular el primer número de Ideas. Órgano de la Sección de Estudiantes Universitarios del Ateneo HispanoAmericano, una revista bimestral de ciento veinte páginas que sería la única publicación estudiantil argentina que aparecería regularmente durante los siguientes cuatro años.

\section{Los primeros propósitos ateneístas}

Unos meses antes de que comenzara a circular Ideas, Monner Sans conseguía que la prestigiosa y cientificista Revista de Criminología, Psiquiatría y Medicina Legal, que dirigía el discípulo de Ingenieros Helvio Fernández, difundiera un discurso del grupo estudiantil. ${ }^{87}$ Allí Monner Sans se autorizaba en numerosas citas de intelectuales consagrados (una lista que involucraba a su padre Ricardo Monner Sans junto a Spencer, Ingenieros, Bunge, Rodó, Ramos Mejía, Mauppas, Meyer, Fernando Giner de los Ríos, Herrero Ducloux, Areco, Anatole France, Emerson y Ortega y Gasset) para presentar el ambicioso programa estudiantil. Si bien el discurso estaba recorrido por la certeza arielista de que la juventud estudiosa debía erigirse en la generación capaz de desencadenar el cambio social, uno de sus pilares fue la convicción de que los estudiantes universitarios estaban "profundamente convencidos del determinismo social, como crecimiento natural de los organismos, que son las sociedades; persuadidos de que el determinismo económico -comúnmente denominado materialismo histórico- nos habrá de proporcionar la más acertada interpretación del desarrollo del

\footnotetext{
${ }^{87}$ Monner Sans, "La función social de nuestra generación”, Revista de Criminología, II, 1915, pp. 292-305. Un breve análisis de este texto, desde una perspectiva diverente a la que proponemos, puede encontrarse en Zimmerman (1994: 74-78). Para un análisis de la antecesora de esa revista y de la matriz criminológica y psiquiátrica en discusión a principios del siglo XX, véase Mailhe (2014).
} 
país" ${ }^{88}$ Esas tesis deterministas junto a la observación de la sociedad argentina, según Monner Sans, habían permitido a la juventud delinear su función social en el campo político, intelectual y moral.

El discurso puntualizaba que la generación de estudiantes debe retomar los señalamientos de la Sociología Argentina de Ingenieros para promover la formación de leyes y partidos políticos que se guíen por los intereses económicos de los distintos sectores de la sociedad, pero también esa generación debe atender a la iniciativa de la republicana Liga de la Educación Política Española (fundada en Madrid por Ortega y Gasset en 1914 bajo el padrinazgo de Melquíades Álvarez) de formar una minoría encargada de la educación política de las masas y, dado el contexto argentino, de la cuestión de la asimilación del inmigrante.

En cuanto a lo intelectual, la juventud tendría que propiciar la superación del utilitarismo creando un ambiente apto para el desarrollo de la ciencia, la literatura y el arte. En cuanto a lo moral, debería erigirse en esa "aristocracia del mérito" esbozada por el Ariel de Rodó y El hombre mediocre de Ingenieros, al tiempo que tendría que procurar la educación del hogar, y sobre todo de la mujer. Pero para realizar esas múltiples tareas, declaraba Monner Sans, era necesario que previamente la juventud estudiosa se conociera y adquiriera una formación general pues "la universidad no cumple con su función social de preparar hombres de ideas generales; sólo produce especialistas". Por ello la Sección también emprendía

la socialización del estudiante, para que su horizonte mental se ensanche dejando de circunscribirse a un solo tema del saber, y evitando que su educación, como factor de adelanto colectivo, sea descuidada. [...] Sociológicamente debemos oponernos a toda especialización; científicamente debemos alentarla, teniendo por norma la enseñanza de las ideas generales para no vivir aislados del ambiente; a descompás con él (Ibid., pp. 303-304; destacado del autor).

Los primeros números de Ideas proponen cierta traducción de los puntos enumerados por Monner Sans. En efecto, la clave sociológica de Ingenieros se descubre en las críticas que la revista desliza a la UCR por su carencia de programa y de interpelación a una clase específica. La misma clave organiza el número cuatro de Ideas, el que, ante la inminente elección presidencial bajo la reforma electoral de la Ley Sáenz Peña, se propone formar el juicio político de los jóvenes lectores. Partiendo de la convicción de que es la afinidad hacia el proyecto del partido político lo que debe decidir el voto, la revista encarga a algunos de sus socios una serie de artículos que sinteticen el programa de cada uno de los partidos argentinos. Asimismo, la preocupación intelectual trazada por Monner Sans puede reconocerse en la versión estudiantil que ofrece Ideas de esos balances culturales que se habían tornado frecuentes en el año del centenario de la independencia argentina: en el número seis de Ideas algunos jóvenes reflexionan sobre "la evolución cultural argentina", al

\footnotetext{
${ }^{88}$ Monner Sans, Idem, p. 294; destacado del autor.
} 
tiempo que en el once se ocupan de "las figuras ya desaparecidas, que en la República han sobresalido como estadistas o han descollado en las esferas de la ciencia, de la literatura y del arte".

Pero a pesar de estas intervenciones, las diversas y precisas preocupaciones que señalaba Monner Sans a comienzos de 1915 encontraron poco lugar en el grupo. Más bien, hasta que los conflictos de los estudiantes cordobeses hagan estallar la Reforma, el Ateneo tendió a reducir su función social a la última de las cuestiones mencionadas por el joven: la socialización o instrucción general del estudiante. Y era el mismo Monner Sans quien, unos meses después del discurso que repasamos, concedía esa reducción en una versión corregida de su discurso que ahora publicaba en el primer número de Ideas.

Ese número era inaugurado con tres textos que oficiaban de editorial: unas "Orientaciones" firmadas por La Dirección, la versión escrita del discurso pronunciado en 1915 por Tomás Casares en su condición de presidente del grupo y la reformulación del programa de Monner Sans que acabamos de reconstruir. A continuación aparecía la serie de artículos y luego las notas breves que componían las secciones "Documentos, crónicas y notas de la Sección de Estudiantes Universitarios", "Variedades y comentarios" y "Libros, folletos, revistas y artículos". Quedaba allí establecido un primer diseño de secciones - bastante frecuente en las revistas de la época- al que, a medida que se adentraban en el oficio, los jóvenes le agregaron algunas variaciones con las que la revista esbozó una impronta propia: desde 1917 Ideas contó con tres nuevas secciones, "Galería del Ateneo", "Dos meses de arte" y "De la vida universitaria", y con una cuidadosa presentación gráfica, que incluyó viñetas, caricaturas de "Nuestros intelectuales" y de los socios, reproducciones de pinturas y un grabado de tapa que evocaba el rostro de un joven arielista.

En el primer número, el tópico compartido por los textos que lo editorializaban era el llamado, de claras resonancias arielistas, a formar una familia estudiantil que se preocupara "desinteresadamente" por los problemas nacionales, y en ello son significativos los cambios que realizó Monner Sans a la nueva versión del programa. El líder del grupo aclaraba que la primera versión suscitó problemas entre los jóvenes porque algunos consideraron que se trataba de un programa que se adelantaba a los acontecimientos; y aunque Monner Sans declaraba que sus críticos defendían un "pseudo-positivismo experimental" que no hacía más que escamotear la dificultad, de modo implícito realizaba importantes concesiones a sus críticos. En efecto, la nueva versión desdibujaba esa "función social” que había dado título al discurso para presentar unos más indefinidos “apuntes para un programa de acción”. Además, eliminaba la enumeración de las tareas de la juventud y no mencionaban las tesis sociológicas deterministas ni el texto de Rodó; tampoco hacía referencia a El hombre mediocre ni a la Liga de Educación Política. ${ }^{89}$

Estas modificaciones difícilmente respondieran a un cambio en las simpatías intelectuales

\footnotetext{
${ }^{89}$ José María Monner Sans, “Apuntes para un programa de acción”, Ideas, nº 1, septiembre de 1915.
} 
del joven, pues por esos años Monner Sans redactó varias notas en las que invocaba el juvenilismo arielista, se interesó auspiciosamente por la renovación laica de la cultura española y adhirió al determinismo y al materialismo histórico -incluso desde 1917 militaba en la fracción internacionalista del PS, posición sobre la que una nota de Ideas ironizaba al definirlo como un curioso "socialista germanizante"-.${ }^{90}$ Más bien, las correcciones que Monner Sans realizaba a su programa parecen haber estado motivadas por la decisión de que el espacio de sociabilidad estudiantil y de discusión de los problemas nacionales que lideraba estuviera compuesto por un grupo numeroso y heterogéneo, dos rasgos que -como habían descubierto los jóvenes del Centro Ariel- sólo podían lograrse si el programa se mantenía lo suficientemente indefinido como para incorporar a los jóvenes que criticaban el determinismo tanto desde la cultura católica (como Casares y Dell'Oro Maini) como desde el libre albedrío y otras tesis antipositivistas (entre quienes se encontraban los jóvenes Adolfo Korn Villafañe, Lidia Peradotto, Francisco de Aparicio y Vicente Sierra). Las memorias de del Mazo confirman los amplios e imprecisos propósitos iniciales del grupo. Allí refiere:

Con estudiantes de otras facultades concurrimos a la constitución y progreso del Ateneo de Estudiantes Universitarios fundado en 1914, a la iniciativa del estudiante de derecho José M. Monner Sans, el principal de sus animadores. Como decían los estatutos, el propósito de la entidad, que llegó a tener trescientos asociados cotizantes, era el de 'estimular los estudios de interés general que traspasan el dominio de las especializaciones científicas, profesionales y técnicas'. Ejercí, conjuntamente con la presidencia del Centro [de Estudiantes de Ingeniería], la presidencia del Ateneo, y participaron en las tareas del nuevo núcleo, caracterizado por la crítica y el estudio de los temas más vivos de la Universidad, varios estudiantes del Centro de Ingeniería (del Mazo, 1976: 72).

Según veremos en el capítulo tercero, las actividades que realizó el grupo en sus primeros años lo asimilan a una versión local de la labor cultural emprendida en Madrid por la Institución Libre de Enseñanza y la Residencia de Estudiantes, dos instituciones de las que -recuerda Monner Sanshacia 1917 los ateneístas copiaron "algunos procedimientos de labor, y la ideología laica de ambas corporaciones adquirió en el Ateneo enorme fuerza" (Monner Sans, 1930: 17-18). Pero instalada en el escenario porteño esa recepción volvía al grupo una suerte de rama cultural de la FUBA, a la que en su primer número Ideas saludaba y felicitaba tanto por ser la "primera asociación estudiantil de la América Latina" como por cohesionar la fuerza de cinco mil estudiantes de seis facultades e impulsar la extensión universitaria y una federación nacional. ${ }^{91}$

Lejos de competir con la FUBA, en sus inicios el grupo de Monner Sans parece haber

\footnotetext{
90 "La comida del Ateneo", Ideas, n 12, julio de 1917, p. 319. La expresión ironizaba sobre la oposición de Monner Sans a que la Argentina declarara la guerra a Alemania desde la fracción neutralista que poco después sería expulsada del PS y daría lugar al PSI.

91 “La Federación Universitaria de Buenos Aires”, Ideas, no 1, septiembre de 1915, pp. 84-86.
} 
propiciado una división de roles: aquella debía centralizar los reclamos de los estudiantes hacia la universidad mientras que la nueva institución organizaría las conferencias y la voluminosa revista necesarias para que la juventud estudiosa asumiera un "programa de acción" ligado no ya a lo gremial sino a la cultura. Y la articulación entre las tareas de las dos instituciones estudiantiles se advierte incluso en la única publicación que consigue editar la FUBA. Los tres números del Boletín de la Federación Universitaria (1917-1918) no sólo tienen como director a un joven proveniente del equipo de redacción de Ideas, Alejandro Terrera, sino que las colaboraciones que abordan temas culturales, en su mayoría, son redactadas por ese equipo y la publicidad de Ideas es el único anuncio no comercial del Boletín.

\section{La revista Ideas y el periodo esteticista del Ateneo}

Como ya desarrollamos, cuando a comienzos de 1914 se fundan la Sección y su revista existía en Buenos Aires una incipiente organización de los estudiantes universitarios. En 1908 había sido fundada la FUBA y desde algunos años antes cada facultad tenía un centro de estudiantes con personería jurídica y una publicación periódica en la que se solían editar los apuntes de las materias y las actividades del centro. Las reuniones de la FUBA, a las que asistían dos representantes de cada centro de estudiantes, eran esporádicas, se realizaban en el Círculo Médico (institución que nucleaba a los egresados de medicina) y sus actas eran publicadas en la Revista del Círculo Médico y el Centro de Estudiantes de Medicina.

En cuanto a las revistas culturales creadas por jóvenes universitarios porteños, seguramente las tres experiencias más cercanas y significativas para los fundadores de Ideas hayan sido Nosotros, Renacimiento (1911-1913) y la analizada Ariel. En el momento en que se funda Ideas, Giusti y Bianchi habían logrado darle a Nosotros una voz propia en la incipiente "república de las letras", pero también una estabilidad económica, asegurada mediante una sociedad cooperativa que involucraba a figuras de distintas generaciones $\mathrm{y}$ afinidades intelectuales. Por su parte, Renacimiento había aparecido en 1911 siguiendo una inquietud juvenil y literaria filiada explícitamente con Nosotros, pero los jóvenes editores (Florencio César González, Horacio P. Areco, J. L. Ferrarotti y Juan Más y Pi) no lograron mantener el proyecto más allá de 1913. En cuanto a Ariel, vimos que dejó de editarse a comienzos de 1915 y, a pesar de que fue mucho más modesta que las anteriores, era para los ateneístas un modelo en el cual espejarse o distanciarse, sobre todo porque el joven que había dirigido Ariel, Alberto Palcos, fue desde los inicios de Ideas un asiduo colaborador -e incluso en los números de 1918 formó parte del equipo de redacción-.

La escasa repercusión entre los estudiantes que parece haber tenido Ariel seguramente pesó en la decisión que tomó el grupo de Monner Sans de no precisar una afinidad política común. Asimismo, las dificultades económicas de aquellas revistas probablemente convencieron a la nueva 
publicación de que debía cobijarse en instituciones intelectuales más sólidas; de hecho, el Ateneo Hispano-Americano colaboró en la financiación de los primeros números de Ideas y desde 1917 el Museo Social les prestó los dos locales en los que realizaban sus reuniones. Por otra parte, si bien Ideas compartió con Nosotros, Renacimiento y Ariel la voluntad de formar a sus jóvenes lectores en lo que entonces se identificaba como la cultura integral, desde sus inicios la primera se distanció del carácter intergeneracional de las otras tres publicaciones.

En efecto, Ideas inauguró un espacio reservado a la publicación de textos provenientes de los estudiantes porteños, haciendo rápidamente un lugar a los jóvenes de otras ciudades universitarias. El director de sus primeros quince números fue Monner Sans. Luego éste permaneció en el equipo de redacción y cedió la dirección, primero, al joven Francisco de Aparicio (quien sólo tuvo a cargo el número dieciséis, fechado en marzo de 1918) y, entre el número dieciocho y el veintidós, a Alberto Britos Muñoz.

Por esa condición estudiantil, los veintidós números de Ideas aparecidos entre 1915 y 1919 ofrecen un rico registro de las ideas sobre filosofía, psicología, historia, arte, sociología y, en menor medida, ciencias naturales con las que simpatizaron los jóvenes que impulsaban la agremiación estudiantil, así como de los nuevos libros, folletos y revistas que bimestre a bimestre leyeron y se preocuparon por reseñar. Pero la revista también permite analizar la trama de relaciones que acompañó a esa construcción de una juventud estudiosa preocupada por la formación integral.

En cuanto a la impronta general de las ideas que circularon por la revista, las intervenciones de Monner Sans, además de difundir el laicismo español, deslizaron la intención de abordar los problemas sociales y culturales desde una matriz cientificista y socialista. También se reconocía esta matriz en las colaboraciones firmadas por Alberto Palcos, Carlos Scotti, Alejandro Castiñeiras y José C. Belbey, entre otros, pero hasta 1918 el abordaje cientificista y socialista convivió, sin demasiado conflicto, con la matriz antipositivista y católica de Héctor Tissone, Tomás Casares, Atilio Dell'Oro Maini, Jorge Max Rohde, Adolfo Korn Villafañe y Vicente Sierra. Es que, como mencionamos, hasta el estallido de la Reforma prevaleció el propósito de construir un grupo numeroso y heterogéneo que alentara la preocupación de los estudiantes por los problemas culturales.

La heterogeneidad ideológica del grupo fue expuesta con orgullo en varios editoriales de Ideas, y era destacada en los breves textos humorísticos con que, desde 1917, la sección "Galería del Ateneo" describía a sus socios junto a una caricatura, una iniciativa que, al igual que las comidas, colaboraba en el afianzamiento de la "familia estudiantil". Sobre el líder del grupo destacaba de Aparicio:

El Ateneo, la Facultad y el Partido constituyen el tríptico de su vida pública. Dentro del 
Ateneo ha sido todo cuanto es posible ser: Fundador, primer Presidente constitucional y Director vitalicio de Ideas (ya van dos reelecciones en su cargo). Su paso por la Facultad no deja huellas muy profundas. [...] El socialismo lo exterioriza en dos formas: "vanguardea" periódicamente y usa chambergo de su exclusiva invención. [...] es, probablemente, el "hijo del país" más versado en política española. A la falta de defectos físicos, cabe consignar uno moral: es germanófilo (Francisco de Aparicio, "GALERÍA DEL ATENEO: José María Monner Sans y Tomás D. Casares”, Ideas, nº 10, marzo de 1917, p. 73).

Poniendo a la luz un rasgo que también se registra en otros intelectuales argentinos de las primeras décadas del siglo XX, de Aparicio recordaba las inscripciones múltiples de su amigo sin preocuparse por las posibles tensiones. Pues el periódico La Vanguardia, que leía y difundía Monner Sans, tenía una línea editorial enfrentada a las afinidades de tres de los seis estudiantes con quienes aquel compartía entre 1916 y 1917 la redacción de Ideas. En efecto, el órgano del PS propiciaba un marcado determinismo social, mientras que los redactores Casares, Dell'Oro Maini y Tissone rechazaban desde Ideas tanto el determinismo como el socialismo, e incluso el laicismo de la formación universitaria. ${ }^{92}$

En cuanto al filón antisocialista, recordemos que Casares, además de presidir en dos oportunidades el Ateneo, es el subdirector de Ideas durante 1916, y su afinidad con la cultura universitaria católica ya es explícita durante esa actividad. Prueba de ello es su reseña del folleto Universidad social de Ricardo Rivarola, en la que critica "la autonomía económica de la Universidad" por ser una "forma de función social que pretende suplantar a la religión". ${ }^{93}$ Por otra parte, uno de los pocos abordajes teóricos del socialismo que publica Ideas lo realiza Sierra en un artículo que se ocupa de "las profundas inconsistencias del materialismo histórico de Juan B. Justo".

El joven Vicente Sierra, quien unos meses después firmará el manifiesto del Colegio Novecentista y durante las décadas siguientes se convertirá en un reconocido historiador del revisionismo nacionalista, ataca sobre todo la pretensión de Juan B. Justo de haber hallado leyes que expliquen el desarrollo histórico. ${ }^{94}$ Esas leyes serían producto del cientificismo biologicista con que el líder del PS estudia la historia, de su indistinción entre "ciencia de sucesión” y "ciencia de repetición", y también del simplismo del concepto de "lucha de clases" para abordar la historia frente a los factores psicológicos que influyen en los pueblos y que ya han sido abordados por Bergson y Labriola. Sierra no niega la existencia de factores económicos, sino su exclusividad para explicar los procesos históricos. Declara sobre Justo:

Su libro no es más que una justificación del socialismo al través de las fuerzas históricas

\footnotetext{
92 Entre el número 5 y 9 de Ideas (mayo de 1916-enero de 1917), conforman el equipo de redacción: Monner Sans como director, Casares como subdirector, mientras que Scotti, Tissone, Dell'Oro Maini y Alejandro Terrera ofician de redactores.

${ }^{93}$ Tomás Casares, "La universidad social de Rodolfo Rivarola”, Ideas n 6, julio de 1916, p. 315.

${ }^{94}$ Vicente D. Sierra, "Teoría y práctica de la historia”, Ideas, no 10, marzo de 1917, pp. 58-64.
} 
[...] Creyendo Justo que la historia está regida por leyes tan regulares como el sistema solar, no es raro que crea que la historia puede dar ideas de previsión [...] Todo esto sería exacto si la historia fuera tan regular como el sistema solar, y si sólo los factores biológicos y económicos produjeran los hechos históricos (Vicente Sierra, "Teoría y práctica de la historia", Ideas, no 10, marzo de 1917. 59-60).

Durante 1917, las críticas al cientificismo tuvieron cada vez más lugar en el Ateneo. Es que Monner Sans no sólo dejaba en un segundo plano su adhesión al socialismo científico para apostar por la socialización de los estudiantes, sino que además consentía que el grupo trocara su atención a los problemas sociales por la formación crítica en las letras, las artes plásticas, el teatro, la escultura y la música.

La historia del grupo que redactó Monner Sans en 1930 ofrece algunas pistas para descifrar ese proceso. Allí se recuerda que en 1916 los ateneístas de Aparicio y Britos Muñoz "contagiaron la preocupación estética en sus aspectos diversos" (Monner Sans, 1930: 11), al punto que durante 1917 "leíamos y escuchábamos con pausa varios diálogos platónicos, algunas tragedias de Eurípides y la Estética integral de Mario Pilo; repasábamos el Apolo de Salomón Reinach, visitábamos el Museo de Bellas Artes” (Monner Sans, 1930: 23).

Por entonces los jóvenes parecen haber desplazado la orientación de Ingenieros por la de Alejandro Korn, quien ya era reconocido como la principal figura local del antipositivismo y al año siguiente se convertiría en el primer decano reformista de la FFyL. Recuerda Monner Sans: “una noche por semana nos reuníamos en el departamento que Adolfo Korn Villafañe tenía instalado en el Pasaje Güemes, y allí escuchábamos, de labios del padre de nuestro amable compañero, la docta y grata lección, con la cual llegaba hasta nosotros, en medio del Buenos Aires fenicio, un sereno soplo del pensamiento helénico" (Monner Sans, 1930: 23).

Es a comienzos de 1917 que Ideas inauguró la sección "Dos meses de arte” y anunció, junto al curso intensivo sobre "Filosofía griega" dictado por Alejandro Korn, la organización de otros tres sobre "Literatura griega y latina" a cargo de Rómulo Martín, "Arte” a cargo de Britos Muñoz y "Música" a cargo de Adolfo Casablanca. ${ }^{95}$ También en 1917 Korn impartió una conferencia sobre la "Filosofía de Indostán", en la que -informa la crónica de Ideas- desarrolló la vida intelectual de un pueblo en el que "afortunadamente" la metafísica no se había emancipado de la religión y la poesía. Por su parte, el padre de Monner Sans disertó para los jóvenes sobre "El castellano en la Argentina".96

Como veremos, estas actividades se inspiraban en la difusión de la cultura greco-latina que desarrollaba la Residencia madrileña como contrapeso de la impronta católica de las universidades

\footnotetext{
${ }^{95}$ Los jóvenes publican los programas y la lista de inscritos en "Cursos intensivos", Ideas, no 11, mayo de 1917, pp. 190-196.

96 “Conferencia del doctor Korn”, Ideas, n” 12, julio de 1917, p. 315, y "Conferencia del profesor Monner Sans”, Ideas, n 13 , setiembre de 1917, p. 83.
} 
españolas. La apropiación de ese proyecto por parte de estudiantes de una universidad como la de Buenos Aires -que había nacido laica y que ofrecía una educación que, más allá de la poca preparación de muchos profesores, era predominantemente científica- no podía más que sufrir una importante resignificación: entre los ateneístas porteños, la Residencia no combatía la cultura católica, sino que ofrecería un modelo para impulsar una comprensión del hombre y sus “manifestaciones espirituales” más allá de las claves científicas predominantes en el ambiente local. En ese sentido, a pesar de la adhesión al cientificismo de su líder, desde 1917 el Ateneo e Ideas participaron decididamente de la "cultura estética" que, en rivalidad con la "cultura científica", se había esbozado en la ciudad de Buenos Aires, sobre todo a partir del Centenario, y que tenía en Ricardo Rojas y Leopoldo Lugones a sus dos figuras más reconocidas, con apuestas estéticas e ideológicas rivales.

\section{La independencia de los jóvenes ateneístas}

Este período en el que los jóvenes conectaron más claramente su construcción de una familia estudiantil con la cultura estética local coincidió tanto con la salida del Ateneo Hispano-Americano como con la acentuación de ese "sistema de elogios mutuos" sobre el que Ideas ironizó en reiteradas oportunidades. Recuerda Monner Sans (1930) que, para lograr un amplio reconocimiento en el espacio intelectual y estudiantil, el grupo buscó ser saludado por distintas publicaciones. Conformaron el sistema de elogios al Ateneo: la reproducción de sus propósitos junto al retrato de la Comisión Directiva que publicó una revista porteña de amplia circulación y carácter comercial como P.B.T. Semanario infantil ilustrado para niños de 6 a 80 años $;{ }^{97}$ las felicitaciones al grupo porteño formuladas por España, el "semanario de vida nacional" madrileño que entonces dirigía el escritor socialista Luis Araquistain y en el que el Ateneo se inspiraría para fundar en 1919 Clarín; la aparición de la nota "Buenos Aires y sus estudiantes. Las Instituciones Universitarias" de Monner Sans en Filosofía y Letras (revista editada por los estudiantes de la carrera de Filosofía de la Universidad Central de Madrid entre 1915 y 1920); y finalmente la publicación en Nosotros de una serie de reseñas del Ateneo y su revista, redactadas por Giusti.

Éste escribió la primera reseña luego del noveno número de Ideas. Allí tributaba su “aplauso a la obra excelente que un número de estudiantes, los mejores de nuestra universidad, porque tienen inquietud espiritual y afán de progreso, realiza desde las páginas de la revista Ideas"; y también aclaraba que el proyecto redimía a la juventud universitaria de su profesionalismo indiferente. ${ }^{98}$ Como sería evidente poco después, el elogio de Giusti se distinguía de los otros arriba mencionados porque en él se cifraba la posibilidad de que las compartidas distancias ante el "profesionalismo

\footnotetext{
${ }^{97}$ Para un análisis del tipo de revistas ilustradas y de carácter comercial que inauguró Caras y Caretas en 1898, véase Romano (2004).

98 "Ideas", Nosotros, n 94, Buenos Aires, febrero de 1917, p. 286.
} 
indiferente" permitiera que ambas revistas realizaran una acción cultural colectiva ligada al socialismo.

En cuanto a la visibilidad del grupo entre los estudiantes, en 1916 Ideas comenzó a extender los lazos estudiantiles más allá de Buenos Aires. Hacia 1917 anunciaba que contaba con corresponsales y puntos de venta en Rosario, Córdoba, Montevideo, La Plata y Madrid, una lista a la que los ateneístas buscaron sin éxito sumar a Santiago de Chile y sí lograron incorporar a Santa Fe y Tucumán. La primera corresponsalía fue la cordobesa y estuvo a cargo de (José) Hiram Pozzo. Luego se sumaron: en noviembre de 1916 la corresponsalía rosarina a cargo del joven socialista Amílcar Razori (quien desde mediados de 1917 dirigió Acción Socialista, "un periódico quincenal destinado a jugar en favor de los ideales políticos de la clase obrera, impulsando su labor gremial y su acción cooperativa"); ${ }^{99}$ en marzo de 1917 la madrileña asumida por el historiador Eugenio López-Aydillo; en mayo de 1917 la montevideana a cargo del literato Eduardo de Salterain Herrera; y en setiembre de 1917 la platense asignada al estudiante Ricardo Calatroni. El número aparecido en medio de los conflictos que iniciaban la Reforma aclaraba que los jóvenes que representaron a las universidades de Córdoba, Santa Fe (H. Gambino) y Tucumán (T. Passaponti) en la asamblea constituyente de la FUA habían aceptado la corresponsalía de Ideas y habían prometido artículos que informaran de cerca y en detalle "la modalidad, vida y orientaciones de los centros universitarios del interior de la República, que tan poco conocemos en la Capital Federal". ${ }^{100}$

Si bien las pocas notas que Ideas recibió de esos últimos corresponsales estuvieron lejos de ofrecer esa información cercana y detallada, su trama de contactos no dejó de ser significativa, pues tendió a construir una primera red estudiantil sin la cual la rápida expansión de la Reforma a nivel nacional hubiera sido mucho más difícil. Es que, como veremos, entre 1918 y 1919 los ateneístas no sólo participaron entusiastamente de las movilizaciones y asambleas a través de las que se fue construyendo un movimiento reformista nacional que excedía la preocupación por las mejoras de las casas de estudio, sino que además aportaron la única revista que circuló por todas las ciudades universitarias del país difundiendo noticias estudiantiles. ${ }^{101}$

Seguramente, el vínculo más significativo para la formación de esa primera red reformista sea el temprano contacto que el grupo porteño estableció con los cordobeses de la asociación Córdoba Libre!, quienes cuando estalle la Reforma se erigirán en los maestros "revolucionarios".

\footnotetext{
99 “Acción Socialista”, Ideas n” 13, septiembre de 1917, p. 171.

100 "Los nuevos corresponsales de Ideas", Ideas, n" 16, marzo de 1918, pp. 62-63.

${ }^{101} \mathrm{Si}$ bien volveremos sobre ello, recordemos que del Mazo fue el representante del Ateneo en la asamblea que en marzo de 1918 dio origen a la FUA. Además, del Mazo asistió, junto a Julio Malarino Cabrera, Horacio Pozzo y Monner Sans, al Primer Congreso Nacional de Estudiantes como delegado del Ateneo, ocasión que los ateneístas aprovecharon para fundar en Córdoba una sede del Ateneo, que parece no haber prosperado. Por otra parte, cuando a fines de 1919 la federación universitaria platense se enfrentó a las camarillas antirreformistas, el Ateneo hizo público el "decidido apoyo a esa obra de renovación universitaria" poniendo "a su disposición las páginas de Clarín, a efecto de que en ellas se desvirtúe la información tendenciosa que sobre el conflicto hace la prensa en general" ("Manifiesto del Ateneo", reprod. en del Mazo, tIII, 1927: 151). Sobre la Reforma en La Plata, véase Biagini (2001) y Graciano (2008).
} 


\section{La Asociación Córdoba Libre!}

Junto al Colegio y al Ateneo porteños, este grupo cordobés también ha sido señalado por del Mazo (1941) como uno de los antecedentes de la Reforma y, a diferencia del Centro Ariel y el Ateneo, sí ha merecido un estudio extenso, centrado en el itinerario intelectual de sus principales miembros (Navarro, 2008). Partiendo de ese estudio, incorporamos aquí fuentes que aportan nueva información sobre la intervención pública del grupo y especialmente sobre su vinculación con el Ateneo porteño.

El origen de Córdoba Libre! se remite a una serie de conferencias organizadas en 1916 en la Biblioteca Central de Córdoba por varias figuras impulsoras de la "causa liberal", esto es, de la introducción en la universidad cordobesa de un amplio conjunto de tendencias laicas y modernas ligadas a filones tan diversos como la cultura estética, el socialismo y el georgismo. La primera de esas conferencias, pronunciada por Arturo Capdevila, provocó una fuerte reacción en la prensa católica y decidió a los jóvenes renovadores a fundar la Asociación Córdoba Libre! (1916-1920). A través de la reconstrucción de Navarro (2008), sabemos que el grupo identificó a la juventud como una suerte de reserva intelectual y moral de la sociedad y que sus principales animadores fueron cuatro jóvenes escritores que se habían graduados en esos años en Derecho: además de Capdevila, lideraban Córdoba Libre! Arturo Orgaz, Deodoro Roca y Saúl Taborda (el único de los cuatro que había estudiado en la Universidad Nacional de La Plata). Los reunían las simpatías hacia una reforma agraria de corte georgista y la batalla contra la cultura clerical e hispánica, pero tenían inscripciones políticas disímiles: mientras Roca se acercaba al socialismo, Taborda difundía críticas al Estado características del anarquismo individualista y Orgaz y Capdevila simpatizaban con la fracción roja del radicalismo cordobés (Ferrero, 1988: 45-46). ${ }^{102}$ A esa lista habría que sumar a Carlos Astrada Ponce, un joven abogado que compartía el estudio jurídico con Roca y que en los treinta acompañará a éste en la campaña antifascista. ${ }^{103}$

Durante 1917, el grupo organizó una Universidad Popular que funcionó en la Escuela Alberdi bajo la dirección de Jorge Orgaz y dictó cursos de derecho, moral, economía y sanitarismo, dirigidos a los obreros, sobre todo sindicalizados (Marcó del Pont, 2005: 62). Una vez que estalló la Reforma, los miembros del grupo se coordinaron actividades con los estudiantes reformistas, entre las que se encuentra el proyecto -finalmente no concretado- de refundar esa universidad. Pero además editaron un periódico de pocas páginas y formato tabloide, llamado La Montaña.

\footnotetext{
${ }^{102}$ La filiación georgista de algunas de esas figuras es analizada por De Lucía (2004 y 2012) y Grisendi (2014). Esta filiación se advierte en la promoción de la ley de enfiteusis que propone uno de los manifiesto de Córdoba Libre! y es un interesante punto de contraste con los grupos estudiantiles porteños, pues sólo entre 1919 y 1920 en la revista que entonces publica el Ateneo, Clarín, y en el órgano del CE de Ciencias Económicas se emprende una entusiasta difusión del georgismo, sobre todo a través de las colaboraciones Cándido Domínguez Villalobos.

${ }^{103}$ Esta abogado suele ser confundido en la bibliografía con el filósofo, también cordobés, Carlos Astrada.
} 
Publicación de "Córdoba Libre", un nombre que seguramente citaba el periódico "socialista revolucionario" que en 1897 habían fundado los jóvenes Ingenieros y Lugones (quien además era cordobés). ${ }^{104}$ Sólo hemos accedido al primer número de la publicación de Córdoba libre!, pero por las reseñas publicadas en otras revistas sabemos que durante 1918 aparecieron, al menos, otros cuatro números y que ellos llegaron a los grupos estudiantiles radicalizados de Buenos Aires. Asimismo, la existencia de una segunda época, compuesta al menos por un número doble aparecido en 1931, nos sugiere que su apuesta alcanzó resonancia en el espacio reformista. ${ }^{105}$

El número inaugural de La Montaña de 1918 confirma la tarea articulada que los jóvenes graduados de Córdoba Libre! realizaban con la recientemente fundada FUC. Su contratapa anuncia que esta federación invita "a los estudiantes y hombres libres de Córdoba a un MAGNO MITIN que organizado por la Asociación CÓRDOBA LIBRE! se realizará el domingo 25 del corriente". ${ }^{106} \mathrm{Y}$ esa invitación sugiere una interesante división de tareas: mientras los estudiantes federados firmaban el "Manifiesto liminar" e invitaban a los actos, los jóvenes graduados se encargaban de precisar los núcleos ideológicos del movimiento que surgía a través de la selección de oradores en los actos y la redacción de ese manifiesto y otros textos programáticos.

Una vez que la intervención del poder nacional reclamada por los estudiantes federados llegó a la universidad, Córdoba Libre! difundió un manifiesto dirigido "Al pueblo de Alta Córdoba" (fechado el 2 de noviembre de 1918 y firmado por la junta directiva) cuya similitud con la prosa del "Manifiesto liminar" sugiere que su redactor no puede haber sido otro que Deodoro Roca. Se declara allí:

Ciudadanos: Aspiramos a un blasón más y a un oprobio menos; queremos menos vergüenza y más justicia; deseamos ciencia, virtud, belleza, libertad, vida multiforme, sana, compleja, digna de ser vivida; luchamos porque nuestro pueblo no sea ya la turba anónima y mediocre, capaz de todas las debilidades, de todos los servilismos, de todas las mentiras y sujeta siempre a todas las tribulaciones e injusticias que le imponen los directores de los pueblos, los caudillos de multitudes, los semi-dioses del potentado, los tartufos de la conciencia ("Nuestras Asociaciones. Córdoba Libre!", Themis, no 73, febrero de 1919, pp. 180-184).

El grupo se declaraba allí “una asociación que aspira y propende al mejoramiento económico, moral y espiritual del pueblo" y listaba las reformas legislativas que impulsaba. Entre el pedido de

\footnotetext{
${ }^{104}$ Sobre el "socialismo revolucionario" de La Montaña editada por Ingenieros y Lugones, véase Tarcus (2007b y 2012).

${ }^{105}$ La denominación completa del número aparecido en 1931 es La Montaña. Renovación, combate, orientación. Periódico universitario. Tribuna del pensamiento reformista. Su tapa aclara que se trata de una segunda época y sus páginas, en las que se advierte una línea reformista radicalizada afín a la primera, editan una pieza de la conocida polémica de Roca con Lugones. Hemos consultado el ejemplar en el Fondo de la Reforma Universitaria del CeDInCI. Bischoff refiere que en 1918, junto a La Montaña, aparecieron las revistas Hermes y Vida Nueva; si bien no hemos podido acceder a ellas, probablemente no mantuvieron relación con los ateneístas porteños pues no son mencionadas en Ideas.

${ }^{106}$ La Montaña. Publicación de “Córdoba Libre”, no 1, 24/08/1918, p. 12; destacado en el texto.
} 
separación de la Iglesia y el Estado, de establecimiento del divorcio, de laicidad de la enseñanza, se encontraba una reforma que no suele aparecer en los grupos porteños, la ley de enfiteusis que reclamaba la corriente georgista, pues como mencionamos el reformismo cordobés va a estar ligado a esa corriente.

En Buenos Aires el manifiesto fue publicado en 1919 por Themis, una revista dirigida por el joven que ese año presidía el Ateneo de Estudiantes, Gonzalo Muñoz Montoro. Pero los contactos entre el grupo porteño y el cordobés no se iniciaron ese año, sino en el mismo momento en que se fundaba Córdoba Libre!. El ciclo de conferencias de 1916 que dio lugar a la asociación contó con un discurso pronunciado por un representante del Ateneo, Hiram Pozzo, el joven que, como mencionamos, había sido anunciado en mayo de 1916 como el corresponsal cordobés de Ideas. A pesar de que en 1918, Pozzo se convirtió en el primer secretario de la FUA y del Primer Congreso Nacional de Estudiantes, las investigaciones sobre la Reforma no han recogido su participación en el movimiento. ${ }^{107}$

La conferencia que pronunció Pozzo en el ciclo de 1916, "Plática cordobesa", describía y festejaba, en una prosa sumamente poética, el combate contra la cultura monástica que llevaban adelante los poetas de Córdoba Libre!. En su defensa de Capdevila, el ateneísta tejía un estrecho vínculo entre el grupo porteño y el cordobés. Sobre Enrique Martínez Paz (el profesor que orienta a Córdoba Libre! y que a mediados de 1918 es el candidato a rector propuesto por los reformistas) sostenía Pozzo:

Sin esperar en esta época de nuestra evolución, una obra fundamental ni definitiva, piensa sí que las agrupaciones con carácter trascendental tienen el inestimable valor de ir formando las respectivas personalidades. [...] La simpatía de Martínez Paz por aquellos que sienten el ansia entrañable de surgir, pudiera compararse al apoyo que constituía Ingenieros para el primitivo grupo estudiantil que fue creciendo al lado del Ateneo Hispano-Americano. Con generosa espontaneidad, se acerca siempre a sus ex alumnos, y su silla de alto respaldo en el Consejo Universitario no le impide percatarse de la honda labor de Raúl Orgaz, de los valientes ensueños de Capdevila, de la serena evolución de Deodoro Roca, de los afanes de Arturo Orgaz (Hiram Pozzo, "Plática cordobesa", Ideas, n 7, septiembre de 1916: 96).

Esta conferencia es significativa no sólo por el paralelismo que traza entre los grupos y por la

\footnotetext{
${ }^{107}$ En cuanto al itinerario intelectual de Pozzo, a través de la breve nota "Hiram Pozzo", publicada en La Gaceta Universitaria de Córdoba $\mathrm{n}^{\mathrm{o}} 10$ (27/06/1918) cuando aquel asumió el cargo de secretario de la FUA, conocemos que el joven comenzó a estudiar Derecho en Buenos Aires y se trasladó a Córdoba entre 1916 y comienzos de 1918. Por otra parte, a mediados de ese año asistió al primer Congreso Nacional de Estudiantes en el que preparó el proyecto de "Formación del profesorado; docencia libre; la periodicidad de la cátedra" (reprod. en del Mazo, 1927 t.III). A través de las publicaciones institucionales de la Universidad del Litoral, sabemos que desde mediados de los veinte Pozzo se trasladó a Santa Fe, donde abrió un estudio jurídico, participó de la gestión del Rectorado de la Universidad y preparó un Bosquejo histórico de la enseñanza superior en Santa Fe, publicado en 1940 por la imprenta de la Universidad. Finalmente, a través de una carta enviada por Sanguinetti a Pozzo (conservada en el Fondo personal Florentino Sanguinetti del CeDInCI) y otra de Pozzo a Julio Brandán (conservada en la Casa de la Reforma de la Universidad de Córdoba) sabemos que durante la década del treinta Pozzo se mantuvo vinculado a los grupos reformistas.
} 
referencia a sus figuras magisteriales, sino sobre todo porque su reproducción en Ideas junto a la caricatura de Capdevila -a las que meses después Pozzo sumó un artículo en el que prosiguió la caracterización de los jóvenes poetas cordobeses- funcionó entre los porteños como una suerte de carta de presentación de quienes, en los años siguientes, liderarían el ala radicalizada de la Reforma. $^{108}$

Estos vínculos entre porteños y cordobeses seguramente se hayan reforzado con la aparición de Cultura, una revista que sólo sacó un número, en 1917, y estuvo ligada al CE de Derecho de Córdoba. Su director fue Pozzo y, a pesar de que hoy es inhallable, sabemos de su vinculación con Ideas a través de la elogiosa reseña que ésta difundió. ${ }^{109}$

Asimismo, al iniciarse los conflictos cordobeses, los lazos entre Córdoba Libre! y el Ateneo se estrecharon a través de las primeras "ceremonias reformistas". Veremos que en junio de 1918, durante el primer Congreso Nacional de Estudiantes, Deodoro Roca, en su calidad de director del Museo Provincial de Córdoba, organizó un acto para difundir por boca de Monner Sans los fines del Ateneo porteño y fundar una sede cordobesa. Y a fines de 1918, cuando Roca pasó unos días en Buenos Aires, el grupo porteño le ofreció un banquete que agasajaba tanto al líder de la "Córdoba Libre" que había hecho crujir a la vieja universidad como al artista amplio y fuerte. ${ }^{110} \mathrm{~A}$ los pocos meses, Roca era destituido del Museo e Ideas respondía publicando las breves cartas que, en repudio a esa destitución, la Comisión Directiva del Ateneo había enviado al líder cordobés y al gobernador de la provincia.

\section{Ideas, la armadora de la primera red de revistas estudiantiles}

Somos curiosos y gustamos de los experimentos, lo que justifica la labor que en este instante emprendemos para suprimir una duda pertinaz e indiscreta que nos molesta: ¿los estudiantes universitarios porteños, viven o vegetan?... He ahí el problema. A fin de dilucidarlo - pues nos preocupa, si bien no nos atormenta-, resolvemos remover los elementos que componen el ambiente donde actuamos.

"De la vida universitaria", Ideas, 1917.

A través de sus corresponsalías, Ideas cumplió un rol clave en la primera vinculación de los estudiantes universitarios del país. Pero además la publicación se erigió en un eslabón central en la construcción de una figura de estudiante que, más allá de la preocupación por aprobar los

\footnotetext{
${ }^{108}$ La segunda "Plática cordobesa" aparece en Ideas casi un año después de la trascripción de la conferencia de Pozzo (Ideas, $\mathrm{n}^{\circ} 12$, julio de 1917, pp. 299-305).

${ }^{109}$ El equipo de Cultura estuvo compuesto por: Miguel A. Pucheta cmo subdirector, Alfredo Brandán Baraffa como secretario; y los siguientes redactores Manuel T. Rodríguez, Ceferino Garzón Maceda, Vidal Ferreyra Videla y Herminio Michelena (Bischoff, s/d).

${ }^{110}$ Horacio Pozzo, "Demostración a Deodoro Roca", Ideas, no 19-20, septiembre-noviembre de 1918, pp. 63-67.
} 
exámenes, se proyectara en el plano social y político y que tuviera como una de sus inquietudes centrales la formación de una primera red de revistas estudiantiles. Como sugerimos, en sus sucesivos números Ideas fue definiendo, a través de nuevas secciones y de las presentaciones de ellas, las preocupaciones propias de los estudiantes que no "vegetan". Y la participación en el armado de esas páginas parece haber funcionado como un provocador semillero de toda una generación de revisteros estudiantiles.

En efecto, muchas de las revistas que aparecieron después de Ideas y recogieron tanto el llamado arielista a una función moral y política de la juventud culta como la apuesta por una cultura estética contaron entre sus animadores con jóvenes que habían participado en el equipo de redacción dirigido por Monner Sans; e incluso el proyecto, fuertemente prescriptivo, de un "Periodismo estudiantil" que se discutió en el primer Congreso Nacional de Estudiantes fue preparado por un activo ateneísta, el mencionado Gonzalo Muñoz Montoro, quien luego del Congreso quedaría a cargo del Boletín de la Federación Universitaria. ${ }^{111}$ Estas nuevas revistas, que en su mayoría tuvieron como único anuncio de carácter no comercial el de Ideas, no sólo amplificaron ideas y prácticas que circulaban en Ideas, sino que en muchas casos se entrentaron a ella. Formaban esa red de revistas: la Tribuna universitaria. Órgano centro católico de estudiantes, fundada a comienzos de 1916 por Dell'Oro Maini; ${ }^{112}$ el mencionado Boletín de la Federación Universitaria que dirigió Terrera y del que aparecieron sólo tres números, fechados entre mediados de 1917 y mediados de 1918; la efímera revista cordobesa Cultura fundada por Pozzo en 1917; los antipositivistas Cuadernos del Colegio Novecentista cuyos dos primeros números, editados a mediados de 1917, estuvieron dirigidos por Julio Noé para luego pasar a cargo de los ateneístas Korn Villafañe y Rohde, sucesivamente; la provocadora y satírica revista La Cureta (1918-1925), con la que el grupo liderado por el ateneísta Belbey logró radicalizar las posiciones políticas de los estudiantes porteños de Medicina; Themis, nombre que tomó la revista del CE de Derecho a mediados de 1918, cuando fue rediseñada desde una impronta militante por Muñoz Montoro, entonces presidente del Ateneo; el Boletín de la Federación Universitaria de La Plata, aparecido a mediados de 1918 y poco tiempo después rebautizado Renovación; y el Boletín de Federación Universitaria Argentina de 1920, cuya dirección fue encomendada a Muñoz Montoro.

Al tiempo que surgía esta constelación de revistas estudiantiles mancomunadas en el proyecto de una formación integral asociada a la cultura estética, veremos que el intento de hacer converger el arielismo con el socialismo científico tramado en 1914 por la revista Ariel y continuado por la Universidad Libre encontraba un nuevo espacio de difusión en la intervención

\footnotetext{
${ }^{111}$ Al igual que el resto de los proyectos del congreso, el de Muñoz Montoro fue recogido por del Mazo (1927, t.III).

${ }^{112}$ Entre 1928 y 1930 Dell'Oro Maini dirige otro proyecto revisteril, ya no estudiantil, central para la construcción de la cultura católica nacionalista y de derechas. Aquel es el primer director de Criterio, revista en la que colaboraron algunos novecentistas y que continúa publicándose en la actualidad.
} 
que realizaba Bermann en el CE de la FFyL y en su órgano Verbum. Una intervención que fue fuertemente criticada por el grupo de ateneístas que a mediados de 1917 fundó el Colegio Novecentista y los Cuadernos.

Para cerrar este capítulo, subrayemos las principales transformaciones en las instancias organizativas de los estudiantes universitarios porteños que generaban tanto la fundación del grupo y la revista Ariel como la fundación del Ateneo e Ideas. Hacia mediados de la década, una nueva generación de estudiantes fundó grupos y revistas estudiantiles a través de los que elaboró distintas estrategias para enriquecer el perfil de esa familia estudiantil. Entre esos grupos y revistas, la prolongación en el tiempo y el gran número de socios que, a diferencia del Centro Ariel, logró el Ateneo de Estudiantes Universitarios sugieren que esa "familia estudiantil" estaba dispuesta a desarrollar una sociabilidad común siempre y cuando quedaran en suspenso las declaraciones sobre el proceso de democratización que se abría en Argentina y sobre la relación de esa familia con los sectores populares.

A partir de esta primera aproximación al Ateneo, en el capítulo siguiente volvemos a ocuparnos del grupo para deslindar una de las particularidades de sus primeros años de intervención: su vinculación ideal con la Residencia de Estudiantes de Madrid. Luego de analizar el animado proceso de recepción de la "Renovación Española" que durante la década del diez se registró en los emprendimientos culturales progresistas de Buenos Aires, nos detenemos en los distintos filones de esa renovación que eligieron el Ateneo y el Colegio Novecentista para tramar su intervención entre los estudiantes. 


\title{
Capítulo 3. Naves españolas en el puerto de la Reforma Universitaria
}

\author{
Mil síntomas por los que ya se revela, en \\ aquellos países [hispanoamericanos], el \\ advenimiento de una civilización propia... Y uno \\ de estos síntomas, tal vez el más elocuente, es la \\ creciente simpatía que allí se siente por España. \\ Eugenio d'Ors, Glosario, 1920
}

En 1914 los jóvenes editores de la revista Ariel decidían abrir dos de sus números con artículos de Ingenieros sobre la filosofía española, al tiempo que el joven Bermann aprovechaba la aparición de una nueva obra de Rafael Altamira para llamar a los estudiantes a imitar el proyecto de educación para obreros que éste dirigía en la Universidad de Oviedo. A su vez, la admiración ante los intelectuales que renovaban la cultura española fue central en la primera intervención que tramó Monner Sans para su grupo, y también se advierte en los ateneístas que fundaron el Colegio Novecentista. Más específicamente, creemos que Ideas y los Cuadernos del Colegio Novecentista (1917-1919) deben reconocerse como los polos más productivos de recepción de dos filones divergentes de la Renovación Española, a saber: la experiencia de la Residencia de Estudiantes de Madrid y la filosofía antipositivista de Eugenio d'Ors.

Entre los difusores del novecentismo también se contaron los animadores de la mencionada asociación Córdoba Libre!, quienes no sólo discutieron la filosofía de d'Ors en las revistas universitarias, sino que además, como analizaremos en el capítulo séptimo, consiguieron que la UNC financiara la llegada de d'Ors a la Argentina en 1921. Ante ese arribo advertía Capdevila:

La "vieja" Universidad no hubiera traído a d'Ors ni a nadie. [...] padecía un cierto miedo que acaso podría llamarse el miedo al siglo... Se cuidaba, recelosa, como quien sabe que a los peligros de afuera se une la conspiración de adentro. Si hemos de comparar con ríos a las corrientes del saber, habremos de decir que en materia de navegación de los ríos, la vieja Universidad sostenía el principio de su exclusivo y excluyente derecho. Y así, iban y venían, aguas arriba y aguas abajo, unas mismas navecillas bajo un mismo y sempiterno pabellón. Hoy -nadie podrá negarlo- van y vienen por estas rutas, que imaginamos fluviales, todas las naves que algo pueden traer o llevar. Y todas las banderas se hacen señales y saludos, como debe ser (La Prensa, 1921, cit. en Díaz-Plaja, 1981: 132). ${ }^{113}$

\footnotetext{
${ }^{113}$ Capdevila alude aquí a la denegación que formuló la UNC del permiso para que Palacios disertara sobre las bases del programa del PS en 1910 y para que, en su paso por Argentina, Enrique Ferri, líder del partido socialista italiano, dictara un curso breve (Vera de Flachs, 2005).
} 
¿Qué "peligros" podía traer Eugenio d'Ors a esa universidad que padecía de miedo al siglo? Y más en general, ¿qué trajeron y llevaron las "naves españolas" por las rutas que ensanchaban los jóvenes universitarios, pero que ya habían sido abiertas por algunos intelectuales inquietos? Como respuesta a esas preguntas, en las páginas siguientes iluminamos el original proceso de apropiación de las ideas españolas que realizaron primero algunos grupos intelectuales porteños y luego las dos agrupaciones estudiantiles más vitales de Buenos Aires en el momento que estalló la Reforma.

\section{La Renovación Española en la cultura universitaria porteña}

Entre los elementos que estructuraron la expresión ideológica argentina de la Reforma suele destacarse la combinación de un juvenilismo arielista con la reacción antipositivista, asociada especialmente a Ortega y Gasset. Éste había visitado la Argentina en 1916 para pronunciar una serie de conferencias en las que sentenció la caducidad del positivismo y la emergencia de una "nueva sensibilidad" ligada al neokantismo.

Si bien la producción temprana de Ortega formó parte de los temas de discusión de los interesados por la filosofía, y con el correr de los años el español tramó sólidos vínculos con la intelectualidad porteña (sobre todo a través de la relación entre su Revista de Occidente y la revista Sur, que editaba en Buenos Aires Victoria Ocampo), una primera aproximación a los grupos estudiantiles surgidos en 1914 muestra que no era Ortega quien les ofrecía sugerentes ideas y prácticas a quienes comenzaban a delinear un ideario estudiantil. Cúneo, en su introducción a la compilación de fuentes reformistas, ha realizado un interesante señalamiento sobre la gravitación local de la cultura española -señalamiento que coincide con el formulado por Biagini (2012: 181-218)-. Sostiene Cúneo que el krausismo de Francisco Giner de los Ríos y su Institución Libre de Enseñanza fueron referentes significativos entre los reformistas, y que

el clima español de debate y cuestionamiento, del que Ortega y d'Ors eran líderes de exportación hacia América Latina, vendría también en la revista España, dirigida por Luis Araquistain; en ediciones de la Revista de Occidente, como Psicología de la edad juvenil de Spranger, y en discursos de incitación juvenilista como los del profesor de derecho penal de Madrid, Luis Jiménez de Asúa (Cúneo, 1978: XIV). 
Y luego precisa que España: "hará de activa central de estímulos. De ninguna otra zona del mundo y sus conmociones llegarán $-\mathrm{y}$ tan bien recibidos- mejores sumas de avisos intelectuales para avituallar las expectativas de los frentes reformistas. Llegan dos comentaristas de rigurosa contemporaneidad: uno, glosador [d'Ors]; el otro, filósofo [Ortega]" (Cúneo, 1978: XIV). ${ }^{114}$

Dos confirmaciones de esas "expectativas de los frentes reformistas" ante la construcción de una cultura política republicana son ofrecidas por el líder estudiantil porteño Carlos Sánchez Viamonte y el profesor reformista Mario Sáenz. En un reportaje para el diario madrileño El Sol -finalmente no publicado por la censura gubernamental-, el primero sostenía que "la juventud argentina sólo demuestra interés por lo que llamamos la España nueva, la que comienza a revelarse en la obra de sus más modernos pensadores y hombres de acción. La España monárquica y aristocrática no la hemos entendido nunca, tal vez porque la contemplamos en su aspecto de teatralidad anacrónica”. Y enfatizaba a continuación:

Nos separan las causas de carácter político social que motivaron la independencia americana; sin embargo hemos reaccionado contra la tendencia francamente antiespañola del siglo anterior y comprendimos la trascendencia de los vínculos institucionales que nos unen a través de espacio y tiempo. La juventud argentina tiene puestos los ojos constantemente en la obra de cultura que los hombres de España realizan (Sánchez Viamonte, 1929: 29).

Por su parte, Sáenz (profesor que, como analizaremos en el capítulo séptimo, en 1921 se erige en el primer decano reformista de la aristocrática Facultad de Derecho de Buenos Aires) era aún más firme en su reconocimiento a la nueva España. En una confencia concedida en 1923, no dudaba en afirmar que España era nuestra cuna intelectual:

Breve y fugaz. La verdadera cultura, repito, es la que nos lleva España. En estos propósitos, justo es recordar la labor de la Institución Cultural Española, que tanto bien hace a España y a la República Argentina. Esta entidad llevó hombres jóvenes, que causaron gran impresión en la Argentina y dieron idea del pujante resurgimiento cultural de España. Lo que sería muy de desear es que se ampliase la meritoria labor de La Cultural, y que, a ser posible, contribuyesen a ello los Poderes públicos ("El catedrático don Mario Sáenz", El Sol, 24/04/1925. Disponible en línea, http://www.filosofia.org/hem/dep/sol/9250424b.htm, fecha de

\footnotetext{
${ }^{114}$ Por otra parte, Cúneo sostiene en ese Prólogo que los textos reformistas no tienen nada de la "contagiosa literatura política que estimulaba la Revolución Rusa", ausencia que seguramente sea válida para muchos de los textos que selecciona en su compilación pero que no se aplica a las revistas y grupos que analizamos en el capítulo sexto.
} 
consulta: $13 / 04 / 2014)$.

Efectivamente, la Institución Cultural Española (fundada en Buenos Aires en 1912 con el propósito de formalizar el padrinazgo de la intelectualidad española en Argentina) procuró la circulación de las nuevas producciones españolas. Encargada de coordinar la llegada de distintos representantes de la Junta de Ampliación de Estudios (JAE) de Madrid, financió la visita, entre otros, de Ortega, Julio Rey Pastor y Pi y Suñer. Asimismo, cuando en 1921 d'Ors llegó al país con el financiamiento de la UNC para impartir un curso en la Facultad cordobesa de Derecho, La Cultural costeó las conferencias que aquel pronunció en Buenos Aires (Campomar, 2009). La Cultural participaba de un doble proyecto. Se trataba de legitimar la cultura republicana que surgía en España, y sobre todo en Barcelona, en rivalidad con la católica y monárquica que predominaba en las universidades, pero también de avalar la "reconquista espiritual de América", esto es, el desarrollo de relaciones culturales como instrumento privilegiado de la política exterior española. Para esta última iniciativa fue clave la formación en Madrid de un Centro de Estudios Históricos encargado, entre otras cosas, de producir una relectura positiva y anticatólica de la conquista de América. Asimismo, fue significativa la colocación de la capital española como el meridiano intelectual de Hispanoamérica, colocación que promovería polémicas en todo el continente, y que en Argentina tendría una célebre respuesta en los escritores vanguardistas que participaban de la segunda época de la revista porteña Martín Fierro (1924-1927). ${ }^{115}$

A pesar de la independencia en el ámbito de la literatura que había declarado América con el modernismo estético y del fuerte cuestionamiento que luego Martín Fierro formuló a la producción literaria española, la cultura republicana española interesó fuertemente a las agrupaciones intelectuales porteñas que buscaban elevar el nivel cultural del país desde coordenadas progresistas. Como explicita la cita de Sánchez Viamonte, esas agrupaciones realizaron una selectiva recepción, y esa condición selectiva se ofrece como una interesante muestra de la dimensión activa involucrada en todo proceso de recepción. Corrigiendo y excediendo la labor de "La Cultural", varios intelectuales porteños tendieron a señalar a las instituciones laicas que desde inicios del siglo XX se venían articulando en torno de la JAE y del liderazgo del krausista Francisco Giner de los Ríos como una rica fuente de ideas y prácticas, pero ese reconocimiento no les impidió continuar la denostación -ya iniciada por la

\footnotetext{
${ }^{115}$ Los artículos de la polémica martifierrista fueron compilados por Prieto (1968: 69-78).
} 
generación del '37- del legado colonial español como causa del atraso de América. ${ }^{116}$

Una de las publicaciones de gran circulación que propició esa recepción fue la Revista de Filosofía. Desde su fundación en 1915, Ingenieros se encargó de reproducir y comentar auspiciosamente los discursos juvenilistas de Baroja, Zulueta, Altamira, d'Ors, entre otros. Asimismo, la revista saludó al CE de Filosofía y Letras cuando, bajo la dirección de Bermann, se solidarizó con el filósofo español (y redactor del semanario España) Julián Besteiro, preso por apoyar la huelga general de 1917. La Revista de Filosofía también difundió artículos de Ingenieros sobre la renovación cultural encabezada por Giner de los Ríos, a quien recuerda Monner Sans que Ingenieros identificaba como el "San Francisco laico". ${ }^{117}$ Asimismo, en 1916 los estudiantes porteños de la FFyL pudieron asistir a un curso breve que Ingenieros dictó sobre la "cultura filosófica en España" y que fue la base de los artículos.

En esa difusión también participó la publicación cultural más importante de las primeras décadas del siglo XX, la revista Nosotros. Desde sus inicios, ésta trasmitió a sus lectores el entusiasmo ante el impulso cultural español (Delgado, 2008). Junto a la incorporación de relaciones culturales con España, Nosotros estableció en 1907 la sección "Letras españolas" a cargo de Alberto Gerchunoff y unos años después la de "Letras catalanas" a cargo de Juan Torrondell. El entusiasmo por "la España que nacía" se trasmitió, además, en las "Notas y comentarios" a cargo de sus directores, Roberto Giusti y Alfredo Bianchi. Y si en sus primeros años la línea editorial de Nosotros se interesó por Miguel de Unamuno y su idea de nación de cuño renaniano (Delgado, 2008: 7), a fines de la década del diez ese interés se redirigió a emprendimientos culturales ligados al socialismo, como el del semanario madrileño España, que fue una fuente de inspiración periodística para varios grupos juveniles del continente.

\section{El periodismo político del semanario España y sus hermanas menores americanas}

Una interesante muestra de las inquietudes que recorren a Nosotros poco antes del estallido de la Reforma, así como de las expectativas que esa revista y otras depositaban en la renovación española, la ofrece la reseña que Giusti le dedicó a España. Luego de saludar a sus redactores, entonces perseguidos por su adhesión a una huelga general, el cordirector de Nosotros

\footnotetext{
${ }^{116}$ Sobre la recepción argentina del krausismo español, véase Roig (2006). Sobre las figuras e ideas difundidas por los intelectuales españoles emigrados a la Argentina a comienzos del siglo XX, véase Biagini (1995).

${ }^{117}$ Los artículos fueron publicados en España en 1916, sin la autorización de Ingenieros, bajo el título La cultura filosófica en España. En 1928 Aníbal Ponce preparó las obras completas de Ingenieros y publicó esos artículos bajo el mismo título en el octavo y último tomo (Ingenieros, 1962 [1928], t.VIII).
} 
declaraba:

[En esas páginas] se siente palpitar el corazón de las nuevas generaciones que allá anhelan la renovación del espíritu ibérico y el resurgimiento de una más grande patria, y en tal sentido se esfuerzan y combaten tenazmente, con rabia y con fe. De veras envidiamos a esos hombres. No hay ese espíritu entre nosotros. ¿O es que no tenemos también nuestros graves problemas? ¡Cuán generosos alientos de lucha nos llegan desde las páginas de España; de los editoriales de Araquistain, que sabe pensar y sabe decir, franca y eficazmente; de las caricaturas endiabladamente agudas y originales de Bagaría; de los artículos de Salvador de Madariaga, de Fabián Vidal, de Ramón López de Ayala, de tantos otros periodistas modernos, que con sobriedad, claridad, sencillez y elegancia, sin tapujos ni rodeos, van al fondo de la cuestión! [...] queremos los de Nosotros que nos tengan por compañeros los redactores de la excelente revista ("España", Nosotros, n" 96, abril de 1917, pp. 572-573).

El semanario España había sido fundado por Ortega en enero de 1915 como órgano de expresión de las ideas renovadoras de la Liga de Educación Política. Las doce páginas, formato tabloide, de cada números eran presentadas por una caricatura de tapa que ridiculizaba la situación política internacional. Desde un comienzo España contó, entre sus colaboradores frecuentes, con Luis Araquistain (1886-1959). Al igual que Ortega, Araquistain pertenecía a la generación del '14 y ejercía el periodismo no desde esa función literaria de corte regeneracionista que había desplegado la generación del '98, sino desde un análisis crítico de la política y de la sociedad. Pero, a diferencia de Ortega, Araquistain se había afiliado al Partiso Socialista Obrero Español (PSOE) y se había convertido en un cronista político internacional (corresponsal primero en Londres, luego en Bruselas y en Berlín), destacado por su prosa polémica y su habilidad para el ensayo breve e impactante. En los números que dirigió Ortega, España propuso la confluencia del reformismo liberal, democrático y antioligárquico con el socialismo antioligárquico y radical. En cambio, desde febrero de 1916 y hasta diciembre de 1922, periodo en el que Araquistain asumió la dirección, España sólo difundió la tendencia socialista. De todos modos, su línea editorial no coincidió plenamente con el PSOE, pues mientras éste aún mantenía una posición internacionalista ante la guerra, los editoriales de Araquistain criticaban al Estado español por demorar su incorporación en el bando aliado. Estas críticas estaban en concordancia con la posición impulsada por la embajada británica, que -según hoy sabemos- financiaba por entonces al semanario (Barrio, 2001).

A partir de ese financiamiento británico, España pudo circular en América Latina, 
ofreciendo un modelo de periodismo de izquierda.

El primer grupo latinoamericano que retomó ese periodismo parece haber sido el que formó José Carlos Mariátegui con sus amigos y periodistas César Falcón y Félix del Valle. A mediados de 1918, los tres jóvenes ponían a circular en Lima el primero de los dos números de la "revista de combate" Nuestra época. Diez años después -en la nota autobiográfica para la conferencia comunista de Buenos Aires-, Mariatégui confirmaba que Nuestra América había estado inspirada en España y aclaraba que había sido el punto de partida de su orientación socialista (Tauro, 1994: 10).

Al igual que a Giusti, al joven peruano los editoriales de Araquistain parecen haberle enseñado cómo "pensar y decir franca y eficazmente", pues en el primer número de Nuestra época Mariátegui aclaraba que dejaría de escribir con seudónimos y firmaba una breve nota, "El deber del estado y el deber del ejército", que no sólo iniciaba su ruptura con el liderazgo esteticista de Abraham Valdelomar, sino que también provocaba una ola polémica que decidiría el reemplazo del ministro de Guerra y el Jefe del Estado Mayor del Perú. ${ }^{118}$ Según Beigel (2005), con Nuestra época Mariátegui diseñaba una revista "abierta al socialismo" que inauguraba el encuentro entre política y literatura que luego con Amauta (1926-1930) adquiriría la forma de esa esmerada vanguardia estético-política. ${ }^{119}$

Sobre la repercusión en Buenos Aires de España declaraba Giusti en otra reseña: “Desde que apareció en Madrid la revista España, fueron muchos los que soñaron por estas tierras, hacer algo similar. La necesidad de contar con un semanario que no se limitase a las consabidas notas gráficas, y sobre todo, el anhelo de realizar en cierta forma, una campaña liberal bien entendida y elevada, dio nacimiento a diversas empresas de éxito relativo". ${ }^{120} \mathrm{El}$ primero que buscó en Buenos Aires instalar ese periodismo de izquierda parece haber sido Evar Méndez (1885-1955). En un momento de fuerte politización motivado por las insurrecciones de la Semana Trágica y la fundación de la Liga Patriótica Argentina, Méndez puso a circular una serie de volantes que, para anunciar la inminente aparición de una nueva

\footnotetext{
${ }^{118}$ El señalamiento del peligroso rol político que comenzaba a jugar el ejército peruano produjo la reacción del teniente José Vásquez Benavides, quien junto a otros militares irrumpieron en la oficina de El tiempo para atacar a Mariátegui en el que sería su "primer accidente de trabajo". La ola de escándalo que ello produjo en Lima decidió al presidente de la república a reemplazar al ministro de Guerra y al Jefe de Estado Mayor (Tauro, 1994). Las notas en defensa de Mariátegui fueron recopiladas en la edición facsimilar de Nuestra época.

${ }^{119}$ Por su parte, Tauro propone el siguiente paralelismo entre la publicación madrileña y la limeña: "La España de Araquistain, Unamuno y Ortega y Gasset atendió a la experiencia europea para romper el enclaustramiento del viejo león ibérico; y Nuestra Época aspiró a captar las intensas lecciones del mundo, para enriquecer las concepciones estacionarias de los grupos privilegiados que en el Perú no querían percibir el dinamismo del siglo XX”' (Tauro, 1994: 10).

${ }^{120}$ Roberto Giusti, "La Palabra", Nosotros, nº 125, octubre de 1919, p. 289.
} 
revista, advertían: "Si en su modesta opinión, las ideas se deben combatir a palos, no lea MARTÍN FIERRO”, "Si Ud. cree que el comisario siembre tiene razón, no lea MARTÍN FIERRO”, "Si Ud. se enfurece con el sastre porque su traje tiene una arruga y disculpa, en cambio, los errores de un gobernante, no lea MARTÍN FIERRO”. A los pocos días, el 15 de marzo de 1919, podía leerse el primero de los tres números del periódico quincenal. ${ }^{121}$

Desde Nosotros, Giusti saludaba la iniciativa de esos "papelitos muy originales" y afirmaba sobre la primera y olvidada Martín Fierro:

Es aquí de todos sentida la necesidad de un periodismo que con entera independencia de nuestros partidos políticos, y con mayor razón por completo ajeno a los intereses de camarillas, afronte con valentía, sin preocupaciones comerciales ni pequeños escrúpulos tradicionales, el problema moral, político y social de la República. Alguien dirá: como la revista España, de Madrid. Ni afirmamos ni negamos. O eso u otra cosa, pero sí se necesita un periódico que viva del espíritu del tiempo, que es espíritu de renovación heroica (Roberto Giusti, "Martín Fierro", Nosotros, no 119, marzo de 1919, p. 437).

Entre las notas polémicas del primer número de Martín Fierro, aparecía una del joven Monner Sans quien, bajo el modelo de Araquistain, buscaba discutir la relación entre obreros y estudiantes y para ello acusaba a la FUA de haber publicado un manifiesto ante la Semana Trágica que, imitando la posición del PS -y no la del PSI-, formulaba una denuncia tibia e irresponsable.

Martín Fierro desaparecía luego de su tercer número y en su segunda época poco quedaría de esa "renovación heroica" ligada a la emancipación del género humano. Pero Giusti parece haber realizado un justo diagnóstico cuando afirmaba que Buenos Aires necesitaba de un tipo de periodismo como el de la primera Martín Fierro, pues la exitosa "puesta en hora" de la literatura nacional que realizó la segunda época de Martín Fierro tendió a opacar que, en los años que mediaron en esa segunda época (1919-1924), distintos jóvenes recogieron y potenciaron aquella experiencia periodística. En efecto, en junio de 1919 Ismael Bordabehere asumía la dirección del órgano de la FUC, La Gaceta Universitaria, y le escribía a Bermann para pedirle colaboraciones porteñas. Si bien volveremos sobre esa carta, destaquemos aquí que para caracterizar rápidamente las intenciones de La Gaceta Bordabehre aclaraba que "el formato es igual al de Martín Fierro y tendrá mucha difusión entre el elemento obrero. [...] pesar de la resistencia que nos oponen los reaccionarios apoyados por el

\footnotetext{
${ }^{121}$ Para una reconstrucción de los episodios obreros que paralizaron la ciudad de Buenos Aires y contra los que se organizaron las guardias civiles de la Liga Patriótica, ver Bilsky (1984) y Godio (1986).
} 
capital, el clero y las fuerzas policiales y nacionales estamos dispuestos a marchar adelante abriendo paso a los nuevos ideales. Necesitamos y aspiramos el apoyo de Uds.". ${ }^{122}$

Pero no sólo La Gaceta buscó vivir de el "espíritu de renovación heroica" ligado a España y la Martín Fierro de 1919. En efecto, entre septiembre de 1919 y marzo de 1920, los ateneístas editaron Clarín, un quincenario que estuvo ligado al PSI y que también se propuso continuar el proyecto de Méndez. Consideraba Giusti en una nueva reseña que Clarín era "un periódico quincenal, satírico, de combate, muy necesario en nuestra ciudad, sobre todo después de la temprana e inexplicable muerte de Martín Fierro". ${ }^{123} \mathrm{Y}$ en un punto, al menos, Clarín se acercó más que Nuestra época, Martín Fierro y La Gaceta al periodismo político de España, pues ilustró sus tapas con sarcásticas caricaturas políticas. Sobre ellas recuerda Monner Sans que fue todo un desafío conseguir dibujantes que, inspirados en España, preparen cada semana polémicas caricaturas sobre la Liga de las Naciones, la "Gran Colecta Nacional" y las campañas electorales. ${ }^{124}$

En la reseña que destinaba a Clarín, Giusti también saludaba al quincenario Bases. Tribuna de la juventud que entonces editaba el joven Juan Antonio Solari. Y concluía afirmando de ambos: "Todas estas hojas que se cruzan por el aire, llevando cada cual una buena palabra de solidaridad humana y un aliento de lucha a todos los cerebros y a todos los corazones, anuncian una era fecunda para el espíritu argentino. En verdad es hermosa esta juventud que se ha puesto gallardamente en pie". ${ }^{125}$

Más allá del entusiasmo que, al igual que otros intelectuales y estudiantes, Giusti buscaba despertar con estas reseñas, éstas prueban que poco tiempo después del estallido de la Reforma era evidente que se había instalado entre los estudiantes un nuevo tipo de intervención que había dejado de estar ligado a las revistas culturales para recoger, de distintos modos, la experiencia de la revista España. Al análisis de ese tipo de intervención dedicaremos nuestro capítulo sexto, aquí consignemos al menos su existencia y detengámonos en el tipo de lazo ideal que antes de la Reforma tramaron dos revistas estudiantiles porteñas con las empresas intelectuales españolas.

\footnotetext{
${ }^{122}$ Carta de Ismael Bordabehere a Gregorio Bermann, Córdoba, 26/06/19. Fondo documental sobre la Reforma Universitaria, Casa de la Reforma, Universidad Nacional de Córdoba.

${ }^{123}$ Roberto Giusti, "Sobre algunas publicaciones", Nosotros, no 124, septiembre de 1919, p. 146.

${ }^{124}$ Precisemos que, de todos modos, para 1919 ya existía en Buenos Aires una prolongada tradición de humor gráfico político. Véase al respecto, Burkart (2007).

${ }^{125}$ Roberto Giusti, “Sobre algunas publicaciones”, Nosotros, nº 124, septiembre de 1919, p. 146.
} 


\section{Una Residencia de Estudiantes porteña}

En el capítulo anterior mencionamos que Ideas fue la articuladora de una serie de revistas estudiantiles fundadas por jóvenes ligados al Ateneo. Ahora bien, ¿cuáles eran las ideas y prácticas que distinguían a la fracción estudiantil que entre 1914 y 1918 permaneció bajo el liderazgo de Monner Sans?

Una respuesta la ofrece el discurso que el joven pronunció poco antes del estallido de la Reforma. En enero de 1918, la Asociación Latino-Americana, que lideraba Manuel Ugarte (1875-1951), organizaba un homenaje a Enrique Soto Peimbert y Adolfo Desentis, los dos estudiantes de la Federación de Estudiantes Mexicanos que visitaban el país en un viaje proselitista gestionado por el gobierno de Venustiano Carranza. Ese acto, suerte de anticipo de las "ceremonias latinoamericanistas" que estarán a la base de la expansión continental de la Reforma, contó con dos oradores estudiantiles: luego del discurso pronunciado por Bermann en nombre de la FUA, le tocó el turno a Monner Sans, quien en representación del Ateneo llamó a ensamblar la fraternidad entre los países latinoamericanos a través del librecambio comercial entre la región y a renegar del imperialismo. ${ }^{126} \mathrm{Si}$ bien este llamado formaba parte de las reivindicaciones de la institución de Ugarte, antes de concluir el joven proponía la admiración por el republicanismo español como la marca distintiva del Ateneo:

Esta simpatía por cuanto trasciende al hispano-americanismo, deriva de nuestro cariño por España, por la España vital que minuto a minuto gesta su reforma revolucionaria contra el enmohecido aparato de Estado, contra la politiquería caciquil de sus dos partidos turnantes y contra la morfina agotadora del flamenquismo torero; en fin, contra la torpe maquinación gubernamental que pena con la cárcel, en este siglo, el noble y sagrado delito de pensar libérrimamente (“Homenaje a los estudiantes mejicanos", Ideas, no 15 , enero de 1918, p. 376). ${ }^{127}$

\footnotetext{
${ }^{126}$ Ugarte acababa de regresar de México, donde seguramente tomó el encargo de difundir las políticas de Carranza, pues se convirtió en un activo publicista de la Revolución Mexicana y de su lucha contra Estado Unidos. Antes de arribar a México, había difundido el antiimperialismo en Santiago, Lima, Panamá y La Habana. Pero esa prédica había comenzado en 1911, cuando, gracias a la holgura económica que le ofrecía la fortuna paterna, viajó por Centroamérica en una "campaña hispanoamericana" y desde entonces ligó sus intervenciones socialistas a una preocupación nacional y antiimperialista que lo alejó del PS -en el que militaba desde comienzos del siglo XX-. Antes de difundir la campaña en el libro Mi campaña hispanoamericana (publicada en 1922), creó, en 1914, en Buenos Aires la Asociación Latinoamericana. Ésta dispuso en enero de 1917 el acto de confraternidad estudiantil argentino-mexicana, con el Ateneo y la FUBA. (Yankelevich, 1999; Merbilhaá, 2009). Si bien es conocida su "campaña hispanoamericana", se ha subrayado poco que desde esa preocupación se vinculó con los grupos estudiantiles y desplegó prácticas como el acto de 1917, fue erigido como el único orador no estudiantil de la asamblea fundacional de la FUA (ocurrida en abril de 1918) y fue identificado por los estudiantes como un referente, según sugiere el primer número de la publicación estudiantil Revista Nacional.

${ }^{127}$ Para un análisis de los viajes proselitistas en el que se incluye el aquí recogido, ver Yankelevich (1999). Sobre la importancia de los viajes en la cultura política reformista, Bergel y Mazzola (2010). Sobre la participación de
} 
El Ateneo participó del acto latinoamericano y hemos visto que tramó múltiples relaciones a nivel nacional, pero las pocas noticias que llegaban del proceso mexicano y el carácter incipiente de la rebeldía cordobesa le impedían encontrar en esas latitudes el proceso de renovación capaz de orientar su labor. Como propone la cita, era a una España que parecía estar cerca de revolucionar su Estado adonde los ateneístas tendían a dirigir su atención; más precisamente, hasta que la Revolución Rusa abra un nuevo horizonte político-cultural el grupo porteño encontró una suerte de brújula en las instituciones laicas y los maestros de juventud españoles.

Ligadas al krausismo y la instauración de una cultura política republicana, la Residencia y la Institución Libre habían sido fundadas a fines de la primera década del siglo XX en el marco de las instituciones laicas que la JAE se proponía coordinar. Hacia los años diez, la Residencia alojaba a más de cien jóvenes llegados a Madrid para realizar estudios universitarios. Además de dormitorios, los estudiantes tenían acceso a una biblioteca, numerosos conciertos, cursos de formación general, ciclos de conferencias (ambos, en su mayoría, sobre temas ligados a la cultura humanista), la versión escrita de esas conferencias (aparecidas en las Publicaciones de la Residencia de Estudiantes) y un laboratorio. A ello se sumó en 1926 la Residencia. Revista de la Residencia de Estudiantes (1926-1934). Esos ciclos funcionaban como un circuito de consagración de los maestros de la nueva educación española. Pasaron por allí, entre otros, Miguel de Unamuno, Rafael Altamira, Azorín, d'Ors, Luis de Zulueta, Federico de Onís, y Henri Bergson. Asimismo, Manuel García Morente y Ortega fueron conferencistas y visitantes casi diarios (Ribagorda, 2011: 64-90).

Como mencionamos, entre 1919 y 1920 los ateneístas porteños propiciaron un perfil de estudiante en el que gravitaba la intervención del semanario España. En cambio, el perfil que propiciaron entre 1914 y 1918 estuvo vinculado a las noticias que les llegaban de aquella residencia madrileña y de sus maestros humanistas. En la segunda versión del programa del Ateneo, Monner Sans había eliminado el llamado a imitar a la Liga de Educación Política, de todos modos varias de las notas aparecidas en su revista intentaron incorporar a la actividad estudiantil porteña las ideas y prácticas juvenilistas de una España que, según el citado discurso de Monner Sans de 1918, se caracterizaba por sus rectificaciones y proyectos

los ateneístas en este tipo de eventos, nos referiremos en el quinto capítulo al acto organizado por la Revista de Filosofia, Nosotros e Ideas ante la muerte del poeta y embajador mexicano Amado Nervo. 
(Biagini, 2012: 199-202). ${ }^{128}$

Mientras que los universitarios porteños accedían al pensamiento nacional a través de la colección de Rojas y la de Ingenieros, las Publicaciones de la Residencia de Estudiantes tendían a ofrecer el primer encuentro con los maestros españoles. Pero además, al igual que lo hacía Ingenieros, Monner Sans motivó ese encuentro desde las páginas de su revista: el joven redactó el elogio de cada uno de los folletos que llegaban a Buenos Aires firmados por los maestros humanistas españoles (Altamira, Azorín, Onis, Zulueta, d'Ors, Baroja, etc.), al tiempo que publicó la reseña de las diversas revistas ligadas a ese magisterio; entre ellas, la mencionada España, La vida internacional y Filosofía y letras -revista en la que recordemos que Monner Sans presentó una breve noticia del Ateneo porteño-.

Pero ese joven también ensayó otras vías para trasladar las ideas ligadas en España a la configuración de una cultura política republicana. Anunciaba el número de mayo de 1917 de Ideas: "Lecturas españolas: ha sido encargado Monner Sans de disponer el orden a que deberán ceñirse varias reuniones en las cuales se leerán diversos trabajos de modernos autores españoles que atañen a las actividades de la juventud estudiosa de hoy". Las reseñas aparecidas en ese número sugieren que esos modernos autores eran d'Ors, Federico de Onís y Luis de Zulueta, de éstos la Residencia de Madrid acababa de publicar los discursos juvenilistas pronunciados ante la juventud estudiosa de esa institución.

El mismo número de Ideas informaba que se había comenzado a planear la formación de una Residencia en Buenos Aires. A ello se sumó la construcción de una "chacra modelo", dispuesta en un "campito" que Monner Sans arrendó junto a otros tres ateneístas para "aplicar aquí los sanos principios de la pedagogía española" (Monner Sans, 1930: 18). También bajo la inspiración de esa pedagogía, el líder del Ateneo inauguró en Ideas las mencionadas "Memorias de un modesto estudiante", una mordaz columna cuya presentación es otra de las muestras del intento de los ateneístas de modelar una voz estudiantil distintiva frente a las revistas culturales de la época. Se leía en esa presentación: “Azorín, el inimitable Azorín, escribió hace algún tiempo Las confesiones de un pequeño filósofo. Nuestro colaborador Aserrín, por no ser menos, ha redactado estas Memorias. Refiérese en el capítulo que aquí publicamos a un joven que cursa actualmente uno de los últimos años de Derecho. LD”. ${ }^{129}$ Esa parodia permitió a Monner Sans ridiculizar las despreciables costumbres tanto de los “pingüinos” o "niños bien” que asistían a la aristocrática facultad porteña de Derecho como

\footnotetext{
${ }^{128}$ Sobre la influencia de la Residencia en La Plata, véase Vallejos (2007: 331-340).

${ }^{129}$ Aserrín, "Memorias de un modesto estudiante. I- El fatuo", Ideas no 11, mayo 1917, p. 211.
} 
las costumbres de quienes procuraban imitarlos. ${ }^{130}$

Esta recuperación de los maestros madrileños y sus proyectos no fue alentada sólo por el líder de los ateneístas. En la segunda "Plática cordobesa" aparecida en Ideas, Hiram Pozzo erigió a Azorín como parámetro para consagrar a los jóvenes poetas cordobeses; y en el informe sobre la vida estudiantil que elaboró para el primer Congreso Nacional de Estudiantes, alentó la fundación de residencias argentinas inspiradas explícitamente en la madrileña. ${ }^{131}$

Por otra parte, la admiración por el proceso cultural español llevó a Ideas a buscar en Madrid a su primer corresponsal internacional. En su condición de director de la revista, Monner Sans le escribió al profesor Rafael Altamira, un especialista en estudios americanos ligado a la JAE con quien el padre de aquel mantenía una estrecha amistad, para que vinculara a los ateneístas porteños con uno de sus discípulos. Eugenio López-Aydillo, un joven profesor del Centro de Estudios Históricos, ${ }^{132}$ fue quien respondió al llamado prometiendo dos notas sobre la universidad española.

Insinuando tímidamente esa "hora americana" que al año siguiente instalaría el "Manifiesto liminar", declaraba Ideas sobre la nueva corresponsalía:

[...] estimamos que es un verdadero delito el permanecer extraños, aislados con el resto del continente que habla la hermosa lengua de Castilla, y existiendo como existen problemas que interesan por igual a todos los pueblos descendientes del tronco ibero.

Animados de estos propósitos, lógico es que el primer corresponsal nombrado en el exterior sea el de Madrid. La juventud española, en estos últimos tiempos, contempla con atención afectuosa la vida de América, y nosotros, en la medida de nuestras limitadas fuerzas, hemos tratado de estimular esa atención afectuosa repartiendo la revista del Ateneo con relativa profusión en algunas ciudades hispánicas. Sea, pues, nuestro Corresponsal otro recio lazo de fraterna cordialidad que nos ligue a los estudiantes madrileños ("Corresponsal de 'Ideas' en Madrid", Ideas, $\mathrm{n}^{\mathrm{o}}$ 10, marzo de 1917, pp. 69-70).

\footnotetext{
${ }^{130}$ La saga, aparecida dentro de la sección "De la vida del estudiante", se ocupó de los siguientes personajes: "IEl fatuo" (Ideas, $\mathrm{n}^{\circ}$ 11, mayo de 1917, pp. 211-212), "II- El provinciano" (Ideas, no 12, julio de 1917, pp. 331333), "III- El adulón" (Ideas, no 13, septiembre de 1917, pp. 104-105), "IV- El candidato" (Ideas, no 14, noviembre de 1917, pp. 251-252) y "V- El político" (Ideas, no 15, enero de 1918). También Saúl Taborda encuentra en Las confesiones de un pequeño filósofo de Azorín la inspiración para criticar el ambiente estudiantil argentino, crítica que dará lugar a su primera novela, Julián Vargas, escrita en 1916 y publicada en 1918.

${ }^{131}$ La versión taquigráfica del informe fue reproducida bajo el título "Formación del profesorado - La docencia libre - La periodicidad de la cátedra" en del Mazo (1927, t.III: 73-90).

${ }^{132}$ Coordinado por la JAE, este centro mantenía estrechos contactos con la Residencia, pues aquel le proveía la mayoría de los conferenciantes. Por otra parte, uno de sus propósitos, como mencionamos, fue revisar la imagen católica y negativa de la Conquista de América.
} 
A pesar de anunciar un "recio lazo de fraterna cordialidad", las prácticas e ideas que venimos recogiendo sugieren que, al menos hasta que estallen los conflictos en las universidades argentinas, el vínculo con los madrileños se pareció más a una admiración y emulación de sus empresas.

Otro índice de ello lo ofrece la autoridad que Ideas le asignó al diagnóstico sobre la universidad realizado por López-Aydillo. En la carta en respuesta a Monner Sans, sostenía el corresponsal madrileño que "la Universidad española ha muerto [...] y aunque he salido de la vieja Universidad, sigo trabajando en la nueva, que tan pocos conocen y que confío ha de salvar a España. En esta nueva Universidad alienta un espíritu moderno, y una simpatía entrañable hacia la joven América Española, objeto de serios y disciplinados estudios". ${ }^{133}$ Las dos notas de López-Aydillo que publicó Ideas profundizaron esa distinción entre nueva y vieja universidad. Y si bien era una distinción frecuente entre españoles y argentinos, una y otra vez Ideas mencionó a López-Aydillo y citó sus notas cuando se ocupó de las modificaciones necesarias para las universidades argentinas.

Por otra parte, así como los cursos de formación musical, literaria, estética y filosófica que organizaron los ateneístas desde 1916 guardaron una clara similitud con los que tenían lugar en la Residencia de Madrid, la conferencia que prepararon a comienzos de 1917 concebida como la primera de un ciclo que no logró realizarse- también parece haber estado pensada en referencia con las que organizaba la institución madrileña. Los ateneístas convocaron al profesor porteño Mario Sáenz para que, como lo venían haciendo los maestros españoles, señalara "la misión social de la juventud". Al poco tiempo, los jóvenes editaron ese discurso en una edición inspirada en los folletos de la Residencia, las "Publicaciones del Ateneo". Estas publicaciones anunciaban la próxima aparición de "las producciones de Ortega y Gasset, José Zorrilla de San Martín, Leopoldo Lugones, José Ingenieros, etc.”, pero -al igual que el ciclo de conferencias- la iniciativa no superó su condición programática. ${ }^{134}$

El estallido de la Reforma convenció a un grupo de ateneístas de que ya no debían dedicarse exclusivamente a la organización de actividades que, inspiradas en las Residencia madrileña, promovieran la formación integral de los universitarios. Fue entonces que el Ateneo redefinió sus propósitos y comenzó a editar Clarín. Pero antes de producirse esa ${ }^{133}$ Ibid, p. 71, destacado en el texto.

134 “Publicaciones del Ateneo", Ideas, n 11, mayo de 1917, p. 197. Adelantemos que la conferencia de Sáenz es significativa no sólo por su emulación de las prácticas llevadas a cabo por los residentes, sino también porque explicita - desde coordenadas afines a las formuladas por Monner Sans en la primera versión del programa del Ateneo- la cuestión de la intervención política de los universitarios y con ello la redefinición del perfil del grupo que se produciría al año siguiente. 
politización del grupo -que analizaremos en los capítulos quinto y sexto-, otro grupo de ateneístas se interesó entusiastamente por un filón distinto de la Renovación Española, el proyecto novecentista que desplegaba el filósofo Eugenio d'Ors en Barcelona. Recuerda Monner Sans:

Tanto en aquel campito perdido entre caminos fangosos como en la biblioteca de mi padre, y a altas horas de la noche, se discutieron extensa y acaloradamente los asuntos del Ateneo y de Ideas, máxime cuando el sarampión 'novecentista' empezó a atacar a Korn Villafañe y a Rohde, conspirando su difusión endémica según creíamos- contra el progreso de nuestra entidad. No fue así, sin embargo, y pese a ciertos debates ruidosos que sostuvimos con sus corifeos, lo indudable es que al fundarse el Colegio Novecentista, mantuvimos frente a él una neutralidad cordial y hasta benévola (Monner Sans, 1930: 18).

Las tensiones entre los simpatizantes de la Residencia y los atacados por el "sarampión novecentista" motivó la fundación, a mediados de 1917, de un nuevo grupo estudiantil y una nueva revista, el Colegio Novecentista (1917-1923) y los Cuadernos (1917-1919). Como veremos en los capítulos siguientes, la cuestión que más pesó en la aparición del Colegio fue la mencionada prédica cientificista y socialista que difundían en la FFyL Ingenieros y su discípulo Bermann. Pero los “debates ruidosos” que menciona Monner Sans se produjeron cuando, luego del estallido de la Reforma, los ateneístas optaron por ligar la identidad estudiantil a un socialismo bolchevique del que participaban muchos de los antiguos arielistas, mientras que los novecentistas propiciaron un nacionalismo aristocratizante y católico. Por su parte, veremos que también los animadores intelectuales cordobeses de Córdoba Libre! También se entusiasmaron con el novecentismo, al punto que consiguen que la Universidad financie la llegada de d'Ors a esa ciudad en 1921, pero ese entusiasmo se ligaba a una definición izquierdista que el mismo d'Ors mantuvo hasta ese año.

\section{El novecentismo orsiano}

El manifiesto inaugural del Colegio, publicado por Ideas junto con una elogiosa reseña, llevó la firma de varios socios del Ateneo y colaboradores de Ideas, e incluso allí se encontraron tres de los nueve miembros de la comisión directiva del Ateneo: el presidente Casares y los vocales Rohde y Korn Villafañe. ${ }^{135}$ Hasta que la Reforma impulse la politización de los

\footnotetext{
${ }^{135}$ La lista se compone de las firmas de: Roberto Gache, Santiago Baqué, Baldomero Fernández Moreno, Carlos Malagarriga, Benjamín Taborga, Alfonso de Laferrère, Julio Noé, Adolfo Korn Villafañe, Vicente D. Sierra, Tomas D. Casares, Ventura Pessolano, Jorge M. Rohde, Carlos Bogliolo, Carmelo M. Bonet, Jose Cantarell Dart
} 
grupos, el Colegio parece haber complementado al Ateneo en su construcción de una cultura estética estudiantil: mientras el primero buscaba agrupar al mayor número de estudiantes de las diversas facultades para que adquirieran una formación integral similar a la que ofrecía la Residencia madrileña, la nueva institución convocaba a un grupo selecto -que según los Estatutos de 1918 no podía pasar los veintitrés integrantes- para que trocara el cientificismo predominante en las aulas de la FFyL por una cultura estética filiada al tipo de antipositivismo que difundía Eugenio d'Ors. Pero veremos que esa labor complementaria se interrumpió a comienzos de 1919 cuando los estudiantes no pudieron evitar que la opción esteticista fuera acompañada de una opción política: como mencionamos, ese año el Ateneo abandonó su admiración hacia la Residencia para alentar una identidad afín al semanario España, el Colegio, en cambio, reunió a los jóvenes que decidieron estrechar el novecentismo a un nacionalismo aristocratizante y católico.

En el momento en que los ateneístas fueron "atacados" de novecentismo, d'Ors se había erigido en el intelectual más influyente de Cataluña. Además de desplegar una intensa actividad periodística (con la que popularizó el seudónimo de Xenius), jugaba un papel destacado en las instituciones que se proponían modernizar Cataluña y vertebrar la región. D'Ors impulsaba un nacionalismo "imperialista" que reafirmaba la lengua y cultura catalanas como entidades "nacionales" modernas y europeas, y se distanciaba del nacionalismo ligado al integrismo francés.

Si bien desde los primeros años del franquismo se convirtió en uno de los referentes teóricos más formados del nacionalismo reaccionario, durante la década del diez d'Ors difundió un imperialismo barcelonés desde el que simpatizó con el sindicalismo revolucionario de Georges Sorel, proyectó junto a Romain Rolland y Bertrand Russell un frente europeísta y neutralista ante la Primera Guerra Mundial y adhirió a la Revolución Rusa. Para d'Ors, la guerra y la revolución harían evidente la "crisis de civilización” y la necesidad de un proyecto revolucionario, esto es, una superación del liberalismo que -como para muchos de los representantes de la generación del '14- debía estar guiada por la aristocracia del saber (Cacho Viu, 1997).

En la sección "Glosari”, aparecida diariamente en el periódico La Veu de Catalunya entre 1906 y 1920, ${ }^{136}$ d'Ors estableció una serie de binomios con los que caracterizó su

\footnotetext{
y José Gabriel (“El Colegio Novecentista”, Ideas, n 12, pp. 340-344).

${ }^{136}$ La mayor parte de esos breves comentarios en los que d'Ors exponía su proyecto filosófico y político fueron traducidos al español y circularon en la Argentina a través de una voluminosa compilación editada en Madrid por la Biblioteca Calleja en 1920 bajo el título Glosas. Páginas del Glosari de Xenius (1906-1917). Otras glosas
} 
novedosa visión política, cultural y social, dando lugar a una "filosofía noucentista" que se consolidó en torno de la Lliga Regionalista, la Diputació de Barcelona y el Institut d'Estudis Catalans. ${ }^{137}$ Pero la filosofía de d'Ors también circuló en los mencionados Quaderns d'Estudi. Éstos eran el órgano del Consejo de Investigación Pedagógica de la Diputación de Barcelona, consejo del que entre 1917 y 1919 d’Ors fue el Director de Instrucción Pública. En cada una de sus entregas mensual, los Quaderns intentaban reflejar el intenso proceso de renovación de la cultura catalana y para ello difundían artículos sobre las nuevas corrientes pedagógicas y su aplicación en la región, informaban sobre las actividades del consejo y publicaban notas sobre temas humanísticos y de cultura catalana (especialmente, sobre música, bailes, costumbres y personalidades). Desde su fundación y hasta abril de 1918, los Quaderns tuvieron a d'Ors como director, quien bajo el seudónimo de El Guaita (El Vigía) desplegó su filosofía novecentista en los editoriales. ${ }^{138}$

En el ambiente intelectual porteño de los años diez, la propuesta filosófica de d'Ors despertaba considerable interés, sobre todo entre los jóvenes universitarios. La "nave orsiana" a la que se refería Capdevila en la nota que citamos al comienzo del capítulo tuvo su primer arribo a la Argentina a través de los pocos libros de d'Ors traducidos al español y de la divulgación realizada por algunos catalanes residentes en Buenos Aires. En las librerías porteñas podían adquirirse la compilación de glosas periodísticas de d'Ors y la novela La bien plantada (traducida al español en 1913 por una editorial madrileña), base de la recepción moralista de d'Ors. También circulaban La filosofía del hombre que trabaja y que juega, una “antología filosófica” (editada en español en 1914) que motivó la recepción académica del catalán, y las trascripciones de las tres conferencias juvenilistas pronunciadas por d'Ors en la Residencia de Estudiantes de Madrid, a saber, De la amistad y del diálogo de 1914, Aprendizaje y heroísmo de 1915 y Grandeza y servidumbre de la inteligencia de 1919.

Sobre todo estas conferencias fueron las que produjeron un fuerte impacto entre los jóvenes universitarios. En sus memorias el martinfierrista Conrado Nalé Roxlo (1898-1971) confiesa que varias décadas después aún podía repetir las "terribles palabras finales" de

fueron recogidas en dos breves compilaciones porteñas aparecidas poco antes de que d'Ors arribara a Argentina: Las obras y los días (Ediciones mínimas. Cuadernos mensuales de Ciencias y Letras, año V, núm. 52) y Del Glosario de Eugenio d'Ors (América literaria. Cuadernos Quincenales de Artes, Ciencias y Letras, Editorial Bayardo).

${ }^{137}$ Fundado en 1916 en Barcelona, el Institut se propone construir una gran biblioteca de Cataluña, una escuela de bibliotecarias y una red de bibliotecas populares. D'Ors es el Secretario del Institut hasta 1921 y organiza allí su "Seminario de Filosofía", el que en 1919 consiguió contar con las lecciones del resonado filósofo británico Bertrand Russell (Díaz-Plaja, 1981).

${ }^{138}$ Agradezco a Horacio Tarcus la posibilidad de consultar la colección completa de los Quaderns d'Estudi. 
Grandeza y servidumbre de la inteligencia: "Lenin, pon tu hierro joven en mis muñecas que aún conservan las huellas sangrienta de las ajorcas doradas de Creso" (Nalé Roxlo, 1978: 159).

A fines de 1921, d'Ors cumplía con la promesa que en distintas cartas le había realizado a las autoridades de la UNC y arribaba a la Argentina para dictar una serie de cursos. Para d'Ors, ese primer viaje a nuestro país -el segundo y último lo realizaría en 1950 cuando llegó como intelectual ligado al franquismo para que una UBA muy alejada del reformismo le otorgara el doctorado Honoris Causa- era la escala antes de dejar Barcelona y su proyecto catalanista para radicarse definitivamente en Madrid y revisar su filosofía. Para los argentinos, ese viaje sería el punto de llegada de un intenso proceso de recepción local de las ideas orsianas, pero también la confrontación de las lecturas divergentes realizadas por el Colegio Noventista y por los animadores de Córdoba Libre!.

\title{
Enunciaciones orsianas
}

\begin{abstract}
No hay pensamiento sin un impensado, no hay una norma sin un fundamento anormal, no hay decir que no se sustraiga a lo dicho. Benjamín Taborga, El novísimo Organon, 1918.
\end{abstract}

Las primeras presentaciones en la Argentina de d'Ors y su Glosari seguramente se deban al catalán Joan Torrendell (quien hasta 1909 fue portavoz en España del movimiento independentista Solidaritat Catalana y en 1917 junto a su hijo creó en Buenos Aires la célebre editorial de libros populares Tor) y al joven Benjamín Taborga, quien había nacido en Santander en 1889 y había llegado a Buenos Aires en la década del diez.

A la elogiosa presentación de d'Ors y su Glosari que realizaba Torrendell en su sección "Letras catalanas" de Nosotros, Taborga sumaba una difusión centrada en las ideas filosóficas de d'Ors, publicada en los periódicos porteños La Prensa y El Hogar, y también en Nosotros. Recuerda su amigo José Gabriel:

[...] tenía por hermano mayor, muy querido y muy respetado, a Benjamín Taborga, espíritu extraordinario, poeta excelente, estudioso de singularísimo saber. Juntos nos iniciamos en la elegancia filosófica y estilística de Eugenio d'Ors, campeón antipositivista que nos asentó en el antipositivismo ya adquirido en otros críticos y filósofos europeos, dorados por nosotros en las noches 
constantes de la Biblioteca Nacional. En d'Ors conocimos el término 'novecentista' (que Taborga usó por primera vez en unas 'Glosas novecentistas' publicadas por mí en El Hogar) con el significado del 'seny' o 'sabiduría' dado por el Glosario (José Gabriel, "Verdadera historia del Colegio Novecentista”, La Libertad Creadora, n 2, 1943, p. 313).

En respuesta al llamado antipositivista que había realizado Ortega y Gasset en su primera visita a la Argentina, Taborga y Gabriel presentaban a la producción de d'Ors como una reconfiguración del saber que partía de los avances científicos ("el hombre que trabaja") para incorporar la dimensión espiritual cancelada por el positivismo ("el hombre que juega"). Así, frente al determinismo biológico o económico de los positivistas, los "hermanos" escribían notas marcadas por el orsismo y su señalamiento de la condición libre del hombre, en la que encontraban una reflexión estética y ética atenta al espíritu pero desligada del catolicismo. Pero además Taborga y Gabriel se valían del orsismo para fundar a mediados de 1917 el primer grupo universitario que se formaba en torno de un pronunciamiento antipositivista.

Particularmente, Taborga se interesó por las últimas discusiones francesas y españolas sobre la relación entre ciencia y filosofía y difundió en la prensa las ventajas de la "nueva teoría de la ciencia" que había propuesto el filósofo catalán. En su artículo de El Hogar subrayó la "individualidad poderosa" de d'Ors, quien conciliaba el espíritu, negado por los positivistas, con la ciencia, al proponer "una síntesis de las dos actividades humanas: una, el trabajo, gasto de energía con fin inmediatamente útil, a la que se debe toda la parte causal de la ciencia; otra, el juego, gasto de energía sin utilidad inmediata, energía contemplativa, por así decirlo, a la que se debe toda la parte legal de la ciencia” (Taborga, 1924: 105).

Taborga profundizó esa cuestión en sus "Glosas sobre la posibilidad de un 'Nuevo Órgano"”, aparecidas en noviembre de 1916 en Nosotros. El juicio de su amigo Gabriel sobre este ensayo no puede ser más halagador: sostiene que "en Argentina podemos decir, no sólo que nuestro intelecto, en un momento dado, se ha puesto a tono con el universo culto, sino que, por primera vez, llevamos a la historia de la filosofía un verdadero aporte" (Gabriel, 1921: 150). ${ }^{139}$ En esas glosas aparecidas en 1916, Taborga sostenía que la última teoría científica, la termodinámica, probaba la existencia de la entidad más discutida entre positivistas y antipositivistas, el Espíritu. A partir de las críticas de d'Ors al universo mecánico

\footnotetext{
${ }^{139}$ Sin formular una valoración tan positiva, el filósofo argentino Francisco Romero señala que Taborga debe inscribirse en la historia de la filosofía local y le dedica una breve referencia en su libro Sobre la filosofía en América, aparecido en 1952. Un juicio similar lo ofrece Torchia Estrada en 1961 en La filosofía en la Argentina. A esa valoración se suma Max H. Alberti, quien le escribe a José Ferrater Mora para que el diccionario filosófico en español más importante destine una entrada a Taborga pero no logra su propósito.
} 
y su propuesta de un "Novisimum Organum" superador de la escisión entre ciencia y ética, Taborga reconstruía la refutación de la concepción mecánica del universo que se encontraba en Carnot para extraer "las consecuencias filosóficas, epistemológicas y éticas". La irreversibilidad del universo probada por la teoría de Carnot produciría una "revolución cultural" en la historia del espíritu humano, pues al inscribir el tiempo y la contingencia en la naturaleza, disolvería el clásico problema filosófico de la conciliación entre libertad y determinismo: "El principio de Carnot no reviste otra significación que el de un nuevo y potentísimo esfuerzo hecho por la Naturaleza para escaparse del palacio teórico en que nuestra razón pretende encerrarla" (Taborga, 1924: 32).

La aceptación del carácter temporal de la naturaleza (sus movimientos contingentes y sus relaciones no reductibles a cálculos matemáticos) pondría al descubierto el trabajo realizado por la razón para construir el "palacio teórico" con el que trabaja el esquema mecanicista; de ahí que "para que la Ciencia 'prevea' tiene que 'ver' el mundo a través de la necesidad". Este reconocimiento abriría un espacio de reflexión propiamente "filosófico": ubicada a la base de la concepción científica o mecánica, la filosofía tendría por objeto el ver del espíritu en su interacción histórica entre el mundo de la razón y el de la experiencia.

Una de las tareas de la filosofía, entonces, sería proporcionar una teoría del conocimiento que ilumine la cambiante disposición del saber, la otra tarea se asociaría a la política. Taborga publicó en febrero de 1918 en Nosotros una "Pequeña requisitoria a la democracia", artículo en el que presentaba una crítica filosófica al orden electoral democrático que regía en la Argentina desde 1912 y que en 1916 había llevado por primera vez a la presidencia del país a un representante de las clases medias. En su requisitoria, Taborga revisaba la doctrina del sufragio libre y la concepción de los derechos del hombre en que la doctrina se apoyaba, y concluía proponiendo el derecho funcional, o bien una democracia fundada en un sufragio que privilegiaba el conocimiento político y que -una vez más siguiendo a Gabriel- "se adelantaba a la concepción política que nos ha traído el régimen ruso de los soviets" (Gabriel, 1921: 155-156).

Sería a mediados de 1917 que la recepción de este filón de la Renovación Española se inscribiría plenamente en una expresión colectiva como la "reacción antipositivista". Por entonces Gabriel conseguía que los ateneístas atraídos por el novecentismo lo acompañaran en la fundación del Colegio Novecentista. Si bien dedicaremos el capítulo siguiente a las características de la reacción antipositivista en Buenos Aires y analizaremos allí la polémica 
que abren los novecentistas con la predica positivista de Ingenieros y Bermann, repasemos como cierre de este capítulo la vinculación material y simbólica con d'Ors que tramó en sus orígenes el Colegio Novecentista.

\section{Los orsianos porteños (1917-1923)}

Por iniciativa del joven José Gabriel, el 23 de junio de 1917 un grupo de estudiantes de la FFyL se reunió en el Círculo de La Prensa (diario en el que aquel trabaja como periodista) para leer el manifiesto fundacional del Colegio Novecentista. Validando una práctica que comenzaba a ser frecuente en el ámbito intelectual de entonces, los novecentistas hacían pública su existencia a través de un documento colectivo. Allí subrayaban provocadoramente su "franco desacuerdo con el medio intelectual" en que vivían y su disposición a "emprender una obra de revisión" a partir del estudio de las nuevas corrientes de ideas. Y precisaban:

Novecentismo quiere ser suerte de nombre o seña de la actitud mental de unos cuantos hombres de hoy -nuevos y del Novecientos- a quienes no conforma ya el catón espiritual vigente. [...] Afectos, sin embargo, a nuevas maneras de pensamiento y con nuevos matices de sensibilidad, reputan insuficiente la explicación positivista y aspiran a columbrar horizonte mental más amplio que sea a un tiempo mismo crítica y superación ("Manifiesto del Colegio

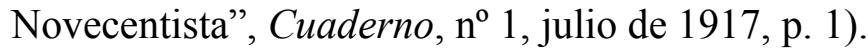

Para realizar esa crítica y superación del positivismo, que también alcanzaba al socialismo, los novecentistas porteños se valían, sobre todo, de la antología filosófica La filosofía del hombre que trabaja y que juega (1912) de d'Ors. El marcado orsismo del primer año se advierte en la mención a d'Ors y su definición de la razón que realizaba Gabriel en el discurso inaugural del Colegio. Pero también recorre otros textos aparecidos en los nueve Cuadernos (1917-1919) que editó el Colegio. Allí se reproduce "El positivismo y el espíritu", un breve texto de d'Ors (extraído de La filosofía del hombre que trabaja y que juega) que oficiaba entre los jóvenes porteños como una suerte de programa de renovación antipositivista, y el prólogo a $L a$ filosofía del hombre que trabaja y que juega, que había redactado el joven filósofo y residente madrileño Manuel García Morente. ${ }^{140}$

\footnotetext{
${ }_{140}$ José Gabriel, "Discurso sobre el Colegio Novecentista", Cuaderno, $\mathrm{n}^{\mathrm{o}}$ 1, julio de 1917, pp. 6-29; Eugenio d'Ors, "El positivismo y el espíritu", Idem, pp. 38-39. Manuel García Morente, "La filosofía del hombre que trabaja y que juega, de Eugenio d'Ors", Cuaderno, n 2, agosto de 1917, pp. 190-114; Cuaderno, n 3, diciembre de 1917, pp. 169-176; Cuaderno, $\mathrm{n}^{\circ}$ 4, febrero de 1918, pp. 43-47. Agradezco a Karina Vásquez el acceso a la colección de los Cuadernos.
} 
Los Cuadernos se propusieron como una suerte de versión local de los Quaderns d'Estudi que aparecían en Barcelona bajo la dirección de d'Ors al tiempo que los cursos de discusión del positivismo que propusieron los jóvenes porteños se inspiraron en el Seminario de Filosofía que dirigía el catalán. Si bien no se ha conservado ninguna carta que permita establecer el tipo de vínculo con d'Ors que mantenían los porteños, varias referencias muestran que la relación era estrecha. En efecto, en la primera de las tres cartas escritas por d'Ors a Ingenieros que se conservan en el Fondo José Ingenieros del CeDInCI, aquel le confiesa que se ha decidido a escribirle porque: "Por una carta de José Gabriel me he enterado más especialmente de las simpatías que usted ha tenido la generosidad de manifestar en torno de algunos incidentes de vida política de Barcelona, que me conciernen". ${ }^{141}$ Además, poco tiempo después de la aparición del primer Cuaderno, d'Ors había accedido a él y publicaba en la prensa catalana dos reseñas con las que intentaba afianzar el vínculo con sus discípulos del otro lado del océano. Por un lado, en los Quaderns correspondientes a enero de 1918, apareció una elogiosa reseña del ensayo filosófico de Taborga publicado en el segundo Cuaderno. ${ }^{142}$ Por el otro, uno de los Glosari de ese año realizaba un dictamen novecentista que no ahorraba en halagos a Taborga y el Colegio. Sostenía Xenius:

\begin{abstract}
Benjamín Taborga es un nuevo escritor argentino, a mí caro por más de un concepto. Con otros selectísimos espíritus forma, en Buenos Aires, el instituto "Colegio Novecentista", el cual da a luz entre otras publicaciones, una revista "Cuadernos", al cual buscaríamos par vanamente entre nuestras revistas (reproducido en "Un juicio de Eugenio d'Ors (Xenius)", en Cuadernos n ${ }^{\circ}$ 6, junio de 1918, p. 198).
\end{abstract}

Con esas otras publicaciones, d'Ors aludía a la primera de las Publicaciones del Colegio Novecentista, La otra arcadia: versos, que Taborga firmaba bajo el seudónimo de Teófilo de Sais y aparecía a comienzos de 1918. Seguramente, d’Ors redactó su Glosari con esta publicación a la vista, pues a continuación del pasaje citado transcribía el epigrama a Víctor Hugo reproducido en la última parte del libro. Y d'Ors encontró una nueva oportunidad de halagar en el Glosari a su discípulo argentino Taborga a fines de 1918, cuando éste falleció de

\footnotetext{
${ }_{141}$ Carta de Eugenio d'Ors a José Ingenieros, Barcelona, 19/10/1920. Fondo José Ingenieros, CeDInCI.

142 "El espacio, la geometría y la lógica (a propósito de una crónica de Amado Nervo) por Benjamín Taborga. Colegio Novecentista (agosto de 1917)", Quaderns d'estudi IV, año 3, vol. I (enero 1918, pp. 303-307). Por otra parte, por la lista de ingresos a la Biblioteca del Consell de Pedagogia que publican los Quaderns de enero de 1918 (p. 311) sabemos que desde entonces los dos primeros Cuadernos estuvieron disponibles en esa biblioteca catalana. Para un análisis de los Cuadernos que recupera algunas cuestiones aquí no desarrolladas, véase Eujanian (2001) y Vásquez (2000). Para la relación del grupo con España, véase Biagini (2012: 202-206).
} 
manera repentina.

Poco antes, Gabriel y Taborga se habían alejado del Colegio por diferencias con la "minoría católica" que participaba del grupo. Y si desde entonces el Colegio hizo converger el orsismo con la cultura católica, Gabriel continuó la difusión laica que había iniciado con su amigo Taborga y por la que se mostraron interesados Deodoro Roca y su otros reformistas cuando en 1921 consiguieron que d'Ors aceptara la invitación a impartir un curso de filosofía en la universidad cordobesa de la Reforma.

Recuerda Gabriel sobre su salida del Colegio:

Tuvimos más tarde disidencias los componentes, sobre todo a causa de la interpretación neocatólica que algunos le daban a nuestro espiritualismo. Nos retiramos Taborga y yo y quedó el Colegio a cargo de Adolfo Korn Villafañe, en cuyas manos se creó la filial de La Plata y no recuerdo qué otra; siguieron publicándose los Cuadernos, se iniciaron las escaramuzas de la reforma universitaria, y se cumplió el ciclo de la entidad (José Gabriel, "Verdadera historia del Colegio Novecentista", La Libertad Creadora, n 2, 1943, p. 314).

Aunque durante la década del treinta, el primer líder del Colegio simpatizaría con Trotzki y con el bando anarquista de la Guerra Civil Española, en los veinte siguió interesándose por la difusión de d'Ors y del orsismo de Taborga. En 1920, Gabriel dictó en la Asociación de exalumnos del Colegio Nacional de La Plata (un grupo que bajo la dirección de Rafael Alberto Arrieta editó entre 1918 y 1920 la revista Atenea) un curso sobre la pedagogía expuesta por d'Ors en los Quaderns y con esos apuntes elaboró "La pedagogía idealista de Eugenio d'Ors", un artículo aparecido en el tercer número de Humanidades. Publicación de la Facultad de Humanidades de la Universidad de La Plata (julio de 1922). Asimismo, en 1921 publicó La educación filosófica, una recopilación de sus artículos que ofreció como una carta de presentación del orsismo argentino a su maestro que visitaba la Argentina. ${ }^{143}$

Ese libro llevó el prólogo de otro revistero que por entonces también simpatizaba con el orsismo, Ernesto Laclau. ${ }^{144}$ En 1921 el Ateneo, entonces prácticamente disuelto, sin una

\footnotetext{
${ }^{143}$ En cuanto al itinerario político-cultural de Gabriel, mencionemos que en enero de 1919 organizó la adhesión de los empleados de La Prensa a la huelga general. Como esa iniciativa le dificultó conseguir trabajo como periodista, decidió instalarse en La Plata, donde, además de ser profesor en el Liceo de Señoritas y en Colegio Nacional de La Plata, coordinó el Coro Ucraniano y la Compañía de Teatro Renovación y hacia 1924 abrió la librería La Estrella y un sello editorial homónimo En 1934, centenario del nacimiento de José Hernández, Gabriel emprendió un nuevo proyecto revisteril: fundó junto a uno de su discípulo Olegario Becerra, Martín Fierro, revista de la que aparecieron 17 números preparado cada uno por distintos intelectuales (Zaccardi, 1963: 362). Además, en esa década retomó la actividad periodística, como redactor del diario Crítica, en los cuarenta su oposición al peronismo le impidió continuar esa actividad, pero en la década siguiente se inscribió en el peronismo y para el Primer Congreso Nacional de Periodistas es el encargado de redactar el informe sobre la libertad de prensa (Tarcus, 2007a).

${ }^{144}$ En junio de 1918 aparece en Buenos Aires Páginas. Órgano de los alumnos del Colegio Internacional. En esa
} 
publicación periódica ni el liderazgo de Monner Sans, organizó un homenaje a Mitre y convocó como orador a ese joven profesor de la Facultad de Derecho. Además de comenzar con un epígrafe de Xenius, Laclau utilizaba la periodización cultural de d'Ors para interpretar la filosofía política argentina: la ilustración de Rivadavia habría tenido los defectos intelectualizantes señalados por d'Ors, mientras que el romanticismo de la generación del '37 habría abandonado la razón; ante ese panorama, el novecentismo llegaba para producir una síntesis, o bien un idealismo que subordinaría la ciencia a la ética. ${ }^{145}$

En el capítulo séptimo veremos que el orsismo también interesó a Deodoro Roca y a los jóvenes graduados que animaban Córdoba Libre! y que la llegada de d'Ors a la Argentina estuvo acompañada de una fuerte disputa por las características y alcances tanto de esa filosofía como del movimiento de la Reforma. En los análisis que realizamos en este capítulo buscamos mostrar que las ideas y prácticas que llegaban de las fracciones liberales españolas produjeron un importante interés no sólo entre los intelectuales de Nosotros y Revista de Filosofía, sino también entre los jóvenes que procuraban modelar una figura de estudiante que trascendiera la formación profesional y que a partir de 1918 tendrá rasgos más claramente políticos.

revista, de la que aparecieron, al menos, veintitrés números, Laclau aparece como redactor junto a Pedro Darracq Requena como director, Eugenio P. Lamberti como secretario y Humberto Tirelli como administrador.

145 Aníbal Ponce reseñó la conferencia (editada junto a la presentación de Korn Villafañe por la editorial Nosotros, bajo el título Filosofía política argentina) en la Revista de Filosofía. El discípulo de Ingenieros le reprochaba a Laclau que su lectura orsiana de la historia argentina no superaba la realizada, hacía un par de años, por La evolución de las ideas argentinas. La misma conferencia recibió otra crítica formulada por el profesor y futuro decano de la Facultad de Derecho Cloromido Zavalia desde la Revista Jurídica. 


\title{
Capítulo 4. La filosofía, ¿aliada de la ciencia o de la literatura? Debates sobre la
} racionalidad y el compromiso político en el proceso de profesionalización de los estudios filosóficos

\author{
Sea la primitiva acepción amplia de amor a la sabiduría, o la \\ más restringida de ciencia del ser, que le dieron \\ posteriormente los socráticos, lo real es que hacia el siglo \\ séptimo antes de Cristo los colonos griegos del Asia Menor \\ inician una especulación teórica sobre el mundo, de dirección \\ y acento desconocidos anteriormente, y que a esa \\ especulación, continuada hasta hoy por las mentes mejor \\ organizadas del hemisferio occidental, es a lo que \\ unánimemente se ha llamado y se llama filosofía. \\ José Gabriel, "Devoción de Benjamín Taborga", 1928.
}

¿Qué es la filosofía? ¿Una búsqueda de los primeros principios que va perdiendo su campo de estudio ante el avance de la ciencia? ¿O es más bien una reflexión sobre las condiciones de posibilidad de la objetividad científica y del mundo mismo, y así un intento de apresar el ser que se escurre tras sus manifestaciones? ¿Su tarea es trazar los límites conceptuales en los que debe moverse el auténtico conocimiento científico? ¿Trasmitir la tradición grecolatina de problemas y soluciones relativos a la psicología, la ética y la estética? ¿O, desde una formulación más contemporánea, poner en evidencia la diferencia y jerarquía que produjo Occidente entre la mismidad y la otredad, la razón y la locura, el discurso argumentativo y la poesía, las palabras y las cosas? Este tipo de cuestiones, cuyas respuestas continúan dividiendo a los interesados en la filosofía, no podía ser pasado por alto en el proceso de profesionalización de los estudios filosóficos en la Argentina, estudios que en la Introducción de esta investigación identificamos como parte de la dimensión cultural de la Reforma.

Cuando en 1915 Ingenieros fundó la emblemática Revista de Filosofía, lo hizo confiando en que la filosofía era la madre de las ciencias y con ello la encargada de trazar la continuidad entre los desarrollos de la psicología experimental, la sociología y la pedagogía, por un lado, y los últimos avances de las ciencias biológicas, por el otro. Frente a esta definición de la filosofía, vimos que un grupo estudiantil dio vida a esa suerte de vanguardia filosófica que fue el Colegio Novecentista. Esos jóvenes liderados por José Gabriel se guiaron por el proyecto que desarrollaba d'Ors en Cataluña para declarar que la "filosofía buscada" debía propiciar una reflexión sobre el espíritu y los valores grecolatinos que excediera la racionalidad científica y con ello superara los límites establecidos por el proyecto filosófico 
encabezado por Ingenieros. 
En este capítulo reconstruimos los debates ligados a la llamada "reacción antipositivista" y a los orígenes de la filosofía profesional en la Argentina. Asimismo, presentamos el vínculo complejo que esa filosofía tramó con el movimiento político-cultural de la Reforma. Para ello recuperamos las ideas e instancias materiales que estuvieron en juego en el debate por la definición de la filosofía de fines de la década del diez, nos detenemos en las polémicas mantenidas por la fracción antipositivista con la cientificista y reconstruimos el modo en que la primera concibió el vínculo de la filosofía con la literatura y con la política, para finalmente trazar las características que adquirió el antipositivismo una vez que, renovada la planta docente en el marco de la Reforma, primó en los estudios filosóficos académicos.

\section{Racionalidad, literatura y política}

Entre la definición de la filosofía que desplegaba la Revista de Filosofía y la propuesta por los Cuadernos se encontraban al menos tres cuestiones en disputa: el tipo de lenguaje y argumentación propios de la filosofía, el tipo de mediación entre las preocupaciones filosóficas y los problemas sociales contemporáneos, y la posibilidad de conocer al hombre desde el determinismo -social o biológico-, o desde una reflexión lógicamente anterior a la ciencia.

En cuanto a la primera cuestión, es notorio que, en sus catorce años de existencia, la Revista de Filosofía no publicó ni un solo verso, y tendió a instaurar una filosofía distante de la literatura y su tipo de aproximación al lenguaje. Más específicamente, la publicación de Ingenieros se preocupó por el rigor terminológico y, si atendía a la literatura, lo hacía para explicar los procesos involucrados en la creación artística a partir de los últimos avances de la biología y la sociología. ${ }^{146}$ En cambio, la "reacción antipositivista" que el Colegio lideró hasta 1919 no temió la contaminación con las formas lingüísticas descartadas por el cientificismo 146

En sus producción escrita, Ingenieros propuso la noción de experiencia como la vertebradora de la disciplina filosófica y la científica. El predominio de esta última fue tan fuerte que, hasta la revisión de 1918 en Proposiciones relativas al porvenir de la filosofia, la filosofía aparecía como parte de las ciencias psicológicas (Ramaglia, 2010; Fernández, 2012). 
ingenieriano, e incluso probó la posibilidad de que el vínculo de la filosofía con la literatura, y sobre todo con el lenguaje poético, permitiera pensar problemas filosóficos fundamentales como el de la relación entre la dimensión biológica y la espiritual del hombre.

El alcance de los problemas propiamente filosóficos nos conduce a la segunda cuestión debatida durante la reacción antipositivista, esto es, el compromiso o la distancia que toda definición de filosofía debe decidir respecto de los modelos de orden social. En Argentina, el proceso de profesionalización de la filosofía se produjo en el marco de la inauguración de la experiencia democrática local y de la "crisis civilizatoria" internacional desencadenada por la Primera Guerra Mundial y las Revoluciones Rusa y Mexicana. Pero también esa profesionalización estuvo recorrida por un vector al que los estudios sobre la reacción antipositivista no le han prestado suficiente atención: el estallido de la Reforma Universitaria y la organización de un movimiento estudiantil nacional con fracciones que, en un momento de fuerte protesta obrera, reclamaban la democratización no sólo de la universidad sino también de la sociedad.

Ese vector motivó que los animadores locales de la filosofía fueran interpelados por el "maximalismo", abriendo con ello un particular mapa de relaciones entre corrientes filosóficas e identidades políticas. En efecto, muchos defensores de la exclusividad de la racionalidad científica simpatizaron con el PS, en el que hasta 1921 convivían fracciones evolucionistas y fracciones revolucionarias, todas ellas marcadas por una fuerte confianza en la ciencia. Entre ellos, se encontraban Ingenieros, Nelson, Bermann, Palcos, Mouchet y Ponce. Asimismo, varios de los promotores de la ampliación de la racionalidad más allá de la ciencia optaron por un modelo social que asegurara las jerarquías sociales. Algunos de sus representantes fueron: Rivarola, Coriolano Alberini, Tomás Casares, Korn Villafañe, Ventura Pessolano y Juan Probst. Pero estos alineamientos predominantes no impidieron que algunos promotores de una racionalidad filosófica trascendente a la ciencia tendieran lazos con la cultura de izquierda, como fue el caso de los cordobeses Deodoro Roca, Saúl Taborda y Carlos Astrada, o que otros propiciaran un socialismo superador de la herencia científica, como el formulado por Alejandro Korn y su grupo platense Renovación, y por José Carlos Mariátegui, a escala latinoamericana. Finalmente, también se registraron figuras filiadas al cientificismo filosófico y alejadas del compromiso socialista, como Carlos Octavio Bunge, Antonio Vidal y Matías Calandrelli.

En cuanto a la tercera cuestión, la opción por el cientificismo o el antipositivismo 
puede ser concebida como una nueva formulación del fraccionamiento entre "cultura científica" y "cultura estética" que, como mencionamos, recorrió el espacio intelectual porteño a partir de la configuración del modernismo a comienzos del siglo XX (Terán, 2008: 15-34). Los partidarios de esas matrices culturales retomaron tópicos de la matriz rival, y seguramente el caso paradigmático sea el de Bunge, quien en Nuestra América (1903) se apropió de tópicos esteticistas, e incluso del sintagma utilizado por José Martí, para formular un discurso de corte positivista muy alejado al formulado por aquel. Pero esas "apropiaciones" no impidieron que el proceso de especialización de las actividades intelectuales -del que emergieron la figura del intelectual moderno y el saber literario y el filosófico como distintivos del saber científico- estuviera recorrido por la confrontación entre el esteticismo y el cientificismo. El espacio donde más se tensó esa confrontación fue en la producción intelectual ligada a la FFyL de Buenos Aires. De ahí que nos ocupemos, en las páginas siguientes, de reconstruir las polémicas allí registradas.

\section{La "desinteresada" Facultad de Filosofía y Letras de Buenos Aires}

En 1896 era fundada la FFyL para erigirse en la difusora del "saber desinteresado", esto es, en la encargada de la formación integral, que la preparación profesional de las otras tres facultades porteñas (Ingeniería, Derecho y Medicina, a las que en los años próximos se sumaron Economía y Veterinaria) tendía a relegar. En un principio, ese saber desinteresado no contó con especialistas y fue impartido por figuras destacadas del ámbito intelectual local, formadas en Medicina o en Derecho (Buchbinder, 1997). La facultad funcionaba por las tardes: durante el día, la mayoría de sus profesores trabajaban en consultorios jurídicos o médicos, y los estudiantes cursaban alguna de las carreras profesionales que les aseguraban un porvenir económico. Asimismo, para aumentar la baja matrícula estudiantil, desde un comienzo la facultad estipuló en sus estatutos el reconocimiento del título de las escuelas normales, esto es, el título de las únicas instituciones previstas para que las mujeres realizaran estudios secundarios. Como mencionamos en el capítulo primero, la admisión de las mujeres en esta facultad era poco problemática porque se otorgaba el título de Doctor, esto es, un título que no habilitaba a ejercer una profesión. La iniciativa consiguió su propósito, pues a mediados de la década del diez un tercio del estudiantado estaba compuesto por mujeres (Denot, 2007).

Desde 1912, la FFyL se organizó en tres secciones y dos ciclos. Los estudiantes 
debían elegir entre las secciones de Historia, Letras o Filosofía, y tenían que optar por el ciclo de profesorado o el de doctorado. ${ }^{147}$ La actas del Consejo Directivo de la Facultad trascritas en la Revista de la Universidad de Buenos Aires muestran el fuerte y prolongado debate que originó el establecimiento del ciclo de profesorado, pues la mayoría de los profesores titulares que componían el Consejo Directivo consideraron que con ello se introducía la "utilidad" en una facultad consagrada al "desinterés". A ello se sumó que quienes optaban por el profesorado eran, en su mayoría, mujeres y muchos miembros de ese consejo asociaban la presencia de las mujeres a la baja del nivel académico.

En cuanto a la sección filosófica, los temas de los cursos confirman la división entre los profesores que -como Ingenieros y Rodolfo Senet- se inclinaban a favor de la veneración de la racionalidad científica y unos pocos -como Rivarola y Alejandro Korn- que, sin fomentar el anticientificismo, impulsaban una "vuelta a Kant", esto es, emprendían la recepción y difusión de las corrientes filosóficas europeas que reflexionaban sobre las dimensiones humanas trascendentales a la experiencia. ${ }^{148}$ Esa veneración a la racionalidad científica estaba acompañada de una preocupación ética que había realizado una significativa operación sobre la currícula. Observando la currícula de 1908, señala Terán que "sobre un total de treinta y una materias dictadas, sólo cuatro (Lógica, Estética, Ética y Metafísica) forman parte del canon filosófico. Es posible suponer entonces que la función filosófica fuera 'transferida' more científico a Psicología y, en el registro estético-humanista, a Latín y Griego" (Terán, 1998: 106-107). ${ }^{149}$

Desde enero de 1915 -y durante casi quince años-, los profesores que animaban la fracción cientificista encontraron una sólida plataforma de intervención y discusión en la Revista de Filosofía. Cultura, Ciencias, Educación, una publicación bimestral, fundada y dirigida por Ingenieros hasta su muerte a fines de 1925 (año en que la revista quedó a cargo de Aníbal Ponce). En un principio, el propósito de la Revista de Filosofía fue abordar con rigor científico los problemas "atemporales" de la cultura. Para ello difundió la producción de

\footnotetext{
${ }^{147}$ El doctorado se aprobaba con una tesis de unas treinta páginas aproximadamente. Por su parte, un número significativo de estudiantes de Derecho solía doctorarse en Jurisprudencia, luego de obtener el título habilitante para ejercer como abogados.

${ }^{148}$ En su estudio sobre la recepción argentina de Kant, Dotti (1992) identifica a Korn y Rivarola, junto con Antonio Dellepiane, Ernesto Quesada, Juan Chiabra y los matemáticos Camilo Meyer, Carlos Dieulefait y Enrique Butty, como las "figuras de mediación" en la reacción antipositivista local. Ésta tiene como marca común una vuelta a Kant desde encontradas doctrinas filosóficas como el neoidealismo, el neocriticismo, el neokantismo, el actualismo, el intuicionismo y las filosofías de la vida.

${ }^{149}$ Poco después, sólo tres materias serían propiamente filosóficas, pues Ética y Metafísica constituirían una misma materia.
} 
los profesores locales que simpatizaban con distintas vertientes ideológicas y logró una amplia circulación en los ambientes universitarios nacionales e internacionales -al punto que, según veremos en el sexto capítulo, la revista fue un punto de referencia para d'Ors y su proyecto de renovación de la cultura catalana-.

Pero en ese reconocimiento que Ingenieros alcanzaba como director de la Revista de Filosofía -y al poco tiempo como editor de la prolífica colección La Cultura Argentinatambién se jugaba su posición en el campo intelectual porteño. En 1915 acababa de regresar del "autoexilio europeo", que se impuso en 1911 en protesta por el veto del presidente de la nación a su cargo de profesor titular en la cátedra de Medicina legal de la Facultad de Medicina. Ese veto le negaba a Ingenieros la posibilidad de participar en el Consejo Directivo de la Facultad, pero sobre todo le impedía imprimir su impronta en una materia que -como Derecho laboral y Derecho político- tenía sensible importancia para los intelectuales que reconocían que el Estado debía legislar sobre la "cuestión social". Una muestra de la importancia que tenía la cátedra de Medicina legal es que, en el marco de la Reforma, son los socialistas y líderes reformistas José Belbey y Gregorio Bermann quienes procuran -y consiguen- la titularidad en la UBA y en la UNC, respectivamente.

Desde mediados de la década del diez, la Revista de Filosofía le ofrecía a Ingenieros un espacio desde el que visibilizar su capacidad intelectual y su condición para ocupar un cargo de profesor universitario titular. Pero Ingenieros perdería esa disputa, pues nunca lograría un cargo titular. Sí logró, en virtud de su cargo "interino" en el primer curso de psicología de la FFyL y de las condiciones de los estatutos universitarios decretados en agosto de 1918, ser incorporado a la Academia de Filosofía y Letras y ser electo vicedecano de la FFyL en el periodo 1918-1919. Pero a fines de 1919, renunció a todos los cargos en disconformidad con la modificación, que decidía del Consejo Directivo, de la terna de aspirantes a titular de la cátedra de psicología. A su vez, por entonces Ingenieros volvía a colocar en el centro de su intervención intelectual el posicionamiento ligado al socialismo, y desde entonces su revista intercalaba los artículos filosófico-científicos de profesores titulares e intelectuales prestigiosos con notas y manifiestos que proponían un abordaje izquierdista de los últimos acontecimientos políticos.

Pero no sólo la Revista de Filosofía procuró una caracterización cientificista y socialista de la filosofía, algunos estudiantes lo intentaron a través de diversos proyectos en los que Ingenieros desplegó su condición de “organizador cultural”. El primero parece haber 
transcurrido en 1914 con la revista Ariel y su convergencia entre socialismo científico y arielismo, a ello continuó la Universidad Libre. Pero además esa convergencia fue alentada entre 1916 y 1918 por Bermann, primero desde la revista del CE de la FFyL y luego desde el mismo centro.

\section{Nuevos filósofos}

En septiembre de 1916 llegaba a Buenos Aires José Ortega y Gasset para impartir una serie de conferencias sobre filosofía neokantiana. Su viaje, como mencionamos, era financiado por la Institución Cultural Española de Buenos Aires, la que en un principio había planeado el arribo de Unamuno. ${ }^{150}$ Julio Noé, quien desde 1916 entabló una estrecha amistad con Ortega, y al año siguiente participó de la fundación del Colegio, ha dejado un breve e interesante recuerdo del impacto que produjo la primera visita del filósofo madrileño:

El joven profesor que había sucedido a Salmerón en la cátedra de metafísica de la Universidad de Madrid vino a Buenos Aires a instancias de la Institución Cultural Española, que luego de traer a Menéndez Pidal intentó sin éxito hacer lo propio con Unamuno. [...] Poco sabía Ortega de nuestro país y de él poco se sabía entre nosotros. Mucho menos conocido entonces que otros conferenciantes de distintas nacionalidades y características -Guillermo Ferrero, Enrique Ferri, Anátole France, Clemenceau, Blasco Ibáñez, Valle Inclán, y el mismo Eduardo Marquina que llegó con él-, en un principio no despertó curiosidad sino en los estudiantes y en los escasos lectores de sus pocos libros. Bastaron ellos, sin embargo, para colmar el aula magna de la FFyL, y fue suficiente que disertara una vez para que sus oyentes quedaran deslumbrados. [...] Tanto fue el asombro que produjo su primera disertación que para escuchar la siguiente abigarrada multitud se agolpó a las puertas de la Facultad [...] Por primera vez la filosofía era un gran espectáculo público (Noé, 1993 [circa 1960]: 106-108).

Durante ese "espectáculo público", Ortega sentenció la caducidad de la matriz positivista, predominante aún en los estudios filosóficos sobre el hombre y sus "manifestaciones espirituales", impartidos en la UBA. ${ }^{151}$ Junto a ello, instruyó sobre la filosofía idealista (específicamente, el neokantismo de la Escuela de Marburg revisado por los primeros desarrollos de la fenomenología de Husserl) que debían tomar como guía quienes emprendieran la renovación del saber (Presas, 1986). Esta legitimación de la renovación

\footnotetext{
${ }^{150}$ Véase el artículo del mismo Unamuno "Mi fracasado viaje a esa Argentina" en La Nación, 25/07/16. Sobre la Institución y Ortega, véase Campomar (2009).

${ }^{151}$ Los cursos filosóficos que Ortega impartió en la Argentina en 1916 y 1928 fueron publicados en Ortega y Gasset (1996).
} 
académica iniciada por Rivarola y Korn no podía resultar indiferente a quienes comenzaban a conformar la "nueva generación” que en 1918 daría vida a la Reforma Universitaria.

Durante la visita de Ortega, la Revista de Filosofía optó por una posición de indiferencia ante la definición de la filosofía que proponía el madrileño: sólo reprodujo el breve resumen de las conferencias que José Gabriel había publicado en P.B.T. Pero, meses después de la partida de Ortega, la revista comenzaría a publicar artículos sumamente críticos del antipositivismo y ello sería una constante en los años siguientes.

En los días que Ortega se encontraba en la Argentina, no fue Ingenieros ni su revista los que refutaron el antipositivismo ortegiano, sino uno de sus jóvenes discípulos, Alberto Palcos. Este joven que encontramos dirigiendo la revista de los arielistas científicos se encargó de explicitar las distancias irreconciliables que separarían a la "verdadera filosofía", el cientificismo, tanto de la prédica de Ortega como de las corrientes kantianas. En la breve nota que publicó en la sección "Filosofía y Psicología" que tenía a cargo en Nosotros, Palcos ofrecía una rápida presentación de las cuestiones que enfrentarían durante los próximos años a cientificistas y antipositivistas. Para Palcos, los últimos sostenían que

mediante la racionalidad el hombre se aniquila como organismo y como materia y se levanta como razón y somete nuestras pasiones y nuestras apetencias [...] las ciencias no penetran en los dominios de la filosofía, la filosofía se reserva el derecho de analizar los fundamentos de las ciencias que bien pueden reposar sobre arenas movedizas (Alberto Palcos, "José Ortega y Gasset. El sentido de la filosofía”, Nosotros, no 87, agosto de 1916, p. 204).

Según Palcos, estas tesis no construían más que una "fillosofía mística", acusación no sólo recurrente en el tratamiento de Kant, Bergson y Ortega realizado por la Revista de Filosofía, sino también expuesta sistemáticamente por Ingenieros primero en sus Proposiciones sobre el porvenir de la filosofía (1919) -suerte de programa cientificista que concedía un lugar marginal a las preocupaciones antipositivistas- y luego en Emilio Boutroux y la filosofía francesa (1922) -donde exponía las inconsistencias y el desinterés social que el antipositivismo habría producido en la academia francesa-. En cuanto a Ortega, Palcos señalaba, como lo venían haciendo la Revista de Filosofía y Nosotros, la importancia de la renovación cultural laica propiciada por aquel. Pero ese señalamiento no le impedía afirmar que el problema del madrileño era que 
no está bien empapado en la médula de las doctrinas evolucionistas y [por ello] no es un filósofo de verdad sino un literato de la filosofía. En efecto: el determinismo y el evolucionismo, lejos de hallarse en decadencia, pueden considerarse como las dos conquistas más valiosas de la filosofía contemporánea (Idem, p. 205).

El joven polemista, que al año siguiente participaría de la fundación del PSI, reconocía que la cultura científica se encontraba cuestionada por la barbarie de la Gran Guerra, pero consideraba que se trataba de un eclipse pasajero que no debía conceder la instalación de filosofías que descartasen el estudio científico - determinista y evolucionista- de lo social para proponer en su lugar planteos místicos y literaturizantes. Ya desde su participación en el Centro Ariel, Palcos había aprendido que la batalla a favor de una filosofía ligada a la ciencia y el socialismo debía darse en distintos planos: a través de conferencias, de ediciones de revistas y de debates sobre los planes de estudio. Y mientras Palcos planificaba la salida de la Revista Socialista, la Revista de Filosofía comenzaba a dedicarse sistemáticamente tanto a refutar las "seudo-filosofías kantianas" entre las que se encontraba la de Ortega como a ironizar sobre ellas. ${ }^{152}$

Iniciando la refutación, de corte sociológico, del antipositivismo que sistematizaría en su Emilio Boutroux..., aparecía en el número de marzo de 1917 de la Revista de Filosofía "El terrorismo filosófico militante" (originariamente publicado el mes anterior en La Nota) de Matías Calandrelli. Además de anudar la filosofía a la ciencia, allí se buscaba separar claramente a aquella de la poesía, y para ello declaraba de los filósofos como Ortega que

se hacen un lío porque no comprenden. Y no comprenden porque no saben: porque la disciplina científica es el antídoto por excelencia de la anarquía mental. Es tan imposible comprender la ciencia a través de los filósofos, como aprender el álgebra leyendo versos de Hugo. Y por eso, indisciplinados e ignorantes como ciertos obreros sociales, los paladines del terrorismo cojean todos del mismo pie como estos últimos, es decir, que se vuelven tan impertinentes y agresivos como ellos.

Así, pues, el terrorismo filosófico, trasunto espúreo del misticismo ignarocientífico-poético-religioso en que se inspiran las modernas "filosofías", es un producto legítimo de la indisciplina mental. Su carácter terrorífico deriva de la misma "incomprensión" ignorante que enciende las mechas de los dinamiteros (Revista de Filosofía, marzo de 1917, pp. 313-316).

A esa equiparación del antipositivismo con el "terrorismo filosófico" se sumaba unos meses

\footnotetext{
${ }^{152}$ Una clara muestra de esa resistencia a las corrientes antipositivistas la ofrecen los artículos que componen la sección "Filosofía: Ortega, Spengler y Croce" de la edición fascimilar de la Revista de Filosofía preparada por Rossi (1999: 345-473).
} 
después el cordobés Raúl Orgaz. De éste la Revista de Filosofía publicó en su número de enero un artículo contra la "filodoxia" que se prolongó en el número siguiente. El segundo artículo comenzaba afirmando:

El agnosticismo y el anti-intelectualismo invasores -característicos de nuestros tiempos- han dado a las ciencias cierto misticismo apacible, que tomando pie en la filosofía de la intuición se remonta a los conceptos de indeterminado, de inconsciente, de irracional, rehabilitándolos, para aspirar a una síntesis éticoestética del mundo (Raúl Orgaz, "Filosofía y filodoxa", Revista de Filosofía, marzo de 1918, p. 96).

Por su parte, Gregorio Bermann, otro arielista que era partidario de las mismas críticas y había aprendido con Palcos la importancia de las iniciativas juveniles colectivas, llevaba ese tipo de críticas a los estudiantes de Filosofía y Letras.

\section{Verbum y la disputa por la resonancia social de la filosofía}

Es preciso que los jóvenes dejen oír sus voces expresivas, no sólo en los dominios generales de la Ciencia y de la Filosofía, sino en la aplicación de éstas a todos aquellos órdenes contemporáneos de la vida que nos afectan, con preferencia de nuestro ambiente y de nuestro país. Y tanto como ello, es para nosotros importante, los diferentes estadios mentales, las manifestaciones íntimas, los anhelos inexpresados, los grandes ideales de la juventud, todo este conjunto de emociones y de ideas que se agitan con vehemencia en las almas juveniles, constituyendo su más preciado tesoro. "Nuestra revista", Verbum, 1916

Luego de cursar algunos años de Medicina, Gregorio Bermann comenzó a combinar esos estudios con una inquietud -que ya no abandonaría- por las cuestiones filosóficas. A partir de 1914 asistió a los cursos de Filosofía que se dictaban en la FFyL, al tiempo que se convirtió en un asiduo visitante de Ingenieros.

En abril de 1916 consiguió que el CE de esa facultad le asignara la dirección de su órgano, Verbum. El joven dirigió tres números dobles: el no 31-32 (marzo-abril de 1916), $n^{\circ}$ 33-34 (agosto-septiembre de 1916) y no 35-36 (mayo-junio de 1917). En ellos participaron los veinteañeros: Adolfo Scilingo como secretario de redacción (reemplazado por Luis Bontempi, 
compañero de Bermann en la Universidad Libre), Clemente Maradona como administrador y Ramón Columba -quien en los años siguientes sería un pionero en la edición de historietas argentinas- como colaborador artístico. La revista contó con un cuerpo de reactores compuesto, por primera vez, por varias mujeres: junto a Carmelo Bonnet, Gregorio Halperín y Romualdo Ardissone, se encontraron Mercedes Daus, María Alcira Villegas y Octavia Josch. Asimismo, Palcos colaboró a través de algunas reseñas.

En comparación con los números anteriores y posteriores de Verbum, los tres dirigidos por Bermann tuvieron propusieron una revista con un perfil "más estudiantil", ligado a la filosofía cientificista y a un compromiso social de cuño socialista. La "nueva" Verbum trazaba el mapa de sus aliadas editoriales a través de elogiosas reseñas a Nosotros, el periódico -entonces semanal- El Universitario, la Colección Ariel de García Monge e Ideas. Ésta era caracterizada como una revista "tan similar a la nuestra bajo muchos aspectos", ${ }^{153}$ e Ideas respondía el saludo afirmando en una reseña anónima que "el esfuerzo merece los más decididos elogios. La dirección cuida con visible interés la revista y su contenido es, en general, valioso. [...] Deseamos que Verbum continúe siempre en la ruta que Gregorio Bermann, su actual Director, señala con acierto a la revista". ${ }^{154}$ Sobre esa "ruta" se lee en el primer número que dirigió Bermann:

VERBUM realizará, demás está decirlo, el programa clásico de toda revista estudiantil: será intérprete y defensora de los intereses del Centro; publicará apuntes de los mejores profesores. Mantendrá también relaciones con las otras publicaciones estudiantiles, y se interesará del movimiento estudiantil mundial, y americano, especialmente. Se preocupará por el movimiento intelectual de sus propios alumnos y egresados. [...] Anhelamos que nuestra Revista sea un documento vivo y palpitante de la juventud que milita rumorosa en la Universidad ("Nuestra revista", Verbum no 31-32, marzo-abril de 1916, p. 103).

Como ya lo había propuesto en Ariel, Bermann buscó que Verbum se convirtiera en un órgano de discusión sobre la relación entre universidad y sociedad, y en particular sobre la necesidad de una formación filosófica ligada a la ciencia y a la función social. La nueva Verbum comenzó a tener animados editoriales, además de dos nuevas secciones: una dedicada a reseñar libros, folletos y revistas, y otra encargada de informar sobre la vida universitaria. El primero de los tres números dirigidos por Bermann llevó un editorial que homenajeaba a los

\footnotetext{
153 "Ideas. Órgano bimestral de la sección Estudiantes Universitarios del Ateneo Hispano Americano.- (Director: J. M. Monner Sans)", Verbum, no 31-32, marzo-abril de 1916, p. 98.

154 “Verbum”, Ideas no 6, julio de 1916, pp. 333-334.
} 
patricios revolucionarios que protagonizaron la independencia del país y otro que destacaba la importancia de una ley de profesorado que habilitara a los egresados y las egresadas de la facultad a dar clases en escuelas medias. El siguiente número reclamó desde su editorial una reforma del plan de estudios que atendiera a los problemas sociales. Y el tercero delineó el tipo de "maestros" que debían buscar los jóvenes. Declaraba ese editorial:

Los universitarios, profesores, alumnos y profesionales, sentirán en toda su amplitud el dicho vulgar: a una mayor cultura, corresponde una mayor capacidad para la acción, más deberes que cumplir. Los universitarios, ante la nueva función de la universidad, que se vislumbra, tendrán una enorme misión que llenar. Este movimiento de renovación de la Universidad tiene, en nuestro sentir, una alta finalidad democrática. La Universidad perderá las características adustas, de privilegio, que le ha trasmitido la tradición hispano-colonial, y conservando el sentido de un alto instinto de estudio, se acercará al pueblo, le servirá con su trabajo espiritual; la Universidad se refundirá con el pueblo, y surgirá por encima, del mismo modo que sobresale la cabeza del nadador por encima de las aguas uniformes, ligeramente encrespadas aquí y allá: tal es el ideal ("En busca de maestro", Verbum, no 35-36, mayo-junio de 1917, p. 2).

Las preocupaciones que despliega el manifiesto serán centrales, desde el año siguiente y durante décadas, para las fracciones más radicalizadas del movimiento reformista latinoamericano. De ahí que no sorprenda que ante los primeros conflictos en la UNC Bermann devenga el más comprometido organizador de instancias porteñas de apoyo a los estudiantes huelguistas cordobeses.

En la trama intelectual local, el llamado a construir una universidad social que propone el manifiesto es -al igual que el proyecto de un arielismo socialista de 1914- un claro testimonio no sólo de que habían llegado a la UBA los hijos de las clases medias que participaban de la animada cultura de izquierda porteña, sino también de que esos hijos tenían un importante guía en Ingenieros. En efecto, en 1917 Bermann seguía mostrándose partidario de la cultura científica, pero ya no la enmarcaba en el ideal rodoniano, sino en las tesis expuestas por Ingenieros en 1916 en su conferencia "La filosofía científica en la organización de las universidades"155 y en las lecciones de eticismo laico que éste había dictado en la facultad en junio de 1917, cuando reemplazó a Rivarola en la cátedra de Ética y metafísica. Esas lecciones fueron publicadas meses después bajo el título Hacia una moral sin dogmas,

\footnotetext{
${ }^{155}$ Para un análisis de la reestructuración de las universidades propuesta por esa conferencia que se volverá una referencia del ala radicalizada de la Reforma, véase Villavicencio (1998).
} 
gracias -según la "Advertencia” que colocó Ingenieros al inicio- a la versión taquigráfica que le acercó el CE de Filosofía y Letras, entonces dirigido por Bermann.

Más precisamente, un documento conservado en el Fondo personal José Ingenieros del CeDInCI sugiere que la pronta publicación de ese libro, así como el editorial "En busca de maestros" publicado en Verbum, eran otra de las recurrentes boutade que proponía Ingenieros, en este caso con la ayuda de Bermann y contra Rivarola y quienes negociaban el ingreso de profesores católicos a la FFyL. En un diario personal, Ingenieros anota una larga narración que vale la pena transcribir en su casi totalidad, pues es uno de los pocos documentos sobre el complejo y frágil "consenso liberal” en la trama institucional de la FFyL:

Viernes 11 de Mayo de 1917 el Dr. Rivarola me hizo llamar por teléfono, por el secretario Juliánez, pidiéndome consentimiento para proponerme como suplente suyo en la cátedra de ética y metafísica.

Sorprendido, fui inmediatamente a la Facultad y le dije a Rivarola que yo no estaba en edad ni posición de aceptar otra suplencia. Rivarola, desconcertado por mi actitud un poco rezongona, me dijo que me eligió para defender su cátedra contra algún mal candidato a suplente que podría colarse; ésto, para halagarme.

Me contó, en seguida, que iba a proveerse la terna de psicología y comprendí que lo anterior era para que no me enojase oliendo to claramente que estaba dispuesto nombrar a otro y temía Rivarola que yo me enojase.

Me hice el desentendido y le manifesté que suspendiera mi propuesta (que pensaba hacer en la sesión del 12); a fin de pensarlo, y decidido a no aceptar lo que me pareció una simple tramoya de tontos.

En la misma conversación me dijo el doctor Rivarola que varios curas, graduados en Roma, se proponían entrar de profesores en la Universidad; me explicó que su competencia en latín era evidente y me dijo que ya andaba en tramites un cura tucumano Molas Terán (Manuscrito, Fondo personal José Ingenieros).

Sabemos que, a pesar de "su edad y su posición” -que, como mencionamos, construyó con sus libros pero también con la tarea que se asignó de "organizador cultural" de la colección La Cultura Argentina, la Revista de Filosofía y los grupos estudiantiles-, Ingenieros nunca ganaría una cátedra titular, ni evitaría que los partidarios de la cultura católica ingresaran a la FFyL. Pero si aceptaba la suplencia, lo hacía acordando previamente con Bermann una forma de no caer en esa "simple tramoya de tontos". En efecto, en los días en que iniciaba el dictado del curso, aparecía un nuevo número de la revista del CE y ella se abría con el citado "En busca de maestros", manifiesto que reponía la impronta de Hacia una moral sin dogmas. A su vez, al terminar el curso, Ingenieros tenía lista la publicación de esas lecciones laicas y cientificistas -que sólo podían escandalizar a los curas que negociaban su ingreso a la 
facultad- como libro y donaba ciento cincuenta ejemplares al CE. Y Bermann, ya presidente del CE, reforzaba el intento de desarmar el pacto de Rivarola con los católicos a través del envío a Verbum de una elogiosa reseña de Hacia una moral sin dogmas preparada por Mouchet y una nota también elogiosa del profesor. La nota aclaraba que el CE había solicitado a Ingenieros licencia para publicar las lecciones, pero "el conferenciante con más tino decidió, a instancias nuestras, publicarlas. De ahí que, aunque en pequeña parte, el Centro ha tomado participación y se complace grandemente en haber sido una causa ocasional de la publicación de este libro", y luego precisaba que los ciento cincuenta ejemplares donados por el "maestro" habían "sido totalmente distribuidos entre los socios y alumnos de Ética y Metafísica" dando "ocasión al Centro para manifestar a Ingenieros el afecto y el aprecio que a él nos unen". ${ }^{156}$

Antes de ocuparnos de la presidencia de Bermann en el CE, detengámonos en la identidad estudiantil que impulsó en los números de Verbum y que Ingenieros -como lo había hecho en 1914 con la revista Ariel-ayudó a consolidar a través del envío de artículos inéditos, en este caso sobre los "revolucionarios de mayo".

El n 31-32 de Verbum se abre con "1816-1916", un editorial que exalta a los patricios revolucionarios. Ya la primera oración toma partido por una disciplina histórica que, alejada del diletantismo literaturizante, se preocupe por el descubrimiento de leyes "científicas": "Dentro del juego de las leyes naturales en que se desenvuelve el devenir de los pueblos, los patricios del año 10 encarnaron virilmente las aspiraciones y necesidades de la época en que les correspondió actuar". Luego exalta el proyecto ilustrado de los patricios ("la libertad interior y la grandeza del alma, el bienestar para todos, la elaboración íntima de la personalidad nacional") frente los caudillos, la oligarquía y "la maraña de la mentalidad indígena”. Y concluye: "al forjar los ideales de mañana, en marcha ascendente hacia su liberación económica y cultural, las naciones de hoy se hacen dignas del pasado noble del que se vanaglorian. Vamos incubando y realizando así, como hace una centuria, nuestra revolución pacífica y honda, por la cual las sociedades de hoy culminarán algún día en la verdad y en la justicia". ${ }^{157}$

El siguiente texto, "La ley del profesorado secundario. La Facultad de Filosofía y letras y la formación del Profesorado", discute con quienes piensan que la facultad debe ofrecer un saber desinteresado y reclama que la facultad comience a emitir un título

\footnotetext{
156 Enrique Mouchet, "Hacia una moral sin dogmas de José Ingenieros", Verbum, no 37-38, p. 92.

157 “1816-1916”, Verbum, no 31-32, p. 2.
} 
habilitante para enseñar. Se propone allí que, lejos de disminuir el conocimiento, la enseñanza permitiría a los estudiantes pobres financiar sus estudios pero, sobre todo, devolverle a la sociedad lo que han aprendido. Luego aparece el largo ensayo "Los ideologistas argentinos", en el que Ingenieros aborda las corrientes radicalizadas que influyeron en los padres de la independencia. La colaboración de Ingenieros cumplía muy bien la intención de Bermann de abrir el debate sobre la relación entre saber y política, pues aquel reconstruía la continuidad entre las ideas filosóficas y la práctica política de quienes protagonizaron la Revolución de Mayo. $^{158}$

El mismo número de Verbum vuelve a ocuparse de la relación entre saber y política en sus últimas páginas. La sección de reseñas trascribe la realizada por Ingenieros -aparecida originariamente en la Revista de Filosofía- al libro La universidad social que acababa de publicar Rivarola. Por su parte, Bermann firma una larga y elogiosa reseña de la conferencia de Ingenieros La filosofía científica en la organización de las universidades. Respecto de esta conferencia, que en los años posteriores deviene uno de los manifiestos del ala radicalizada de la Reforma, Bermann aprovechaba la oportunidad para insistir en la defensa del evolucionismo frente al antipositivismo:

Este ensayo, brillante como los que sabe escribir Ingenieros, marca, sin duda alguna, un jalón principal en el pensamiento contemporáneo que a estas cuestiones se dedica. [...] La transformación de la Universidad, como de lo demás, no depende de tales o cuales hombres, sino que estos son factores de toda una evolución, de la que el gran motor es, sintetizando, la Filosofía Científica. Haber dejado esto claramente establecido, es uno de los méritos de este trabajo. Una vez más, se pone de manifiesto la grandísima influencia de la Ciencia en la redención del hombre (Gregorio Bermann, "La filosofía cientifica en la organización de las universidades. Por José Ingenieros", Verbum n 31-32, marzoabril de 1916, p. 92).

Al igual que Ingenieros y Palcos, Bermann no descontaba la posibilidad de la redención del hombre y una de las herramientas para ello era la consolidación de una filosofía cientificista y socialista, que no podía más que oponerse a las "seudo-filosofías" antipositivistas (Croce, Gentile, Bergson, Ortega y Gasset, d'Ors y los filósofos identificados con la "vuelta a Kant") así como al griego y el latín en tanto núcleos del saber filosófico. En efecto, en su reclamo de un nuevo plan de estudios de la carrera de Filosofía, el editorial de Verbum n n 33-34 señalaba

\footnotetext{
${ }^{158}$ Ingenieros publica en 1918 una reformulación de este artículo en el primer tomo de La evolución de las ideas argentinas.
} 
las dos grandes deficiencias del plan vigente. La primera residía en los requisitos excesivos para obtener el diploma de profesor que habían establecido los profesores que creían que la habilitación para la enseñanza significaba la mercantilización del saber, en lugar de una herramienta para que los estudiantes prosiguieran sus estudios. La segunda deficiencia consistía en las "maravillosas virtudes" atribuidas al latín, "que sería algo así como un bálsamo de Fierabrás para el espíritu". ${ }^{159}$ Bajo la obligatoriedad de las lenguas clásicas que estipulaba el plan vigente se agazaparían tanto la vinculación de la filosofía con la religión como la oposición a la ciencia y las problemáticas sociales, como si el latín enseñara "a razonar mejor que la Lógica, disciplinaría la mente mejor que las matemáticas y [fuera] tan eficaz como las Ciencias Naturales para desarrollar la observación”. ${ }^{160}$

El siguiente número vuelve sobre el tema a través de "Sin comentarios", título que agrupa un fragmento de "Federación de Estudiantes Católicos" del estudiante cordobés Juan Díaz Salazar, publicado en El Universitario, y la respuesta que apareció en La Vanguardia, "El peligro clerical en la Universidad". Una polémica que es interesante porque traza la oposición entre cultura católica y cultura liberal que, si bien tendrá su expresión más álgida en Córdoba, también recorría a la FFyL.

Presentada por Verbum como "un extenso plan de invasión clerical y religiosa en la enseñanza", la nota de Díaz Salazar procura el ingreso de los profesores católicos en la universidad para remediar "el injusto desaire hecho hace algunos años a la Universidad Católica". ${ }^{161}$ Y especifica:

En la Facultad de Filosofía, que es, por su espíritu la llamada a ejercer mayor influencia moral en el porvenir, podrían tener acceso a las cátedras de lenguas muertas, filosofía e historia, muchos venerables sacerdotes argentinos de reconocida competencia; ya se han iniciado gestiones en este sentido y es seguro que muy en breve las cátedras de latín, lógica, historia, etc., tendrán en sus suplencias virtuosos sacerdotes ("Sin comentarios", Verbum, n” 35-36, mayojunio de 1917, p. 57).

A continuación, la respuesta del diario del PS, con la que simpatizan estos números de Verbum, explica que "no pueden estar en la universidad, porque con ellos está el dogmatismo, su moral eunuca, porque ellos constituyen un pesado lastre para el progreso institucional del

\footnotetext{
159 "El plan de estudios", Verbum, nº 33-34, mayo-junio de 1916, p. 5.

${ }^{160}$ Ibid., pp. 5-6.

161 Para un análisis de intento, véase Devoto (2009).
} 
país. Ya es bastante con que se hayan erigido en dueños del cerebro y del corazón de la juventud rica de la república, inoculándoles su seudociencia, su moral, el espíritu de casta, aislándola de las nuevas corrientes idealistas". ${ }^{162} \mathrm{Y}$, después de nuestro recorrido, es claro que ese novedoso "idealismo" es el cientificismo socialista y no el orteguismo kantiano.

El siguiente número de Verbum ya no tiene esta impronta militante ni mujeres en su equipo de redacción. Bermann ganaba la presidencia del CE y la revista quedaba a cargo de Jacinto Cuccaro y Juan Probst, los dos estudiantes que habían encabezado la lista rival y que, en términos de Bermann, proponían un academicismo "sin resonancia social". Desde entonces, prima en Verbum la recepción del idealismo kantiano y la asociación de la actividad filosófica con una reflexión abstracta sobre la "condición espiritual" del hombre, enfrentabda abiertamente a la "condición social" del hombre propuesta tanto por Ingenieros como por los jóvenes Bermann y Palcos.

Más precisamente, los números de Verbum dirigidos por Cuccaro y Probst deben leerse como una decidida reacción contra la universidad social a la que Bermann intentaba allanarle el camino. En "En busca de maestros" de Verbum no 35-36, Bermann denunciaba la apatía que se esconde en la critica a la universidad formulada por Carmelo Bonnet en "No sabemos pensar" (texto aparecido en Nosotros). En el número siguiente Cuccaro muestra sus simpatías ante ese exdirector de la revista y egresado de la facultad, al republicar el artículo de Nosotros con una provocadora nota de editor. Pero el enfrentamiento es aún más explícito en la carta al lector que, bajo la firma de "Verbum", abre el número. En contraste con la identificación de las deficiencias de la formación universitaria y la apelación a la acción para resolverlas que promueve Bermann, se afirma allí que la preocupación del estudiantado gira en torno del "duelo entre materialismo e idealismo" sobre el que no se tomará partido. Pero la opción por el idealismo es explícita, pues, apelando a citas en latín y a autores del idealismo alemán, se llama a la meditación y tolerancia que eviten "perder el timón”. Sostiene la "Carta a guisa de confesión":

Tengo entendido que lo que más preocupa a tu mente, en estos días, es la embrollada madeja de la Metafísica; oyes hablar de materialismo, intelectualismo, intuicionismo... y otras semejantes palabras en ismo, y te es forzoso detenerte, en tu apacible vida que quisieras ver deslizar tranquilamente, para meditar un tanto y, tu indiferencia imposible, debes afanarte en darte una explicación (Verbum, "Carta a guisa de confesión”, Verbum n ${ }^{\text {o } 37-38, ~ s e t i e m b r e-o c t u b r e ~ d e ~ 1918, ~ p p . ~ 1-2 ; ~}$

162 “Sin comentarios", Verbum, n” 35-36, mayo-junio de 1917, p. 58. 
destacado del texto).

Partiendo de que es innecesaria su discusión, la carta desdibuja el compromiso de refundir la Universidad con el pueblo que Bermann formulaba a la comunidad educativa y que, en esos mismos días, intentaba llevar adelante desde el CE. Los siguientes números de Verbum practican un inquebrantable silencio ante el llamado ingenieriano de "En busca de maestros": "a una mayor cultura, corresponde una mayor capacidad para la acción, más deberes que cumplir. [...] La Universidad [...] se acercará al pueblo, le servirá con su trabajo espiritual” (Verbum $\mathrm{n}^{\circ} 35-36$, mayo y junio de 1917, p. 2).

Puesto en primer plano el enfrentamiento entre corrientes filosóficas, las pocas referencias que, desde el $n^{\circ} 37-38$, realiza la revista a cuestiones gremiales y a la función social del saber provienen de Bermann o son respuestas irónicas a éste. Verbum n n 39-40 abre con una larga nota titulada "Sobre la validez de nuestros títulos" en la que aquel, dando pruebas de ese ímpetu militante varias veces enunciado, informa sobre la fundación de una Liga pro Ley de Profesorado Secundario (compuesta por varias asociaciones estudiantiles). Esta iniciativa es criticada por Probst desde Verbum y luego desde el CE. Al igual que para los jóvenes que en los años siguientes hegemonizarán Verbum y el CE, para ese novecentista y futuro titular de la cátedra de Literatura alemana, el problema a discutir no es la "utilidad" del título sino la calidad de la enseñanza, pues los egresados de la FFyL no deben aspirar a la docencia sino a la "dirección espiritual del país". Y para ello la facultad tendría que ser más exigentes con los ingresantes, sobre todo con las mujeres que provienen de las escuelas normales. Sostiene el programa con el que en 1920 Probst llega a presidente del CE:

Hay que empezar por nosotros mismos. Al lado de pocos estudiantes que trabajan seriamente, hay muchos, demasiados, que no lo hacen. Cuantitativamente aumenta año por año la concurrencia a las aulas, pero cualitativamente, no descenderá? Las condiciones de ingreso deben hacerse más severas aún, para permitir una mayor selección desde el principio. [...] [Tenemos que] evitar que se convierta en una escuela normal con algunas pretensiones superiores (Juan Probst, "Las elecciones de renovación de la C. D.", Verbum, no 53, marzo-mayo de 1920, p. 93).

El pronunciamiento antipositivista que prevalece en Verbum desde 1918 estará acompañado por ese tipo de representación del estudiante, al tiempo que casi no tiene eco el debate sobre los reclamos de los estudiantes cordobeses. Al punto que la única referencia a los conflictos que hicieron estallar la Reforma proviene de una colaboración de Bermann, en un número que 
también reproduce el saludo de Ingenieros a una de las iniciativas que aquel propuso desde la dirección del CE. ${ }^{163}$

\section{El arielismo socialista en el Centro de Estudiantes de Filosofía y Letras}

Las elecciones que Bermann ganó en mayo de 1917 estuvieron precedidas de un conflicto estudiantil que fue significativo en la conformación de una reacción antipositivista estudiantil. Como en el resto de las facultades, el presidente anual del CE se elegía en marzo y asumía en abril. Cuando se realizaron las elecciones en 1917, ganó la lista encabezada por el ateneísta Jorge Max Rohde, pero la lista opositora, encabezada por Camaño y Narciso Binayán no reconoció las elecciones y fundó un centro paralelo. Para resolver el conflicto, la FUBA envió a una comisión encabezada por el joven del Mazo, quien decidió llamar a nuevas elecciones. Éstas dieron como presidente a Bermann y como secretario a Luis Bontempi.

En el mes en que ambos asumían sus cargos, José Gabriel convencía a Rohde y a otros dos miembros de la comisión directiva del Ateneo de Estudiantes Universitarios, Tomás Casares y Adolfo Korn Villafañe, de que fundaran un grupo estudiantil antipositivista, el Colegio Novecentista. De este modo, la recepción del novecentismo orsiano que venían realizando Taborga y Gabriel convergía con el tipo de preocupación esteticista que -como vimos en el segundo capítulo- predominaba entre 1916 y 1917 en el Ateneo, y de esa convergencia nacía una suerte de CE de Filosofía y Letras paralelo y comenzaban a editarse los Cuadernos, publicación que, como mencionamos, estaba inspirada en los Quaderns dirigidos por d'Ors en Barcelona.

Si bien la mención de este conflicto en torno de la presidencia del CE ya sugiere que, desde la fundación del Colegio, quedan esbozados dos frentes filosóficos rivales, otras pruebas de esa rivalidad se encuentran tanto en las páginas de la Revista de Filosofía como en las de Ideas, Cuadernos, Nosotros, Verbum y La Cureta. En cuanto a la primera, a mediados de 1917, Bermann, en su condición de presidente del CE, había enviado una carta en solidaridad con el profesor español de lógica Julián Besteiro, preso y condenado a muerte por participar de la organización de una huelga obrera general. ${ }^{164}$ En una breve nota, la Revista de

163 Bermann, "Movimiento estudiantil de Córdoba: fundación de la Federación Universitaria Argentina", Verbum, $\mathrm{n}^{\circ}$ 41-42, marzo-abril de 1918, pp. 66-73.

${ }^{164}$ Besteiro tenía a cargo la cátedra de Lógica en la Universidad Central de Madrid, donde Ortega impartía Metafísica. Ambos se habían formado en el Instituto Libre de Enseñanza y habían sido becados para asistir a los cursos de neokantismo en Marburgo, Alemania. Si bien en 1910 Besteiro y Ortega habían participado del Partido Radical que dirigía Lerroux, durante ese viaje Besteiro se entusiasmó con el marxismo de Kautsky, y a su 
Filosofía destacaba “el bello gesto" de los estudiantes de la FFyL, reproducía la carta enviada a Besteiro por Bermann y la respuesta desde la cárcel de aquel. Pero también Ingenieros aprovechaba ese saludo para defender explícitamente el proyecto de una filosofía "idealista" comprometida con lo social que promovían sus libros y que su discípulo, en rivalidad con los novecentistas, buscaba instalar entre los estudiantes de Filosofía y Letras. Declaraba Ingenieros:

[...] no podemos sino mirar con simpatía a todo hombre que sabe comprometerse y sacrificarse por sus ideales; y ya que es la posteridad, y no los contemporáneos, quien puede juzgar mejor, sólo podemos aplaudir el saludable ejemplo de carácter del profesor Besteiro. Para él no es la filosofía un entretenimiento profesional, ni una cavilación erudita, ni un camino para hacer carrera, ni un modo de disfrazar con palabras las creencias que es peligroso profesar; tampoco es un refugio para eludir los compromisos inherentes a la acción militante ("Estudiantes de Filosofía y Letras: Mensaje a Julián Besteiro.-Buenos Aires, 1917”, Revista de Filosofía, año IV, vol. 7, p. 147; reproducido en Verbum, no 41-42, marzo-abril de 1918, p. 73).

Esa acción militante que hermanaba las preocupaciones filosóficas de Besteiro, Bermann e Ingenieros era saludada tanto en una publicación de amplia circulación como la Revista de Filosofía como en otra publicación de importante peso entre los universitarios como Verbum. En cambio, la otra revista de amplia circulación entre los estudiantes, Ideas, publicaba una breve nota que ridiculizaba la militancia de Bermann. En el apartado "En la FFyL" de Ideas no 11, "Max" (Rohde), el ateneísta que acababa de ser desplazado de la presidencia del CE, firmaba "La inútil cuestión de títulos", una nota que calificaba como un "enojoso asunto" la campaña que encabezaba Bermann por la habilitación de los títulos de esa facultad para la enseñanza y no dudaba en identificar a la filosofía como parte de una "cultura desinteresada y complementaria de otras disciplinas".

Al iniciar su campaña, Bermann había redactado un largo artículo en el que no pueden ser más claras sus diferencias con Probst y los estudiantes que liderarán el CE. Allí declaraba:

La creación de la FFyL ha sido el fruto de nobles anhelos nacionales. Sería un laboratorio nacional de trascendentales resultados idealistas, fuente perenne de belleza y verdad. Cultura filosófica, vale decir, conocimiento integral y profundo de la realidad, y cultura estética, que es amor a lo bello, llegar a

regreso en 1912 se convirtió en un activo militante del PSOE. Ortega, por su parte, hasta 1917 participó de las iniciativas republicanas de Melquiades Álvarez, liderando la Liga de Educación Política y el semanario España. 
formar los espíritus armónicos y sabios [...] pero ¿basta acaso esa cultura con que se adorna a unos cuantos elegidos, para justificar su existencia? No podemos creer que el rol de la Facultad se agote con la formación de unos cuantos espíritus selectos, sibaritas del pensamiento, plumas ágiles. [...] La FFyL debe ser uno de los más decididos cofactores en el realzamiento del ambiente groseramente materializado, que entre nosotros ha amenazado asfixiar todo germen de vida superior.

Para ello, los egresados de esta casa deben reobrar intensamente sobre el medio en que se hallan. Y qué mejor medio de influir sobre el ambiente que la educación de la juventud en la edad en que se es más plástico y accesible a las ideas y sentimientos nobles [...]? ¡Dedicarse a la formación, no es rebajarse, no es función accesoria, sino principal! (La Dirección, "La ley del profesorado secundario. La FFyL y la formación del profesorado", Verbum, no 31-32, mayojunio de 1916, pp. 10-11).

A ello "Max" respondía de modo breve y tajante: "Tal criterio es una consecuencia del positivismo ambiente, Filosofía y Letras debe ser una Facultad inútil, que expida títulos inútiles (como en la actualidad) para ganar sueldos. Su misión consiste en difundir una cultura desinteresada y complementaria de otros diplomas, adquiridos en los institutos de 'entrenamiento áureo', como ser la Facultad de Derecho y Ciencias Sociales". ${ }^{165}$ A este cuestionamiento se sumaba el ateneísta Francisco de Aparicio. Si bien en un comienzo Ideas saludó a Verbum, luego de Aparicio criticó el peso del cientificismo, e incluso afirmó que, a diferencia de los Cuadernos, Verbum no innovaba culturalmente.

Casi un año después, se incorporaba otra participante a esos dos frentes políticofilosóficos, La Cureta, órgano que fundó el joven José Belbey para radicalizar los reclamos reformistas de los estudiantes porteños de Medicina. En su primer número, fechado en julio de 1918, La Cureta publicó “El novecentismo”, una nota en la que el joven Binayán crítica al antipositivismo del Colegio porque sólo el cientificismo puede procurar la resolución de los problemas sociales.

Más allá de los particulares pareceres de los distintos grupos estudiantiles, estos saludos, críticas y cambios de valoración de las iniciativas universitarias son significativos porque muestran que las batallas de ideas no tienen en las revistas un mero soporte, sino una plataforma desde la que construir, enunciar y revisar la identidad del estudiante. Específicamente, a través de las revistas se conformaron -ya antes del estallido de la Reforma- dos frentes con posiciones rivales sobre la función social del egresado de la FFyL, a saber: la de profesor de enseñanza secundaria o la de director espiritual del país. A

${ }^{165}$ Max, "La inútil cuestión de los títulos", Ideas, nº 11, mayo de 1917, p. 204. 
su vez, la existencia de esas polémicas estudiantiles también sugiere que, para mediados de 1917, los grupos preocupados por la formación cultural son varios y pueden comenzar a precisar sus posiciones sin que ello implique, como en el caso de los arielistas socialistas de 1914, la disgregación de los pocos participantes.

Desde la dirección del CE, Bermann continuó el esbozo que inició en Verbum de perfil estudiantil militante y cientificista. Y durante 1918, además de participar del movimiento de opinión a favor de la libertad de Besteiro, publicó en el Boletín de la Federación de Estudiantes de Buenos Aires una nueva reseña a un libro de Altamira, "Para la juventud", del que destacaba el compromiso moral de los estudiantes con la sociedad, ${ }^{166} \mathrm{y}$ organizó desde la presidencia del CE un ciclo de conferencias de Extensión Universitaria.

Se preveía que el ciclo contara con reconocidas figuras ligadas a la cultura científica y de izquierda: el filósofo uruguayo Carlos Vaz Ferreyra disertaría sobre los problemas filosóficos contemporáneos; el profesor español Julio Rey Pastor sobre la filosofía matemática; el pedagogo y director del internado del Colegio Nacional de La Plata Ernesto Nelson sobre las nuevas orientaciones de la educación; y la médica y militante del feminismo socialista Alicia Moreau sobre la educación de la mujer y los problemas contemporáneos. Moreau abrió el ciclo el 24 de abril de 1918 con una conferencia que, lamentablemente, hoy es inhallable.

Por las iniciativas en las que entonces participaba, podemos suponer que allí discutió la inferioridad intelectual de la mujer que las instituciones alegaban para vetar la habilitación universitaria a las profesiones liberales, habilitación que -como mencionamos en el primer capítulo- las mujeres venían reclamando desde comienzos de siglo a partir de instancias como la Asociación de Universitarias Argentinas y el primer Congreso Femenino Internacional, desarrollado en 1910. Si bien no contamos con los argumentos a favor de la educación de la mujer que expuso Moreau ante los estudiantes de la FFyL -matrícula compuesta prácticamente por un tercio de mujeres-, tenemos al menos los que difundió, unos meses antes, una de sus compañeras de militancia, Mercedes Gauna. En el artículo que publicó en La Cumbre. Revista mensual de difusión cultural, Gauna encuentra no sólo pruebas científicas de la igualdad entre el hombre y la mujer, sino también las que ofrecen, por un lado, el "número grandísimo de mujeres científicas" y, por el otro, la "importante

\footnotetext{
${ }^{166}$ Bermann, "La educación moral de la juventud", Boletín de la Federación de Estudiantes de Buenos Aires, $\mathrm{n}^{\mathrm{o}}$ 3, marzo de 1918, pp. 4-5.
} 
labor que mostraron en el campo de la industria" a partir de la Gran Guerra. ${ }^{167}$ Probada la igual condición psico-fisiológica de la mujer por "la Antropología, la Fisiología, la Clínica y otras ciencias", la Sociología debería señalar que la función social de la mujer en la vida de las sociedades organizadas

No puede ser de menor categoría que la del hombre, puesto que al fin el trabajo del útero no desmerece el del cerebro, si se considera a la mujer en una de sus excelsas funciones, la maternidad. [...] impónese la reforma de su educación, que hasta ahora ha sido extraviada. Los partidarios de la inferioridad mental de la mujer, quieren cerrarle el acceso a todas las carreras liberales, condenándola al vasallaje del hogar, donde debe agotarse en las funciones de la reproducción para complacer al amo, entregada durante toda su vida a la crianza de los hijos (Mercedes Gauna, "La mujer", La cumbre, enero de 1918, s/d).

En junio de 1918, el CE cambiaba de autoridades y tanto el ciclo de conferencias diseñado por Bermann como la prédica feminista difundidas por Moreau y Gauna caían en el olvido. Desde entonces, Bermann se dedicaría a elaborar un plan de estudios del ciclo de filosofía, para ser presentado en el Consejo Directivo de la FFyL, que filiaba a la filosofía con las ciencias naturales y los problemas sociales contemporáneos, y con ello la alejaba de la tradición clasicista identificada con la "formación del espíritu". ${ }^{168}$ Veremos en el siguiente capítulo que, al iniciarse el conflicto estudiantil, buscó estrechar los lazos de los estudiantes porteños con los cordobeses y, a comienzos de los veinte, ingresó en la UNC.

En cuanto al tipo de reclamos de Moreau y Gauna, éstos no tuvieron prácticamente resonancia en el movimiento reformista, e incluso fueron combatidos por los estudiantes que, desde la salida de Bermann, dirigieron el CE y su órgano. Veremos que en 1919 Herminia Brumana y otras pocas mujeres colaboraron en Bases. Tribuna de la juventud, una revista estudiantil radicalizada que dirigió el joven Juan Antonio Solari, pero no hemos encontrado entre los grupos reformistas una explícita reivindicación -como la que citamosdel derecho de las mujeres a la formación universitaria.

\footnotetext{
${ }^{167}$ La Cumbre, de la que aparentemente sólo apareció un número de doce páginas, se anunció como el órgano del centro de cultura "Idealismos juveniles", estuvo administrada por Nicolás Pietro y difundió notas breves sobre cultura, poemas y noticias del centro. Sobre los problemas para visibilizar la genealogía de las mujeres y sobre el tipo de estrategia que aquí seguimos, véase Ciriza (2008).

${ }^{168}$ Gregorio Bermann, "Los estudios filosóficos en nuestra Facultad de Filosofía y Letras" (Nosotros, n 119 , marzo de 1919) y "La enseñanza de la filosofía" (Revista de Filosofía, septiembre de 1919). Ambos artículos son publicados cuando el Consejo Directivo de la FFyL discute, en el marco de los nuevos estatutos de agosto de 1918, la reforma de los plantes de estudio, y guardan continuidad con la propuesta formulada en "El plan de estudios" (Verbum, no 33-34).
} 
Como sugerimos, los estudiantes que desde 1918 se sucedieron en Verbum y el CE de FFyL otorgaron una matriz antipositivista a ambas instancias, y no descartaron la convergencia del antipositivismo no sólo con la literatura, sino también con la cultura católica. Lejos de la impronta militante o del reclamo por la igualdad de la mujer que promovía Bermann, el CE decidió invitar -en uno de los momentos de mayor confrontación de los estudiantes federados cordobeses con la cultura católica y de entusiasta organización de las derechas católicas- al presbítero Ayala para que, "en un ambiente en el que por lo común, los concurrentes no son del todo adeptos a las ideas fundamentales del conferencista", extendiera "su pensamiento más allá del círculo en que habitualmente se agita". ${ }^{169}$ La posición de estos estudiantes no podía estar más alejada de la proyección filosófica de Bermann e Ingenieros, y éste, unos meses antes de la conferencia del presbítero, presentaba su renuncia a todos sus cargos en la facultad, pues el Consejo Directivo acababa de vetar la terna de aspirantes al segundo curso de Psicología por su impronta cientificista y proponía una nueva en la que figuraba Alberini, quien ganaría el cargo. El CE apoyó la elección de Alberini con su voto y con "Un epitafio al 'viejo régimen"' en el que saludaba y reproducía el documento institucional que decidió el veto. ${ }^{170}$

Por su parte, las voces femeninas que desde la FFyL se ocuparon del lugar de la mujer en la universidad se alejaron de las "imposiciones" formuladas por Gauna para exaltar la condición sentimental de la mujer. Sostiene una de las estudiantes, en el momento en que el movimiento reformista discute su apoyo a la Liga Patriótica o a la Federación Obrera:

[En esa facultad en que] hemos recibido sabias lecciones de prudencia y de integridad moral [...] la mujer pone la nota de dulce ingenuidad en el conjunto; la mujer, que en lugar de acaudillar multitudes, yo quisiera fuera el ritmo dulcísimo de los consuelos, alma sensitiva para enjugar lágrimas que lloran los vencidos; aproximación afectuosa en la suprema desventura de los que pisan el dintel de la última esperanza [...]. Magdalena simbólica de todos los dolores de la tierra, para enjugar los infortunios que lloran, las plegarias que sangran, las flagelaciones que envilecen, las desolaciones que hielan... (Celina Balán, "De nuestro ambiente", Verbum, no 49, marzo-abril de 1919, p. 236)

\footnotetext{
${ }^{169}$ Carlos Sfondrini, "Las conferencias del presbítero Ayala. Algunas observaciones generales y críticas", Verbum, $\mathrm{n}^{\circ}$ 50, mayo-junio de 1919, p. 391.

${ }^{170}$ Verbum, no 48 , enero-febrero de 1919, pp. 113-114.
} 
También la egresada Isabel Saithú participó del desplazamiento del feminismo socialista de las aulas de la FFyL y fue difundida en las paginas de Verbum. Pero Saithú llegaba más lejos que Balán, pues en su discurso a favor de la elección de Ventura Pessolano como presidente del CE se ocupaba de la educación y la ciudadanía de las mujeres desde un "nacionalismo político" $"$ tajantemente enfrentado al internacionalismo del feminismo y el socialismo:

Uno de los problemas más importantes en el momento actual es, sin duda, el feminista. Y a nosotras como argentinas y universitarias nos corresponde estudiarlo con detención, ver cómo se desarrolla en los distintos países para formarnos luego, con nuestro criterio de argentinas, un ideal de mujer, al que trataremos de acercarnos y elevar a las demás.

Consideramos hoy por hoy un anacronismo el pedir para la mujer el voto y la banca del Congreso, y creemos que el camino por que el se quiere llevar a la mujer argentina es el peor de todos. Esos cientos de obreras y empleadas que cruzan las calles de nuestra ciudad dando gritos, haciendo flamear banderas, esas mujeres que incendian, que levantan vías, que se valen del respeto que siembre ha tenido el hombre por la debilidad femenina, para detener trenes y tranvías, nos dice que la mujer va hacia el desprestigio, y el desprestigio de la mujer encierra en sí el desprestigio de la nación a que pertenece (Isabel Salthú, "Proclamación", idem, p. 240).

Y si, luego de asociar la cuestión femenina a la cuestión nacional, Salthú coincidía con Gauna y Moreau en la necesaria educación de la mujer, lo hacía para apoyar un proyecto de extensión universitaria temeroso del caos social -como el que encontraremos en 1919 y 1920 en la Revista Nacional y el grupo Unión Universitaria-. Oponiéndose explícitamente a la cultura socialista en la que participaban Gauna y Moreau, proseguía Salthú:

La mayoría de las obreras apenas ha aprendido a leer y escribir, y esto es peor que el mismo analfabetismo, porque va a tratar de descifrar cuanta hoja caiga en sus manos y los papeles y revistas que circulan por talleres y fábricas son de los peores, de los que le dan un concepto irreal de la vida, de los que despiertan en ella los sentimientos de rebeldía hacia el superior y de odio al resto de la sociedad. Eduquemos a la obrera. [...] presentémosle ejemplos de mujeres laboriosas y sencillas, que fueron el honor de la Argentina. [...] Enseñémosle estética para que sepa, según sus cánones, arreglar su salón y su persona (Idem, p. 241).

\footnotetext{
${ }^{171}$ Utilizamos aquí la distinción, con la que Devoto (2002) estudió los procesos ideológicos argentinos, entre un "nacionalismo cultural", activo sobre todo durante la década del diez y preocupado por precisar los rasgos culturales definitorios del ser argentino, y un "nacionalismo político", que comienza a gestarse a fines de esa década y que, además de definir rasgos culturales, formula una legitimación del orden social centrada en las nociones de nación, corporativismo y jerarquías sociales, y se enfrenta al socialismo y el liberalismo.
} 
Pero antes de que este tipo de discurso sobre la mujer y el rol de los estudiantes se instale en la FFyL, en 1917 los jóvenes reunidos en el Colegio Novecentista -que también serían parte en los años siguientes del CE y de Verbum- habían iniciado una intensa redefinición de la filosofía para desligarla del cientificismo y filiarla a esa "literaturización" que cuestionaban Ingenieros y sus discípulos.

\section{Filosofía novecentista y expresión poética}

Cuando el Colegio cumple un año, los jóvenes se dan unos Estatutos. Allí sostienen que

otro de los mayores defectos de la cultura nacional es el abandono ilegítimo que se ha hecho de los estudios estéticos, circunstancia que por sí sola explica el arte menguado de nuestros tiempos, y no habiendo, en su opinión, otro medio para rehabilitarlo que el retorno por vía directa a la antigüedad grecolatina, [el Colegio] bregará por un arte libre, en el sentido filosófico de la palabra, que al asimilar a las ideas contemporáneas los elementos eternos y universales de las grandes culturas clásicas, realice, bajo los auspicios de la libertad creadora, la armonía del sentir moderno con la majestuosa pulcritud de la expresión antigua ("Estatutos del Colegio Novecentista", Cuaderno, no 6, junio de 1918, p. 181; destacado nuestro).

Mientras los jóvenes ligados a Ingenieros (estudiantes, en su mayoría, de Medicina y de Filosofía y Letras) encontraban el "sentir moderno" en los últimos avances de la biología, la economía y el socialismo cientificista, los novecentistas (estudiantes de Derecho y de Filosofía y Letras, mayoritariamente) optaban por fundar unos Cuadernos, de corte filosóficoliterario, que intentaban armonizar lo moderno y lo grecolatino. ${ }^{172}$ Sobre el cientificismo declaraban los novecentistas en el primer párrafo de esos Estatutos:

El Colegio Novecentista es asociación de idealismo militante porque reacciona contra el criterio materialista de la época, que al mecanizar el espíritu, degrada a la personalidad humana, y la resguarda de toda sanción ética y la exime de toda responsabilidad moral. [...] [Luchará] contra el cientificismo claudicante de nuestros tiempos [...]. Y es, últimamente, idealismo militante porque a la vez que proclama su más profundo respeto a la ciencia que cultiva honestamente, y cuyas

\footnotetext{
172 En el estudio citado, Dotti (1992) inscribe al Colegio entre las "figuras de ruptura" en la reacción antipositivista, junto a Coriolano Alberini, Alfredo Franceschi, Jacinto J. Cuccaro, Raúl V. Martínez, Nimio de Anquín, Alberto Rougés, Lidia Peradotto, Carlos Astrada, entre otros. Específicamente, el Colegio es identificado como parte del "primer vanguardismo filosófico", que tiene una nueva expresión en 1923 con la formación del grupo de la revista Inicial. Revista de la Nueva Generación (1923-1927).
} 
conclusiones acata en cuanto éstas se reducen a explicar los fenómenos de su pertinencia, le niega el derecho de extender su dominio hasta el campo de la conducta y máxime el de fijarle normas a la conducta humana (Idem, p. 181. Destacado nuestro).

Para los oídos de la época, la crítica a Ingenieros y sus discípulos no podía ser más clara. Los orsianos porteños se enfrentaban a la "moral sin dogmas" y a la pretensión de fijar normas al hombre desde la ciencia, tarea que -como mencionamos- Ingenieros organizaba colectivamente a través de su Revista de Filosofía y había sistematizado en El hombre mediocre y Hacia una moral sin dogmas. Si bien importantes protagonistas de la Reforma se sintieron interpelados por lo que Ingenieros definía como un "idealismo experimental", los novecentistas optaron por un idealismo que partía del reconocimiento de una libertad que excedía la determinación científica y abrevaba en los desarrollos de La filosofía del hombre que trabaja y que juega. ${ }^{173}$

Para esa refundación de la filosofía, encontraron cierta guía en Ortega. Como mencionamos, Gabriel había reseñado las conferencias filosóficas del madrileño en el semanario P.B.T. Además, junto a Taborga publicó un artículo que defendía a Ortega de las duras críticas que le formulaba el artículo de Palcos aparecido en Nosotros. Pero fue Julio Noé, el "encargado de negocios" del Colegio, quien llevó más lejos las simpatías por Ortega al punto que, además de iniciar una prolongada amistad, se embarcaron juntos en el viaje de regreso a España. ${ }^{174}$

Para comenzar la refundación de la filosofía, los novecentistas organizaron un Seminario de Filosofía Contemporánea, "a semejanza de los instalados con tanto éxito en el Ateneo de Estudiantes Universitarios" pero también de los organizados por d'Ors en Barcelona. Un breve nota informa que el Seminario fue dictado por un "joven y sabio profesor, cuya inquebrantable buena voluntad intelectual solo iguala su vasta ilustración”, halago que evitaba nombrar a Coriolano Alberini, y precisa: “con 14 inscriptos se ocupó en diez sesiones del problema filosófico de la psicología, tomando como pretexto la obra de Binet, El cuerpo y el alma, libro del cual hizo la señorita Lidia Peradotto una luminosa

\footnotetext{
${ }^{173}$ El Colegio editó nueve Cuadernos, aparecidos entre julio de 1917 y diciembre de 1919. Sin una publicación, el grupo continuó reuniéndose al menos hasta 1923. El único estudio centrado en los Cuadernos realiza una minuciosa reconstrucción de las corrientes culturales que conviven en el grupo (Eujanian, 2001). A ese análisis, nuestra investigación suma la existencia de un noveno Cuaderno, así como la procedencia de muchos jóvenes del Ateneo y la atracción que ejerció la filosofía de d'Ors.

${ }^{174}$ Noé prolonga esa amistad a través del envío de cartas, una madrileña visita a Ortega en 1921 y un encuentro porteño en 1928.
} 
exposición crítica". ${ }^{175}$ El estudio de esa obra positivista habría permitido a los novecentistas puntualizar sus críticas a la matriz que imperaba en los dos cursos obligatorios de Psicología.

Como sugerimos, en esa cátedra se encontraba el núcleo de discusión más álgido entre positivistas y antipositivistas. A fines de 1918, los estudiantes y profesores antipositivistas buscaron que el primer curso mantuviera la orientación experimental que le otorgaba Ingenieros, pero que el segundo siguiera las nuevas corrientes especulativas de Bergson, Boutroux, etc. Para ello, el decano, entonces Alejandro Korn, objetó la terna de postulantes del segundo curso, porque los tres respondían a la matriz positivista, y propuso a Alberini. Ingenieros renunciaba entonces a todos sus cargos, mientras que Alberini obtenía, junto al curso en cuestión, un lugar en el claustro de profesores titulares del Consejo Directivo de la FFyL, desde el que inició una prolongada carrera institucional que modeló el perfil "sin resonancia social" del estudiante y del egresado de esa facultad. ${ }^{176}$ Recuerda el futuro presidente de Guatemala que había llegado a Argentina a estudiar Filosofía Juan José Arévalo:

De la mano de corrientes neokantianas o de la del vitalismo o de la del espiritualismo o de la del historicismo, Alberini consiguió ganar la batalla contra los césares criollos del cientificismo: los Ingenieros, los Bunge, los Ramos Mejía, los Ferreira. La juventud, desde 1910, lo rodeó y lo apoyó en la pelea, y de reformista filosófico pasó insensiblemente a caudillo universitario, hasta erigirse en amo y señor de la Facultad de Filosofía y Letras de Buenos Aires" (Arévalo, 1975: 142-143).

Sobre ese señor Héctor Agosti formuló en 1955, a pedido del CE, un breve balance político. El intelectual comunista, que había participado a comienzos de los treinta en el segundo grupo Insurrexit, sostenía que los decanatos de Alberini no sólo instalaron el academicismo, sino que además lograron que el reformismo de esa facultad sea el más sosegado de todos. ${ }^{177}$

Volviendo a la intervención novecentista de 1917, el Colegio buscó acercar la filosofía

\footnotetext{
175 "Seminario de filosofía contemporánea (informe anual)", Cuaderno, n 3, diciembre de 1917, p. 184. Además de ser la única mujer que participa del Colegio, Peradotto es la primera que obtiene por concurso un cargo de profesora en la FFyL. Desde sus primeros años como estudiante, Peradotto se liga a la investigación que realiza el profesor antipositivista Alfredo Franceschi desde su cátedra de Lógica. Por otra parte, en 1919 es directora del Liceo de Señoritas de La Plata.

${ }^{176}$ El borrador de la carta presentada por Ingenieros al Consejo Directivo de la facultad puede consultarse en el Fondo de José Ingenieros del CeDInCI. En cuanto a la carrera institucional de Alberini, con ese cargo se incorporó el Consejo Directivo y luego fue vicedecano, entre 1921 y 1924, y decano entre 1925 y 1928, 1931 y 1932, 1936 y 1940. Su obra no sólo tuvo una clara impronta antipositivista, sino que además no ahorró en descalificativos a la calidad filosófica de Korn y sobre todo de Ingenieros.

${ }^{177}$ Héctor Agosti, "Los recuerdos actuales", Centro n 10, noviembre de 1955, p. 47.
} 
a la racionalidad extracientífica que ofrecía la literatura, y no descartaba la posibilidad de que el lenguaje poético abordara los problemas filosóficos. Una prueba de ellos la ofrece el poema publicado en el primer Cuaderno:

El ser y el deber ser. Ideas y hechos

Siempre en penoso esfuerzo disyuntivo

¿Conciliarán un día sus derechos

Lo pensado y lo vivo?

En nosotros -muy íntimo- perdura

Ese combate. ¿Quién matará a quién?

Si somos alma pura

Somos nervios y músculos también.

Porque tal es la siempre abierta herida

De nuestra vocación:

Siempre que somos fieles a la vida

Somos infieles a Platón (Teófilo de Sais, "Momentos", Cuaderno n ${ }^{\circ}$ 1, julio de 1917, p. 37).

A esta problematización, desde la expresión poética, de la superposición en el hombre de la dimensión biológica y la ética, se agregaba, en el segundo Cuaderno, el elogio que realizaba el joven Ventura Pessolano (futuro profesor de Estética de las carreras de Filosofía de Buenos Aires y de La Plata) a Rojas por su rescate filosófico de las producciones literarias clave de la identidad nacional. En el mismo sentido, en el tercer Cuaderno, otro futuro profesor de la facultad, el joven Jorge Max Rohde, publicaba unos “Apuntes estéticos” en los que anhelaba

Que el alma del novecientos se derrame con la limpidez soberanamente hermosa de la edad clásica. Despierte, en esta tierra 'la progenie nueva con el nuevo canto': aquel que recoja, dentro de la poesía épica o narrativa, las rapsodias dispersas como flores silvestres en nuestras pampas, y refleje en sus estrofas el sol de la 'argentinidad' (Jorge M. Rohde, “Apuntes estéticos”, Cuaderno, n 3, diciembre de 1917, p. 138).

Esta identificación de la poesía grecolatina como el instrumento filosófico capaz de elevar la cultura nacional fue una constante no sólo en las manifestaciones del Colegio, sino también en la profusa producción posterior de Rohde, quien desde mediados de 1918 se convirtió, junto a Adolfo Korn Villafañe, en el principal animador del grupo. ${ }^{178}$

\footnotetext{
${ }^{178}$ En los veinte, Rohde publica, en cuatro tomos, Las ideas estéticas en la literatura argentina (1921-1924), una historización de las influencias estéticas europeas que, en rivalidad con la impronta evolutiva que Rojas retoma de Taine, recoge la impronta del clasicista católico Menéndez Pelayo. A lo largo de su prolongada trayectoria, Rohde persistirá en la construcción de una literatura que abreva en lo grecolatino para ofrecer principios estético-moralizantes reactivos a la modernidad. Para un tratamiento de ese proyecto, véase Gasquet (2007: 233267).
} 
La crítica al cientificismo recorre los nueve Cuadernos, pero en ellos se descubre una diversa relación de la filosofía con la política. En los primeros, la alianza entre la filosofía y los valores éticos y estéticos ligados a la literatura sólo se pronuncia contra el liberalismo y la variante positivista del socialismo. De aquí que en sus inicios el Colegio pudiera reunir a jóvenes cercanos al socialismo como Gabriel y Taborga junto a activos miembros del Ateneo que eran partidarios de un orden social jerárquico ligado a la cultura católica como Rohde, Korn Villafañe y Tomás Casares. Al igual que el Ateneo, hasta el estallido de la Reforma el Colegio parece haber puesto entre paréntesis las afinidades políticas para reunir a sus miembros en torno de una primacía filosófica ligada a la corrección esteticista y eticista de la cultura científica. Como ejemplo de la recurrente denuncia que realizan los novecentistas a la amoralidad de la pretendida objetividad científica, traigamos un pasaje del breve manifiesto que abre el tercer Cuaderno, un texto firmado por "La redacción", pero seguramente proveniente de la pluma de Alejandro Korn, quien, a pesar de conciliar antipositivismo y catolicismo, no formaba parte de los profesores identificados con la cultura católica sino de la liberal y simpatizante del socialismo:

Queremos que la ciencia con su criterio amoral no sea sierva de apetitos y concupiscencias, que no sofoque los impulsos más nobles del alma humana, queremos que sea instrumento de una voluntad ética, queremos oponer al utilitarismo vulgar altos valores estéticos, queremos que la cultura nacional ascienda un tramo.

Pocas líneas después señalan los novecentistas sobre el credo que reemplazará al positivismo:

¡Y lo hallaremos bajo los auspicios de la libertad creadora! Lo realizaremos en la obra de arte como en la obra honestamente pensada y sobre todo en la afirmación consciente de la propia personalidad (La Redacción, “QQué es el novecentismo?”, Cuaderno, $\mathrm{n}^{\mathrm{o}} 3$, diciembre de 1917, pp. 129-130).

Para realizar esa "afirmación consciente de la propia personalidad", los novecentistas contaron, además de los Cuadernos, con una editorial que puso en circulación las obras de los jóvenes. De las cinco editadas, sólo la última, El Estado y la religión, es estrictamente filosófica, un ensayo de orientación neotomista que Casares había presentado en 1919 para acceder al grado de doctor en Jurisprudencia en la Facultad de Derecho de Buenos Aires. Las otras cuatro obras son de carácter literario: los versos de Taborga La otra Arcadia, los Cantos 
de Rohde, las Impresiones de Alberto Britos Muñoz y la novela El irredimido de Korn Villafañe (en ésta se anuncia la pronta aparición -finalmente no conseguida- de La historia secreta del novecentismo). En consonancia con el primer fragmento de los Estatutos que citamos, la literatura no tiene en esas producciones un carácter recreativo, sino formativo. Los libros de la editorial del Colegio parecen responder a la urgencia por dignificar la condición humana señalada, entre otros textos, por el manifiesto que abría el cuarto Cuaderno. Ese texto firmado por "La redacción" y actualmente atribuido a Korn declara:

La solución 'científica' [propuesta por Marx] no resuelve sino una parte del problema y exige para completarse una solución ética. [...] Urge fundar las aspiraciones económicas de la sociedad actual en una ética que sea expresión ideal de una personalidad consciente y libre. Solamente valores éticos y estéticos, no valores económicos, pueden dignificar la condición humana (La Redacción, "Socialismo ético", Cuaderno, no 4, febrero de 1918, pp. 5-7).

Esta opción por una ética y estética conciliadas con la literatura -en lugar del idealismo científico- que decide una institución filosófica como el Colegio explica que, entre la veintena de jóvenes que pasaron por el Colegio y publicaron sus primeros textos en los Cuadernos, se encuentren figuras que tendrán una destacable carrera académica como profesores de filosofía en la UBA y en la UNLP (entre ellos, Alberini, Casares, Korn Villafañe, Pessolano y la única mujer que participa, Lidia Peradotto) junto a futuras figuras relevantes del saber literario, como los críticos y poetas neoclacisistas Álvaro Melián Lafinur y Rohde, el germanista Juan Probsty el crítico literario Noé. ${ }^{179}$

Más allá de estas trayectorias, la propuesta filosófica del Colegio aparece particularmente desarrollada en la obra de Taborga y Héctor Ripa Alberdi, pues ambos se preocuparon por difundir una lectura exegética de las últimas corrientes filosóficas, pero también se reconocieron como poetas y publicaron versos en los que se destacaba la admiración por la cultura clásica y la preocupación por los problemas filosóficos. ${ }^{180}$ Sobre el

\footnotetext{
179 Juan Probst (1892-1973) nació en Nuremberg y llegó al país como representante de la empresa textil de su padre, al poco tiempo se inscribió en la FFyL, donde, además de participar del Colegio Novecentista, dirigió Verbum y luego el CE. Asimismo, desde la década del treinta hará una exitosa carrera académica en la cátedra de Literatura alemana. Por su parte, Julio Noé, a pesar de haberse recibido de abogado, será profesor titular en la FFyL y se preocupará por la construcción del periodismo cultural y de una crítica literaria capaces de subrayar la evolución de la cultura argentina. Desde esa preocupación prepraró en 1923 Nuestra literatura y en 1926 la pionera y discutida Antología de la poesía argentina moderna. En su selección, Noé mostró una clara admiración por el modernismo, pero también admitió el coloquialismo porteño y a los ultraístas.

${ }^{180}$ Héctor Ripa Alberdi (1897-1923) se había sumado al Colegio a mediados de 1918. Desde entonces, además de participar de la "academia platónica" de Rohde, difundió las corrientes del idealismo antipositivista en la UNLP: hasta su muerte en 1923 fue profesor ayudante en la cátedra de filosofía que dictaba Alejandro Korn.
} 
programa filosófico novecentista declaraba el segundo en el discurso de inauguración de la efímera sede platense del Colegio:

Y así como [el amor] llevó a la punta del cincel antiguo un inefable temblor de emoción bella, también ha de traer la misma inquietud misteriosa, cuando nuestra frente se incline a labrar el pensamiento, síntesis excelsa de la meditación tranquila. Amor a la armonía serena, amor a la belleza pura y a la concepción filosófica: todo, bajo la diáfana claridad de una orientación idealista (Héctor Ripa Alberdi, "El Colegio Novecentista de La Plata", Cuaderno, nº 8, julio de 1919, p. 178).

Deudores de lo que concebían como una impronta platónica, para estos filósofos-poetas, al igual que para otros antipositivistas, la verdad no tenía su fundamento último en la biología ni en la economía, como proponían los escritos de Ingenieros, sino que formaba parte de la tríada que se completaba con el bien y la belleza.

Pero, como anticipamos, la imprecisa ética grecolatina que trazaba la continuidad entre filosofía y literatura no pudo resistir la interpelación política que produjeron las primeras manifestaciones de la Reforma, y sobre todo la reacción nacionalista de la Semana Trágica. Y, en torno de esas precisiones, el Colegio terminó asociado a un catolicismo jerarquizante.

\section{Novecentismo y compromiso político}

En los primeros Cuadernos, los jóvenes parecen concentrar sus discrepancias con Ingenieros en las tesis metafísicas. Una muestra de ello es la reseña de Taborga a la tercera edición de $E l$ hombre mediocre y las afirmaciones del primer manifiesto del Colegio Novecentista (atribuido luego a Gabriel). En su reseña, Taborga sostiene que el ensayo de Ingenieros adhiere a un idealismo positivista que cae en un "doble error de diagnóstico y terapéutica". ${ }^{181}$ Gabriel retomaba ese señalamiento pocos meses después, pues el manifiesto inaugural del Colegio sostenía que los jóvenes se encontraban en "un ambiente que bien poco sabe de las disciplinas filosóficas", o sea le quitaban todo valor filosófico a la difusión que venía realizando desde hacía más de dos años la voluminosa Revista de Filosofía.

Asimismo, su participación en la FULP lo llevó a presidir la comitiva que representó a la juventud argentina en el Primer Congreso Internacional de Estudiantes, realizado en México a fines de 1921. Esa participación se prolongó en una gira latinoamericana financiada por el estado mexicano, en la que Ripa Alberdi entabló amistad con Pedro Henríquez Ureña (Biagini, 2012: 165-168).

${ }^{181}$ La larga reseña aparece en 1917 en la prensa porteña bajo el título "Recetas de sabiduría y de moral"; en 1924 es compilada por Gabriel en las obras completas de Taborga (1924: 211-216). 
A ello los Cuadernos sumaban declaraciones más explícitas: en el primer Cuaderno, Vicente D. Sierra publicaba "El ilusionismo en filosofía", una breve reseña que respondía a un artículo aparecido en la Revista de Filosofía que acusaba al movimiento espiritualista de propiciar una filosofía ilusionista; en el segundo, Gabriel ironizaba sobre la "influencia de la ciencia sobre la metafísica" que alentaba Bermann en un artículo aparecido en Nosotros ${ }^{182}$ y en el sexto y séptimo Cuaderno, Juan Probst publicaba reseñas que señalaba las "incoherencias cientificistas" de las Proposiciones relativas al porvenir de la Filosofía y el "hispanismo come-frailes" de La evolución de las ideas argentinas. Y ello mientras que, por un lado, Bermann junto a otros simpatizantes de la filosofía científica y socialista, como Palcos, Giusti y Monner Sans, se reunía en una cena íntima con motivo de la presentación de Ingenieros de La evolución de las ideas argentinas; ${ }^{183} \mathrm{y}$, por el otro, Nosotros publicaba una crítica reseña al primer Cuaderno, firmada por Giusti.

Ante los primeros números de Ideas Guisti saludaba desde Nosotros la congregación de la juventud estudiosa. En cambio, respondía con dureza a los tímidos gestos rupturistas que ensayaba el Colegio. Luego de recordar que la mayoría de los novecentistas eran colaboradores de Nosotros e incluso el "encargado de negocios" del Colegio, Julio Noé, era el secretario de Nosotros, Giusti sostenía que no era cierto el señalamiento de Gabriel de que faltara "policía literaria": "la hemos hecho, modestamente sin duda, también en Nosotros durante diez años; que otros la han hecho antes y conjuntamente, y que si nuestros amigos los novecentistas pretenden ser los primeros, padecen una ilusión óptica tan sin importancia como evidente". Y precisaba:

Sintetizando, a nosotros nos parece ver que el novecentismo, -como llama Gabriel a su orientación, con un nombre ya empleado por Eugenio d'Ors (Xenius), y antes, si no estamos equivocados, por Marinetti-, es radical oposición al positivismo y a la ciencia experimental, oposición que no compartimos, pero que nos explicamos perfectamente, por causa de los extremos en que ha incurrido aquella misma ciencia hasta convertirse en ciertos casos en el ya traído y llevado cienticismo (Roberto Giusti, "Colegio Novecentista", Nosotros, $\mathrm{n}^{\circ}$ 100, agosto de 1917, p. 660).

Mientras Giusti y Gabriel iniciaban con ese texto una polémica pública sobre el cientificismo, los novecentistas le encomendaban a Alejandro Korn la redacción del

\footnotetext{
${ }_{182}$ José Gabriel, "Las orientaciones de la filosofía contemporánea", Cuaderno n ${ }^{\circ}$ 2, agosto de 1917, pp. 116-118.

183 "En honor de José Ingenieros", Nosotros n ${ }^{\circ} 115$, noviembre 1918, p. 508. Sobre la importante recepción que tuvo esa obra de Ingenieros en el campo historiográfico de la época, véase Pasolini (2007).
} 
manifiesto "Socialismo ético", que citamos arriba. A través de ese texto, el Colegio se inscribía en un socialismo que, en línea con la II Internacional Socialista, resaltaba la dimensión libre y moral del hombre para corregir el determinismo económico que habría introducido Marx al socialismo -y que en la escena local sería propiciado por Juan B. Justo e Ingenieros-. ${ }^{184}$

Esta primera tentativa de traducción política del antipositivismo orsiano fue acompañada de un breve manifiesto aparecido en el Cuaderno de abril de 1918. Allí el grupo declaraba que era una "institución de idealismo militante" y que "tratándose, pues, en el conflicto estudiantil cordobés de un movimiento francamente progresista, el Colegio se adhiere a los revolucionarios". Y afirmaba hacia el final: "En el Colegio Novecentista todo impulso de juventud encuentra un voto de aplauso y un gesto fraternal y todos los excesos juveniles el olvido y la discreción". ${ }^{185}$

Pero con el estallido de la Reforma a mediados de ese año, se producen fuertes discusiones al interior del grupo, las que, recuerda Alberini (1973 [1928]: 88-91), terminaron con el "alzamiento" exitoso de la minoría católica del Colegio contra la mayoría liberal que lideraban Taborga y Gabriel. Desde entonces las críticas a Ingenieros se dirigieron también a sus posiciones políticas. Ante la aparición de las nuevas obras de aquel, Probst redactaba dos reseñas en las que criticaba la posición maximalista del principal referente del cientificismo y lo acusaba de una parcialidad "hispanófoba" y "come-fraile". Concluía sobre las Proposiciones relativas al porvenir de la filosofia:

En resumidas cuentas, el nuevo libro de Ingenieros nos ha dejado desengaños en todo sentido. Recogemos de las afirmaciones que contiene solamente una: la que pregona el fracaso del positivismo. En esto sí que estamos con Ingenieros.

Mala señal es ésta para el positivismo si ya abandona el capitán el buque naufragante (Juan Probst, "Proposiciones relativas al porvenir de la filosofia de José Ingenieros”, Cuaderno n 6, junio de 1918, pp. 171-174).

En el siguiente número aparecía otra reseña que, en sintonía con el "Epitafio para el 'viejo régimen"” aparecido en el número de enero-febrero de Verbum, formulaba descalificaciones más rotundas:

[...] a nuestro juicio, Ingenieros ha abordado con La evolución de las ideas

\footnotetext{
184 La redacción, "El socialismo ético", Cuaderno no 4, febrero de 1918, pp. 3-7.

185 El Colegio Novecentista, "El conflicto universitario de Córdoba", Cuaderno no 5, abril de 1918, p. 102.
} 
argentinas una tarea que está por encima de sus fuerzas; primeramente porque le falta la suficiente preparación filosófica, hecho demostrado en sus Proposiciones; segundo, porque no tiene la vasta erudición histórica que reclama el asunto; y tercero, porque su temperamento no es el requerido para un historiador, faltándole la serenidad de ánimo para apreciar los hechos y los hombres con imparcialidad y con justicia (Juan Probst, "La evolución de las ideas argentinas de José Ingenieros", Cuaderno no 7, enero de 1919, pp. 65-68).

Junto a este tipo de críticas a Ingenieros, desaparecía del Colegio el aplauso y la fraternidad incondicionales a los impulsos de la juventud. En lugar de ello, los cuatro Cuadernos publicados entre mediados de 1918 y fines de 1919 asimilaban el antipositivismo orsiano a una renovación de los planes de estudio que se oponía, desde un nacionalismo aristocratizante, a la conexión del movimiento estudiantil con la izquierda que se había producido en Córdoba y La Plata. Más precisamente, a través de un texto de Casares y otro de Korn Villafañe aparecidos en el Cuaderno de enero de 1919, el Colegio condenaba a los revolucionarios cordobeses porque no hacían más que promover el caos maximalista. ${ }^{186} \mathrm{Y}$ el noveno y último Cuaderno se abría con un manifiesto que declaraba que el Colegio apoyaría el reclamo estudiantil platense sólo si se limitaba a una renovación "idealista" del conocimiento, esto es, al reemplazo de las disciplinas científicas por una formación humanista centrada en la enseñanza del griego y del latín y distante de los posicionamientos políticos izquierdistas. ${ }^{187}$ Como veremos en el capítulo siguiente, otro novecentista, Ventura Pessolano, se sumaba a la condena a los cordobeses a través de un informe en el que acusaba a la FUC de promover acciones políticas que excedían su función gremial y conseguía que en 1919 la FUBA se separara de la FUA hasta que no se corrigiera ese accionar.

Desde mediados de 1918, Korn Villafañe y Rohde lideraron el grupo antipositivista. A partir de entonces, los mencionados frentes filosóficos fueron también frentes políticos rivales: el frente antipositivista que, aunque propuso una formación profesional sin un compromiso político inmediato, simpatizó con un nacionalismo de resonancias católicas y temeroso de la pérdida de jerarquías sociales, por un lado, ${ }^{188} \mathrm{y}$ el frente cientificista, ligado al

\footnotetext{
${ }^{186}$ Tomás Casares, "El maximalismo" y Adolfo Korn Villafañe, "Carta. Contestación a la pastoral de S. S. I. fray Zenón Bustos, Obispo de Córdoba", ambos en Cuadernos, n 7, Buenos Aires, enero de 1919, pp. 41-49 y 50-52, respectivamente.

${ }^{187}$ Colegio Novecentista, "El Colegio Novecentista y el conflicto universitario de La Plata", Cuadernos, no 9, diciembre de 1919, pp. 209-211. En ese número figuran como miembros: A. M. Romariz Elizalde, Presidente; Luis Magnani, Santiago Biggi, Juan Probst, Jorge M. Rohde, Álvaro Melian Lafinur, B Ventura Pessolano, Casares, Leopoldo G. Castella, Carlos C. Malagarriga, Juan Rómulo Fernández. No se menciona la sede de La Plata. Para una inteligente reconstrucción de la trayectoria temprana de varios novecentistas, véase Vásquez (2000)

${ }^{188} \mathrm{El}$ antipositivismo y el nacionalismo jerarquizante, y no la afinidad católica, parecen haber sido los núcleos
} 
socialismo y a la democratización de la universidad y la sociedad, así como simpatizante de la reforma educacional rusa.

Pero el fraccionamiento no fue tan sencillo, pues tanto Ingenieros como Alejandro Korn desplegaron dos estrategias diversas para reformular esos frentes. En su Libertad Creadora (1920) y algunos manifiestos anteriores, Korn corrigió el cientificismo del socialismo con una receta eticista, que concebía al hombre y su libertad como una condición cualitativamente distinta de los hechos positivos. Y desde esa receta animó el grupo Renovación de La Plata y su órgano, Valoraciones (1923-1928). Por su parte, en las Proposiciones relativas al porvenir de la filosofía (1919), Ingenieros, además de delinear el compromiso social del filósofo, concediá un lugar filosófico a la problemática metafísica que reclaman los antipositivistas.

Más allá de esos intentos de reformulación, entre 1920 y 1924 el Colegio ya no contó con una publicación ni se compuso de estudiantes universitarios. Por esos años, sus miembros colaboraron o dirigieron Verbum, otorgándole un perfil antipositivista, y continuaron reuniéndose, ahora de modo semanal y en casa de Rohde, con el propósito de leer y discutir las cuestiones que "ennoblecían la cultura nacional". El acercamiento entre filosofía y literatura que propusieron, además de rivalizar con el cientificismo y contar a fines de 1921 con la presencia de d'Ors, se enfrentó durante 1924 a la vanguardia estética de la revista Martín Fierro (Ripa Alberdi, 1925: 109-110). Justamente ese reservorio de valores éticos y estéticos que los novecentistas encontraban en "la literatura" fue el mismo que para los vanguardistas "atrasaba" respecto de Europa. Es que el latinismo del Colegio no podía estar más distante al experimentalismo vanguardista de los martinfierristas. Como parte de esa polémica, el joven Conrado Nalé Roxlo dedicó unos de sus satíricos epitafios del "Cementerio de Martín Fierro" a Rodhe:

Yace aquí Jorge Max Rohde.

Dejadlo dormir en pax

que de este modo no xode

Max.

\section{Antipositivismo en las aulas}

aglutinantes, pues, ante la aparición del ensayo neotomista de Casares, Probst publicó en los Cuadernos una reseña en la que criticaba esas tesis filosóficas desde una posición neokantiana. 
Sin sospecharlo fueron la avanzada aventurera de un ejército en marcha. No obstante la exaltación agresiva de la hora, en su manifiesto inaugural hallaron para la ansiada renovación filosófica una fórmula que, después de los años transcurridos, los hechos confirman como la única viable. Alejandro Korn, "Filosofía argentina", 1927.

En las secciones anteriores, procuramos reponer el cuestionamiento al "idealismo experimental" ingenierianos que formularon los novecentistas. Éstos optaban por un idealismo kantiano ligado a una dimensión ética que extraía los valores de la "cultura estética" grecolatina, trascendía la racionalidad científica y pronto mostraría una preferencia política por el nacionalismo jerarquizante. A comienzos del siglo XIX uno de los referentes de las letras latinoamericanas le pedía a éstas que no se sometieran a la fría racionalidad de la filosofía. Declaraba Andrés Bello:
Abandona esa región de luz y de miseria, en donde tu ambiciosa rival Filosofía, que la virtud a cálculo somete, de los mortales te ha usurpado el culto; donde la coronada hidra amenaza traer de nuevo al pensamiento esclavo la antigua noche de barbarie y crimen (“Alocución a la poesía”, Andrés Bello, 1823, cit. Rama, 2008, p. 17).

Como vimos en las páginas anteriores, el movimiento que realizaron los antipositivistas fue el inverso: intentaron que la filosofía se acercara a la poesía. Para independizar la filosofía de la ciencia, la enlazaron a la literatura, y más específicamente a valores asociados a la cultura grecolatina, valores de los que se había valido el modernismo literario, pero también Ricardo Rojas cuando, desde su cátedra de Literatura Argentina de la FFyL y su Historia de la Literatura Argentina, "fundó" la literatura argentina y el saber profesional literario (Altamirano, 1983). ${ }^{189}$

En la FFyL los estatutos de agosto de 1918 se aplicaron sin demasiado conflicto. La

\footnotetext{
${ }^{189}$ Desde 1912 Rojas tuvo a cargo la primera cátedra de Literatura Argentina de la FFyL. Pero para "fundar" la literatura argentina Rojas no sólo se valió de esas lecciones, sino que además desde 1915 creó la referida editorial Biblioteca Argentina y en 1917 editó el primer tomo de su Historia de la literatura argentina. En 1922 Rojas sucedió a Alejandro Korn en el decanato de Filosofía y Letras. Durante esa gestión fundó el Instituto de Literatura Argentina, que dirigió entre 1922 y 1946, cuando renunció. La intervención de 1955 le devolvió el cargo, pero no lo aceptó y el titular nombrado fue José María Monner Sans.
} 
asamblea que, procediendo según esos estatutos, renovó los cargos del Consejo Directivo designó como decano a Korn y como vicedecano a Ingenieros. ${ }^{190}$ Como señala el epígrafe de Korn que abre este apartado, la definición novecentista de la filosofía guió la renovación de los estudios académicos. Por su parte, los jóvenes que se sucedieron en el CE, si bien mantuvieron algunas disputas, coincidieron en alentar una definición restringida de la Reforma en la que ésta no se ligaba a la emergencia del estudiante como un nuevo actor social con un compromiso político inscrito en las izquierdas, sino a una renovación de los contenidos, desde entonces ligados al antipositivismo, y a la organización de una Federación Universitaria comprometida exclusivamente con las cuestiones gremiales de los estudiantes. La interrogación filosófica sobre la cultura nacional comenzaba a ser desplazada para años después ocupar un lugar sumamente marginal. En términos de Terán:

Hubo un tiempo en que la práctica filosófica desde el interior de la universidad -pienso en los nombres de Ingenieros, Korn o Alberini-, llegó a comunicarse productivamente con las regiones de la cultura nacional [...] en busca del entramado de ideas sin el cual resulta difícilmente comprensible el perfil de cualquier sociedad. [Esto se quiebra en 1930] abriéndose para el filósofo la tentación de abroquelarse en la Universidad como un bastión que lo defendiera de la realidad. Arrojada a los Márgenes, la innovación filosófica volvió a tomarse recelosa de la Institución (Oscar Terán, "Filosofía en la Argentina: ¿hacia el fin de la errancia sin fin?", Espacios, no 1, p. 1984).

Entre quienes se abroquelaron en la universidad se encontraron varios novecentistas, quienes a partir de las reformas de 1918 ingresaron como profesores en la carrera de Filosofía de la UBA y de la UNLP-. Desde esos espacios separaron la filosofía respecto de la ciencia, para promover un perfil de filósofo que combinó la recepción de ideas antipositivistas, la admiración por lo grecolatino y la filiación de la cultura argentina con la alta cultura europea. La orientación del proceso de recambio de profesores tuvo una expresión clara en el ingreso de Alberini al segundo curso de Psicología, en el que se promovió una reflexión sobre el espíritu de resonancias neokantianas y bergsonianas.

Durante la década del veinte, quienes asistían a la FFyL ya contaban con una nueva generación de profesores, que no sólo había recibido una formación disciplinar sistemática, sino que promovía el conocimiento de la cultura griega y latina desde una amplia matriz antipositivista -al interior de la que se distinguían varias corrientes filosóficas-. En las

190 Para un análisis de ese decanato, véase Ruvituso (2010) y Ramaglia (2010). 
carreras de Filosofía de la UBA y de la UNLP, la psicología tendió a salir del laboratorio para ofrecer una aproximación a la dimensión trascendental del hombre; la estética también se ligó a lo transcendental en lugar de asociarse a un refinamiento del gusto del hombre culto; y la discutida metafísica dejó de ser un asunto problemático para tener un espacio curricular propio. Juan José Arévalo dejó una breve descripción de la sorpresa que le despertó en 1927 esa curricula:

tenía enorme ilusión por conocer el Plan de Estudios [de la FFyL]. Un cuarto de hora después se había derrumbado mi castillo de naipes. Según esos textos, la Facultad de Filosofía y Letras se consagraba con profundidad a las Humanidades clásicas: Filosofía, Historia, Literatura, Griego, Latín. Me costó encontrar materias pedagógicas: Ciencias de la Educación, Didáctica, Práctica de la Enseñanza. Eran simples asignaturas en función de servicio a las Humanidades" (Arévalo, 1975: 37).

En cuanto a la UNLP, los antipositivistas, aunque no lograron erigir a Alejandro Korn como decano, sí consiguieron en 1920 cambiar la denominación cientificista de "Facultad de Ciencias de la Educación" por la actual, en la que las Humanidades no se identifican explícitamente con una condición científica y preceden a las “ciencias de la educación". ${ }^{191}$ En la FFyL de Buenos Aires, los antipositivistas, sobre todo a partir de los decanatos de Alberini, consiguieron un perfil de egresado identificado con el "humanismo clásico" y el doctorado. En efecto, luego de la tensa disputa en torno a la renovación de los planes de estudio, el conocimiento del griego y del latín continuaron siendo obligatorio en los estudios filosóficos así como la formación doctoral sobre la pedagógica; y ello contra la posición a favor de un “humanismo moderno" propuesta por Ingenieros, Bermann y otros cientificistas. ${ }^{192}$

Pero el acuerdo entre los principales referentes del antipositivismo se quebró a mediados de la década del veinte. ${ }^{193}$ La ruptura se selló cuando en mayo de 1924, en disconformidad con el criterio con que Alberini, desde su condición de vicedecano, negociaba la incorporación de los profesores, renunció a su cargo en la FFyL. Luego de tomar esa decisión, Korn le envió a Alberini una carta que deja traslucir las diversas opciones políticas

\footnotetext{
${ }^{191}$ Sobre esta cuestión y el proceso más amplio de la Reforma en La Plata, véanse los estudios citados de Graciano (2008) y Biagini (2001 y 2012).

${ }^{192}$ Recordemos que en 1919, en medio de esos debates, Bermann presenta su ensayo para recibir el título de doctor en Medicina. El tema que aborda era central en la disputa filosófica, "el determinismo en la ciencia y en la vida". Seguramente fue la primacía antipositivista lo decidió a presentar el ensayo en Medicina y no en Filosofía. Para un análisis de las tesis allí desarrolladas, véase Celentano (2005).

${ }^{193}$ Para una reconstrucción de la rivalidad entre la definición de la Reforma promovida por Korn y la alentada por Alberini, centrada en el perfil de sus decanatos, véase Ruvituso (2010).
} 
de los referentes antipositivistas:

La Plata

Mayo 7, 1924

Mi estimado Coriolano:

Le escribo porque hoy no tendré ocasión de verle y mañana tampoco. Por otra parte las cosas desagradables las digo mejor por escrito, que de palabra.

El Honorable Consejo de la Facultad de Filosofía y Letras, ha encargado la cátedra de Estética al Dr. Chiabra. Esto, es obra exclusivamente de usted.

A mucho obliga la amistad pero no a todo. Ni Ud. habrá supuesto que yo aguantaría esta viveza.

Espero que la actitud que asumiré no lo ha de molestar, en primer lugar porque en realidad nada valgo y detrás del grupo que lo acompaña no tengo sino una función decorativa. El hueco que yo deje será fácil de suplir.

Con profunda pena, lo abraza quizá por última vez, con todo afecto de nuestra vieja amistad.

Alejandro Korn (Alberini, 1981, t.II: 33-34).

Desde entonces los artículos de Alberini, así como la producción de los discípulos de éste y de los de Korn, se disputaron la fundación del Colegio Novecentista y la condición de forjadores de la renovación filosófica argentina. Como veremos en el capítulo séptimo, Korn concentró su apuesta de un socialismo antipositivista en la Facultad de Humanidades y Ciencias de la Educación de La Plata. Sus discípulos -entre los que se destaca Francisco Romero- tendrán una proyección importante en el desarrollo de la filosofía en la Argentina y mantendrán una fuerte rivalidad con el conformado en torno de Alberini, esto es, Diego Pro, Luis Farré y Manuel Gonzalo Casas, entre otros. Sobre las resonancias políticas que acompañaron a esa rivalidad, en la década del sesenta el estudiante de la FFyL Jorge Lafforgue formulaba un interesante y rotundo juicio. Por entonces aparecía Cincuenta años de la filosofía en Argentina de Farré, en el prólogo Alberini declaraba que Korn y Rivarola no ofrecieron más que una "incipiente gnoseología", mientras que los jóvenes como él procuraban la "aventura metafísica".Lafforgue no podía evitar leer allí una manifestación más de las disputas que atravesaban a sus maestros -y que las lecturas actuales de la obra de Farré suelen pasar por alto-. Sostenía el joven que el juicio de Alberini:

aparte de ratificar la "altura" del tan mentado "vuelo" de Alberini, carece de todo valor. Sin embargo sus conceptos son repetidos a pie juntillas por varios 
meritorios alberinistas que, beligerantes, pretenden acabar con los dogmas instituidos por sus enemigos liberales. Éstos, al parecer bajo las directivas de Francisco Romero, han hecho de Korn su bandera; aquellos, según el testimonio presente, redescubren la "genialidad" de Alberini. En realidad, no se trata más que de una de las múltiples facetas de una larga rencilla, que tiene sus primeras sordas manifestaciones durante la hegemonía alberinista en la Facultad de Filosofía y Letras de Buenos Aires y que cobra un tinte bastante agrio durante el peronismo y la época siguiente, sobre todo a raíz de las distintas actitudes políticas que asumen las partes en discordia. Aquí los protagonistas no desempeñaron siempre el mismo papel: las veleidades de muchos de ellos los hacen estar alternativamente en uno $\mathrm{u}$ otro grupo, según caliente el sol (Jorge Lafforge, "Dos comentarios sobre la filosofía en la Argentina", Cuestiones de filosofía, no 1, primer trimestre 1962, p. 74).

En cuanto a la posición que asumieron a partir del peronismo algunas de las figuras que aparecieron a lo largo de los capítulos de esta primera parte, mencionemos, al menos, que Cuccaro, Monner Sans, Peradotto, Rojas, Rohde y de Aparicio se alejaron de la FFyL en 1947, cuando la intervención nacional nombró como decano a Enrique Francois (quien había participado en la década del veinte de la Verbum antipositivista), y varios de ellos volvieron con la intervención de 1956 que nombró como decano a Francisco Romero. En cambio, Casares y Probst permanecieron en la FFyL hasta 1955 y fueron expulsados en 1956. Por otra parte, hasta mediados de la década del cuarenta fueron parte del plantel de profesores del Colegio Nacional dependiente de la UNLP: Palcos como profesor de filosofía, del Mazo como profesor de matemática y física, Britos Muñoz como profesor de estética, Binayán y Gabriel como profesores de literatura.

Para concluir el capítulo subrayemos que el recorrido sugiere que tres fueron los acontecimientos filosóficos que, en los años previos a la instalación del antipositivimo, alimentaron el debate sobre la relación entre filosofía y ciencia, así como la profesionalización de la filosofía: desde 1915 Ingenieros organizó el frente filosófico cientificista a través de su Revista de Filosofía (1915-1929); en 1916 Ortega y Gasset impartió un curso sobre la Crítica de la Razón Pura y unas conferencias públicas sobre la relación de la filosofía con la vida, en las que insistió en la caducidad del cientificismo; y finalmente en 1917 un grupo de estudiantes de la FFyL fundó el antipositivista Colegio Novecentista, que vinculó la filosofía con la racionalidad extracientífica asociada a la poesía y la literatura grecolatinas -literatura que estaría en el centro del ataque emprendido por la vanguardia martifierrista-. 
Los novecentistas logran que hacia 1918 predomine en las aulas la matriz antipositivista y el impulso profesionalizador, y ello estuvo marcado por un doble desplazamiento. La alianza entre filosofía y literatura así como el estudio de las corrientes kantianas ofrecían la posibilidad de pensar en una clave no determinista la cuestión de la libertad y la responsabilidad, y con ello de recortar una problemática filosófica a distancia de la ciencia. Pero la recepción en las aulas desplazó no sólo la inscripción de la filosofía en la "cultura científica", sino también la preocupación filosófica por una sociedad más igualitaria. Y con ello la profesionalización de los estudios filosóficos consagraba un perfil de filósofo que, a pesar de la apuesta de Ingenieros y la de Korn, evitaba un diálogo intenso con su época. A comienzos de la década del treinta, los estudiantes que fundaron el segundo grupo Insurrexit reintrodujeron la necesidad un perfil de filósofo preocupado por las cuestiones sociales del presente. De todos modos, la búsqueda de una filosofía científica y ligada a las izquierdas se realizaría por canales extrauniversitarios, como la Revista de Filosofía, el Colegio Libre de Estudios Superiores, la Universidad Popular Alejandro Korn y los pequeños círculos intelectuales ligados al socialismo o al comunismo. Y estas iniciativas junto a los grupos estudiantiles como Insurrexit fueron clave en la prolongación argentina de lo que llamamos la "dimensión política" de la Reforma, dimensión que ocupa la segunda parte de esta tesis. 
SEGUNDA PARTE

EL MOMENTO POLÍTICO 


\section{Capítulo 5. La revolución universitaria de 1918, o la inscripción de la sociabilidad estudiantil en la cultura de izquierda}

Hacia 1928 tiende a quedar configurada una cultura reformista que liga al estudiante a una identidad latinoamericana antiimperialista y que durante décadas funciona como la iniciación política de muchos jóvenes que ingresan en las universidades de la Argentina y Latinoamérica. Pero ese latinoamericanismo antiimperialista no aparece como la definición inicial de la Reforma sino como un punto de llegada de diversas empresas -todas ellas autodefinidas como reformistas- que entre 1918 y 1928 asociaron la figura del estudiante a identidades políticas tan diversas como el nacionalismo de resonancias católicas y el socialismo bolchevique.

En sus memorias Julio Irazusta, quien, antes de convertirse en uno de los referentes del nacionalismo de derecha, había codirigido la Revista Nacional (1918-1920) y había participado del grupo estudiantil que identificaba la Reforma con el nacionalismo, recuerda sobre el movimiento que se iniciaba en 1918:

No había en la llamada reforma universitaria un pensamiento basado en un estudio preciso de la realidad nacional, en su pasado y su presente, y en materia doctrinaria no había hecho más que agregar al ideario de los liberales ochocentistas, fundadores del régimen imperante, las nociones más vulgares de la izquierda revolucionaria contemporánea (Irazusta, 1975: 72-73).

Si se atiende a la franja de intelectuales socialistas que durante la primera mitad del siglo XX hicieron de la Reforma su identidad política (Palacios, Sánchez Viamonte, Sanguinetti, Julio V. González, Guillermo Korn, Luis Aznar, Enrique Mouchet, entre otros) -y que recientemente han merecido un detenido análisis (Graciano, 2008)-, esa alusión a una izquierda revolucionaria parece una exageración de un intelectual antiliberal y antisocialista. Exageración en la que también caería el filósofo tomista Alberto Caturelli cuando refiere que la fundación de la FUA fue colateral a la fundación de la Federación Juvenil Comunista (Caturelli, 1992: 139). Sin embargo, si la mirada se dirige a la serie de grupos y periódicos estudiantiles que aparecieron entre 1918 y 1922 -a los que dedicamos los próximos capítulos-, puede afirmarse que el cruce entre liberalismo e izquierda revolucionaria del que se horroriza Irazusta tuvo una importante recepción entre los estudiantes argentinos. Según veremos, ese cruce fue alentado entusiastamente por la olvidada Federación de Asociaciones Culturales, por una serie de revistas también poco recordadas $\mathrm{y}$, como refiere Caturelli, por la conducción de la FUA, y ello mientras que los estudiantes federados de Buenos Aires criticaban la politización de ambas federaciones.

Entre las reivindicaciones del '18 se encontraban: la flexibilización de las condiciones de regularidad (aranceles y plazos), sobre todo en las facultades de Medicina y de Derecho; la 
recusación de profesores por su escasa calidad académica -y, en el caso cordobés, por su inscripción en la cultura católica-; la incorporación de cursos libres; la participación estudiantil en el gobierno universitario; y la ampliación de los cupos de ingresantes y de aprobados en cada examen. Pero junto con esas reivindicaciones, el grupo que lideró la FUA y otros que surgían entre 1918 y 1922 buscaron que la identidad estudiantil se asociara a un movimiento socialista revolucionario compuesto también por los sectores obreros.

En su detallada reconstrucción, Buchbinder (2005) muestra que la reforma institucional de 1918 fue mucho más gradual en la UBA que en la UNC. La Reforma estallaba en Córdoba no tanto por

el espíritu clerical y conservador de la universidad sino [por] el carácter familiar y cerrado de los círculos que la gobernaban. En gran medida, el movimiento estudiantil de Córdoba traducía una reacción contra una elite muy renuente a incorporarse al proceso de renovación de elencos directivos, que se verificó en otros lugares de la Argentina en forma mucho [más] armónica. El rol que la casa de estudios cordobesa tenía en los procesos de promoción y control de las elites dirigentes de la ciudad era central (Buchbinder, 2005: 99).

De ahí que no sorprenda que los estudiantes porteños no encontraran demasiadas resistencias para que en 1918 se implementaran sus reivindicaciones académicas: la UBA había nacido laica, pero además las reformas de 1906 habían suprimido los consejos directivos vitalicios lo que, en principio, habilitaba la renovación de los elencos directivos. Como veremos en el capítulo séptimo, fue en la Facultad de Derecho donde se registró la resistencia más enérgica a la democratización de la universidad. La aplicación de los estatutos vigentes desde agosto de 1918 desató un prolongado y violento conflicto. Entre 1923 y 1929 ese conflicto tuvo una resolución clara a favor de la fracción de profesores antirreformistas pero además dio lugar a un activo grupo reformista, el Partido Unión Reformista Centro-Izquierda, que sería central en la construcción de la identidad latinoamericana y antiimperialista de la Reforma.

La "revolución universitaria" que continuó a la de Córdoba no se dio entonces en Buenos Aires, sino en La Plata, donde los estudiantes, ante la negativa de las autoridades universitarias a modificar los estatutos según las bases establecidas por el gobierno nacional, iniciaron una prolongada huelga que contó con cierto apoyo de los sindicatos obreros. Este conflicto fue paralelo al de la Federación Universitaria de Santa Fe, la que en octubre de 1919 logró, a través de la acción de la FUA, el decreto de nacionalización de la universidad, recién en vigencia en 1922. A esas revueltas le sucedió la de los estudiantes rosarinos en solidaridad con las huelgas de la Forestal y Santa Cruz, actitud que desde Buenos Aires sólo sería saludada por los estudiantes que editaban la revista Insurrexit. ${ }^{194}$ 
Para continuar nuestro análisis de la cultura política y de la figura de estudiante que acuñaron los jóvenes que estudiaban en la ciudad de Buenos Aires, el presente capítulo reconstruye las características y principales intervenciones de los grupos porteños que, en ese contexto de modernización económica, democratización política y tensiones sociales en el que estalló la Reforma, disputaron entre 1918 y 1919 la identidad política de los estudiantes. Estos grupos fueron la Federación de Asociaciones Culturales, que lideró Bermann, el Ateneo de Estudiantes Universitarios y Colegio Novecentista, a los que se sumaron el grupo editor de Themis (1918-1919) y el de la Revista Nacional (1918-1920).

\section{El estallido de la Reforma Universitaria}

Enorme mitin callejero ratificó declaratoria de huelga. Adhiriéronse rebelión los estudiantes colegios nacionales y especiales. Entusiasmo indescriptible. Gracias por vuestra palabra de aliento. Pedimos mucha actividad, porque mayor parte del éxito depende de los camaradas de las demás universidades.

Telegrama del presidente de la Federación Universitaria de Córdoba, Enrique Barros, al presidente de la Federación Universitaria Argentina, Osvaldo Loudet, 11/06/1918.

Desde 1917 un grupo de estudiantes de la UNC vinculado a la asociación Córdoba Libre! mantuvo fuertes conflictos con las autoridades universitarias. Sus reivindicaciones inmediatas giraban en torno de la renovación de la planta docente y gubernamental. A diferencia de la UBA, esa planta era vitalicia y estaba ocupada por figuras ligadas a la cultura católica. Construyendo esa caracterización clerical de la UNC -cuyo carácter monolítico comienzan a revisar estudios más recientes como el de Buchbinder (2005) y sobre todo el de Agüero (2010)-, refería Julio V. González:

Sus academias estaban constituidas por miembros ad vitam, que dirigían las Facultades como señores de un feudo; la asistencia obligatoria hacía del estudiante un cómplice fortuito de la mixtificación de la cátedra, ejercida por profesores incapaces; la enseñanza, cristalizada en fórmulas suplantadas en medio siglo atrás, convertían al alumno en receptáculo pasivo del anacronismo de la Facultad de Derecho, cuyo programa oficial traía un punto que trataba sobre los "deberes para con los siervos" 
(González, 1931: 32). ${ }^{195}$

Para organizar sus reclamos, los estudiantes cordobeses fundaron a fines de 1917 el Comité ProReforma Universitaria, cuya presidencia estuvo formada por un representante de cada una de las tres facultades: Ernesto Garzón por Ingeniería, Gumersindo Sayago por Medicina y Horacio Valdés por Derecho. Ante el inicio del ciclo lectivo de 1918, el Comité declaró una huelga estudiantil, con fuerte acatamiento, y organizó varios actos masivos. ${ }^{196}$

La UNC contaba entonces con un poco más de mil estudiantes mientras que en la UBA estudiaban casi cinco mil jóvenes. De ahí que, como muestra el telegrama del epígrafe, el Comité cordobés, desde un comienzo, considerara decisivo el apoyo de la juventud universitaria porteña: el éxito del movimiento estudiantil dependía tanto de la repercusión que alcanzara como del apoyo del gobierno nacional. Por ello, además de entrevistarse con los representantes del gobierno, el Comité estableció un intenso flujo de telegramas, cartas y representantes estudiantiles, destinado a tensar una red de apoyo estructurada en torno de la oposición a la cultura católica y la defensa de la cultura liberal, red que -como muestran las investigaciones recientes mencionadas- tenía por finalidad práctica la apertura de los canales de renovación profesoral.

Del Mazo ofrece una breve caracterización de esa red liberal cuando recuerda que, a mediados de 1918, suspendió sus estudios en Ingeniería para dedicarse "a algo que podía pintar como muy importante" y comenzó entonces a tener "entrevistas de aspecto conspirativo" en algunos bares porteños (del Mazo, 1976: 74). A esas entrevistas pronto se sumaron las "giras de propaganda [de los delegados cordobeses] por los centros universitarios del país para explicar los orígenes del movimiento y darse cuenta de la amplitud adquirida en su desarrollo", ${ }^{197}$ pero también

${ }^{195}$ El programa al que se refiere González es el de la cátedra de Filosofía del Derecho a cargo del dr. Ignacio M. Garzón. Durante el Congreso Nacional de Estudiantes ese programa fue uno de los símbolos de la universidad a la que se oponían los reformistas de todo el país. Entre ellos, los ateneístas denunciaron el programa de Garzón en una nota que transcribe las distintas bolillas y concluye ironizando: "Como se ve, la cátedra de filosofía del derecho en la Universidad de Córdoba, es cátedra de teología, de moral y doctrina cristiana. Todo A. M. D. G. [Ad maiorem Dei gloriam]" ("La filosofía del Derecho en Córdoba", Ideas, n 18, julio de 1918, p. 357). Por su parte, también el máximo líder del PS, Juan B. Justo, ridiculizó ese programa en su intervención en la Cámara de Diputados de la Nación. La vigencia de ese programa se tradujo en su defensa de los "revoltosos" cordobeses y en el pedido de que el gobierno nacional se pronuncie del mismo modo (Buchbinder, 2005: 96).

${ }^{196}$ En esta reconstrucción seguimos a Buchbinder (2005), Del Mazo (1926-1927), Marcó del Pont (2005) y Portantiero (1978).

197 "El conflicto universitario de Córdoba", Boletín de la Federación Universitaria de La Plata, no 1, junio de 1918, p. 6. La cita pertenece al apartado "Visita de los delegados cordobeses" y es significativa al menos por dos motivos. Por un lado, consignan a los participantes cordobeses y con ello la presencia de muchas más figuras de las que quedaron inscritas en la historia de la Reforma. Los cordobeses que en 1918 llegaron a Buenos Aires y luego a La Plata fueron: Horacio Valdés e Ismael Bordabehere como presidentes de la FUC, Cortés Pla como secretario de la FUC, junto a Carlos Astrada Ponce, Manuel T. Rodríguez, Ramón Ferrerira y Carlos Suárez Pinto. Por otro lado, la referencia a las actividades sugiere que, si bien en Córdoba la confrontación era álgida, en Buenos Aires y La Plata era aún poco "revolucionaria", pues se inscribía en espacios laicos que, lejos de la vinculación obrero-estudiantil, eran propios de las elites político-culturales. En efecto, la FULP llevó a la delegación cordobesa a recorrer "la ciudad en varios automóviles, y se detuvieron en el Museo y en la Asociación de ex alumnos del Colegio Nacional. Hicieron también una visita de cortesía al vicepresidente de la Universidad, doctor Alejandro Caró. En el hotel Sportsman, la Federación les obsequió con un té. Por la noche fue servido en el Jockey Club un banquete reducido, de cincuenta cubiertos" durante el que varios jóvenes "pronunciaron brillantes discursos" (Ibid, p. 6). 
para confirmar afinidades y estrechar vínculos visibles, como lo fue la designación de corresponsales de las revistas estudiantiles.

El primer producto de esas "conspiraciones" fueron los manifiestos firmados por reconocidos intelectuales porteños ligados a la cultura liberal. Entre quienes apoyaron a los jóvenes cordobeses se encontraron José Ingenieros, Leopoldo Lugones, Ricardo Rojas y Alfredo Palacios.

Otra expresión de esa red fue la llegada a Córdoba de Palacios y Bermann -aquel en calidad del "primer diputado de América" 198 y éste en calidad de representante de la FUBA- para participar como oradores en uno de los actos masivos organizados durante la huelga estudiantil. Y una nueva evidencia del fraccionamiento entre cultura liberal y cultura católica con que se iniciaba el movimiento de la Reforma la ofrece la compilación "Antecedentes sobre los sucesos de la Universidad de Córdoba” que Ingenieros publicó en su revista a mediados de 1918.

En la nota que abría la compilación, Ingenieros, bajo el seudónimo de Julio Barreda Lynch, saludaba las reivindicaciones reformistas y definía la crisis de la universidad cordobesa como "el resultado de una lucha empeñada hace ya algún tiempo entre sus elementos clericales, manejados por los jesuitas y agrupados en la sociedad semi-secreta Corda Frates, y los elementos liberales que desean renovarla de acuerdo con los resultados de la ciencia contemporánea". ${ }^{199}$ La compilación también publicaba una nota de Juan Díaz Salazar, quien, como mencionamos, había abierto la polémica a mediados de 1917 y había sido criticado por La Vanguardia y uno de los números de Verbum dirigidos por Bermann.

Díaz Salazar defendía la formación tanto de una Universidad Católica como de una Federación de Estudiantes Católicos, y declaraba que no era la UNC sino la liberal UNLP la “institución peligrosa para la moral y el orden”. Lo que aquí nos interesa es que en su justificación Díaz Salazar ofrecía un mapa del fraccionamiento intelectual sobre el que se apoyaría la primera red reformista:

Ya estamos cansados de oír como autoridad en materia educacional al doctor Joaquín V. González, cuyo mérito principal en materia educacional ha consistido en inventar ese organismo sin funciones que se llama Universidad de La Plata, rodeándose allí, para que le den bombo, de todos los corifeos liberales del país. Esta ha sido, sí, una obra sectaria levantada exclusivamente contra el cristianismo argentino. Allí fue vicepresidente Agustín Álvarez, el jefe de la masonería, y secretario del Valle Iberlucea, el senador socialista. Allí han sido decanos Piñero, Rivarola, Matienzo, Mercante, Besio Moreno, todos liberales; allí han sido profesores Holmberg, Lugones, Ferreyra, Senet, Rojas, Nelson, Ingenieros, Herrero Duclout, Herrera, Chiabra y tantos otros enemigos

\footnotetext{
${ }_{198}$ Palacios había sido expulsado del PS en 1916, al que reingresó en 1928. En 1918 lideraba el pequeño Partido Socialista Argentino desde el que simpatizaba con los bolcheviques. Sobre su itinerario político-intelectual, véase Tarcus (2007a). Si bien volveremos sobre su intervención en el movimiento estudiantil, mencionemos que pueden consultarse los trabajos de Graciano (2005 y 2008).

${ }^{199}$ Julio Barreda Lynch, "La 'Corda Frates' en la Universidad de Córdoba”, Revista de Filosofía, año IV, n IV, julio de 1918, p. 135 (publicado originalmente en El Estudiante).
} 
declarados de la iglesia, científicos los unos, teósofos los otros y normalistas los demás (Juan Díaz Salazar, "La escuela y la religión”, El Universitario, 24/03/1917; rep. en Revista de Filosofía, año IV, no IV, julio de 1918, p. 141).

Los estudiantes católicos cordobeses se expresaban en el periódico Los Principios, al tiempo que fundaban a fines de junio de 1918 El Heraldo. Unicuique suum (Cicerón), editado por el Comité pro-defensa de la Universidad bajo la dirección de José Oro. ${ }^{200}$ Asimismo, durante 1919 tuvieron un aliado en el Colegio Novecentista de Buenos Aires. Por su parte, los científicos, teósofos y normalistas firmaban manifiestos y apoyaban a los estudiantes que fundaban la FUA, una instancia que sin duda agilizó la red nacional de apoyo a los reformistas cordobeses.

El 11 de abril de 1918, los representantes de la FUBA aprovecharon la estadía de dos representantes del Comité Pro-Reforma, Sayago y Valdés, para reunirse en la sala de la dirección de la Revista del Círculo Médico Argentino y CE de Medicina (sala en la que sesionaba la FUBA) junto a delegados de la FULP y de las universidades provinciales de Tucumán y Santa Fe y fundar la FUA. $^{201} \mathrm{La}$ actividad inaugural de la primera organización estudiantil argentina de alcance nacional fue un acto de apoyo a los estudiantes cordobeses. Además de los estudiantes que representaban a cada universidad, fueron allí oradores del Mazo en calidad de representante del Ateneo de Estudiantes Universitarios y Manuel Ugarte en tanto "maestro de la juventud". Este reconocimiento de los estudiantes seguramente provenía de la intensa campaña antiimperialista y latinoamericanista ligada a una sensibilidad de socialista, que Ugarte venía realizando hacía algunos años, y que en 1918 se orientaba a dar publicidad a la revolución que estaba teniendo lugar en México, país del que acababa de regresar.

El conflicto que mantenían los estudiantes cordobeses con los profesores y estudiantes filiados a la cultura católica funcionaba como el detonante de la organización estudiantil nacional que, desde hacía algunos años, propiciaba la FUBA y el Ateneo estudiantil. Sobre el papel del Ateneo en la fundación de la FUA, subrayemos que el importante papel que jugó en la primera sociabilización de los estudiantes porteños se advierte, por un lado, en el hecho de que del Mazo participó de la asamblea constituyente de la FUA como representante del Ateneo y, al año siguiente, se convirtió en el tercer presidente de la FUA y, por el otro, en que fue otro ateneísta, Alejandro Terrera, quien fue el primer director del Boletín de la Federación Universitaria (1917-1918) de Buenos Aires, publicación que impulsó la creación de una federación estudiantil nacional y que

\footnotetext{
${ }^{200}$ Dos números de esta inexplorada revista se han conservado en el CeDInCI.

${ }^{201}$ Bajo la convocatoria de joven Guillermo Watson, asistieron a la asamblea fundacional los siguientes representantes de las federaciones regionales: por Buenos Aires Osvaldo Loudet, Gabriel del Mazo, Gregorio Bermann (como enviado especial a Córdoba) y José Belbey (como secretario de la asamblea); por La Plata, Carlos Lloveras y Antonio G. Pepe; por Córdoba Gumersindo Sayago y Horacio Valdés; por Santa Fe Humberto C. Gambino y Paulino A. Pezzia y por Tucumán Marcial E. Bognón y T. Passaponti ("Constitución de la Federación Universitaria Argentina", Verbum, n 4142, marzo-abril de 1918, pp. 72-73). El acta fundacional de la FUA, los discursos en apoyo a los reformistas cordobeses que se pronunciaron en la asamblea constituyente y otras pocas actas han sido publicadas en del Mazo (1927, t.II).
} 
sdejó de editarse luego de su tercer número. ${ }^{202}$

El mismo día de abril en que se fundaba la FUA, el Comité cordobés conseguía que Yrigoyen decretara la primera intervención de la Universidad. Poco tiempo después, el primer mandatario enviaba a Córdoba como presidente de la intervención a José Nicolás Matienzo, uno de los claros exponentes del liberalismo que mencionaba Díaz Salazar. Matienzo establecía unos estatutos que reabrían el internado del Hospital de Clínicas, cerrado a fines de 1917, desplazaban de sus cargos a varios de los profesores católicos y reemplazaban los consejos vitalicios por consejos de profesores elegidos por éstos en asamblea. Dejando todo dispuesto para que el 28 de mayo se eligieran los decanos y el 15 de junio el nuevo rector, Matienzo regresaba a Buenos Aires.

Los estudiantes reformistas promovieron la candidatura a rector de Enrique Martínez Paz, justamente ese profesor al que en 1916 el estudiante Hiram Pozzo se refería como el solícito consejero de los jóvenes de Córdoba Libre!. En el marco de esa campaña, el Comité Pro-Reforma lanzó el primer número de un periódico de ocho páginas, formato tabloide y aparición semanal llamado La Gaceta Universitaria. Órgano de la juventud universitaria. A través de éste, los jóvenes reformistas publicitaron las últimas novedades de sus luchas, difundieron ideas ligadas a sus reivindicaciones y anunciaron sus próximas actividades. A mediados de mayo, el Comité se convirtió en la FUC y La Gaceta Universitaria en su órgano. El triunvirato presidencial de la FUC pasaba entonces a estar presidido por Ismael Bordabehere por Ingeniería, Enrique Barros por Medicina y Horacio Valdés continuaba representando a los estudiantes de Derecho; asimismo, los dos últimos jóvenes asumían la dirección de La Gaceta Universitaria.

Las elecciones de los decanos transcurrieron sin mucho conflicto, pero la del rector hizo estallar la Reforma Universitaria. A través de una maniobra fraudulenta, la fracción clerical de profesores consiguió que ganara su candidato; ante ese hecho los estudiantes federados irrumpieron en la sesión del Consejo Directivo y tomaron el Rectorado. Sobre las primeras repercusiones porteñas, recuerda del Mazo:

Los telegramas oficiales y particulares de los amigos de Córdoba comenzaron a llegar al día siguiente, 16. Literatura típicamente romántica. Todo el día me lo pasé telefoneando y telegrafiando a estudiantes dirigentes, instándolos a la necesidad de la reunión en mi casa, el día siguiente quedamos comprometidos a pensar en las líneas generales de la organización y gobierno de la Universidad que queríamos levantar (del Mazo, 1976: $85)$.

\footnotetext{
${ }^{202}$ Los archivos de la FUA se han perdido. A partir de diversas fuentes, sabemos que los primeros presidentes de la FUA fueron: 1918, Osvaldo Loudet; 1919, Julio V. González; 1920, Del Mazo; 1921, Eduardo Araujo; 1922, Pablo Vrillaud. Aparentemente, al año siguiente la FUA se disolvió hasta 1926. No contamos con ninguna fuente que nos informe de las discusiones que antecedían a las candidaturas presidenciales de la FUA. Sólo sabemos, a través de del Mazo (1976), que la elección de Vrillaud se proponía darle más fuerza al reclamo de los estudiantes federados de la Universidad del Litoral.
} 
A ese flujo de llamadas y telegramas -sobre los que Bergel y Martínez Mazzola (2010) han llamado la atención para estudiar los canales que posibilitaron la idea de Latinoamérica- ${ }^{203}$ se sumaba unos días después el envío del célebre "Manifiesto liminar". Éste aparecía originariamente en la primera página de La Gaceta Universitaria, junto a las firmas de la mesa directiva de la FUC, y proponía una condensación ideológica de las demandas estudiantiles. Señalando la llegada de una "hora americana", se dirigía a los hombres libres de Sudamérica para informarles sobre los acontecimientos que llevaron a la toma de la Universidad e invitarlos a defender tanto un gobierno universitario con participación estudiantil como una sociedad más democrática.

Junto a la primera publicación del manifiesto, La Gaceta Universitaria convocaba a un nuevo acto que se realizaría el domingo 23 de junio. Sobre ese acto sostenía el siguiente número que "salvo la ausencia muy sentida de Leopoldo Lugones, se cumplió totalmente el programa anunciado"; allí fueron oradores Raimundo Meabe, presidente de la FUBA, y Alfredo Palacios “debiendo agregarse los discursos de Arturo Capdevila, Deodoro Roca y [el joven] Pablo Vrillard, este último en su carácter de delegado de la Federación Universitaria de la ciudad de Santa Fe". ${ }^{204}$

Enrique Barros asumía la representación de la FUC ante el gobierno nacional. Del Mazo recuerda a su camarada, que entonces contaba con 25 años y en los meses próximos sería salvajemente atacado por un grupo de estudiantes católicos, como "una figura muy combatiente y a la vez diplomáticamente diestra, con plan y penetrante inteligencia" (del Mazo, 1976: 94). Barros consiguió que el 2 de agosto de 1918 Yrigoyen decretara una nueva intervención. Ésta sería encabezada por el médico y político, referente del anticlericalismo, Telémaco Susini. La designación motivaba una fuerte resistencia de los sectores clericales y a los pocos días Susini desistía del cargo. Mediante un nuevo decreto, fechado el 23 de agosto, el presidente designó como nuevo interventor a José Salinas, entonces ministro de Instrucción Pública. Su llegada se demoró hasta el 11 de septiembre y dispuso una elección de autoridades que, con el apoyo de los estudiantes reformistas, terminó otorgándole el cargo de rector a Eliseo Soaje.

Mientras los estudiantes federados de Córdoba esperaban el arribo de Salinas, sesenta representantes estudiantiles de las cinco federaciones que componían la FUA viajaron a aquella ciudad, con el financiamiento del gobierno nacional, para realizar el Primer Congreso Nacional de Estudiantes. La sesión preparatoria tuvo lugar el 20 de julio, el congreso se inauguró el 21 y sus sesiones ordinarias se extendieron desde el 22 hasta el 30 de julio. Durante esos días los jóvenes discutieron una serie de informes que algunos estudiantes habían preparado previamente. Las votaciones terminaron aprobando resoluciones que tendían a no inscribirse en el campo de la

\footnotetext{
${ }^{203}$ Confirmando la autoconciencia que tenían del acontecimiento histórico que estaban protagonizando, los líderes de la Reforma conservaron varios de esos telegramas y actualmente ellos pueden consultarse en la Casa de la Reforma de la Universidad de Córdoba y en el Museo Histórico de la Universidad del Litoral.

204 “Ecos del mitin del domingo", La Gaceta Universitaria, n 10, p. 1.
} 
izquierda, como sí lo haría la FUC durante esos años y el Primer Congreso Internacional de Estudiantes, que tuvo lugar en México DF en 1921. De todos modos, los jóvenes escucharon, al menos, dos encendidos discursos, proferidos por dos graduados recientes que desde la asociación Córdoba Libre! reclamaban una cultura universitaria laica: Saúl Taborda, quien tenía 33 años, y Deodoro Roca, que contaba con 26 años.

Taborda pronunció unas "Reflexiones sobre el ideal político de América", síntesis del libro homónimo, dedicado a Ingenieros, que había publicado en Córdoba, dos semanas después del estallido de la Reforma, en una edición de autor. Allí llamaba al hombre americano no sólo a oponerse a los Estados Unidos, como lo venía haciendo el arielismo, sino también a rectificar a esa Europa que había perdido el rumbo luego de la Gran Guerra, un llamado que, a pesar de su inscripción en la reacción antipositivista, guardaba importantes puntos de contacto con el que realizaría unos meses después Ingenieros en su célebre discurso de adhesión al maximalismo. ${ }^{205}$

Por su parte, Roca cerró el congreso con "La nueva generación americana”, una conferencia que proponía otorgarle un peculiar signo socialista al movimiento estudiantil. Este joven también señalaba la guerra europea como un parteaguas, pero se inscribía junto a los congresales en la “generación del '14" llamada a cambiar los tiempos desde las casas de estudio. Sostenía en ese discurso que "en la Universidad está el secreto de la futura transformación” y por ello se debía "ir a nuestras universidades a vivir, no a pasar por ellas; ir a formar allí el alma que irradie sobre la nacionalidad; esperar que de la acción recíproca entre la Universidad y el Pueblo surja nuestra real grandeza" (del Mazo, 1926, t.I: 16). ${ }^{206}$

Si bien, como señalan Cattáneo y Rodríguez (2000), Roca trabajaba allí con paradigmas clásicos y jerárquizantes en cuanto a la relación entre estudiantes y obreros, las discursos que por esos años pronunció sugieren que ese señalamiento de una "acción recíproca" intentaba inscribir la acción estudiantil en el reclamo de igualdad y justicia social ligado tanto al socialismo bolchevique como a figuras -citadas frecuentemente en esos discursos- como Trostky, Lenin, Gorki, Rolland, Nicolai y d'Ors (entonces simpatizante del sindicalismo revolucionario). A ello Roca y otros líderes de Córdoba Libre! Sumaron el saludo a aquellas federaciones estudiantiles que apoyaban, a través de huelgas y manifiestos -algunos seguramente redactados por aquel-, a las múltiples protestas del movimiento obrero organizado en la Federación Obrera de Córdoba. Y una prueba de que esa

\footnotetext{
${ }^{205}$ Taborda difundía entonces las críticas anarquistas al Estado, saludaba la Revolución Rusa y participaba de la sociabilidad georgistas. Como vimos, la ley de enfiteusis georgista era una de las reivindicaciones de Córdoba Libre!. A pesar de ser cordobés, Taborda había hecho sus estudios secundarios en el Colegio Nacional de Rosario (junto a Florentino Sanguinetti y Enzo Bordabehere) y había estudiado Derecho en la UNLP durante la primera década del siglo XX. Luego regresó a Córdoba, aunque, como veremos, entre 1921 y 1922 se asentó en La Plata junto a los cordobeses Héctor Roca, Emilio Biagosch y Carlos Astrada para liderar la renovación del Colegio Nacional dependiente de esa universidad. Para una reconstrucción del pensamiento de Taborda, véase Ferrero (1998).

${ }^{206}$ Los informes estudiantiles y el discurso de Roca, así como los de los jóvenes Manuel Rodríguez y Alberto Mendioroz -que junto al de Roca cerraron el Congreso-, fueron publicados en del Mazo (1927, t.II) y con ello comenzaron a circular de modo organizado por el continente como un aliciente para nuevos proyectos estudiantiles.
} 
primera afinidad del movimiento estudiantil con el horizonte político socialista era sumamente clara en la época la ofrece la enérgica y célebre pastoral de mediados de 1918 del obispo de Córdoba, Zenon Bustos y Ferreyra, quien acusaba a los estudiantes de "echarse a las calles con la revolución" maximalista.

Varios ateneístas habían viajado al congreso cordobés y se encontraban entre el auditorio de Roca, mientras que los casi trescientos jóvenes porteños que estaban suscritos al órgano del Ateneo, Ideas, conocerían a través de éste las palabras de Roca. Quienes participaron en el Congreso como representantes del Ateneo fueron: del Mazo, Julio Malarino Cabrera, Horacio Pozzo y José María Monner Sans. Asimismo, el Ateneo acordó una "representación subsidiaria a los miembros del congreso, nuestros consocios Hiram Pozzo, Muñoz Montoro, Watson y Terrera" ${ }^{207}$ Aprovechando la estadía de los ateneístas, Roca organizó en el Museo Provincial de Córdoba -del que era directoruna conferencia en la que el líder del Ateneo explicó los propósitos del grupo porteño y fundó una sede cordobesa, que parece no haber prosperado. A su vez, cuando en octubre de 1919 Roca visitó Buenos Aires el Ateneo le organizó un banquete en homenaje y al poco tiempo repudió públicamente la expulsión de Roca del Museo. ${ }^{208}$

Por otra parte, unas semanas antes del congreso estudiantil de 1918, era fundada otra agrupación que, a pesar de permanecer olvidada por los estudios sobre la Reforma, se asignó la tarea de coordinar el apoyo de los grupos porteños a los estudiantes federados de Córdoba, y con ello fue también la promotora de la difícil radicalización de la juventud universitaria de Buenos Aires. En sus memorias, del Mazo se refiere indirectamente a esa agrupación cuando afirma que “Gregorio Bermann, siempre diligente y definido, [...] se especializó en mantener al día las relaciones con los jóvenes de Córdoba, al punto que definitivamente fue a vivir a esa ciudad. Tenía implícitamente, además, el encargo de las relaciones de estudiantes y obreros encarecida por el Congreso de Estudiantes" (del Mazo, 1976: 101). De ese encargo seguramente haya surgido la Federación de Asociaciones Culturales de Buenos Aires, agrupación a la que dedicamos los apartados siguientes.

\footnotetext{
207 "El Ateneo en el Congreso", Ideas, n 18, julio de 1918, p. 327. Al volver del Congreso, uno de los representantes de la FUL, el joven estudiante de ciencias de la educación Walter Elena, publicó en la revista Themis -sobre la que volveremos en este capítulo- una alegre crónica que describía a varios de los representantes estudiantiles. Allí Muñoz Montoro era recordado del siguiente modo: "en fila primera de la derecha veía una cabeza crespa, un cuello muy fino que nacía de unos hombros bajísimos, estrafalariamente. Su propietario era Muñoz Montoro, de Buenos Aires, ilustrado y satírico, y al cual, por su porte delgaducho y galante, al par que por su palabra, llena de ternezas, se le había apellidado 'la angélica Manuelita"' (Walter Elena, "Informe del Congreso Nacional de Estudiantes", Themis, n 70, agosto de 1918, p. 97, cit. en Ciria y Sanguinetti, 1968: 36). Sobre su compañero platense Arnaldo Orfila Reynal, a quien encontraremos en 1921 viajando a México para asistir al Congreso Internacional de Estudiantes, Elena sostenía que había sido apodado "el turista" "por su gusto de embarcarse en cualquier discusión" y aclaraba que "mucho era su tino y generalmente salía triunfante" (idem).

${ }^{208}$ El acto en el Museo Provincial de Córdoba fue noticia en los periódicos cordobeses La Voz del Interior (25/07/1918) y La Opinión (26/07/1918). Los ateneístas trascribieron esas notas bajo el título "La conferencia de Monner Sans en Córdoba" (Ideas, n 18, julio de 1918, pp. 327-29). Asimismo, Idea reseñó el banquete, reprodujo los discursos y luego hizo públicas las cartas en repudio de la expulsión de Roca del Museo. El discurso de Roca fue además compilado por del Mazo (1926, t.I: 181-185).
} 


\section{8 y la primera articulación de los estudiantes revolucionarios}

Señalamos insistentemente una nueva moda porteña.
Cada vez que hay un hecho de alguna importancia,
muchas instituciones producen un manifiesto
comentando la situación, criticando actitudes y
aconsejando soluciones.
Esteban Hernández, "Dos manifiestos", Revista
Nacional, 1919.

Más allá de que con esa apelación a "una nueva moda porteña" la revista de Mario Jurado y Julio Irazusta se propusiera explicitar sus distancias con la solidaridad obrera que, luego de la Semana Trágica, habían declarado la FUA y el Ateneo, el señalamiento de esa moda es una interesante prueba de que para comienzos de 1919 era evidente que una serie de grupos estudiantiles habían hecho entrar la identidad estudiantil en un "momento político" y que para ello habían acuñado nuevas prácticas que llegaban para quedarse. Entre esas prácticas sería central la de redactar un manifiesto ante cada "hecho de alguna importancia".

Seguramente, el joven que, en los inicios de la Reforma, más se comprometió en el intento de que la identidad de los estudiantes porteños se ligara al socialismo haya sido Gregorio Bermann. En 1918, este hijo de inmigrantes judíos tenía 24 años, cursaba el último año de Medicina en la UBA, escribía reseñas para la Revista del Círculo Médico y el Centro de Estudiantes de Medicina, al tiempo que estudiaba Filosofía y vimos que participaba activamente de las instancias gremiales de esa facultad. A ello le sumaba la fundación de una federación que se propuso apoyar desde Buenos Aires a los estudiantes cordobeses y que, desde un cientificismo distante de la prosa esteticista de Roca, buscó dotar de un sentido socialista al movimiento universitario que nacía.

Como citamos, al cerrar el congreso estudiantil de julio de 1918, Roca llamó a los estudiantes a "ir a nuestras universidades a vivir, no a pasar por ellas" y a "esperar que de la acción recíproca entre la Universidad y el Pueblo surja nuestra real grandeza”. Los estudiantes que animaban la FUC respondieron a ese doble llamado fundamentalmente a través de tres empresas: la redacción de manifiestos y periódicos, la participación en varias de las huelgas obreras que se produjeron entre 1918 y 1922 y la organización de mitines. A los documentos editados por del Mazo entre 1926 y 1927 sobre esas empresas, podemos sumar el recuerdo de otro protagonista, el médico anarquista Juan Lazarte, quien en 1918 estaba finalizando sus estudios de Medicina en Córdoba y se sumaba a la FUC. ${ }^{209}$

En 1935 Lazarte editó su balance de la Reforma. Como mencionamos en la introducción, el

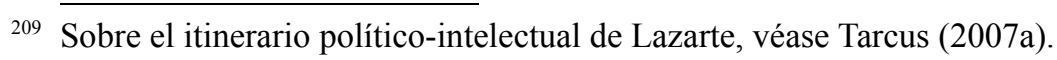


libro intentaba legitimar la lucha antifascista que habían iniciado un año antes los sectores comunistas y anarquistas del movimiento estudiantil y obrero, y para ello insistía en que, en los primeros años de la Reforma, una mayoría estudiantil que aspiraba a reducir la Reforma a las cuestiones pedagógicas era cuestionada por una minoría revolucionaria. Según Lazarte, por iniciativa de esa minoría entre 1918 y 1923

en Córdoba el movimiento exclusivo universitario tiende a dejar de serlo para convertirse en un puesto de lucha más, en las batallas sociales. Estudiantes y obreros se encuentran infinidad de veces juntos no sólo en la huelga estudiantil, sino en la Huelga General y en el Sindicato donde se trata de unir y capacitar al elemento obrero. La Federación Universitaria llega a apoyar unas veces rotundamente el movimiento gremial nacional e internacional. Es cierto que retrocede como asustada, pero los acontecimientos superan y dejan seguir la avalancha (Lazarte, 1935: 31).

Y refiere allí sobre los estudiantes federados cordobeses: "En asamblea memorable que durara tres sesiones se discutió ante un público en su mayoría estudiantil, de más de 700 personas, si el progreso debía hacerse por evolución o por revolución y por una mayoría enorme se votó que el único camino que marcaba la época era la Revolución" (Lazarte, 1935: 86). El resultado de la votación pone en evidencia tanto que entre los reformistas el evolucionismo biologicista dejaba de ser parámetro para pensar lo social, como que la FUC había recogido el llamado de Roca a una acción recíproca entre la universidad y el pueblo.

También la Federación Universitaria de la ciudad de Santa Fe parece haber recogido ese llamado, pues entre los pocos números conservados de La Gaceta Universitaria. Órgano de la Federación Universitaria puede leerse una breve y desafiante nota anónima que asegura:

Durante los días del conflicto, los estudiantes [santafesinos] trasladaron la Universidad a los locales obreros y a las bibliotecas de esta ciudad, en los cuales, a pesar de no haber "cuerpo académicos vitalicios" se vivió la verdadera Universidad Social, como la que Altamira supo realizar en Oviedo.

Los actos se desarrollaron dentro de una sencillez y de una sinceridad que faltaban en aquellas ridículas conferencias del magister.

Muchas veces, al terminar el acto, los estudiantes y el pueblo expandían la Universidad por la calle, poniendo una nota de entusiasmo y alegría en la tranquila Santa $\mathrm{Fe}$, que se sintió alborozada.

Cuando la juventud vuelva a "la casa" que ha sido Universidad tan sólo por el letrero que ostentaba, la verdadera universidad, la Social, habría entrado en ella, después de un peregrinaje de luz, nacido de la confraternización de los estudiantes con el pueblo.

Entonces, los "papás" catedráticos podrán aprender muchas verdades ("Las conferencias organizadas por la Federación Universitaria", La Gaceta Universitaria, n ${ }^{\circ}$ 2, Santa $\mathrm{Fe}, 17 / 07 / 1919)$.

Los estudiantes federados de Santa Fe se referenciaban en la experiencia de la Universidad de Oviedo -la que, según vimos, ya era invocada en 1914 por los arielistas porteños- para establecer 
vínculos obrero-estudiantiles, como los alentados por Roca. Por su parte, la FUBA y la FULP, a distancia de la FUC y los federados santafesinos, intentaban mantenerse en una posición gremialista y apolítica. En cuanto a la federación platense, para que fuera recogido el llamado de Roca a estrechar los vínculos de los estudiantes con el pueblo, habría que esperar hasta que las autoridades universitarias se negaran al cogobierno estudiantil y los estudiantes iniciaran, a fines de 1919, la "huelga grande". 210

La participación en el Congreso motivaba a la FULP a fundar su primer periódico: el Boletín de la Federación Universitaria de La Plata tenía como director al joven Luis H. Sommariva, acompañado por un cuerpo de redactores de las distintas facultades. Si bien el primer número está fechado en junio de 1918, fue preparado después del encuentro cordobés de julio, pues su última nota, "Periodismo universitario", aclara que fue la exposición sobre la prensa estudiantil, que presentó Muñoz Montoro en ese Congreso, la que decidió a la FULP a armar el proyecto. ${ }^{211}$

Los primeros números del Boletín difundieron noticias y documentos a través de los que los estudiantes platenses buscaban consolidar vínculos con agrupaciones estudiantiles de otras ciudades. Especialmente, se vincularon con la FUC -de la que habían recibido a una delegación, en compañía de representantes de la FUA, y dos mil ejemplares del "Manifiesto liminar"- y con la revista Atenea, editada por los exalumnos del Colegio Nacional de La Plata entre 1918 y 1920, bajo la dirección del poeta y profesor Rafael Alberto Arrieta (1889-1968), y la porteña Ideas. Tanto de Ideas como de Atenea, el Boletín anunció una publicidad y mantuvo intercambio.

El 20 de octubre de 1919 los estudiantes federados platenses iniciaban la "huelga grande" y, al calor de esas luchas, rebautizaban su órgano para poner de manifiesto el tono más confrontativo que adquiría la FULP en su relación con las instituciones educativas de la ciudad. En los años próximos el Boletín pasó a llamarse Renovación y -según las referencias de otras publicacionesllegó a más de veintidós números.

En octubre de 1920 era fundado el Boletín del Centro de Estudiantes de Ciencias de la Educación en el que, sin consignar su equipo de redacción, se recogía explícitamente la intervención de 1918 de Muñoz Montoro, pero también se reproducían artículos del líder pedagógico de la Revolución Rusa, Máximo Gorki, y se saludaba a Alborada de La Plata (órgano, hoy inhallable, de un activo centro ligado al anarquismo) e Insurrexit de Buenos Aires, "dos periódicos simpáticos y valientes, encausados en las nuevas corrientes ideológicas y que estudian con preferencia la faz social del problema del momento”. Este saludo concluía destacando el mérito

\footnotetext{
${ }^{210}$ Para un análisis del movimiento estudiantil platense desde los años previos hasta la década del cuarenta pasando por una detenida reconstrucción de la huelga grande, véase Biagini (2012: 111-180).

${ }^{211}$ Los redactores eran anunciados del siguiente modo: J. Rafael Guerrero (de la Facultad de Derecho); Carlos Rodríguez Jáuregui (de Ingeniería); Walter Elena (de Ciencias de la Educación); Federico F. Falco y Arnaldo Orfila Reynal (de Química y Farmacia); Maximiliano Carbó (de Agronomía y Veterinaria). Administrador: José M. Ahumada (h).
} 
del grupo de universitarios de Insurrexit, pues eran una excepción "en el ambiente frío y aplastado de esa ciudad". 212

En cuanto a la FUA, las autoridades de la UBA, como mencionamos, no ofrecieron demasiadas resistencias a la reforma institucional. Los nuevos estatutos nacionales estipulaban la renovación de las autoridades a través de una asamblea de representantes en la que los estudiantes estaban por primera vez representados; asimismo, preveían la aprobación de nuevos planes de estudio para los que debían armarse comisiones especiales. Algunos profesores renunciaban en disconformidad con la participación estudiantil mientras que en la Facultad de Derecho se abría una prolongada confrontación. Es que era en esa institución formadora de la clase política nacional donde había algo similar a esos "cuerpos académicos vitalicios" que buscaban destronar los estudiantes cordobeses y santafesinos (Buchbinder, 2005; Candelari y Funes, 1999; Graciano, 2008; Halperín Donghi, 1963).

Esta llegada a la UBA de las demandas de carácter institucional, sin necesidad de un anclaje obrero ni interuniversitario, era correlativa al primado de una agremiación estudiantil que se resistía a identificar la condición estudiantil con actividades que trascendieran el estudio. "Todos somos reformistas" titulaba Monner Sans a una breve nota en la que denunciaba el "dernier cri" de profesores y alumnos de llamarse reformistas y no saber nada de "docencia libre, de sistema de seminario, de renovación periódica y completa de autoridades, de representación equitativa de profesores suplentes y de alumnos en los Consejos Directivos, etc, etc.". ${ }^{213}$ Y a continuación el líder del Ateneo ironizaba sobre los "despreciables" rasgos de los estudiantes porteños, tan distantes de los jóvenes que acababa de conocer en el Congreso Nacional de Estudiantes:

Conviene que los jóvenes que, en la actualidad, cursan sus estudios secundarios, sepan dos cosas que, con afanoso empeño, quieren mantenerse ocultas: $1^{\circ}$, que los estudiantes universitarios porteños son hombres, por lo común, poco estudiosos, incapaces de llevar a cabo seriamente una cruzada renovadora, debilitados por una apatía enfermiza, y carentes del necesario carácter para soportar con estoicismo las represalias de los malos catedráticos; $2^{\circ}$, que, en estas revoluciones recientes, la mayoría sólo quiere provocar el tumulto y el escándalo, para agregar una "farra" más a la lista de sus famosos desórdenes en "cabarets", o en otros lugares de pública diversión (José María Monner Sans, "Todos somos reformistas", Ideas, no 19-20, septiembre-noviembre de 1918, pp. 69-70).

Frente a esta indiferencia de la mayoría de los estudiantes porteños y a la resistencia de la FUBA de precisar una identidad inscrita en las izquierdas, Monner Sans y algunos de los estudiantes que conformaban el comité de la FUA emprendían diversas iniciativas. Según veremos en el capítulo

\footnotetext{
212 "Periodismo Universitario", Boletín del Centro de Estudiantes de Ciencias de la Educación, 15/10/1920, pp. 10-11. Este CE se había opuesto a la "huelga grande", pero los estudiantes que ganan las elecciones, una vez finalizado el conflicto, sí promueven la democratización universitaria y la vinculación con el movimiento obrero que alienta la FULP.

${ }^{213}$ José María Monner Sans, “Todos somos reformistas”, Ideas, n 19-20, septiembre-noviembre de 1918, p. 70.
} 
siguiente, en 1919 aquel conseguía que el Ateneo se definiera a favor de la lucha proletaria y editara la revista político-cultural Clarín. Por su parte, el estudiante de Medicina José Belbey se proponía radicalizar la posición del CE de Medicina a través de la revista La Cureta (1918-1926). Ésta criticó irónicamente a los malos profesores y alentó las demandas institucionales de la Reforma. Pero junto a ello se propuso conectar al movimiento que nacía con un programa político ligado al horizonte socialista abierto por la Revolución Rusa.

Una prueba de la apuesta de La Cureta la ofrece el saludo que pronunció junto a la reproducción del decreto (firmado por Valdez, Bordabehere y Barros) con el que la FUC adhería a la huelga de la Federación Obrera Local. En una inequívoca prosa emancipatoria -que es otra muestra de que debe revisarse la tendencia a negar la existencia, ya en los inicios de la Reforma, de fracciones, si bien minoritarias, decididamente radicalizadas-, proponía un tal Hernán Vargas, seudónimo que seguramente ocultase la pluma de Belbey:

Surgen las luces de un nuevo día, que prometen alumbrar toda una era de transformación social en la República. Sus primeros destellos nacieron en la docta Córdoba [...] hoy esa misma juventud -para nuestro ejemplo y el de las futuras generaciones- se estrecha en fraternal abrazo con el proletariado, se une a él convencida que su alma forma parte integrante del pueblo que sufre y que trabaja y rompiendo con convencionalismos anticuados, con las tradiciones ridículas no vacila un sólo instante en marchar en pos de la bandera roja -que no era emblema de sangre y fuego, ni anarquía y destrucción como alguien ha dicho, sino que representaba en ese instante la reivindicación de los derechos del proletariado y señalaba con su color de fuego el sendero que debían seguir los que se creían dignos de cumplir una misión honrosa sobre la tierra -así lo comprendió la juventud de Córdoba y marchó tras ella entonando el himno de los trabajadores mostrando a todo un pueblo que la contemplaba que los futuros doctores y jueces, que el futuro cerebro de la nación conoce desde ya el sitio en que reside la razón y la justicia (Hernán Vargas, "El ejemplo de la juventud cordobesa", La Cureta, no 5, 25/09/1918, pp. 116-117).

Por su parte, Gregorio Bermann encabezaba una iniciativa más pretenciosa: fundaba la mencionada Federación de Asociaciones Culturales, en la que participarían, junto a más de veinte grupos socialistas, la Universidad Libre fundada por los antiguos arielistas y el ateneo estudiantil que lideraba Monner Sans.

\section{Una nueva iniciativa de Bermann: la Federación de Asociaciones Culturales (1918-1919)}

El propósito principal de esta Federación parece haber sido que distintos grupos y bibliotecas participaran en las actividades realizadas en Buenos Aires en apoyo a los reformistas cordobeses. Algunas referencias rescatadas nos permiten precisar las actividades y la sensibilidad política de la empresa que tuvo como presidente en 1918 a Bermann y en 1919 al profesor socialista Nicolás Besio Moreno, enotnces decano de la Facultad de Ciencias Exactas de La Plata. En una de las 
piezas de la polémica que en 1921 mantuvo Barros con el diputado socialista y director de $L a$ Vanguardia Nicolás Repetto, aquel calificaba a Bermann como "mi amigo, mi compañero de luchas, mi hermano casi”. Además, Barros se definía como un socialista revolucionario y recordaba:

Aparte de algunas episódicas agitaciones estudiantiles de solidaridad de Buenos Aires, con la muy valiosa del grupo de camaradas de la FUA, no siempre debidamente apoyada por los estudiantes porteños, sólo conseguimos la acción disciplinada y tenaz de la Federación de Asociaciones Culturales que yo fundara el 8 de julio de 1918. Soñamos en forjar una gran fuerza popular que nos amparara, allí como en las 14 provincias, de las maniobras políticas y gobernantes. Queríamos una falange nueva de la juventud y para la juventud [...]. Bajo la valerosa dirección de Bermann alzó la única voz de protesta escuchada en Buenos Aires en los días tenebrosos subsiguientes a la Semana de Enero (Barros, "Al director de La Vanguardia", Insurrexit, no 8, abril de 1921, p. 2).

Sobre ese intento de expandir la actividad de la Federación de Asociaciones más allá de Buenos Aires, Barros ofrece alguna información en una de las cartas que le envió a Bermann. Al regreso de un viaje a Santa Fe, el cordobés le informaba a su camarada porteño: "tengo el agrado de participarte que allí está todo ya listo para la constitución en esa ciudad de la Federación de Asociaciones Culturales (y las hay muchas) filial de la que tu vicepresides. Están nombrados los delegados y es necesario que tu envíes estatutos, etc, cuanto antes, a Agustín Dillón, Salta 127 (oeste), Santa Fe, para afilar todo de seguido. Esperan tu palabra únicamente!" y agregaba al margen: “Escríbele con la misma confianza que a mí mismo, pues está al tanto de todo!” $(24 / 02 / 1919){ }^{214}$

Más allá de que nuestra condición de historiadores del siglo XXI nos dificulta reponer ese "todo", podemos estar seguros de que allí se cifraba la intención de acompañar y propagar propuestas de la FUC que en en las asambleas estudiantiles no alcanzaban eco porque resultaban demasiado radicalizadas. Sobre esa radicalización, recordemos que en una nota aparecida en Bases, sobre la que volveremos, Bermann saludaba las distintas "revoluciones" estudiantiles del país y no dudaba en que "la acción conjunta del proletariado y de los estudiantes llevará a los hombres a liberarse de las fuerzas que los oprimen". ${ }^{215}$ Asimismo, unos meses después Bermann pronunciaba una conferencia en Montevideo en la que identificaba a "su querido compañero Barros" como el “jefe indiscutido de la revolución”, y se refería a la Federación en el tono grandilocuente de los discursos:

un grupo de jóvenes cordobeses secundado por algunos más [...] llevó de un extremo al otro del dilatado país el evangelio de su palabra, predicando la buena nueva, hasta conmover a los espíritus aún más adormilados y levantando a las masas contra las

\footnotetext{
${ }^{214}$ Fondo documental sobre la Reforma Universitaria, Casa de la Reforma, Universidad Nacional de Córdoba.

${ }^{215}$ Gregorio Bermann, "La nueva argentina", Bases, n 5, 05/10/1919, p. 4.
} 
camarillas y contra un mal sistema educacional, e instruyéndolas acerca del peligro clerical. [...] En Buenos Aires se constituyó la Federación de Asociaciones Culturales a base de bibliotecas obreras, centros de cultura populares y una que otra sociedad estudiantil. Esta Federación nació al calor del entusiasmo popular, ya que las asociaciones universitarias de la capital, se mostraban remisas en aunar sus fuerzas a las de los hermanos de Córdoba (Bermann, "La revolución estudiantil argentina", Ariel, no 12, agosto de 1920, p. 10).

Por la correspondencia conservada, sabemos que fue Barros quien juntó y le facilitó a Bermann el material con el que preparó la conferencia montevideana. Le escribe Barros desde Rosario: "Querido Bermann: Hoy debes recibir los cajones repletos de documentos relativos a la Revolución Universitaria. Me ha absorvido su preparación largo tiempo sin que me bastara para ordenarlos debidamente. Los pongo en tus manos con plena confianza. Utilízalos como convenga y después los volverás a mi poder". 216

Seguramente, Barros también envió esos cajones a del Mazo, pues en su voluminosa compilación de documentos reformistas reproduce numerosos manifiestos elaborados por la FUC y cinco redactados por la olvidada Federación de Asociaciones Culturales: el primer manifiesto del grupo, las bases bajo las que se conformó, el orden del día de su primer mitin (del Mazo, 1927, t.II) y dos manifiestos aparecidos luego de la Semana Trágica (del Mazo, 1927, t.V). Asimismo, como presentación al “Orden del día del mitin en Buenos Aires, el 28 de julio de 1918”, del Mazo preparó una breve nota que nos ofrece más información sobre esa federación:

Este documento es un producto del movimiento social derivado de Córdoba en todo el país. En el mes de julio de 1918 se constituyó en Buenos Aires, con fines de agitación y propaganda, la federación de asociaciones culturales, cuya composición queda explicada con su propio nombre. Presidida por Gregorio Bermann, organizó un gran mitin el domingo 28 de julio que recorrió las calles de la ciudad. En esa manifestación popular se leyó y aclamó el orden del día transcrito. Como puede verse, esta declaración armoniza y complementa la producida un mes antes (del Mazo, 1927, t.II: 177).

A través de las memorias de otro miembro de esa Federación, Conrado Nalé Roxlo, sabemos que el grupo estaba animado por más jóvenes reformistas: Ernesto Palacio y Pablo Suero (quienes en 1920 prepararon la primera traducción de El resplandor del fuego de Barbusse), Horacio Trejo (quien en 1926, en calidad de presidente del CE de Medicina, polemizó con el proyecto encabezado por Bernardo Houssay de establecer un cupo de ingreso en la Facultad y financió la mencionada compilación de documentos de la Reforma preparada por del Mazo), el futuro martinfierrista Pablo Barrenechea, Alejandro Cárdenas, Carlos Raúl Muñoz del Solar (conocido luego como Carlos de la Púa), Francisco Villaflor y los antiguos ateneístas, entonces miembros del comité ejecutivo del PSI,

${ }_{216}$ Carta de Enrique Barros a Gregorio Bermann, Córdoba, 16/02/1920, Fondo documental sobre la Reforma Universitaria, Casa de la Reforma, Universidad Nacional de Córdoba. 
Luis Bontempi y Mario Massa. A su vez, sabemos por las mismas memorias que cuando la policía detuvo a algunos de esos jóvenes fue Alfredo Palacios quien intercedió para que fueran liberados. Recuerda Nalé Roxlo sobre esa militancia de la que en su vejez se sentía sumamente alejado:

El grupo activista, la brigada de choque, como ahora se dice, de que yo formé parte, se reunía por las noches en el "Hotel Biarritz", de Rivadavia y Callao, haciendo cruz con el Congreso. Allí estaba Enrique Barros, líder cordobés que estuvo a punto de perder la vida a manos de traidores enemigos, serio y apasionado como un jacobino; Gregorio Bermann, hoy notable psiquiatra y entonces notable por sus cuellos a la Saavedra Lamas y su empaque profesoral, que por suerte para los amigos que tanto lo estimamos, perdió con el tiempo [...] Formábamos parte de una Federación de Asociaciones Culturales, y así obteníamos permiso para hablar en los lugares más extraños y ante gentes quienes nuestra propaganda debía importarles muy poco. Hasta en los intervalos en los bailes de los centros recreativos de lejanos barrios levantamos tribunas: entre tango y tango, ideas (Nalé Roxlo, 1959: 169-170).

Esas ideas entre tango y tango seguramente formaron parte de alguna de las tres campañas que organizó la Federación. En su surgimiento, promovió el "Comité de agitación pro Córdoba Libre". Desde noviembre de 1918, coordinó la repercusión porteña de la "Campaña a favor de la separación de la Iglesia y el Estado" que había iniciado la FUC cuando Barros se encontraba hospitalizado por los golpes que le propinaron los estudiantes católicos. Como mencionamos, este joven había encabezado las negociaciones con el gobierno nacional para la llegada, en septiembre de 1918, de la segunda intervención de la UNC. La reglamentación establecida por la intervención, y halagada por Barros, fue mucho más moderada que la reclamada por la FUC; de ahí que una parte de ésta acusara al representante estudiantil de haber pactado esas reformas con un sector del radicalismo. Pero cuando el 26 de octubre Barros fue agredido, la FUC hizo a un lado esos cuestionamientos para convertir al joven en la bandera de una nueva campaña liberal en la que participaron diversas agrupaciones estudiantiles, culturales y obreras, y que en Buenos Aires fue articulada por la Federación de Asociaciones Culturales. ${ }^{217}$

En su número de enero de 1919, Ideas publicaba el documento a través del que el Ateneo se sumaba a la campaña liberal, lanzada por la FUC y coordinada en Buenos Aires por la federación que presidía Bermann. Luego de citar el manifiesto en el que la FUC llama a "señalar ante el país el peligro clerical como enemigo de su progreso, incitando a los hombres libres de la República a que colaboren en la obra de la inmediata separación de la Iglesia y el Estado”, Ideas lista las múltiples actividades que se comprometían a realizar los ateneístas. Entre ellas se encontraban dos que hacen explícita la inscripción en la izquierda de este Ateneo que en los próximos meses dejaría de definirse como apolítico: la invitación a colaborar activamente en la campaña a todos los partidos

\footnotetext{
${ }^{217}$ Sobre el itinerario político-intelectual de Barros, véase Bustelo (2014b); sobre la segunda intervención universitaria, Vidal (s/d).
} 
políticos, a todas las agrupaciones obreras de la República y a las entidades de reconocida orientación liberal, como la Sociedad Luz, el Ateneo Popular y la Liga de la Educación Racionalista, y el compromiso de que la propaganda liberal se realizara mediante discursos, conferencias, mitines, hojas, volantes y folletos. ${ }^{218}$

Pocos meses después la Federación de Bermann intentó iniciar su tercera y última campaña, en este caso orientada a contrarrestar la violenta reacción nacionalista que se desplegada desde la "Semana Trágica". En ese clima de fuerte represión y de fundación de la Liga Patriótica Argentina, aparentemente la Federación sólo logró publicar dos manifiestos. A partir de las notas que Bermann envió a La Gaceta Universitaria de Córdoba y a Bases de Buenos Aires, sabemos que la Federación no consiguió que la policía nunca le otorgó el permiso para realizar los mitines proyectados.

Aunque siguiendo a Nalé Roxlo esa propaganda no logró mucha resonancia, la Federación al menos coordinó un evento que sí es significativo para la historia intelectual argentina. La olvidada Federación fue la organizadora de la tumultuosa asamblea del Teatro Nuevo de Buenos Aires en la que habló Ingenieros la noche del 22 de noviembre de 1918, a los pocos días de firmado el armisticio con el que finalizaba la Primera Guerra Mundial. Esa asamblea pertenecería "a la historia de las ilusiones políticas colectivas" -según el recuerdo de un protagonista ya alejado de ese entusiasmo político (Giusti, 1965: 253)-, pues, luego de la presentación de Giusti y de Bermann, Ingenieros pronunció su célebre y polémico discurso de adhesión al maximalismo y a la "Internacional del Pensamiento". ${ }^{219}$

Prosiguiendo con el rastreo de las actividades emprendidas por la Federación de Asociaciones Culturales, algunas notas breves de La Vanguardia informan sobre una serie de "actos públicos de solidaridad con 'Maestros Unidos' de Mendoza" organizados por la Federación durante 1919. Por su parte, fue en la Revista de Filosofía donde se publicó la primera solicitada del grupo ante la Semana Trágica; ésta y una segunda solicitada aparecieron en el diario porteño lencinista, $L a$ Montaña. A la cabeza de las asociaciones que firmaban el manifiesto se encontraba la Universidad Libre, esto es, el grupo que habían fundado a fines de 1915 los arielistas socialistas y que en 1918 estaba presidido por Ingenieros. Completaban la lista de firmas: la Liga Nacional de Maestros, el

\footnotetext{
218 "Separación de la Iglesia y el Estado", Ideas, n 21, enero de 1919, pp. 247-248.

${ }^{219}$ Bajo el título "Significación histórica del movimiento maximalista" y la aclaración de que el acto fue organizado por la Federación de Asociaciones Culturales, la conferencia fue reproducida primero en Nosotros (noviembre de 1918) y luego en la Revista de Filosofía (enero de 1919). A través de la correspondencia que Ingenieros mantenía con su padre, sabemos que por esa y otras declaraciones a favor de los bolcheviques aquel fue acusado de instigar las huelgas obreras de 1919 y fue celosamente vigilado por la policía (Fondo personal José Ingenieros, CeDInCI). Con esa conferencia, Ingenieros iniciaba una peculiar adhesión a la Revolución Rusa: saludaba la reforma educativa y el gobierno antiparlamentario de los soviets, pero, a distancia del PSI, consideraba que la democracia funcional que debía impulsarse en la Argentina no debía estar encabezada por obreros sino por una elite intelectual. Según veremos en el capítulo octavo, el alejamiento de Ingenieros con el comunismo fue mayor pues, a distancia del obrerismo, propició un partido de intelectuales vinculado al ala izquierdista de la Reforma Universitaria, la ULA, que procuró la denuncia del antiimperialismo latinoamericanista. Sobre el itinerario político-intelectual de Ingenieros, véase Terán (1986b) y Tarcus (2007b).
} 
Ateneo Popular, la Liga de Educación Racionalista, la Unión Feminista Nacional, el Ateneo Universitario (nombre que entonces había adoptado el Ateneo de Estudiantes Universitarios que lideraba Monner Sans), la Biblioteca Agustín Álvarez, el Ateneo Racionalista de Villa Crespo, el Ateneo Carolina Muzzilli, la Biblioteca Gabriela L. de Coni, la Biblioteca Florencio Ameghino, la Biblioteca Luz y Vida, la Agrupación Feminista Socialista, el Centro Obrero del Oeste, las Bibliotecas: Carlos Marx, Sol de la Humanidad, Andrea Costa, Internacional, Luz y Progreso, Antorcha de la Verdad, Labor y Progreso, La Comuna, Pedro Chiesa y Federico Engels. ${ }^{220}$

Esta lista revela que la Federación consiguió, fundamentalmente, la adhesión de asociaciones de inscripción socialista, muchas de ellas centradas en la emancipación de la mujer. Y ello sugiere que en la búsqueda de adherentes no sólo participaron los varones recordados por Nalé Roxlo, sino también la profesora Leonilda Barrancos, esposa entonces de Bermann. Como mencionamos, Barrancos participaba desde 1912 de la Liga de Educación Racionalista, y para 1919 militaba en algunos de los centros socialistas y feministas que firmaron los manifiestos de la Federación. Por otra parte, en 1919 la Revista de Filosofía publicaba el único documento extenso que parece haber elaborado la Federación. En un largo artículo, el entonces presidente de la Federación, Nicolás Besio Moreno, exponía "las cuatro formas primordiales de elevación del espíritu" que procuraba el grupo: la económica, la moral, la intelectual y la artística. ${ }^{221}$

Un dato no menor sobre el pronunciamiento de la Federación contra la Liga Patriótica es que se realizaba en el momento en que las fuertes tensiones entre la FUBA y la FUC se traducían en la primera escisión del movimiento estudiantil federado. A pesar del receso lectivo, el 12 de enero de 1919 la FUC publicaba un manifiesto en el que declaraba su adhesión al "paro obrero de protesta por los sucesos de Buenos Aires" (del Mazo, 1927, t.V: 55-56), y doce días después ponía a circular otro texto en el que aseguraba que eran legítimas las causas por las que se había iniciado la huelga obrera (del Mazo, 1927, t.V: 61). Con esos pronunciamientos, la adhesión o distancia a las protestas de carácter obrero quedaba instalada en el centro de la discusión de la juventud universitaria. La FUC, al igual que la FUA, el Ateneo y la Federación de Asociaciones Culturales, repudiaba el argentinismo de la Liga Patriótica y exigía una legislación obrera que resolviera la carestía de la vida del pueblo. Pero la FUBA se resistió a declaraciones que excedieran reclamos estudiantiles concretos, al tiempo que cuestionó la pertinencia de la vinculación obrera que mantenían los estudiantes federados cordobeses. Ante ello, uno de los fundadores del Colegio Novecentista -y futuro profesor de estética en la FFyL y en el Colegio Nacional de Buenos Aires-, Ventura

\footnotetext{
220 "UN MANIFIESTO. La Federación de Asociaciones Culturales, a la conciencia de los hombres libres", La Montaña, 27/06/1919. Como muestra Doeswijk (2014), este diario es un interesante documento sobre los cruces políticos de la época, pues fue editado en Buenos Aires por un grupo de anarco-bolcheviques pero financiado por el gobernador de Mendoza José Lencina para cuestionar a su rival Yrigoyen.

${ }^{221}$ Véase "Federación de Asociaciones Culturales", La Vanguardia (6/10/1919) y (15/09/1919); "Manifiesto de la 'Federación de Asociaciones Culturales"', Revista de Filosofía (marzo de 1919); "Federación de Asociaciones Culturales. Sus fines y objetivos", Revista de Filosofía (noviembre de 1919, pp. 341-369).
} 
Pessolano, se ofrecía para viajar a Córdoba como representante de la FUBA y redactar un informe sobre el accionar de la FUC.

Sobre esa visita de Pessolano a Córdoba encontramos una breve y significativa referencia en la citada carta que, a su regreso de Santa Fe, Barros enviaba a Bermann. Entre las noticias sobre el devenir del movimiento cordobés, Barros aclaraba que Ventura Pessolano "en todo momento de la conversación pasó por uno de los nuestros. Aunque, como te digo, ni nos enteramos de su 'investigación', conviene que tú pongas los puntos sobre las íes, pues a la F. U. de Bs As no le reconocemos jurisdicción alguna" (24/02/1919). ${ }^{222}$ Efectivamente, Ventura Pessolano realizó su investigación y la presentó en la asamblea de la FUBA que decidió separarse de la FUA. Para dar curso a su separación, la FUBA redactó un manifiesto y una serie de cartas que anunciaban que esa decisión era tomada hasta tanto la FUA no sancionara las actividades no universitarias (obreristas) que venía realizando la FUC. Específicamente, el manifiesto de la FUBA, fechado en mayo de 1919, recalcaba: "Nuestra prescindencia sistemática en todo asunto de índole política, nuestra falta de intereses creados en el orden económico y la tranquilidad de espíritu con que siempre hemos contemplado los problemas que afectan la vida nacional", para concluir invitando al resto de las federaciones regionales a alejarse de la federación nacional (del Mazo, 1927, t.V: 75). La FUA debió abandonar el local de la FUBA, lo que, recuerda del Mazo (1976: 101), entonces presidente de aquella, no llevó a la suspensión de las reuniones sino a que ellas e realizaran en su casa.

Volviendo a la Federación de Asociaciones Culturales, otras pocas noticias aparecen en dos notas publicadas en 1919 por La Gaceta Universitaria. Órgano de la Federación Universitaria de Córdoba. Una carta conservada en el Fondo documental sobre la Reforma Universitaria (UNC) nos permite conocer cómo llegaron esas noticias, al tiempo que nos da más pistas sobre la sensibilidad que acompañaba la estrecha vinculación entre los reformistas porteños y los cordobeses. A comienzos de julio de 1919, Bermann recibía correspondencia de un joven que, al igual que él, se había convertido en parte de los agitadores izquierdistas de la Reforma, el estudiante de Ingeniería y líder de la FUC Ismael Bordabehere. ${ }^{223}$ Al quedar a cargo de La Gaceta Universitaria, Bordabehere le escribía a su par porteño:

Te quedaré muy agradecido si me acompañas en este trabajo. Nuestro programa será el que ha seguido la F. U. Intervendremos en todos los asuntos de orden social y cultural con un criterio sustancialmente liberal y amplio. Te pido tu colaboración y te ruego me consigas todas las que puedas entre los buenos amigos de esa, Palcos, [Mario Massa?] Maza, [Horacio Pozzo?] Pozo, Palacios, [Ubaldo] Isnardi, Ingenieros, etc, etc. También te pido subscriptores, a cuyo efecto te enviaré mañana unos cartelitos de propaganda y

\footnotetext{
${ }^{222}$ Subrayado en original. Fondo documental sobre la Reforma Universitaria, Casa de la Reforma, Universidad Nacional de Córdoba.

${ }^{223}$ Este joven había sido uno de los representantes estudiantiles en el Primer Congreso Nacional de Estudiantes, para el que preparó el proyecto de "Supresión de fórmulas para el juramento" (del Mazo, 1927 t.III).
} 
en estos días unos formularios de solicitud [...] Como he leído y conozco las incidencias de la Federación de A. C. [Asociaciones Culturales] con la policía, te invito a que me mandes algo al respecto. También sería muy conveniente el que me tuvieras al corriente de la acción de la FUA enviándome las noticias con sus correspondientes comentarios [...] tendrá mucha difusión entre el elemento obrero. [...] A pesar de la resistencia que nos oponen los reaccionarios apoyados por el capital, el clero y las fuerzas policiales y nacionales estamos dispuestos a marchar adelante abriendo paso a los nuevos ideales. Necesitamos y aspiramos el apoyo de Uds (26/06/1919, Fondo documental sobre la Reforma Universitaria, Casa de la Reforma, Universidad Nacional de Córdoba).

Además de explicitar la red de sociabilidad que venimos rastreando a través de otros documentos, la carta de Bordabehere permite reconstruir las múltiples tareas que debían realizar quienes emprendían la redacción de una revista orientada a radicalizar el movimiento estudiantil. Esas tareas involucraban, al menos, el pronunciamiento sobre los asuntos de orden social y cultural con un criterio sustancialmente liberal y amplio, el tramado de contactos que aseguraran un número de notas afines a la línea editorial y suficientes para llenar cada número, la obtención de subscriptores que financiaran la publicación y la pusieran a circular, la edición de circulares de propaganda y formularios de subscripción, la difusión de la publicación no sólo entre los estudiantes sino también entre los obreros y finalmente la convicción para responder a las acusaciones y obstáculos que les presentaban quienes se oponían a esa radicalización. Como se encarga de mostrar del Mazo en su compilación de 1926 y 1927 -y ya no en las posteriores-, ese "elemento obrero" organizado en torno de la Federación Obrera de Córdoba había mantenido una "acción recíproca", afín a la reclamada por Roca, con los estudiantes federados: desde los comienzos los estudiantes habían encontrado el respaldo del movimiento obrero, al tiempo que éste había protagonizado numerosas huelgas que fueron acompañadas por los estudiantes (Doeswijk, 2013; Marcó del Pont, 2005: 3744).

La respuesta de Bermann a Bordabehere se ha perdido, pero las páginas de La Gaceta testimonian que el joven acompañó a los cordobeses en este nuevo proyecto. Los "buenos amigos" hicieron llegar sus colaboraciones. Entre ellos, Ingenieros envió un texto junto a un ejemplar de su libro sobre Ameghino ${ }^{224}$ y Bermann redactó tres notas: dos sobre el conflicto de su federación con la policía y otra -que apareció en dos entregas- sobre la extensión universitaria. Asimismo, al joven porteño seguramente corresponda la pluma que se esconde en las tres notas de La Gaceta firmadas por “Amelius", pues éstas se ocupan de la extensión universitaria y destacan la labor de los Centros Ariel, la Universidad Libre y la Federación de Asociaciones Culturales.

El artículo sobre esta federación apareció en el cuarto número de La Gaceta Universitaria, fechado el 11 de julio de 1919, bajo el título "La mordaza" y la firma de Bermann, como presidente

\footnotetext{
${ }^{224}$ La carta que Ingenieros envía a Bordabehere el 21 de agosto de 1919, junto a su colaboración y su libro, está disponible en línea: http://www.uba.ar/reforma/lareforma/documentos.php.
} 
de la Federación, y por A. [Alfredo] Aprile, como secretario. Allí se relatan las dificultades que tuvo la Federación para que el jefe de policía de la ciudad de Buenos Aires le otorgara el permiso reglamentario -finalmente denegado- para realizar un "mitin pro-afianzamiento de las libertades constitucionales y derogación de las Leyes de Residencia y de Defensa Social”. En el mismo número aparece "Cultura popular", un artículo -continuado en el número siguiente- en el que Bermann, siguiendo a Altamira, muestra la importancia de experiencias de extensión universitaria, como las que había realizado en 1914 con el grupo de arielistas socialistas.

Sobre la federación de Bermann también aparecía por entonces un manifiesto y una nota en Bases, revista que analizaremos en el capítulo siguiente. Ambos textos no llevan firma y versan sobre los problemas que el grupo había tenido con la policía. Apoyando el frustrado acto contra la ley de residencia, la "liberal jacobina" Bases concluía señalando sus afinidades políticas con el grupo de Bermann: "Los estudiantes, la juventud en general, deben contribuir a salvaguardar las libertades públicas argentinas, y ser digna de los sabios fundadores de nuestra nacionalidad". ${ }^{225}$ En la misma fecha, La Gaceta Universitaria de Córdoba publicaba "Sin comentario", una nota sin firma que reproducía fragmentos de un manifiesto en el que la Federación se declaraba en contra de la expulsión de inmigrantes por sus ideas, pues ello implicaba un "desconocimiento total del programa de la Revolución de Mayo".226

\section{EI "doctor" Bermann en la trama del socialismo bolchevique}

Hoy la lucha se ha iniciado más formidable entre aquellos mismos principios democráticos y los eminentemente sociales de la Revolución Rusa: entre Wilson y Lenin, aquel se dirige a los gobiernos aliados, éste habla a los trabajadores del mundo. ¿Cuál triunfará? Quién sabe si como dice Romain Rolland: 'El reloj del mundo está atrasado y hay que ponerlo a la hora con el de Petrogrado'. Amelius, "Cámara obscura. Lenin y Wilson", 1919.

Hacia 1920, cuando ya no tenemos noticias de la Federación, tanto Bermann como Aprile aparecen ligados al grupo porteño Claridad del PS y su olvidado órgano Claridad. Revista socialista quincenal de crítica, literatura y arte, de la que aparecieron nueve números durante 1920 bajo la iniciativa de Ingenieros y la dirección del joven José P. Barreiro (1900-1973). La primera revista porteña Claridad acompañaba, desde la difusión cultural y doctrinaria, el intento del grupo de instalar en el PS la línea comunista o tercerista, esto es la adhesión a las veintiún condiciones que proponía la III Internacional. Para ello, entre otras cosas, Claridad emprendió una intensa difusión

225 “Arrestos y deportaciones. La actitud de la Federación de Asociaciones Culturales”, Bases, n” 2, 07/07/1919, p. 4.

226 "Sin comentario", La Gaceta Universitaria de Córdoba, n 13, 04/07/1919, p. 6. 
de Barbusse y sus iniciativas. Sus páginas contaron tanto con el anuncio profesional del "doctor" Bermann y del "contador" Aprile como con algunos artículos redactados por ambos. Asimismo, Claridad publicó un artículo de Besio Moreno que elogiaba a Bermann por la defensa del cientificismo realizada en su tesis doctoral. ${ }^{227}$

En los meses en que aparecía Claridad, el Centro Estudiantil Ariel de Montevideo, que lideraba el futuro referente de la izquierda nacional uruguaya Carlos Quijano, también se entusiasmó con el socialismo bolchevique de la "Internacional del Pensamiento". Como veremos, por entonces el grupo reformuló sus propósitos y rediseñó su revista para lograr una intervención que atendiera no sólo a lo cultural sino también a lo político. Y una de las primeras iniciativas ligadas a ese pasaje a lo político fue la convocatoria al "Dr. Gregorio Bermann [...] prestigioso intelectual de la nueva generación argentina” para que en una conferencia pronunciada en marzo de 1920 en la Universidad de la República explicara a los estudiantes uruguayos "La revolución estudiantil argentina”. Esta conferencia fue al poco tiempo difundida tanto por Ariel de Montevideo como por La Gaceta Universitaria de Córdoba. ${ }^{228}$

Al año siguiente, Bermann se dejaba convencer por la insistente propuesta de su camarada Barros de radicarse junto a su esposa en Córdoba para ocupar la cátedra de Medicina Legal y Toxicología. Como un modo de precisar la sensibilidad política que en torno de la Reforma se estaba gestando en una parte de la "nueva generación", traigamos algunos pasajes de las cartas que Barros le envió a Bermann. Asegura el líder cordobés en la primera misiva que alude a la radicación de Bermann en Córdoba:

No me doy por vencido. Creo que te hubiera convenido Córdoba. Por mil razones: primero hubieras llegado pronto a una de las cátedras de Neuropatología, Mentales o Med. Legal; $2^{\circ}$ porque tendrás clientela aquí, donde se necesita un especialista. Además, estoy seguro de que te habríamos conseguido una cátedra en el Nacional. He pedido concurso para la referida jefatura y creo lo obtendré. ¿Quieres probar fortuna? Pues, pides licencia en tu puesto y yo en la jefatura, proponiéndote como mi reemplazante por un mes, que yo aprovecharía para irme a descansar al campo; te consigo prestado un consultorio para que puedas trabajar ese tiempo y veas si te produce siquiera $300 \$$ mensuales $\mathrm{y}$, entonces, decides de tu destino. Contéstame pronto, cuanto antes, porque

\footnotetext{
${ }^{227}$ Según la única colección, lamentablemente incompleta, de acceso público de Claridad, Bermann publicó "El miedo a la luz" (Claridad, no 5, 10/04/1920) y "Filosofía de la justicia. La justicia de clase" (Claridad, n 6, 01/05/1920). las otras referencias son: "El determinismo en la ciencia y en la vida" de Besio Moreno (Claridad, nº 9, 15/08/1920), "Algo sobre gremialismo y cooperativismo" de Aprile (Claridad, no 6) y "Alcornoque trascendental" también de Aprile (Claridad, $\mathrm{n}^{\circ}$ 9). Mencionemos aquí que -como veremos en el capítulo siguiente- este intento de radicalizar la línea del PS en lugar de sumarse al PSI fue criticado por la revista estudiantil comunista Insurrexit y la anarco-bolchevique Via Libre. A comienzos de 1921, el grupo Claridad era expulsado del PS y muchos de sus miembros decidían ingresar al PSI, pero al poco tiempo regresaban al PS, sobre todo porque no se había respetado la promesa de reconocer la antigüedad en el PS que habilitaba a participar del Comité Ejecutivo.

${ }^{228}$ Bermann, "La revolución estudiantil argentina", Ariel, $\mathrm{n}^{\circ} 12$, agosto de 1920 y Ariel $\mathrm{n}^{\mathrm{o}} 13$, septiembre-octubre de 1920; reprod. en: La Gaceta Universitaria de Córdoba, 10/10/1920. A pesar de esa invitación, veremos que es a través de otro estudiante comprometido con la orientación socialista de la Reforma, Juan Antonio Solari, que los arielistas montevideanos estrechan vínculos con los porteños.
} 
yo también necesito determinar mi situación (Carta de Barros a Berman, 30/04/1920. Fondo documental sobre la Reforma Universitaria, Casa de la Reforma, Universidad Nacional de Córdoba).

Y luego de la respuesta de Bermann, insistía Barros en una nueva y extensa carta que ofrece interesante información sobre el tipo de estrategias que -junto a la publicación de una prensa que se enfrentaba al clericalismo y a la elite gubernamental y era difundida entre estudiantes y obreroscomenzaban a desplegar las figuras que se identificaban con una versión radicalizada de la Reforma. Citamos la carta de Barros en extenso:

Querido Bermann: Creo que tú puedes y debes ser profesor aquí. Si no lo hubiera creído así, no te lo hubiese propuesto. Sé que harás en la cátedra un papel brillante y debes resolverte esta vez ya que no es probable que haya otra oportunidad como ésta que se te presenta. Casualmente hoy Castellanos Cámara contestó aceptando una cátedra en la Fac. de Ingeniería de Rosario que acaban de ofrecerle. Dejará vacante una de Anatomía e Higiene en el Colegio Nacional. Tú pides licencia en tu puesto, te haces cargo de la cátedra del Nacional y de la jefatura de Clínica Neurológica (330\$ en total), abres consultorio conmigo y te aprontas a desempeñar la cátedra de Medicina Legal. Adviértote que Stucchi aspira a la de Criminología y Medicina Legal creada en Derecho. Para la suplencia de Med. Legal (Medicina) sólo se presentó un pobre hombre jesuita González, incompetente en absoluto. Considero necesario, de urgencia, que pidas allí licencia y te traslades a ésta para arreglar estos asuntos. Tengo la convicción de que de entrada y sin pensar todavía en facetas de instalación (pues podrías trabajar en el consultorio de Sayago) obtendrás no menos de $300 \$$ mensuales de la clientela particular. Con eso, la jefatura y el Nacional, hasta conseguir Med. Legal, puedes vivir perfectamente en Córdoba. Podrá aquí también trabajar Leonilda, cosa imposible allá. Y no te digo trabajar porque pudiera llegar a necesitarlo, sino porque sé que le agradaría. Hazme el favor de reflexionar seriamente y sobre todo de venirte si puedes para que hagas tus trabajos, que es mejor así. Por lo pronto, envía una nota al C. D. de la Facultad (será presentada por mi intermediario), diciendo que te has enterado tardíamente del llamado a concurso para proveer las suplencias (Carta de Barros a Bermann, s/f, mayo de 1920, aprox.. Subrayado del autor. Fondo documental sobre la Reforma Universitaria, Casa de la Reforma, Universidad Nacional de Córdoba).

Además de sugerir los inconvenientes que debían sortear los reformistas cordobeses para modernizar la universidad, esta carta muestra la mayor conquista de posiciones que, en comparación con Buenos Aires, habían conseguido allí, pues Barros da por hecho de que en Buenos Aires era más difícil que una profesora socialista y feminista como Barrancos consiguiera un cargo educativo. Finalmente, la carta explicita una estrategia que es confirmada en otros epistolarios de reformistas: ante la vacancia de un cargo, era necesario conseguir prontamente un candidato afín a las iniciativas que se impulsaban en cada casa de estudios.

A vuelta de correo, Barros redactaba otra carta a su camarada porteño. Allí le confirmaba:

Tengo cartas terminantes y favorables de Córdoba sobre tu cátedra. Jorge Orgaz dice que queda comprometido a que sea tuya la cátedra titular, que la suplencia valía nada. La cátedra de Filosofía general (en derecho) queda vacante pues Deodoro Roca ha sido 
nombrado en Rosario. No hay quien pueda desempeñarla en Córdoba y si tú no la quieres manda a alguno bueno.

Ten absoluta confianza; tienes ambiente favorable en Córdoba, tu ocuparás Medicina Legal y de Filosofía si lo quieres[...]. Dice Jorge Orgaz que te invitarán para curso libre de Psicopatología.

En Córdoba la F. U. y todo lo demás marcha muy bien.

Saludo

Tu amigo

Enrique Barros (Carta de Barros a Bermann, s/f, fines de 1920, aprox., subrayado del autor. Fondo documental sobre la Reforma Universitaria, Casa de la Reforma, Universidad Nacional de Córdoba).

Mientras que en la UBA los grupos que impulsaban la reorganización de la universidad desde el igualitarismo izquierdista eran minoritarios y el recambio de profesores podía hacerse con los mismos egresados, en Córdoba los grupos izquierdistas se aliaban al radicalismo azul o yrigoyenista para iniciar la construcción de una universidad científica y social, cuyo éxito no sólo dependía de las alianzas sino también de los profesores que lograran convocar. En ese proceso la FUC esquivó su definición a favor de la adhesión al maximalismo, e incluso declaró, al igual que otros grupos de carácter gremial que se politizaban, que su adhesión al maximalismo era una acusación falsa que buscaba aislarla de los estudiantes y de los obreros. ${ }^{229}$ De todos modos, veremos en el capítulo séptimo que entre 1921 y 1922 Barros -a pesar de ser acusado por una fracción de la FUC de establecer alianzas con el yrigoyenismo- extendió la convocatoria para ingresar como profesores de la FUC a importantes científicos europeos explícitamente ligados al maximalismo, entre ellos al arquitecto berlinés Bruno Taut. Barros logró que el joven Bermann se mudara a Córdoba, pero sólo consiguió que arribaran a la UNC dos reconocidos científicos europeos inscritos en las izquierdas: el fisiólogo y humanista Georg Nicolai fue contratado por cuatro años y el economista marxista Alfons Goldschmidt, por menos de un año -arribos sobre los que volveremos en el capítulo séptimo-.

A fines de 1921, Bermann ganaba el concurso de la cátedra de Medicina legal -en la que dictó clases hasta 1936-. Poco después aceptaba suplir a Roca en la cátedra de Filosofía. Además el joven porteño se haría cargo de otros dos espacios, también claves, para la construcción de la nueva universidad: el rector Francisco de la Torre, entonces cercano a los reformistas, designaba a

\footnotetext{
${ }^{229}$ Como muestra de ese tipo de declaraciones, traigamos una de las varias aparecidas en La Gaceta Universitaria de Córdoba: "La F. U. de Córdoba, que nació sin orientación alguna, como surge la violeta sedienta de luz, no fue caída en cuenta allá en sus comienzos, sencillamente porque se confiaba en la ignorancia del pueblo, pero la semilla se derramó, cayó en terreno fértil, y entonces se trató de combatirla, vano empeño! [...] Pero para suerte de nuestros enemigos, aparece el maximalismo, que ellos lo acomodan a su paladar y lo simbolizan en guillotinas, en horcas, en asesinatos, etc. etc, Como es lógico este tipo de fantasma macabro espanta a cualquiera por tranquilo que sea, y se valen de la impresión que él produce, para combatir a la F.U." (Aníbal A. Acosta, "El maximalismo de la F.U.", La Gaceta Universitaria de Córdoba, $\mathrm{n}^{\circ}$ 13, p. 5). Pero esta suerte de recusación del maximalismo, que no se privaba de concluir afirmando que los estudiantes federados eran tan maximalistas como los revolucionarios de Mayo, convivía con declaraciones, como la firmada por "Amelius" que citamos como epígrafe de esta sección, en las que se saludaba a Lenin y Trotsky.
} 
Bermann como director de la Revista de la Universidad Nacional de Córdoba, en reemplazo de Felix Garzón Maceda, ${ }^{230}$ y al poco tiempo lo erigía en el director de la Biblioteca Mayor de la Universidad.

Barros había terminado sus estudios en Medicina y partía a la Universidad de Friburgo para especializarse en neurología. Pero la distancia no interrumpía su labor reformista. Por el contrario, veremos en el séptimo capítulo que Bermann encontró en su camarada cordobés el gestor más importante de la Revista de la Universidad y un importante colaborador en la empresa de renovación bibliográfica de la Biblioteca Mayor.

Como es conocido, el otro fiel compañero de andanzas político-intelectuales de Bermann fue Deodoro Roca. Al asumir la cátedra de Filosofía de la Facultad de Derecho, éste había reemplazado el programa neotomista que impartía Luis Martínez Villada para iniciar la difusión en la UNC de las filosofías antipositivistas. ${ }^{231}$ Como vimos, entre 1916 y 1919 el cientificista Bermann había liderado las críticas al antipositivismo en las aulas porteña de la FFyL. Pero el desacuerdo filosófico no impedía que Bermann trabara una importante hermandad político-intelectual con Roca, pues éste, a diferencia de las derivas del Colegio Novecentista, conciliaba el antipositivismo con el compromiso en la emancipación de la humanidad. ${ }^{232}$

En cuanto a las figuras magisteriales, una vez que se instaló en Córdoba Bermann fue el enlace de los reformistas cordobeses con Ingenieros, quien, como veremos, fue clave en la construcción de una identidad política reformista ligada al latinoamericanismo antiimperialista. En marzo de 1923 Bermann era exonerado tanto de su cátedra como de la dirección de la Revista de la Universidad y de la Biblioteca Mayor. Los reformistas reclamaban una nueva intervención de la UNC pero temían que la figura designada por Alvear no respondiera a sus reclamos. ${ }^{233} \mathrm{Y}$ es a través de Bermann que la fracción radicalizada de la Reforma le consultaba a Ingenieros sobre la posición que asumiría el nuevo interventor, Antonio Sagarna.

Querido doctor Ingenieros:

Merced a las gestiones del diputado [Roberto] Bas, "el santón negro", viene la

\footnotetext{
${ }^{230}$ Este profesor fue un aliado circunstancial de los reformistas, pues algunas notas breves de 1918 de La Gaceta lo repudian por su pertenencia al Partido Demócrata y su poca formación científica, pero en 1920 parece haber recompuesto los lazos, pues publica su anuncio profesional en La Gaceta.

231 Éste participaba junto a Rodolfo Martínez Espinosa y Dimas Antuña del Centro Católico de Estudiantes y colaboraba con la revista porteña Signos que dirigía Carlos Sáenz. En las décadas siguiente, Martínez Villada mantuvo una tertulia filosófica interesada particularmente en la "restauración metafísica". En ella participaban la figura cordobesa más destacada de la filosofía tomista, Nimio de Anquín (quien, además, es desde 1934 líder del Partido Fascista Argentino y luego de la Unión Nacional Fascista), Manuel Río y Rodolfo Martínez Espinosa (fundadores ambos en 1932 del Instituto de Estudios Superiores Tomás de Aquino). Para un análisis de la filosofía de Martínez Villada y algunos datos de su itinerario político-intelectual, véase Caturelli (2001).

${ }^{232}$ Recuerda uno de los hijos de Bermann que esa hermandad se suspendió por unos años hasta 1924, cuando luego de fallecer un hijo de Bermann, Roca le mandó unas líneas. Entonces volvieron a liderar iniciativas político intelectuales hasta la muerte de Roca en 1942 (Entrevista a Claudio Bermann, cit. en de la Cruz Argañaraz, 2007: 81).

${ }^{233} \mathrm{El}$ conflicto mayor se desató cuando las nuevas autoridades se negaron a incorporar a los líderes reformistas Gumersindo Sayago y Horacio Miravet al Consejo Superior (Vera de Flachs, 2006).
} 
intervención a esta universidad, favorecida por la felonía del Rector.

Viene [Antonio] Sagarna como interventor. ¿Cree Ud. que ha dejado de ser el liberal rojo desde que es ministeriable? ¿Viene con las mismas intenciones que Nazar Anchorena fue al Litoral? ¿Puede evitarse, y en qué forma, la entrega de la universidad en manos reaccionarias?

En espera de su respuesta lo saluda su affmo,

Bermann (s.f., fines de 1923 aprox.). ${ }^{234}$

La entrega no pudo evitarse y las reformistas radicalizados pronto perdieron los puestos clave de gestión. La intervención llegaba el 2 de mayo para dejar vacantes los cargos del gobierno universitario y elaborar nuevos estatutos que eliminaban varios de los cambios incorporados por la intervención de Salinas. El candidato de los reformistas volvía a ser Martínez Paz, quien volvía a perder, esta vez ante Ernesto Romagosa. Bermann recuperaría la cátedra de Medicina Legal, pero la de Filosofía volvía a quedar a cargo de Martínez Villada al tiempo que la Revista de la Universidad y la Biblioteca Mayor tampoco serían dirigidas por los primeros reformistas. ${ }^{235}$

Al año siguiente, los reformistas cordobeses le proponían a Ingenieros, también por intermediación de Bermann, que aceptara la candidatura a rector de la UNC "aunque más no sea por unos meses, para regocijarse con sus doctores". ${ }^{236}$ Como veremos, por esos años Bermann apoyó el proyecto, aupiciado por Ingenieros, del boletín Renovación, primero con el envío de algunas colaboraciones y luego con la fundación de una sección cordobesa de la ULA, que presidió Roca y contó con Barros en la comisión directiva. Y cuando a fines de 1925 Ingenieros falleció, Bermann se encargó de publicar la primera biografía del maestro.

En cuanto a su itinerario posterior, en el periodo de entreguerras Bermann y sus “compañeros de lucha” asimilaron la sensibilidad política acuñada con la Reforma a la campaña antifascista. Además de crear en 1932 con Barros el Instituto Neuropático de Córdoba (dirigido por Bermann hasta 1955), Bermann y Barros conformaron entre 1935 y 1936 el grupo de redactores de la revista Flecha que fundó Roca como órgano del Comité Por la Paz y la Libertad de América. ${ }^{237}$ Algunos años después, los tres fueron figuras destacadas de las secciones cordobesas de tres grupos antifascistas: Acción Argentina y su periódico Argentina Libre (ligada al PS), la Asociación de Intelectuales, Artistas, Periodistas y Escritores (AIAPE; ligada al PC) y la Agrupación Pro Unidad

\footnotetext{
${ }^{234}$ Carta de Bermann a Ingenieros, s/f (1923). Fondo personal José Ingenieros, CeDInCI. La Gaceta Universitaria ${ }^{\circ} 16$ (25/06/1919) le dedica una breve nota a Roberto Bas a partir de la que sabemos que dirigía, redactaba y repartía el periódico radical El obrero argentino (ed fac.: 194).

${ }^{235}$ Sobre los avances y retrocesos de las reivindicaciones reformistas en la década del veinte, véase Schenone (2009) y Vera de Flachs (2006). Como prueba del reconocimiento intelectual que entonces rodeaba a la figura de Ingenieros, mencionemos que Sagarna -a pesar de que su irreconciliable diferencia con el posicionamiento izquierdista de aquel- le envió la edición de los documentos de su intervención, Intervención a la Universidad nacional de Córdoba. Año 1923, con la siguiente dedicatoria: "Querido Ingenieros: No sé si Ud., conoce los documentos que se publican en este folleto. Por eso se lo envío. Algo le hará conocer del... complejo de la cultura universitaria cordobesa. Una de estas noches cenaremos y charlaremos. Enero 19/925" (Fondo personal José Ingenieros, CeDInCI).

${ }^{236}$ Carta de Bermann a Ingenieros, 17/02/24. Fondo personal José Ingenieros, CeDInCI.

237 Sobre esta publicación, véase Bergel (2012) y Sanguinetti (2003).
} 
Democrática. $^{238}$

Con este recorrido por las memorias, correspondencias y otras fuentes no convencionales buscamos precisar el tipo de sensibilidad política y la compleja red de sociabilidad, tramada entre Buenos Aires y Córdoba, que fueron constitutivos de un acontecimiento tan visitado como el estallido de la Reforma. Para continuar la reconstrucción de las repercusiones porteñas de los conflictos cordobeses, volvamos ahora a centrar la mirada en las revistas estudiantiles y revisemos la actitud que, en este marco de creciente politización de los intelectuales, decidieron los otros dos grupos estudiantiles que en la primera parte de la tesis encontramos actuando en la ciudad de Buenos Aires, esto es, el grupo de jóvenes que conformaban el Ateneo e Ideas y los estudiantes que animaban el Colegio Novecentista y los Cuadernos. Asimismo, repasemos la definición de la Reforma que propusieron dos revistas que, en vinculación con aquellas, editaron los estudiantes porteños de Derecho, esto es, Themis y Revista Nacional.

\section{Los ateneístas y los novecentistas porteños frente a la política}

La política, una cosa tan viviente como es,
sólo falta en los escritores artificiosos, en
aquellos que viven recluidos en su egoísta
torre de marfil.
Manuel Gálvez, "El espíritu de los partidos",
1923.

Como hemos sugerido, desde fines de 1918 el Ateneo participó del intento que encabezaba la Federación de Asociaciones Culturales de radicalizar la posición de los grupos estudiantiles porteños. De todos modos, es a comienzos de 1919 que el grupo revisó su declarado apolíticismo, primero a través de un manifiesto que reformulaba las orientaciones y propósitos y que circuló profusamente en las revistas de la época, y luego mediante la edición de Clarín. Primero quincenario y luego semanario, Clarín se inspiró en la revista madrileña España y la porteña Martín Fierro para realizar una intervención política que completaba la cultural que el Ateneo venía realizando desde Ideas. De todos modos, en los hechos la aparición de Clarín significó el cierre de Ideas. En la decisión de politizar lo que -como vimos en la primera parte de la presente investigación- hasta entonces había sido una intervención cultural estudiantil, los ateneístas encontraban el respaldo de varios intelectuales porteños reconocidos.

La mundialización de la Gran Guerra, que impulsó Estados Unidos al ingresar en el conflicto en 1917, había promovido la politización de muchos intelectuales argentinos, pero fue entre 1919 y 1920, con la desilusión ante el wilsonismo, cuando ese proceso tendió a registrar

\footnotetext{
238 Sobre los núcleos intelectuales antifascistas, véase Bisso (2007), Celentano (2006b) y Pasolini (2005).
} 
expresiones más radicales. Entonces las noticias de la Revolución Rusa y el fin de la Gran Guerra confluyeron con el estallido de la Reforma y la Semana Trágica para generar, en numerosas figuras reconocidas, el convencimiento de que se vivía una aceleración de los tiempos y que ante ello su intervención pública debía orientar no sólo el progreso cultural sino también el político. Dos interesantes ejemplos de que la política se había tornado una cuestión que involucraba a los intelectuales como tales los ofrecen Ricardo Rojas y José Ingenieros. En 1917 cada uno había fundado un proyecto editorial a través del que ponían a circular las obras del pensamiento nacional. Como proponen los recuerdos de dos líderes reformistas (del Mazo, 1976; Monner Sans, 1958) y muestra el estudio de De Giovanni (2007), las ediciones de La Cultura Nacional que dirigió Ingenieros y las de la Biblioteca Argentina, a cargo de Rojas, fueron centrales para encauzar el interés por los temas culturales y políticos de la nueva generación, y específicamente de los jóvenes que encabezaron la Reforma.

Pero hacia 1919 -cuando el radicalismo gobernante optaba por la censura, las izquierdas argentinas se entusiasmaban ante el clima insurreccional internacional y las derechas buscaban combatirlo a través de iniciativas como la Liga Patriótica y la Gran Colecta de la Iglesia Católicatanto Rojas como Ingenieros se convencieron, desde afinidades políticas encontradas, de que la intervención de tipo cultural no bastaba. El primero proclamó la existencia de una generación del '19, y desde un bagaje krausista y antipositivista días después de concluida la emana Trágica llamó a una discutida, aunque poco exitosa, “Alianza de la Nueva Generación”, en la que Hiram Pozzo asumía la representación de las “Juntas universitarias". ${ }^{239}$ Por su parte, Ingenieros, además de pronunciar el mencionado discurso de adhesión al maximalismo, promovió la primera revista Claridad -en la que, como mencionamos, colaboró Bermann y Aprile- y decidió que su Revista de Filosofía, en principio preocupada por los problemas atemporales del pensamiento, también debía pronunciarse sobre los últimos acontecimientos políticos. Es entonces que desde Nosotros Giusti podía felicitar a la revista de Ingenieros por haber bajado "a combatir por la causa del futuro, [por] una mayor justicia para todos", ${ }^{240}$ combate que se tradujo en la difusión de los manifiestos del grupo Clarté y en la aparición de números dedicados a la Revolución Rusa, la Reforma Universitaria y la Semana Trágica.

Otra muestra de la interpelación izquierdista que se registró hacia 1919 en los intelectuales porteños la ofrece la revista Nosotros y especialmente Giusti, quien desde 1916 estaba afiliado al PS. Hasta 1921 el director de Nosotros participó del ala tercerista del PS y buscó que su revista también "bajara a combatir", para lo que desplegó más claramente esa figura de "maestro-

\footnotetext{
${ }^{239}$ La Alianza se propuso resignificar los propósitos del Comité Juvenil Pro-aliados que entre 1917 y 1918 buscó que la Argentina abandonara su posición neutral en la Gran Guerra. Sobre esa movilización ciudadana, véase Tato (2007). Los discursos pronunciados en el acto de lanzamiento de la Alianza fueron puestos inmediatamente en circulación en un folleto, véase Rojas (1919).

${ }^{240}$ Roberto Giusti, "Revista de Filosofía”, Nosotros, n 119, marzo de 1919, p. 437.
} 
ciudadano" analizada por Prislei (1992). Ésto produjo fuertes tensiones entre los intelectuales de distintas generaciones y afinidades políticas que colaboraban en la revista y la financiaban a través de la Sociedad Cooperativa. Luego de que la prensa los acusara de maximalistas, la desmentida de los directores convenció tan poco que su secretario de redacción, Julio Noé, decidió renunciar. Ante esa renuncia, Bianchi y Giusti redoblaban su apuesta, pues en el siguiente número se leía que la secretaría acababa de ser asumida por el joven socialista -internacionalista- Alejandro Castiñeiras, "un hombre de acción, el cual entiende que el arte debe estar subordinado a un ideal de vida y ser instrumento de perfeccionamiento moral". ${ }^{241}$ Pero las reticencias y renuncias que presentó la Sociedad Nosotros ante la asociación del proyecto con el maximalismo tuvieron mayor peso, y a fines de 1920 Noé se reincorporó como codirector de la revista, pues Giusti renunciaba luego de declarar que, desde su condición de socialista, no podía mantener el "silencio político de los intelectuales". Sostenía en esa carta de renuncia, que nos permite reponer rápidamente la discusión sobre la relación entre cultura y política que recorría entonces el campo intelectual:

No concibo en los actuales momentos históricos, ninguna publicación apolítica [...]. Hombre de ideas políticas definidas, socialista militante, yo no podría hablar en Nosotros más que en un solo sentido, en el que corresponde a mis sentimientos e ideales [...] no siéndome ya posible soportar que los acontecimientos se precipiten en el mundo y en la Argentina, sin que yo diga mi palabra de crítica, de indignación, de protesta, de esperanza, de fe, en las páginas de mi revista, renuncio a toda responsabilidad ("La dirección de Nosotros. Carta de Roberto Giusti al Dr. Carlos Ibarguren, presidente del directorio de la Sociedad Cooperativa Nosotros", Nosotros, n ${ }^{\circ} 136$, septiembre de 1920, p. 6).

Un índice más de ese impulso politizador lo ofrece el itinerario del novelista Manuel Gálvez. Para los festejos del Centenario, había ofrecido una versión hispanista y católica del "nacionalismo cultural" (Prislei, 1999) y desde mediados de los veinte simpatizaría con el fascismo, pero ello no le impedía convertirse en 1919 en la figura que inscribió a la intelectualidad argentina en la "Declaración de la Independencia del Espíritu” preparada por Romain Rolland. Allí se realizaba un llamado a una intervención izquierdista de los intelectuales que, en lugar de incorporarse a un partido político, mantuviera la "Independencia del Espíritu" y que sería una antecesora de la Internacional del Pensamiento (1921-1923) que lideró Henri Barbusse y Anatole France y que edito la revista Clarté..$^{242}$

Si bien esta Internacional tuvo una importante resonancia en el continente, también dejó su

\footnotetext{
${ }^{241}$ Nosotros, ${ }^{\circ} 123$, julio de 1919 , p. 509.

${ }^{242}$ Reproducida en la prensa de distintas ciudades de Europa, la declaración de Rolland de 1919 circuló por primera vez en el periódico socialista parisino L'Humanité y contó con el apoyo de un millar de firmas de intelectuales de distintos puntos del mundo. La única firma argentina fue la de Gálvez (Fisher, 2012). Si bien Rolland había liderado con Barbusse la Internacional de los Intelectuales, no participó de su sucesora, la Internacional del Pensamiento, pues hacia 1921 se oponía a que los intelectuales se pronunciaran tan claramente probolchevique. Para la recepción de Rolland en el movimiento estudiantil argentino, véase Biagini (2012: 221-240).
} 
huella la intervención de Rolland. En efecto, en 1919, meses antes de que apareciera el primero de los nueve números de la revista Claridad, aparecía el primer volumen publicado por Pax, editorial porteña propiciada por el líder del PS, entonces tercerista, Augusto Bunge y dirigida por su cuñado, Manuel Gálvez. Entre las obras de esta pequeña editorial se encontraron dos ensayos de Rolland: Clerambault: una historia de una conciencia libre durante la guerra (traducido por Gálvez y Roberto Giusti) y El gran europeo Nicolai (con una breve introducción de Manuel Gálvez). La única carta que se conserva entre Rolland y Gálvez está fechada en febrero de 1921 y proviene del intelectual parisino. Éste respondía al pedido que le había hecho Gálvez de unas fotografías para publicar junto a una traducción en español de su obra, y con ello confirmaba el papel de embajador local del Rolland que pretendía ejercer Gálvez. ${ }^{243}$

Los estudiantes universitarios porteños que participaban del Ateneo y del Colegio no permanecieron indiferentes al sentimiento de aceleración de los tiempos ni a la politización que se registraba en la generación de intelectuales que los precedía. Al interior del Ateneo, el comienzo de la definición política seguramente deba establecerse a inicios de 1917, cuando dejaron la redacción de Ideas los jóvenes de orientación católica Tomás Casares y Adolfo Korn Villafañe, para pasar a ocuparla tres socialistas (Monner Sans, Scotti y de la Mota), un demócrata-progresista y dos independientes (Britos Muñoz, de Aparicio y Casablanca). Este equipo reiteró una y otra vez que expresaba las inquietudes de un grupo políticamente heterogéneo, pero inició un proceso de inscripción del Ateneo en el socialismo bolchevique, que se sellaría en 1919, con la aparición de un manifiesto en el que el grupo se colocaba "del lado del proletariado" y declaraba que se había liberado de los estudiantes reaccionarios. ${ }^{244}$

La condición políticamente heterogénea del Ateneo entre 1917 y 1918 es confirmada por las diversas respuestas que recibió la "inquisición" sobre la neutralidad argentina en la Gran Guerra, formulada por la revista a sus socios. Esas respuestas oscilaron entre la decidida adhesión en defensa de los valores civilizatorios y la neutralidad ante un belicismo que debía repudiarse. Ideas abría su número de mayo de 1917 con las respuestas de los seis miembros de la redacción sobre la posibilidad o imposibilidad de la neutralidad argentina, pero antes aclaraba:

Deseábamos y deseamos mantener nuestra publicación ajena a discusiones violentas que reconocen por germen las contrapuestas simpatías, antes que los razonamientos serenos aunque contrarios, y que, casi siempre también, se revisten de un tono hiriente y pasionista [...] bien es cierto que algunas opiniones, aun sin quererlo, dimanarán más del sentimiento que del imparcial estudio de todo lo ocurrido, pero ello en estos instantes es inevitable (“América y la guerra (Inquisición)”, Ideas, nº 11, mayo de 1917, pp. 125-126).

\footnotetext{
${ }^{243}$ Carta de Rolland a Gálvez, 08/02/1921, disponible en "Epistolario. Correspondencia recibida por Manuel Gálvez", Academia Argentina de Letras: http://www.cervantesvirtual.com/bib/portal/aal/epistolario2.shtml.

244 “Orientaciones y propósitos”, Ideas, no 22, agosto de 1919, p. 77.
} 
El número siguiente extendía la inquisición a otros socios del Ateneo para reproducir las respuestas de Amílcar Razori, Ernesto Aráoz, Horacio Pozzo, Rohde y Juan Arzioni. ${ }^{245}$

Desde esas simpatías contrapuestas, el Ateneo acompañó al Colegio en la denuncia de los malos profesores que se inició con las "Cartas Novecentistas" redactadas por Korn Villafañe. Mientras la sección de Ideas "De la vida universitaria" cuestionaba la mediocridad de algunos docentes y propiciaba la organización de seminarios de estudio, la primera de las tres cartas, publicada en los Cuadernos, exigía la renuncia de Antonio Dellepiane, quien dictaba la cátedra de Historiología en la FFyL y de Filosofía Jurídica en la Facultad de Derecho. Afirmaba el hijo mayor de Alejandro Korn:

Cumplo, pues, con el penoso deber novecentista, de insinuar a usted la urgente necesidad y alta conveniencia cultural de renunciar cuanto antes a las cátedras que inmerecidamente ocupa usted en las FFyL y de DyCS, para que sea posible entregar la enseñanza de esas materias a una cabeza más apta, de preparación menos superficial (Adolfo Korn Villafañe, "Carta Novecentista", Cuaderno, no 3, diciembre de 1917, p. 177).

Si bien el Ateneo saludaba este vanguardismo juvenilista y difundía pareceres diversos ante la guerra, la nueva dirección de su órgano intentaba orientar a los estudiantes hacia iniciativas políticas. Una de las herramientas para ello fue la organización en abril de 1917 de la ya referida conferencia de Mario Sáenz sobre la misión juvenil. Sostenía el profesor:

Como remedio de las insuficiencias y perturbaciones sociales observadas, analizadas e incriminadas en distintas formas por el mundo entero, juzgo menos importante $\mathrm{y}$ urgente la reforma de las universidades que la formación de un ambiente extrauniversitario, donde las fuerzas juveniles, libres de la aspiración profesional, se vinculen profundamente a la colectividad en que viven, por móviles menos egoístas, por aspiraciones más permanentes, por esfuerzos más generosos y por intereses más humanos e igualitarios que gremiales y privilegiados (Sáenz, 1917: 4).

Sáenz elegía esas palabras para saludar la obra de carácter cultural que el grupo de Monner Sans venía realizando desde 1914. Pero a continuación declaraba que esa no bastaba y llamaba a los ateneístas a que precisaran los "intereses más humanos e igualitarios” que excedían lo gremial:

¿Es posible admitir que la juventud universitaria mire con indiferencia cómo marcha, sin dogma y sin principios, esa otra juventud no universitaria, que vive a su lado una vida espiritualmente inferior y cuyo único porvenir se fía a los azares del juego, a los vaivenes de la política o a otras combinaciones más inmorales todavía, porque afectan los hogares hasta en la idealidad de los sentimientos, que han de ser la más sólida base

245 “América y la guerra (Inquisición)”, Ideas, n 12, julio de 1917, pp. 285-290. 
de su organización? (Sáenz, 1917: 10).

Cierta repercusión de esta llamada se advierte en la inauguración de la sección de Ideas "De la vida universitaria", en la que los seudónimos de "Tikonidos", "Aserrín", "Gervasio Toro" y "Simón Porra", entre otros, permitieron a los jóvenes redactores lanzar irónicas críticas sobre los malos hábitos fomentados por la universidad. Recuperando la misión que trazaba Sáenz, la sección atacaba el individualismo de los intelectuales que no se ofrecían como maestros y el de los estudiantes que sólo se interesaban por el título, críticas a las que desde 1918 se agregó el contraste entre la quietud de los jóvenes porteños y el brío revolucionario de los cordobeses, y que serían centrales en el esbozo del estudiante como una figura de intelectual ligado al compromiso político.

A su vez, el discurso de Sáenz también parece resonar en el siguiente anuncio publicado por Ideas:

\section{Curso para obreros}

Sin orientación partidista de ninguna especie y con móviles genuinamente prácticos, un grupo de estudiantes se distribuirá en los centros obreros -cada cual según sus ideas y de acuerdo con la índole de sus preferencias-y tomará a su cargo una o varias lecciones semanales (Ideas, n 11, mayo de 1917, p. 196).

Allí se aclaraban los nombres de los cinco ateneístas que formaron la comisión organizadora: ésta estaba formada por jóvebes de orientaciones tan diversas como el católico Casares, el independiente Horacio Pozzo y los socialistas Palcos, Hernández y de la Mota. Los siguientes números de Ideas no registraron el tipo de acercamiento de los ateneístas a los obreros. Podemos conjeturar que en los centros obreros socialistas participaron los jóvenes mencionados más Monner Sans, Scotti, Castiñeiras y Arturo de la Mota, mientras que Korn Villafañe, Rohde y Dell'Oro Maini acompañaron a Casares en los centros católicos. De todos modos, el intento de asentar la unión obrero-estudiantil en "móviles genuinamente prácticos" fue abandonado al poco tiempo, pues unos números después la nueva redacción de Ideas rompía el "pacto pluralista" para insinuar la orientación izquierdista que desde entonces sería cada vez más marcada en el grupo.

La primera ruptura de ese pacto parece haberse realizado a fines de 1917. Durante el mes de junio de ese año, se debatió en la Cámara de Diputados la ley de divorcio, Ideas se declaró francamente divorcista, al tiempo que denunció a los diputados que habían evitado la discusión de la ley y destacó "la actitud decidida y solidaria de la diputación socialista, que, en este caso como en todos, contrasta notablemente con los otros grupos políticos de la Cámara, incoherentes e inarmónicos, a quienes la más pequeña discusión los divide". ${ }^{246}$ Los numerosos ateneístas católicos estaban convencidos de que la ley en cuestión conducía a la disolución de la familia y no podían más que pedir la corrección de las declaraciones de Ideas. Pero en esta oportunidad -y como tendió

\footnotetext{
${ }^{246}$ La redacción, “El divorcio”, Ideas, n 12, julio de 1917, pp. 337-338.
} 
a hacerlo desde entonces-, Ideas no priorizó la unión de los estudiantes: en el número siguiente el equipo de redacción refrendó las declaraciones divorcistas, ante lo que, cumpliendo con lo anunciado, el presidente del Ateneo, Casares, y el primer vocal, Korn Villafañe, se retiraron del grupo. Ambos concentraron su intervención en el Colegio Novecentista y la renuncia no impidió que, durante algunos meses más, los dos grupos continuaran un contacto estrecho.

La apuesta por la definición política del Ateneo prosiguió con el saludo a la formación del Partido Reformista, de orientación georgiana, y el Partido Socialista Internacional, de orientación neutralista y luego bolchevique, así como con la noticia de marzo de 1918 en la que, bajo el título "Palcos, candidato a diputado", se informaba sobre las candidaturas políticas de algunos ateneístas: José B. Maril como diputado de la provincia de Buenos Aires por el PS, Amílcal Razori como diputado de la provincia de Santa Fe por el mismo partido, Eduardo Miranda Gallino como diputado nacional de la Capital también por el PS. Luego el breve texto concluía marcando su preferencia por el antiguo arielista que actuaba en el Ateneo desde principios de 1915 y se presentaba por el PSI, una preferencia que era inesperada para el tipo de intervención cultural que venía realizando Ideas pero que anunciaba la deriva del grupo. Declaraba la nota: "No todos los socios del Ateneo comparten sus ideas avanzadas, pero todos reconocen en él a un excepcional y laborioso estudiante [...] IDEAS cree que con ciudadanos como Palcos, el Parlamento Argentino ganaría en talento y en respetabilidad". 247

La mayoría de los ateneístas no simpatizaba con la filosofía cientificista, e incluso continuaba adhiriendo a las críticas a ésta que se leían en los Cuadernos, pero al calor de la politización que motivaba la Reforma aquellos decidieron priorizar la construcción de espacios socialistas que interpelaran no sólo a los estudiantes sino también a los obreros e intelectuales, más allá de la afinidad cientificista o antipositivista. En cambio, quienes permanecieron en el Colegio se preocuparon por la cuestión obrera desde posiciones nacionalistas, antiizquierdistas y aristocratizantes.

\section{Distanciamiento político entre ateneístas y novecentistas}

Ideas ofrece varias pruebas de la "neutralidad cordial y hasta benévola" que, según recordaba Monner Sans, mantuvieron el Colegio y el Ateneo en un comienzo: Ideas publicó el manifiesto fundacional del Colegio reseñando elogiosamente su reunión inaugural; reprodujo el anuncio publicitario de los Cuadernos y, a diferencia de Verbum, los declaró un aporte cultural significativo. Además, al dejar la dirección de Ideas, Monner Sans pronunciaba un discurso en el que declaraba que la tarea de la juventud era "“universalizar' lo que, espiritualmente, produce el pueblo argentino", tarea que no sólo estaría realizando el Ateneo sino también el Colegio. Allí aclaraba que

247 "Palcos, candidato a diputado", Ideas, no 16, marzo de 1918, pp. 59-60. 
Korn Villafañe y Rohde le habían pedido una historia del Ateneo para editar a través del Colegio. ${ }^{248}$ La hermandad entre ambos grupos volvía a evidenciarse semanas después, cuando el nuevo director de Ideas, Alberto Britos Muñoz, editaba su primer libro, Impresiones, en la serie de las Publicaciones del Colegio Novecentista. ${ }^{249}$

Pero la historia del Ateneo recién aparecerá en 1930 en las páginas de Nosotros, pues a los pocos meses estallaba la Reforma y comenzaba un vertiginoso distanciamiento entre los grupos. En su número de enero de 1919, Ideas explicitaba las diferencias entre los dos grupos a través de un largo artículo del joven Justo Pallares Acebal. En "El novecentismo argentino", el estudiante de Derecho declaraba que filosóficamente el novecentismo era "un plato recalentado" y que políticamente defendía el statu quo. ${ }^{250}$ Casares contestaba en el octavo Cuaderno (fechado en julio de 1919) con la reproducción del discurso que había pronunciado en abril de 1917 al asumir por segunda vez la presidencia del Ateneo. Ese discurso, rescatado para mostrar su persistencia en la labor cultural entre los estudiantes, era dedicado a Monner Sans, "hoy que se ha definido tan categóricamente nuestra oposición intelectual”. 251

La oposición intelectual también se advierte en otras intervenciones. Durante 1919 el Ateneo participó de los mitines, asambleas y actos estudiantiles ligados a la Federación de Asociaciones Culturales y a la FUA. Además, redactó un manifiesto para repudiar la violencia nacionalista y editó desde septiembre el quincenario izquierdista que analizaremos en el siguiente capítulo. En cambio, el Colegio no sólo no participó de esas instancias, sino que además las deslegitimó tanto desde su revista como desde el CE de Filosofía y Letras y su órgano. En 1919 ese CE estuvo dirigido por el novecentista Ventura Pessolano y al año siguiente por el novecentista Juan Probst. Si el primero fue quien -como vimos- alentó la separación de la FUBA de la FUA en rechazo del obrerismo que advertía en una institución de carácter estudiantil, el segundo alentaría esa misma línea "apolítica", primero desde los Cuadernos y la dirección de Verbum, y luego desde el CE. Confesaba Probst antes de ganar la presidencia del CE:

Yo, señores, tengo sentada fama de conservador en la Federación Universitaria, porque trataba de moderar a veces los impulsos juveniles de mis compañeros y los invitaba a reflexionar antes de obrar [...] Es muy fácil decretar medidas extremas, huelgas por ejemplo, cuando los que tienen que sufrir sus consecuencias son los otros [...] Mucho se ha discutido en estos últimos tiempos sobre si los centros estudiantiles deben pronunciarse con respecto a los problemas sociales de actualidad y federaciones hubo que han celebrado formales alianzas con los sindicatos obreros. Para mí, esta tendencia

\footnotetext{
248 José María Monner Sans, “Dieciseis números de 'Ideas"”, Ideas, nº 16, marzo de 1918, p. 52.

${ }^{249}$ En Ideas $\mathrm{n}^{\circ} 18$ (julio 1918) se reseñan las cuatro publicaciones editadas hasta entonces por el Colegio: La otra Arcadia de Teófilo de Sais (seudónimo de Taborga), Impresiones de Alberto Britos Muñoz, El irredimido, novela de Korn Villafañe. y Cantos de Rohde. Como mencionamos, la quinta y última edición hecha por los novecentistas es la tesis neotomista con la que Casares se doctoró en Derecho, titulada La Religión y el Estado.

${ }^{250}$ Justo Pallares Acebal, “El novecentismo argentino”, Ideas, n 21, enero de 1919, pp. 176-198.

${ }^{251}$ Tomás Casares, "Discurso", Cuaderno, no 8, julio de 1919, p. 159.
} 
es equivocada. El carácter de los centros estudiantiles debe ser gremial y como gremios de los estudiantes deben ocuparse exclusivamente de los problemas universitarios. Por agremiación obligatoria, cuyo proyecto, presentado por las delegaciones de Filosofía y de Derecho, está en estudio del Consejo Superior, se acentuará aún más este carácter gremial (Juan Probst, "Las elecciones de renovación de la C. D.", Verbum, n 53, marzomayo de 1920, pp. 94-95).

Y a continuación, este joven que había llegado de Nuremberg para organizar una filial textil de la empresa de su padre, proseguía tomando aún más distancia de las iniciativas que comenzaba a alentar el Ateneo en coordinación con la Federación de Asociaciones Culturales y en afinidad con el PSI:

Sí, soy burgués, y no puedo con este bolcheviquismo de salón que lo gasta en melena y chambergo y el cual profesan los mismos que anteayer fueron decadentistas con Rubén Darío y ayer socialistas con Alfredo Palacios. Pero no soy burgués con gorro de dormir y chancletas, como a ellos les gusta pintarlos, mi cuna estaba en una de estas ciudades libres cuyos ciudadanos más de una vez declararon jaque a los reyes ensombrecidos y que en su lucha por la libertad de conciencia desafiaron los anatemas papales y los edictos conciliares. Así es como soy burgués y como tal tengo el ánimo abierto a todas las novedades, pero también las peso y las medito, y no las acepto inconscientemente (Idem, p. 95).

Estos novecentistas, que se oponían al ingreso de la política -y sobre todo de la cultura de izquierdaen la organización estudiantil, se reconocían antipositivistas kantianos y convivían en el Colegio con otros que conciliaban el antipositivismo y el antibolcheviquismo con el cristianismo y el nacionalismo político. Específicamente, bajo la editorial del Colegio, Casares publicó a fines de 1918 La Religión y el Estado, un ensayo neotomista -dedicado “a la memoria de José Manuel Estrada cuya obra despertó en mi espíritu el entusiasmo por las cosas esenciales"- con el que había accedido al título de doctor en Jurisprudencia en la Facultad porteña de Derecho. El futuro líder de los Círculos de Cultura Católica refutaba allí el rousseaunismo por su negación del individuo libre frente al cuerpo social, al tiempo que sostenía que el Estado no podía más que basar su ordenamiento moral en el conocimiento racional de Dios que ofrecía el cristianismo.

Probst se apuraba a criticar duramente, desde las páginas de los Cuadernos, ese "catolicismo ortodoxo" que defendía una causa perdida "con las ya melladas armas de la escolástica tomista", en lugar de aceptar el subjetivismo intuicionista demostrado incontestablemente por Kant. ${ }^{252}$ Pero ninguna crítica le despertaba a Probst el apéndice del libro de Casares, "El maximalismo", en el que se exponían los peligros de las ideas bolcheviques en la escena local. Y ello sugiere que lo que unía entonces a los miembros del Colegio no era el neotomismo ni el kantismo, sino las tesis antipositivistas en cuanto al libre albedrio del hombre -o bien, la imposible reducción determinista

\footnotetext{
252 Juan Probst, "La Religión y el Estado de Tomás Casares”, Cuaderno, no 8, julio de 1919, pp. $202-204$.
} 
de sus acciones- junto a un antisocialismo de resonancias nacionalistas.

Según el apéndice de Casares, la Revolución Rusa y la cuestión obrera no se originaban en la falta de una legislación obrera, sino en el materialismo y la escasa cultura moral establecidas por la ambición capitalista. Reconociéndose parte de la reacción antipositivista, Casares leía el materialismo histórico como una continuación de la filosofía positivista:

El materialismo implicado en la negación del espíritu, se convierte, para el sistema, en la afirmación del primario valor de las fuerzas económicas de la historia que todo lo hacen y lo explican todo; el determinismo justifica la existencia de leyes sociales y desplaza todas las contradicciones que contra semejante orden determinado alza la libertad; el agnosticismo, en fin, le sirve para negar a la ley moral sus caracteres de objetiva y absoluta reduciéndola a producto del medio, relativa y utilitaria (Casares, 1919: 129).

Para que no quedaran dudas, concluía: “el maximalismo nos parece la terrible liquidación de los errores más graves de la cultura materialista y su consiguiente política amoral, hecha por los que más han sufrido a causa de ella". Aunque consideraba que esa revolución se basaba en ideas erróneas, encontraba un modo de aprovecharlas para restablecer una sociedad "armónica" guiada por el Evangelio: "solidaridad, colectivismo y mayor justicia social, que la revolución no inventó -pues son tan viejos como la civilización cristiana- [...] de hoy en más, serán postulados indiscutibles de todo equilibrio universal futuro" (Casares, 1919: 131-132).

Un posicionamiento afín se desliza en el noveno y último Cuaderno (fechado en diciembre de 1919). Allí aparece un manifiesto que reduce la Reforma a una Weltanschauung antipositivista y advierte a los estudiantes de la FULP, que desde octubre protagonizaban la "huelga grande", que no han entendido en qué consiste la Reforma. El mismo número publica un tratado sobre Dios proveniente de la esposa de Manuel Gálvez, Delfina Bunge de Gálvez (quien desde 1921 dirige el órgano del Centro de Estudios Religiosos para Señoras y Señoritas), ${ }^{253}$ y un homenaje al profesor que con más fervor se había opuesto al laicismo educativo -y al que Casares le había dedicado su obra-, José Manuel Estrada.

Al señalamiento de la moral cristiana como correctora de los problemas sociales y a la definición de la Reforma como renovación antipositivista, se sumó Korn Villafañe con su prolongado intento de instalar una versión nacionalista de la Reforma en la Facultad de Derecho. En abril de 1919 fundaba el grupo Unión Universitaria y se candidateaba como presidente del CE de Derecho. Para ello presentaba unas "Bases para la nueva vida estudiantil” en las que, a distancia del

\footnotetext{
253 "El Colegio Novecentista y el conflicto universitario de La Plata" y Delfina Bunge de Gálvez, "Divagaciones acerca de la idea de Dios", Cuaderno, no 9, diciembre de 1919, pp. 209-211 y 212-232, respectivamente. La revista que dirigió Bunge llevó el nombre de Ichthys (anacrónico de Iesus Christos Theou hYios Soter) y editó ciento siete números entre julio de 1921 y abril de 1931. Agradezco a Horacio Tarcus el acceso al noveno Cuaderno, desconocido hasta ahora por la bibliografía crítica.
} 
discurso de Roca en el congreso estudiantil y de la labor emancipatoria previa a la revolución socialista desde la que Scheimberg, Bermann y otros arielistas socialistas convocaban a los estudiantes a instruir a los obreros, proponía una extensión universitaria marcada por una misión ética "idealista" y "nacionalista":

Seamos nacionalistas en ideología, en ciencia, en arte -tengamos una industria nacional. [...] El analfabetismo ha sido y es la gran obsesión argentina. Se creyó que enseñando a leer y a escribir, se había resuelto el problema educacional, cuando en realidad sólo se había planteado. Corresponde a la Universidad la solución de este problema y es su misión más noble vincular al obrero, por intermedio de los estudiantes, a una cultura superior. Cada estudiante universitario debe ser de hecho un maestro obrero y no olvidar que la mejor enseñanza moralizadora es la del ejemplo. En verdad que no tendría objeto disminuir en 3 o 4 horas el horario de trabajo de los obreros, si estas horas las han de dedicar al vicio, por falta de orientación ética y de ocupación mental.

Y esta es la primera misión de la Universidad Nueva (Korn Villafañe, 1922: 39-40).

El CE era ganado por la Lista Blanca, que encabezaba Enrique Torino y Muñoz Montoro, entonces presidente del Ateneo. En enero de 1920, Korn Villafañe ponía a circular "Incipit vita nova", manifiesto que adoptaba el mismo nombre que el preparado en 1918 por su padre para Atenea. Pero mientras Alejandro Korn proponía una revisión del socialismo capaz de reemplazar su corset economicista por el antipositivismo, Adolfo Korn Villafañe sugería un antiliberalismo ligado a un nacionalismo antidemocrático, que luego sería característico del revisionismo histórico de derecha. El joven lograba que su texto se convirtiera en la plataforma ideológica de la Unión Universitaria, agrupación estudiantil que, como veremos en el capítulo séptimo, se erigió en el ala nacionalista y aristocrática de la Reforma y condujo el CE de Derecho entre 1920 y 1926.

Mientras que el nacionalismo de Korn Villafañe y el neotomismo de Casares rescataban de la Revolución Rusa su inscripción más allá del individualismo burgués para desde allí proponer una definición de la Reforma que la restringía a una renovación de los planes de estudio, el Ateneo se preocupaba por reivindicar el internacionalismo revolucionario de la experiencia rusa y la posibilidad de que la universidad ocupe en la sociedad argentina un rol orientado a solucionar la desigualdad social. Un interesante testimonio lo ofrece el discurso pronunciado por Monner Sans en marzo de 1919. Ante la muerte de Amado Nervo, Ideas organiza, junto a sus "mayores" y "cientificistas" Revista de Filosofía y Nosotros, un homenaje que insinúa la formación de una nueva red de "revisteros descontentadizos". El líder del Ateneo sostenía que su grupo representaba al "núcleo más joven que forma en la falange de los inadaptados", y precisaba que lo que compartían esos inadaptados no era la juventud sino la complacencia ante

la nueva aurora roja que despunta, alumbrando, con sus resplandores ígneos, regímenes sociales donde la palabra justicia no entraña la aquiescencia ante la explotación 
económica del hombre, o la ceguera voluntaria ante la iniquidad o la tolerancia servil ante el despotismo político de caudillejos fatuos e ignorantes. Observamos también en personas que nos doblan ya la edad, una rebelión inesperada y una receptividad intelectiva dispuesta a percibir los lamentos del varón aprisionado en las redes del capitalismo opresor y de la hipócrita moral burguesa (Nosotros, $\mathrm{n}^{\mathrm{o}}$ 120, Buenos Aires, abril de 1919, pp. 578-580).

Más allá de la grandilocuencia retórica propia de los discursos, esas palabras ofrecen una rápida idea de los ánimos revolucionarios que, a distancia del Colegio y de la Unión Universitaria, despertó la Revolución Rusa no sólo entre ciertos grupos estudiantiles, sino también entre los pretendidos maestros “que les doblaban ya la edad". Por entonces, el Ateneo le encargó a del Mazo la reformulación de los estatutos. Luego de aprobar una versión en la que se realizaban muy pocos cambios, el grupo dio a conocer unas “Orientaciones y propósitos", seguramente provenientes de la pluma de Monner Sans, con las que el Ateneo inscribía plenamente su labor en el campo de las izquierdas. Allí se declaraba:

En la hora actual -terminada la tragedia europea- dedicarse exclusivamente a la dilucidación de problemas científicos, literarios y artísticos, cerrando las puertas al rumor de las luchas que libran oprimidos y opresores, sería el más inicuo de los egoísmos. [...] Libre ahora la institución de elementos reaccionarios, tiene un rumbo fijo, sabe qué quiere y adónde va... (“Orientaciones y propósitos", Ideas, $\mathrm{n}^{\mathrm{o}} 22$, agosto de 1919, p. 77).

Al mes siguiente, el Ateneo formaba una "Junta de Estudios" y un "Comité de Acción Social", y ponía en circulación el primero de los diecinueve números de Clarín, un quincenario de diez o doce páginas de "prédica en hojas menos doctas, pero más al alcance popular" (Monner Sans, 1930: 2122). Desde el Comité de Acción Social, el Ateneo dio su apoyo a los maestros mendocinos sindicados en "Maestros Unidos" que mantenían una huelga general, junto a los telefonistas y toneleros. Una nota breve de La Vanguardia (09/10/1919) anunciaba que la FUA acababa de organizar un comité a favor de "Maestros Unidos" "con el objeto de promover en toda la república un enérgico movimiento a favor de los maestros mendocinos impagos, ofendidos y despojados de sus puestos por la intolerancia de las despóticas autoridades que oprimen aquel estado argentino" y que el comité había quedado compuesto por Julio V. González por la FUA, Francisco Suárez por la Liga Nacional de Maestros, Gregorio Bermann por la Federación de Asociaciones Culturales, Muñoz Montoro por el Ateneo Universitario y José de la Mota por el Círculo de Profesores Normales.

En cuanto a la nueva publicación del Ateneo, si bien Clarín fue totalmente olvidada por la historiografía, tuvo una amplia tirada e importante difusión entre los estudiantes y -según veremos en el capítulo siguiente- participó del primer periodismo político junto a Bases. Tribuna de la 
juventud, la revista Ariel de Montevideo, Insurrexit. Revista Universitaria y Hoy. Antes de analizar esta serie de publicaciones izquierdistas aparecidas en 1919, recuperemos otras dos iniciativas estudiantiles que surgieron en 1918 en vinculación con el Ateneo una y con el Colegio la otra.

\title{
Themis (1918-1919), la revista izquierdista de los estudiantes de Derecho
}

\author{
Bárbaros de todas las regiones golpean las puertas de \\ esta casa. Piden precio y calidad de cada uno de \\ nosotros. Vengan en buena hora, si les somos útiles y \\ en ellos a la Patria. Pero que sepan que todos llevamos \\ algo más que nuestro diploma. Que en ti aprendan que \\ aquí no se elabora mercancía humana y también \\ salimos "almas de acero con sonrisa de oro". [...] \\ Suave calor de idealidad del alma, clara luz al espíritu. \\ Gonzalo Muñoz Montoro, “Óyeme”, 1919.
}

Así como algunos miembros de la comisión directiva del Ateneo participaron de la fundación del Colegio Novecentista y de los Cuadernos, otros se propusieron modificar el perfil profesionalista y gremialista del Centro porteño de Estudiantes de Derecho y su publicación, dos instancias mucho más disputadas que el ámbito de la FFyL en el que intervenía el Colegio, pues la Facultad de Derecho formaba a la clase política argentina y, junto a Medicina, era la facultad con mayor número de estudiantes. El CE había sido fundado a mediados de 1905 y desde 1909 editaba la Revista del Centro de Estudiantes de Derecho. El objetivo casi exclusivo de esta publicación fue el de estimular los estudios jurídicos. Allí se difundían monografías de docentes y alumnos, y en algunos casos se reseñaban libros sobre derecho. En 1917 el estudiante, ateneísta y colaborador de Ideas, Gonzalo Muñoz Montoro se sumaba al equipo redactor de la Revista del Centro Estudiantes de Derecho, y a mediados del año siguiente asumía su dirección. Al igual que los números del órgano del CE de Filosofía y Letras dirigidos por Bermann, los seis números de la olvidada revista del CE de Derecho a cargo de Muñoz Montoro renovaron la publicación desde una impronta militante. Pero esta impronta no estuvo marcada por el socialismo científico, sino por la convergencia, que desde 1918 pregonaba Ideas, entre cultura estética y socialismo.

La prueba más clara de esa afinidad con Ideas es el hecho de que, durante 1919, Muñoz Montoro presidió el Ateneo, pero una prueba más interesante la ofrece la dedicatoria que el joven eligió para su primer libro, del que extraímos la cita del epígrafe. Allí Muñoz Montoro publicó, bajo el título de Cosecha política y el seudónimo de Gervasio Toro, una compilación de notas, aparecidas en su mayoría en Ideas, dedicada “a Alberto Britos Muñoz y José María Monner Sans, espíritus representativos del alma y nervio de mi generación” (Muñoz Montoro, 1919).

Muñoz Montoro fue el director de los números 69 a 74 del órgano estudiantil de Derecho, 
los que aparecieron entre julio de 1918 y abril de 1919. ${ }^{254}$ Si bien la numeración marcaba la continuidad de la revista, la nueva impronta fue subrayada a partir de la modificación del nombre: desde entonces la publicación se llamó Themis. Órgano del Centro de Estudiantes de Derecho y Ciencias Sociales. Luego del número 74, la revista dejó de editarse, pues el CE consiguió que el Centro Jurídico, asociación profesional de los egresados de la Facultad, les traspasara la dirección de la Revista Jurídica y de Ciencias Sociales, publicación a la que nos referiremos en el capítulo séptimo.

Los números de Themis se abrieron con entusiastas editoriales y tuvieron una organización en secciones similar a la de Ideas. Bajo esta organización, los estudiantes de Derecho comenzaron a contar con una publicación que no sólo difundía estudios sobre derecho sino también ideas juvenilistas y proyectos ligados a la expansión de la Reforma, como el mencionado Congreso Nacional de Estudiantes y las plataformas de las distintas asociaciones culturales y profesionales.

Alejándose de los “canastos de apuntes" que criticaba Bermann, el editorial del número 70 sostenía que a la revista no le molestaba "la crítica sincera de quienes entienden que nuestra revista debiera ser así como unos anales destinados exclusivamente a llenar los fines unilaterales de nuestra especialidad científica, práctica arraigada en todo nuestro periodismo universitario", pues a pesar de esos pareceres “THEMIS está en marcha. Revista de juventud y para la juventud, eliminará de sus páginas todo aquello que huela a apoltronamiento senil. Poco a poco con su propia obra se irá convirtiendo en el más alto censor de la erudición postiza de algunos profesores y la impericia mental de muchos alumnos". ${ }^{255}$

Esta pertenencia a una "nueva generación", que será central en las intervenciones reformistas a lo largo de la década del veinte, también era invocada en el editorial que abría el número 72. Ofreciendo otra prueba del común interés de la dirección de Themis y la de Ideas por la formación integral y por la mayor participación de los jóvenes porteños, se afirmaba allí:

Hace ya tiempo que hombres envejecidos prematuramente, reciben con despectivo gesto a quienes llegan con el alma abierta a los nuevos ideales de una vida más amplia, más natural y bella. Juzgan que la pasión de éstos por la cultura integral y su inquietud por las cosas del espíritu, son tan solo medios cómodos de disimular su haraganería mental y fácil manera de esquivar el persistente esfuerzo cerebral que requiere la árida preparación profesional. [...] Es indudable que la mayoría de nuestra juventud ha tenido que hacerse autodidacta y de que la mayor parte de los frutos que ella recoge se los debe a sí mismo. Pocos, demasiado pocos son los maestros de esta casa ("Cosecha política", Themis, $\mathrm{n}^{\mathrm{o}} 72$, octubre-diciembre de 1918, pp. 3-4).

\footnotetext{
${ }^{254}$ Las fechas en que aparecieron esos números de Themis son las siguientes: $n^{\circ}$ 69, julio de 1918 (dedicado a Bunge); $n^{\circ}$ 70 , agosto de 1918; $\mathrm{n}^{\mathrm{o}} 71$, septiembre de 1918, $\mathrm{n}^{\mathrm{o}} 72$, octubre-noviembre-diciembre, $\mathrm{n}^{\mathrm{o}} 73$, enero-febrero $1919 \mathrm{y} \mathrm{n}^{\mathrm{o}} 74$, marzo-abril de 1919. Recordemos que Muñoz Montoro había viajado a Córdoba en julio de 1918 para presentar en el Primer Congreso Nacional de Estudiantes un proyecto de "Periodismo estudiantil" que sería aprobado y retomado por varios de los grupos que por entonces comenzaban a fundar revistas.

${ }^{255}$ La Dirección, "En marcha", Themis, no 70, agosto de 1918, p. 4.
} 
Esta nueva "revista de juventud" publicó los manifiestos de apoyo a los reformistas cordobeses y de crítica al nacionalismo de la Semana Trágica, las crónicas que mandaban los jóvenes desde el Primer Congreso Nacional de Estudiantes, el citado discurso en el que Roca llamaba a los estudiantes a unirse al pueblo y la "Composición de lugar de la nueva generación”, en la que el joven intelectual Alejandro Shaw le proponía a los universitarios que se dedicaran a elevar la cultura nacional.

Pero esos materiales convivieron con algunas notas en las que el juvenilismo mantenía las expresiones aristocráticas que habían comenzado a ser objeto de critica desde 1914 por los arielistas socialistas. Un ejemplo de la convivencia de expresiones aristocráticas lo ofrece la colaboración enviada por el joven José Negri, quien llamaba a los centros de estudiantes a abandonar esas actividades políticas que no producían más que "división y discordia", para ocuparse de actividades exclusivamente recreativas, como las que primarían entre los universitarios europeos. Sostenía en ese llamado:

Reforma universitaria, no es, como pretenden espíritus retrógrados o reaccionarios, mayor o menor dificultad de graduarse, ni mayor o menor exigencia en el estudio, ni tampoco un simple cambio de personas en la dirección de las Facultades: es, con un criterio más amplio y más actual, y para decirlo en pocas palabras, un cambio de sistema en la universidad misma; es pretender la influencia directa y decisiva de la universidad en la vida nacional, auscultando sus necesidades, resolviendo sus problemas, proveyendo en fin al Estado, no abogados, ni médicos, ni ingenieros más o menos buenos; no simples profesionales de la ciencia, sino ciudadanos aptos para encauzar en la espera de su acción, la marcha constante del país hacia el progreso (José A. Negri, "La reforma y los Centros", Themis, no 72, p. 283).

Si bien Negri declaraba su oposición a los "retrógrados y reaccionarios", su preocupación por una formación que produjera ciudadanos útiles para el Estado establecía una gran distancia con la inscripción de la Reforma en la cultura socialista que realizaban tanto los discursos de Roca, Bermann y otros jóvenes como los proyectos de extensión universitaria que proclamaban que los universitarios estaban obligados a educar al pueblo para posibilitar la llegada del socialismo. El tipo de definiciones reformistas formuladas por Negri no primaron en Themis, sino en los Cuadernos y en la Revista Nacional, otra "revista de juventud" que editaron desde octubre de 1918 los estudiantes de Derecho Mario Jurado y Julio Irazusta.

Sobre el fraccionamiento político que producía la Reforma, precisemos que, en el número de junio de 1918 de la Revista del Centro de Estudiantes de Derecho, Muñoz Montoro había publicado una elogiosa reseña del Colegio. Sobre el grupo antipositivista en el que comenzaba a participar 
declaraba: "bien puede llegar a ser horizonte de nuestra desorientada generación" ${ }^{256}$ y el siguiente Cuaderno listaba su nombre entre la veintena de miembros del Colegio. Pero al iniciarse la politización estudiantil, Muñoz Montoro quedaba del lado de los ateneístas. En efecto, mientras el último número de los Cuadernos (diciembre de 1919), en el que ya no figuraba el nombre del director de Themis, le pedía a los huelguistas que centren sus reclamos en una renovación antipositivista de los estudios, Muñoz Montoro llegaba a La Plata para representar a los ateneístas en un acto que contó con el discurso de Saúl Taborda y que versó sobre la importancia de la unión de los reclamos obreros y los estudiantiles. ${ }^{257}$

En 1919 Muñoz Montoro secundó a Enrique Torino en la Lista Blanca que, en rivalidad con la Unión Universitaria que encabezaba Korn Villafañe, ganó el CE de Derecho. ${ }^{258}$ En octubre de ese año aparecía el último número de Themis; Muñoz Montoro asumía entonces la dirección de los primeros números del Boletín de la Federación Universitaria Argentina, en el que fueron publicadas notas tanto de estudiantes como de las figuras que apoyaban las expresiones más radicalizadas de la Reforma, como el discurso platense de Taborda y el texto de Goldschmidt a favor del revolucionarismo. Unos años después, Muñoz Montoro se recibía de contador y se radicaba en Montevideo. Desde entonces su trayectoria es difícil de seguir. A través de una reseña y de una carta conservada en el Fondo personal Florentino Sanguinetti del CeDInCI, sabemos que en 1921 se instaló en Montevideo, donde preparaba el libro la Revolución Universitaria, se vinculó a la vanguardia literaria de esa ciudad y se ganaba la vida como contador en un estudio propio. ${ }^{259}$ En un intento de rescatar la trayectoria de este reformista, citemos la caracterización que de Muñoz Montoro proponía en 1929 una de las revistas más importantes de la vanguardia montevideana:

Después de haberse encendido y modelado en una inquietud social templada sobre lo vivo y en una paralela preocupación por los destinos de la cultura, Gonzalo Muñoz Montoro se entregó a la vida combativa, orientó y en parte dirigió los movimientos universitarios reformistas que agitaron hace algunos años La Plata, Buenos Aires, Córdoba y otras ciudades de la Argentina. En los momentos de tregua y sin disminuir la

\footnotetext{
${ }^{256}$ Cuaderno, ${ }^{\circ}$ 5, p. 128.

${ }^{257}$ El acto tuvo lugar el 7 de mayo de 1920 y la participación de Taborda no es un dato menor cuando se atiende a que en los meses siguientes encabezará el nuevo reclamo reformista ligado al ala radicalizada del movimiento. Veremos en el próximo capítulo que en agosto de 1920 Taborda asumió el Rectorado del Colegio Nacional de La Plata y propuso una reestructuración educativa violentamente resistida por los sectores conservadores. El discurso de Taborda, "La docencia emancipadora", fue publicado en el Boletín de la Federación Universitaria Argentina, n 1 . Del Mazo rescató ese texto y el de Muñoz Montoro, "La emancipación estudiantil y la gesta de un nuevo derecho", en sus compilaciones de 1926-1927 y de 1941.

${ }^{258}$ En el Fondo personal Florentino Sanguinetti del CeDInCI se conserva el Manifiesto que editó la Lista Blanca en mayo de 1919, luego de ganar las elecciones. Allí figuran como presidente Torino, vicepresidente Muñoz Montoro, secretarios Horacio Morixe, Carlos C. Colombres, tesorero Adriano Bourgignon, pro-tesorero Lázaro Nieto Arana; la comisión de cuentas la componen Guillermo Garbarini, Carlos Zabala y Carlos Pereira Iraola.

${ }^{259}$ Confiesa J. De Souza Sola: "Gonzalo Muñoz Montoro anda por aquí desde hace 8 meses. Tiene la intención de darme largas latas. Se acuerda mucho de Ud. Saca el cuero (juntos) a medio Bs. As. intelectual y prepara aquí la Revolución Universitaria. Haremos trabajos juntos" (Carta de J. De Souza Sola a Florentino Sanguinetti, Montevideo, 09/01/1921. Fondo personal Florentino Sanguinetti, CeDInCI).
} 
intensidad de su vida de acción, Gonzalo revisaba postulados tradicionales con una máxima desaprensión, aumentaba su experiencia sobre los impulsos concéntricos de la psicología colectiva, ordenaba datos sobre las líneas movedizas de la muchedumbre, completaba sus múltiples lecturas filosóficas y meditaba (Guido, "Cartas Lunarias por Gonzalo Muñoz Montoro”, La cruz del sur, n 25, agosto septiembre de 1929, p. 38).

Unas líneas después la reseña evoca el vínculo del porteño con los escritores montevideanos:

Empezó entonces a reunirse con los amigos junto al mar, a escribir glosas, a desenvolver su diario íntimo, a ejercer gran ascendiente sobre los que le escuchaban. [...] Al borde del estuario, sobre la arena solitaria, ante la magia nocturna del cielo austral, Gonzalo paseaba con sus amigos discurriendo sobre Platón, Martín Fierro, el "gaucho malo", la revolución soviética, la intuición bergsoniana o las actividades de la Federación Obrera Regional Argentina (idem., pp. 38-39).

Sin duda, esa entusiasta convivencia entre acción combativa y estudio meditado que menciona la reseña no fue un rasgo exclusivo de Muñoz Montoro. Como han sostenido algunos estudios, ella fue central en líderes indiscutidos de la Reforma como Bermann, Roca, González y Sánchez Viamonte, entre otros (Celentano, 2006a; Ciria y Sanguinetti, 1968; Graciano, 2008; Navarro, 2009). La citada caracterización nos recuerda que esa convivencia entre acción y estudio tendió a traducirse en una sensibilidad intelectual perdurable y que se extendió a muchos jóvenes olvidados por la historiografía.

\section{La Revista Nacional, la impugnadora de Themis}

Otra vez el señalado verbalismo suplantado a la acción. Son palabras, palabras, palabras. Y lo peor del caso, ni siquiera con oportunidad pronunciadas; allá se volcaron, hiriendo susceptibilidades, haciendo política y buscando popularidad.

Esteban Hernández, "Dos manifiestos”, 1919

En octubre de 1918 aparecía una nueva revista que rivalizaba con la identidad estudiantil propuesta por Themis e Ideas, la Revista Nacional (1918-1920). Esta publicación mensual, de la que entre octubre de 1918 y abril de 1920 aparecieron once números (en nueve entregas, de sesenta páginas aproximadamente cada una y formato libro), es sumamente significativa para recuperar la disputa por la inscripción de la Reforma en la cultura de izquierda. A pesar de ello, la Revista Nacional ha merecido muy poca atención: sólo Vásquez (2000) se ocupó brevemente de ella en su análisis de los primeros años de la Reforma.

A distancia de las publicaciones estudiantiles que venimos analizando, la Revista Nacional no surgía de la disconformidad ante el medio universitario. Para el primer número, Irazusta y Jurado 
preparaban una "Presentación", pero en los siguientes no publicaron ningún manifiesto que proclame la importancia de los ideales y de la socialización del estudiante ni que denuncie la mediocridad del positivismo. Seguramente ello se asocie al diagnóstico complaciente ante el ambiente universitario que, meses antes de editar la Revista Nacional, refería Irazusta a su padre: "La vida universitaria, ya lo sabemos, es muy libre, y por eso cómoda. Los profesores dictan su cátedra y no molestan en nada con preguntas apremiantes. Casi todos son buenos profesores. Ahora que es época de elecciones hay mucha agitación. Y nadie prohíbe los barullos, a veces los tumultos que se producen por exaltación propagandista. Es un gozo más". ${ }^{260}$

La Revista Nacional tendió a ser exclusivamente estudiantil. Allí los estudiantes de Derecho publicaron artículos sobre historia o literatura, algunas poesías y notas breves aparecidas en la sección de crónica musical, la de teatro y la de bibliografía. La publicación contó con anuncios comerciales y profesionales, entre otros el de Alicia Moreau y Alfredo Palacios. Para el primer número, los directores consiguieron el saludo de Manuel Ugarte y publicaron una nota con seudónimo contra el panamericanismo. ${ }^{261}$ Por otra parte, los primeros números llevaron la publicidad de la editorial La Cultura Nacional, de la Revista de Filosofía y de Nosotros, en la que Irazusta acababa de publicar una nota literaria sobre Barbusse.

Entre los colaboradores frecuentes de la Revista Nacional se encontraron Bernardo González Arrili -quien, además de publicar en Ideas, había fundado en 1914 la revista Reunión Americana, de la que apareció un número ese año y tres entre enero y abril de 1917-, Alfredo Genser -del que recuerda Irazusta (1975: 62) que fue su compañero en el último año del bachillerato y desde entonces mantuvo una amistad para toda la vida-, Esteban Hernández -seguramente un seudónimo de Irazusta- y Eduardo Araujo -quien desde el número 7 reemplazó a Irazusta en la dirección de la revista-.

A partir de las reseñas y de algunos artículos, es claro que el principal interés de los directores fue disputar la identidad izquierdista que proponía el CE y su órgano. El segundo número publicó breves y halagadoras reseñas de Nuestra América. Revista mensual de difusión cultural americana, de Hebe. Revista mensual de literatura y arte y de Helios. Revista de literatura, historia, filosofia, crítica, pedagogía y arte. En cambio, dedicó una reseña más extensa a Themis para pedirle "algún pulimento" y más específicamente:

Aceptada y proclamada la bondad del afán renovador, es el caso de analizar si corresponde a una revista, órgano de un centro universitario de vida restringida a un determinado campo, convertirse en publicación de cariz general, cada vez más acentuado. O si por el contrario, debe ella mantenerse en su órbita, estimulando el

\footnotetext{
${ }^{260}$ Carta de Julio Irazusta a su padre, 07/05/1918, cit. en Irazusta (1975: 65).

${ }^{261}$ Manuel Ugarte, "Para Revista Nacional" y Alfa, "Panamericanismo", Revista Nacional, octubre de 1918, pp. 5-6 y 13 , respectivamente.
} 
cultivo de las disciplinas que le atañen, con el propósito de ser eficaz colaboradora en la formación de futuros profesionales bien preparados en las ramas de su dedicación (“THEMIS", Revista Nacional, n², noviembre de 1918, p. 119).

Como mencionamos, desde ese "cariz general" Themis difundía las noticias del Primer Congreso de Estudiantes y reproducía y saludaba los manifiestos estudiantiles que repudiaban la reacción nacionalista. Por su parte, la Revista Nacional cerraba su segundo número con unas "Notas" que enfatizaban sus distancias con ese tipo de saludos al tiempo que sugerían el modo en que estos jóvenes se interesaban por la cultura. Se sostiene allí que "el acontecimiento literario de los últimos días fue la aparición del libro de José Ingenieros sobre La evolución de las ideas argentinas. [...] Al mismo tiempo que el goce de tener la perspectiva de conocer algo bueno nuevo, se produce la satisfacción de saber que eso es nuestro". ${ }^{262}$ Y subrayando el filón desde el que se interesaban por Ingenieros, la caracterizaban como parte del "hermoso tema de nacionalismo" y a continuación aclaraban que se ocuparían del tema cuando los redactores superen las preocupaciones de examen y los apuros de estudio, aclaración que reforzaba la acusación de que los reformistas izquierdistas no les interesaba el estudio o, al menos, les permitía distanciarse de jóvenes como Bermann, Monner Sans y del Mazo que dedicaban una parte importante de su cotidianidad a las reuniones estudiantiles y la edición de revistas. ${ }^{263}$

En el número siguiente de la Revista Nacional aparecía una extensa crítica de Irazusta a los libros que acababan de publicar Delfina Bunge y Enrique Larreta. ${ }^{264}$ Allí es claro que el joven buscaba instalar una valoración de las producciones literarias a partir de un impreciso prisma nacionalista orientado a medir el progreso de la cultura nacional. Cuestión que también se advierte en el espacio que la publicación dedicó a la reseña de los eventos musicales y teatrales porteños, y que apareció ligada a la difusión de un idealismo filosófico que incluyó notas sobre Friedrich Nietzsche, Benjamín Taborga, Agustín Álvarez y Romain Rolland.

Pero luego de la Semana Trágica, el nacionalismo de esta publicación estudiantil comenzó a adquirir una clara traducción política. En su número cuatro-cinco (fechado en febrero de 1919), la Revista Nacional se distanciaba de la identidad estudiantil que defendían tanto el director de Themis como el halagado Ingenieros en los siguientes términos:

A pesar de ser universitarios, no hemos sentido el horror del Ateneo Universitario, por estos "hechos inusitados". Lamentamos sinceramente las injusticias cometidas; pero sepamos comprender al patriotismo, que en ciertas ocasiones se indigna y comete errores. "La colectividad respetable por todos conceptos", víctima de los atropellos de la semana trágica, continúa viviendo en paz en esta ciudad, y descubre hoy fue víctima de injustas iras populares. El tormento resucitado a que alude el Ateneo Universitario, no lo

\footnotetext{
262 "Notas", Revista Nacional, no 2, noviembre de 1918, p. 130.

263 Sobre la importante polémica que despertó esa obra de Ingenieros, véase el mencionado estudio de Pasolini (2007).

264 Julio Irazusta, “Dos libros en francés”, Revista Nacional, enero de 1919, pp. 138-152.
} 
apercibimos y agradeceríamos se nos indique quién puede probar su existencia (Esteban Hernández, “Dos manifiestos", Revista Nacional, no 4-5, febrero 1919, p. 278).

Para a continuación realizar una valoración similar del manifiesto de la FUA:

[...] está impreso en papel más grande que el del Ateneo Universitario; exagera la nota de la nueva moda de los manifiestos. Contiene una disertación pedestre sobre la importancia del extranjero en la República; sinceramente lamentamos que universitarios firmen tales elucubraciones, propias de un periódico provincial o de una composición escrita de estudiante secundario.

La segunda parte del manifiesto habla de la necesidad de estudiar y resolver la cuestión social. Novedades tenemos (idem).

Aunque los Cuadernos se declaraban apolíticos, los jóvenes que animaban el Colegio hacia 1919, así como los que dirigían el CE de Filosofía y Letras y su revista Verbum, encontraban una fuerte afinidad con el rechazo de la Revista Nacional a los posicionamientos izquierdistas de los grupos estudiantiles. Y el "patriotismo" de la tácitamente referida Liga Patriótica, que los jóvenes de la Revista Nacional comprenden aun cuando "se indigna y comete errores", adquiere más precisiones en ése y los números siguientes. En el mismo número en que aparecía la crítica a los manifiestos, se difundía, entre los artículos de arte y cultura, una nota de Julio Cruz Ghio ${ }^{265}$ dedicada a esbozar un programa juvenil. Advierte allí el reciente graduado de Derecho que

El país sólo tuvo, en más de un siglo, dos generaciones de vigorosa y positiva juventud: la de Mariano Moreno, allá en 1810, y la de Enrique Barros, en 1918. La de Moreno para la revolución política; la de Barros, para la espiritual. [...] A esa juventud liberal, toda valiente, toda grande, toda desinteresada, que no es anarquista, que no es socialista, que no es radical; que ni siquiera es cordobesa. Que es sencillamente argentina, porque es liberal [va este artículo]. La estoy esperando en esta nueva acción de la calle, la del número, la de la fuerza colectiva, en el basto escenario de la nación. La estoy esperando en un formidable Partido Liberal Cultural, que haga e imponga hombres de talento y de hombría en todos los órdenes de la vida de la República (Julio Cruz Ghio, "La juventud liberal”, Revista Nacional, no 4-5, pp. 126-127).

Cruz Ghio formula aquí uno de los primeros llamados a precisar la sensibilidad de la Reforma en un partido político. Como mencionamos, desde sus primeros reclamos los reformistas cordobeses se reunieron en torno de una cultura liberal opuesta a la cultura clerical, y la campaña que por entonces buscaba desplegar la Federación de Asociaciones Culturales en Buenos Aires evidencia que ese liberalismo no sólo incluía al anarquismo y al socialismo, sino que justamente era un modo de establecer reivindicaciones comunes entre distintas posiciones inscritas en el campo de las izquierdas. Pero en su nota, Cruz Ghio recupera la identidad liberal para realizar una arriesgada resignificación del programa reformista: rescata la figura revolucionaria de Barros para inscribirla

${ }^{265}$ Dirigió Las Letras. Revista mensual de difusión cultural, de la que aparecieron cuarenta y seis números entre 1914 y 1920 . 
en un revolucionarismo de carácter estrictamente cultural que, borrando la afinidad que Barros y sus compañeros tenían por el socialismo antiparlamentario, se distancia de la cultura de izquierda.

Ese Partido Liberal Cultural parece no haber logrado demasiada resonancia, pero en el número siguiente la Revista Nacional publicó otro llamado a construir un partido ligado a la Reforma que sí logró interpelar, al menos, a los estudiantes porteños de Derecho. Al igual que el de Cruz Ghio, el programa que presentaba el novecentista Adolfo Korn Villafañe se oponía al socialismo y el anarquismo, pero a ello sumaba un nacionalismo antiberal que sería una constante en la producción posterior no sólo de ese joven sino también en la de Irazusta. Luego de descartar a la generación del 80 por su positivismo y de reivindicar a la del 90, sostenía Korn Villafañe:

1919. Los novecentistas no podemos, pues pertenecer a ninguno de los viejos partidos políticos conservadores, porque todos ellos, más o menos representan el positivismo, el alberdismo, la sola riqueza material del país, el olvido de los valores éticos. Ni podemos ser socialistas, porque este partido es antinacionalista. Ni podemos tampoco ser radicales, porque la ética del radicalismo ha resultado más verbal que efectiva y porque no podemos aceptar una ética reñida con el intelectualismo, basada sobre la ignorancia.

Debemos fundar un Partido Nacionalista Argentino, sin intervención de desacreditados ex radicales y ex conservadores - de viejos analfabetos y de viejos piratassencillamente nosotros los muchachos, así como se hizo el partido socialista en veinte años de lucha oscura y heroica.

No nos conformemos con sistematizar: busquemos la acción. Nuestra tarea, tarea heroica, será restablecer en la consciencia oscura del buen pueblo argentino, que se puede ser intelectual y honesto, para que estas dos palabras a la inversa del juarismo, las cristalice en esta otra: novecentismo (Adolfo Korn Villafañe, "Vistazos", Revista Nacional, n" 6, septiembre de 1919, pp. 315-316).

Esta intervención será la primera de una serie a través de la que Korn Villafañe consiguió instalar la distinción, al interior del movimiento reformista, entre quienes se reconocían seguidores del “jacobinismo diosciochesco" y los que apelaban al nacionalismo antiliberal de 1919. Los primeros hegemonizarían la FUA al tiempo que fundarían entre 1919 y 1922 revistas como Clarín, Ariel, Bases, Insurrexit y Hoy (desde las que conectarían al movimiento estudiantil con el revolucionarismo ruso y proyectarían las iniciativas que analizaremos en el capítulo siguiente), formarían el Partido Unión Reformista para que la Reforma llegase a la Facultad de Derecho y desde 1925 participarían de la ULA y su construcción de una sensibilidad latinoamericanista y antiimperialista. Los segundos hegemonizarían la FUBA, dirigirían el CE de Filosofía y Letras y su revista Verbum, al tiempo que fundarían la Unión Universitaria, grupo que dirigió el CE de Derecho durante varios años.

Como ya sugerimos, el nacionalismo antiliberal de los reformistas del '19 reformuló la concepción de la extensión universitaria que puede rastrearse en las intervenciones de Bermann. 
Sobre esa reformulación es elocuente una nota, aparecida en el sexto número de la Revista Nacional y firmada por ese amigo “de toda la vida” de Irazusta, que afirma:

En menos de diez años fue adquiriendo palpitante interés y actualidad, lo que durante medio siglo no ocupó sino un lugar secundario en la atención de los hombres dirigentes y en la conciencia del pueblo: la misión de las Universidades. Puede decirse que hoy ya nadie desconoce el importantísimo rol que les toca desempeñar en nuestra democracia, el solícito cuidado con que los gobernantes deben atenderlas y el amor y el respeto que deben inspirar a todos los ciudadanos, desde el más encumbrado hasta el más humilde. $[\ldots]$

Allí está el caso de Córdoba. Él nos dice elocuentemente lo que ha avanzado la Universidad en el concepto público y cómo ha ido ganando las simpatías del pueblo y vinculándose estrechamente con él. [...] Afortunadamente, los estudiantes han sabido ver con claridad cuál era la labor que les estaba reservada en tal empresa, y ya se disponen a cooperar en ella organizando cursos de extensión mediante los cuales la Universidad irá relacionándose con el pueblo e irradiando sus beneficios directamente sobre él. Ya no será la ciencia privilegio exclusivo de una casta especial, ni sus frutos patrimonio odioso de un corto número de iniciados en ella (Alfredo Genser, "La extensión Universidad de la Facultad de Derecho", Revista nacional, nº, p. 354).

Ahora bien, a estas afirmaciones que parecen aprobatorias de la labor de la FUC y Córdoba Libre!, Genser suma un programa alejado de la revisión de las legislación obrera y social que era central para aquellos grupos. Luego de recalcar que la Reforma ya ha concluido su obra al echar a los malos profesores y renovar los estudios, precisa la misión de los estudiantes:

Es necesario enseñar al pueblo lo que significan las leyes, lo que representa el Derecho, lo que entrañan las normas jurídicas para el individuo considerado como formando parte del organismo social y al mismo tiempo es necesario demostrarle claramente, sencillamente, sin fórmulas, sin frases, sin el cientificismo vanidoso y frío de las cátedras, que ese derecho depositado en manos de sus mandatarios, es un atributo propio e inconfundible de su personalidad (Idem, pp. 354-355).

En ese acercamiento al pueblo está ausente tanto la necesidad de revisión del derecho como el enriquecimiento de los estudiantes a partir del contacto con el pueblo, que vimos que Deodoro Roca proponía a los congresales de Córdoba. Es que para estos reformistas del '19 la extensión no procuraba preparar al pueblo para su emancipación sino evitar que éste fuera capturado por el desprecio y la venganza difundidas por la "prensa sediciosa", como vimos que sostenía la joven graduada Isabel Salthú ante los estudiantes de la FFyL. En el mismo sentido, declaraba Ventura Pessolano al presentar -y ganar- su candidatura a la presidencia del CE de Filosofía y Letras:

Los centros universitarios [deben lograr] que el obrero, a cuya dignificación asistimos, no siga viendo en cada uno de nosotros al futuro señor que, con los prestigios de su título, se incorporará a la clase social que le desprecia, cuando no le explota, sino al amigo, que en cambio de las comodidades materiales que él le proporciona con su 
trabajo doloroso, le da para solas de sus rudas jornadas, un poco de las luces que adquirió en esta institución sostenida con el centavo que las leyes gravan sobre el pan de sus hijos. [...] El Estado no tiene recursos, señores, para instalar nuevos institutos oficiales, aparte de que puede discutirse de nuevo el alcance de sus obligaciones en materia de enseñanza pero los centros universitarios, se recabaran para sí la tarea que en los Estados Unidos y algunos países de Europa se adjudican las instituciones similares, podrían de "motu propio" [...] quitarle el carácter afrentoso que tiene ese guarismo para la cultura nacional (Ventura Pessolano, "Proclamación de la fórmula PessolanoGonzález”, Verbum, nº 49, mayo-junio de 1919, pp. 243-244).

En definitiva, lejos de identificar una sociedad regida por la lucha de clases o recorrida por injusticias sociales que pudieran eliminarse, los jóvenes nacionalistas proyectaban un contacto con el pueblo que estableciera lazos de amistad entre los representantes de las distintas clases sociales y colaborara con el Estado en la resolución del problema educativo.

Pocas semanas después de la aparición de esos textos, la construcción de una identidad nacionalista de la Reforma era organizada a través del mencionado programa "Incipit vita nova" con el que Korn Villafañe y los directores de la Revista Nacional fundaban el grupo Unión Universitaria. En el siguiente número de la revista, Irazusta era reemplazado por Eduardo Araujo, quien en 1920 presidió, bajo la gestión de Unión Universitaria, el CE de Derecho y durante 1921 dirigió la FUA. ${ }^{266}$

En 1920 sólo apareció un número de la Revista Nacional, pero ésta junto a la agrupación estudiantil publica ese año una compilación de artículos y conferencias de Korn Villafañe. El libro llevó justamente el título de 1919 y desarrolló el núcleo ideológico en torno del que convergían esos estudiantes de Derecho, a saber, la refundación de la Argentina a partir de bases nacionalistas que superaran el liberalismo positivista. Sobre el liderazgo de Korn Villafañe entre este grupo reformista recuerda Irazusta que en su juventud, a pesar del mérito que le reconocía a Alejandro Korn y a otros profesores, le despertaba más interés el hijo del filósofo. Afirma Irazusta:

[...] hablaba enfáticamente, siempre en fórmulas antitéticas, [...] daba el mayor valor a cada una de las actitudes de su vida. Su pensamiento era reformista. No sólo en la acepción que tomó con la reforma universitaria (uno de cuyos adalides fue) sino en la de reaccionar contra el positivismo y el cientificismo del siglo XIX. Su anécdota acerca del día en que fue a la costa del río (antes de que se hubiese construido la Costanera) a tirar un ejemplar del Código Civil de Vélez Sárfield, era un refrán. [...] Su cultura, que sin duda se beneficiaba del diario trato con su padre, era vastísima. [...] Si fui yo u otro camarada el que, interpretando el sentir de muchos, le dio el título de príncipe de la juventud, no lo recuerdo bien. Pero estoy seguro de que era merecido (Irazusta, 1975: 72).

\footnotetext{
${ }^{266}$ Irazusta recuerda que Araujo participó de las primeras reuniones de su revista maurrasiana La Nueva República, pero se alejó por su adhesión al radicalismo yrigoyenista.
} 
A pesar de que la cultura política de la Reforma quedó ligada a la izquierda latinoamericanista y antiimperialista, nuestro recorrido sugiere que la identidad nacionalista propuesta por Korn Villafañe tuvo una significativa vitalidad durante la década del veinte. Entre las figuras que la alimentaron jugó, sin duda, un papel clave Carlos Cossio (1903-1987). ${ }^{267}$ En 1923 éste presentó en la Facultad de Derecho de Buenos Aires una tesis de doctorado sobre la Reforma Universitaria en la que repasaba las corrientes filosóficas del movimiento y colocaba a Korn Villafañe como su máximo sintetizador. Además, veremos que en 1927 publicó una versión ampliada de ese texto para rivalizar con la identidad latinoamericanista que se cristalizaba en torno de la ULA, el Partido Unión-Reformista Centro Izquierda que actuaba en Derecho y la primera compilación de documentos de la Reforma realizada por del Mazo.

A través del rastreo de las cartas, telegramas, memorias y revistas y de la reconstrucción de grupos e itinerarios personales buscamos recuperar el modo en que los grupos estudiantiles transitaron desde una intervención cultural hasta una política en la que el tipo de vínculo de los estudiantes con el movimiento obrero produjo una primera y olvidada escisión entre reformistas izquierdistas y nacionalistas. En el capítulo siguiente veremos que la intervención estudiantil, de carácter político, que se inicia con la Reforma da lugar a un periodismo izquierdista marcado por el sentimiento de aceleración de los tiempos emancipatorios.

En términos más generales, con esta apuesta por la reposición de la trama cultural de los años 1918 y 1919, continuamos esa aplicación al ámbito de los estudios sobre la Reforma -iniciada en trabajos como los de Vásquez (2002), Graciano (2008) y Bergel y Martínez Mazzola (2010)- de la atención a las condiciones de posibilidad de las ideas, central para la historia intelectual y de los intelectuales. E intentamos mostrar que sólo si se iluminan las ideas, las prácticas y las personalidades es posible precisar tanto la repercusión que alcanzó en la ciudad de Buenos Aires el inicio del conflicto cordobés como la reconfiguración que éste motivó en el mapa de los grupos estudiantiles existentes, dos cuestiones centrales para conocer la cultura política que estuvo en disputa en los primeros años de la Reforma Universitaria.

$\overline{267}$ Para una reconstrucción de su itinerario intelectual, véase Lértora de Mendoza (s/d). 


\title{
Capítulo 6. Los ladrillos de la gran casa del porvenir social. Los periódicos internacionalistas de la Reforma (1919-1921)
}

\author{
La minoría revolucionaria levantó como antecedente \\ histórico en Córdoba a Bakunin y Kropotkin en un \\ principio, y más tarde la otra minoría revolucionaria, que \\ al calor del desarrollo de los partidos comunistas toman \\ carta de ciudadanía en las universidades del país, \\ levantan a Lenin y Marx. \\ Juan Lazarte, Lineas y trayectorias de la Reforma \\ Universitaria, 1935.
}

Desde la última década del siglo XIX, la prensa periódica ocupó un lugar central en la propaganda política e ideológica. En Buenos Aires, socialistas y anarquistas construyeron un campo periodístico alternativo destinado a los trabajadores, campo que en los últimos años ha sido objeto de iluminadores análisis (Suriano, 2004; Tarcus, 2007; Lobato, 2009). Específicamente, entre principios de 1919 y fines de 1921 ese periodismo se ofreció como la plataforma de difusión y discusión del intenso ciclo de protestas obreras que revitalizó a las izquierdas y fue acompañado por una novedosa prensa política estudiantil, a través de la que algunos jóvenes universitarios buscaron soldar la unión obrero-estudiantil. Y una de las condiciones centrales de esa búsqueda que emprendieron algunos grupos y revistas estudiantiles fue la reformulación de la figura intelectual del estudiante, pues debía revisarse su preocupación por una "formación integral" y su intervención de tipo cultural, en las que desde 1914 el Ateneo de Estudiantes Universitario de Buenos Aires tenía un rol protagónico.

Para esa reformulación entre 1919 y 1922 aparecieron diversas revistas que, a distancia tanto de los "canastos de apuntes" a los que se asemejaban las revistas de los Centros de Estudiantes como de las revistas culturales diseñadas por universitarios, pregonaron una identidad estudiantil ligada al socialismo bolchevique. Entre esas publicaciones -que permanecen prácticamente inexploradas por la bibliografía crítica- se encuentra la revista quincenal porteña La Cureta. Órgano de la Agrupación de Estudiantes de Medicina "Pro Reformas", que fundó en agosto de 1918 el estudiante José Belbey (1894-1960). Como mencionamos, convertido en un activo intelectual del PS y en un reconocido defensor de la democratización de la universidad ligada a los reclamos reformistas, Belbey ocupó, en la década del treinta, la polémica cátedra de Medicina legal de la Facultad de Medicina de Buenos Aires que el presidente de la nación Roque Sáenz Peña le había negado a Ingenieros en 1911.

Hasta agosto de 1921 aparecieron quince números, de aproximadamente veinte páginas cada uno y formato libro, de La Cureta. Bajo seudónimos satíricos como "Cirujano Artista", "Matías el 
Pildorero", "Sabañón” y "Obdulio Hierofante (hijo)", los jóvenes de la agrupación presentaron notas sumamente sarcásticas sobre el ambiente universitario del que participaban y, polemizando con la versión moderada de la Reforma que tendía a presentar la Revista del Círculo Médico y del Centro de Estudiantes de Medicina, saludaron y dieron su apoyo a las publicaciones $\mathrm{y}$ emprendimientos más radicalizados del movimiento estudiantil argentino, como La Montaña. Publicación de "Córdoba Libre" y la mencionada adhesión de la FUC a la huelga de la Federación Obrera Local. En abril de 1925, cuando Belbey ya había terminado sus estudios, apareció una segunda época de La Cureta. Los pocos números editados estuvieron dirigidos por un nuevo director que se mantuvo en el anonimato y se referenciaba en Belbey.

Como mencionamos, hacia 1919 el Boletín de la Federación Universitaria de La Plata se politizaba y para ello reemplazaba su nombre por el de Renovación. Órgano de la Federación Universitaria de La Plata (1919-1920). Otros ejemplos del nuevo periodismo estudiantil que se instalaba entre 1919 y 1922 los ofrecen, por un lado, la decisión del Ateneo de Estudiantes Universitarios de reemplazar Ideas por Clarín y, por otro, la iniciativa de Simón Scheimberg de publicar entre 1919 y 1921 cuarenta y cinco entregas de los Documentos del Progreso. A través de éstos, el antiguo arielista se desdecía de la defensa que había formulado en 1914 del socialismo evolucionista frente al revolucionario para poner a circular tanto las primeras traducciones de los teóricos de la Revolución Rusa como las noticias del las insurrecciones obreras europeas. ${ }^{268}$

Como mencionamos, en su breve revisión de las publicaciones estudiantiles reformistas Guillermo Korn propone que la revista Ideas inauguró en 1915 un ciclo de intervención estudiantil que, a través de la fundación de otras revistas, se prolongó hasta el cierre de Valoraciones en 1928. ${ }^{269}$ A partir de las publicaciones que analizamos en este capítulo, buscamos mostrar que entre 1919 y 1921 ese ciclo estuvo acompañado por otro en el que participaron una serie de revistas que, en lugar de preocuparse por la construcción de una identidad cultural del estudiante, lo hicieron por la construcción de una identidad estudiantil ligada al socialismo bolchevique. Un ciclo que fue alimentado, al menos, por Bases, Clarín, Insurrexit, Hoy, La Gaceta Universitaria de Córdoba y Ariel de Montevideo y que se expresó en revistas de pocas páginas, formato tabloide, papel de baja calidad, frecuencia quincenal o mensual y circulación tanto entre los estudiantes como entre los obreros.

El presente capítulo comienza por trazar los rasgos generales del tipo de periodismo que irrumpe en 1919 entre los estudiantes. Luego caracteriza la prédica que realizó el Ateneo entre 1919 y 1920 para detenerse en el recorrido desde una identidad cultural hasta una identidad política que, a partir de su vinculación con algunos estudiantes porteños, realizó el grupo de arielistas

\footnotetext{
${ }^{268}$ Simón Scheimberg, "El ritmo de la vida”, Ariel, n 1, pp. 19-20.

${ }^{269}$ Guillermo Korn, "Filiación ideológica europea de la Reforma Universitaria”, Cuadernos de La Plata, n 1, La Plata, 1968, p. 19.
} 
montevideanos liderado por Carlos Quijano. Finalmente, se analiza la intervención de Bases, fundada por Juan Antonio Solari, Insurrexit -en la que participó Solari- y Hoy, creada por Solari al alejarse de Insurrexit.

\section{El primer periodismo político estudiantil}

Creemos, acaso con la pedantería que dan los veinte años, en la fuerza incontrastable de la juventud. Y ahora más que nunca, en el momento de desorientación espiritual en que se encuentra la

humanidad, le corresponde a América, y dentro de América a su juventud, la nobilísima tarea de lanzar a los cielos la nueva esperanza. "Nuestro programa", Ariel n" 1, 1919.

Desde 1914 algunas revistas culturales elaboradas por los estudiantes universitarios porteños, como Ariel, Ideas, Cuadernos y Revista Nacional, destinaron un lugar, en su mayoría marginal, a los pareceres políticos entre los artículos sobre literatura, historia y sociología, entre las críticas musicales, teatrales y de los salones de pintura, y entre las reseñas bibliográficas. En cambio, un conjunto de revistas aparecidas a partir de 1919 se consagraron a la construcción de los pareceres políticos de los estudiantes, y para ello reprodujeron fragmentos de quienes identificaban como los pensadores señeros, difundieron manifiestos y noticias sobre los acontecimientos revolucionarios y redactaron notas breves -muchas veces sin firma- que interpretaban los últimos hechos desde las simpatías a una "Revolución en los Espíritus" a la que llamaba Barbusse y a una organización estudiantil articulada con el agitado movimiento obrero argentino.

Sobre este nuevo periodismo estudiantil, recordaba Monner Sans que una de las dificultades de Clarín fue que entró en competencia "con otras revistas de contextura análoga que entonces se fundaron en Buenos Aires" (Monner Sans, 1930: 22). Si bien Monner Sans no menciona a las competidoras, las notas que Giusti publicó en Nosotros ante la aparición de cada nueva revista nos ayudan a precisar ese periodismo que nacía. En una reseña de septiembre de 1919, el director de Nosotros sostuvo que Clarín continuó el periodismo satírico y de combate que, inspirándose en el semanario España, había introducido, a comienzos de 1919, Evar Méndez con los tres números de su quincenario Martín Fierro. En el número siguiente de Nosotros, Giusti aclaraba que los propósitos de Clarín la hermanaban tanto con el periódico estudiantil Bases de Solari como con La Palabra, revista que fundaron los jóvenes abogados de Mariano Barrenechea y Ricardo Paz. ${ }^{270}$ Además, resaltando la distancia entre la organización de brigadas estudiantiles nacionalistas y

270 "Sobre algunas publicaciones", Nosotros, no 123, setiembre de 1919, pp. 146-147. "La palabra", Nosotros, n 124 , octubre de 1919, p. 283. 
antiobreras durante el Centenario de Mayo y la de grupos estudiantiles que, como el Ateneo, saludaban a los bolcheviques, Giusti declaraba a fines de 1919 en Clarín:

Nuestra juventud universitaria, que todavía era, hace pocos años, casi sin excepción mezquinamente tradicionalista y conservadora, hasta asombrar a los extranjeros que la comparaban con la de su propio país; esa juventud sin ideales y ninguna preocupación, salvo la de conquistar el diploma, milita ahora en el ejército de los intelectuales y trabajadores que riñen diaria batalla, en el periódico, la tribuna, el sindicato, contra todas las fuerzas del pasado que se oponen a la improrrogable y legítima renovación de la vida nacional. Bien sé que aún son los menos; pero ya son muchos, cuando antes eran poquitísimos, y su número va creciendo cada día (Roberto Giusti, "Nuestra juventud", Clarin, $\mathrm{n}^{\mathrm{o}}$ 6, 02/12/1919).

La sensibilidad que reunía a ese nuevo periodismo universitario se encontraba recorrida por el juvenilismo, las simpatías a los revolucionarios rusos y a Barbusse. Siguiendo la cita del epígrafe de esta sección, se vivía un momento de "variación brusca" y la juventud era la encargada de fundar revistas con "la nobilísima tarea de lanzar a los cielos la nueva esperanza". O bien, según la maestra y narradora Herminia Brumana (1897-1954), una de las pocas revisteras que participó de ese nuevo periodismo, se trataba de editar "hojitas pobres" pero edificadoras del porvenir social. Declaraba en el primer número de Bases:

Aparecen en todas partes -junto al gran periódico, a la gran revista- esas hojas pobres, de papel ordinario, revistitas oscuras, humildes [...] que son escritas, corregidas con cariño, a veces por una sola mano. A veces por un grupo de manos descarnadas, nerviosas, cansadas de luchar.

El gran diario, la revista lujosa, con su papel, sus grabados, sus carátulas soberbias me indignan casi siempre. Se me antoja que quieren engañarme con el exterior y que dentro no hay nada, nada, para el corazón.

Libros a la rústica, periódicos pequeños, pobres, feos, revistas de papel ordinario se me ocurre al veros que sois los ladrillos de la gran casa del porvenir social (Herminia Brumana, "Las pobres hojitas", Bases, n 1, 31/05/1919).

Años después, otro de los redactores de estas "revistitas luchadoras" al que ya nos referimos, Juan Lazarte, insistía en que entre 1919 y 1923 la Reforma había contado con una interesante minoría revolucionaria. Sostenía:

Entre los jóvenes, entonces, que lucharon en las primeras filas durante los cuatro primeros años del movimiento hay una mayoría conservadora y una minoría revolucionaria. La primera se atiene a lo Universitario, eran estudiantes puros, bastante anquilosados por la política; ellos andaban del rectorado de la universidad a las casas de gobierno. La minoría estaba en la calle, en el sindicato, en las bibliotecas populares, en las Escuelas Modernas, luchando en una noble lucha por la cultura y la elevación del pueblo (Lazarte, 1935: 22-23). 
Y en las páginas siguientes arriesgaba una audaz explicación del modo en que los animadores de esas revistas habían alcanzado la politización:

La reforma no encierra, al nacer, una corriente revolucionaria, sino que la corriente revolucionaria de los tiempos se aproxima y trata de englobar a este movimiento estudiantil. Desde la Universidad no se puede hacer ninguna revolución, en cambio de la revolución se pueden hacer mil universidades nuevas y hasta cambiarlas fundamentalmente. Hay pues un entrelazamiento que va de la calle a la universidad, que obliga a los universitarios a aproximarse a la calle que es donde se juega el pueblo su porvenir y su destino (Lazarte, 1935: 75).

Más allá de que efectivamente ése haya sido el camino de la politización estudiantil, es indudable que no sólo la Revolución Rusa sino también la huelga general que se inició a principios de 1919 luego de la represión a los obreros metalúrgicos de Buenos Aires y la represión que encabezaron los grupos de civiles organizados en la Liga Patriótica, produjeron una fuerte interpelación entre las agrupaciones estudiantiles. ${ }^{271}$ La mayoría de éstas inició una discusión interna que se tradujo en la redacción y publicación de un manifiesto que expresaba el repudio a lo sucedido y esbozaba las medidas que el Estado debía tomar para evitar su repetición, medidas que oscilaban entre una legislación obrera y la expulsión de los agitadores sociales extranjeros. Ese año se sumaban otros dos acontecimientos, iniciados en este caso en el ámbito universitario, a los que los grupos estudiantiles respondían con manifiestos y actividades de apoyo: los conflictos que mantenían los estudiantes santafesinos y la "huelga grande" realizada por los reformistas de la UNLP.

En efecto, la revolución estudiantil de 1919 no fue cordobesa sino santafesina y platense. De ahí que Barros respondiera con el siguiente telegrama al enviado por la Federación Universitaria del Litoral: "Córdoba ha iluminado escenario nacional. Santa Fe debe eclipsarlo. Fraternalmente. Enrique Barros" (cit. Caballero Martín, 1931: 115). Las adhesiones o distancias frente a las huelgas obreras y a esos conflictos universitarios tendieron a ser los nuevos parteaguas políticos del movimiento de la Reforma.

En estos años, los distintos grupos porteños publicaron sus solicitadas de apoyo a los conflictos, pero no encontramos una agrupación porteña como la Federación de Asociaciones Culturales que se dedicara a organizar las actividades de adhesión de los estudiantes "revolucionarios". En 1919 fue la FUA la que, bajo la impronta de su presidente Gabriel Del Mazo, coordinó el apoyo tanto a la demanda de la Federación Universitaria de Santa Fe por la fundación de una universidad nacional en la región como a los reclamos de la FULP por la implementación de estatutos renovados. Esta organización estudiantil estuvo acompañada por un nuevo periodismo

\footnotetext{
${ }^{271}$ La huelga general fue apoyada sobre todo por la Federación Obrera de la Regional Argentina $V^{0}$ Congreso (de tendencia anarquista) pero fue resultado de una organización espontánea que reaccionaba ante una represión inesperados. Así para toda la izquierda esa huelga era la prueba de un espontáneo malestar social, al que las tendencias revolucionarias buscaban dirigir hacia nuevas insurrecciones mientras que las tendencias parlamentarias intentaban encaminar a una legislación obrera (Bilsky, 1984; Godio, 1986).
} 
que, además de difundir y apoyar esos reclamos, se proyectó formando parte de la construcción de esa "gran casa del porvenir social" que saludaba Brumana. Detengámonos entonces en los distintos "ladrillos" que los estudiantes acercaron a esa construcción.

\section{Clarín, o el arribo al Ateneo de la "pérfida política"}

A comienzos de 1919, el Ateneo de Estudiantes Universitarios cambiaba su nombre por el de Ateneo Universitario, reformulaba sus propósitos y se dividía en una Junta de Estudios y en un Comité de Acción Social. La Junta tenía como órgano Ideas y se concentraba en la reforma de la universidad mientras que el Comité se preocupaba por los problemas sociales y ponía a circular Clarín.

Si bien, luego de agosto de 1919, la Junta no logró editar nuevos números de Ideas, los anuncios de la revista siguieron apareciendo durante 1920 en otras publicaciones estudiantiles y el grupo organizó, al menos, un ciclo de conferencias en la FFyL y -según una reverencia de Inicialeditó una inhallable Revista de Indias. A fines de 1919 la Junta publicaba un manifiesto en el que declaraba:

[...] el decreto del P. E. [es] el primer acto de una obra impuesta por el estado social e invita a todos los universitarios a contribuir, con el estudio del problema a la realización de la verdadera reforma. [...] la reforma que nuestra enseñanza necesita no se labra en artículos ni se impone por un decreto; ella ha de ser la conquista enérgica y serena que triunfe de prejuicios rancios y desplantes de advenedizos, asequible sólo mediante el estudio reposado y completo del problema universitario ("El Ateneo Universitario. La reforma universitaria", Clarín, n $^{\circ}$ 6, 02/12/1919).

La traducción de ese diagnóstico fue, por un lado, el ciclo de conferencias en la FFyL sobre cuestiones universitarias que se abrió con el análisis de Ernesto Nelson y que preveía la participación de Alfredo Colmo, Juan B. Justo y Ricardo Rojas; y por el otro, la aparición en Clarín de la sección "Asuntos universitarios" en la que notas, en su mayoría de Colmo, reflexionaban sobre las reformas necesarias, y otras informaban sobre la huelga estudiantil que mantenía la FULP.

Por su parte, el Comité editó, entre septiembre de 1919 y marzo de 1920, diecinueve números de Clarín. Los tres primeros fueron quincenales y estuvieron dirigidos por Monner Sans. Luego los jóvenes intentaron una periodicidad semanal y designaron como director a Juan Carlos Del Giúdice. Clarín n ${ }^{\circ} 2$ llevaba una breve nota en la que justificaba del siguiente modo la mayor asiduidad de la revista y la ampliación de las ocho páginas a doce:

Quienes redactamos esta revista hemos observado, complacidos, el interés que por ella se advierte entre cierto público de la capital y del interior del país, preferentemente en los círculos universitarios y en los centros obreros. Es que las sanas fuerzas liberales, frente a la desesperada reacción conservadora actual buscan en los periódicos no 
mercantilizados la expresión de su propio sentir (“Al lector”, Clarín, n 2, 01/10/1919).

Más allá del efectivo interés que haya producido el primer número de Clarín, la nota hace evidente un rasgo que definirá a varias revistas estudiantiles de esos años: la voluntad de "expresar el sentir" no sólo entre los universitarios sino también entre los obreros. Para precisar las "sanas fuerzas liberales" de ese sentir, traigamos el recuerdo del líder del grupo:

Clarín insistió en la necesaria conjunción de "las izquierdas" -así decíamos- para ofrecer al enemigo común el estratégico frente único. Leopoldo Lugones -que recordaba, todavía, su terrible acracia de otrora-, Ingenieros y Palacios nos alentarán en el propósito, pero el Partido Socialista mirábanos con natural desconfianza, puesto que no escondíamos nuestra animadversión al parlamento, órgano atrofiado de la conciencia colectiva. Nada esperaba Clarín de la lucha comicial, y conceptuaba que en la esfera económica iban a librar sus combates definitivos las clases sociales en pugna: no encubría, por ende, su tendencia sindicalista (Monner Sans, 1930: 23).

Ese antiparlamentarismo, sumado a la "tendencia sindicalista", a las críticas al "falso patriotismo" que propondría la Liga Patriótica y al boicot a la Gran Colecta Nacional organizada por la Iglesia Católica, acercaron a los ateneístas al PSI. Y ese acercamiento no sorprende, pues -como mencionamos- el partido que surgía le criticaba fundamentalmente al PS su dedicación a las reformas parlamentarias en detrimento de la presencia del socialismo en las luchas sindicales de los obreros (Campione, 2007: 173).

En cuanto al tipo de periodismo político -que, como ya mencionamos, incluía tapas con caricaturas mordaces sobre los sucesos locales- y a su insistencia de unir a las izquierdas, el Ateneo pudo inspirarse en el mencionado semanario España de Madrid. En 1917 el semanario dirigió toda su capacidad de convocatoria hacia el famoso "mitin de las Izquierdas Españolas", que reunió en la Plaza de Toros de Madrid a socialistas, republicanos y reformistas (Beigel, 2005: 74-76). Ensayando un gesto similar, Clarín n 3 publicaba "Nuestro frente único. Derechas e izquierdas", una nota en la que Monner Sans explicitaba el propósito del Ateneo -seguramente alentado a través de numerosas charlas, reuniones y actos de los que no han quedado documentos- de unir a la izquierda argentina en un frente en el que deberían integrase "la Federación Obrera Regional Argentina, los partidos socialistas, la Federación de Asociaciones Culturales, el Ateneo Universitario, la Federación Universitaria Argentina, más Lugones, Ingenieros, Rojas y algunas otras figuras representativas del país". ${ }^{272}$

Clarín no respaldó su iniciativa en artículos doctrinarios, sino en notas que analizaban la política local y unas pocas que abordaban la política europea y que apoyaban el proceso soviético. Las únicas reflexiones de orden netamente teórico fueron, por un lado, las frases de intelectuales

\footnotetext{
272 José María Monner Sans, “Nuestro Frente único. Derechas e izquierdas”, Clarín, nº 3, Buenos Aires, 16/10/1919.
} 
reconocidos que aparecieron en algunos pie de página como una suerte de cita de autoridad a la opinión vertida en los artículos y, por otro, los pasajes que junto a un gran retrato compusieron la sección "Subrayamos" (entre los autores de esos pasajes se encuentran figuras tan diversas como Oscar Wilde, José Ingenieros, Juan B. Justo, Juan B. Alberdi y Pío Baroja). Por otra parte, con Clarín descubrimos un reformismo que no coloca en el centro de interés la preocupación latinoamericana y antiimperialista. En efecto, ningún artículo se ocupó de las problemáticas de los países latinoamericanos, ni siquiera en cuanto al conflicto estudiantil. Es que, a diferencia de lo que pasará en los años posteriores, en este periodismo político estudiantil la problemática política aún no era la denuncia del imperialista del continente sino la inminente revolución social emancipatoria.

El pronunciamiento antiimperialista que unos años después se convertirá en el núcleo de la cultura política de la Reforma se encuentra aquí desplazado por la crítica a la evolución gradual al socialismo, o bien por la certeza de que la Revolución Rusa ha acelerado los tiempos políticos. Al igual que las otras revistas que analizaremos en este capítulo, Clarín confirma la existencia de esa minoría estudiantil revolucionaria que elogia Lazarte y, en términos más generales, es una prueba del entusiasmo revolucionario que se había instalado tanto en una minoría estudiantil como en ciertas fracciones de la intelectualidad porteña. Ese entusiasmo es el que motivó al grupo estudiantil a declararse "del lado del proletariado", a difundir los manifiestos del grupo parisino Clarté, a preparar notas que criticaban el parlamentarismo del PS y a recomendar la lectura de los "meritorios" Documentos del Progreso. ${ }^{273}$ Pero ese entusiasmo también los conecta con intelectuales de una generación anterior.

En efecto, los ateneístas contaron con la colaboración de reconocidos intelectuales locales de izquierda como Palacios e Ingenieros. A partir de 1922, ambos serían fervientes organizadores de la red intelectual antiimperialista y latinoamericana, pero en 1919 no se preocupaban por ese tipo de denuncias sino por separar al socialismo del evolucionismo parlamentario que primaba en el Comité Central del PS. Para saludar el revolucionarismo universitario del Ateneo, Ingenieros envió a Clarín “Obispos y Belakunes”, una breve nota en la que, desplegando su conocido sarcasmo político, se declaraba asombrado ante las críticas que la revista había proferido a la Gran Colecta y proponía que, de modo similar a las medidas que tomaba el gobierno comunista de Béla Kun en Hungría, esa colecta era el comienzo de la expropiación revolucionaria. Ironizaba el futuro organizador de la red antiimperialista de la Reforma:

Creo que se trata de una laudable iniciativa. Representa una expropiación de los pudientes realizada con métodos coactivos que las víctimas aceptan con noble

\footnotetext{
${ }^{273}$ Respecto de los Documentos del Porgreso, al igual que Bases e Insurrexit, Clarín no dudaba en declarar que sus números "han de ser leídos con interés y provecho por todos aquellos que quieran opinar honesta y fundadamente sobre la Rusia del Soviet, que los diarios capitalistas de todo el mundo hánse empeñado, con explicable tesón, en difamar con peregrinos relatos" (“Las Revistas", Clarín, n 8, 16/12/1919).
} 
resignación. ¿No cree Usted que es un signo de los tiempos?

Considero que estas pequeñas sangrías despertarán en quienes las soportan el sentimiento de la ilegitimidad de la miseria y los acostumbrará a mirar con ecuanimidad el gran movimiento de justicia social que está renovando el mundo [...].

Tendrán que darse prisa los que desean llegar a la paz social por esos caminos de santidad. Una colecta por mes. Una por semana, una por día... Y que suba el termómetro de la autoexpropiación; pues, al fin y al cabo, -como dicen los "coleccionistas"- es mejor apresurarse a dar algo antes de que el demonio ponga malas intenciones en la cabeza de los que han perdido el temor de Dios.

Saluda al señor director muy atte.

José Ingenieros (“Obispos y belakunes”, Clarín, no 3, 15/10/1919,)

En el mismo número, los ateneístas expusieron una posición similar, pero en este caso proveniente de una colaboración de Palacios. En "Hay que devolver" el primer diputado socialista de Latinoamérica refutaba los argumentos de los promotores de la colecta reemplazando el sarcasmo de Ingenieros por referencias al movimiento obrero nacional e internacional y por citas de Zolá. Otro ejemplo del apoyo de la generación precedente que obtuvieron los ateneístas en su conversión revolucionaria lo ofrece Giusti y las múltiples notas en las que saludó a esa nueva juventud. En la citada en este apartado, aquel comenzaba refutando a Unamuno por sus críticas al grupo Clarté, emitidas en su sección del diario La Nación. Y en esa refutación Giusti encontraba otra oportunidad para exponer su camaradería política con el socialismo del Ateneo. Sostiene el director de Nosotros:

Los ergotistas de la historia, interpretando a su antojo el concepto de evolución y convirtiéndolo en dogma estrechísimo, se dan el lujo de desconocer la formidable renovación o reorganización o revolución -llámese como se quiera- de que actualmente es teatro el mundo. [...] permítasenos sonreír de quien pretende negar la evidencia de los cambios bruscos, de las revoluciones renovadoras y de la aceleración de la evolución en ciertos momentos ¿Es que hay quien no ve cómo la guerra ha precipitado el derrumbamiento de la sociedad capitalista, o por lo menos su rápida evolución hacia un régimen de propiedad y trabajo fundamentalmente diverso del que aquella sustentaba? [...] Existe en el país una "izquierda" perfectamente definida y coherente en materia religiosa y moral; y en lo económico, solidaria con respecto al principio básico de que urge una mayor justicia en la distribución de los bienes de la vida. Pues bien gran parte de la juventud universitaria ocupa en esa izquierda un puesto de vanguardia. [...] renegar de esa juventud, cuyo espíritu me complazco en reconocer en Clarín, que es una de sus más autorizadas expresiones, es un error manifiesto (Roberto Giusti, "Nuestra juventud", Clarín, no 6, 02/12/1919).

Al saludo revolucionario de Giusti, Ingenieros y Palacios se sumó el futuro filósofo peronista y luego maoísta Carlos Astrada (1896-1970). En el número once de Clarín se lee "Por el camino infinito...", una nota en la que también Astrada defiende al grupo Clarté del sofisma, que habría introducido Unamuno, “de asignar a las antinomias sociales un juego puramente mecánico que reduce toda su acción a un cambio de sujetos". Pero, a diferencia de los otros intelectuales, en su defensa del advenimiento de una sociedad más justa y libre, Astrada defendía el sindicalismo 
revolucionario de Sorel: "la falacia del progresismo ha culminado en la democracia parlamentarista que, como es muy natural, hace las delicias de los socialistas socializantes. Sorel al evidenciar la falsedad e ineficacia de la concepción progresista, y de todo su andamiaje político, nos muestra que otros son los caminos de la emancipación social”. Si bien Astrada le reconocía rasgos progresistas a la propuesta de Clarté, proponía que ésta era más bien una parte del "camino infinito de la emancipación social", sobre todo porque cuando no se la toma al pie de la letra, como hizo Unamuno, esa propuesta muestra "que hay que trabajar por el advenimiento de una humanidad mejor, [que] para emprender esta magna obra debemos comenzar por aceptar los dictados del pensamiento o sea crear la soberanía del espíritu". ${ }^{274}$ Otro miembro de la generación precedente que colaboró con Clarín fue Ricardo Rojas. Si bien estaba distante del socialismo bolchevique, les envió una nota en la que explicaba que el auténtico nacionalismo no era el difundido por la Liga Patriótica -y saludado por los estudiantes reunidos en los Cuadernos del Colegio Novecentista, Verbum y la Revista Nacional-, sino el que defendía el liberalismo.

Pero las figuras de la generación anterior de las que Clarín publicó más frecuentemente colaboraciones fueron el mencionado Alfredo Colmo -que se dedicó a los temas universitarios en artículos que, en muchos casos, no coincidían con el revolucionarismo de los manifiesto del Ateneoy el profesor Cándido Villalobos Domínguez. Este georgista socialista y colaborador de $L a$ Vanguardia se había alejado del PS en 1917 para convertirse en uno de los máximos impulsores locales del georgismo ortodoxo (De Lucía, 2012). Y entre 1919 y 1920 publicó en Clarín varias notas sobre la aplicación de la doctrina georgista en la estructura económica argentina.

Entre los jóvenes, Herminia Brumana introdujo en Clarín la discusión sobre la igualdad de la mujer y la importancia de que éstas reclamasen y conquistasen esa igualdad. ${ }^{275}$ La futura esposa de Solari fue acompañada por Ada Velmar, personaje creado por Solari. El ultimo número de Clarín difundió "Electorerías", una nota en la que Velmar retomaba la crítica al PS que le formulaba su fracción izquierdista: la atención a los votos lo habría llevado a desatender a los reclamos obreros e incluso alejarse del socialismo. Por su parte, Palcos publicó en Clarín dos artículos que, al igual que el de Velmar, reivindicaban el socialismo y se distanciaban de las “desviaciones” del PS. En "La verdad social", Palcos acusaba a la reacción antipositivista de ser la ciencia burguesa y clerical difundida "para mayor satisfacción de los poderosos, adormeciendo al pueblo con sus fábulas y sus parábolas, explotando, sobre la tierra, la archiprovechosa industria del tráfago de almas".

\footnotetext{
${ }^{274}$ Carlos Astrada, "Por el camino infinito...", Clarín, no 11, 06/01/1920 (fechado en diciembre de 1919). Adelantemos aquí que, a mediados de 1920, Astrada publica artículos con similares tesis en Mente, revista cordobesa editada por el grupo Justicia, y en 1922 Astrada ofrece a los estudiantes cordobeses de derecho "Nuestro Kulturkampf. Perspectivas de la Reforma Universitaria. La arcadia prehistórica", un ensayo que narra en tono sumamente irónico la "lucha cultural" de los reformistas, conectándola con la ciencia, la justicia social conquistada por el pueblo ruso y la defensa de la libertad de los espíritus.

${ }^{275}$ La serie de artículos de Brumana se compuso de: “Contra el feminismo y para las mujeres" (Clarín $\mathrm{n}^{\circ} 10$, 15/12/1919), “¿Literatos!” (Clarín, n 15, 02/02/1920) y “Contra el feminismo” (Clarín, n 18, 15/02/1920).
} 
Anticipando la decepción ante la universidad que prevalecerá en el PC durante el periodo de "clase contra clase", Palcos concluía:

[...] la ciencia social y la ciencia económica se elaboran fuera de las academias oficiales en el seno del pueblo. Son ciencias de partido, ciencias de clase. ¿Son por esto ciencias falsas, adulteradas, sectarias? La emprenderá la clase proletaria misma, que afirma su pleno derecho a participar de las luces de la instrucción superior. Es que la ciencia y la clase proletaria están unidas por un lazo potente e indestructible (Alberto Palcos, "La verdad social", Clarín no 4, 07/11/1919).

En el número siguiente de Clarín aparecía otra colaboración de Palcos. A través de "La revolución rusa. Su segundo aniversario", el miembro del Comité Ejecutivo del PSI se encargaba de elogiar el "experimento político" que se estaba realizando en Rusia, sobre el que dos meses después aparecía "La obra constructiva en Rusia. Derecho sobre el control obrero (texto oficial)" (Clarín, $\mathrm{n}^{\mathrm{o}} 17$, 17/02/1920). Este documento, que Clarín presentaba con el encabezamiento "Para la historia", implicó la irrupción directa de la política del PSI en una intervención hasta entonces centrada en opiniones y manifiestos inscritos en un amplio espectro de izquierda -que, como vimos, podía abarcar a Rojas, Colmo y Villalobos Domínguez-. Pero esa irrupción de la izquierda revolucionaria no marcaría una nueva apuesta sino el ocaso del proyecto.

En efecto, sólo aparecerían dos números más de Clarín (el último fechado en marzo de 1920). El Ateneo comenzaba entonces su disgregación. Por algunas reseñas sabemos que en el homenaje a Monner Sans de 1921 el Ateneo estuvo representado por Pablo Barrenechea, que a mediados de la década del veinte el grupo editó una Revista de Indias y que en 1922 organizó una sesión de homenaje a Mitre en la que el joven abogado Ernesto Laclau expuso, desde una impronta orsiana, la filosofía política argentina. Finalmente, en las citadas memorias del grupo, Monner Sans (1930) recuerda que en 1928 proyectó, junto a otros ateneístas, la refundación del grupo y que, a pesar de realizar varias reuniones, sólo llegaron a publicar un manifiesto.

El numeroso grupo, que había logrado que los estudiantes porteños excedieran el momento corporativo para erigirse en intérpretes y actores políticos capaces de disputar la interpretación de los acontecimientos nacionales e internacionales, rápidamente se reducía cuando muchos de sus integrantes concluían sus estudios y el propósito pasaba a ser la conjunción de las izquierdas. A pesar del entusiasmo político de 1919 y de que surgieron otras revistas estudiantiles que propusieron un periodismo político similar, la identidad revolucionaria de la Reforma no logró pervivir más allá de 1922, e incluso hasta ahora ha permanecido poco recordada en la historia del movimiento reformista.

Durante los años veinte, Monner Sans ingresaba como profesor en la FFyL y en la Faultad de Derecho, donde -sin el protagonismo de su juventud- participó de la fracción izquierdista que 
lideraba su amigo Florentino Sanguinetti y a la que en 1923 se sumaron los jóvenes abogados platenses Julio V. González y Carlos Sánchez Viamonte; y veremos en el capítulo séptimo que esta fracción fue central en la construcción de una identidad latinoamericanista y antiimperialista de la Reforma. Por otra parte, mientras del Mazo se convertía en una figura clave de un reformismo ligado a la fracción juvenilista y nacionalista de la UCR, Monner Sans y otros ateneístas reingresaban en las filas del PS.

\section{Los arielistas de Montevideo}

En 1917 surgía en la otra margen del Río de la Plata un grupo estudiantil que realizó un pasaje similar al del Ateneo desde una apuesta cultural y estudiantil a otra socialista bolchevique y dirigida a estudiantes y obreros. Con una importante renovación de sus miembros, los arielistas montevideanos pervivieron hasta 1931, editaron cuarenta y un números de su revista Ariel y desde mediados de los veinte, cuando el Ateneo ya se había disuelto, se conectaron con la fracción latinoamericanista y antiimperialista de la Reforma porteña.

Este grupo de arielistas era nucleado por la iniciativa del Carlos Quijano (1900-1984), entonces un estudiante inicial de Derecho en la Universidad de la República. Entre 1917 y 1919 el Centro de Estudios Ariel organizó algunas reuniones y conferencias en las que participaron una veintena de jóvenes. Y desde agosto de 1919 editó el primer número de Ariel. Revista mensual del Centro Estudiantil "Ariel" (1919-1931). Ese Centro y su publicación nos interesan aquí porque, además de ser la más duradera y organizada plataforma reformista del Uruguay, mantuvieron estrechos vínculos con algunas fracciones reformistas porteñas, de las que se nutrieron y con las organizaron iniciativas conjuntas.

En cuanto a las similitudes de estos nuevos arielistas con el Ateneo, ambos grupos reunieron a jóvenes pertenecientes a los sectores medios en ascenso y, en sus primeros años, funcionaron como una suerte de ateneo, esto es, los estudiantes se reunían periódicamente para escuchar conferencias, discutir sobre cuestiones culturales y preparar una revista. ${ }^{276}$ Siguiendo el reclamo de Rodó, a través de esas instancias los jóvenes adquirían una formación estética y moral ligada al modelo de la cultura clásica y con ello contrarrestaban el utilitarismo y profesionalismo que les ofrecía la universidad.

Pero en 1920 el Centro Ariel modificó el diseño de su revista y revisó su programa para asumir un compromiso socialista similar al que unos meses antes había declarado el Ateneo estudiantil porteño. Como veremos, la coincidencia no se debía a la vinculación con los ateneístas

\footnotetext{
${ }^{276}$ Como mencionamos al comienzo del segundo capítulo, en 1916 había aparecido en Uruguay una primera revista llamada “Ariel”. Los pocos números, editados entre septiembre y diciembre de ese año, fueron el órgano de un grupo de estudiantes secundarios de la ciudad de Treinta y Tres que se dio el nombre de Asociación Estudiantil "Cervantes". Para un detenido análisis de la apuesta ideológica del joven Quijano, véase Caetano y Rilla (1986). Sobre las recepciones uruguayas del ensayo Ariel en el periodo, véase Penco (2010).
} 
sino a un común entusiasmo ante la Internacional del Pensamiento y el clima de agitación obrera, pero también a los contactos que los montevideanos habían establecido con el joven Juan Antonio Solari (1899-1980) y su revista Bases (1919-1920).

Aunque la escala fue mucho menor que en Buenos Aires, a comienzos del siglo XX se registró en Montevideo un proceso de modernización y constitución de las clases medias que repercutió en la universidad. Con el ingreso de los jóvenes que anhelaban el ascenso social, la matrícula de las tres facultades que componían la Universidad de la República (Medicina, Abogacía y Matemática, en la que se dictaba las carreras de Arquitectura e Ingeniería) se incrementó significativamente. Y, como los porteños, los universitarios montevideanos que buscaban el ascenso social comenzaron a dar vida a formaciones culturales preocupadas no sólo por lograr condiciones que agilizaran y democratizaran la carrera, sino también por la posibilidad de delinear la identidad política del estudiante. La Asociación de los Estudiantes de Medicina, fundada en 1919, y su órgano El Estudiante Libre (1919-1956) fueron los que en el caso uruguayo más avanzaron en la democratización académica. Por su parte, el mencionado Centro de Estudios Ariel y su órgano conformaron las instancias más comprometidas en una tarea cultural y política que, excediendo el profesionalismo, precisara la misión social del estudiante. ${ }^{277}$

Como una primera caracterización, traigamos la definición de la Reforma y de las peculiaridades uruguayas propuestas por Caetano y Rilla. Subrayando algunos rasgos que hemos venido encontrando en las intervenciones de los grupos estudiantiles porteños y que encontraremos en los arielistas montevideanos, así como las peculiaridades que asumió el reformismo en cada ciudad universitaria, afirman los autores:

Fue el reformismo universitario una disidencia generacional y una disidencia ideológica; ambas comprometieron a toda la sociedad, aunque la sociedad y la Universidad uruguayas no ofrecían, ni por asomo, las inercias aristocráticas de Córdoba o de Lima. Fue más buen expresión del proceso de creciente politización de sectores sociales emergentes con la modernización, de las clases medias con espacio para el ascenso social y la inserción política y que a menudo se empeñaron en radicalizar las líneas programáticas de los partidos tradicionales o en promover la formación de nuevos partidos, cuando aquellos aparecían impermeables. Si Víctor Raúl Haya de la Torre puede inscribirse en este último grupo (y la renovación que en todo sentido marcó al APRA en su primera época es prueba contundente), Carlos Quijano se ajusta al primero, en tanto partía del supuesto de la posibilidad y la necesidad de renovación de uno de los partidos tradicionales del Uruguay, a través de la formación de una nueva elite dirigente. [...] Se trataba en síntesis, de una generación contestataria, dispuesta a la conmoción y a la batalla, pero no irreverente con algunos de sus mayores contemporáneos, en quienes reconocía cierta paternidad espiritual, la que a la postre -como a menudo ocurre- sería cuestionada u olvidada (Caetano y Rilla, 1986: 20-23).

\footnotetext{
${ }^{277}$ Para una detallada caracterización de la universidad montevideana, véase Oddone y París de Oddone (2010). Para una historia centrada en los estudiantes, véase Van Aken (1990).
} 
Quijano fue anunciado en el primer número de Ariel como presidente del Centro y como parte de los redactores de la revista. Junto a él se encontraban: Arturo Lerena Acevedo, Luis E. Piñeyro Chain, Adolfo Coppetti, Eugenio Fulquet y Agustín Ruano Fournier. A ellos se sumaron Justino Zavala Muñiz como secretario de redacción y Alberto Pérez y Vicente Elorza como administradores. Unos números después, Ariel consignaba a Quijano como director, cargo que ocuparía junto con la presidencia del Centro hasta 1923, cuando se recibía de abogado y partía a París a estudiar Economía y a alentar otras iniciativas estudiantiles.

Durante los años en que Quijano dirigió el Centro y la revista, ésta tuvo una periodicidad sorprendentemente regular para las publicaciones estudiantiles de la época: entre julio de 1919 y febrero de 1923 se editaron treinticinco números de Ariel (la mayoría de ellos dobles). Luego de la partida de Quijano, la revista estuvo dirigida primero por el joven filósofo marxista Héctor González Areosa y luego por distintos equipos de redacción. En estos años no se logró una aparición regular: entre julio de 1924 y junio de 1931 sólo se publicaron seis números de Ariel. Dejando para el capítulo séptimo el análisis de los últimos números, nos interesa aquí el periodo en que, bajo el liderazgo de Quijano, el Centro y la revista redefinieron su arielismo apolítico por uno adherente a la Revolución Rusa y a la Internacional del Pensamiento.

Los once primeros números de Ariel tuvieron un tamaño pequeño, fueron impresos en papel de calidad y contaron con unas sesenta páginas cada uno. Si bien se anunciaba una frecuencia mensual, la periodicidad tendió a ser cumplida a través de números dobles. En esta primera etapa, los estudiantes montevideanos declararon como uno de sus propósitos principales la vinculación con otras asociaciones y propusieron una intervención centrada en la cultura letrada. Declaraba el manifiesto inaugural:

Nuestra obra de cultura será nacionalista y por extensión americana; trataremos así, de reflejar en la medida de nuestras fuerzas la vida cultural del país y de América, y como queremos ser la voz nueva, la voz que venga de la juventud [...] Una obra de mutuo conocimiento intelectual queda aún por realizar, para que se haga carne el ensueño de solidaridad. Conozcámonos y comprendámonos, ese será el primer paso en el camino de la fraternidad continental. Nuestra revista no olvidará esa obra, abierta a to lo que sea pensar noble, sentimiento elevado, ella pretende hermanar a la juventud de América en la lucha empeñosa por el triunfo de Ariel: un mismo ideal y una misma sagrada inquietud de justicia y amor ("Nuestro programa", Ariel, nº 1, julio de 1919, p. 5).

Ese primer número estaba dedicado al poeta modernista mexicano Amado Nervo, quien acababa de morir en Montevideo cumpliendo el cargo de embajador de la Revolución Mexicana. Los números siguientes difundieron las respuestas a la encuesta realizada por Ariel sobre el papel social de la universidad junto a textos literarios y notas sobre literatura y música, provenientes no sólo de los veinteañeros sino también de figuras reconocidas como Rodó, Vaz Ferreira, Nin Frías, Paulina Luisi 
y Leopoldo Lugones.

Si bien en los primeros años el grupo de redactores no varió demasiado, el tipo de intervención de Ariel se modificó fuertemente a partir de su número doce, fechado en agosto de 1920. Entonces se convirtió en una revista escrita fundamentalmente por estudiantes, al tiempo que comenzó a aparecer en formato tabloide, papel de baja calidad y no más de veinte páginas. Este diseño, que se mantuvo hasta el cierre, fue acompañado por la organización en cuatro secciones sumamente estables: "Editoriales", "Cultura", "Crónicas" y "Exterior". Pero además desde ese nuevo formato los arielistas comenzaron no sólo a difundir la alta cultura y a vincularse con otros grupos estudiantiles, sino también a procurar la instrucción del pueblo que encabezaría la revolución socialista. ${ }^{278}$ Realizando una inesperada variación del arielismo, propusieron ese compromiso de carácter político en continuidad con el llamado que había pronunciado Rodó a las juventudes cultas para que ocuparan su función moral. Específicamente, entre 1920 y 1924 -año en que publican su revisión de Rodó-, los jóvenes montevideanos proponen una convergencia entre arielismo y socialismo bolchevique. Si bien no formulaban unas marcadas simpatías cientificistas como lo habían hecho los arielistas porteños de 1914, sí compartían con éstos la corrección a las resonancias aristocratizantes de la prédica de Rodó.

Ariel, una revista estudiantil en la que no habían tenido resonancias las revueltas cordobesas que en junio de 1918 iniciaron la Reforma, ni los nuevos estatutos universitarios conseguidos por los estudiantes argentinos en agosto de ese año, propone desde mediados de 1920 una poco explorada conciliación entre arielismo y socialismo. Y para formular esa propuesta fue significativa la estrecha vinculación de los montevideanos con los porteños que conformaban el ala radicalizada de la Reforma, pues ese vínculo permitió a la veintena de arielistas montevideanos tanto el conocimiento de iniciativas que podían replicarse en Uruguay como la llegada de figuras argentinas reconocidas, la formación de un espacio más amplio de difusión y la organización de actividades conjuntas.

Como han analizado Caetano y Rilla (1986), fue en 1927, luego de formarse en Economía en París y de desarrollar esa mirada antiimperialista en clave nacional que dejará su impronta en la izquierda uruguaya, que Quijano expuso críticas precisas al arielismo. En efecto, poco antes de regresar a Montevideo, publicaba una carta de lectores en el diario montevideano El País (16/09/27) en la que acusaba a su antiguo maestro de carecer de una mirada económica y de alentar un vago idealismo que no aportaba ideales concretos. Más allá de esta separación del arielismo, veremos en la sección siguiente que entre 1920 y 1924 Quijano y su grupo ya identificaban esos problemas en el arielismo, pero para superarlos no emprendían su superación sino la conciliación con el socialismo bolchevique.

\footnotetext{
${ }^{278}$ Una prueba de que este nuevo objetivo no interrumpió los primeros propósitos del grupo es su participación en el
} homenaje a Rodó de comienzos de 1920 y la posterior preparación de los dos tomos Homenaje a José Enrique Rodó. 


\section{Ariel, aliada del ala radicalizada de la Reforma}

El segundo número de Ariel informa que ha regresado de Buenos Aires el delegado de la revista: "su viaje ha tenido como primer resultado positivo, el hacer conocer nuestro Centro por los más distinguidos intelectuales argentinos, al mismo tiempo que fomenta un acercamiento con los universitarios del vecino país". ${ }^{279}$ La primera evidencia de ese acercamiento se descubre unos meses después. A partir del número cuatro-cinco, Ariel publica el siguiente anuncio:

"BASES".

Tribuna de juventud universitaria liberal argentina PUBLICACIÓN MENSUAL Director: JUAN ANTONIO SOLARI Suscripción adelantada (6 Nros) \$5,25-- $\mathrm{N}^{\circ}$ atrasado $\$ 0,40$ Se reciben suscripciones en la Administración de la Revista "Ariel”

Entre mediados de 1920 y mediados de 1922, Ariel consigna que su corresponsal argentino es el director de Bases. Como veremos en el apartado siguiente, los ocho números de esta revista porteña, buscaron contrarrestar el "apoliticismo" alentado por la FUBA. Para ello Bases llamaba a la juventud universitaria a asumir un liberalismo jacobino que promovía una llegada revolucionaria al socialismo distante del gradualismo que, en la escala argentina, había diseñado la "hipótesis de Justo" (Aricó, 1999). Cerrada Bases, esta versión radicalizada de la Reforma encontró una nueva plataforma de difusión en la emblemática Insurrexit. Revista Universitaria (1920-1922), a la que Solari se sumó hasta que, a comienzos de 1921, el PS se declaró en contra de la vía revolucionaria.

El grupo de Quijano parece haberse entusiasmado con la tribuna de liberalismo jacobino de Bases, pues los cambios de diseño y de propósitos que registró Ariel desde mediados de 1920 no sólo coinciden con la vinculación con Solari, sino que además asemejan notoriamente la revista montevideana a la porteña. Tanto Ariel como Bases contaron con una sección que difundía las reflexiones de quienes consideraban los auténticos ideólogos liberales de Uruguay y de Argentina, respectivamente. Asimismo, Solari cumplió entusiastamente su tarea de mediador de los grupos rioplatenses, pues desde que asumió la corresponsalía fueron frecuentes en Ariel las colaboraciones de jóvenes porteños del ala radicalizada de la Reforma, como Liborio Justo, José Belbey y Gregorio Bermann. En una nota aparecida en Bases, Bermann saludaba la "revolución" estudiantil cordobesa y las que se sucedieron en Santa Fe, Mendoza y Chivilcoy para concluir defendiendo la posición de la fracción izquierdista del PS. Declaraba allí Bermann:

\footnotetext{
${ }^{279}$ Ariel, $\mathrm{n}^{\circ}$ 2, agosto de 1919, p. 103.
} 
La acción conjunta del proletariado y de los estudiantes llevará a los hombres a liberarse de las fuerzas que los oprimen. El trabajo, en vez de ser un elemento de esclavización, se transformará en un poder de emancipación. Entonces el hombre será factor consciente de su propia historia en vez de ser un elemento extraño que lo mueven. Entonces el hombre creará con la admirable pujanza de su Pensamiento "faro eterno y el único verdadero en las tinieblas de la vida" -como canta Gorki en su himno inmortal al Hombre (Bermann, "La nueva argentina", Bases, no 5, 05/10/1919, p. 4).

Unos meses después, Bermann viajaba a Montevideo invitado por el Centro Ariel para difundir ideas similares en el ciclo de conferencias dispuesto por los arielistas en la Universidad de la República. Su discurso, "La revolución estudiantil argentina", sería publicado tanto en La Gaceta Universitaria de Córdoba como en Ariel.

En el mismo número de Ariel en que aparecía la primera parte de la conferencia de Bermann, se difundía la redefinición de propósitos arielistas. Explicitando no sólo la intención de corregir las resonancias aristocratizantes del arielismo, sino también la de convertirse en una tribuna de liberalismo jacobino que convergiera con Bases, declaraban los jóvenes montevideanos:

Nuevamente ARIEL, ahora afirmada en la experiencia de los números anteriores, surge a la lucha. Troqueladas nuestras aspiraciones iniciales en el esfuerzo y en el estudio, hoy, al aparecer con el mismo programa idealista y renovador de antes, hemos ampliado nuestra visión y fortificado la conciencia de nuestra obra [...] el momento es de afirmación. No se puede ir a la lucha sino con ideales absolutos; y si en la conciliación está la verdad, esperemos que esa conciliación la realice la vida. Ser jóvenes y andar buscando prudentemente conciliaciones y ambiguos términos medios, sólo revela cobardía. [...] vivimos un momento de una trascendencia jamás superada en la humanidad, más trascendente y compleja, más 'plena' de inquietud, de esperanza y de fervor, que la hora turbulenta de nuestra emancipación, bebió su Ideal en la gesta de los revolucionarios del 89 y que sólo consagró, bajo la inspiración de la ideología individualista, el principio, estéril en su aislamiento, de la libertad ("Nuestro Programa", Ariel, n 12, agosto de 1912, p. 3).

Como mencionamos, desde entonces los arielistas mantuvieron unidos los reclamos gremiales de los estudiantes al compromiso con el socialismo. Y los números siguientes confirman que si esos jóvenes habían ampliado la visión y fortificado la conciencia de la obra pedida por la hora histórica era porque habían encontrado dos aliados de diverso relieve. Junto con las iniciativas promovidas por el ala estudiantil radicalizada del país vecino, podían retomar el llamado a una "Revolución en los Espíritus" que, a escala internacional, realizaba el grupo Clarté.

De los argentinos recibieron una serie de colaboraciones que llevaban a que la sección “Cultura” del Ariel n ${ }^{\text {o }} 20$ estuviera compuesta íntegramente por textos de jóvenes porteños: a la primera parte de la conferencia de Bermann le seguía "Sugestiones para la renovación de la Filosofía y Letras", nota breve en la que el antiguo líder del Colegio Novecentista de Buenos Aires y futuro trotskista, José Gabriel, criticaba el futurismo y los "ismos" de moda entre la juventud; 
luego otro futuro trotskista, el joven Liborio Justo, alentaba la unión de los estudiantes del continente con "El americanismo universitario" 280 y el joven José Belbey, director de la sarcástica revista porteña $L a$ Cureta y futuro intelectual del PS, daba a conocer sus poemas "Estudiando... soñando" y “Tienes razón, Bergson”.

En cuanto a la filiación internacional, la breve presentación que inauguraba la sección "Exterior" de ese número volvía sobre el compromiso de realizar de modo integral la obra de los revolucionarios franceses "ya que sólo tuvo consagración en las construcciones sociales el principio primordial de la libertad, no llegándose a la plenitud de los humanos y generosos postulados de igualdad y fraternidad". ${ }^{281}$ Para colaborar en esa obra, los distintos números de Ariel daban a conocer los manifiestos y emprendimientos del movimiento continental de la Reforma. Entre ellos, la fundación de la Universidad Popular en Lima y de la Universidad de Concepción de Chile así como la aparición de la Asociación de Estudiantes de las Repúblicas Soviéticas y de la efímera Federación de Estudiantes Revolucionarios en Rosario, sobre la que volveremos.

Pero de modo especial la revista montevideana se preocupó por la divulgación de los debates producidos en distintos puntos del planeta en torno del lugar de los intelectuales en la revolución. El número doce de Ariel publicó el difundido manifiesto "La Internacional de los Intelectuales" que habían firmado Henri Barbusse, Georges Duhamel y Romain Rolland, junto con la respuesta de Máximo Gorki. Luego de leer la convocatoria realizada por los intelectuales franceses a un Congreso Internacional de los Intelectuales orientado a rearmar los vínculos "entre quienes luchan por la paz y el progreso de la humanidad", los lectores de Ariel podían conocer las críticas que realizaba el orientador cultural de la Revolución Rusa: Gorki declaraba el carácter trágico de la situación de los intelectuales y exigía la fusión de "la razón organizada" (de los intelectuales) con "la voluntad exaltada" (del pueblo).

El número siguiente de Ariel continuaba esa reflexión a través de la difusión de otro pequeño debate relativo al llamado a una "Revolución en los Espíritus", a saber la carta abierta a Rolland que había redactado el intelectual comunista estadounidense Max Eastmann y la respuesta del francés. Eastmann abría las sospechas sobre el carácter abstracto de la noción de Espíritu y, citando el Manifiesto Comunista, consideraba políticamente inviable que los intelectuales se concibieran como una clase privilegiada separada de los trabajadores asalariados. La respuesta de Rolland era breve y tajante: consideraba que tenía grandes distancias con Eastmann porque "no adhiero a una fe religiosa ni marxista" sino al escepticismo de Montaigne, y en virtud de ello a los valores de una humanidad libre y feliz, pero también a la necesaria libertad de pensamiento ("Max Eastmann y

\footnotetext{
${ }^{280}$ Justo había ingresado a la Facultad de Medicina de Buenos Aires en 1919, la que abandonó en 1924 cuando partió a Lima con su padre, el militar y futuro presidente argentino Agustín P. Justo, y la comitiva oficial para participar de los festejos de la independencia. Sobre su itinerario político-intelectual, véase Tarcus (2007a).

281 “Exterior", Ariel, n 12, agosto de 1912, p. 14
} 
Romain Rolland", Ariel, $n^{\circ} 13-14$, septiembre y octubre de 1920, 17-18). ${ }^{282}$

A pesar de que los arielistas no lograron despertar en los estudiantes el entusiasmo que esperaban, sí consiguieron que ese debate sobre el rol del intelectual revolucionario tuviera una versión montevideana. En las notas que compusieron la sección "Editoriales", Ariel insistió en que el Centro de Estudios era el encargado del aspecto cultural del problema social. Y ello "no para oponer, como recurso de baja política, una barrera al clamor por justas reivindicaciones; sino como medio, el más sabio, de garantir la estabilidad, la salud de los futuros progresos", el objetivo de ese método sería "lograr para la sociedad por lo menos correlativamente, con antelación si fuera posible, a las conquistas políticas y económicas, una superior unidad de cultura, por expansión de la mejor aquilatada". ${ }^{283}$ Pero al interior del campo de las izquierdas uruguayas una empresa que se concentrara en la educación del pueblo no podía ser vista con buenos ojos por quienes concebían que la vanguardia política debía ser exclusivamente obrera y que el objetivo primordial era su organización. A esos críticos respondían los arielistas con las siguientes definiciones:

No somos indecisos, ni divagamos solemnemente, ni desconocemos cuales son las exigencias del momento, ni ignoramos nuestro imperioso deber... El nervio central de nuestro pensamiento y de nuestra acción es la "revolución en los espíritus"; conocemos y sentimos la injusticia, sabemos que se impone la "renovación total de los fundamentos económicos". Iluminados por ese espíritu guía pedimos la reforma total de la Universidad. Porque nuestra obra es obra de cultura y enseñanza y el espíritu que nos dirige en esa obra es el mismo que encarna fundamentalmente el régimen cultural de la República del Soviet. Nos decís indecisos porque no concretamos nuestro programa social, porque declarando nuestra ansia de renovación no corremos a ponernos al lado de los oprimidos... [...] Somos un grupo numeroso de estudiantes que guiados por el mismo espíritu renovador, se han unido en la tarea de realizar la cultura... puede que la obra total sea de los que como vosotros, quieren dar la justicia al hombre unida a la que, como la de nosotros, quiere alcanzar a los espíritus el pan de la alta cultura... ("Nuestra indecisión!...", Ariel, n 13-14, septiembre y octubre de 1920, p. 5).

Esta adhesión a la República de los Soviets se mantenía a distancia respecto del PS uruguayo, que, a diferencia del argentino, se había vuelto "tercerista", pues había adherido a las veintiún condiciones de la III Internacional Socialista. Entre 1920 y 1924 los arielistas buscaron un equilibrio entre la inscripción en las filas del socialismo bolchevique y una identidad grupal que no renunciaba a su carácter universitario y cultural. Y si eran cuestionados por el socialismo uruguayo, podían en cambio reconocerse en algunas iniciativas estudiantiles de la región.

A mediados de 1920, Bases dejaba de circular y aparecían dos publicaciones que también difundían una versión radicalizada de la Reforma: en Chile, el ala estudiantil radicalizada fundaba

\footnotetext{
${ }^{282}$ La nota que sucede a ese debate también se ocupa de los problemas del "proletariado intelectual". Bajo el título "El porvenir de los intelectuales", los arielistas trascriben parte de la defensa de la tarea intelectual que propuso Paul Boulat, entonces ministro de Instrucción de Francia, porque "muchos de los conceptos enunciados tienen aplicación en nuestro ambiente" (Ariel, $\mathrm{n}^{\circ} 13-14$, septiembre-octubre de 1920, p. 19).

283 "Extensión universitaria", Ariel, n 13-14, septiembre-octubre de 1920, p. 3.
} 
Claridad y en Buenos Aires, una fracción reformista también radicalizada editaba Insurrexit, a la que se sumaban Solari y Brumana. Desplegando la prosa latinoamericanista que, junto a la denuncia imperialista, se volverá característica de la Reforma, Ariel saludaba la aparición de Claridad e Insurrexit del siguiente modo:

Con la propia finalidad superior de cultura y de combate, ARIEL siente la hermandad espiritual de aquellos órganos de publicidad que son bandera de idealismos y afirmación en la obra de inspirar a la juventud de América, los deberes que determina el desconcierto de la hora actual.

Con propósito de realizar obra de comprensión y de convencimiento mutuo como primer paso en el camino de la fraternidad americana, ARIEL ofrece, a sus hermanos en ideales, cordial amistad y decidido concurso ("Claridad e Insurrexit", Ariel, n 16-17, noviembre y diciembre de 1920, p. 19).

Más allá de las problemáticas universitarias particulares de cada país, estas publicaciones se hermanaban a partir de un socialismo que encontraba en Barbusse y su grupo la posibilidad de legitimar un espacio intelectual que adhiriera al comunismo ruso, pero mantuviera una distancia tal con el programa de la Internacional Comunista que les permitiera delinear, en el plano local, la tarea cultural previa a la revolución.

Al igual que sus hermanas, Ariel reseñaría elogiosamente los libros de Barbusse y reproduciría sus diversos documentos. Entre ellos, publicaría a comienzos de 1921 "A los intelectuales y estudiantes de la América Latina. Mensaje de Anatole France y Henri Barbusse”, un manifiesto que destacaba la experiencia del grupo Clarté en Francia para proponer la fundación de "partidos de intelectuales" en nuestro continente y que no sólo tuvo una fuerte circulación en las revistas de la época a través de la difusión de Ingenieros, sino además una suerte de expresión local en la fundación de la ULA, también promovida por Ingenieros. ${ }^{284}$

Los números de Ariel aparecidos entre 1921 y 1923 continuaron la difusión de los emprendimientos estudiantiles radicalizados que se desplegaban en el mundo, al tiempo que llamaron a imitarlos. Asimismo, los jóvenes arielistas asumieron posiciones izquierdistas en cuestiones nacionales e internacionales y se interesaron por la figura de Benedetto Croce. A ello sumaron, por un lado, la campaña de 1922 por la autonomía universitaria, para la que convocaron a Alfredo Palacios, entonces decano reformista de la Facultad de Derecho de La Plata; y, por el otro, la campaña, encabezada por Vaz Ferreira, por la fundación de una Facultad de Filosofía y Letras uruguaya que, desligada de la habilitación profesional, desarrollara el pensamiento nacional y la investigación desinteresada.

\footnotetext{
${ }^{284}$ Por las cartas conservadas en el Fondo personal José Ingenieros del CeDInCI sabemos que Ingenieros fue uno de los encargados de distribuir el manifiesto en las revistas culturales latinoamericanas. En Buenos Aires el mensaje fue publicado por revistas consolidadas y de amplia difusión como Revista de Filosofía y Nosotros, así como por publicaciones estudiantiles izquierdistas como Insurrexit, el Boletín de la Federación Universitaria Argentina y la Revista de Ciencias Jurídicas y Sociales. A esa lista porteña se suma la revista Claridad limeña, la que no sólo estuvo estrechamente vinculada a la FUA sino que consignó en todas sus tapas a Ingenieros como su primer auspiciante.
} 
Como mencionamos, la publicación arielista perduró hasta 1931, pero perdió su regularidad cuando en 1923 Quijano terminó sus estudios. Ese año aparecía sólo un número de Ariel y para el próximo habría que esperar más de un año, ambos dirigidos por Héctor González Areosa. Unos pocos números más de Ariel aparecerían entre 1927 y su cierre. En consonancia con las nuevas inquietudes que se registraban en el ala izquierdista de la Reforma porteña, en sus últimos números Ariel desplazaba del centro de su identidad el bolcheviquismo para participar del tramado de una sensibilidad antiimperialista latinoamericana.

\section{Bases, la primer tribuna de la juventud revolucionaria porteña}

El pueblo despertará antes. Tú que crees en Dios y en los obispos puedes ir confesándote: tu hora suprema se aproxima. El pueblo duerme, más, a fin de que pierda tiempo, tú mismo, con tu torpeza y criminal conducta le incitas, le provocas, le afilas la cuchilla... Jaime Judá, “El pan”, Bases nº 6 (octubre de 1919, p. 4).

A fines de mayo de 1919, cuando la FUBA se acababa de separar de la FUA y el Ateneo se acercaba al PSI pero aún no había puesto en circulación una prensa estudiantil izquierdista, aparecía el primero de los ocho números de Bases. Tribuna de la Juventud. ${ }^{285}$ La revista sería la segunda de las múltiples empresas editoriales que emprendería el futuro líder del PS Juan Antonio Solari. De formato tabloide, las ocho páginas de cada número estuvieron densamente cargadas de notas. En cuanto a sus propósitos, el primer número reprodujo junto al título la siguiente frase alberdiana: "Bases mejores y más fuertes sobre las que levantaremos, con amor y con inteligencia, en obra de bondad, de verdad y de belleza, una Argentina más libre y civilizada entre los países civilizados y libres del mundo nuevo que llega". ${ }^{286}$ Los distintos números no dejarían dudas de que se proponían una audaz apropiación del romanticismo de la generación del '37, pues “ese mundo que llegaba" era el abierto por la Revolución Rusa y para realizar la "obra de bondad, de verdad y de belleza" los estudiantes debían participar en la FUA y en las iniciativas obrero-estudiantiles.

La intervención de Bases no ha sido analizada por los estudios sobre el movimiento estudiantil. La única referencia la realizan Lafleur, Provenzano y Alonso (2006), quienes mencionan

\footnotetext{
${ }^{285}$ Agradezco a Ada y Herminia Solari por haberme posibilitado el acceso a la colección completa de Bases así como por sus gentiles respuestas a mis inquietudes.

${ }^{286}$ En sus números siguientes precisa: "BASES no es publicación de determinada Facultad, Escuela o Colegio porque cada una de estas casas de estudio tiene, o debe tener, su periódico o revista. No es informativa porque para eso está la prensa diaria que, bien o mal, cumple su cometido. BASES se ocupa de todos aquellos problemas que interesen a la juventud en general y es la tribuna desde la que ésta expresa su pensar y su sentir sobre todos y cada uno de los asuntos, educacionales o no, que se plantean en el país, especialmente en esta hora histórica del mundo. La juventud liberal argentina, consciente de su responsabilidad y de su misión quiere discutir, opinar y hacer. BASES es la tribuna de esa juventud".
} 
los datos bibliográficos y la inscriben, junto a la primera revista Claridad, en la tradición boedista. Se trataría de "órganos literarios, pero con el acento puesto en las reivindicaciones sociales y políticas" (Lafleur, Provenzano y Alonso, 2006: 112). Más precisamente, las reivindicaciones de las dos revistas provenían de jóvenes que buscaban que el PS argentino, como lo había hecho el uruguayo, adhiriera a la Internacional Comunista, búsqueda que tenía en el senador Enrique del Valle Iberlucea a su máximo referente y que se definiría en contra de la adhesión a comienzos de 1921, momento en que ninguna de las dos continúa editándose.

Las páginas de Claridad -sobre la que tampoco contamos con un análisis específicosugieren que fue elaborada por el mítico grupo Claridad, en el que sabemos que participaron jóvenes como Barreiro y Mouchet -y seguramente Aprile y Bermann- junto a intelectuales de la generación anterior como Ingenieros, Giusti y Bianchi. Bases, en cambio, fue fundamentalmente obra del entusiasmo revolucionario de Solari, quien, desde una prosa irreverente y provocadora -que se advierte en el fragmento que elegimos como epígrafe del presente apartado-, también buscaba la adhesión del PS a la Internacional Comunista pero con su revista se propuso, sobre todo, impregnar de entusiasmo revolucionario a la juventud culta de Buenos Aires y las ciudades universitarias cercanas.

En 1919 Solari contaba con veinte años. En una de sus memorias, recuerda que en 1919 ya se definía como socialista, aunque no se había afiliado al PS (Solari, 1976: 8-9). Dos años antes, como estudiante secundario, había participado del CE de la Escuela Superior de Comercio Carlos Pelegrini y de su órgano, Mercurio, de la que aparecieron diecisiete números entre abril de 1917 y septiembre de 1918. Por las memorias de otro reformista y luego líder comunista, Paulino González Alberdi (1903-1989), sabemos que el Mercurio desaparecía justo cuando un nuevo grupo asumía el CE (Paulino Alberdi, 1968: 8). ${ }^{287}$

Antes de la aparición de Bases, Solari publicó algunos artículos sobre la Gran Guerra y el asesinato de Jean Jaurès, y sobre otros temas políticos y literarios en periódicos socialistas. En esas notas utilizó algunos de los seudónimos que aparecerían en Bases: Olindo Riasol, Jean d'Aloris y Ada Velmar. Respecto de la fundación de esta revista recuerda:

No completé los estudios. Trabajé en el Frigorífico de Berisso y luego en el Ministerio de Agricultura. En mayo de 1919 edité -con la secretaría de redacción de Eduardo Rodríguez Berdier- el periódico Bases, cuya "redacción y administración" figuraba en Chile 424, donde se hallaba la imprenta "La Aurora". Aparecía como "Tribuna de la juventud" [...] logró una difusión importante en un año de existencia. En realidad los trabajos de redacción del periódico, como mis colaboraciones, se realizaban en la oficina del ministerio. Es conocido que la burocracia tiene eso de bueno, si hay quien

${ }^{287}$ Sobre su itinerario político-intelectual, véase Tarcus (2007a). González Alberdi publicó una interesante compilación de sus textos sobre la Reforma en la que se pueden encontrar algunos datos sobre su militancia reformista, pero sobre todo el balance sobre el movimiento que realizaba el PC en la década del cincuenta y sesenta (González Alberdi, 1968). 
quiera aprovechar el tiempo... Luis de Villalobos y Ubaldo Pepe, que eran mis compañeros de "labor", me alentaron y ayudaron mucho (Solari, 1976: 9).

Como puede imaginarse, en esta nueva empresa estudiantil ligada al socialismo no podía faltar la colaboración de Ingenieros ni la presencia del semanario España. El primer número de Bases publicó "Firmeza y luz" de Ingenieros, una nota que, con algunas modificaciones, formó parte de los "sermones laicos" de Las fuerzas morales, compilación editada en 1925, poco después de morir Ingenieros y preparada por su discípulo Aníbal Ponce. Asimismo, los números contaron con la publicidad de la colección La Cultura Argentina. En cuanto a España, bajo el título "Nueva inquisición" el tercer número de Bases trascribió un fragmento de una nota sobre el patriotismo que Unamuno había publicado en aquella revista. Además, Bases fue saludada tanto por Barros como por el entonces “Dr." Bermann, junto a quien Solari, a comienzos de 1920, representó a la FUC ante la FUA y fue orador en un significativo acto estudiantil del $1^{\circ}$ de mayo de ese año que buscaba sellar la unidad obrero-estudiantil. De Bermann, recordemos que Bases publicó la nota que saludaba las distintas revoluciones estudiantiles argentinas y subrayaba la unión obrera-estudiantil.

Una importante colaboradora de los ocho números de Bases fue Herminia Brumana. La futura esposa de Solari vivía entonces en Pigüé, un pueblo de la provincia de Buenos Aires en el que trabajaba como maestra y editaba Pigüé, una revista que había fastidiado a las autoridades educativas. Solari recuerda que en 1919 sólo conocía a Brumana a través de unas pocas cartas que se habían cruzado y de los retratos aparecidos en las revistas y periódicos en que ella colaboraba. Además de la nota citada, "Las pobres hojitas", Brumana envío a Bases: "Estas maestras..." (nota aparecida en el segundo número), "Decir las cosas pronto" (Bases no 6), "Susana" (Bases n ${ }^{\circ}$ 7) y "Palabras a mi enemigo" (Bases no 8). Una serie que, como la que Brumana envió a Clarín, instalaba, entre esos grupos estudiantiles radicalizados formados exclusivamente por varones, el reclamo de la igualdad de las mujeres a través de un llamado a éstas a conquistar esa igualdad.

En comparación con Clarín y Ariel, en Bases tuvieron más presencia las mujeres. Además de las notas de Brumana apareció en el número 7 el poema "La mujer estéril" de la pedagoga de ideas avanzadas Gabriela Mistral (1889-1957) y en el número 5 “El periodismo”, un artículo, de prosa enérgica, en el que la escritora Salvadora Medina (1894-1972), entonces ferviente anarquista, le pedía a los periodistas que no sometieran sus ideales a la "farándula de los prostitutos".

Sobre el propósito que reunían esas colaboraciones recuerda Solari:

Como Mercurio había logrado distinguirse entre los periódicos de estudiantes, Bases llegó a ser una voz nueva, podría decir vibrante, valiente, surgida de gente apenas veinteañera. Reaparecieron en ella desde luego Jean d'Aloris y el infaltable Olindo Riasol. Combatimos la prédica reaccionaria de la Asociación del Trabajo y de la "Liga Patriótica Argentina". En una sección -"El mandato de nuestros muertos"- propagamos 
el pensamiento de Echeverría, Sarmiento, Alberdi, Moreno, etcétera. Publicamos colaboraciones de jóvenes del país y de autores ya consagrados. [...] Llegamos a tener agentes -no todos puntuales con el pago...- en casi todas las capitales de provincias, delegados estudiantiles, y un canje nutrido, por el que comprobábamos que muchos de los artículos eran transcriptos. Apoyamos a la Federación Universitaria Argentina y la reforma de 1918, que culminara en Córdoba, Enrique F. Barros y otros muchos nos hicieron llegar su voz de aliento (Solari, 1976: 10-11).

No se mencionan allí las revistas con las que Bases mantenía canje, pero la revisión de algunas de ellas confirma una importante circulación, e incluso esa ubicación como "una voz nueva, vibrante y valiente". Como mencionamos, hasta 1922 Solari fue el corresponsal argentino de la Ariel montevideana, a la que Bases declaró una revista "con muy buen material de índole literaria y científica" y mantuvo una notable similitud de diseño desde agosto de 1920.

Otra revista conectada con Bases fue La Gaceta Universitaria. Órgano de la Federación Universitaria de Santa Fe. Ésta se fundó en julio de 1919 y tomó su formato de La Gaceta Universitaria de Córdoba. El primer director fue Humberto Gambino, el estudiante que representó a la Federación Universitaria del Litoral en la asamblea constituyente de la FUA; su número seis avisó que Gambino había renunciado y que la publicación quedaba provisoriamente a cargo del estudiante de Derecho Mariano R. Tissembaum. ${ }^{288}$ Ese número trascribió la nota aparecida en Bases n 6 "Recetas de actualidad. ¿Qué quieres ser, camarada?”. Bajo los subtítulos "Para ser un agitador 'profesional"” y "Para ser hombre de 'orden"”, la breve nota caracterizaba sarcásticamente las opciones políticas propuestas por la Liga Patriótica. Allí se sostiene:

debes resistirte a perder el tiempo en los cabarets y tu plata en las carreras, y aplicarte al estudio como espiritual compensación del desgaste material a que te obliga tu trabajo diario. Aprenderás qué cosas son el deber y el derecho, la ley y la dignidad, la libertad, el trabajo y los ideales [...] Les hablarás entonces a tus desgraciados compañeros y despertarás sus consciencias como despertó la tuya el maestro de escuela primero y los libros después. [...] Te producirás con tanto entusiasmo y calor, que parecerá que vives de ello y se te llamará "agitador profesional" (Bases, no 3, 01/08/1919, p. 6; La Gaceta Universitaria, $\mathrm{n}^{\mathrm{o}}$ 6, 27/08/1919, s/n).

La otra posibilidad sería:

Ingresar en la primera congregación religiosa que te recomienden a condición de que en ella den tarjeta [...]. No estudies la historia de tu patria, pero nómbrala mucho e insulta a los gringos. [...] Pon tu plata en una empresa extranjera y exprime el jugo de los trabajadores argentinos y no te preocupes de los niños argentinos que pierden la patria por el disgusto y la miseria de sus padres extranjeros. Si tus intereses corren peligro porque una mayor justicia social se va abriendo fatalmente paso en el mundo, apela a la

288 De esta Gaceta Universitaria sólo hemos podido consultar dos números, conservados en el Museo de la Reforma de la Universidad Nacional del Litoral, Santa Fe. Unas pocas referencias a esta publicación pueden consultarse en Caballero Martín (1931). 
bandera, a la patria y a la patota armada y persigue y mata a todo cuanto obrero no sea analfabeto y se haya atrevido a hablar a sus hermanos en desdicha, de justicia, de libertad, de pan y de escuela. Deporta o mata a los agitadores, y entonces se te honrará llamándote "hombre de orden" (Idem).

Unas páginas después, La Gaceta de Santa Fe reproducía un texto que había aparecido en el segundo número de Bases, el llamado contra el nacionalismo de la Liga Patriótica. Allí se les exige, entre otras cosas, a los estudiantes:

Negaos, sobre todo, a oponerla [la bandera patria] a los trabajadores, porque ellos son los que la destejieron de la urdimbre celeste para tejerla en la tierra. [...] Porque ellos son los que hoy más la honran proclamando con la voz y con la acción la esencia trina y una de nuestro célico jirón de gloria: Justicia, Trabajo, Libertad.

Como mencionamos -y es esperable luego de leer estas definiciones de los estudiantes que proponía-, Bases saludó y recomendó los Documentos del progreso. De éstos declaró su quinto número que eran una "muy recomendable publicación que registra los más importantes de la historia social contemporánea (sic)". El saludo no fue correspondido, pues, salvo el editorial del primer número, las páginas de los Documentos se restringieron a la traducción y difusión de notas sobre la Revolución Rusa y las insurrecciones mundiales provenientes de publicaciones extranjeras. En cambio, Bases trabó un vínculo recíproco con Cuasimodo, revista de tendencia anarcobolchevique fundada en Panamá como "magazine internacional” por el puertorriqueño Nemesio Canale y el argentino Julio R. Barcos, quien no sólo había organizados la Liga de Educación Racionalista, sino que también -como vimos- había alentado la primera definición política del estudiante que proponía la revista Ariel de 1914. El número sexto de Bases reseñó los tres primeros números de Cuasimodo declarando que se trataba de un "excelente magazine interamericano" de "sano liberalismo" y transcribió fragmentos de "Nuestros profesores de idealismo en América", artículo en entregas en el que Barcos advertía sobre el nada confiable compromiso político de los intelectuales. Por su parte, en el número quince de Cuasimodo (abril de 1921), cuando la revista comenzó a editarse en Buenos Aires, aparecía una nota de Solari, "Las mulas del capitalismo", que retomaba las desconfianzas de Barcos a los intelectuales.

Finalmente, otra publicación con la que se hermanó con Bases fue La Palabra, según aquella un "interesante semanario que aparece en esta capital y que viene a sumarse a las publicaciones que inspiran su acción en un amplio liberalismo que queremos cada vez más combativo y definido".

Sobre todo a través de notas breves que combinaron la interpretación de los acontecimientos nacionales e internacionales en clave socialista con la ironía y la insolencia, Bases convocó a los jóvenes universitarios a que se asumieran revolucionarios y liberales, esto es, a que reconocieran en 
la generación de Moreno, Alberdi y Sarmiento a los "capitanes de la juventud" y a que se enfrentaran al "falso y peligroso" patriotismo desplegado por la Liga Patriótica. A distancia de la Revista Nacional y los Cuadernos, la revista de Solari no definió a los estudiantes como los portadores de la alta cultura nacional, sino que los ubicó junto a los trabajadores como los protagonistas de una organización social que erradicaría la injusticia social. Y si la citada nota de Bases n 5 en la que Bermann llamaba a la "acción conjunta del proletariado y de los estudiantes" para llevar "a los hombres a liberarse de las fuerzas que los oprimen" es una clara muestra del intento de una unión obrero-estudiantil, otra muestra la ofrece la nota de la columna "Temas universitarios" del pedagogo y miembro de la Universidad Libre Ernesto Nelson, en la que se afirma que "de nuestras universidades salen diariamente los estudiantes como salen los operarios de una fábrica; acaso tan inconscientes como éstos sobre el valor humano y altruista de la labor que realizan, pero sobre todo, y esto es lo grave, sin llevar nada de la Universidad consigo". ${ }^{289}$

\section{El llamado a la juventud porteña a aliarse al movimiento obrero}

Durante 1919, el movimiento obrero estaba fuertemente organizado y protagonizó numerosos conflictos. Como ya mencionamos, Bases intentó colaborar en la definición de una juventud universitaria que acompañara y guiara a ese movimiento desde el linaje de los revolucionarios de mayo pero también desde el horizonte de justicia social abierto por la Revolución Rusa. Su intento de una unión obrero-estudiantil se acentuará en los sucesivos números hasta afirmar en el último (fechado en junio de 1920) que la revista es una tribuna no sólo de la juventud sino también de los obreros y converger, luego del cierre, con el grupo Insurrexit y su revista homónima (aparecida en septiembre de 1920).

En el llamado a la definición de los universitarios, Solari no se privó de ensayar una interpelación insolente e irónica a sus lectores, que podría remitir a la que luego proponen las revistas de la vanguardia estética. En efecto, lejos de esos editoriales de Ideas que entre 1915 y 1917 subrayaban que los estudiantes debían conocerse más allá de sus diferencias y que el Ateneo reunía a una tribuna políticamente heterogénea, el primer número de Bases fue rematado con la siguiente advertencia: "Bases no es agencia de bombo mutuo ni refugio de serviles y mentecatos", y antes había advertido:

¿Ud. es un estudiante que, más que poseer un título, tiene interés por saber y capacitarse?

¿A Ud. más que ir a la moda o jugar a las carreras, le interesa el progreso del país y una más acertada orientación de la enseñanza argentina?

289 Ernesto Nelson, “Temas universitarios”, Bases, nº 2, 07/07/1919, p. 6. 
¿Es Ud. un joven libre a quien preocupan los problemas que la hora excepcional del mundo plantea a la República y se esfuerza por contribuir, como sabe y puede, a su más satisfactoria solución?

¿Ha llegado o quiere llegar a la dignidad de hombre, íntegro, consciente y capaz?

Lea entonces BASES, tribuna de la juventud estudiosa que se siente heredera de la liberal y democrática tradición argentina y anhela completar y cumplir las ideas $\mathrm{y}$ propósitos de nuestros más grandes hombres (Bases, $\mathrm{n}^{\mathrm{o}} 1,31 / 05 / 1919, \mathrm{p} .8$ ).

El número siguiente está casi exclusivamente dedicado a disputar el patriotismo propuesto por la Liga. Inaugurando la sección "El mandato de nuestros muertos", la primera página trascribe un fragmento de Esteban Echeverría en el que éste llama a defender la patria. Junto a ello un editorial anónimo declara:

Y nuestra conciencia de jóvenes estudiantes y de neófitos periodistas nos dicta la intransgredible ley, a la que es en verdad vano resistirse, de ser veraces y justos. [...] El momento es grave porque no son ingentes intereses materiales los que pueden perderse, sino porque es el espíritu mismo de nuestra raza, definido en el aliento heroico con que los padres de la patria fundaron sus instituciones. Y a este momento queremos acudir con este contingente de pensamiento, de difusión y de voluntad que significa BASES, que son las de Alberdi en esencia tanto como en potencia y en posibilidad lo son las de un suelo de futurismo constructivo y definitivamente reparador para la patria, cuyo nombre compran y venden los que por carecer de razón ponen en la balanza su dinero ("El deber", Bases, no 2, 07/07/1919, p. 1).

Ese deber también se invoca en la transcripción del manifiesto de la FUC y del de la FUA, y en la denuncia a la falta de libertad de prensa, entre otras notas. Hacia el final de ese número, Bases vuelve a realizar una audaz interpelación a la juventud universitaria, que desde entonces republica con algunas modificaciones:

Tribuna de la juventud, no quiere decir, precisamente, vaciadero de inactualidades, lacrimonías y decadentismos. [...] No hay lugar en esta tribuna para los jóvenes viejos con taras mortales del pasado muerto y de la literatura vacía, porque toda la plaza queremos que no sea demasiado exigua para la pujante juvenilia innovadora, renovadora, creadora, audaz, optimista, esforzada y altiva que necesita la patria para vivir cada nuevo día con un renovado Sol que alumbren sin tedio y sin fatalismo nuestra historia: de nuestros muertos, los huesos para tenernos en pie; el corazón y el cerebro queremos que sean nuestros. No nos escriban, pues, los que no sepan decir guapo y breve lo que piensen alto y sientan fuerte (“A los colaboradores”, no 2, 07/07/1919, p. 7).

A esa "pujante juvenilia" Bases la convoca a integrarse a la FUA (desde el tercer número aparece un recuadro anunciando la importancia de la organización estudiantil bajo esa Federación). Desplegando el tono sarcástico que recorre la mayoría de las denuncias de Bases, se lee en el sexto número: 
Queremos saber:

$1^{\mathrm{o}}$ ¿Por qué razón esa Federación, siguiendo el bello ejemplo dado por las de Córdoba, Santa Fe y La Plata, no se pronuncia contra la gran colecta?

$2^{\mathrm{o}}$ ¿Que motivos existen para que la Federación no haya realizado todavía ningún acto secundando a los maestros y ciudadanos que trabajan por salvar la instrucción pública argentina?

$3^{\circ}$ ¿Por qué, en el caso particular de Mendoza, los miembros de la Federación que fueron a esa provincia como delegados no informaron al pueblo?

$4^{\circ}$ ¿Por qué la Federación no asume una actitud más decidida y define posiciones en esta hora del país, no ya solamente por medio de declaraciones y manifiestos, sino con una activa y resuelta participación en todos aquellos movimientos que persigan fines de mejoramiento y reforma social? (“A la Federación Universitaria de Bs As", Bases, n 6, 15/11/1919, p. 3).

En octubre estalla la "Revolución Platense" y, mientras los Cuadernos les advertían a los huelguistas que lo importante era erradicar el materialismo positivista, Bases les pedía mayor audacia, esto es, que fueran implacables con los malos profesores: "Los muertos, a sus tumbas". ${ }^{290}$ Ese número difunde una advertencia que propone una interesante explicitación del pasaje realizado por el movimiento estudiantil desde una organización de carácter corporativo a otra de carácter político: "La Dirección de este periódico es una Dirección, y se solidariza absolutamente con todos los artículos firmados y sin firmar que publica, y no publica nada con lo que no se solidarice". ${ }^{291} \mathrm{El}$ número siguiente saluda la fundación del Centro Cultural Evolución de Rosario y reproduce la primera parte de su "valiente y oportuna" declaración de principios. Los jóvenes rosarinos -que al poco tiempo fundarían, con el grupo Insurrexit, una fracción de los estudiantes federados de Córdoba y los estudiantes revolucionarios de Santa Fe, una "Federación de Estudiantes Revolucionarios"- declaran:

1-Causas que determinaron nuestra unión

a) Tomando el ejemplo de la Juventud Universitaria de Córdoba, Buenos Aires y Santa Fe nos proponemos seguir su obra libertaria y crear en esta ciudad ambiente donde puedan germinar todas las ideas e iniciativas que implicaron una tendencia renovadora; ideas e iniciativas que apoyaremos y fomentaremos con todos nuestros medios.

b) La necesidad de apoyar a las clases proletarias en este movimiento universal de emancipación.

c) El deber moral en que nos vemos de oponer a las fuerzas reaccionarias organizadas del país (que con el pretexto del patriotismo obstaculizan el progreso económico e intelectual de las mismas clases proletarias) otra fuerza para contrarrestar su acción.

d) Los beneficios que pueden aportar en pro de la causa libertaria la unión de obreros y estudiantes.

La secretaria funciona en la calle España $n^{\circ} 763$, Rosario (Bases $n^{0} 7,15 / 01 / 1920$, p. 8).

Al igual que Clarín, Bases no publica ninguna nota que aborde sistemáticamente cuestiones

290 “Jubilaciones y pensiones. Actitud de los estudiantes platenses", Bases, n 6, p. 3.

291 Bases, n 6, p. 4. 
doctrinarias ni que se ocupe de las diferencias entre socialismo, anarquismo y maximalismo. Pero no puede evitar que algunas líneas deslicen discusiones doctrinarias. Bases $\mathrm{n}^{\circ} 7$ trascribe "La Internacional de los Estudiantes Socialistas. Carta abierta al ciudadano Henri Barbusse". Ésta había sido enviada a L'Humanité por el Comité Internacional de Estudiantes Socialistas, con sede en Ginebra, para apoyar la Internacional del Pensamiento y formar un frente de las izquierdas: los jóvenes se sumarían a un bureau conformado por los "Comités de la Internacional Obrera, de la Internacional Sindicalista, de la Internacional de Juventudes Socialistas y de la Internacional del Pensamiento": "Desarrollemos el sindicalismo -medio legal- en todas sus formas. Opongamos a la organización burguesa, carcomida y cada día más vacilante y débil, una organización socialista precisa y formidable, para que nada sea dejado al acaso el día en que el proletariado internacional alcance el Poder".

Más allá de sus claras simpatías con el socialismo bolchevique, Bases publica en sus primeros números algunas notas que separan la identidad estudiantil del anarquismo y del maximalismo. En efecto, la breve nota anónima "Reforma social y violencia", aparecida en el segundo número de Bases, le pide a la juventud universitaria que nutra su conciencia y su entendimiento de luz para no "identificar dos conceptos que con harta frecuencia se confunden en espíritus, que, por otra parte, parecen bastante cultivados: el concepto de reforma social y el concepto de violencia". Un pedido en el que resuena la acusación a las fracciones del anarquismo que justifican la propaganda por los hechos. Por otra parte, la nota de Nelson ya citada se aleja explícitamente de los maximalistas:

El insoportable aristócrata que todavía habla de "plebe" y de "populacho"; el apasionado comunista, poseído de las más radicales concepciones sobre la sociedad y el Estado; el sensualista y el místico; el diplomático sutil y bohemio ingenuo; el liberal intransigente y el reaccionario estrecho; el logrero y el apóstol; el hombre de vistas tolerantes y humanas, el espíritu pequeño y dogmático, que será más tarde nefasto en el hogar, en la cátedra o en el parlamento, todo sale de la universidad confundido, llevando cada cual incólume su instinto indeciso (Ernesto Nelson, "Temas universitarios", Bases, $\mathrm{n}^{\mathrm{o}} 6,15 / 11 / 1919$, p. 3).

A pesar de esa distancia con los comunistas, los números siguientes explicitan las simpatías hacia la Revolución Rusa. En la portada del cuarto número se lee “¡Viva Rusia!”, una nota breve anónima que enlaza el sentimiento patriótico argentino con el de "un pueblo que de la libertad hizo su condición, de la generosidad su culto y de la justicia su idea”. Ese número también publica en recuadro "La guerra", nota que propone definiciones del nacionalismo, el pariotismo y la soberanía de los pueblos que se inscriben en la posición internacionalista que sostenía el grupo de del Valle Iberlucea. Por su parte, el sexto número tiene en su tapa otra breve nota anónima que elogia y apoya al pueblo ruso; y el octavo y último saluda, con una nota de tapa, a "El triunfo bolcheviki en Europa 
y en Asia", específicamente a través de un "servicio especial" informa del avance de los maximalistas en Varsovia, Berlín, Budapest, Roma, Londres y París.

Otro núcleo que recorre las páginas de Bases es la renovación de los temas de estudio. Además de publicar algunas notas que cuestionan la utilidad de los exámenes, la sección "Cómo queremos aprender" publica artículos que reclaman teorías modernas que permitan entender la actualidad "sin el prefacio erudito de doctrinas muertas" y que se aboquen "al estudio de la realidad del trabajo como fuente del capital". En ese sentido, a pesar de que no se hagan referencia a la disputa entre positivismo y antipositivismo, esas notas y las que aparecen en la sección "Hechología" referidas al motor, las máquinas y el capital así como al convencimiento de que "la verdad no es patriótica sino científica" inscriben a Bases -y sobre todo a sus últimos números- en un una defensa del economicismo marxista -tan criticado por la reacción antipositivista que ganaba las aulas de la FFyL-.

Luego de su octavo número (fechado en junio de 1920), la edición de Bases fue interrumpida: los problemas con los corresponsales y paqueteros -anunciados en los últimos números- ocasionaban, sin duda, demasiados gastos al joven director. Pero seguramente también pesó otro motivo: hacia mediados de 1920 había comenzado a reunirse el grupo Insurrexit y la prédica de Solari podía tornarse más eficaz si se sumaba, junto a sus colaboradores, a esos jóvenes que apostaba a una alianza obrero-estudiantil y adhería decididamente a la Revolución Rusa.

\section{Insurrexit y Hoy, o las primeras tensiones estudiantiles entre comunistas y socialistas}

En septiembre de 1920 aparecía el primer número de Insurrexit. Esta "revista universitaria" -según declaraba su subtítulo- contaba con veinte páginas aproximadamente y alcanzó las doce entregas (la última fechada en noviembre de 1921). Sin consignar un director, se presentaba como el producto del grupo estudiantil y "esencialmente antiparlamentario" Insurrexit y anunciaba en cada uno de sus retiros de tapa la organización de ciclos de conferencias para estudiantes y obreros.

Como la Ariel porteña e Ideas, Insurrexit tuvo tamaño pequeño y, al igual que aquellas, sus tapas estuvieron ilustrada por un grabado con el rostro de un joven de reminiscencias grecolatinas. A pesar de contar con un grabado y destinar las tapas a su reproducción, el editorial inaugural declaraba que se trata de una revista "pobre". Retomando tácitamente la clasificación de las revistas que había realizado Brumana en el primer número de Bases, declaraba la nueva publicación: 
Insurrexit es pobre. Tu mismo lo ves, apenas está decentita con las pilchas que lleva. "Hay un gran constraste entre la pobreza que lleva y la riqueza que es ella misma", como en el cuento de Barbusse.

Nos apenaría verla mal vestida entre sus "colegas" ticos... No quisieramos en verdad para ella más que un poco más de abrigo. No sea cosa... Hace frío, todavía, amigo.

¡Si se nos muriera en la primer saluda!... (Insurrexit, $\mathrm{n}^{\mathrm{o}} 1,08 / 11 / 1920, \mathrm{p} .1$ ).

A diferencia de las revistas estudiantiles que hasta entonces habían aparecido en el Río de la Plata, estas nuevas "hojitas pobres" exponían como su riqueza notas doctrinarias de figuras del pensamiento revolucionario mundial, reseñas de los libros de Barbusse así como notas suyas, pero también notas polémicas que informaban sobre la organización socialista local, el movimiento estudiantil y el obrero. Muchas de esas notas no llevaron firma, otras pertenecían a jóvenes porteños que en los años próximos se incorporarían al PC.

Entre los colaboradores de la generación anterior, se destacó la colaboración de Barcos, pues, como en 1914, le ofrecía a los jóvenes una nota juvenilista en la que los alentaba a definirse políticamente. Comienza anhelando Barcos en la sexta entrega de Insurrexit: “ $¡ A h$, si yo pudiera deslizar cuatro reflexiones al oído del grupo jóven de rimadores que gastan tan deplorablemente su tiempo y su fósforo cerebral en cantar lo que todos han cantado". Y, a modo de consejo, el director de Cuasimodo explicitaba el programa estético-político inscrito en las izquierdas revolucionarias que debería seguir la juventud. ${ }^{292}$

Como ha señalado Tarcus (2004), la "hermana mayor" de Insurrexit fue Cuasimodo, la que por entonces se refundaba en Buenos Aires, bajo la misma dirección conjunta de Barcos y Canale. Tanto Cuasimodo como Insurrexit publicitaron en su retiro de tapa la suscripción conjunta de esas revistas. Pero Insurrexit tuvo también "hermanas menores" a las que se unió por la común definición "esencialmente antiparlamentaria". En 1920 La Gaceta Universitaria de Córdoba quedaba a cargo de Lazarte y la nueva dirección saludaba y publicitaba a Insurrexit. Lo mismo hacía el Boletín del Centro de Estudiantes de Ciencias de la Educación de La Plata. Por su parte, la poco recordada Vía Libre. Publicación mensual de crítica social de Buenos Aires -de la que aparecieron treinta y seis números entre octubre de 1919 y septiembre de 1922 bajo la dirección del anarcobolchevique Santiago Locascio- ${ }^{293}$ se hermanó con Insurrexit al publicar, además de reflexiones de los mismos referentes doctrinarios, algunos manifiestos de los jóvenes porteños.

En enero de 1921 el PS organizaba en Bahía Blanca su IV Congreso Extraordinario. En medio de intensas discusiones, ganaba la fracción que se oponía a la adhesión a la III Internacional Socialista. Con esta definición se sumaba al campo de las izquierdas argentinas una nueva tensión

\footnotetext{
${ }^{292}$ Sobre el grupo Insurrexit, véase Tarcus (1997 y 2004). Para una caracterización del tipo de interpelación que ejerce durante la década del veinte y del treinta el comunismo entre los intelectuales argentinos, véase Petra (2013).

${ }^{293}$ La detallada investigación de Doeswijk (2013) es la única que ofrece una caracterización y análisis de la intervención de esta revista.
} 
que también alcanzaría al naciente movimiento de la Reforma: quienes simpatizaban con el socialismo bolchevique debían optar entre permanecer en un partido organizado y con presencia en el movimiento obrero pero que se declaraba partidario de un acceso gradual al socialismo y no reconocía los lineamientos propuestos desde Rusia, o bien participar de la formación de un nuevo partido que reivindicaba la Revolución Rusa pero que debía construir su presencia en el movimiento obrero y definir quiénes eran sus referentes locales.

Como mencionamos, luego de ese Congreso, Solari y Brumana no volvieron a publicar colaboraciones en Insurrexit. La explicación se encuentra en el noveno número de Insurrexit (fechado en mayo de 1921). Allí se publica “Otro. Juan Antonio Solari”, una nota a través de la que el grupo critica a Solari por ser "uno más que se despeña", esto es, que tiene una prosa revolucionaria pero que permanece en las filas del "reformista" PS. Solari no era el único que optaba por ese camino, del Valle Iberlucea, Moreau, Giusti y varios miembros del grupo Claridad permanecían en el PS -otros como Barreiro ingresarían por un tiempo en el PSI, entonces ya renombrado como PC-.

Un mes después de que Insurrexit criticara a Solari, éste iniciaba un nuevo y breve proyecto revisteril: fundaba Hoy, una revista que tuvo un formato similar al de Bases -e incluso mantuvo la sección “Hechología”- y de la que sólo aparecieron dos números. ${ }^{294}$

En una de sus notas de tapa, el primer número de Hoy ridiculizaba implícitamente al grupo Insurrexit al recordar la actitud de "papagayos declamadores de lecciones mal aprendidas" que propiciaban quienes adherían a las 21 condiciones para incorporarse a la III Internacional. Y en el cuerpo del número Solari presentaba su respuesta irónica a las críticas burlonas que había recibido de Insurrexit. Bajo el título "Industrias nacionales. 'En pleno pantano'....”, el director aclaraba que nunca se había incorporado oficialmente al grupo Insurrexit y pedía a esos "comunistas probados" que no olvidaran destinarle un puesto el día que realizaran "la Revolución Social”. La ironía continuaba en la nota siguiente: allí se reproducía una serie de saludos que habría enviado "el gran Barbusa" a esa prensa que busca la "iluminación de Clarté", iluminación que -como veremos en el capítulo octavo- no dejaran de buscar las revistas estudiantiles rioplatenses.

Las ridiculización de la opción seguida por Insurrexit que realizaba Solari no implicaba la renuncia de éste al socialismo. En la última línea de su primer número, Hoy aclaraba su posición en el campo de la izquierda local: "Luchamos, amigo, por contribuir al triunfo de la justicia social; y

\footnotetext{
${ }^{294}$ En 1924 aparecería otra revista estudiantil, aparentemente no relacionada con la de Solari, que elegía el nombre de "Bases". Su director fue Pedro Verde Tello (1896-1987), un estudiante platense que como Solari sería un importante intelectual del PS pero que en la década del veinte, al igual que Barreiro, participó en el fracción tercerista del PS, ingresó en el PC y luego reingresó en el PS. Verde Tello quedaba a cargo del periódico estudiantil de la Facultad de Derecho de La Plata y lo rebautizaba Bases. Según veremos, en 1925 Verde Tello fue secretario de redacción de Sagitario. Por su parte, Solari fundaría en las décadas siguientes una prolífica colección editorial bautizada Bases y dedicada a la difusión de autores progresistas argentinos. Para una reconstrucción del itinerario político-intelectual de Verde Tello, véase Tarcus (2007a) y Graciano (2008).
} 
combatimos por igual la democracia burguesa y el revolucionarismo de opereta, tan criollo". El siguiente y último número aparecía en julio de 1921. Allí Solari republicaba "Negaos", el citado texto que se dirigía a los estudiantes para que no se sumaran al nacionalismo de la Liga Patriótica. Brumana publicaba "Este era un siglo..." y se anunciaba que la colaboradora pronunciaría una conferencia sobre sus novelas a beneficio de Hoy en el cine-teatro Roca, de Avellaneda, donde "se exhibirán, además, interesantes películas de tendencia social y se recitarán poesías. Amenizará el acto una excelente orquesta".

Al igual que en Bases, aparecen en Hoy varias notas críticas del nacionalismo de la Liga Patriótica, pero mientras la primera alentaba a los estudiantes a que se incorporaran a la FUA, Hoy ironizaba en "Y la Federación Universitaria Argentina" sobre la poca combatividad que tenía una FUA -entonces dirigida por Araujo-. Ese número también informaba que Solari comenzaba a ser el pro-secretario del Ateneo Popular (fundado en 1907 por Del Valle Iberlucea) y de la revista Humanidad Nueva, órgano del Ateneo hasta entonces dirigido por Moreau.

El mismo mes en que aparecía el segundo y último número de Hoy, Vía Libre elogiaba y difundía, bajo el título "Documentos para la historia", una declaración de principios del "Grupo Universitario Insurrexit de Buenos Aires”. Tanto Insurrexit como Vía libre habían criticado la apuesta del grupo Claridad de radicalizar la línea política del PS. En efecto, poco después de fundarse el grupo argentino, el director de Vía libre firmaba una nota en la que reconocía en el Clarté parisino "un grupo de lucha y de avance. Sus ideas son revolucionarias y sus declaraciones son concretas y uniformes. Están con las últimas aspiraciones del pueblo obrero internacional, están con la Revolución Rusa y con todas las revoluciones por venir, que tengan el carácter comunista o simplemente de imposición obrera”. Pero a continuación descartaba cualquier posibilidad de algo similar en nuestro país, pues "la generación intelectual argentina no aporta ningún acervo provechoso para las generaciones futuras. Es una generación abúlica”. Y Loscacio aprovechaba para formular nuevamente el juicio obrerista y descalificador de una posible tarea intelectual revolucionaria -sumamente frecuente en la publicación-: "sólo la juventud puede dar algo de sí en un mañana venturoso. Los obreros, solos, podrán ir más lejos que adonde desean ir estos señores de pluma, huecos de ideas y enclenques por natural degeneración". 295

Unos números después, Vía Libre publicaba su reseña del primer número de la revista Claridad que dirigió José Barreiro. Sostiene la publicación anarco-bolchevique sobre el grupo en el que alentaba Ingenieros y en el que participaba Bermann y otros arielistas cientificistas:

Desde hace unos meses los socialistas buscan abrirse cancha entre el pueblo con manifestaciones maximalistas, después de haber negado todo a los verdaderos amigos de la Revolución.

\footnotetext{
${ }^{295}$ Santiago Loscacio, "Lo que nos sugiere la organización del grupo Claridad”, Vía Libre, no 3, diciembre de 1919
} 
Hoy se presentan con una revista netamente revolucionaria con firmas más o menos cotizables.

Entendemos que no seremos sólo nosotros los que haremos la revolución. Todos los elementos contribuirán a ella, pero no podemos dejar de hacer resaltar la falsa postura de estos señores que después de calumniar, infamar y vituperar a los revolucionarios, se presentan haciendo alarde de un revolucionarismo maquiavélico y loyolesco.

No. No les creemos ni les creeremos nunca (S. L. "Claridad. Revista socialista. Número 1", Vía Libre, n $\left.{ }^{\circ} 5,02 / 02 / 1920\right)$.

En las páginas de Insurrexit, la nota anónima "Alrededor de un congreso" formulaba una descalificación similar a la posibilidad de mantener una postura revolucionaria dentro del PS que buscaba Claridad y en la que insistiría Solari luego del IV Congreso Extraordinario. Al igual que Vía Libre, Insurrexit le recordaba al grupo Claridad que ya existía en el país una sección de la Internacional Comunista "en cuyo seno sólo es concebible que sumen sus energías". ${ }^{296}$ La común intención de los grupos editoriales de Insurrexit y Vía libre -también registrada en Clarín hasta su cierre en marzo de 1920- de participar de un frente comunista argentino que, en lugar de disolver los grupos intelectuales existentes, otorgara a los grupos cierta autonomía, se advierte en la publicación en Vía libre de "Psicología de la patota", nota en la que Monner Sans critica a los "patoteros natos" que sólo actúan cuando se asocian por "móviles bajos y mezquinos". Pero la apuesta por ese frente es notoria sobre todo en la difusión que realiza Vía Libre de la que probablemente fue la última iniciativa del grupo Insurrexit. Éste ponía a circular un manifiesto que proponía:

Que el orden social establecido debe desaparecer y dejar lugar a un orden nuevo fundado sobre los principios absolutos del Comunismo Internacional;

Que el establecimiento e este orden nuevo no puede venir por una serie sucesiva de reformas sino por la destrucción radical del sistema capitalista; Que el pasaje del orden actual al orden nuevo no puede provisoriamente ser asegurado sino por la dictadura de la clase hasta hoy explotada y expoliada;

Para preparar y realizar la Revolución Social es preciso dar a cada hombre la conciencia de sus derechos y de sus responsabilidades de clase. "El Grupo Universitario Insurrexit" ejerce su acción por medio de la conferencia, del libro, del folleto, del diario, etc.

El "Grupo Universitario Insurrexit" no pertenece como entidad a ningún partido político ("Documentos para la historia", Vía Libre, n’ 23, julio de 1921).

Seguramente, varios de los jóvenes que participaban de las conferencias obrero-estudiantiles dispuestas por el grupo Insurrexit, así como de las reuniones en las que se decidía el armado de la revista, asistían a las reuniones del PC o bien apoyaban y participaban de sus iniciativas. Pero la mayoría de los miembros de Insurrexit, al igual que Vía Libre, optarían por no participar de las álgidas discusiones que terminarían por definir a fines de la década del veinte quiénes eran los líderes del PC argentino reconocidos por el bureau ruso.

\footnotetext{
296 S/d, “Alrededor de un congreso", Insurrexit, no 4, febrero de 1921, p. 4.
} 


\section{La apuesta por una federación estudiantil revolucionaria}

En agosto de 1920, la FUA por primera vez ponía a circular una publicación periódica. El Boletín de la Federación Universitaria Argentina anunció una periodicidad trimestral, comenzó siendo dirigido por Muñoz Montoro y contó al menos con cuatro números y un suplemento. Este suplemento estaba fechado en septiembre de 1920 y reproducía las "Bases de organización universitaria votadas por el primer Congreso Nacional de Estudiantes Universitarios". ${ }^{297}$

Los números del Boletín son interesantes porque, en simultaneidad con Bases, despliegan un claro intento de radicalizar a los estudiantes federados, esto es, de extender sus preocupaciones más allá de las cuestiones gremiales hacia la agenda emancipatoria de las izquierdas y ello en un momento en que varios jóvenes universitarios participaban de la Liga Patriótica y la FUBA se había separado de la FUA en disconformidad con el perfil izquierdista. En tanto órgano de la federación que representaba a todos los estudiantes argentinos, el Boletín no podía evitar la publicación de notas que propusieran una identidad de la Reforma centrada en la exclusiva modificación de las casas de estudio. De todos modos, a través de los artículos que seleccionó -entre los que se encuentran "La docencia emancipadora" de Taborda, "La universidad y el espíritu libre" de Roca, “¿Qué es la revolución?” de Goldschmidt y “Algunas consideraciones sobre el problema educacional" de Palcos-, es claro que los editores del Boletín buscaron conectar el movimiento estudiantil con la reforma social y los obreros organizados. Además, allí se publicó una resolución en la que la FUA se pronunciaba contra el imperialismo mundial, de la que, gracias a la aclaración de del Mazo (1927, t.VI: 33), sabemos que fue votada por unanimidad por los asistentes a la sesión extraordinaria y que fue redactada en lo fundamental por Palcos.

En principio, para dejar en claro que la Reforma no comenzaba en 1919, como proponía el grupo nacionalista de Korn Villafañe, sino en 1918, los editores transcribieron en el retiro de tapa del primer número un largo fragmento del "Manifiesto liminar", al que presentaban como el “primer manifiesto de la Reforma Universitaria: 'La juventud argentina de Córdoba a los hombres libres de Sud América', Junio de 1918”. Asimismo, a través de sus tres secciones -“Cuestiones universitarias", "Temas generales" y "Oficial"-, intentaron conciliar la difusión de resoluciones universitarias -que no podían faltar en una publicación de ese tipo- con noticias estudiantiles nacionales y latinoamericanas y con ensayos que subrayaban la importancia de vincular el movimiento estudiantil no sólo a la democratización de la universidad y la renovación de los

\footnotetext{
${ }^{297}$ El primer número apareció en agosto de 1920, el segundo en noviembre de ese año, el tercero en febrero de $1921 \mathrm{y}$ un cuarto a fines del año siguiente. Éste abarcaba el "periodo 1921-22”. El primer número consignaba a los jóvenes como miembros de la dirección directiva de la FUA: presidente, Gabriel del Mazo (representando a Tucumán); secretaría general, Roberto E. Garzoni (Santa Fe); vocales: Luis H. Sommariva (La Plata), Alberto Palcos (Córdoba); Alejandro Terrera (Tucumán); Edgar Latorre Lelong (La Plata); Francisco Villaflor (Córdoba); electos: Eduardo Araujo (Buenos Aires); Eduardo Ordoñez (Buenos Aires); una vacante (Santa Fe).
} 
programas, sino también a la reforma educativa que por entonces impulsaba Lunacharsky en Rusia, a la revisión de la democracia parlamentaria y a las luchas "clasistas" que entonces mantenía el movimiento obrero. ${ }^{298}$

Si bien eran pocos los representantes de la FUA que, como Palcos y Bermann, podían ofrecer colaboraciones en las que se interpretaran los conflictos obreros y estudiantiles bajo el signo de la lucha de clases, los redactores del Boletín buscaron artículos de estudiantes y figuras extranjeras que también ofrecieran esa interpretación. Entre ellos se encontraron la nota "La Federación de Estudiantes ante la Revolución Rusa", firmada por el líder estudiantil chileno Alfredo Demaria, y la proclama de la Revolución Rusa como el nuevo orden económico mundial que realizó el profesor Goldschmidt bajo el título “¿Qué es la revolución?”.

A fines de 1920, la Sociedad Científica organizaba el Congreso Universitario, al que era invitada la FUA. El rechazo a esa invitación la ofrecía a la FUA una nueva oportunidad de explicitar el lugar social que debían asumir los estudiantes. En su condición de referente reformistas, Palacios ponía a circular una carta pública que cuestionaba el congreso porque no habían sido invitadas las "fuerzas vivas" de la industria, los obreros. Y la FUA difundía en su Boletín y en numerosas revistas un manifiesto que señalaba a la denuncia de Palacios como un gesto ejemplarizante y rechazaba públicamente la invitación. ${ }^{299}$

Este intento de radicalizar la FUA convergía con la prédica reformista que venía realizando La Gaceta Universitaria de Córdoba y la que emprendería el CE de Derecho de Córdoba, el que también en agosto de 1920 fundó una publicación mensual, la Revista de Derecho y Ciencias Sociales del Centro de Estudiantes de Derecho (1920-1922). ${ }^{300}$ Bajo la dirección del joven Oscar R. Orgaz, la secretaría de redacción de Luis Alberto Despontin y la administración de Ricardo Vizcaya, allí se publicaron no sólo apuntes de cátedra y noticias estudiantiles, sino también artículos sobre marxismo y sobre los debates político-económicos que éste despertaba. A su vez, a través de notas como la de Astrada sobre "Nuestro Kulturkampf" -sobre la que volveremos en el capítulo siguiente-, se asociaba la Reforma a una dimensión política que excedía la reforma de los estatutos para ligarse a una universidad científica y social.

La iniciativa de la FUA además rivalizó con una efímera Federación de Estudiantes Revolucionarios, que no tendría su eje en Buenos Aires sino en Rosario. El número de septiembre-

\footnotetext{
${ }^{298}$ Entre los temas generales se encontraron los problemas sociales y el telegrama enviado por la FUA a la Federación de Estudiantes de Chile en apoyo a su campaña contra la posible guerra con Perú y en repudio al ataque a su local que acababa de sufrir. Sobre el movimiento estudiantil chileno, véase la citada investigación de Valle Moraga (2007).

299 Puede consultarse una reproducción en Del Mazo (1927, t.V: 116).

${ }^{300} \mathrm{Su}$ número siguiente apareció casi un año después con nuevo director y un nuevo inicio de la numeración. Los próximos números tendieron a cumplir la periodicidad mensual, aunque -acorde con los tiempos estudiantiles- al comenzar el periodo de exámenes y durante el receso escolar no se publicaron números. Despontin dirigió los números de 1921 y Enrique Velasco los aparecidos durante 1922. En septiembre 1923 el Centro comenzó a editar otra publicación, la Revista del Centro de Estudiantes de Derecho de Córdoba, cuyo primer director fue Lisandro González Vocos.
} 
octubre de 1920 de Ariel de Montevideo trascribía bajo el título "Manifiesto revolucionario" y el subtítulo "a los estudiosos y a los hombres nuevos" un texto redactado en Rosario y firmado por los estudiantes Juan Lazarte, José Miguel Lurá, Luis di Filippo, A. Navarro, Francisco Bendicente, R. Parajón Ortiz, Ruíz Gómez. Desde una impronta anarquista, se proponía allí una estrecha vinculación de los estudiantes con las luchas obreras. Los mismos jóvenes ponían a circular una declaración de principios de la Federación de Estudiantes Revolucionarios, que Ariel saludó y publicó en la página siguiente.

Lazarte recuerda que en esa federación se reunieron cuatro grupos: la FUC, el grupo Insurrexit de Buenos Aires, el Centro Evolución de Rosario y el Centro de Estudiantes Revolucionarios de Santa Fe. Y precisa:

No pudo avanzar ni consolidarse. La reacción y la segregación de sus componentes la liquida, no llegando a reunirse el congreso que se había preparado en Buenos Aires. Los componentes de este sector estudiantil tienen acción en la Semana de Enero, hasta la gran Huelga Revolucionaria campesina y proletaria de la provincia de Santa Fe que llevara a la acción más de 100 gremios, tiene relación también con los conatos revolucionarios de un sector de la Alianza Libertaria (Lazarte, 1935: 34).

Disuelta esa Federación, el número de mediados de septiembre de 1921 de La Gaceta Universitaria de Córdoba se quejaba de la indecisión política de la conducción vigente de la FUA, a cargo de Araujo, y llamaba a convertir el Comité de Agitación Liberal que componían grupos estudiantiles y obreros en la base de un sindicato central de obreros y estudiantes. ${ }^{301}$ Ese número también informaba que se había constituido "en la Casa del Estudiante una comisión formada por los compañeros Alfredo Morcillo, Juan Lazarte y Edmundo Tolosa a fin de hacer todo lo que sea necesario para allegar socorros a los trabajadores que en Rusia son víctimas de la miseria y del hambre". Su contratapa publicitaba la existencia de un Comité local Pro-Hambrientos de Rusia. Confirmando el vínculo con los grupos obreros que entonces impulsaba la FUC, se aclaraba allí que "se ha invitado igualmente a la F. O. Provincial y a la F. O. Local, y centros culturales de esta ciudad a fin de llevar una acción conjunta que pueda responde a propósitos tan plausibles". 302

Al poco tiempo, se producía en la FUC un debate sobre el alcance de su acción estudiantil similar al que había ocurrido en la FUBA en 1919, pero su resolución era la inversa. En efecto, aquella discutió su condición de "institución estrictamente gremial” y la pertinencia de que su

\footnotetext{
301 "Necesidad urgente de un Congreso Universitario" y "Sindicalización de estudiantes y obreros", La Gaceta Universitaria de Córdoba, p. 2.

${ }^{302}$ La Gaceta Universitaria, 15/09/1921. Los Comité Pro-Hambrientos eran alentados por la III Internacional para recolectar víveres pero también para extender el apoyo a Rusia. En Buenos Aires se dispusieron varios, entre ellos a comienzos de 1922 por la iniciativa de la Cooperativa Artística del PC y el antiguo arielista Simón Scheimberg, se organizó una exposición artística a beneficio de los hambrientos de Rusia (Lucena, 2007). Meses después, la campaña se reactivaba un manifiesto que firmaba Goldschmidt y una nueva campaña bajo su coordinación. Además de estudiante de derecho, Edmundo Tolosa era poeta, maestro y militante del Partido Socialista. Durante 1921 dirigió la FUC y en diciembre de ese año sería elegido constituyente provincial (Dujovne, 2004).
} 
acción no sea de "estricto carácter universitario y educacional". Ante ello la Junta Directiva de la FUC decidió que propondría en la próxima asamblea estudiantil

que en lo sucesivo nuestro órgano de publicidad sea una escuela de estudio de libérrima discusión de los problemas colectivos, estudios y discusión que por sus caracteres de seriedad y de ilustración científica, puedan servir con eficacia a los estudiantes y al proletariado, al cual nos sentimos vinculados por más de un recuerdo de confraternización y de gratitud y por más de un objetivo común en la vida de nuestro propio ambiente social ("El conflicto de la F. U.", Revista de Derecho y Ciencias Sociales del Centro de Estudiantes de Derecho de Córdoba, nº 6, julio de 1921, p. 98).

La asamblea aprobó una resolución que, entre otras cuestiones, reconocía "la justicia que asiste a la clase obrera en su lucha contra la clase capitalista" y le otorgaba a La Gaceta Universitaria "libertad completa para dar cabida en sus columnas a toda publicación firmada de cualquier tendencia ideológica moderna". ${ }^{303}$ Pero esa identidad estudiantil izquierdista perdía su plataforma nacional pues la FUA entraba en conflicto y no sólo no lograba cumplir con el compromiso de organizar el Segundo Congreso Internacional de Estudiantes -que había tomado en el primero, desarrollado en México- sino que además hasta fines de la década no lograba congregarse.

Como un modo de recuperar una plataforma nacional, a fines de 1921 Lazarte alienta junto a otros jóvenes de un proyecto editorial libertario. El número veintiuno de Cuasimodo anuncia bajo el título "Una buena iniciativa" que se había conformado en Rosario un grupo encargado de fundar una revista y una editorial "que contribuyan al enriquecimiento de la cultura libertaria entre los elementos estudiosos del país". José Torralvo en Santa Fe (de quien ese número publica una fuerte crítica cientificista contra la filosofía "literaturizante" de Eugenio d'Ors), Juan Lazarte en Córdoba, Julio B. Barcos en Buenos Aires y Luis Di Filippo en Rosario. ${ }^{304}$ Por entonces, Di Filippo seguramente colaboraba en el armado del nuevo "periódico quincenal" Tribuna universitaria. Órgano de la Federación Universitaria de Rosario (1921-1922), del que se publicaron, al menos, once números, de cuatro páginas y formato tabloide.

Más allá de esas iniciativas, al poco tiempo no quedaban en Buenos Aires periódicos que como Clarín, Bases e Insurrexit llamaran a los estudiantes a una unión revolucionaria con los obreros y que también ese politizante Boletín de la Federación Universitaria Argentina dejaba de editarse.

\section{El cierre del ciclo estudiantil revolucionario}

En sus memorias, el intelectual nacionalista Juan Carulla, quien -como mencionamos- en su juventud había sido anarquista y había participado en el movimiento reformista, refiere sobre el tipo

303 "El conflicto de la F. U.", Revista de Derecho y Ciencias Sociales del Centro de Estudiantes de Derecho de Córdoba, nº 6, julio de 1921, p. 100.

304 "Una buena iniciativa", Cuasimodo, no 21, diciembre de 1921, p. 23. 
de iniciativas que analizamos en el presente capítulo, que el bolcheviquismo

fue una fiebre, una llamarada que lo tiñó todo de rojo, especialmente los grandes centros urbanos, cuyas Universidades, cuya juventud intelectual, cuyos centros de cultura, cuyos gremios, cuyas masas, en fin, se dejaron contaminar casi instantáneamente por el virus maximalista. [...] salvo excepciones, nuestros intelectuales, aquellos que habíamos erigido en guías de la juventud, callaban, y, muchas veces, transaban, vencidos y aun convencidos por la presión del comunismo agresivo y desenfadado (Carulla, 1964: 214)

A fines de 1922, esa "fiebre" no había pasado, pero quedaba muy poco de las iniciativas estudiantiles dirigidas a coordinar actividades conjuntas con los obreros y a editar revistas que fomentaran esa coordinación. En ello convergían dos rasgos de la coyuntura local: el gobierno de Alvear iniciaba un periodo de prosperidad económica ante el que disminuían las protestas obreras y los jóvenes universitarios e intelectuales ya no tenían un movimiento obrero que protagonizaba intensas jornadas de lucha al que saludar y orientar. Ninguna de las revistas porteñas que analizamos en este capítulo pervivieron más allá de 1922. Pero si por entonces dejaba de registrarse ese entusiasmo por construir un periodismo político estudiantil y grupos estudiantiles "revolucionarios", el estudiante como una figura intelectual con una relación necesaria con los problemas sociales ya había alcanzado una configuración persistente. Como veremos en los capítulos siguientes, esa figura del estudiante adoptaría nuevas formas pero no se disolvería. Es que figuras como Ingenieros y Barcos -quien desde hacía más de una década se preocupaban por la pedagogía de los obreros y la orientación de la universidad y sus asistentes-, así como jóvenes universitarios -que habían intervenido por primera vez en cuestiones político-culturales en el marco del estallido de la Reforma-, seguirán diseñando plataformas de intervención político-cultural pero probarán otras vías para relacionar el campo intelectual con el campo político.

Para finalizar este capítulo, recordemos que la historiografía sobre la Reforma ha tendido a mostrar que el movimiento estudiantil argentino no necesitó asumir posiciones y prácticas tan radicalizadas como el peruano porque contó con la empatía del gobierno de Yrigoyen (Candelari y Funes, 1997; Portantiero, 1978). Si bien es indudable que el yrigoyenismo fue sumamente permeable a la democratización de la universidad, en el presente capítulo nos propusimos mostrar que, desde 1919, aparecieron varios grupos estudiantiles -minoritarios pero sumamente activos- que condicionaron esa democratización a una revolución socialista y desde esa convicción trazaron intensos lazos con el movimiento obrero organizado.

De otro modo, esa convicción estuvo en el centro de dos nuevas publicaciones fundadas en 1923: el boletín Renovación que por iniciativa de Ingenieros dirigió Gabriel Moreau y Córdoba, “decenario de Crítica Social y Universitaria” a cargo de Julio Acosta Olmos. Esta revista cordobesa 
contó con varias colaboraciones de quien luego fue el principal reivindicador de la "minoría revolucionaria", Juan Lazarte. En una de esas notas Lazarte denunció las excusas puestas por la policía para allanar las casas de los militantes de izquierda y violar las leyes sociales, en otra criticó el pesimismo de teoría de las revoluciones de Spengler y de Ortega y Gasset. ${ }^{305}$ Asimismo, en 1925 el exiliado peruano en Buenos Aires Oscar Herrera publicó en Córdoba el manifiesto "Formemos un Frente Único de la Justicia”, uno de los primeros llamados a formar la Alianza Popular Revolucionaria Antiimperialista (APRA), cuando ésta se proponía como una estructura latinoamericana y no como un partido político peruano. ${ }^{306}$

Por otra parte, en 1923 aparecía en Buenos Aires el primer número de Inicial y en La Plata el de Valoraciones. Dos revistas que, como veremos en el último capítulo, apostaban a la politización del movimiento estudiantil pero, a diferencia de las estudiadas en el presente capítulo, desplazaban la afinidad con el movimiento obrero y el sentimiento de aceleración de los tiempos revolucionarios que recorría a Clarín, Ariel, Bases e Insurrexit.

\footnotetext{
${ }^{305}$ Juan Lazarte, "Valor ético de los once evadidos", Córdoba, no 8, diciembre de 1923; "Relativismo y Revolución", Córdoba, $\mathrm{n}^{\circ} 12$ y 13, 30 de octubre y 10 de noviembre de 1923.

${ }^{306}$ Veremos en el capítulo séptimo que en 1927 este futuro líder aprista formaba la célula porteña del APRA, al tiempo que mantenía una cálida correspondencia con Mariátegui a través de la que coordinaba la distribución argentina de la revista Amauta.
} 


\title{
CAPÍTULO 7. Fragmentos de la construcción de una universidad científica y social (1918-1923)
}

\author{
La Universidad, si ha de cumplir la misión \\ que le corresponde, tiene que difundir su \\ pensamiento y su obra en el organismo social \\ de que forma parte y del cual ella es la más \\ elevada expresión cultural; al mismo tiempo \\ que en su seno deben tener eco todas las \\ preocupaciones sociales, todos los problemas \\ que atañen al destino de la Humanidad. \\ Carlos Astrada, "Nuestro Kulturkampf", 1922.
}

Al calor de las actividades y la identidad estudiantil que propusieron los grupos y revistas analizados en el capítulo anterior, se registró en las universidades argentinas un proceso de democratización institucional y de renovación de la planta docente, de alcances muy diversos en las cinco universidades que existían entonces en la Argentina.

La UNC, y sobre todo su Facultad de Derecho y Ciencias Sociales, fue la que entre 1918 y 1923 más avanzó en la renovación de su perfil, sobre todo a través del ingreso de nuevos profesores. En 1922, uno de los miembros de Córdoba Libre! y partícipe de esa renovación, Arturo Orgaz, declaraba: “desde largos años -años en que el espíritu argentino fue un simple acueducto del desagüe cultural europeo- hasta el año 18, la Universidad fue, apenas, para la ciencia un 'flatus vocis' que dijeran los escolásticos y sólo el supersticioso respeto que infunde una fecha -1614-".307 Ante ello el desafío de los reformistas era la construcción de esa universidad científica y social que también sugiere el epígrafe del capítulo.

Hacia 1919 y a través de Barros, la UNC contactó a numerosas figuras europeas, pero sólo tres profesores fueron los que arribaron a Córdoba financiados por la universidad: el filósofo catalán Eugenio d'Ors, el fisiólogo judeoalemán Georg Nicolai y el economista, también judeoalemán, Alfons Goldschmidt. Estos intelectuales, conocidos por sus posiciones izquierdistas, dictaron cursos regulares en la UNC, al tiempo que viajaron por el país participando de charlas y actos organizados por grupos estudiantiles y ofrecieron sus artículos a las revistas de esos grupos. Es que la presencia de esos profesores involucraba no sólo la

307

Arturo Orgaz, "Lo que fue, lo que es y lo que debe ser nuestra facultad de derecho", Revista de la Universidad Nacional de Córdoba, no 8-9-10, 1922, p. 15. 
difusión especializada de las últimas teorías filosóficas, fisiológicas y económicas, sino también el esbozo de un "maestro de la juventud", que fue seguido con interés o con preocupación por la gran prensa, las revistas institucionales y las publicaciones culturales.

El presente capítulo se propone iluminar el perfil político que acompañó, en los inicios de la Reforma, a lo que llamamos su "dimensión institucional". Para ello descentramos la mirada de la fundación de grupos y revistas y nos detenemos en tres eventos diversos que, si bien fueron significativos en la construcción de una cultura reformista de izquierda, permanecen muy poco analizados por la bibliografía crítica. Esos eventos son: la visita de d'Ors, la contratación de Nicolai y Goldschmidt por la UNC y el decanato de Mario Saenz en la Facultad de Derecho de Buenos Aires. Antes de ello mapeamos brevemente los avances y retrocesos de las reivindicaciones reformistas que tuvieron lugar en las distintas universidades del país, pues ese análisis general -ausente en la bibliografía crítica- permite comprender la relevancia de los eventos que reconstruimos. 


\section{La dimensión institucional de la Reforma Universitaria}

En agosto de 1918, Yrigoyen aprobaba unos nuevos estatutos universitarios que, entre otras cuestiones, estipulaban concursos periódicos de los cargos universitarios -sin la aprobación del poder ejecutivo-, la renovación periódica del gobierno universitario -que en la UBA ya se venía realizando-, la participación en él de los estudiantes, la asistencia libre y las cátedras libres. La aplicación de esos estatutos motivó intensos conflictos en las universidades de Córdoba y de La Plata, y, si en la UBA no causó mucho revuelo, la clara excepción fue su Facultad de Derecho. Mientras que en la FFyL se registró una progresiva renovación de la planta docente -que en la carrera de filosofía terminó por implantar una matriz antipositivista y profesionalista-, en la de Derecho el intento de aplicar reformas mínimas producía fuertes conflictos, pues sus profesores titulares pertenecían, en su gran mayoría, a una elite política ligada a la elite económica, crítica del cogobierno estudiantil y de las corrientes del derecho social. Para aquella elite, la facultad debía formar tanto a los profesionales del derecho como a una dirigencia política nacional que rechazaba la democratización social. Recién en 1921, con el decanato de Mario Sáenz, se implementaron en esta facultad algunas de las reivindicaciones reformistas, pero ese proceso fue frenado violentamente a comienzos de 1923. Si bien volveremos sobre ello, traigamos un pasaje de las memorias de Del Mazo que ofrece una rápida idea de la resonancia que en su momento alcanzó ese conflicto:

La Facultad contaba con un grupo de profesores individualmente buenos, pero funestos cuando se asociaban con determinados otros, asociación que se volvía todopoderosa por el propio sistema oligárquico. [...] Ya implantado el sistema estatuario de la Reforma, tal Facultad fue la única que dio el espectáculo de la sublevación de los profesores contra sus autoridades legítimas. Pues quedó en buena parte subsistente el claustro profesoral, y 27 profesores, que después llegaron a 45, dieron un golpe de mano contra el Consejo reformista, y en combinación con los círculos áulicos del alvearismo [...] exigían como puede adivinarse, la reforma de los estatutos, o sea, la vuelta de la oligarquía profesoral. [...] la mayoría del núcleo de esos profesores insurrectos, ligados a los intereses extranjeros, pasó directamente de la Facultad al gobierno dictatorial (Del Mazo, 1976: 76).

En cuanto a la UNLP, su presidente, Rodolfo Rivarola, y un grupo importante de profesores pretendían conceder un cogobierno estudiantil sin voto y otras condiciones. Ello se sumó a una denuncia de corrupción en el uso de los fondos de la Facultad de Veterinaria y dio inicio, 
a fines de 1919, a una prolongada huelga, protagonizada por la FULP y conocida como la "huelga grande". Después de casi un año de conflicto, Rivarola y algunos profesores antirreformistas, como Ricardo Rojas, renunciaron y se realizaron las reformas a los estatutos universitarios. Pero pronto los grupos reformistas platenses encontraron nuevas dificultades en su intento de renovar la planta docente y otorgarle una impronta democratizadora a los estudios. El nuevo conflicto estalló en 1921 en el Colegio Nacional dependiente de la Universidad. La FULP había logrado que en octubre de 1920 Saúl Taborda -cordobés pero egresado en Derecho de la UNLP- dejara la cátedra de Sociología en la Facultad de Economía de Rosario para dirigir el Colegio. Taborda apoyó el cierre del Internado del Colegio -donde, bajo la dirección de Ernesto Nelson, un número pequeño de estudiantes residía y recibía una formación exclusiva acorde a su condición de futura elite política- y la creación de una Casa del Estudiante, que debería alojar a un número mayor de jóvenes y desjerarquizar la relación entre profesores y alumnos. Además, Taborda organizó una asamblea docente para reformar los estatutos del Colegio, sobre todo porque estipulaba que la capacidad de decisión recaía en el Consejo Directivo de la UNLP y no en la planta docente del Colegio (Vallejo, 2007; Biagini, 2012). Estas iniciativas, a las que se sumaron la clara simpatía de la gestión a la Revolución Rusa y la doctrina maximalista, produjeron una fuerte reacción del sector antirreformista, el que finalmente logró expulsar a Taborda. ${ }^{308}$

Durante el conflicto, Taborda contó con el apoyo del CE del Colegio, de la FULP y de la FUA (entonces presidida por del Mazo). Además, las revistas anarco-bolcheviques Vía Libre y Cuasimodo publicaron manifiestos en su apoyo y difundieron las últimas noticias. Para respaldar la gestión, el CE del Colegio Nacional fundó el boletín La Escoba. Si bien sus números se han perdido, se conserva el saludo que le formuló el Boletín del Centro de Estudiantes de Ciencias de la Educación de La Plata. Sugiriendo que La Escoba participaba del ala más confrontativa del movimiento reformista, confiesa el Boletín:

308

La afinidad de la Reforma con la renovación educativa que tenía lugar en Rusia impulsada por Taborda junto al CE del Colegio y la FULP permanecen prácticamente olvidadas. Entre las iniciativas que alentaban esa afinidad se encuentra la organización, en el Colegio, de un acto por el $3^{\circ}$ aniversario de la Revolución Rusa al que el CE invitó a la Unión Gráfica y a otros gremios obreros y en el que fueron oradores, además de Taborda, Barcos y Canale, quienes habían refundado en Buenos Aires la revista "anarco bolchevique" Cuasimodo y participaban del Consejo Federal de la FORA del V, entonces rebautizada "comunista". Además, el CE era dirigido por Verde Tello, quien junto a Najera encabezaba el grupo Claridad platense y su prédica por la adhesión del PS con la III Internacional. 
Nos agrada mucho el boletín de los muchachos del C. N. y sobre todo su título tan sugestivo; y como tenemos una gran esperanza en la nueva muchachada ya nos parece ver la Escoba transformada en barredora automóvil. [...] Han cambiado tanto las cosas por el Colegio y tanto cambiarán gracias a La Escoba y a Taborda, que al fin tendremos en La Plata un Colegio Nacional. Sepan los directores de $L a$ Escoba, que esperamos ansiosos la barrida, y que nos llena de alegría el pensar que detrás nuestro, llega rebelde y entusiasta "el tropel que nos va a superar" ("Periodismo universitario", Boletín del Centro de Estudiantes de Ciencias de la Educación, no 1, 15/10/1920, p. 11).

Los estudiantes secundarios y la FULP lograron barrer con el presidente de la UNLP: a comienzos de junio de 1921, Rivarola presentó su renuncia. En su lugar asumió, con el apoyo de los reformistas, el decano de la Facultad de Ciencias Jurídicas y Sociales, Benito Nazar Anchorena. Pero éste, a los pocos meses, rompió sus acuerdos reformistas y no sólo no reincorporó a Taborda sino que además introdujo muy pocas medidas renovadoras (Biagini, 2001; Castiñeira, 1985; Vallejo, 2007). ${ }^{309}$

En los años inmediatamente posteriores, la UNLP encontró cierta estabilidad institucional. El proyecto renovador más radical estuvo encabezado por Palacios, quien asumió como decano en las elecciones que sucedieron a la salida de Nazar Anchorena. Aquel dispuso una serie de iniciativas de marcada tendencia reformista -como el Laboratorio de Psicofisiología que, guiado por los modernos principios de la psicología experimental, realizaba experimentos a obreros orientados a precisar el proyecto de una legislación laboral que serían centrales en su identificación como un "maestro" de la Reforma y en la elección de su figura como presidente de la ULA en 1925. A pesar de ello, esas iniciativas no lograron la fuerza institucional que las perpetuara más allá de 1925, año en el que Palacios terminó su mandato y fue elegido Ángel Casares como nuevo decano (Graciano, 2008: 91-111). Por su parte, los jóvenes que en 1920 habían protagonizado la huelga grande, y luego habían convocado y apoyado a Taborda, hacia 1922 perdieron la conducción de la FULP. Reunidos en el grupo Renovación -nombre con el que habían bautizado al boletín de la FULP durante 1920-, iniciaron una experiencia teatral de extensión universitaria -luego reivindicada como la antecesora del Teatro del Pueblo- y entre 1923 y 1928 editaron, bajo el padrinazgo de Alejandro Korn, doce números de la revista Valoraciones -a la que nos referiremos en el

\footnotetext{
${ }^{309}$ Sánchez Viamonte (1928: 44-48 y 96-106) ofrece una breve pero elocuente reconstrucción de las alianzas que le permitieron a Nazar Anchorena romper el pacto con la revoltosa FULP y sin embargo mantenerse durante dos mandatos en la UNLP. Una de esas alianzas fue con la conducción de la FULP, liderada por Sommariva, quien asumió el cargo de Taborda y es calificado por Ciria y Sanguinetti (1968: 45) como un "tránsfuga". Sobre la gestión antirreformista de Nazar Anchorena en la UBA en 1930, véase Halperín Donghi (1962) y Buchbinder (2005).
} 
capítulo siguiente-.

Otros acontecimientos relevantes en este mapa son la fundación, en 1919, de la Universidad Nacional del Litoral y la nacionalización, en 1921, de la hasta entonces provincial Universidad de Tucumán, dos iniciativas que la FUA había colocado a la cabeza de su agenda de reclamos. La Universidad Provincial de Tucumán había sido creada en 1914 para proveer de técnicos agrarios a la región y su nacionalización, en abril de 1921, parece haber sido recibida sin mucho conflictivo (Bravo, 2008). ${ }^{310}$

En cambio, la Ley Nacional con que, el 17 de octubre de 1919, se fundaba la Universidad Nacional del Litoral, era antecedida por una masiva y radicalizada agitación estudiantil y sus facultades recién serían inauguradas en 1922 (Caballero Martín, 1931; del Mazo, 1927, t.III: 227-235). ${ }^{311}$ Desde 1912, una fracción de las clases medias santafesinas se agrupó en el Ateneo Popular y, entre otras cosas, comenzó a reclamar la nacionalización de la Universidad Provincial de Santa Fe. Durante 1919, los estudiantes reunidos en la Federación Universitaria de Santa Fe protagonizaron nuevos reclamos. Sus actos inundaron la ciudad y contaron con la solidaridad de los estudiantes federados de otras ciudades, quienes instalaron el conflicto en las publicaciones estudiantiles y llegaron como oradores de los actos. El primer logro fue que el gobernador de Santa Fe, el médico perteneciente a un sector progresista de la UCR Manuel Menchaca, interviniera la Universidad Provincial de Santa Fe y pusiera como autoridad máxima a José Araya. En un comienzo, los estudiantes impulsaron la candidatura a rector de Pedro Martínez. Pero rápidamente desistieron de nombrar nuevas autoridades para concentrarse en el reclamo de la fundación de una universidad nacional bajo la que se disolvería la provincial.

Los estudiantes estaban vinculados a la fracción de la UCR santafesina que lideraba Menchaca, pero varios hechos sugieren que sus aspiraciones rebasaban a ese partido. En efecto, en 1919 uno de los líderes estudiantiles, el poeta y estudiante de Derecho Pablo Vrillaud, rechazó la candidatura a diputado que le había propuesto la UCR. La convicción que acompañó ese rechazo se advierte en el comentario que el joven formuló, en una carta a su familia, sobre la impresión que le causó el ministro radical Salinas: "bastante raro el bicho físicamente, del otro lado es un vulgar radical de tuto a veinte. Conversamos largo; sin querer,

\footnotetext{
310 Importantes documentos de esa nacionalización pueden consultarse en del Mazo (1927, t.III: 260-276)

${ }^{311}$ La Universidad se fundaba sobre la base de tres instituciones existentes: la Universidad Provincial de Santa Fe (compuesta de la Facultad de Derecho y la Facultad de Farmacia y Obstetricia), las Escuelas de Estudios Superiores de Rosario y la Escuela Normal de Paraná.
} 
cometió conmigo una injuria, date cuenta ¡me confundió con un diputado santafesino!". 312 Asimismo, Vrillaud escribía a su familia una breve pero significativa descripción de los sucesos. Informa el líder estudiantil:

Tuvimos tres días de huelga y anduve hecho un "bolsebicki" -por poco me mandan a presidio-. No te asustes, esto es para nosotros un diploma de honor. Lo que te aseguro es que a pesar de los pesares, estoy entero y no pierdo la esperanza de ser mañana o pasado el jefe del soviet. [...] La huelga ha terminado, aunque el ambiente siempre continúa cargado. No sería extraño que de aquí a unos días volviera a explotar con mayor violencia (Carta de Pablo Vrillaud, s/d, mayo de 1919, aproximadamente, Fondo personal Pablo Vrillaud, "Cartas y alguna prosa", Museo de la Reforma, Universidad del Litoral).

Como los "revolucionarios" cordobeses de 1918, los que surgían en Santa Fe sabían que el éxito de los reclamos necesitaba del apoyo de los estudiantes de las otras ciudades. De ahí que en mayo de 1919 Vrillaud redactara, para las distintas federaciones que componían la FUA, el siguiente telegrama:

Conflicto en pie. Asamblea ratificó declaración huelga federación hasta tanto se resuelva favorablemente movimiento. Pedimos estatutos dignos y profesorado capaz. Rector negóse a renunciar no obstante solicitud insistente. Los nores cambian de nombre pero no de alma. Vivimos bellos días de acción y pensamiento. Reivindicamos con este gesto uno que se nos discutía. Ante pasividad academias desprestigiadas, resoluciones enérgicas adquieren fuerza simbólica. Es la muerte de un régimen. Como en Córdoba, hay defensores de lo anacrónico, minoría familiar, guardianes de sus papás catedráticos; esto en vez de desalentarnos nos conforta. Santa Fe aguarda ansioso pronunciamiento solidario de esa federación. Pablo Vrillaud, presidente. J. A. secretario (cit. Caballero Martín, 1931: 114-115).

Respondiendo a esa convocatoria, uno de los líderes del movimiento cordobés se apuraba a enviar un breve telegrama que ya citamos: "Córdoba ha iluminado escenario nacional. Santa Fe debe eclipsarlo. Fraternalmente. Enrique Barros, mayo de 1919” (cit. Caballero Martín, 1931: 115). En busca del eclipse, Barros viajaba a Santa Fe junto a otros representantes estudiantiles cordobeses y porteños. Allí participaría del masivo acto estudiantil del 25 de mayo de 1919 pronunciando un discurso y leyendo el saludo de Arturo Capdevila. A través de Barros, ese líder de Córdoba Libre! Les confirmaba a los estudiantes santafesinos que "la obra democrática que realizan tiene una inmensa trascendencia patriótica; que tienen razón; que las

\footnotetext{
${ }^{312}$ Carta de Pablo Vrillaud, s/d, mediados de 1918, aproximadamente, Fondo personal Pablo Vrillaud, "Cartas y alguna prosa", Museo de la Reforma, Universidad del Litoral.
} 
universidades deben ser de los universitarios [...] si les llaman abanderados de la bandera roja, respondan así: nuestro rojo es el rojo del gorro frigio. Aquí no hay otra bandera roja que la que resulta de la negra bandera jesuítica ardiendo en llamas" (cit. Caballero Martín, 1931: 132-133).

A pesar de que la nacionalización llegaba en un contexto de fuerte confrontación estudiantil con las autoridades universitarias y gubernamentales, el PS no vio allí la "muerte del régimen" que anunciaba el telegrama de Vrillaud, sino el intento del yrigoyenismo, al que estaba vinculado la Federación Universitaria de Santa Fe, de cooptar al movimiento estudiantil y de afianzar su presencia en la región. Más precisamente, los parlamentarios socialistas votaron en contra del proyecto de nacionalización luego de denunciar las alianzas con las elites locales sobre las que se decidían las ciudades en que se localizarían las distintas facultades, e incluso el director de La Vanguardia propuso, sin éxito, que fueran expulsados del PS los profesores que habían aceptado cargos en la nueva universidad. ${ }^{313}$

Finalmente, en Córdoba la renovación institucional tuvo un importante alcance a partir de septiembre de 1918, cuando Salinas encabezó la segunda intervención de la UNC. Pero esa renovación, posible por un frágil equilibro con el yrigoyenismo, tendió a revertirse cuando cambió el gobierno nacional. En efecto, a comienzos de 1923 los grupos antirreformistas lograron una nueva intervención, esta vez encabezada por Sagarna y enviada por Alvear, un presidente nacional que no procuraba tener de aliados a los estudiantes e incluso parece haber presionado para reorganizar una fuerza antirreformista.

Si bien en 1918 la FUC no consiguió que se concursaran los cargos de profesores, sí

\footnotetext{
${ }^{313}$ La polémica se inició cuando Nicolás Repetto publicó en La Vanguardia "Cátedras para socialistas. Nueva táctica del señor Yrigoyen". Aquel acusaba a los intelectuales socialistas nombrados por decreto como profesores de la Universidad Nacional del Litoral de haberse dejado cooptar. Enumeraba allí los cargos otorgados a los socialistas: primero fueron nombrados Amílcar Razori en la sede de Rosario y Luis Bonaparte en la de Santa Fe. Luego se designó a Arturo de la Mota. A su vez, Giusti, que entonces encabezaba la campaña a candidatos a concejal del PS, era nombrado en una cátedra en el Colegio Nacional de La Plata y unos días después "se produce la designación del socialista internacional, ya adherido a la 3a., Alberto Palcos, para profesor del Colegio Nacional de La Plata". Una carta abierta a Giusti, firmada por Ángel M. Giménez, reiteró la denuncia de Repetto y le exigió a Giusti su renuncia al cargo de profesor. Exponiendo un malestar muy extendido entre los militantes hacia el origen social del Comité Ejecutivo del PS, Giusti contestó en una carta abierta que "ese gesto pueden tenerlo Giménez, Justo, Repetto, del Valle Iberlucea, que son los cogotudos de la secta, con más plata que sinceridad de ideales" (s/d). Las piezas del debate se conservan en el Fondo personal Roberto Giusti, CeDInCI.

La mejor reconstrucción del surgimiento de la Universidad del Litoral continúa siendo la preparada en 1931 por uno de los jóvenes que protagonizaron las luchas, Ángel Caballero Martín. Varios documentos relativos a la nacionalización de esta universidad (1912-1922) fueron recogidos por del Mazo (1927, t.III: 229-259). Algunos documentos estudiantiles del conflicto de 1919 son reproducidos en del Mazo (1927, t.V: 35-54). El rector interventor de la nueva Universidad Nacional del Litoral fue Benito Nazar Anchorena, quien fue sucedido por Benjamín Avalos y, luego de nuevos reclamos estudiantiles, por Pedro Martínez, el candidato de la Federación Universitaria del Litoral.
} 
logró que ingresaran en cátedras de sensible importancia graduados jóvenes ligados a la "cultura liberal". En la Facultad de Derecho (que comprendía las escuelas de notariado, derecho y procuración) ingresaron quienes lideraban Córdoba Libre!: Arturo Capdevila quedó a cargo, por un breve período, de la cátedra de Filosofía de las Ciencias Jurídicas y Sociales; Arturo Orgaz ocupó Introducción al Derecho y las Ciencias Sociales; Enrique Martínez Paz Derecho Civil Comparado; Raúl Orgaz Sociología y Deodoro Roca Filosofía General (Grisendi, 2013). Asimismo, luego del conflicto en La Plata, Taborda y Astrada volvían a Córdoba, el primero era elegido consejero junto a Arturo Orgaz y Roca, el segundo se encargaba de las Sección de Librería y Publicaciones de la Facultad.

Estos profesores emprendieron una renovación de los debates universitarios marcada por la construcción de una universidad científica y preocupada por resolver los problemas sociales. Dos expresiones de esa renovación fueron, por un lado, la mencionada Sección de Librería y Publicaciones, que publicó folletos y libros sobre problemas contemporáneos proveniente de intelectuales europeos y nacionales, ${ }^{314} \mathrm{y}$, por el otro, el Boletín de la Facultad de Derecho y Ciencias Sociales de Córdoba, que apareció entre junio de 1921 y agosto de 1922 bajo la dirección de Capdevila -en 1923 se editó un número más, de menos páginas, bajo la dirección de Arturo Orgaz-. ${ }^{315}$

El elogio estudiantil que recibió esta publicación de carácter institucional nos ofrece una rápida idea de la renovación que ella introducía. Si bien el CE de Derecho se decepcionó ante el segundo número del Boletín, sobre el primero elaboró una reseña que halagaba cada uno de los artículos y antes declaraba: “Acostumbrados como estábamos a aquellos insignes mamotretos que, con el nombre de Anales o Memoria, dan a conocer los cuerpo académicos o los institutos de enseñanza sus inquietudes ante los problemas científicos, sociales o filosóficos, claro está que grata nos resulta la publicación oficial de la Facultad de Derecho y Ciencias Sociales de la Universidad de Córdoba".316

\footnotetext{
${ }^{314}$ Hasta donde pudimos relevar esa colección se editó entre 1921 y 1925 y se compuso de cinco series. La primera estuvo constituida por el Boletín, la segunda por un boletín bibliográfico, la tercera por "Conferencias", la cuarta por "Varia" y la quinta por "Actas y Documentos". En la tercera serie se editaron al menos: 1. Orientaciones del pensamiento en México de José Vasconcelos y 2. El nuevo Código Penal de Julio Herrera. En la cuarta serie aparecieron: 1. El conflicto de la cultura moderna de Georg Simmel (traducido por Astrada y reproducido en la revista Ariel de Montevideo), 2. Los fundamentos filosóficos de la obra de Spengler de Kurt Sternenberg (anunciados pero inhallable), 4. La obra de Osvaldo Spengler: una cultur-psicología mística de Raúl A. Orgaz, 5. "Lo desconocido” en las ideas y en las instituciones de Arturo Orgaz. Agradezco mucha de esta información a Ana Clarisa Agüero.

${ }^{315}$ Un agudo análisis de estas iniciativas reformistas puede consultarse en Grisendi (2012).

316 "Boletín de la Facultad de Derecho y Ciencias Sociales", Revista de Derecho y Ciencias Sociales del Centro de Estudiantes de Derecho de Córdoba, n 6, julio de 1921, p. 85. Los estudiantes retiran ese saludo en el siguiente número a través de una reseña que comienza afirmando: “francamente, ante sus trescientas cincuenta
} 
Los cuatro números que dirigió Capdevila buscaron difundir no sólo contenidos específicos de las ciencias jurídicas, sino también cuestiones ligadas a la cultura general. Allí apareció el catálogo de las obras con las que Bermann, desde la dirección de la Biblioteca Mayor, había renovado la cultura universitaria, se publicó un artículo sobre la teoría política helenista -y profundamente anticristiana- de Leopoldo Lugones, entonces simpatizante de la Revolución Rusa, y dos sobre la filosofía de Eugenio d'Ors, quien desde una impronta soreliana simpatizaba también con Rusia. Y la edición de estos textos sugiere que ante la ausencia de una facultad de filosofía y letras cordobesa fue en la de Derecho donde tendieron a procesarse los problemas de la cultura.

Específicamente, mientras que al llegar Raúl Orgaz a la cátedra de Sociología se exponía, por primera vez, un estudio científico de la sociedad, con Roca en la de Filosofía se iniciaba la difusión de las corrientes antipositivistas. Al igual que los jóvenes porteños que animaban el Colegio Novecentista, el líder reformista se interesaba por el novecentismo orsiano e incluso iniciaba contactos con d'Ors para que impartiera un curso filosófico en Córdoba. De todos modos, la recepción cordobesa de d'Ors iba a portar un signo político muy distinto al de la recepción porteña.

Por un lado, la escasa impronta cientificista que tenían antes del '18 los estudios universitarios de la UNC vuelve confuso aludir a una "reacción" antipositivista en esa universidad. En efecto, la reflexión sobre el hombre y sus manifestaciones espirituales que propiciaba Roca no se enfrentaba a una matriz cultural que explicaba la psicología humana desde las conductas, sino desde el tomismo. El antecesor de Roca en la cátedra de Filosofía era Luis Martínez Villada, quien desde 1918 participaba, junto a Rodolfo Martínez Espinosa y Dimas Antuña, del Centro Católico de Estudiantes y colaboraba con la revista porteña Signos que dirigía Carlos Sáenz. ${ }^{317}$ Por otro lado, Roca y los líderes de la FUC simpatizaban con el horizonte político antiparlamentario abierto por la Revolución Rusa y con la posibilidad de una filosofía que pudiera dar las claves de unos nuevos tiempos marcados por el igualitarismo socialista. Para precisar esas claves es que Roca propiciaba la llegada de d'Ors a Córdoba.

\footnotetext{
páginas de apretado tipo, nos hemos decepcionado. Trae el Boletín que dirige Arturo Capdevila, selecto y buen material de lectura, no obstante ello, la impresión, de que su director nos daría periódicamente esa publicación ágil, pletórica de espíritu nuevo, cual hoy se estila, se ve defraudada ante la pesadez académica del Boletín que se nos antoja aquellos voluminosos mamotretos de antaño" ("Boletín de la Facultad de Derecho y Ciencias Sociales", Revista de Derecho y Ciencias Sociales del Centro de Estudiantes de Derecho de Córdoba, $\mathrm{n}^{\circ} 8$, octubre de 1921, p. 105).

${ }^{317}$ Como mencionamos, con la intervención de Sagarna, en 1923, Martínez Villada recupera la cátedra de Filosofía. Véase nota 240.
} 
En los apartados siguientes nos ocupamos de la visita de d'Ors y de las disputas en torno de las implicancias políticas de su filosofía. Luego abordaremos los "eventos reformistas" que significaron la llegada de Nicolai y Goldschmidt, por un lado, y el decanato de Sáenz, por el otro.

\section{Eugenio d'Ors, el filósofo de la reacción antipositivista}

Creo ver claramente que, más que por filósofo, o por escritor, o por fundador, por otra razón me quieren. Me quieren porque me consideran así como un artesano, diría como un escultor, en alguna tarea nacional suya.... D'Ors, "Discursos en banquete a d'Ors", 1921.

Como analizamos en el capítulo tercero, desde mediados de los diez Eugenio d'Ors se había instalado entre los jóvenes porteños interesados por la filosofía como una de las figuras señeras del antipositivismo. Pero el proyecto orsiano también despertó el interés entre de uno de los intelectuales más destacados de la "cultura científica", José Ingenieros, y de algunos reformistas cordobeses.

En la recepción de d'Ors que propuso desde mediados de 1917 el Colegio Novecentista, la "filosofía del hombre que trabaja y que juega" era identificada con la superación del cientificismo de Ingenieros. A pesar de ello, tanto éste como d'Ors se interesaron de modo recíproco por la producción filosófica y el posicionamiento político del otro. Como vimos en el capítulo cuarto, en su Revista de Filosofía, Ingenieros se empeñó en resistir, desde un singular "idealismo cientificista", al avance del "idealismo seudo-filosófico del kantismo", fundamentalmente porque éste eliminaría la resonancia social de la filosofía. También mencionamos que Ingenieros estaba convencido de que la renovación cultural española y especialmente la labor del novecentismo catalán no participaban de aquella seudofilosofía. Más precisamente, en 1916 dictó en la FFyL de Buenos Aires un curso breve sobre esa renovación en el que se dedicó a "Los estudios filosóficos en Cataluña" y se refirió auspiciosamente a d'Ors. Asimismo, Ingenieros publicó una versión escrita del curso en la Revista de Filosofía y en forma de libro bajo el título La cultura filosófica en España.

En cuanto al catalán, el tercer Quaderns muestra que d'Ors estaba al tanto de la Revista de Filosofía de Ingenieros. Allí se reseña auspiciosamente un artículo sobre psicología 
de Víctor Mercante. ${ }^{318}$ Además, en su largo editorial del quinto Quaderns, "El problema de la universidad", d'Ors elegía como punto de partida de su reflexión sobre la estructuración del conocimiento la comunicación que "un profesor americano, el Dr. José Ingenieros, de Buenos Aires, acaba de pronunciar con convincente elocuencia [...] en el Congreso Científico Panamericano de Washington". ${ }^{319}$ Y los números siguientes reseñaron las nuevas obras de Ingenieros La cultura filosófica en España y Ciencia y Filosofía. Seis ensayos. ${ }^{320}$ Asimismo, entre 1920 y 1921 Ingenieros y d'Ors mantuvieron un afectivo contacto epistolar a través del que ambos se reconocieron como camaradas en la lucha por instalar una filosofía y una intervención intelectual que explicitara su compromiso con los tiempos abiertos por la Revolución Rusa.

En Córdoba, las condiciones de recepción de d'Ors fueron muy distintas de las porteñas ya que, como sugerimos, no existía un proyecto cientificista que reuniera a un número importante de intelectuales locales como el de Ingenieros. Allí la formación universitaria no estaba marcada por la reverencia a la ciencia sino al cristianismo. Hacia 1920 Deodoro Roca parece convencerse de que el movimiento necesita precisar su conciencia filosófica y d'Ors (a quien Roca citaba en los discursos orientados a articular la ideología del movimiento estudiantil) parece ser la figura capaz de ofrecer esa precisión. A instancias de Roca, el vicerector de la UNC, Enrique Martínez Paz, escribe al catalán en junio de 1920 para invitarlo a impartir un curso sobre filosofía en aquella universidad. A los pocos días, d'Ors contesta la carta aceptando la invitación:

\section{Mi distinguido Señor, \\ conozco la Universidad de Córdoba y estoy ya informado del movimiento de renovación que realizan ustedes. Por esto la atenta invitación [...],}

\footnotetext{
318 “'Resultado generales de la psicología pedagógica', por Víctor Mercante. Revista de Filosofía (Buenos Aires, mayo de 1915)", Quaderns n 3, año I, vol. I (diciembre de 1915), pp. 85-86. En números posteriores, los Quaderns reseñan otros dos artículos de la Revista de Filosofia: "VÍCTOR MERCANTE: OFICINA CENTRAL DE INFORMACIÓN PEDAGÓGICA. Revista de Filosofia (Buenos Aires, noviembre de 1915)", Quaderns de febrero de 1916, pp. 70-71, y "Universidad y filosofía" de Antonio Vidal, Quaderns de noviembre de 1916, pp.73-74. En este número también es reseñada "La vieja y la nueva universidad española", uno de los artículos enviados por Eugenio Lopez-Aydillo a la revista Ideas. Por otra parte, los Quaderns de febrero de 1916 reseñan la edición porteña de La vindicación de la memoria de d'Ors por el Monitor de la Educación Común (pp. 72-73). 319 El Guaita, "El problema de l'universitat", Quaderns de febrero de 1916, pp. 1-6. D'Ors retoma estas reflexiones en "L'altre problema", editorial de los Quaderns de mayo de 1916, pp. 246-249, y "S'hi segueix parlant de l'altre problema", editorial de los Quaderns de junio de 1916, 321-323.

${ }^{320}$ Quaderns de noviembre de 1916, pp. 217-219, y Quaderns de octubre de 1918, pp. 61-62. En cuanto a la conferencia de Ingenieros, recordemos que su versión definitiva es editada bajo el título "La universidad del porvenir" y funcionó en Argentina, luego del estallido de la Reforma, como uno de los catalizadores de las inquietudes de la fracción más radicalizada del movimiento estudiantil.
} 
sobre hónrame en gran manera, ha venido a ligarse con los auténticos impulsos de una previa simpatía (Carta de d'Ors a Martínez Paz, 30/06/1920, Correspondencia de Eugeni d'Ors, Universidad de Navarra, disponible en línea: http://www.unav.es/gep/dors/correspondencias16.htm.).

El catalán proponía que su estadía fuera en octubre, aclaraba de modo muy cortés los honorarios por los que le había consultado Martínez Paz, sugería como tema una síntesis de su filosofía y le pedía "conocer directamente el mayor número de elementos posible de vida intelectual argentina, que desde lejos acompaño también desde hace tiempo con mi entusiasmo" (Idem).

Pero d'Ors no pudo cumplir con la fecha y en octubre de 1920 decidió iniciar correspondencia con Ingenieros. En la primera carta que le envió, el catalán le aclaraba a su par argentino: "Por una carta de José Gabriel me he enterado más especialmente de las simpatías que usted ha tenido la generosidad de manifestar en torno de algunos incidentes de vida política de Barcelona, que me conciernen", ${ }^{321}$ con ello se refería al apoyo a d'Ors declarado por la Revista de Filosofía ante la "defenestración" que en enero de 1920 le había realizado la Asamblea General de la Mancomunidad de Cataluña por su afinidad obrerista soreliana. ${ }^{322}$ En esa primera carta, d'Ors también subrayaba que tenía altas expectativas en las nuevas producciones culturales argentinas, elogiaba la revista de Ingenieros y le aclaraba que deseaba concretar la invitación que le había realizado la UNC. Se mostraba allí afín al proyecto filosófico de Ingenieros y seguro de saber "de qué lado de la barricada se había colocado [Ingenieros] en las luchas de nuestros días".

La segunda carta fue escrita por d'Ors casi un año después. El 15 de junio de 1921 el catalán restablecía su contacto con Ingenieros para confirmarle que arribaría a Buenos Aires el próximo mes, y también para subrayar que se proponía desplegar una tarea exclusivamente filosófica. "Nada de política para mí en la Argentina" le aclaraba a Ingenieros, luego de conocer el reportaje de La Nación en el que aparecía afirmando que llegaba para secularizar la UNC:

¿Qué voy a secularizar yo? ¡Con qué autoridad podría hacerlo, aunque se me antojara este dislate? Supongo que aquella Universidad está secularizada y me parece muy bien, claro; pero si no lo estuviera, yo no tendría qué hacer... [...] ¿He

\footnotetext{
${ }^{321}$ Carta de d'Ors a Ingenieros, 19/10/1920, Fondo José Ingenieros, CeDInCI.

${ }^{322}$ El mismo d'Ors ofrece una breve reconstrucción de las acusaciones que le realiza la asamblea en "El 'Yo acuso' de Xenius", El diluvio, 12/01/1920; disponible en línea: http://www.unav.es/gep/dors/entrevistas17.htm. Ver también Guillermo Díaz-Plaja (1981: 101-112).
} 
de decirle que una de las esperanzas que alegran más mi perspectiva de viaje es de estrecharle la mano, después de tanto tiempo?

Ahora mi saludo, en espera de la para mí tan grata presencia y con el ruego de que me ponga a los pies de la Señora Ingenieros.

Eug. d'Ors. ${ }^{323}$

Pero en la trama universitaria de 1921 que venimos reconstruyendo la pretendida ausencia de política resultaba totalmente imposible. El mismo día en que redactaba la carta a Ingenieros, d'Ors enviaba otra, con prácticamente la misma información pero un tono más formal, al rector de la UNC, Eliseo Soaje. ${ }^{324} \mathrm{Si}$ bien éste había llegado al cargo con el apoyo de los estudiantes federados, el grupo católico que se oponía a la Reforma accedió a la carta y la publicó en su periódico más importante, Los Principios. En la breve presentación que acompañaba la reproducción de la carta, los católicos la proponían como una prueba de que el inminente visitante no era el representante de los "tiempos nuevos" como pretendían los revolucionarios, sino una figura comprometida con la "filosofía desinteresada" que promovía el periódico.

La publicación de la carta de d'Ors anticipaba la álgida disputa política que acompañó la visita, nada neutral, de d'Ors a la Argentina. A su llegada, la revista Nosotros organizó uno de sus tradicionales banquetes. Los oradores fueron tres representantes de la reacción antipositivista: el novelista Manuel Gálvez, el filósofo Alejandro Korn y su discípulo platense Ripa Alberdi, quien oficiaba como representante del Colegio Novecentista y se destacaba en la FULP. Cuando le llegó el turno de hablar a d'Ors, éste declaró que la tarea nacional era esculpir la juventud, el "nuevo y máximo monumento de la República Argentina”, y no dudó en afirmar: "Es ello vuestro, bien vuestro, pero también un poco mío. Porque el ritmo que ha sosegado clásicamente su impulso y le ha permitido alcanzar la nobleza, es -ni lo ignoro ni lo oculto, como no lo ocultáis ni lo ignoráis vosotros- un ritmo que un día dictaba mi propio corazón". ${ }^{325}$ Esta, poco modesta, autocolocación de mentor de la renovación argentina parece haber sido una constante en el vínculo que d'Ors entabló con sus discípulos argentinos. Sobre ello es elocuente la sarcástica descripción de la visita al "maestro" que ofrece Nalé Roxlo en sus memorias:

Íbamos desbordantes de preguntas, pero el autor de "De la amistad y del diálogo"

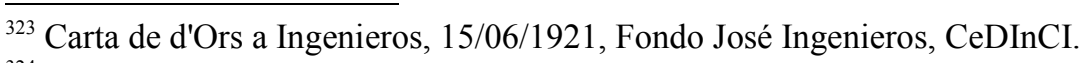

${ }^{324}$ Correspondencia de Eugenio d'Ors, Universidad de Navarra, disponible en línea: http://www.unav.es/gep/dors/correspondencias15.htm

${ }^{325}$ Nosotros, $\mathrm{n}^{\circ} 147$, agosto de 1921, pp. 512-513.
} 
se las ingenió muy bien para que no hubiera diálogo, lanzándose a un brillante elogio de la belleza física de la juventud argentina. Es posible que asediado como estaba por toda clase de delegaciones y grupos visitantes, nos tomara por estudiantes deportistas o algo así. Sea por lo que fuere, menudearon las comparaciones con la estatuaria griega, y, permítaseme la irreverencia, nos sirvió el longplay del Discóbolo (Nalé Roxlo, 1975: 159).

Por otra parte, si bien Nosotros organizó el banquete, ello no le impidió publicar -en el mismo número en que se reproducían los elogiosos discursos a d'Ors- un artículo que, desde la defensa del cientificismo, criticaba fuertemente la filosofía de d'Ors. Mientras que, en el caso de la visita de Ortega, vimos que Nosotros exponía su crítica al antipositivismo a través de un artículo de Palcos, en el caso de la visita de d'Ors, quien sistematizaba el mismo tipo de crítica era un estrecho camarada de Palcos, Gregorio Bermann. Ya desde el título, "La filosofía del señor Eugenio d'Ors: de los límites de la filosofía y la literatura”, Bermann señala el tipo de críticas que comenzaban a ser frecuentes en la Revista de Filosofia. ${ }^{326}$

Ni Bermann ni Ingenieros ni otras figuras identificadas con el cientificismo socialista asistieron al banquete en honor a d'Ors. Sin embargo, Ingenieros intentó un encuentro con el catalán. D'Ors le escribió desde La Falda la tercera carta que se conserva de ese vínculo. Después de conocer personalmente a los novecentistas Korn Villafañe y Gabriel, el catalán no sólo le insinuaba a Ingenieros un "desacuerdo teórico" sino que se apenaba ante la posibilidad de que las diferencias filosóficas entre ambos llegaran al punto de impedir un encuentro personal. Luego de mencionar uno de los desencuentros, escribía d'Ors a Ingenieros:

[...] me prometo entonces una estancia sin prisas para estrechar la mano al admirado decano de mis amigos en la Argentina y para charlar de muchas cosas. Estoy seguro, y esta seguridad me importa mucho, que para nada han de estorbarnos los puntos de posible disentimiento teórico. Acaso haya leído usted en una vieja glosa mía: “Amigo de la verdad, pero más amigo de Platón todavía. Platón es, para mí, el escogido y cerrado huerto que nos rinde cosecha de cien verdades por año" [...] Mándeme usted una palabra amiga a estas cumbres con la "Dirección Universidad de Córdoba", para asegurarme de que usted siente lo mismo estas cosas y empezar a combinar el plan para que nos veamos sin falla a mi regreso a la metrópoli.

Mis respetuosos recuerdos a la señora Ingenieros, mis saludos a toda la familia.

De antiguo su más amigo devotísimo, Eug. d'Ors (17/08/1921, Fondo José Ingenieros, CeDInCI).

\footnotetext{
${ }^{326}$ La confrontación entre d'Ors y Bermann se reabrió en 1940, cuando en una carta abierta editada en junio de 1940 en Nosotros el argentino contestó a la crítica que d'Ors había realizado en su libro Tradición a la conferencia madrileña "Psicología del Fascismo" de Bermann. Éste recopiló esa carta en su libro Conciencia de nuestro tiempo, publicado en 1971.
} 
La palabra amiga no se hizo esperar, cuatro días después Ingenieros le envió una carta que confirmaba y precisaba la campaña de proyección intelectual que ambos habían comenzado. Comienza aclarando Ingenieros:

\begin{abstract}
Muy Querido Amigo,
he seguido con vivo interés sus primeros pasos en la Argentina, complacido de la simpatía y del éxito que le acompañan en todas partes. Sus amables líneas me encuentran asociado a esas manifestaciones; ayer escribí al profesor Raúl Orgaz, de Córdoba, pidiéndole para mi revista un estudio especial sobre sus lecciones de Córdoba; en el número de la misma que está imprimiéndose va el discurso de Deodoro Roca y tres notas bibliográficas relacionadas con su viaje. Era mi intención, por fin, pedirle el texto de alguna o todas sus conferencias, con el mismo destino (25/08/1921; Fondo personal Eugenio d'Ors, Arxiu Nacional de Catalunya).
\end{abstract}

Allí Ingenieros le aclaraba que no había concurrido al banquete por las distancias ideológicas -no filosóficas- que lo separaban de los organizadores, al tiempo que buscaba convencer a d'Ors de que mantenía las mismas distancias con los porteños que lo agasajaron. Escribe Ingenieros: "Me ha sorprendido un poco su vaga sospecha de que alguna divergencia ideológica me apartara de Ud.; creo poder asegurarle que muy pocas personas, aquí, están más de acuerdo con sus orientaciones filosóficas y culturales". Y a continuación se anima a precisar las cuestiones política que antes había insinuado:

Lo probable es que en Buenos Aires -al revés que en Córdoba- se hayan comedido a admirarle personas que en España serían enemigos militantes de Ud. y de sus ideas; pero eso no puede evitarlo quien viaja por tierras extrañas. Se trata de pequeñeces que han invertido en Buenos Aires y La Plata el sentido inicial de la reforma estudiantil de Córdoba. Invertido, exactamente.

De todo ello tendremos oportunidad de conversar; y advertirá que aquí, como en su terruño, la política actual es un factor de corrupción e inmoralidad que ha logrado envenenar las fuentes de renovación que mayor confianza nos inspiraban al terminar la guerra (Idem).

Ingenieros suponía que para d'Ors también implicaba una "inversión" de la Reforma la versión nacionalista y jerarquizante que promovían los jóvenes porteños que continúan vinculados al Colegio Novecentista, así como los que lideraban la FULP. Pero la oportunidad de conversación no llegó y la advertencia de Ingenieros no logró torcer el perfil político que estaba teniendo en Buenos Aires la presencia del catalán. En efecto, a pesar de que d'Ors llegó 
invitado por los revolucionarios cordobeses, es con el novecentista Korn Villafañe con quien se paseó por las calles de Buenos Aires. Recuerda Julio Irazusta:

[...] Korn Villafañe ocupaba el primer plano en la escena estudiantil. Recuerdo que al visitarnos Eugenio d'Ors, él era quien lo piloteaba entre los estudiantes. Estaba yo una tarde, a la hora que concurría a la Biblioteca Nacional, mirando un escaparate de librería, cuando se me acercan por atrás dos personas, una de las cuales me interpela por mi nombre. Eran Adolfo Korn Villafañe y Eugenio d'Ors. [...] [Korn Villafañe] me invitó a las dos reuniones de los jóvenes con Eugenio d'Ors, que él organizó, la primera en casa de Jorge Max Rohde, donde funcionaba un simposio novecentista, empezando el año anterior un seminario sobre Dante, y uno de cuyos centenarios conmemoraba la cristiandad; y la segunda, en la Asociación Cristiana de Jóvenes (Irazusta, 1975: 73-74).

Una confirmación de la condición de "piloto de d'Ors" que ejerció Korn Villafañe la ofrece una lacónica nota conservada en el Fondo personal Florentino Sanguinetti.

Sanguinetti:

Alejandro me dice escribirá el artículo sobre la Reforma, para la Revista de Derecho, pero que necesita 10 días.

Mañana a las 18 en el local de la "Young Men" [Asociación Cristiana de Jóvenes] Ud. lo podrá ver a d'Ors con toda la comodidad. Queda Paseo Colón y Alsina. Suyo afmo, Adolfo Korn (s/d, Fondo personal Florentino Sanguinetti, CeDInCI). ${ }^{327}$

El tono lacónico de la carta responde a la rivalidad política entre el destinatario y el remitente. Como mencionamos en el capítulo anterior y veremos en éste, por entonces el hijo mayor de Alejandro Korn lideraba el grupo nacionalista de la Facultad de Derecho Unión Universitaria, y disputaba el significado de la Reforma Universitaria con el grupo izquierdista que encabezaba el joven graduado Florentino Sanguinetti.

Poco después de la partida de d'Ors, la Revista de Filosofía publicó los textos que Ingenieros le había pedido a aquel por vía postal. Pero, a comienzos de 1923, bajo el seudónimo de Julio Barreda Lynch, Ingenieros aprovechó su irónica refutación al pesimista "ocaso de las revoluciones" declarado por Ortega, para agregar una nota final que explicitaba

\footnotetext{
${ }^{327}$ Seguramente, José Gabriel también haya formado parte de la organización de la segunda reunión, pues Korn Villafañe no pertenecía a la Asociación Cristiana de Jóvenes mientras que Gabriel participaba activamente. Es más, en la carta que le envió al año siguiente a Ingenieros Gabriel consignaba junto a su firma la condición de miembro de la Asociación y en los años posteriores esa filiación es consignada en su entradas biográficas de los distintos Quién es Quién.
} 
un rotundo distanciamiento político con el catalán, quien dejando atrás sus simpatías al sindicalismo revolucionario se convertía en un importante referente del nacionalismo reaccionario. La nota de Ingenieros trascribe un telegrama aparecido en La Prensa en el que se advierte que las tesis de Ortega sobre el fin de las revoluciones coinciden "con el reciente ingreso a las filas laciervistas del escritor Eugenio d'Ors, de ideas avanzadas, y al que se considera como futuro diputado por uno de los distritos de La Cierva en la provincia de Murcia". Ante ello aclaraba Ingenieros: "Mucho nos complacería, por supuesto, ver desmentida semejante información, ya que fuimos de los que auspiciamos la venida a Córdoba de Eugenio d'Ors, no porque fuera más o menos filósofo, sino porque lo creíamos sinceramente izquierdista y revolucionario".328

En rivalidad con Ingenieros y Bermann, el joven porteño que lideraba la "inversión del sentido inicial de la Reforma" fue quien más prolongadamente continuó reconociéndose novecentista. En efecto, en la década del cincuenta, cuando se destacaba como un jurista católico (especialista en derecho municipal), dirigente de Acción Católica y simpatizante del fascismo, Korn Villafañe se reconocía novecentistas y decidía publicar una serie de folletos en los que exponía sus pareceres sobre la cultura nacional a los que tituló "Páginas novecentistas" y presentó como una suerte de continuación de la serie "Disciplinas de la nueva generación" que había proyectado en la década del veinte.

Por su parte, el entusiasmo novecentista de José Gabriel parece haberse prolongado hasta fines de la década del veinte. Como mencionamos, este receptor laico de las tesis orsianas se alejó del Colegio a mediados de 1918 por sus diferencias con los católicos, entre los que se encontraba Korn Villafañe. Pero el alejamiento del Colegio no impidió que Gabriel siguiera declarándose partidario de la matriz antipositivista -y en particular del novecentismo-, y que acompañara esa filosofía con las simpatías por la Revolución Rusa. En 1921, ante la confirmación de la llegada de d'Ors, Gabriel preparó La educación filosófica, una suerte de carta de presentación del orsismo argentino en la que afirmaba que Taborga, su compañero de aventuras novecentistas, "se adelantaba a la concepción política que nos ha

\footnotetext{
328 Julio Barreda Lynch, "Un ocaso de Ortega y Gasset", Revista de Filosofia, mayo de 1923, p. 333. Como es esperable, también Bermann presentó su refutación del ocaso sentenciado por Ortega. El texto del madrileño era publicado por entregas en "La página de los maestros" de los números 8 a 12 (fechados entre septiembre y octubre) del decenario Córdoba. Concluida la entrega, el número 13 se abría con "Un nuevo pragmatismo", un artículo en el que Bermann repasaba los distintos libros y artículos de Ortega para mostrar las incoherencias y la poca novedad que implicaba esa filosofía. En el mismo número aparecía "Relativismo y revolución", un artículo en el que Lazarte proponía una refutación de Ortega y Spengler, sobre todo por sus comparaciones inviables con las civilizaciones antiguas y sus consecuencias políticas pesimistas. Sobre el compromiso de d'Ors con el nacionalismo reaccionario, véase el agudo análisis de García Queipo de Llanos (1988).
} 
traído el régimen ruso de los soviets" (Gabriel, 1921: 155-156). ${ }^{329}$ Y si bien el anuncio que realizaba Gabriel de una necesaria reacción antipositivista lo enfrentaba en el plano filosófico con Ingenieros, las afinidades que ambos compartían en el plano político seguramente hayan decidido al joven a reemplazar las fuertes descalificaciones contra Ingenieros -como las que formulaba Probst en los Cuadernos- por el intento de colocarse como un digno interlocutor filosófico.

En efecto, Gabriel consiguió que Ingenieros le enviara las pruebas de imprenta de su libro Emilio Boutroux y la filosofía francesa. Luego de leerlas, Gabriel le confesó a Ingenieros -en la única carta entre ambos que se conserva- que, a pesar de las concesiones a la metafísica que éste había realizado en los últimos años, persistían núcleos positivistas poco consistentes. Refiere el joven: "He leído su trabajo con el vivo interés con que, a pesar de los más hondos desacuerdos ideológicos, leo siempre todo lo suyo. Pone V. pasión en lo que escribe y eso me atrae mucho; aparte, naturalmente, de otros motivos, entre ellos a menudo el de un acuerdo ideológico también". Y se atreve a precisar sus diferencias filosóficas:

Si V. me permite decírselo, observo que su personalidad se está precisando cada vez más en su obra. Santo Dios, no quiero decir que V. no fuera ya un hombre definido. Todo lo contrario: es V. de los pocos que en nuestro país han tenido la valentía y el talento de definirse. Pero su curiosidad se ha asomado a muchos campos, y la definición que ha tenido que adoptar para cada uno no siempre ha parecido relacionada con las demás. Ahora, es como si lo común de todas esas definiciones o actitudes fuese uniéndose y formando a su vez una actitud superior que abarca a todas las otras. Por eso digo que me parece que su personalidad se precisa. Se ve coincidir los cabos de muchos libros que favorecían discursos y surge una mentalidad orgánica. Es, seguramente, el producto de la madurez. [...] Su liberalismo político [se va ensamblando] con su positivismo científico, con su irreligiosidad y con su independencia de carácter, y de aquí que hable de la organicidad -permítame el término- de este nuevo trabajo suyo (28/06/1922). ${ }^{330}$

Por otra parte, la ligazón entre el antipositivismo orsiano y el socialismo bolchevique que propone Gabriel también se descubre en la recepción cordobesa de d'Ors. Más allá de las tensiones entre el grupo porteño ingenieriano y el antipositivista, la visita de d'Ors adquiere una nueva dimensión significativa para un estudio de recepción cuando se la analiza a partir

\footnotetext{
${ }^{329}$ Durante 1920 Gabriel prosigue su difusión de la filosofía de d'Ors a través de un curso sobre la pedagogía que expuso d'Ors en los Quaderns, este curso es organizado en la Asociación de ex alumnos del Colegio Nacional de La Plata. Asimismo, con los apuntes del curso Gabriel elabora "La pedagogía idealista de Eugenio d'Ors", un artículo aparecido en el número tres de Humanidades. Publicación de la Facultad de Humanidades de la Universidad de La Plata (julio de 1922). Para una biografía de Gabriel, véase Tarcus (2007a).

${ }^{330}$ Fondo José Ingenieros, CeDInCI.
} 
de los orsianos cordobeses. Pues si bien el catalán llegó al país por iniciativa de Deodoro Roca, el interés de éste por el novecentismo no respondía exclusivamente a una inquietud filosófica personal, sino que, al igual que en el caso del Colegio, se asociaba a la posibilidad de construir una fuerza juvenil colectiva, la que, a diferencia del devenir academicista del Colegio, tenía una impronta izquierdista.

\section{Eugenio d'Ors, el filósofo de la revolución universitaria}

A fines de 1919, Córdoba Libre! difundía un manifiesto "Al pueblo de Alta Córdoba", que hacía explícitas las reformas sociales a las que aspiraba el grupo. Entre ellas se encontraban la separación de la Iglesia del Estado, la eliminación del Senado, la ley del divorcio, la ley de enfiteusis, la legislación obrera y la reforma educativa. Al año siguiente, algunos miembros de aquel grupo prepararon el manifiesto del olvidado grupo Justicia. Bajo las firmas de Saúl Taborda, Carlos Astrada, Emilio Biagosch, Ceferino Garzón Maceda, Deodoro Roca y Américo Aguilera, ${ }^{331}$ el manifiesto comienza declarando:

Convencidos de que en esta hora en que el mundo insiste en nacer de una nueva civilización, ningún espíritu puede permanecer indiferente a los hondos afanes que lo presiden, a los urgentes problemas que propone su advenimiento y las comunes esperanzas que lo acompañaban, sin abdicar la función que le está asignada en la actividad consciente, hermanamos nuestros ideales y lo disponemos para las justas de la voluntad creadora bajo los prestigios de la palabra "Justicia". Suma y síntesis de los anhelos que constituyen el proceso mismo de la historia de los hombres, la erigimos en lema porque solo con ella podemos expresar el contenido mental de nuestra actitud ("Manifiesto del grupo 'Justicia'", Via Libre, no 11, agosto de 1920). ${ }^{332}$

Aunque las reformas buscadas ya habían sido claramente formuladas en 1919 y luego en 1920, faltaba aún precisar la filosofía capaz de interpretar sistemáticamente los cambios y a esta tarea se abocó esa generación de jóvenes maestros. En un espacio universitario cordobés marcados por las conquistas reformistas, las ideas de d'Ors aparecían asociadas a la posibilidad de pensar filosóficamente los tiempos abiertos por la Gran Guerra y la Revolución

\footnotetext{
${ }^{331}$ En cuando a la sociabilidad de estas figuras, una carta de Taborda a Sanguinetti, conservada en el fondo de éste, muestra que durante los veinte aquel compartía el estudio jurídico con Aguilera. Asimismo, en 1925 Biagosch fundó en Buenos Aires el grupo "Verdad y educación" y su órgano Verdad, y en 1929 fue candidato a Consejero Estudiantil por el Partido Unión-Reformista Centro-Izquierda. Finalmente, es conocido que a comienzos de la década del treinta varias de esas figuras se incorporaron al PS, y en las elecciones de 1931 Roca fue candidato a intendente de Córdoba y Bermann a vicegobernador, bajo la fórmula presidencial Justo-Repetto. ${ }^{332}$ El manifiesto también fue reproducido en Mente (1920), revista cordobesa difusora del anarquismo bolchevique.
} 
Rusa.

En 1920, mientras Roca se encargaba de los preparativos para que d'Ors expusiera su Doctrina de la Inteligencia en la Facultad de Derecho de Córdoba, el dramaturgo y filósofo cordobés Raúl V. Martínez publicaba Xenius, una "comedia satírica" en verso que tenía como protagonista a d'Ors y había sido puesta en escena en 1917. Allí las prácticas políticas corruptas, aliadas al poder religioso y militar, son conmocionadas por las ideas renovadoras de un desconcertante filósofo que se hace llamar Xenius y vaga por las calles de una imaginaria Mundópolis. ${ }^{333}$

Por su parte, Capdevila abría las páginas del mencionado Boletín de la Facultad de Derecho y Ciencias Sociales de Córdoba a la difusión exegética de la filosofía de Xenius: el joven Carlos Astrada se ocupaba del "Pragmatismo y esteticismo. En torno a la Filosofía del hombre que trabajo y que juega"334 y Saúl Taborda de las "Ideas pedagógicas de Eugenio d'Ors" (ambos ensayos aparecidos en el segundo número del Boletín, fechado en setiembre 1921). Taborda no sólo identificaba su "anarquizante" reforma pedagógica en el Colegio Nacional de La Plata con la filosofía de d'Ors y las prácticas de la Residencia de estudiantes de Madrid, sino que además había planeado la presencia de D'Ors en el Colegio. ${ }^{335}$

Las reseñas de los embajadores cordobeses de d'Ors son elogiosas, pero el catalán no parece haber aportado la filosofía revolucionaria que aquellos buscaban. En efecto, en discusión con la recepción cordobesa de d'Ors, escribe Juan Álvarez inmediatamente después de la partida de d'Ors:

Es de esperar [...] que la visita del doctor d'Ors produzca muy benéficos efectos en cuanto ha obrado a modo de calmante sobre ciertos núcleos estudiantiles cuya agitación se estaba prolongando demasiado. Prestigiosa, de suyo, la palabra del filósofo catalán cobró a este respecto singular importancia por haber sido precisamente los "revolucionarios" quienes le invitaron primero, y sostuvieron luego que su llegada señalaba uno de los más bellos frutos del movimiento reformista, dado que tal innovación jamás se hubiera podido introducir conservando los viejos ideales de la Universidad. [...] d'Ors se presentó a los estudiantes como un defensor de la tradición que ellos aspiraban a demoler; y sin embargo, lo han aplaudido (La Prensa, Buenos Aires, 11/12/1921).

\footnotetext{
${ }^{333}$ La obra es estrenada en 1917 en el importante Teatro Rivera de Córdoba y en 1920 es publicada por la editorial Coni. Martínez había fundado el Círculo de autores de teatro de Córdoba y en las décadas siguientes difunde las filosofías antipositivistas en la UNC. Para un análisis de la pieza teatral, véase Yukelson (2005).

334 Este artículo también es reproducido, en tres entregas, en el periódico porteño de orientación anarcobolchevique El trabajo. Diario de la mañana (23, 24, 25/09/1921).

335 Cuando el catalán llegó a la Argentina Taborda ya no dirigía el Colegio platense, de todos modos aquel fue convocado a dictar cinco lecciones sobre "La teoría de la cultura".
} 
A continuación, Álvarez extrae la única conclusión que se desprendería de esas tensiones: "no valía la pena de haber hecho una revolución tan sonada para que en la UNC fuese posible explicar las ventajas del tradicionalismo y los inconvenientes de que la filosofía se reduzca a los estrechos campos de la lógica y la psicología experimental". Pero los "revolucionarios" cordobeses estuvieron lejos de extraer una conclusión semejante. Si bien d'Ors no les ofreció las claves filosóficas para animar una fuerza colectiva que rompiera con la tradición -e incluso les reclamó desde Madrid una suma mayor de dinero por sus conferencias-, ${ }^{336}$ durante las próximas décadas el grupo prosiguió su búsqueda de una filosofía renovada.

Los dos grupos filosóficos más importantes de la Argentina creyeron encontrar en la filosofía de d'Ors las claves para interpretar e intervenir en la época que se abría. Y si los cordobeses se decepcionan rápidamente del catalán, en 1927 Korn -entonces la figura argentina más importante del antipositivismo- se refirió a la rotunda desilusión que causó d'Ors entre los porteños -de la que ya mencionamos que estuvo exento su hijo Adolfo-. En "Filosofía argentina", una breve historia de la tradición filosófica local aparecida en Nosotros, Korn sostiene que la visita de 1921 le mostró que no se trataba más que de un "periodista eximio" y traza como tarea de los filósofos argentinos la conciliación del "socialismo ético" con la filosofía de Bergson, un filósofo antipositivista que, al igual que d'Ors, había arribado al puerto argentino gracias a las "naves" construidas por el activo filósofo de la Residencia García Morente. ${ }^{337}$

Los cordobeses siguieron la clave bergsoniana anunciada por Korn en 1927, pero en los años anteriores su búsqueda filosófica se orientó hacia la recepción de otras figuras. Una muestra de ello es la publicación en 1923 por la editorial de la Facultad de Derecho de Córdoba del folleto de Georg Simmel "El conflicto de la cultura moderna", con la traducción de Astrada y la republicación en la Ariel de Montevideo -un folleto hoy reconocido como la primera edición del filósofo alemán en la Argentina- y el anuncio de la próxima aparición de "Los fundamentos filosóficos de la obra de Spengler" de Kurt Sternberg, una publicación en

\footnotetext{
${ }^{336}$ En 1922 Alfonso Laferrère, un antiguo miembro del Colegio Novecentista, escribe "El precio de la filosofía", una breve nota en la que ironiza sobre la demanda de d'Ors a la UNC. Laferrère recopila la nota en 1928 en su libro Literatura y política. Agradezco el dato a Martín Bergel.

${ }^{337}$ En contraposición al destino que tuvo la filosofía del hombre que trabaja y que juega, la propuesta bergsoniana fue recogida por la generación de filósofos argentinos de las décadas del treinta y cuarenta. Una prueba de ello es que en 1934 el grupo filosófico cordobés eligió a Bergson como la primera figura a homenajear por el Instituto de Filosofía y en 1936 publicó la compilación de ensayos Homenaje a Bergson, eligiendo el artículo de Korn para abrir el libro.
} 
cierto modo reemplazada por el homenaje a Spengler de $1923 .{ }^{338} \mathrm{Y}$ en esa búsqueda también se inscribió la llegada, a comienzos de 1922, de los científicos alemanes Georg Nicolai y Alfons Goldschmidt.

\section{Georg Nicolai y Alfons Goldschmidt, los maestros cientificistas y revolucionarios}

[El empeño de la generación del 18] hubo de asegurar a la Universidad de Córdoba el concurso de los más reputados sabios del mundo, hombres como no pueden ni ostentarlos aquellas universidades que, cual la de Buenos Aires, no tienen por galardón su prehistórica antigüedad, sino su importancia científica y cultural, universalmente reconocidas. Enrique Barros, "Discurso", 1924.

A fines de 1920, Enrique Barros partía a Alemania para especializarse en neurología en el Instituto de Anatomía Patológica de la Universidad de Friburgo. Desde allí polemizaría con Nicolás Repetto. El diputado socialista y director de La Vanguardia lo acusaba de haber realizado un nuevo pacto con el yrigoyenismo, esta vez para viajar a Europa en una misión oficial del gobierno argentino. Barros contestaba en octubre de 1920 a través de una carta pública que declaraba que esa acusación era una ofensa a sus convicciones y conducta. En el marco de su enfrentamiento con el "moderatismo" del PS, la revista Insurrexit reproducía esa carta en la que Barros afirmaba que la clase universitaria es "la primera y mayor esperanza de la Revolución en América" y simpatizaba tanto con el grupo Claridad de Buenos Aires como con la campaña de apoyo a los cordobeses organizada por Bermann. Asimismo, Barros se confesaba, a pesar de una momentánea reclusión en el laboratorio de trabajo, un socialista revolucionario y concluía recordándoles a los socialistas "el ejemplo luminoso de Lenine y Trotzky, igualmente difamados cuando a través de esas mismas tierras de mi peregrinaje, marchaban hacia su pueblo para levantar a los esclavos". ${ }^{339}$

Parte de esa voluntad revolucionaria es confirmada por las cartas que le envió a

\footnotetext{
${ }^{338}$ Este homenaje dio lugar a La concepción spengleriana del derecho, un folleto aparecido en 1924 en la misma colección que el de Simmel, compuesto de una conferencia de Ernesto Quesada y un breve prólogo del filósofo cordobés Raúl Orgaz (Grisendi y Requena, 20009). A través de sus cursos y conferencias, Quesada se había erigido en un difusor de La decadencia de Occidente (1918) de Spengler, antes de que Calpe editara en 1924 la traducción en español.

${ }^{339}$ Enrique Barros, “Al director de La Vanguardia”, Insurrexit, n 8, abril de 1921, p. 3.
} 
Bermann desde Alemania, pero sobre todo ellas ofrecen interesantes noticias de los intentos que realizaron esos "camaradas de lucha" para construir una universidad científica y social. Por un lado, la correspondencia conservada muestra que Barros se convirtió en el más importante gestor de la Revista de la Universidad Nacional de Córdoba, que desde fines de 1921 había quedado bajo la dirección de Bermann. Hasta comienzos de 1924, cuando regresó a Córdoba, Barros le envió a su amigo más de sesenta artículos para que la UNC finalmente contara con una publicación a la altura de los últimos avances científicos. A través de la correspondencia, sabemos que la Universidad tardó más de un año en remitir el dinero a Barros y que, aunque éste se quejó ante Bermann y otros responsables porque el pago a los científicos lo dejaba en bancarrota, continuó enviando colaboraciones.

Otra forma a través de la que Barros buscó contribuir a la construcción de la "nueva Universidad" fue la búsqueda de proyectos novedosos. En una de las cartas, Barros le contaba a su amigo que algunas universidades alemanas ofrecían talleres de oficios dirigidos a los estudiantes; y le pedía a Bermann que lo ayudara a iniciar tratativas ante el rector de la UNC, Francisco de la Torre, para que se emprendiera en Córdoba un proyecto similar. Si bien el proyecto parece no haber pasado del entusiasmo de Barros -y seguramente también del de Bermann-, sin duda es interesante recuperar el perfil "revolucionario" de universidad que allí estaba en juego. Escribe desde Friburgo Barros:

\begin{abstract}
Querido Bermann:
sabes que anoto todo lo que observo o leo que pueda encontrar aplicación en la nueva Universidad que nos empeñamos en crear en reemplazo de aquellos conventos jesuíticos que heredamos de España. De acuerdo con ello, adjúntote, para de la Torre, recorte de un periódico alemán que informa del propósito de establecer en las universidades talleres auxiliares donde los estudiantes adquieran nociones de oficios prácticos con los cuales contribuir a ganarse la vida durante las vacaciones. Para los pobres, esto es muy útil y para los demás una enseñanza necesaria: que el trabajo del obrero es tan respetable como el de 'Doctor'. Pero, antes de realizar iniciativa semejante habría que asegurarse de que no se emprende la preparación profesional de "Rompehuelgas" (Carta de Barros a Bermann, Freiburg, 23/01/1922. Fondo documental sobre la Reforma Universitaria, Casa de la Reforma Universitaria, Universidad Nacional de Córdoba).
\end{abstract}

La carta es significativa no sólo por la referencia al proyecto de abrir talleres de oficios, sino también porque explicita el rasgo del estudiantado que seguramente más tensionó la construcción de un movimiento reformista: la convivencia de los reformistas con jóvenes que, 
además de no pertenecer al mismo sector social, imaginaban de modo jerárquico su vínculo con los sectores obreros y el trabajo manual.

En el momento en que eran redactadas esas líneas, Bermann acababa de asumir la dirección de la Biblioteca Mayor y, como lo hicieron los reformistas de la Universidad de San Marcos, se aprontaba a renovar los libros disponibles. ${ }^{340}$ Para ello Barros le enviaba a su amigo una lista de librerías en las que se podían adquirir las obras de la "nueva Universidad". Trascribimos la breve referencia pues el tono irónico y confidencial de la carta es sugerente sobre el proyecto universitario en el que Bermann y Barros estaban involucrados: "para tu Biblioteca, infórmote de librerías inglesas donde puedes conseguir la literatura pacifista y la revolucionaria en ese idioma, salvo que tú sigas empeñado en comprar, como hasta ahora sucedía en Córdoba la vida de los apóstoles y de las once mil vírgenes por separado...” (idem).

Como mencionamos en el primer capítulo, bajo la dirección de Bermann, la Biblioteca Mayor tendría un importante perfil democratizador ligado a esa difusión del conocimiento que era característica de los proyectos culturales socialistas y con la que aquel desde 1914 estaba entusiastamente comprometido. Es que Bermann atendió al viejo reclamo que se les hacía a las bibliotecas respecto de las pocas horas que permanecían abiertas, abréndola entre las ocho de la mañana y las once de la noche. Pero además publicitó en La Gaceta Universitaria que estaba siendo fuertemente renovada ("integra continuamente su caudal bibliográfico con obras recientes de Derecho, Medicina, Ingeniería, Filosofía, Literatura, Artes, etc. Se halla suscrita y establece canje con las más importantes revistas del extranjero y del país") y que tenían acceso "estudiantes y público".

Volviendo a la estadía alemana de Barros, éste asumía una cuarta tarea clave para reemplazar a esos "conventos jesuíticos" en los que se había formado. Además de buscar proyectos aplicables en la universidad cordobesa, de conseguir artículos originales para la Revista y de listar las librerías con las que debía renovarse la Biblioteca Mayor, Barros se encargó de ofrecer a algunos de los científicos europeos la firma de un contrato con la UNC a través del que asumirían la fundación de un instituto de investigación y de la respectiva cátedra universitaria. En un discurso que pronunció en un acto de la FUC preparado para el

\footnotetext{
${ }^{340}$ Sobre los conflictos estudiantiles en Lima -y la importancia de la renovación de la biblioteca-, el estudiante peruano, exiliado en Buenos Aires, Enrique Cornejo Koster preparó una crónica que publicó en entregas en Acción Universitaria y seguramente en otras revistas reformistas del continente. La crónica fue recogida además por del Mazo, 1927 (t.VI: 87-139). Respecto de la relación entre la Reforma Universitaria en Perú y el nacimiento del APRA, véase Bergel (2009).
} 
sexto aniversario de la Reforma, Barros recordaba que entre las figuras que contactó se encontraban: el arquitecto berlinés Bruno Taut para el Instituto de Arquitectura, Heinrich Poll para el de Morfología, Rusztem Vambery y Hübner para el de Criminología, Jacoby para el de Química, Robert Wildbrandt y Goldschmidt para el de Economía Política y Otto Karl Willy Prausnitz para el de Higiene. ${ }^{341}$

A pesar de la amplia convocatoria, sólo fueron concretados los arribos a Córdoba de Alfons Goldschmidt y de Georg Nicolai, dos profesores judeoalemanes cuestionados en Alemania por sus posiciones antibélicas izquierdistas. Desde comienzos de 1922 y hasta su tácita expulsión a fines de 1922, el primero dictó cursos de extensión sobre economía marxista y ocupó la cátedra de Economía Política de la Facultad de Derecho cordobesa; el segundo fue el titular de la cátedra de Fisiología de la Facultad de Medicina cordobesa hasta su expulsión en 1927, cuando fue contratado en un cargo similar por la Universidad del Litoral.

Si bien la presencia de Goldschmidt y Nicolai en la UNC fue breve, el inexplorado arribo de esos profesores no deja de ser un "evento reformista" significativo pues implicó un fuerte debate y una concretización del cruce entre perfil científico y compromiso social que proponía el ala más radicalizada de la Reforma. Más específicamente, la revisión de las publicaciones estudiantiles de esos años sugiere que con esos arribos el ala radicalizada reforzaba su presencia en Córdoba. Antes de revisar esas fuentes, subrayemos que la llegada de Nicolai y Goldschmidt tiene un peso reformista cualitativamente diferente que las visitas realizadas el mismo año 1922 por Lucien Levy-Bruhl y José Vasconcelos. Al igual que los profesores judeoalemanes y d'Ors, aquellos ligaban la universidad a un proyecto social y despertaron afinidades izquierdistas, pero esas visitas no fueron el resultado de un compromiso firme de la UNC con un proyecto social: la llegada de Levy-Bruhl era financiada por el Instituto Universitario de París en Buenos Aires y la de Vasconcelos por el gobierno mexicano.

Sobre Nicolai refiere Barros en la carta que citamos arriba que hizo gestiones para que aquel y otros profesores judíos fueran contratados por la Universidad de Friburgo. Y la primacía que Barros decidió del compromiso político sobre la formación profesional -por la que había viajado a Alemania- se trasluce en la confesión que le realizaba a Bermann de que probablemente fuera echado de la universidad por haber mostrado que no admiraba a los

\footnotetext{
${ }^{341}$ Enrique Barros, "La contrarreforma”, Renovación, 1924, reproducido en Del Mazo (1927, t.V: 239-244).
} 
pangermanistas, pues Ludwing Aschtoff, el profesor alemán bajo el que Barros realizaba su especialización, "es un gran sabio, pero...... también, presidente de sport que me parece tienen la misión de preparar material humano para las guerras futuras". ${ }^{342}$

\section{Campañas cruzadas: Los Principios y La Voz del Interior}

Después de varias gestiones y de una campaña que se desplegó en La Voz del Interior, ${ }^{343}$ Godschmidt, Nicolai y sus esposas arribaban a Buenos Aires el 21 de abril de 1922. Al pisar suelo argentino los profesores eran detenidos por el Departamento de Inmigraciones, que alegaba una denuncia contra el primero que lo acusaba de agente de los bolcheviques. Aunque el profesor, la FUC y el diario La Voz del Interior negaron la acusación, Goldschmidt participaba desde 1919 del círculo de propaganda bolchevique que, por encargo de la Internacional Comunista, coordinaba desde Berlín Willi Münzenberg y en septiembre de 1921 había sido uno de los fundadores de la Ayuda Obrera Internacional (AOI, Internationale Arbeiterhilfe o Mezhrabpom), desde la que se organizó hasta 1925 la creación de comités de apoyo a Rusia. Aunque esto podía desconocerse en Argentina, sí se sabía que en 1920 Goldschmidt había visitado Rusia y que poco después había publicado un diario de viaje, Moskau 1920, y un libro de análisis económico, Wirtschaftsorganization Sowjet-Russland, sumamente elogiosos del proceso revolucionario. ${ }^{344}$

Entre abril de 1922 y noviembre de ese año -cuando partió a Alemania-, Goldschmidt negó una y otra vez -incluso desde las páginas de La Nación- que su defensa de la economía soviética tuviera un correlato militante, y lo mismo hicieron La Voz del Interior y la FUC. Sin embargo, los archivos de la Unión Soviética registran que en 1921 Münzenberg informó a la Internacional sobre la decisión del Comité Central de la AOI de enviar a la Argentina su representante para participar en la creación del Comité de Ayuda al Pueblo Ruso (Jeifets, Jeifets y Huber, 2004). Justamente esa es la tarea que realizó Goldschmidt junto al dictado de

\footnotetext{
342 Carta de Barros a Bermann, Freiburg, 23/01/1922. Fondo Bermann, Casa de la Reforma, Universidad Nacional de Córdoba.

${ }^{343}$ En una de las piezas de esa campaña se sostiene: "nuestro coprovinciano el doctor Enrique R. Barros cuyo recuerdo se conserva a través del tiempo asociado a los grandes momentos de la vida universitaria local, gestionó en Alemania doonde radica actualmente perfeccionando sus estudios, la venida del doctor Nicolai a Córdoba, a fin de que se hiciera cargo de un curso. Aceptado ello por el maestro solo faltaba ultimar los detalles y esto incumbía directamente a las autoridades universitarias. Estos trámites son los que hay que activar. [...] para traer un hombre de la talla de Nicolai se requiere allanarle todas las dificultades, de orden económicas como internacional, porque aquel perdió todos sus bienes en las vicisitudes dolorosas porque ha atravesado ( $\mathrm{La}$ Voz del Interior, 28/0/1922).

${ }^{344}$ En su Alemania natal, Goldschmidt se ganaba la vida como profesor de economía y redactor de artículos de análisis económicos en diarios masivos, como Berliner Tagesbllatt y B. Z. am Mittag. Además era conocido por sus mordaces artículos, firmados con el seudónimo de Lorarius, en el semanario antimilitarista berlinés Die Weltbühne (1918-1933) y por la dirección, junto a Philipp Dengel, del Räte-Zeitung (1919-1920).
} 
lecciones sobre economía política en las que Rusia era identificada con la experiencia económica a seguir. Sus defensores cordobeses no podían desconocer la afinidad con la Internacional tanto porque estaban vinculados a la conducción de la Federación Obrera Local, de orientación comunista, como porque la FUC ya venía organizando una Campaña pro Hambrientos en Rusia desde mediados de $1921 .^{345}$

A través de las notas de $L a$ Voz del Interior sabemos que al enterarse de la detención de los profesores, la FUC declaró una huelga por 24 horas "con el propósito de si dentro de ese plazo no se les pone en libertad, dicha resolución quedará planteada por tiempo indeterminado" (LVI, 22/04/1922). Los profesores y sus esposas fueron liberados al día siguiente y llegaron a Córdoba el 25 de abril, en medio de una campaña nacionalista que rechazaba la contratación de profesores extranjeros y la capacidad, sobre todo de Goldschmidt, en la materia. La FUC -dirigida ese año por el estudiante de derecho Edmundo Tolosa y con una marcada orientación izquierdista- invitó a los estudiantes a concurrir a la estación de trenes para recibir a los profesores y la Universidad designó a Bermann como el representante del acto oficial. ${ }^{346}$ Estaba previsto que tres días después arribara a Córdoba Raúl Haya de la Torre -entonces el joven presidente de la Federación de Estudiantes del Perú conocido por haber encabezado las exitosas reivindicaciones de los estudiantiles limeños-, pero su llegada se demoró hasta el 10 de mayo y la FUC esperó hasta entonces para realizar el acto conjunto de recibimiento.

La Voz del Interior tomó rápidamente contacto con los profesores y una semana después de la llegada publicitaba dos entrevistas tituladas "Con los profesores Nicolai y Goldschmidt. Sus impresiones, la forma de los cursos que dictarán”. Tanto Goldschmidt como Nicolai refirieron que quien les había ofrecido el puesto era Barros y, además de traer el saludo de éste, aseguraron que estaban dispuestos a proseguir la construcción de la universidad social de la Reforma, declaraciones que dieron nuevo impulso a la campaña de desprestigio.

\footnotetext{
${ }^{345}$ Entre 1924 y 1925 la AOI publicó la revista Not und Brot (Escasez y Pan) en la que, seguramente por iniciativa de Goldschmidt, aparecieron artículos sobre el movimiento social argentino y el mexicano. El tipo de oganización de apoyo a Rusia a través de Comités que impulsa la AIO es reformulado a partir del V Congreso de la Internacional (1924), en el que se decide impulsar la política de frentes a través de las Ligas Antiimperialistas. La primera en Latinoamérica sería la fundada en México, país al que se vinculó desde 1923 Goldschmidt. Por otra parte, la presencia de Goldschmidt en la Argentina debe inscribirse en la saga de enviados de la Internacional que aparentemente se inició a fines de 1920 con el regreso de Mijail Alexandrowski (un obrero ruso exiliado en Argentina que fue enviado en 1919 a Moscú y volvió como delegado de la Internacional) y la presencia del alemán Felix Weil.

346 "Nicolai y Goldschmidt. Su llegada a ésta", 25/04/1922, p. 6.
} 
La campaña tuvo su vocero en Los Principios y su principal líder en Lucas Olmos, el profesor titular de la cátedra de Economía Política y miembro de la Corda Frates. A Olmos lo secundó el Centro de Estudiantes de Derecho no federado, que dirigía el joven Héctor Antonio Blanco. Mientras el neotomista Olmos presentaba su renuncia ante lo que entendía como el intento de ser desplazado por el marxista Goldschmidt, aquel centro estudiantil acrecentaba la descalificación a Goldschmidt a través de una encuesta orientada a averiguar su preparación científica y capacidad docente.

Intentando calmar las tensiones, los reformistas aclaraban desde La Voz del Interior que el nuevo profesor trataría temas específicos en un curso paralelo al dictado por Olmos al tiempo que iniciaban una campaña de apoyo al nuevo profesor que se desplegó en la difusión de notas en su favor así como en la publicación de textos del mismo Goldschmidt. ${ }^{347}$ Protagonizaron esa defensa, además de la FUC y el diario cordobés, la mencionada Revista del Centro de Estudiantes de Derecho y las publicaciones reformistas editadas en Buenos Aires, el Boletín de la Federación Universitaria Argentina y la Revista Jurídica. Y a ello se sumaron las autoridades universitarias -sólo unos meses, pues cuando a fines de 1922 la presidencia de la Argentina fue ocupada por Alvear, rompieron su pacto con los reformistasy, naturalmente, la izquierda local que apoyaba el proceso soviético, a saber el PSI -ya convertido en el PC-, su órgano La Internacional y los grupos anarco-bolcheviques que, entre otros, editaban el diario montevideano La Batalla (esta defensa inició una breve polémica con el diario anarquista y antibolchevique porteño La Antorcha). ${ }^{348}$

A pesar de la fuerte campaña de desprestigio que organizó la fracción clericalconservadora, la universidad cordobesa contrató a los profesores: Goldschmidt debía dictar un curso de Economía Política en la Facultad de Derecho durante 1922 y Nicolai fundaría la cátedra de Fisiología y el respectivo instituto de investigación en la Facultad de Medicina, de los que quedaba a cargo en los siguientes tres años. Según el programa que Goldschmidt presentó a la Universidad, su curso libre se distanciaba de las lecciones neotomistas de Olmos para disertar sobre Economía Política y Finanzas e incluir temas de economía nacional, historia económica, sistemas monetarios y políticas bancarias de bancos alemanes para

\footnotetext{
${ }^{347}$ La primera de las notas de La Voz del Interior en defensa de Goldschmidt sostiene que éste no sólo contaba con las credenciales académicas suficientes para dictar el curso planteado, sino que además ya había dictado un seminario similar en la prestigiosa Universidad de Estocolmo ( $L V I, 09 / 05 / 1922: 7)$.

${ }^{348}$ Agradezco esta última referencia a Ricardo Melgar Bao, quien generosamente compartió sus fichas de registro. Aunque no hemos podido documentar el contacto de los anarcobolcheviques rioplatenses con Goldschmidt, sí sabemos que estuvieron vinculados al enviado ruso que había llegado casi un año antes que Goldschmidt.
} 
América del Sur. También se abordarían las formas de reconstrucción económica durante la posguerra, la sobreproducción y la inflación, la economía de la tierra en Europa, la organización económica en la Rusia Soviética, el problema de socialización de los medios de producción y una introducción a la teoría de Karl Marx. Confirmando la importancia que la labor periodística tenía en su itinerario intelectual -y en el perfil de muchos intelectuales comunistas-, Goldschmidt incluía como último tema de su curso la "técnica periodística".

El día anterior a la firma del contrato, la FUC realizó un acto de bienvenida y "de carácter puramente estudiantil" para los dos profesores y el joven Haya de la Torre. Luego de los discursos de los homenajeados, la FUC elegía como sus maestros-oradores a Deodoro Roca, Jorge Orgaz y Carlos Astrada, cuyos discursos fueron elogiados por la Revista de Derecho y Ciencias Sociales del Centro de Estudiantes de Derecho. Sobre Goldschmidt aclaraba la revista que respondió a las acusaciones sosteniendo que "el fuego de la reacción era peor que el de la guerra porque es de emboscada, cobarde", además saludó a la nueva juventud argentina y a Barros, a través de quien comenzó a conocerla (La Dirección, 1922).

El 12 de mayo de 1922 la Universidad realizó el acto de recibimiento de Nicolai y Goldschmidt. Allí era el rector quien subrayaba la función social para la que fueron llamados los alemanes. En su discurso, Francisco de la Torre declaraba que en la época moderna, si la Universidad quiere volverse el alma mater de la sociedad, debe abandonar las disquisiciones abstractas para atender a los hechos proporcionados por los centros de investigación. Y respondiendo a la prensa nacionalista que cuestionaba la incorporación de extranjeros, sostenía que también las universidades europeas y estadounidenses habían recurrido a profesores especializados en disciplinas científicas, y que en la Argentina esa tradición había sido iniciada por una figura de indiscutible prestigio como Sarmiento.

Sobre Goldschmidt, de la Torre precisaba que los cuestionamientos no tenían razón de ser, ya que era uno de los hombres más versados en economía y "su archivo de planos y gráficos, uno de los más nutridos de Alemania, si no el más, es fuente viviente, frecuentemente consultada para las deducciones científico-económicas". Desplegando una firme defensa -que abandonaría en octubre de 1922-, aclaraba que "lo han preocupado tanto los problemas de la antigua economía política como los de la hora presente, los problemas de la trustificación como los de la Rusia soviética, la situación del obrero con respecto al capital, como la explotación de la grande y la pequeña industria. Ha profesado la materia en una de las más altas escuelas de estudios de Berlín, la Berliner Lansing Hochschule, es director en la 
parte comercial del seminario de investigación de Leipzig" (De la Torre, 1921-1922: 16). Luego de este discurso, Nicolai pronunció la conferencia "La vida" y Goldschmidt “Economía del estado, social y mundial”, ambas reproducidas en los días sucesivos en La Voz del Interior (16, 17 y 18/05/1922) y poco después en la Revista de Filosofía y en el sexto número de la revista cordobesa Cátedra Universitaria (LVI, 05/09/1923). ${ }^{349}$

Además del rector, el decano de la Facultad de Derecho, Pedro S. Rovelli, y el Secretario General de la Universidad, Ernesto Deheza, salieron al cruce cuando el diario católico Los Principios difundió artículos que impugnaban la capacidad profesional de Goldschmidt. A esta defensa realizada por las autoridades de la UNC y que desde un comienzo formulaba La Voz del Interior y los grupos reformistas se sumaba desde Buenos Aires la FUA.

\section{La campaña estudiantil}

Como mencionamos, la Revista de Derecho y Ciencias Sociales del Centro de Estudiantes de Derecho de Córdoba también defendió a los nuevos científicos. Entre 1920 y 1922, esta publicación no sólo publicó apuntes de cátedra y noticias estudiantiles, sino que también emprendió una insistente difusión del marxismo y de los debates político-económicos que éste despertaba, al tiempo que buscó que la Reforma fuera asociada a una dimensión política que excediera la reforma de los estatutos para ligarse a una universidad científica y social. De ahí que no sorprenda que, además de difundir los discursos del acto de la FUC, declare en su editorial que los profesores alemanes "han llegado a nuestra casa, con el aplauso y el regocijo de la juventud embanderada en los ideales de la reforma universitaria. Hemos reconocido en ellos, no sólo a dos sabios profesores que traerán mejor ciencia al aula y al laboratorio, sino también, a dos valientes maestros del ideal". Luego recordaba que Goldschmidt es "un viejo luchador como Nicolai" y sostenía sobre los que lo acusaban de agente bolchevique: "la juventud reaccionaria y vesánica, que lucha solapadamente por reconquistar las posiciones perdidas el 18, ha lanzado sobre Goldschmidt, como lanzara antes sobre Ferri o sobre Palacios, toda la bilis de la maledicencia y la calumnia de su fariseísmo". 350

Ese número también reproducía el discurso de Edmundo Tolosa, entonces presidente

\footnotetext{
${ }^{349}$ Este semanario cultural es hoy inhallable, pero por una carta de su director, Francisco Jurado Padilla, conservada en el Fondo personal José Ingenieros, del CeDInCI, sabemos que existía al menos desde abril de 1921. Asimismo, por las referencias de $L V I$ sabemos que a mediados de 1923 continuaba editándose.

${ }^{350}$ La Dirección, "Nuestro saludo a Goldschmidt y Nicolai", Revista de Derecho y Ciencias Sociales del Centro de Estudiantes de Derecho, $\mathrm{n}^{\circ}$ 10, junio de 1922, pp. 5-6.
} 
de la FUC, durante el mencionado acto que organizó la Federación para recibir a los nuevos profesores y a Haya de la Torre. Asimismo, aparecía la primera entrega de un largo artículo de Goldschmidt, "La teoría de Carlos Marx", dedicado a aclarar algunas de las tesis que habían sido expuestas en las conferencias, entre ellas el carácter científico de la economía política y la condición judía de Marx. Ese número difundía además "El hambre en Rusia", una nota en la que el científico noruego Fridjof Nansen señalaba la importancia de que la Sociedad de las Naciones envíe su ayuda a Rusia. Si bien con ello se daba publicidad a la campaña que coordinaba la FUC desde mediados de 1921, también visibilizaba un problema que Goldschmidt se encargó de exponer en Argentina a través de sus clases, discursos y manifiestos.

Para el número siguiente, los jóvenes revisteros cordobeses contaron con una defensa de Nicolai y Goldschmidt firmada por Carlos Astrada, quien entonces tenía 38 años. Éste ofrecía un largo ensayo que comenzaba narrando la lucha de las "ideas" (científicas y ligadas a la justicia social) contra la "arcadia" de los doctores católicos, para luego advertir al movimiento reformista:

Un mal permanente exige una defensa también permanente, y, en nuestro caso, ésta no puede ser otra que la constante lucha para afirmar, en contra de los intentos del enemigo secular, los valores del espíritu. [...] Ha bastado que la Universidad incorpore a su docencia, honrándose, a los insignes maestros Nicolai y Goldschmidt para que el furor teológico-chauvinista haga sentir, mediante el chisme avieso y solapado, su hostilidad hacia estos dos hombres sabios y buenos. [...] Goldschmidt, gran economista cuya enseñanza, inspirada en la libertad de la ciencia, no tiene compromisos con la ideología del régimen imperante, y al rebelde profesor Nicolai, gloria de su raza y de la Humanidad; a Georg Friedrich Nicolai autor de La biología de la guerra, el libro más corrosivo de la bárbara ideología que santifica la matanza y la prepotencia, y de los preconceptos de un patriotismo liberticida (Carlos Astrada, "Nuestro Kulturkampf. Perspectivas de la Reforma Universitaria. La arcadia prehistórica", Revista de Derecho y Ciencias Sociales del Centro de Estudiantes de Derecho de Córdoba, no 11, julio de 1922, pp. 169).

El ingreso a la UNC de los científicos alemanes no podía ser pasada por alto por los reformistas porteños, que no lograban un amplio eco en las iniciativas izquierdistas. En efecto, ese ingreso ostraba una clara conquista de la identidad izquierdista que, en rivalidad con la FUBA, proponía la FUC y la FUA. Para que no quedaran dudas de sus simpatías con una identidad estudiantil hacia el sector izquierdista, Goldschmidt ofrecía a la FUA “¿Qué es 
la revolución?”, un breve texto que abrió el cuarto número del Boletín de la Federación Universitaria Argentina. Enfrentándose a los burgueses que se espantaban ante la revolución, el nuevo profesor declaraba que "vivimos porque la Revolución es. De la Revolución vivimos, sin ella no habría goce ni padecimiento, aspiración ni decadencia, ni avance ni tropiezo". Luego sintetizaba el programa revolucionario en "el derrocamiento de la nobleza, el derrumbamiento del imperialismo y el derroque del socialismo [bersteniano]", y realizaba una serie de señalamientos en los que no quedaba ninguna duda del tipo de enseñanzas que el científico alemán buscaba impartir en Argentina: Goldschmidt afirmaba que en Rusia había comenzado a realizarse el programa revolucionario, que el proletariado era su principal actor y que la revolución implicaba "la confluencia de los luchadores instintivos, para que del instinto de la masa surja la alianza consciente. [...] la lucha por la supresión de toda servidumbre, por la refundición de las pocas voluntades conscientes en una voluntad colectiva consciente, por la federación de las libertades humanas". 351

El número del Boletín también reproducía los discursos de bienvenida ofrecidos por los universitarios porteños a Nicolai, Goldschmidt y Haya de la Torre; y publicaba el manifiesto, redactado por el Comité pro hambrientos de Rusia, pero firmado por Goldschmidt, en el que se llamaba a los argentinos a colaborar contra el hambre en Rusia. ${ }^{352}$

Otra publicación estudiantil porteña que difundió ese manifiesto y saludó la llegada de los profesores alemanes fue la Revista Jurídica y de Ciencias Sociales. Órgano del Centro de Estudiantes de Derecho y Ciencias Sociales de Buenos Aires, dirigida entonces por una fracción empeñada en instalar una identidad izquierdista de la Reforma. Resaltando el perfil militante de Nicolai, una crónica anónima aparecida en la Revista Jurídica festejaba el arribo del "notable pensador alemán" y recordaba que las primeras noticias y comentarios sobre él habían arribado a la Argentina a través del sabio biólogo August Pi i Suñer. ${ }^{353}$ El cronista tomaba partido a favor de la construcción de una universidad científica y de perfil izquierdista y destacaba la convergencia entre conocimiento científico y compromiso político que distinguía al profesor "alemán” -definición sumamente significativa pues Nicolai era

\footnotetext{
${ }^{351}$ Alfons Goldschmidt, “¿Qué es la revolución?”, Boletín de la Federación Universitaria Argentina, nº 4, 1921 1922, pp. 3-4.

${ }^{352}$ En ese llamado, Goldschmidt sostenía que los argentinos debían mandar ayuda a Rusia para que no se repitiera "la indolencia que los hombres mostraron ante el espectáculo de millones de seres humanos que agonizaron en el campo de batalla" y, valiéndose de su formación económica, precisar las cifras de las últimas cosechas rusas. Goldschmidt, "El Hambre en Rusia. Un llamado a la conciencia argentina", Boletín de la Federación Universitaria Argentina, ${ }^{\circ}$ 4, 1921-1922, pp. 49-50.

${ }^{353}$ Éste había viajado a la Argentina en 1919 con el financiamiento de la JAE para ocupar la cátedra de cultura española que mantenía la Institución Cultural Española.
} 
cuestionado en Alemania por su pacificismo "antigermánico" y su condición judía-.

Se caracterizaba allí a Nicolai como un "profesor de cardiología en la Universidad de Berlín que acababa por aquel entonces de ganar celebridad, publicando en Zurich (1917) un libro incendiario, un libro demoledor, Die Biologie des Krieges, de gran estridencia en toda Europa y de insospechada eficacia impulsora para los fermentos iniciales de la revolución alemana". Y se precisaba:

Andando el tiempo le conocimos mejor, gracias a un estudio que Romain Rolland cedió a la revista Demain de Ginebra, donde perfila la extraordinaria personalidad de ese profesor alemán que por sobre sus dignidades académicas, su condición de médico de la emperatriz, sus éxitos mundanos y los halagos de un cuantioso caudal, no quiso ser cómplice de la matanza, y alzó voces contra el sometimiento de la inteligencia a la espada, contra la colaboración que la ciencia y el arte, presentaron al crimen universal de la guerra.

Como mencionamos, ese estudio de Rolland, El gran europeo Nicolai, circuló en la Argentina desde 1921 como un folleto dentro de la editorial Pax, que había diseñado el socialista internacionalista Augusto Bunge y dirigido Manuel Gálvez. El cronista presentaba a Nicolai a través de ese folleto: para no ser cómplice de la Gran Guerra, Nicolai

suscribió junto con Einstein, el astrónomo Foerster, una protesta rechazando las conclusiones del manifiesto servil de los 93, fulminando luego desde la cátedra, críticas tan violentas contra los mantenedores del pretorianismo universitario, que fue encerrado en la fortaleza de Gaudenz. Allí compuso los capítulos preliminares de La Biología de la Guerra, cuya edición significole una nueva condena y la censura inquisitorial, el acoso implacable de los junkers que lo desterraron al salir en libertad, por pacifista y que por judío, consiguieron expulsarlo de la cátedra, sobrevenida la paz.

Una formidable cultura ha servido de base al trabajo de Nicolai. Sus estudios enciclopédicos completados en Koenisberg, Heidelberg, Berlín, Leipzig y París, le dan autoridad, no sólo dentro de las especialidades médicas, sino también en antropología, en historia, en ciencias sociales, en filosofía, a parte de la aptitud para la observación, que agudizó andando el mundo [...] ("Jorge Federico Nicolai", Revista Jurídica y de Ciencias Sociales, año XXXIX, enero-mayo de 1922, p. 347).

La nota de los reformistas porteños proseguía con más precisiones y elogios a la biografía político-intelectual de Nicolai. Es que, como mencionamos, la llegada del profesor ofrecía al ala radicalizada de los reformistas porteños la oportunidad de prescribir el perfil que debían tener sus "maestros" y el naciente movimiento estudiantil, pero, al igual que en Córdoba, 
despertaba una fuerte reacción entre los sectores conservadores. La nota debía también desmentir las voces que desde la prensa cuestionaba la capacidad científica de Nicolai y asociaban su contratación a una elección netamente política de los reformistas cordobeses.

Para que los estudiantes porteños no tuvieran duda del partido a favor de Nicolai que debían tomar, el CE concluía declarándolo un "gran héroe civil" y deseaba que fuera "bienvenido a nuestra tierra abierta siempre a todas las empresas generosas y que su palabra caiga sobre los espíritus ansiosos, como rocío seminal en campo fértil" (idem: 349).

En cuanto a Goldschmidt, durante su breve estadía dictó en Córdoba el mencionado curso libre, una serie de conferencias sobre San Agustín y Santo Tomás y fue designado profesor interino en la cátedra de Economía Política para la carrera de Derecho. Además de dictar esos cursos en Córdoba, Goldschmidt pronunció conferencias de extensión ante los estudiantes de Santa Fe, La Plata y Buenos Aires. Específicamente, en septiembre de 1922 viajaba a la ciudad de Santa Fe para dar un ciclo de seis conferencias sobre economía política en la Facultad de Derecho -en la que el ateneísta y socialista Amílcar Razori era el vicedecano- y para disertar en el teatro Municipal, a beneficio de los hambrientos de Rusia, sobre las "Causas económicas de la Revolución Rusa". 354

En octubre de 1922, Goldschmidt regresó de urgencia a Alemania y la UNC designó nuevamente a Olmos en la cátedra de Economía política. Ese mes llegaba a la presidencia de la nación Alvear y los reformistas comenzaban a perder peso en las políticas universitarias, al punto que no pudieron lograr que Goldschmidt volviera a ser nombrado en la cátedra ni consiguieron evitar que en 1923 llegara a la UNC la intervención de Sagarna. Considerándose expulsado, Goldschmidt no regresó a Argentina. Sobre el asunto, Barros le aclaraba desde Friburgo a Bermann:

He leído las múltiples notas cambiadas con el Decano de Derecho y las encuentro indignas y más indignas todavía si es que el motivo de arrancarle la cátedra en vísperas de su venida para entregarla a ese infeliz de Lucas Olmos fue debida a miedo ante el nuevo Gobierno. Eso tenía que haber sacado a Goldschmidt de sus casillas mucho más después de las ovaciones alcanzadas en muchos puntos del país. [...] A Goldschmidt lo vi a su llegada pero después no sé nada más de él. Espero que escriba antes de irse a Méjico y entonces le haré llegar las cartas que Uds. le mandan (Carta de Barros a Bermann, 10/01/1923, Fondo documental sobre la Reforma Universitaria, Casa de la Reforma, Universidad Nacional de Córdoba).

\footnotetext{
354 "Conferencia del prof. Godlschmidt", Santa Fe, 22/09/1922, p. 1. "La primera conferencia del dr. Goldschmidt en la Facultad de Derecho", idem, p. 2.
} 
En su breve estadía argentina, Goldschmidt se entrevistó con el presidente Yrigoyen y conoció a José Vasconcelos, un contacto fundamental para que el alemán llegara en 1923 a la Universidad de México a dictar cursos similares a los impartidos en Argentina -cursos en los que Haya de la Torre, entre otro, haría su formación en economía política- y para establecer vínculos con los intelectuales comunistas mexicanos. ${ }^{355}$

Desde las páginas de Córdoba (1922-1925), otra de las publicaciones comprometidas con la fracción izquierdista de la Reforma, el mismo Goldschmidt sintetizó, en un artículo que envió desde Alemania y que apareció en cinco entregas, el contenido de los cursos que dictó al tiempo que precisó las tesis que decidieron a "clericalistas" y "pangermanistas" a iniciar una campaña para expulsarlo de la UNC. Por otra parte, si los reformistas no lograron reincorporarlo en la Universidad, ello no quitó que Goldschmidt continuara siendo durante los años siguientes una figura de referencia entre los grupos más radicalizado. Un interesante ejemplo de ello lo ofrece la Revista de Oriente. Órgano de la Asociación Amigos de Rusia, publicación vinculada a la ULA, dirigida por Orzábal Quintana y de un importante tiraje (sus números declararon 3.800 ejemplares). Cuando esa asociación edite, en junio de 1925, el primer número, reproducirá -junto a una elogiosa presentación de Goldschmidt- "La prostitución”, un fragmento de la conferencia que aquel había dictado el 4 de julio de 1922 en el curso de Economía Política en la UNC.

A fines de 1922, Palacios viajó a Montevideo a apoyar la formación de una Facultad de Filosofía y Letras. Poco antes del evento, el Consejo Central Universitario le niega al Centro de Estudiantes el salón Universidad. Centro Ariel publica un manifiesto y su órgano los telegramas que se cruzan el centro de Derecho y Palacios antes la noticia (ver Ariel $\mathrm{n}^{\mathrm{o}} 30$ 31, septiembre 1922)

El cambio en la correlación de fuerzas en la UNC a partir de 1923 obstaculizó los proyectos que los reformistas alentaban desde el Consejo Directivo de la Facultad de Derecho. Sobre esos avances y retrocesos, Palacios recordaba en el libro que publicó como síntesis reivindicatoria de su decanato en la Facultad de Ciencias Jurídicas de La Plata (1922-1925):

\footnotetext{
${ }^{355}$ Durante los tres años en que permanece en México, Goldschmidt entabla una importante relación con Diego de Rivera, al punto de que en 1925 ambos viajan juntos a Rusia e intentan instalar en la agenda del comunismo internacional la cuestión indígena azteca. Sobre la red mexicana aprista y la comunista, véase Melgar Bao (2012).
} 
La nueva generación destruyó las universidades fosilizadas. Vientos de renovación soplaron también en Buenos Aires y en La Plata. Hoy en los laboratorios de la Facultad de Medicina de Córdoba trabaja Nicolai, el maestro de renombre universal. La cátedra de Economía política, donde se seguía al padre Liberatore, fue ocupada transitoriamente, después de la Reforma, por Goldschmidt que habló de los grandes constructores que en Rusia creaban un nuevo derecho. Será necesario decir, no obstante esto, que la Universidad de la colonia se mantiene, conservadora y que su Facultad de Jurisprudencia resiste, todavía, los más modernos métodos (Palacios, 1925: 35)

Tres años después de la llegada de los profesores judeoalemanes, el primer diputado socialista de América -entonces distanciado del PS y "maestro" reformista- destacaba esa llegada, e incluso elegía la referencia a Goldschmidt para insinuar que así como en 1923 los reformistas no habían lograron su permanencia en la Facultad de Derecho cordobesa -ni la incorporación de Palacios como profesor titular en la Facultad equivalente de Buenos Aires-, en 1925 tampoco lograrían la permanencia de los modernos métodos y proyectos que su gestión -que finalizaba ese año- había introducido en la Facultad platense de Derecho.

\title{
La Facultad porteña de Derecho y la Reforma Universitaria
}

\begin{abstract}
La educación siempre en aumento de la masa ciudadana, exige a su vez en los elementos universitarios, una mayor preparación, para la mejor orientación de las todavía vagas preferencias idealistas del pueblo, y como única manera de gravitar en la fuerte corriente democrática, a la cual deben mezclarse sin pretensiones, para producir la conjunción de todos los elementos, por ahora disociados, $\mathrm{y}$ cimentar un sistema cuyas excelencias son peligros cuando no consagra el gobierno de los mejores.
\end{abstract}

Alberto Padilla, "La extensión universitaria", 1920.

La discusión disciplinar en torno del derecho que la Reforma Universitaria colocó en el centro se formuló en términos sumamente diferentes a los empleados en el debate filosófico. En la FFyL se discutió la relación de la filosofía con la ciencia y las fracciones disciplinares se tensaron entre cientificistas y antipositivistas, al tiempo que en una y otra fracción existieron diferentes posiciones políticas, esto es, hubo cientificistas socialistas -o más bien filocomunistas- como Bermann, Palcos e Ingenieros, pero también antipositivistas socialistas 
como Alejandro Korn, José Gabriel -y quienes en 1923 fundaron la revista Valoraciones-, y finalmente también existió una fracción de antipositivistas nacionalistas, en la que se destacaron Adolfo Korn Villafañe, Cossio y Juan Villoldo. En las tres facultades nacionales de derecho que existían en Argentina (la de Córdoba, la de Buenos Aires y la de La Plata), la discusión disciplinar también se dividió en tres amplias fracciones: quienes defendieron el código romano, consintiendo adecuaciones menores relativas a la sociedad moderna; quienes alentaron una revisión legal atenta a las condiciones nacionales y descreída de la posibilidad de una sociedad sin diferencias sociales y económicas; y quienes también bregaron por la revisión legal pero la justificaron en el desarrollo de un estudio científico de los problemas sociales contemporáneos, capaz de superar esas diferencias sociales y económicas.

Así, mientras que en la FFyL de Buenos Aires se registró, desde fines de la década del diez, una reacción "antipositivista", en la Facultad porteña de Derecho la reacción fue “nacionalista” o "positivista”. En términos de uno de los animadores de esta última:

El empirismo y la metafísica, arrojados de todas las demás ciencias físicas y naturales, propiamente dichas, se han refugiado y atrincherado -lo dijo ya De Greef- en esta última y formidable ciudadela, donde están los juristas, los legalistas, los políticos, fortaleza que no caerá sino cuando todas las ciencias sociales, comprendidos naturalmente, el derecho y la política, hayan adquirido de las ciencias antecedentes, las armas, es decir los métodos positivos que dieron la victoria a sus "hermanas mayores". Por eso en ninguna otra parte se ha resistido tanto a la Reforma, como en las Facultades de Derecho. Aun después del esfuerzo de la juventud, en Buenos Aires y en Córdoba sólo se ha implantado en lo que se refiere a sus aspectos externos (Palacios, 1925: 9).

Si bien en la UBA las modificaciones de los estatutos universitarios decretadas en agosto de 1918 se aplicaban sin mucho conflicto, la excepción sería la Facultad de Derecho. Como una prueba más consignemos que en la FFyL los tres decanos elegidos entre 1918 y 1930 concluyeron sus cuatro años de gestión mientras que en Derecho, sólo en los cinco años que van de 1918 a 1923, se sucedieron seis decanos y recién en 1923 se estabilizó la institución y un decano terminó su mandato.

Muchos de los que, en el marco de la Reforma, buscaron instalar "métodos positivos" en las facultades de derecho adhirieron a la Revolución Rusa. Sin duda, entre estos últimos se encontraron comunistas como Goldschmidt, pero también reformistas como Palacios, González, Sanguinetti y Sánchez Viamonte. Durante la década del veinte, los tres últimos se mantuvieron a distancia del PC y el PS -e incluso buscaron radicalizar al Partido Demócrata- 
Progresista a partir de la fundación de su Juventud-, simpatizaron con filosofías antipositivistas como la de Ortega, pero procuraron un derecho basado en la ciencia y adhirieron a la Revolución Rusa en tanto identificaban en ella la instalación de un orden legal científico que solucionaría la injusticia económica y social. ${ }^{356}$ Para alentar la introducción de los métodos científicos, desde 1923 jóvenes graduados ligados a Florentino Sanguinetti (1893-1975) se propusieron -y consiguieron ser elegidos- como representantes estudiantiles en el Consejo Directivo de la Facultad porteña de Derecho.

Pero antes de asumir esos cargos, se producía en la Facultad un evento significativo para comprender la cultura política de la Reforma: el decanato que, entre junio de 1921 y marzo de 1923, encabezó Mario Sáenz (1879-1943). Este profesor, que había sido funcionario del gobierno de Sáenz Peña y en la década siguiente sería diputado radical, estuvo vinculado al Ateneo de Estudiantes Universitarios ${ }^{357}$ y hasta 1930 fue el único decano reformista de la Facultad de Derecho. Según veremos, la impronta renovadora -ligada al cientificismo y a la izquierda- de su gestión se advierte no sólo en las reivindicaciones del grupo estudiantil que lo apoyó, sino también en el perfil que adquirieron los cursos de Extensión Universitaria y la Revista de la Facultad de Derecho y Ciencias Sociales. Órgano del Centro de Estudiantes de Derecho y Ciencias Sociales, así como en la iniciativa de fundar un Ateneo Universitario y un Consultorio Jurídico Gratuito dedicado a asuntos de interés general.

En octubre de 1918 había asumido como decano de la Facultad de Derecho Estanislao S. Zeballos. Según los estudiantes, ese político conservador que en 1919 lideró la Liga Patriótica había sido elegido bajo unos estatutos que seguían reservando el poder de decisión a los profesores titulares. Los reclamos estudiantiles motivaron que el Rectorado formara una comisión investigadora, la que en enero de 1919 confirmó a Zeballos en su cargo. Al poco tiempo, se producía un nuevo reclamo estudiantil, ante el que Zeballos denunciaba judicialmente al CE y a Korn Villafañe, pero el decano no podía evitar la presentación de su renuncia. En octubre era designado como decano interventor Ernesto Quesada, quien dispuso

\footnotetext{
${ }^{356}$ Respecto del pensamiento jurídico de Sánchez Viamonte contamos con la detallada reconstrucción de Herrera (2001). El autor muestra que, en consonancia con Palacios, aquel asignaba un papel decisivo a la economía y sostenía que la lucha de clases era el motor de la historia. En ese sentido era "marxista", pero en tanto apostaba a un cambio progresivo, guiado por una revisión de las leyes, sostenía un "socialismo jurídico" que identificaba el derecho como el cauce necesario de circulación de la justicia. Seguramente, esa caracterización también pueda extenderse a González y Sanguinetti. Sobre el itinerario político-intelectual de los dos primeros, véase Tarcus (2007a).

357 Como mencionamos, en 1917 Mario Sáenz pronunció para los jóvenes del Ateneo una conferencia sobre "la misión de la juventud" en la que alentaba dos núcleos centrales de la Reforma: la mejora de la calidad académica de las casas de estudio y la vinculación de los estudiantes con la juventud que no ingresa a la universidad.
} 
las elecciones de abril de 1920 en las que ganó Leopoldo Melo (como una muestra del peso que tenía ocupar ese decanato, recordemos que Melo era por entonces un referente de la UCR antipersonalista y en 1928 se presentó como candidato a presidente nacional en representación de esa corriente). Melo renunció a los pocos meses, y luego de las nuevas elecciones de junio de 1921, asumía Mario Sáenz.

Durante casi dos años, la gestión de Sáenz instaló muchas de las reivindicaciones reformistas pero la presión de las fracciones antirreformistas se hizo más fuertes a partir de la presidencia de Alvear y en marzo de 1923 Sáenz renunció, quedando como decano provisorio Francisco Oliver. Las nuevas elecciones se realizaron en noviembre de 1923 y erigieron como decano, contra la candidatura de Palacios (un candidato-testigo pues entonces era decano de la Facultad platense de Derecho), a Ramón Castillo, el primer decano que logró terminar el mandato y poner a su sucesor, Juan Ramos. ${ }^{358}$

Los materiales conservados en el Fondo personal Florentino Sanguinetti del CeDInCI muestran que Sáenz llegaba al decanato con el apoyo tanto de un grupo de profesores "liberales", entre los que se encontraban Palacios, Rafael Bielsa, Juan Carlos Rébora y Ricardo Levene (decano de la Facultad de Humanidades de La Plata entre 1920 y 1923 y entre 1926 y 1930), como de algunos estudiantes, entre los que se destacaba Florentino Sanguinetti, quien en octubre de 1921 ingresó, por primera vez, como consejero estudiantil en el Consejo Directivo de la Facultad. ${ }^{359}$

Nacido en Rosario en 1893, Sanguinetti pertenecía a una familia de comerciantes genoveses, cursó estudios secundarios en el Colegio Nacional de Rosario junto a jóvenes que se destacarían en la escena cultural y política argentina, como Amadeo Sabattini, Enzo Bordabehere, Saúl Taborda y Juan Lazarte. Ya egresado, Sanguinetti llegó a Buenos Aires en 1916 para estudiar Derecho y se vinculó al Partido Demócrata-Progresista. A partir de las cartas conservadas en su fondo personal, sabemos que, al igual que del Mazo y otros líderes

\footnotetext{
${ }^{358}$ Éste asumiría en noviembre de 1927 ganando la elección frente al candidato apoyado por los estudiantes Juan Carlos Rebora. Los siguientes decanos fueron: en diciembre de 1929 Ricardo Rojas y en julio de 1930 Alfredo Palacios. Luego del golpe de Estado de septiembre de 1930, se sucedieron los siguientes decanos: en setiembre Ángel Casares; en octubre Ramón Méndez; en noviembre Enrique Butty; y en diciembre Carlos Rodríguez Egaña. En 1931 asumió Clodomiro Zavalía, quien al igual que su sucesor Agustín Matienzo, lograría concluir los cuatro años de gestión. Tomamos los datos de los números de la Revista de la Universidad correspondientes a esas fechas y de Ortiz (2004).

${ }^{359}$ Entre los materiales del Fondo personal Florentino Sanguinetti del CeDInCI se encuentra el folleto con los discursos de apertura de los cursos del año 1922, allí figuran conformando la gestión de Sáenz: como vicedecano Vicente C. Gallo; como consejeros Esteban Lamadrid, Jesús H. Paz, Héctor Lafalleille, Raymundo Salvat, Agustín Pestalardo, Tomás Arias, Juan José Díaz Arana, Mariano de Vedia y Mitre, Santiago Baqué, Osvaldo Rocha, José María Monner Sans, Leonidas Anastasi y Florentino V. Sanguinetti (el único que aún no era doctor); y José A. Quirno Costa como secretario.
} 
reformistas, el Ateneo fue la primera instancia estudiantil en la que participó. Seguramente, haya conocido al líder del Ateneo, que era tres años menor que Sanguinetti, en la Facultad. En una de las pocas cartas que se conservan entre ambos, Monner Sans interpela a quien sería su entrañable amigo:

Necesitamos en Ideas que Ud. escriba, ya sea en "Art. oficiales", ya en las diversas secciones de la rev. El n ${ }^{\circ} 14$ se cierra, más o menos, el 15 noviembre. ¿Qué le pareció el $\mathrm{n}^{\mathrm{o}} 13$ ?

Hay que ser socio dinámico, superior categoría de los activos. El Ateneo necesita que Ud. lo ayude. Escriba.

Aguardo su respuesta (Carta de José María Monner Sans a Florentino Sanguinetti, Buenos Aires, s/d, octubre de 1917 aprox, Fondo documental sobre la Reforma Universitaria, Casa de la Reforma, Universidad Nacional de Córdoba; destacado en el texto).

La insistente convocatoria de Monner Sans no logró hacer de Sanguinetti un "socio dinámico", pues sólo colaboró con dos notas. Pero a partir de entonces los jóvenes tejieron una prolongada amistad ${ }^{360}$ y una vez iniciada la Reforma participaron juntos del intento de que ésta alcanzara a la Facultad de Derecho. Monner Sans egresó de la Facultad en marzo de 1920. Mientras el Ateneo se dispersaba, Monner Sans asumía como profesor suplente en la Facultad de Derecho y en la FFyL, además trabajaba como profesor en el Colegio Belgrano y tenía un estudio jurídico. Por su parte, Sanguinetti continuaba estudiando y se volvía uno de los principales referentes de la fracción de "izquierda dieciochesca" de la Facultad de Derecho, en la que participó Monner Sans y a la que en 1923 se sumaron los graduados platenses Julio V. González (1899-1955) y Carlos Sánchez Viamonte (1892-1972).

\section{Reformistas nacionalistas versus reformistas izquierdistas}

Recordemos que con el estallido de la Reforma se configuraron en la Facultad de Derecho dos grupos estudiantiles que se declaraban reformistas: el nucleado en torno de la revista Themis e identificado con las fracciones simpatizantes del socialismo -o que, más concretamente, no veía en los bolcheviques y las simpatías obreras la amenaza del caos social sino la evidencia

\footnotetext{
${ }^{360}$ La correspondencia inédita conservada en el Fondo personal Florentino Sanguinetti del CeDInCI muestra que esa amistad fue tan estrecha que, cuando en marzo de 1921 Sanguinetti se recibió de abogado y no conseguía un cargo universitario o estatal por su militancia estudiantil, Monner Sans le hizo un lugar en su estudio jurídico para que comenzara a ejercer la profesión (allí permanecieron juntos hasta que en 1925 Monner Sans buscó un estudio más grande). Asimismo, cuando en enero de 1923 Monner Sans se casó, Sanguinetti fue el encargado de recolectar el dinero entre los amigos para regalarle los muebles del escritorio y de organizar la cena en homenaje. A través de esas cartas, también sabemos que fue Sanguinetti quien a fines de 1917 puso a Monner Sans en contacto con Pallares Acebal, quien, como mencionamos, publicó a comienzos de 1919 en Ideas una nota sumamente crítica del Colegio Novecentista.
} 
de que debían realizarse importantes reformas jurídicas y sociales-, por un lado, y el grupo nacionalista de la Revista Nacional, que en 1919 fundó Unión Universitaria y tendría durante toda la década del veinte a Korn Villafañe como su líder, por el otro. Desaparecida Themis y alejado Muñoz Montoro de la Facultad, quienes lideraron una prédica reformista afín fueron los jóvenes graduados Sanguinetti, González y Sánchez Viamonte. ${ }^{361}$ Veremos en el siguiente capítulo que en 1923 intentaron erigirse, desde esa afinidad reformista e izquierdista, en la Juventud del Partido Demócrata-Progresista; en 1924 participaron junto a un grupo de estudiantes, de la fundación del grupo de la Facultad de Derecho "Partido Unión Reformista", desde el que propusieron la candidatura-testigo de Palacios a decano; y en 1925 dejaron ese grupo para crear el Partido Unión Reformista Centro-Izquierda, que en 1926 conseguiría desplazar a la Unión Universitaria del CE.

En cuanto a los primeros años de la Reforma, los puntos de mayor divergencia entre los dos grupos "reformistas" fueron, por un lado, el cariz y la función de la extensión universitaria $y$, por el otro, el tipo de renovación de las teorías jurídicas. La Unión Universitaria aclaraba en sus "Bases generales" que se proponía continuar "en el camino de reformas iniciadas tan brillantemente por la Juventud de Córdoba, hasta conseguir la completa modernidad de nuestros institutos universitarios" y subrayaba que la Unión

contribuirá con todos sus esfuerzos a dar a la Reforma Universitaria su pleno alcance y desenvolvimiento y su efectivo cumplimiento. La juventud debe de tener muy en cuenta la acción de los que bajo el rótulo de Reformistas de la Reforma tratan de contenerla en los viejos moldes. La Unión Universitaria cree que la Reforma es una definitiva conquista de la Juventud progresista y que la labor de construcción meditada y mesurada que la hora presente impone debe tener por base los altos principios que en ella se proclamaron y sustentaron ("Bases Generales del Partido Unión Universitaria", Fondo personal Florentino Sanguinetti, CeDInCI).

Esa "construcción meditada y mesurada" cambiaba el año 1918 por 1919, al tiempo que se

\footnotetext{
${ }^{361}$ En el Fondo personal Florentino Sanguinetti del CeDInCI se conserva el borrador de una caricatura a Korn Villafañe -sin duda, elaborada en 1920 por el grupo de Sanguinetti para criticar la interpretación de la Semana Trágica difundida por aquel-. En el centro, aparece Korn Villafañe con garras, adornado de billetes, dándole la espalda a un cuervo y a un grupo de judíos que lo acusan y tienen a sus pies la frase: "Dios destruye el hogar de los perversos". Asimismo, en los bordes fueron dibujados supuestos recortes de prensa con anuncios de Korn Villafañe. El del diario La Nación es ilegible. En el de La Prensa sólo se lee "Conferencia del Dr Korn Villafañe". Y el de Crítica sostiene: "POLICÍA. Anoche fue detenido el crápula conocido como rey de los judíos prestamistas de alcaloides el sujeto pica pleito. Korn Villafañe”, y al lado la agrupación estudiantil aconseja: "Amigo: todo esto le parecerá a Usted una broma ¿no? Todo, todo será una realidad”. Una reproducción de esa caricatura puede encontrarse en la sección "Documentos" de Los trabajos y los días, no 3, noviembre de 1912, p. 120.
} 
asociaba, a través de las notas y el libro 1919 de Korn Villafañe, a un antipositivismo kantiano y al reemplazo del Código Civil por una legislación anclada en características nacionalistas y corporativistas. Una de las figuras mayores que apoyó al grupo fue Carlos Saavedra Lamas, profesor entonces de Legislación industrial. Frente a esa meditación y mesura, Sanguinetti y su grupo procuraron, en sintonía con la universidad social y científica de los reformistas cordobeses, una Reforma concentrada no en los rasgos nacionales, sino en la solución de la injusticia social que se registraba en todos los países capitalistas. Más precisamente, los reformistas con los que competía la Unión impulsaban una "modernización” o adecuación científica de la legislación según el desarrollo capitalista y atenta al riesgo de trabajo y a la "cuestión social". Esa modernización los filiaba al amplio frente de "cultura liberal" de la Reforma, así como a figuras que -como Palacios y Sáenz- rivalizaban explícitamente con Saavedra Lamas. En 1919 los reformistas ligados a Sanguinetti promovieron a Sáenz para que dictara un curso sobre "La posición didáctica de la filosofía del derecho en la enseñanza universitaria y en la vida" dedicado a mostrar que "la idea del derecho presupone la existencia social". Al año siguiente, Palacios impartió un curso libre de "Legislación del Trabajo", compuesto de tres conferencias en las que también instalaba la vinculación entre derecho y sociedad moderna, pero en este caso se sostenía que la legislación laboral debía basarse en investigaciones experimentales realizadas a obreros a partir de los modernos principios de la psicología experimental. ${ }^{362}$

Los reformistas vinculados a Sanguinetti lograrían que Sáenz fuera elegido como decano, al menos por un breve período. En cambio, no conseguían que Palacios tuviera una cátedra titular desde la que llevar a cabo esas investigaciones, las que, de todos modos, realizaría desde la cátedra de Legislación industrial -rival a la de Saavedra Lamas- que conseguía en la Facultad de Ciencias Económicas de Buenos Aires y, entre 1922 y 1925, desde su decanato en la Facultad platense de Derecho. ${ }^{363}$

\footnotetext{
${ }^{362}$ La conferencia inaugural de Sáenz y las tres conferencias de Palacios fueron publicadas en los Anales de la Facultad de Derecho y como separata por la editorial Coni. Asimismo, en 1920 Palacios publicó una versión ampliada del texto en la editorial Claridad bajo el título El Nuevo Derecho: legislación del trabajo.

363 En 1922 Palacios publicó, bajo el título La fatiga y sus proyecciones sociales, las investigaciones experimentales realizadas, en el marco de la mencionada cátedra, entre los obreros metalúrgicos del barrio de La Boca. A su vez, en 1925 editó los proyectos desplegados en su gestión junto a una exposición de las tesis que los sustentaban, primero como un número de la revista institucional de la Facultad de Derecho de La Plata y luego como un libro titulado La Universidad Nueva. Sobre estos desarrollos y el prestigio que ya había acumulado entre los reformistas, véase Graciano (2008: 91-111). Respecto de la mayor apertura que se registró en la Facultad de Ciencias Económicas de Buenos Aires frente a la de Derecho, no existe aún un análisis detenido sobre el tema. Mencionemos, al menos, que esa apertura estaba ligada a que, como había sido fundada hacía pocos años, la Facultad de Ciencias Económicas no era un espacio de prestigio y de formación ideológica disputado por la elite política desplazada por el yrigoyenismo. Una clara prueba de ello es que, mientras Sáenz
} 
Por su parte, a través de Korn Villafañe, la Unión Reformista proponía una interesante apropiación nacionalista de la iniciativa de reforma laboral impulsada por Palacios. En diciembre de 1921, aquel presentaba el ensayo "El idealismo y el nacionalismo como bases de un derecho administrativo", para acceder al grado de doctor en Jurisprudencia y, al año siguiente, lo publicaba en una edición privada, bajo el elocuente título Los derechos proletarios: ensayo novecentista. ${ }^{364}$

Las treinta páginas que componen la tesis proponen una revisión filosófica de los regímenes políticos argentinos desde el combate entre "el alma cosmopolita de Buenos Aires" y el "alma nacional de las provincias". Desarrollando tópicos que serán centrales en el revisionismo histórico, Korn Villafañe destaca allí "la figura gigantesca de don Juan Manuel de Rosas" en tanto representante de un nacionalismo antiburgués que, a diferencia de la Generación liberal de Caseros, entendió la causa proletaria. Además, traza una oposición entre Ingenieros y Palacios que es sumamente significativa para entender la posición jurídica de estos reformistas nacionalistas y el diferente prestigio al que estaban asociados esos dos "maestros"de la Reforma. A pesar de que Palacios declara profundizar la obra liberal de Alberdi mientras que Korn Villafañe sostiene que se debe superar, éste señala en aquel a un "maestro de la Nueva Generación":

Es verdaderamente extraño que el ideal de muchos proletarios consista en llegar a ser pequeños burgueses. Marx, con su socialismo económico hizo la filosofía de esta paradojal posición proletaria. En nuestro país, el doctor Ingenieros es el representante intelectual de esta primera etapa -ya anacrónica- del socialismo económico. [...] Jaurès inicia en el socialismo una segunda etapa de porvenir incalculable. Nuevo Socialismo que ha hallado en nuestro medio intelectual su expresión jurídica en El nuevo derecho, publicado recientemente por un maestro de la Nueva Generación, el doctor Alfredo L. Palacios (Korn Villafañe, 1922: 1617).

Esa oposición entre Palacios e Ingenieros puede parecer artificiosa si se tiene en cuenta que en 1925, cuando Ingenieros logra fundar la ULA, alienta la designación de Palacios como su

en 1923 debió renunciar a su decanato en la Facultad de Derecho por la violenta presión de los profesores antirreformistas, dos años después asumía el decanato de la Facultad de Ciencias Económicas e impulsaba medidas reformistas similares a las que intentó en Derecho sin que se generara esa resistencia de los profesores.

${ }^{364}$ El libro se anunciaba como el tercer cuaderno novecentista, de una serie que estaría compuesta por los siguientes volúmenes: Cuaderno I, El irredimido (aparecido en 1918 por la editorial del Colegio Novecentista); Cuaderno II, Incipit vita nova (editado en 1920 por la Unión Universitaria y la Revista Nacional); Cuaderno III, Los derechos proletarios (de edición privada); y los volúmenes -aparentemente no publicados-: Cuaderno IV, Flor de fuego y Cuaderno V, El hijo del sol. 
presidente. Pero, por el contrario, la cita ofrece la clave para comprender la elección de Ingenieros. En efecto, el cuestionamiento que provocaba la radicalidad de las intervenciones de Ingenieros también lo advertimos en las reseñas de Probst y en las cartas en las que Ingenieros le refiere a su padre la intensa campaña en su contra que realizaba la prensa en 1919 -campaña a la que, en las décadas siguientes, se sumó la vertiente de la historiografía de la filosofía argentina conformada por Alberini y sus discípulos-. Por su parte, la mayor moderación y aceptación a la que estaba asociado el liderazgo de Palacios se advierte en que -a pesar de no poder acceder a una cátedra titular en Buenos Aires- lograba ser elegido como decano en la Facultad platense de Derecho. Y estas características sin duda fueron sopesadas por un entrenado organizador cultural como Ingenieros cuando proyectaba para la ULA no sólo una denuncia precisa y ampliamente difundida, sino también un perfil que pudiera ser recepcionado por amplios sectores sociales.

Volviendo al ensayo de Korn Villafañe, luego de desligar la reforma legislativa de Palacios del socialismo para ligarla al nacionalismo antipositivista, el joven saludaba la llegada de los soviet como el comienzo de una economía organizada por el Estado y sin propiedad privada, esto es, como la superación de un liberalismo burgués que "con su monstruoso minimum de gobierno" tiende a la anarquía. Pero también señalaba que la Reforma Universitaria tenía un alcance cristiano en tanto fuerza renovadora del orden económico, un alcance nacional en tanto lucha por "la protección acordada al proletariado obrero frente a las grandes empresas capitalistas" y un alcance jurídico en tanto preparación lenta y metódica de "los materiales científicos necesarios para la creación de nuevos instrumentos administrativos de una Nueva Justicia". Y el texto terminaba saludando la presidencia de Yrigoyen por su nacionalismo abierto a las tareas reformistas.

A pesar de reivindicar a Palacios, esta definición nacionalista de la Reforma estaba sumamente alejada de la que impulsaban -sin lograr desplegarla sólidamente en la Facultad de Derecho- el mismo Palacios, Sáenz y varios alumnos. En efecto, al asumir junto a Raymundo Salvat como consejero estudiantil en 1921 Sanguinetti declaraba que las "alternativas iniciales [de la Reforma] han dejado suponer a las gentes desprevenidas, que ella se reduce a un simple mecanismo electorarero. [...] debemos escoger los profesores entre aquellos que actualizan sus estudios, y hacen una exploración prolija en las inquietudes contemporáneas, manteniendo una manera de unidad vertebral en los rumbos de la enseñanza”. Y para criticar esa reducción del naciente movimiento estudianti Sanguinetti especificaba unas "inquietudes 
contemporáneas" sumamente alejadas a las enunciadas por Korn Villafañe y su grupo, que conviene citar in extenso:

[Las] responsabilidades [de la Facultad] crecen a medida que los problemas postguerra, entran en el terreno jurídico. Tocará, sin duda, a la generación de 1920, participar de los comienzos de una nueva edad humana. Siendo el derecho un fenómeno de creación social, debe seguir inevitablemente las transformaciones del momento histórico. A propósito de las dificultades promovidas por la aplicación de la ley sobre alquileres, se evidencia el misoneísmo panglosista en que vivía mucha gente, respecto a la verdadera crisis jurídico-social, porque atraviesa el mundo. Hay muestras de que en el desquiciamiento también se liquidaron viejas armaduras legales. Han quebrado igualmente muchos derechos que antes parecían axiomáticos y muchas normas seculares carecen ahora de contenido. Diversas fuerzas sociales justifican estas rectificaciones $o$ eliminaciones. La crisis económica que trajo la guerra continúa siendo el más enérgico factor revolucionario de la paz. A ella se suman, un afán de justicia exaltado por la violencia y el estrago, y un principio de solidaridad que la lucha universalizó, mientras debilitaba la soberanía de las naciones. Todo esto y mucho más, ha desmigajado el canon romanista de la propiedad imperio los códigos del interés particular, se corrigen cada día con leyes fragmentarias de interés colectivo, que preparan las bases de una nueva estructura jurídica [...] A la Facultad le corresponde dar un sistema de ideas crítico y revisionista, que injerte en el estudio de los fenómenos jurídico-sociales, las nuevas corrientes idealistas o reconstructoras. Sometidos a estos métodos, los estudiantes irán examinando las leyes escritas, abordarán su análisis sin prejuicios y podrán despegarse del mito legal (Sanguinetti, "Entrevista", s/d. Fondo personal Florentino Sanguinetti, CeDInCI).

Esta reubicación de la Facultad sería intentada por la gestión de Sáenz pero no llegaría a convencer a los estudiantes. En efecto, quien ganaba las elecciones de CE en mayo de 1920 era Eduardo Araujo, el candidato de la Unión Universitaria que también asumiría la presidencia de la FUA, y hasta 1926 la Unión conseguiría erigir a sus representantes -presentándose en varios de esos años como única lista estudiantil-. ${ }^{365}$ Lejos de esa preocupación social urgente que declaraba Sanguinetti, los volantes de campaña que el grupo repartió en 1919 ligaban el reformismo a un juvenilismo vanguardista. Se lee en los dos conservados en el Fondo personal Florentino Sanguinetti del CeDInCI:

\section{P. U. U.}

\footnotetext{
365 A partir de la reconstrucción que realizamos, sabemos que el sucesor de Araujo fue Jacinto Armando. En 1922 el CE estuvo presidido por Víctor J. Paulucci Cornejo, en 1923 por Pilades Dezzeo y en 1925 por Alfredo Taylor. Desde 1926, como mencionamos, el CE estuvo dirigido por el Partido Unión Reformista CentroIzquierda.
} 


\title{
SI Ud. PIENSA COMO SU ABUELO, NO VOTE POR LA Unión Universitaria
}

\author{
La Comisión de Propaganda
}

\section{P.U.U.}

Contra-reforma restauración y reacción son TRES expresiones distintas y UN SOLO Partido Blanco.

\author{
La Comisión de Propaganda
}

Bajo la dirección de Korn Villafañe, una comisión del CE organizó en mayo de 1919 la primera experiencia de extensión universitaria. Se dictaron entonces cursos de impronta nacionalista y antipositivista -y específicamente antimarxista- que, según el recuerdo de uno de los jóvenes identificados con el proyecto, prescindieron "de los centros populares sectarios, teniendo en cuenta el riesgo de desviación que implicaban". ${ }^{366}$ Estos cursos fueron inaugurados por Saavedra Lamas quien "se declaró partidario de la reforma universitaria, no en el sentido de los reglamentos de elecciones [...] sino en el sentido de la extensión universitaria, que había transformado las universidades de Oxfort y Cambridge [...] [con] institutos como el Ruskin College en que se vinculaban los estudiantes con los obreros, y se compenetraban en sus jugos recíprocos y sustancias fecundas, la Universidad y la vida exterior, la sociedad circundante". La Unión Universitaria reprodujo las declaraciones de Saavedra Lamas en un folleto que concluía que identificando los cursos como una "docencia social", "verdadera función de la Universidad Moderna", pues "abrió al pueblo las puertas de la Universidad" comprendiendo y sirviendo a la Reforma. ${ }^{367}$

Los jóvenes ligados a Sanguinetti también se preocuparon por la legislación obrera y por abrir la universidad al pueblo, pero sus cursos tuvieron una impronta izquierdista que no temía a los "centros populares sectarios". Asimismo, no buscaban la reciprocidad, sino que el objetivo era elevar el nivel cultural del pueblo como condición previa a un orden social más justo. En la citada entrevista, Sanguinetti declaraba que, además de adecuar el derecho a los nuevos tiempos, la Facultad tenía una función social "externa o sociológica":

Hasta 1918, el instituto vivía un régimen hermético y contemplativo. Daba cada año su cosecha de doctores, más o menos doctos, pero no devolvía ningún beneficio directo. Después de aquella fecha, algunos comprendieron que el pueblo

\footnotetext{
${ }^{366}$ Alejo M. Moris, "La extensión universitaria. Un aspecto de la Reforma", Revista Jurídica, $\mathrm{n}^{\circ}$ 4, mayo de 1926, p. 132.

${ }^{367}$ La Razón, 07/05/1919, reprod. en Folleto de la Unión Universitaria. Fondo personal Florentino Sanguinetti, CeDInCI.
} 
sostenía esa complicada máquina con sacrificios sin retribución [...]. Esta advertencia dio origen a los cursos gratuitos para obreros y empleados. Durante el último año se dictaron más de 200 conferencias en la Facultad y en locales obreros, especialmente sobre temas económicos, legislación obrera, sindicatos y las constituciones rusa (1918) y alemana (1919), asuntos ambos que atraían nutridos auditorios. [...] entrevemos la posibilidad de ensayar algunas instituciones del tipo inglés, como los "settlements", focos de acción social instalados en barrios proletarios con bibliotecas, conferencias, proyecciones, consultorios jurídicos (Sanguinetti, "Entrevista", s/d. Fondo personal Florentino Sanguinetti, CeDInCI). ${ }^{368}$

Esos cursos rivalizaban con los dictados por el CE y fueron en 1921 aprobados por el Consejo como parte de un programa de extensión universitaria compuesto por una comisión de estudiantes y profesores. En 1921 esa comisión estuvo presidida por Francisco Carreño y en 1922 por Sanguinetti. ${ }^{369}$ El único volante publicitario conservado promocionaba del siguiente modo los cursos:

Si Ud. se rompe una pierna mientras trabaja, tiene derecho a una indemnización ¿SABE CÓMO COBRARLA?

Si no lo sabe, asista a los CURSOS GRATUITOS que dictan los Estudiantes de Derecho y conocerá los medios que le concede la ley de accidentes de trabajo.

CENTRO DE ESTUDIANTES DE DERECHO COMISIÓN DE EXTENSIÓN UNIVERSITARIA Balcarce 278

El programa anunciaba una "enseñanza popular y gratuita en la Facultad y en locales obreros" y se legitimaba en una argumentación de clara impronta socialista y revolucionaria, que simpatizaba con la FORA. Declara la crónica que, buscando una Universidad Social, la

\footnotetext{
${ }^{368}$ Por una carta conservada en el Fondo personal Florentino Sanguinetti sabemos que las concurridas conferencias sobre legislación rusa y alemana fueron impartidas por Mariano de Vedia y Mitre, quien, a pesar de que luego sería intendente de Buenos Aires durante el gobierno de la "restauración conservador" de Agustín P. Justo, en los veinte era un firme aliado de los reformistas izquierdistas de Buenos Aires (Carta de Florentino Sanguinetti a la FULP, s/d. Fondo personal Florentino Sanguinetti, CeDInCI). Por otra parte, en ese Fondo pueden consultarse algunos de los afiches de promoción de los cursos. Uno de ellos anuncia: "La comisión de EXTENSIÓN UNIVERSITARIA, acepta pedidos para dictar en los locales obreros, conferencias sobre los siguientes temas: Nociones de Derecho Civil, Nociones de Derecho Penal, Nociones de Derecho Comercial, Nociones de Derecho Procesal, Nociones de Derecho Constitucional, Leyes Argentinas de Trabajo, Economía Social, Lg. Industrial y Obrera, Organización Municipal, Régimen de los Sindicatos. Temas especiales: Ideas económicas de los saintsimonianos argentinos: Echeverría; Alberdi y Sarmiento; La Revolución Rusa; Nueva Constitución de la República Alemana; Parlamento y Soviet; Organización del Trabajo en Rusia; la Nueva Constitución Rusa; Constitución Mejicana de 1917".

${ }^{369}$ En 1921 conformaron el cuerpo de vocales: Beltrán Benedit, Raúl González, Julio Dillón, E. Cabrera Relora y Eduardo L. Canedo. En 1922, los profesores Dres. Alejandro Ruzo y Fernando Cermesoni y los estudiantes Federico Moyano y Juan Antonio Villoldo (Carta del Decano de la Facultad de Derecho y Ciencias Sociales, Mario Sáenz, a Florentino Sanguinetti, Buenos Aires, 03/10/1922. Fondo personal Florentino Sanguinetti, CeDInCI).
} 
comisión envió

a cada una de las asociaciones obreras, centros de cultura y órganos de prensa la conveniencia de su apoyo, ya que [...] la miseria y el dolor son, sin duda, poderosos factores insurreccionales, pero sólo constituyen fuerzas primarias de arranque, no bastan para realizar un movimiento provechoso y duradero. En cambio, la reacción resultante de toda injusticia, lo que vale decir resultante de un conocimiento más denso del Derecho, acelera la evolución, y se alza, contra las iniquidades que violan la armonía social ("Notas del Centro", Revista Jurídica, enero-mayo de 1922, p. 333).

Esa convicción de que la difusión del derecho era la condición para un "movimiento provechoso y duradero" y con ello para acelerar la evolución hacia una sociedad más justa -como la que se estaría instalando en Rusia- era el punto de mayor confrontación con los reformistas nacionalistas.

Como es esperable, esos cursos que buscaban "organizar la reacción frente a la injusticia social" fueron inaugurados por el profesor más claramente identificado con una legislación laboral de signo socialista, Alfredo Palacios. Según el último texto citado, esa inauguración recibió el comentario elogioso de los diarios y las felicitaciones de los diversos centros obreros "siendo de subrayar entre ellas, la de la FORA. Solicitaron conferencias 53 centros obreros, las cuales fueron todas concedidas". ${ }^{370}$ Sobre la impronta de esos cursos unos apuntes conservados en el Fondo personal Florentino Sanguinetti muestran que la conferencia dictada por éste explicó y defendió la Revolución Rusa. Habría declarado el joven:

Según mi modo de ver particular, la forma de soviet está destinada a reemplazar al actual régimen parlamentario. En sustancia se trata de un nuevo sistema parlamentario en el cual a la representación cuantitativa suplanta la representación cualitativa. [...] A mí me parece también que es la forma específica de la representación socialista. Una sociedad socialista es ante todo una sociedad economica. Dentro de ella, todo elemento no económico es un parásito, es una fuerza nefasta. Al posturado igualitario de que el que no trabaja no come puede agregarse este otro, el que no trabaja no vota [...] Los rusos han creado una sociedad socialista, una sociedad económica, constituida por una sola clase: la trabajadora. De ahí que les parezca lógico y natural, quitar el voto a los que no trabajan y a los que viven del trabajo ajeno, de la explotación del hombre por el hombre. [...] ha sido la gran fuerza de ese gran movimiento emancipador (Manuscrito, Fondo personal Florentino Sanguinetti, CeDInCI; destacado en el texto).

370 "Notas del Centro", Revista Jurídica, enero-mayo de 1922, p. 333. 
En 1928 Andrés Alberto Carnevale, un estudiante del Partido Unión Reformista CentroIzquierda, recordaba esos cursos y declaraba que la voz de Sanguinetti "fue la primera que saliendo de las aulas, llegó hasta los suburbios de Buenos Aires a compenetrarse con la vida anónima del trabajador". ${ }^{371}$ Los cursos junto a la fundación de un Ateneo, la apertura de un Consultorio Jurídico y la redefinición de la Revista Jurídica y de Ciencias Sociales constituyeron los pilares en los que se apoyó y desplegó el intento de reformar la aristocrática Facultad porteña de Derecho.

\section{La llegada del reformismo a la gestión de la Facultad de Derecho}

El 28 de junio de 1921 Sanguinetti se encontró con una breve carta de un compañero de militancia reformista en la que éste le informaba: "Hoy salió tu nombramiento de Director de la Revista (te felicito y me felicito) y el de [Luis] Veneroni para el Ateneo". ${ }^{372}$ Esta institución asumía una tarea similar a la que había realizado hasta 1918 el Ateneo liderado por Monner Sans: se proponía difundir una cultura general, que excediera el profesionalismo, entre los estudiantes de Derecho. En 1921 esa difusión se tradujo en la organización de dos conferencias: el antiguo novecentista José Gabriel disertó sobre "El socialismo ante la guerra" y Olivera Lavié sobre "Pío Baroja". ${ }^{373}$ En 1922 el Ateneo parece no haber organizado ninguna actividad y con la salida de Sáenz seguramente se haya disuelto.

En cuanto a la Revista Jurídica y de Ciencias Sociales, ésta había sido fundada en 1889 por el Centro Jurídico de Buenos Aires y tuvo como director, hasta 1904, a Carlos O. Bunge. Junto a la Revista de Derecho, Historia y Letras (1898-1923) de Estanislao Zeballos, aquella constituyó la publicación periódica local más importante en lo relativo al derecho. Desde 1919 el CE se hizo cargo de la Revista Jurídica. Sanguinetti dirigió los dos voluminosos números editados durante el decanato de Sáenz, uno correspondiente a mayodiciembre de 1921 y el otro a enero-mayo de 1922. Los números anteriores e inmediatamente posteriores estuvieron a cargo de Jacinto Armando, quien pertenecía a Unión Universitaria y

\footnotetext{
${ }^{371}$ Carta de Andres Alberto Carnevale a Florentino Sanguinetti, Buenos Aires, 25/06/1928. Fondo personal Florentino Sanguinetti, CeDInCI. En 1923 Sanguinetti y González presentaron al Consejo Directivo otro proyecto de extensión universitaria que generaría una fuerte resistencia antirreformista, pues proponía utilizar como sostenimiento financiero los descuentos a los profesores por inasistencia, lo que ponía en cuestión las prolongadas y frecuentes licencia con goce de sueldo que venía aprobando el Consejo.

${ }^{372}$ Nota de "Pancho" (¿José Díaz Arana?) a Florentino Sanguinetti, Buenos Aires, 28/06/1921. Fondo personal Florentino Sanguinetti, CeDInCI. Lamentablemente, no hemos encontrado información sobre el itinerario político-intelectual de Veneroni, sabemos al menos que participó del Ateneo de Estudiantes Universitarios y que publicó algunas notas en Clarín.

${ }^{373}$ Ambas disertaciones fueron publicadas en la Revista Jurídica.
} 
en 1921 presidió el CE. En septiembre de 1922, cuando Armando volvió a dirigir la Revista Jurídica, la trasformó en una publicación de menos páginas, aparición mensual y más centrada en temas académicos que sociales y culturales.

Desde sus inicios, la Revista Jurídica se había propuesto la difusión de estudios sobre cuestiones legales. Bajo la dirección de Sanguinetti, además de publicar los apuntes de las cátedras, la revista difundió: información sobre la vida estudiantil; artículos sobre cuestiones culturales y políticas, provenientes o relativos a Spengler, Posada, Unamuno, Nicolai y d'Ors -e incluso reprodujo el mencionado manifiesto probolchevique "A los estudiantes e intelectuales de la América Latina" de Barbusse y France-; y notas sobre problemas sociales, cedidas por Palacios, Levene y Sáenz. Una muestra clara del tipo de impronta reformista que, en sintonía con el decanato de Mario Sáenz, buscaba instalar Sanguinetti la ofrece el siguiente anuncio:

Revista Jurídica y de Ciencias Sociales editará durante el año comprendido entre junio de 1921 y junio de 1922 números extraordinarios, donde se estudiarán con preferencia los siguientes temas: Centenario de la Universidad, la Reforma Universitaria, Sindicalismo, Estudio crítico del Proyecto de Código de Trabajo y las nuevas teorías sociales y jurídicas sobre el Estado. [...] SUSCRIBASE, y tendrá a mano múltiples elementos de estudio, e investigación sobre los problemas jurídicos y sociales de mayor actualidad, al propio tiempo que mantendrá su contacto con la vida universitaria y con el desenvolvimiento de la cultura contemporánea (Revista Jurídica y e Ciencias Sociales, nº, abril-marzo de 1921, $\mathrm{s} / \mathrm{d})$.

Esos números extraordinarios parecen no haberse editado, pero Sanguinetti consiguió instalar la discusión sobre el significado de la Reforma. Para ello diseñó una encuesta que envió tanto a figuras aliadas a la gestión como a opositores. Entre las respuestas publicadas figuran las de: José Arce, Jacinto Armando, Rómulo Cabrera, Daniel Facorro, Guillermo Garbarini, Tomás Jofre, José María Moner Sans, Agusto Moyano, Ernesto Nelson, Carlos Saavedra Lamas, Mario Sáenz y Clodomiro Zavalía. Además, en ese intento de despertar el interés por los estudios sociales, consiguió que Quesada lo autorizara a reproducir las conferencias sobre Spengler que entonces dictaba en la FFyL.

Por las cartas conservadas en su fondo personal, sabemos que Sanguinetti también buscó despertar ese interéssocial a través de colaboraciones de diversas figuras locales. A Saúl Taborda le pidió un artículo sobre la reforma educacional y éste le prometió "La universidad y el trabajo", un capítulo sobre la extensión universitaria que preparaba para su ensayo sobre la 
nueva conciencia histórica y la reforma educacional. ${ }^{374}$ A Pablo Santos Muñoz, quien había viajado a Lima con números de la revista y había conseguido nuevos suscriptores, ${ }^{375}$ le encargó una crónica sobre los sucesos universitarios del Perú de 1919 y de 1921. Santos Muñoz le envió una síntesis de los movimientos junto a una carta que aclara que buscó evitar partidismos políticos. ${ }^{376}$

Otro que respondió a la demanda de Sanguinetti fue José Belbey. Éste prometió una reseña de el texto sobre Moreno y la Revolución de Mayo que acababa de publicar Sanguinetti. La reseña sería escrita no "con la pretensión de hacer la crítica [...] sino en el sincero deseo de realizar cierta exégesis de las ideas madres o conclusiones a que llegue el libro, con el objeto de que los estudiantes que lean la revista puedan formarse una idea sobre la obra y el criterio que la inspira". ${ }^{377}$ Y también el profesor Rafael Bielsa envió desde Rosario la colaboración pedida por Sanguinetti, al tiempo que prometió impartir en julio de 1922 las conferencias que había acordado. ${ }^{378}$ Por otra parte, una carta de Jacinto Armando muestra que ese joven, a pesar de pertenecer a la Unión Universitaria, continuó participando en la elaboración de la revista y que ésta circuló por Perú y Montevideo causando "muy buena impresión". 379

A su vez, la carta del joven graduado venezolano Emiro Atencio confirma que algún ejemplar de la Revista Jurídica llegó a Caracas y fue recibido con interés. ${ }^{380} \mathrm{Y}$ otra carta de "Paz" (?) da cuenta de que circuló en Rosario a través del canje con la publicación del CE de Medicina de Rosario. ${ }^{381}$ Dos cartas de un estudiante apellidado "Basey" muestran que la

${ }^{374}$ Carta de Saúl Taborda a Florentino Sanguinetti, Unquillo, 23/09/21. Fondo personal Florentino Sanguinetti, CeDInCI.

${ }^{375}$ Uno de esos suscriptores fue Guillermo Romero, quien aclara que "la importancia de la publicación no puede ser discutida", que tiene "verdadero interés profesional en recibirla" y que gira dinero para la suscripción (Carta de Guillermo Romero a Florentino Sanguinetti, Lima, 16/12/1921. Fondo personal Florentino Sanguinetti, CeDInCI).

376 Se lee en la carta: "como las versiones que he podido recoger en Lima han sido muy contradictorias, no es imposible que en la mía se deslice algún involuntario error; creo innecesario advertirle que si incurro en alguna omisión ello se debe a esa misma discrepancia de informes, entre los cuales es muy difícil a veces, descubrir dónde está la verdad" (Carta de Santos Muñoz a Florentino Sanguinetti, Buenos Aires, 24/09/21. Fondo personal Florentino Sanguinetti, CeDInCI). Esta aclaración sugiere que, a diferencia de los grupos analizados en el capítulo anterior, en éste no estaba tan claramente precisada la afinidad política como para defender la versión de los conflictos estudiantiles difundida por los estudiantes radicalizados peruanos.

377 Carta de José Belbey a Florentino Sanguinetti, Buenos Aires, 27/12/1921. Fondo personal Florentino Sanguinetti, CeDInCI.

378 Carta de Rafael Bielsa a Florentino Sanguinetti, Rosario, 14/06/1922.

379 Carta de Jacinto Armando a Florentino Sanguinetti, Buenos Aires, ?/01/1922. Fondo personal Florentino Sanguinetti, CeDInCI.

380 Carta de Emiro Atencio a Florentino Sanguinetti, Caracas,09/03/1922 y 17/03/1922. Fondo personal Florentino Sanguinetti, CeDInCI.

${ }^{381}$ Carta de Gr. Paz a Florentino Sanguinetti, Rosario, 09/08/1921. Fondo personal Florentino Sanguinetti, CeDInCI. 
Federación Universitaria de Santa Fe no sólo recibía la Revista Jurídica, le buscaba suscriptores y la distribuía (los diez ejemplares "ya se han vendidos todos otra vez"), ${ }^{382}$ sino que además esa federación buscó imitar a sus pares porteños. En efecto, Basey le pide a Sanguinetti que le "mande una copia del reglamento del Consultorio Jurídico gratuito, y, si no es mucha molestia para Ud., le pido también me dé algunas ideas sobre esta institución. Nosotros organizaremos un consultorio gratuito -sobre la base del de Uds.- y quisiera que Ud. me favoreciera con sus luces". 383

Sobre el consultorio porteño -que sólo funcionó durante el decanato de Sáenz- los reformistas rosarinos sabían por la Revista Jurídica que atendía los días hábiles de 16 a 18 horas y tenía los siguientes doctores a cargo: Manuel F. Pascual, Florentino Sanguinetti, Lucio Aquerreta, Antonio Camarota, Herculano Oliver Saráchaga, Paulino di Benedetto, Bernardo Caushnir y Sansón Raskowsy. Asimismo, sabían que "desde el 29 de septiembre hasta el 9 de noviembre [de 1921] fueron atendidos 65 asuntos que dieron lugar a 77 consultas así distribuidas: ley de alquileres 47 , desalojos 8 , accidentes de trabajo 2 , nulidad de contratos 2 , cobro de fianza, inhibición, cobro de pesos, sociedad, etc, etc". ${ }^{384}$

A partir del primero de junio de 1922, esos reformistas porteños tuvieron dos nuevos aliados de cierto peso: Palacios asumía como decano de la Facultad de Derecho de La Plata y poco después fundaba la Revista de Ciencias Jurídicas y Sociales (1924-1925), la que en tanto se presentó como órgano oficial de la Facultad y, siguiendo los pilares del cogobierno estudiantil, tuvo una comisión directiva compuesta por un representante de la Facultad, uno del CE y un tercero del Centro de Egresados. ${ }^{385}$ Pero ni el apoyo de los estudiantes y profesores de la facultad porteña ni los aliados platenses fueron suficientes para que Sáenz se

\footnotetext{
${ }^{382}$ Carta de Basey a Florentino Sanguinetti, Santa Fe, 25/08/1921. Fondo personal Florentino Sanguinetti, CeDInCI.

${ }^{383}$ Carta de Basey a Florentino Sanguinetti, Santa Fe, 05/12/1921. Allí también se comenta que Razori, amigo de ambos, sería el candidato a decano de la Facultad de Ciencias Jurídicas y Sociales de la Universidad del Litoral. 384 "Notas del Centro", Revista Jurídica, enero-mayo de 1922, p. 339.

${ }^{385}$ El noveno número de esa revista consistió en la publicación del ensayo de Palacios Los nuevos métodos. Como mencionamos, Palacios publicó la justificación teórico-ideológica de su gestión bajo el título La Universidad Nueva (Palacios, 1925). Allí Palacios expone los proyectos educativos, basados en la observación y el experimento -y en tesis deterministas biológicas sobre el delito social-, que debería impulsar el movimiento reformista y que aquel desplegó durante su gestión, sobre todo a partir de la vinculación con las iniciativas relativas al delito social de Juan Vucetich. Asimismo, Palacios traza una historia de las universidades argentinas -centrada, de las facultades de derecho- y propone una definición de la Reforma filiada a la nueva generación y al programa alberdiano. Palacios adhiere explícitamente a la interpretación de la Reforma difundida por González desde 1923. A ella declara que le corregiría su distancia con el socialismo (recordemos que González fue elegido por Palacios como secretario de su gestión). Con esa corrección, Palacios se opone, de modo tácito, a la superación de Alberdi proclamada por Adolfo Korn Villafañe y la Unión Universitaria. La obra concluye anunciando la fe antiimperialista y la defensa de la democracia. Para un análisis de esa gestión, véase Graciano (2005 у 2008: 91-111).
} 
mantuviera como decano y los reformistas continuaran esos proyectos; y hacia 1923 las diversas iniciativas eran interrumpidas cuando, no pudiendo contrarrestar la violenta presión de la oposición, la gestión de Sáenz presentaba su renuncia.

\section{La salida de la gestión de Mario Sáenz}

Es imposible que la campaña
tendenciosa de los diarios "grandes",
pueda dar a Uds. noticias exactas de
los múltiples factores puestos en juego
para contener la resolución del consejo
en el asunto Q... C...
a de Florentino Sanguinetti a su madre, 1923.

A fines de 1922, el Consejo Directivo aprobaba tanto la creación de un Instituto de Enseñanza Práctica -con el que se intentaba establecer una plataforma institucional más sólida para los cursos de extensión- como un nuevo plan de estudios y doctorado. Esta plan se proponía reemplazar la primacía privatista y la interpretación literal de los códigos por la formación integral en ciencias sociales, y para ello se incorporaban las siguientes materias: Derecho político, Finanzas, Derecho constitucional argentino y comparado, Economía política, Filosofía del Derecho y Derecho público provincial y municipal (Sanguinetti, 2013).

Varios profesores titulares que pertenecían a la elite política y económica del país no sólo no se reconocieron en el perfil de ese plan ni en el que adquirieron los cursos de extensión y la publicación oficial de la facultad, sino que además intentaron frenar estas iniciativas. Con el paso de los meses, la presión contra la gestión fue cada vez más violenta y diversificada. El conflicto se agudizó cuando la gestión revisó la asistencia de la planta docente y pidió la renuncia de aquellos profesores que mantenían un prestigioso cargo y cobraban un sueldo, pero no impartían clases porque se encontraban ejerciendo funciones públicas o políticas.

El CE se sumó al grupo de profesores titulares a través de una campaña de desprestigio del decanato. Dando muestras del protagonismo de los estudiantes izquierdistas en la gestión de Sáenz, así como del fuerte enfrentamiento con los nacionalistas, uno de los volantes repartidos por el CE denunciaba: 
Un señor que responde al nombre de Sanguinetti, otro que dice llamarse Veneroni y un tercero a quien denominase Monner Sans, han votado la aceptación de la renuncia colectiva de los profesores más calificados de la Facultad en una sesión celebrada a altas horas de la noche al amparo de los sables policiales! ¡Perdonadlos, compañeros, porque son irresponsables, pero exigidles que se vayan de la Facultad! (Fondo personal Florentino Sanguinetti, CeDInCI).

Y otros volantes incriminaban:

El decano Doctor Mario Sáenz en defensa de la Reforma Universitaria designó a su hermano, sin título profesional ni capacidad técnica alguna, para desempeñar el puesto de Inspector en los trabajos de construcción del nuevo edificio de la calle Las Heras, con la insignificante retribución de cuatrocientos pesos mensuales (Idem).

La reforma universitaria es sagrada y no tienen derecho a medrar con ella los disfrazados de reformistas como el decano y sus secuaces (Idem).

Verdaderos Estudiantes:

Estrechad las filas en defensa de los principios de la VERDADERA REFORMA UNIVERSITARIA, manifestando vuestra adhesión al Centro de Estudiantes de Derecho y Ciencias Sociales, Florida 230.

¡No queremos inmorales! (Idem)

El Doctor Mario Sáenz, decano de la Facultad sin capacidad intelectual ni moral, es el culpable de la salida de los mejores profesores de la casa. ¿Recordáis al Profesor Eduardo Prayones? Recordáis la tentativa frustrada para expulsar de la Facultad al Doctor Carlos Ibarguren? (Idem).

A estas acusaciones y al hostigamiento que organizaron los profesores opositores, se sumó la quita del respaldo del gobierno nacional. Una nota aparecida en un periódico ligado a la gestión de Sáenz ofrece una minuciosa descripción del conflicto. Allí se sostiene que, siguiendo los renovados estatutos ligados a la Reforma, el Consejo Directivo

resolvió obligar a los profesores, que desde hacía años detentaban cátedras, las cobraban, pero no las dictaban o lo hacían a intervalos, a cumplir con su deber de docentes o a renunciar a sus cargos. En cualquier país del mundo la ética y la decencia indican que esto es lógico. Pero los eminentes maestros parecieron no entenderlo así y dictaminaron que había en la actitud del Decano, del Consejo y de los estudiantes una evidente falta de respecto, un acto de notoria y escandalosa indisciplina!

Y se insubordinaron contra la autoridad de la casa, ellos los disciplinados, los maestros del orden, y formaron una agrupación sediciosa, se negaron a integrar las mesas examinadoras y lanzaron aquella célebre renuncia colectiva, publicada por 
todos los diarios; dos o tres veces reiterada, aplazada y renovada, y que termina ahora, adueñados momentáneamente de la situación de la casa, por el empleo de uno de los ardides en que son prácticos por ser rechazada en sesión secreta!

Los postulados de la Reforma, la extensión universitaria, la asistencia libre, los cursos para obreros, el consultorio jurídico, son frases cuyo sentido ellos no alcanzan a comprender. [...] el núcleo estudiantil que los apoyó, ínfimo como expresión numérica, a pesar de su nombre de Liga Independiente, tiene en su comisión directiva a siete hijos de profesores (Recorte periodístico, s/d, Fondo personal Florentino Sanguinetti, CeDInCI).

En torno de esa disconformidad ante el pedido de renuncia, los opositores a la gestión de Sáenz se reunieron primero para publicar un manifiesto en el que acusaron al decano de ser "la escoria política, social y económica", y luego para comenzar una huelga de profesores en la que participaron, entre otros, Prayones e Ibarguren (los dos profesores defendidos por los volantes del CE), (?) Calatayud, (?) Jantus, Ramón Castillo, quien ganaría las próximas elecciones de decano, Juan Ramos, quien sucedería a Ramos, y Cloromido Zavalía, que sería decano entre 1931 y 1935 (Sanguinetti, 2013). En marzo de 1923, la gestión de Sáenz ya no pudo hacer frente a las presiones y renunció sin lograr un cambio significativo en la matriz con que se concebía el derecho y su relación con los problemas sociales.

Una vívida reconstrucción del tenor de la violencia en el marco de la que se produjo esa renuncia, pero también de la importancia del apoyo del gobierno nacional -cuya ausencia vimos que también frustró en 1923 las iniciativas de los reformistas cordobeses-, la ofrece Sanguinetti en una carta que envió a su madre -carta a la que pertenece el epígrafe del apartado-. En 1923 Sanguinetti debía convencer a sus padres del valor de esa militancia universitaria que lo llevaba a continuar dependiendo económicamente de su familia y a demorar su compromiso de casamiento (recién se casaría en 1927, a los 34 años). En las largas cartas que enviaba a su madre justificando esa doble demora, le informaba acerca de los avatares del movimiento estudiantil. En la fechada el 29 de marzo de 1923 explicaba que

Después de sostener durante un mes largo una lucha sin cuartel contra quienes quieren restaurar en la facultad de derecho el espíritu viejo, ayer a medio día, presentamos nuestra renuncia colectiva de los cargos [...]. Durante el conflicto recibí toda clase de amenazas y el asalto al local de la calle Victoria y Ceballos fue con el propósito de darme una paliza. Tenían gente asalariada y uno de los métodos del Dr. P...., es el terror. A mi socio Lartigau, lo asaltaron cerca de la facultad a donde acudía para acompañarme sabiéndome en peligro y le han golpeado malamente. A Monner Sans le apedrearon la casa y el decano ha tenido permanentemente un escuadrón de seguridad, custodiando la suya. Yo contaba 
siempre con la compañía de varios buenos amigos y entre ellos Ángel Luis que vive conmigo y que no me ha abandonado en ningún trance. Estaba también dispuesto a defenderme y así lo anticipé en una denuncia a la policía [...] el adversario conoce la fuerza de mis afectos entre los estudiantes y querían amilanarme para reducirme en la acción [... ] yo he trabajado allí con la convicción de que se puede mudar la orientación espiritual de los estudios e indicarlos dentro de los nuevos soplos que sacuden a la humanidad. Contra ello se han alzado los intereses de casta, de clase, de círculo [...] Deben Uds. saber que nuestra renuncia se resolvió a raíz del retiro de las fuerzas policiales que custodiaban la facultad, por orden del presidente de la república y a instancias de Leopoldo Melo (Sanguinetti, 2002: 30-31).

Sáenz, Sanguinetti, Monner Sans, Veneroni y otros perdieron la plataforma institucional para reformar la Facultad "dentro de los nuevos soplos que sacuden a la humanidad", pero no los decide a abandonas esa iniciativa. Con la salida de Sáenz, Francisco Oliver asumía como interventor disponiendo un nuevo estatuto que otorgaba voto -y no sólo voz- a los estudiantes, bajo el que se eligió en noviembre de 1923 al nuevo decano. En esas elecciones, los reformistas de izquierda se reunieron en el Partido Unión Reformista y propusieron a Palacios como decano, pero el triunfo fue para el futuro presidente nacional Ramón Castillo. Muchos profesores decidieron su voto a favor de Castillo por influencias, presiones y amenazas, denunciadas sin éxito por la Unión Reformista. Específicamente, ésta declaró que se había "recurrido a todos los procedimientos con el propósito de matar la reforma, lo que no se conseguirá, por cierto, porque todavía queda una fuerza sana, incontaminada, y esa fuerza es la juventud, que, a pesar de los malos ejemplos de sus maestros, se mantiene pura". ${ }^{386}$ Pero la gestión de Castillo lograría estabilizar el conflicto institucional, e incluso reducía el número de consejeros, consiguiendo, por primera vez luego del estallido de la Reforma, que en la Facultad de Derecho un decano concluya su mandato.

Desde 1923, Sáenz cambió de "escenario de acción": partió a España, donde se vinculó a grupos intelectuales republicanos, impartió algunas conferencias y sufrió la censura del régimen de Primo de Rivera; a su regreso, a fines de 1924, fue elegido decano de la Facultad de Ciencias Económicas. Sanguinetti continuó su militancia reformista en la Facultad de Derecho: en 1923 fue nuevamente elegido consejero estudiantil por un período de cuatro años. ${ }^{387}$ En esas elecciones también fueron elegidos otros tres consejeros estudiantiles: Manuel Rodríguez Ocampo, Julio V. González y Carlos Sánchez Viamonte. Los dos últimos

\footnotetext{
${ }^{386}$ Recorte periodístico, Fondo personal Florentino Sanguinetti, CeDInCI.

${ }^{387}$ Entre 1921 y 1953 y entre 1955 y 1966 Sanguinetti fue profesor del Colegio Central. Entre 1927 y 1943 , 1944 y 1946 y 1955 y 1966 fue profesor suplente en la Facultad de Derecho.
} 
serían importantes y prolongados aliados de la construcción reformista que habían comenzado Sanguinetti, Veneroni y Monner Sans.

Por su parte, Korn Villafañe, siguiendo un programa nacionalista afín al de su Unión Universitaria, fundó en 1923 junto a Carlos Cossio y Juan Antonio Villoldo el grupo Concordia. Sus miembros actuaron en lo que había subsistido del Ateneo fundado por Monner Sans -y del que éste ya no era parte-, llegaron a lanzar un manifiesto y, seguramente, presentaron una lista de consejeros estudiantiles. Pero no consiguieron erigir a ninguno de sus candidatos y rápidamente volvieron a reunirse en la Unión Universitaria (Cossio, 1927: 268$169) .^{388}$

\section{Los consejeros estudiantiles de la Unión Reformista}

A diferencia de Sanguinetti, González y Sánchez Viamonte eran egresados de Derecho de la UNLP y pertenecían a familias de la elite político-cultural. ${ }^{389}$ Cuando estalló la Reforma, González estaba terminando sus estudios y participó activamente de los grupos reformistas: además de asistir al Congreso Nacional de Estudiantes como delegado platense y de presentar el proyecto de "La casa del estudiante", en 1919 presidió la FUA y en 1922 fue secretario de la gestión de Palacios en la Facultad platense de Derecho. Al año siguiente, se vinculó a Sanguinetti y sumó a su amigo "Carloncho" Sánchez Viamonte. Éste era seis años mayor que González, se había recibido de abogado en 1914 y desde 1919 era profesor de Historia Universal y de Instrucción cívica en el Colegio Nacional de la UNLP.

Recuerda Sánchez Viamonte que González fue quien en 1923 lo visitó en su bufete

por objeto de obtener mi consentimiento para que el Centro de Estudiantes de Derecho de Buenos Aires sostuviese nuestra candidatura para consejeros de la Facultad. Los alumnos habían conversado con él al respecto y habían convenido que yo debía integrar el sector de la representación estudiantil en el Consejo. Era evidente que mi candidatura la había sugerido "Palito", como le llamábamos los amigos [...]. En los debates que debimos sostener en el Consejo Directivo de la Facultad de Derecho de Buenos Aires nos completábamos. Frecuentemente Julio V. González tomaba la iniciativa y se limitaba a pedirme que estuviera atento para la contrarréplica que, acaso, era mi fuerte. En un determinado momento me

\footnotetext{
${ }^{388}$ Una reproducción del manifiesto del grupo Concordia puede consultarse en Cossio (1923).

${ }^{389}$ Sánchez Viamonte provenía de una familia patricia asentada en La Plata y su padre había sido un destacado abogado constitucionalista. González era el hijo de Joaquín V. González, fundador y prolongado presidente de la UNLP. Como el resto de los proyecto presentados en el Congreso Nacional de Estudiantes, el de González fue reproducido por del Mazo (1927, t. III). Sobre el itinerario político-intelectual de ambos, véase Tarcus (2007a). Además sobre González, véase Kohan (2000) y Ciria y Sanguinetti (1968: 317-322).
} 
confesó: "Si no contara contigo para la contrarréplica, no me animaría a decir lo que necesito" (Sánchez Viamonte, 1971: 340-342). ${ }^{390}$

En las sesiones del Consejo Directivo, González, Sanguinetti y Sánchez Viamonte se dedicaron a rebatir con esmeradas argumentaciones las iniciativas antirreformistas y propusieron proyectos que las reemplazaran. Desde allí construyeron una jerarquía moral como conductores reformistas. En cuanto a esa figura de conductor, es elocuente otra carta de Sanguinetti a su madre en la que vuelve a justificar la demora en su casamiento:

Me censuran Uds y la gente ajena, mi intervención en los asuntos universitarios. Que pierdo tiempo, que no me rinde más, que me hago de enemigos. Y bien, me toma tiempo, dinero y salud, pero has de reconocer conmigo que es el camino necesario que debo seguir para triunfar. Que toda mi actuación gira en torno de un principio idealista que dignifica mi vida, agita mis inquietudes espirituales, y es la fuerza animadora de mi acción. [...] equivocados o no, sostenemos una esperanza de la nueva generación argentina, tenemos ideas claras, luchamos por ellas, necesitamos hasta de una vida virtuosa para oponerla como valor, al ataque de los intereses creados. Cuántas veces yo he podido aceptar canonjías y prebendas, que resolverían sin dudas mis dificultades, a cambio de una simple actitud pasiva. [...] Mi compañero González acaba de renunciar la secretaría de la Facultad de Derecho de La Plata y su cátedra de profesor suplente, por temor a que las nuevas autoridades puedan considerar que su posición administrativa le prive de la libertad de palabra y de crítica que usa en su cargo metropolitano. Y así, con sacrificio, pero con íntimas convicciones, vamos mostrando la jerarquía de los nuevos. [...] De mi cargo universitario, he ganado honores. Me conocen en América y me alcanzan las voces de muchos espíritus oprimidos o inquietos, por la gran ilusión que sopla el mundo (Carta de Florentino Sanguinetti a su madre, Buenos Aires, 08/06/1925; Sanguinetti, 60-62).

Para mostrar la "jerarquía de los nuevos", los consejeros prepararon -como lo venían haciendo los parlamentarios del PS- intervenciones que se asemejaban a declaraciones de principios, luego difundidas como parte del ideario reformista en artículos de diarios y revistas o editadas en publicaciones fundadas por ellos. Entre ellas se encontraron Unión Reformista. Órgano oficial del Partido Unión Reformista de la Facultad de Derecho y C. S., fundada en 1924 y

\footnotetext{
${ }^{390}$ En esas memorias, Sánchez Viamonte traza también un fuerte paralelismo entre el itinerario políticointelectual de ambos: "juntos fuimos dos veces consejeros de la Facultad de Derecho de Buenos Aires; simultáneamente fuimos nombrados profesores en el curso de ingreso de la Facultad de La Plata [durante el decanato de Palacios]. Casi simultáneamente ingresamos en el Partido Socialista en el año 1931; en el año 1940 resultamos candidatos a diputado nacional por ese Partido entre los cinco que luego resultaron elegidos por la minoría. Como candidatos iban juntos nuestros nombres y no nos separó la elección. Juntos fundamos la Revista de Humanidades "Sagitario" en La Plata y ambos hemos usado ese seudónimo en artículos periodísticos (Sánchez Viamonte, 1971: 342).
} 
reemplazada al año siguiente por Centro Izquierda. Órgano del Partido Reformista Centro Izquierda de la Facultad de Derecho y C. S. (1925-1933), la revista Sagitario (1925-1927) y tres libros publicados por la editorial vinculada a la revista -también llamada Sagitario-: Derecho político y Del Taller Universitario, ambos de Sánchez Viamonte, y La Reforma Universitaria de González. ${ }^{391}$

Cierta eficacia en esa difusión se advierte en la siguiente carta -de la que lamentablemente se ha conservado sólo la primera página-:

De mi mayor consideración:

Me he tomado la libertad de dirigirme al distinguido universitario para formularle una pregunta sobre asuntos que afectan a la Universidad del Litoral y en especial a la Facultad de Ingeniería de Rosario, de la que soy alumno. Habiendo ejercido la representación estudiantil ante el C. D. en el año $1922[\ldots]$ presenté un proyecto sobre las asistencias de profesores a clases y exámenes, imponiendo como pena el descuento a los sueldos que ingresarían a la Biblioteca. [...] Sabiendo que Ud. en compañía del Dr. Julio González presentaron en 1923, al C. D. de la F de Derecho, un proyecto de "E. Universitaria"; entre su articulado y como sostenimiento financiero, concurrían los descuentos a los profesores por inasistencia, es decir un fin tal loable (Carta de (?) [representante de la Federación Universitaria del Litoral] a Florentino Sanguinetti, Rosario, 5/12/1926. Fondo personal Florentino Sanguinetti, CeDInCI).

Otro de los proyectos fue la disposición en 1924 de un curso breve, impartido por Quesada, sobre las “doctrinas excitantes y dinámicas” de Spengler. La carta que Sanguinetti le envió a aquel ofrece una interesante confirmación tanto de la perseverancia en el intento de renovar la facultad como de los nulos logros alcanzados hasta entonces:

Hasta ahora la facultad ha ofrecido una enseñanza profesional, preferentemente jurídico-positiva, cuya creciente ineficacia agravan los métodos docentes en uso y la falta de categoría intelectual en la casi totalidad de sus profesores. Los hombres nuevos, interesados en los problemas que plantean, la crisis universal de la cultura y la crítica aplicada al ideario de la pre-guerra, aspiran a que la facultad retorne al cuidado de las disciplinas sociológicas, ofreciéndoles a sus alumnos, cursos breves sobre las doctrinas más promisorias en posibilidad (Carta de Ernesto Quesada a Florentino Sanguinetti, Buenos Aires, 27/03/1924. Fondo personal Florentino Sanguinetti, CeDInCI).

\footnotetext{
${ }^{391}$ Casi la totalidad de las trescientas páginas que componen el libro de González reproducen versiones taquigráficas de sus intervenciones en el Consejo Directivo. En cambio, Derecho político, aparecido en 1925, Del taller universitario, del año siguiente, se componen de discursos y notas relativos a la militancia reformista. Aparentemente, éstas fueron las únicas obras que publicó el sello Sagitario.
} 
Durante ese mandato, Sanguinetti, González y Sánchez Viamonte, junto a algunos líderes estudiantiles, consiguieron articular un grupo reformista, el Partido Unión Reformista, del que en 1925 se escindieron para formar el Partido Unión Reformista Centro Izquierda, que encabezó el joven estudiante Manuel Cruz. A los graduados reformistas pronto se sumó un antiguo miembro del grupo Justicia, Emilio Biagosch, quien en los años siguientes fu parte de los tres consejeros que no se cansaron de denunciar en la prensa estudiantil que la facultad era "un refugio de reaccionarios". ${ }^{392}$ Además, -como muestra la carta arriba citada- mantuvieron una red de apoyo y difusión de las actividades de los reformistas de las otras universidades. Otra prueba de esa red es el siguiente telegrama que recibió Sanguinetti: "Nuestro movimiento continúa en inmejorable estado. El domingo celebramos gran acto público. Le pedimos encarecidamente quiera contribuir a él. Contamos con Ud. Agradeceríamos invitase compañeros consejo y muchachos centro. No dejen de venir y comuniquen. Saludos". ${ }^{393}$

Hasta los conflictos de 1929, cuando fue brevemente erigido González como decano "revolucionario" de la Facultad de Derecho, la fracción izquierdista de la Reforma no pasó de la perseverante denuncia "ejemplar" en el Consejo Directivo y el CE. ${ }^{394}$ Si algo les había enseñado la frustrada experiencia de 1921-1923 era que el logro de sus reivindicaciones era difícil y necesitaba de la vinculaciones con grupos y proyectos que excedieran la facultad $-\mathrm{y}$ el país-. En efecto, así como entendieron que la extensión universitaria tenía sentido cuando se ligaba a sindicatos obreros que buscaban un orden social más justo, comprendieron que la intervención en el Consejo Directivo no valía por los proyectos de renovación de la universidad -que presentaban sin conseguir una traducción institucional- sino por la amplia propaganda que acompañaba a esa intervención y por la posibilidad de aunar la pertenencia al Consejo Directivo con la pertenencia a la ULA, el partido de intelectuales reformistas e izquierdistas que diseñó en 1925 Ingenieros y que presidió hasta su disgregación en 1930, Palacios. Y, como ya mencionamos, la ULA sería clave en la cultura política a la que quedaría

\footnotetext{
392 "La Facultad de Derecho es un refugio de reaccionarios", El Telégrafo, 24/02/1927, p. 5. Fondo personal Florentino Sanguinetti, CeDInCI. Otra nota conservada en el mismo archivo -escrita por un estudiante y publicada en la prensa, pero sin más datos- es un interesante ejemplo de la figura moral que construían los consejeros y sus referentes. Allí se narra la visita de los estudiantes a Palacios, entonces decano de la Facultad de Derecho de La Plata y llevado como candidato testigo del grupo de Sanguinetti en las elecciones porteñas de 1924. Lo primero que declara este "maestro de la juventud", al hacerse un tiempo para conceder una entrevista a la mañana siguiente de las elecciones, es que su fe en la Reforma sólo está en los estudiantes.

393 Telegrama de Del Castillo y Guevara a Florentino Sanguinetti, 18/09/1924, Fondo documental sobre la Reforma Universitaria, Casa de la Reforma, Universidad Nacional de Córdoba.

${ }^{394}$ Una prueba más de la condición ejemplar de esa labor en el Consejo la ofrece Julio Barcos. Éste dedicó el capítulo sobre las universidades del libro Cómo educa el estado a su hijo "a los doctores Florentino Sanguinetti, Emilio R. Biagosch, Carlos Sánchez Viamonte y Julio V. González, gallardos mantenedores de la Reforma en el seno del Consejo Universitario de la Capital".
} 
asociada la Reforma, cultura que implicó el reemplazo del entusiasmo bolchevique por un latinoamericanismo antiimperialista.

\title{
Cambios institucionales, cambios de fuerzas políticas
}

\author{
El alumnado reformista encabezado por Barros, \\ Deodoro Roca y otros más ha triunfado. Pero \\ las camarillas docentes derrotadas usarán una \\ táctica más peligrosa: se adaptarán. Simularán \\ amor a la Reforma y a la juventud estudiosa: \\ halagarán, confundirán, corromperán cuanto \\ puedan, para que sigan las cosas como antes \\ bajo una etiqueta nueva. Mientras tanto \\ esperarán su hora: 6 de septiembre de 1930. \\ Paulino González Alberdi, "En el 25 \\ aniversario de la Reforma Universitaria",
}

En este capítulo, propusimos concebir la visita de d'Ors, la llegada de Nicolai y Goldschmidt, y el decanato de Mario Sáenz como tres "eventos reformistas" que permiten iluminar la relación entre las afinidades político-intelectuales de grupos formados por profesores, jóvenes graduados y estudiantes, por un lado, y la inserción institucional de la Reforma, por el otro. A su vuelta a Lima en junio de 1922, el joven Haya de la Torre declaraba en la prensa peruana que en la Argentina había podido comprobar que no existía "ninguna sacudida más poderosa ni más eficaz que ese movimiento [reformista] que ha transformado el espíritu de maestros y estudiantes estableciendo una verdadera democracia universitaria" (del Mazo, 1927, t.VI: 149-150). El recorrido que propusimos en este capítulo sugiere que esas afirmaciones de Haya de la Torre eran más un modo de animar a sus pares peruanos que una descripción fiel de las iniciativas a las que se había vinculado. Y en 1923 sería evidente tanto que los importantes avances reformistas logrados entre 1918 y 1922 no habían sacudido la inercia de las universidades como que sus construcciones institucionales democráticas dependían de un frágil equilibrio de fuerzas que se quebraba con la reagrupación de los profesores y estudiantes y la llegada a la presidencia de Alvear.

Asimismo, nuestro recorrido sugiere que si bien Ortega fue la figura que funcionó como un referente reformista y propuso gran parte de la "gramática" del movimiento, la gravitación del filósofo madrileño encontró en cierta competencia con el magisterio que 
proyectaron d'Ors, Nicolai y Goldschmidt, así como con sus disímiles y disputadas "gramáticas".

A través de la lectura de cartas, reseñas y artículos en torno de la llegada de d'Ors, pusimos de relieve la tensión entre la "apropiación" del orsismo que intentó Ingenieros y la desplegada por la fracción nacionalista y/o antipositivista de la Reforma. Pero también esa lectura iluminó la impronta antipositivista y revolucionaria desde la que leyeron a d'Ors los cordobeses. Ello indica la existencia de dos planos que se solaparon y entraron en disputa en el movimiento reformista argentino, a saber, el plano filosófico -en el que se disputó el reemplazo del cientificismo por el antipositivismo- y el político -en el que la confrontación giró en torno de una afinidad nacionalista o una revolucionaria, simpatizante de la experiencia rusa-. Específicamente, la atención a las conferencias orsianas en Córdoba sugieren que ellas no pueden comprenderse si no se tiene en cuenta que la fracción de alumnos y profesores ligados a Deodoro Roca había conseguido un espacio en la UNC tal como para presionar y lograr que la institución financiara la llegada de un intelectual prestigioso que simpatizaba con el sindicalismo revolucionarismo.

Por su parte, las cartas de Barros a Bermann, así como las notas aparecidas en las revistas estudiantiles en torno de la contratación de los "revolucionarios" Nicolai y Goldschmidt muestran una trama similar. La inserción institucional de los profesores judeoalemanes no hubiera sido posible sin el espacio conquistado por los revolucionarios cordobeses, y con ello se descubre el modo en que la dimensión política estuvo fuertemente implicada con la institucional.

Finalmente, también la conservación de algunos archivos y fuentes -durante mucho tiempo consideradas “menores"- nos permitió revisar la inexplorada gestión de Sáenz en la Facultad porteña de Derecho y con ello descubrir una densa trama de relaciones institucionales y afinidades político-intelectuales. Tal como veremos en el capítulo siguiente, esta trama de relaciones opera como una primera red de sociabilidad sobre la que se construye la ULA y la definición latinoamericanista y antiimperialista de la Reforma. 


\title{
CAPÍTULO 8. La Reforma Universitaria como identidad antiimperialista latinoamericana (1923-1928)
}

\author{
No hay antirreformistas ni arreformistas, todo el \\ mundo es reformista, pues decirse en estos tiempos \\ "antirreformista" es cometer una estupidez tan gorda \\ como el llamarse públicamente "católico apostólico \\ romano". \\ Pero hay reformistas del predieciocho, del postdieciocho y del \\ dieciocho y that is the cuestion. \\ B. O., "Reformistas y reformistas", 1923.
}

A fines de 1926, aparecía en Buenos Aires el primero de los seis tomos de La Reforma Universitaria, la compilación -hasta la actualidad- más voluminosa y ambiciosa de fuentes sobre el movimiento continental reformista. Las casi dos mil páginas, que seleccionó y presentó del Mazo y financió el CE de Medicina de Buenos Aires, confirman la observación que el mismo año realizaba el joven Alfredo O'Connell y que resulta central para la presente investigación:

Desde el año 18 hasta aquí, la Reforma ha estado infinitamente más que en los actos oficiales de la Facultad y en las actividades y votaciones eleccionarias, en diversas manifestaciones individuales, o de pequeños grupos que, por el libro, por el artículo, la conferencia, o el estudio en común, han intentado la justificación filosófica de la Reforma, contribuyendo a darle significación propia en el mundo de la cultura (Alfredo O'Connell, "Anotaciones sobre la Reforma Universitaria", Revista Jurídica, $\mathrm{n}^{\circ}$ 4, enero-febrero de 1926, p. 125).

Pocos meses después, dos de los tomos de del Mazo llegaban a Lima y motivaban la aparición de una breve reseña en el octavo número de Amauta (fechado en abril de 1927) firmada por Manuel Vásquez Díaz, y de una nota, aparecida unos números después, proveniente de José Carlos Mariátegui. Éste comienza afirmando:

El movimiento estudiantil que se inició con la lucha de los estudiantes de Córdoba, por la reforma de la Universidad, señala el nacimiento de la nueva generación latinoamericana. La inteligente compilación de documentos de la Reforma Universitaria en la América Latina realizada por Gabriel del Mazo, cumpliendo un encargo de la Federación Universitaria de Buenos Aires, ofrece una serie de testimonios fehacientes de la unidad espiritual de este movimiento. [...] el anhelo de la reforma se presenta, con idénticos caracteres, en todas las universidades latinoamericanas. Los estudiantes de toda la América Latina, aunque movidos a la lucha por protestas peculiares de su propia vida, parecen 
hablar el mismo lenguaje (José Carlos Mariátegui, "La Reforma Universitaria", Amauta, $\mathrm{n}^{\circ}$ 12, febrero de 1928, p. 2).

Los diferentes grupos y publicaciones porteños que venimos rastreando -y los que analizaremos en el presente capítulo- sugieren que esos "testimonios fehacientes de la unidad espiritual" de la Reforma, que Mariátegui encontraba en la compilación, no primaron en las empresas estudiantiles registradas entre 1918 y 1923. Más bien, esos testimonios fueron el resultado de la apuesta latinoamericanista que, en rivalidad con otras, comenzaron a desplegar hacia 1923 algunos grupos en los que participaban Mariátegui, del Mazo, Ingenieros y otras figuras. Específicamente, desde 1918 un similar impulso democratizador de las casas de estudio se registró en distintas ciudades del continente, pero los jóvenes que se reunían para organizar ese impulso parecen no haberse sentido más unidos espiritualmente con el continente latinoamericano que con la lucha redentora internacional. Y a ello debemos sumar que en 1927 Mariátegui sabía muy bien que la unidad espiritual reformista que festejaba era sumamente frágil, pues estaba recorrida por la discrepancia sobre el antiimperialismo que mantenían los apristas y los socialistas, e incluso el mismo Mariátegui decidió, poco después, que esa discrepancia era irreconciliable. ${ }^{395}$

En el presente capítulo procuramos reconstruir, entonces, los grupos y las revistas que buscaron -y consiguieron hasta las luchas antifascistas que recorren la década del treinta- que la Reforma se identificara con un movimiento político-cultural que expresaba la "unidad espiritual latinoamericana". En los capítulos anteriores vimos que, entre 1919 y 1922, varios grupos y revistas realizaron el pasaje desde una intervención cultural "arielista" y un modelo de estudiante preocupado por su formación integral hasta una política referenciada en la Internacional del Pensamiento y en un estudiante preocupado por la unión obrero-estudiantil y una sociedad más justa. En este capítulo veremos que, a partir de cuestiones de diversa índole -como el reflujo del movimiento obrero, la impronta obrerista que adquiría el comunismo organizado, la vinculación con figuras y grupos ubicados en otras ciudades universitarias del continente y la llegada de estudiantes exiliados bolivianos, peruanos y chilenos-, la problemática imperialista del continente pasó a tener un peso central en una serie de grupos reformistas argentinos y, finalmente, en la cultura política ligada a la Reforma. Asimismo,

\footnotetext{
${ }^{395}$ Recordemos que, además de la fundación del Partido Socialista de Perú, un momento importante de esa ruptura es el saludo que realiza Mariátegui a “¿Qué es el ARPA?”, el célebre artículo del reformista cubano Julio Antonio Mella que apareció originariamente en México en 1928 y que se oponía al tipo de frente nacional propuesto, poco antes, por Haya de la Torre en “¿Qué es el APRA?”. Para un análisis de la ruptura de Mariátegui con Haya de la Torre, véase Beigel (2003), Bergel (2009) y Funes (2006).
} 
encontraremos que esa apuesta no impidió que se intentaran articular instancias políticas de alcance nacional. A diferencia de los estudiantes peruanos y cubanos, los argentinos no encontraron una plataforma sólida en un frente de masas ni en un partido político, sino en una red de intelectuales y estudiantes tramada entre el boletín Renovación (1923-1930), la ULA (1925-1930), la revista Sagitario (1925-1927), la revista Acción Universitaria (1924-1926) у su sucesora 1918 (1926-1927), la revista Inicial (1923-1927), la revista Cultura (1924-1926) y la Revista de Oriente (1925-1926). Disueltas esas instancias y producido el golpe de Estado de 1930, no primó en los animadores de esa red la apuesta por grupos intelectuales, sino el ingreso en las filas de los tres partidos de masas argentinos, el PS, el PC o la UCR.

\section{Los primeros intentos de proyectar políticamente el movimiento reformista argentino}

Los estudiosos sobre la Reforma Universitaria acuerdan en identificar la propuesta que realizó Julio V. González en 1927 de un Partido Nacional Reformista como el intento local más importante de otorgarle una traducción política al movimiento reformista argentino (Graciano, 2008; Kohan, 2000; Portantiero, 1978). Los mismos estudios señalan el fracaso de ese partido y el nuevo marco institucional y económico surgido en los treinta como los factores decisivos para que un número importante de líderes reformistas se sumasen a las filas del PS -y en menor medida a las del PC y de la UCR-.

Reconocido esto, las nuevas fuentes que relevamos sugieren que no fue una cuestión menor en la fundación del Partido Reformista Nacional la fuerte tensión interna que recorría a la ULA en 1927. Asimismo, debería atenderse a que el proyecto de González no fue el primero, sino que se inscribió en una serie de intentos de organizar una fuerza política nacional ligada al movimiento estudiantil de la Reforma. A esa serie pertenece la frustrada incorporación de los reformistas al Partido Demócrata-Progresista que promovió en 1923 el mismo González, así como las iniciativas que reseñamos a continuación.

Seguramente, el primer llamado a fundar una organización política argentina ligada a la Reforma sea la mencionada “Alianza de la Nueva Generación”, que proyectó en enero de 1919 Ricardo Rojas bajo lineamientos krausistas. Esta Alianza es un interesante índice tanto de la búsqueda de canales políticos asociados a la Reforma como de la tendencia de los intelectuales a participar en política desde instancias extrapartidarias. Sin embargo, permanece muy poco recordada por la bibliografía, seguramente por la adscripción posterior de Rojas al yrigoyenismo. 
Este "maestro de la juventud" mantuvo una compleja relación con el movimiento estudiantil, pues revistas como Ideas, los Cuadernos y Clarín lo consideraron un referente por la calidad de sus clases de literatura argentina y su preocupación por la cuestión nacional. Pero al menos la FUA, la FULP y sus publicaciones se enfrentaron a Rojas a fines de 1919, pues apoyó a Rivarola y a la fracción de profesores que se opuso a la aplicación de los estatutos reformistas en la UNLP y fue acusado de ser el autor de los editoriales anónimos del diario La Nación contra los reformistas. ${ }^{396}$ Esa relación entre Rojas y los reformistas se recompuso en 1926, cuando con el apoyo estudiantil fue elegido rector de la UBA.

A su perfil universitario, Rojas sumó uno público: desde 1917 fue un orador asiduo en los actos multitudinarios organizados por el Comité Nacional de la Juventud. Ante la prolongación de la Gran Guerra y la posición neutral de la Argentina, ese Comité reunió a socialistas, radicales e independientes con el propósito de que la Argentina se pronunciara a favor del bando aliado, o bien de la "civilización" frente a la "barbarie" germánica (Tato, 2007). Cuando concluyó la guerra, Rojas no sólo no abandonó ese perfil público, sino que le confirió una dimensión más política. A comienzos de 1919, pronunció la profesión de fe de la Alianza de la Nueva Generación. Ésta se concebía como "una liga de ciudadanos jóvenes, con el propósito de afrontar, en la meditación y en la obra, los problemas que la instauración del sufragio libre y la guerra mundial han traído para nuestra patria, anarquizando su opinión interna y desluciendo su renombre exterior". 397

Esa liga, que no mencionaba a la Revolución Rusa como un acontecimiento político y que propiciaba el panamericanismo, se declaró una agrupación político-cultural distante del socialismo, el conservadurismo y el radicalismo. Allí debían reunirse tanto los antiguos

\footnotetext{
${ }^{396}$ A fines de 1920, el CE de Ciencias de la Educación comenzó a editar un boletín y en su primer número dedicó un apartado a Rojas en el que no dudaba en calificarlo como "el más destacado inspirador y actor" del antirreformista Consejo Superior y como "el león reaccionario" (Boletín del Centro de Estudiantes de Ciencias de la Educación, $\mathrm{n}^{\circ}$ 1,15/10/1920, p. 8). Allí el CE lo denunciaba por gozar de una licencia en sus cátedras de Literatura: una vez terminada la prolongada huelga, Rojas presentó su renuncia a las cátedras ante el Consejo Académico de la Facultad de Ciencias de la Educación, los delegados estudiantiles la aceptaron porque con ello "demostraba no estar de acuerdo con la reforma y no tener deseo de trabajar", pero el Consejo la rechazó y le otorgó una licencia por un mes, prorrogada a pedido de Rojas por lo que restaba del año. La nota concluye afirmando que ello demostraría respecto de Rojas "la maleabilidad y duplicidad de su carácter y termina de quebrar el falso prestigio que gozaba entre los espíritus ingenuos. Ya no ruge, maulla" (idem). La nota siguiente está dedicada a Ernesto Nelson, el antiguo director del Internado del Colegio Nacional de La Plata que encontramos participando en la Universidad Libre. Al cerrarse en 1920 el Internado, Nelson era asignado a un "curso de Ciencias de la Educación", los jóvenes del CE declaraban que sus clases son "deficientes en sumo grado" (Idem). Una documentada reconstrucción del debate entre las FULP y Rojas (que toma partido a favor del último) puede consultarse en Castillo (1999).

${ }^{397}$ Los discursos pronunciados en el acto de lanzamiento de la Alianza fueron circularon en un folleto, véase Rojas (1919).
} 
integrantes del Comité Nacional de la Juventud como los jóvenes que estaban dando continuidad a la Reforma -reunión difícil pues los jóvenes participaban de grupos que habían entrado en contacto con los estudiantes mexicanos y peruanos, y tendían a asumir una posición latinoamericanista enfrentada al panamericanismo-. Para atraer a los reformistas la Alianza nombró como encargado de su "Junta Universitaria" a un líder de la Reforma: Hiram Pozzo, el estudiante de derecho y ateneísta que -tal como vimos en el capítulo quinto- había ocupado en 1918 el cargo de secretario de la FUA y del Primer Congreso Nacional de Estudiantes.

En cuanto a la orientación krausista de la Alianza, ella se reconoce en la convicción de transformar la cultura política a través de una instrucción general centrada en los valores democráticos. Asimismo, es desde una matriz krausista que se intenta elaborar soluciones a los problemas sociales y políticos a distancia de los partidos políticos existentes y de la religión, pues se propone allí la figura del intelectual como un mediador entre la producción de saber y la dirección del poder político. Finalmente, también se advierte esa matriz en la identificación de la Alianza como una coordinadora política de tres asociaciones de carácter cultural: la mencionada Junta Universitaria, el Instituto de Estudios Argentinos (a cargo del físico Teófilo Isnardi) y el Comité Nacional de la Juventud (a cargo del abogado Mariano Villar Sáenz Peña).

En su profesión de fe, Rojas declaraba que la Alianza debía aún alcanzar la precisión de un programa político, pero ya había tomado partido en las siguientes cuestiones: participaría en un futuro en los comicios, se opondría en el presente a la política interna y externa del gobierno de Yrigoyen a través de conferencias, mitines, asambleas y publicidad, y en ese sentido propiciaría una idea de nación laica ligada a la democracia parlamentaria, el panamericanismo y la incorporación de la Argentina en la Sociedad de las Naciones.

Si bien Rojas identificaba la Alianza con la renovación de los estudios universitarios y con el antipositivismo, otros tópicos -el panamericanismo, la democracia parlamentaria y la posición aliada, sobre todo- no podían atraer a los grupos estudiantiles que simpatizaban con la Revolución Rusa, e incluso se asumían antiparlamentarios. Así, no sorprende que la Alianza fuera criticada por Ideas y Nosotros, pero saludada por los Cuadernos. Lo que sí tal vez sorprende es que, luego de que la Alianza mostró su incapacidad para definir una nueva identidad política, el Ateneo identifique a Rojas -junto a Ingenieros, Palacios y Lugonescomo un participante del referido "frente único de las izquierdas" que propuso a fines de 
1919.

Fracasada la Alianza de Rojas, desde la Revista Nacional se propusieron dos instancias que, como mencionamos en el capítulo anterior, no lograron superar su carácter programático: Juan Cruz Ghio llamó a formar el Partido Liberal Cultural y Adolfo Korn Villafañe, el Partido Nacional. Otro intento de fundar una agrupación política reformista fue impulsado en septiembre de 1923 por Julio V. González y estuvo ligado al Partido Demócrata-Progresista.

Recuerda González que desde 1923 se preocupó por "encontrar la forma que reciba el contenido ideológico de la nueva generación" (González, 1931: 45) y en esa búsqueda recorrió tres sendas: "la primera, remozar un partido, y es la 'Declaración de principios de la Juventud Demócrata-Progresista'; la segunda, incorporarse a un partido ya existente, y son los capítulos Política y Pensamiento en acción; la tercera, crear un partido, transformando la Reforma Universitaria en una organización política, y es el capítulo titulado El Partido Nacional Reformista" (González, 1931: 45-46).

La extensa Declaración, así como los múltiples artículos sobre la Nueva Generación de la Reforma que publicó González, se inscribían en esas fracciones reformistas que, como señalaron Cattáneo y Rodríguez, "todavía confiaban en que la República estudiantil era el núcleo de la Reforma Social” (Cattáneo y Rodríguez, 2000: 52). Además de preparar la Declaración, González pronunció, en un acto organizado por el CE de Derecho, la "Significación social de la Reforma Universitaria”, probablemente la primera de sus múltiples intervenciones en las que propuso una interpretación generacionista -de matriz orteguiana y rival a la clasista- de la Reforma. En ese discurso - que González publicaría posteriormente en varios de sus libros sobre la Reforma-, el joven señalaba que el movimiento "no es un hecho que se limita a la universidad, porque es parte de la cuestión social” (González, 1927: 49), para luego aprovechar algunos tópicos que Ortega y Gasset había difundido en Buenos Aires durante su visita de 1916, y proponer que la Reforma es producto de una "nueva generación", la que "recogiendo la nueva sensibilidad que [asociada al idealismo rebelde y al reconstructor de la Revolución Rusa] fluctuaba por el mundo, irrumpió con un solo grito de rebeldía y de protesta contra todo. Iconoclasta e irreverente como ninguna otra, la nueva generación americana negó a sus maestros, y haciendo del dolor de su orfandad la fuente de su energía, se lanzó sola a conquistar su propio destino" (González, 1927: 50). En escritos posteriores, González introduciría más precisiones conceptuales provenientes de la teoría de Ortega -como la distinción entre "épocas acumulativas" y "épocas revolucionarias"- y extendería esa clave 
al análisis de la historia argentina.

La clave orteguiana acotada a la Reforma se advierte en la mencionada "Declaración" de 1923 con la que pretendió fundar una Juventud que renovara el Partido DemócrataProgresista. Allí González comienza declarando que, con la Reforma, había nacido una nueva generación que superaba a la generación del 80 y realizaba las cuestiones dejadas pendientes por la generación del '37. La tarea social, la justicia económica y la igualdad de derechos señaladas por ésta no bastaban, la nueva generación debía también revisar la legislación vigente así como el perfil de los egresados de la Facultad de Derecho.

Los firmantes de la "Declaración" -luego de declararse simpatizantes de las reivindicaciones obreras pero portadores de una "sensibilidad de clase" distinta, de descalificar "a la Iglesia católica como organización temporal de proselitismo y de lucha en orientación conservadora de sus propios privilegios y los de la clase social que la sostiene", de combatir "a las sociedades que se dan el nombre de patrióticas, porque no son sino una forma de reacción, porque explotan, en beneficio de intereses materiales de clase, a un sentimiento que es patrimonio de todos los argentinos"- los firmantes de la Declaración precisaban sobre el sistema legal vigente:

Los fenómenos sociales y económicos que se producen y sistematizan dentro de las fronteras de cada país, como el arraigo del trust y del sindicato, nos inducen imperiosamente a interrogarnos hasta qué punto el sistema representativo de las democracias responde a la realidad de la vida nacional con la forma actual del Parlamento. [...] Sufragio universal y educación popular será nuestro lema. [...] con respecto a las instituciones de Derecho privado [...] nuestro pensamiento es obtener la emancipación civil de la mujer y la implantación del divorcio absoluto (González, 1931: 198-200).

Y concluían declarando: "Nuestro contenido filosófico: El ideal revolucionario de Mayo. Nuestra acción: Crítica y reconstrucción. Nuestro medio: La Convención Nacional” (González, 1931: 210; destacado en el texto).

Esa larga declaración -marcada por el antiparlamentarismo y rescatada por González en sus tempranas memorias- fue saludada y discutida en Política, el periódico mensual del Partido Demócrata-Progresista fundado en junio de 1923 bajo la dirección de Julio Noé y Alfonso Laferrère. Como vimos, ambos habían formado parte de los revisteros que animaron el Colegio Novecentista, pero además recuerda de ellos Irazusta (1975: 178) que en 1927 asistieron a las reuniones preliminares de su revista maurrasiana La Nueva República (1927- 
1930).

Política responde al tipo de "periódicos políticos" que entonces aparecían en Buenos Aires. De formato tabloide, cada número tiene unas quince páginas, se abre con un editorial sin firma en el que se cuestionan las nuevas medidas tomadas por el presidente Alvear, a ese editorial le siguen cuatro o cinco artículos provenientes de los líderes del partido (fundamentalmente, de quienes habían sido los candidatos a presidente y vicepresidente en las elecciones del año anterior, Lisandro de la Torre y Carlos Ibarguren) y algunas notas breves.

Sobre la Reforma Universitaria, Política publicó pocas notas. Entre ellas una de Alberto Gerchunoff, otra sin firma titulada "Un manifiesto político de la nueva generación" (que saluda la citada "Declaración”) y una breve aclaración que confirma no sólo a González como el autor de esa "Declaración", sino también su voluntad de radicalizar la línea política del Partido Demócrata-Progresista. Se aclara allí:

La circunstancia de figurar en él el nombre de Julio Noé en forma que podría hacer suponer que es su autor, o por lo menos, el gestor de la "Agrupación" mencionada, nos determina a dejar establecido que dicho documento ha sido redactado por el Dr. Julio V. González y que el programa de la referida "Agrupación" no es exactamente el del Partido Demócrata-Progresista, expresado en publicaciones oficiales del mismo (Política, $n^{\circ}$ 6, diciembre de 1923, p. 15).

No hemos podido rastrear las firmas de esa "Declaración", pero sí su destino. Recuerda González que ella "cayó en el vacío. Viejos y jóvenes recogieron aquello con aplauso, pero sin entusiasmo, y, a poco andar, sólo quedaba en el recuerdo, como una discreta pieza literaria" (González, 1931: 46).

Al igual que la Alianza de Rojas, el proyecto de González no lograba aglutinar a los jóvenes que se habían interesado por la política y la cultura a partir del estallido de la Reforma, ni tampoco lo lograría el Partido Nacional Reformista que anunció en 1927. Pero ello no implicaba que la "nueva generación" hubiera dejado de desplegar una animada intervención político-cultural.

\section{La identidad reformista en disputa: ¿vanguardismo estético-político, reacción antipositivista o latinoamericanismo antiimperialista?}

En el mismo mes de septiembre de 1923 en que González hacía pública la "Declaración de la Juventud Demócrata Progresista", el grupo platense Renovación ponía a circular el primero de 
los doce números de la revista Valoraciones (1923-1928) y, al mes siguiente, aparecía en Buenos Aires el primero de los once de Inicial. Revista de la nueva generación (1923-1927). Dos publicaciones que, a diferencia de varias de las analizadas, han sido objeto de importantes análisis.

Inicial fue la apuesta de cuatro graduados jóvenes de la Facultad de Derecho que asistían a cursos de la FFyL: Roberto Smith, Roberto A. Ortelli, Homero Guglielmini y Alberto Brandán Caraffa. Las páginas de Inicial sugieren que los jóvenes se reunieron en torno del interés por el movimiento reformista y de una misma sensibilidad "intensa" para pensar los males y la renovación de la modernidad, pero que no compartían una misma interpretación de la Reforma ni un proyecto político-cultural. ${ }^{398}$ Sobre la compleja y heterogénea intervención de Inicial sostiene Rodríguez: “mientras en lo estético tiende un puente entre el modernismo epigonal y la vanguardia en sus formas plenas, en lo ideológico recorre el camino entre el decadentismo de Spengler, el vitalismo irracionalista de factura nieztscheana y el fascismo, hacia el ensayo discursivo de lo que podríamos provisoriamente definir como 'socialismo espiritualizado"' (Rodríguez, 2003: 13).

Al igual que los graduados que ese año ingresaban como Consejeros Estudiantiles en la Facultad de Derecho y del grupo nacionalista que lideraba Korn Villafañe, el primer número de Inicial se propuso expandir la formación del Derecho más allá de la "exégesis rutinaria de códigos". Y, aunque no explicitó su adhesión a la fracción izquierdista, el manifiesto inaugural concluyó protestando "contra el Sr. Korn Villafañe, que se arroga el derecho de hablar públicamente en nombre de la Nueva Generación, para atribuirle una ideología política que de seguro ésta no profesa". ${ }^{399}$

Durante el armado del quinto número, el grupo editor mantuvo una fuerte discusión, según el recuerdo de Brandán Caraffa, por la "tendencia racista y ultranacionalista" que quiso darle a la revista Guglielmini (cit. en Rodríguez, 2010: 106). Y en junio de 1925 aparecieron dos números 5, uno dirigido por un grupo editor en el que se encontraba "el sociólogo" Brandán Caraffa y que no prosperó, ${ }^{400}$ y otro compuesto por los otros tres fundadores de

\footnotetext{
${ }^{398}$ La noción de "modernos intensos" fue acuñada por Terán (1997) para pensar la sensibilidad política de una serie de intelectuales argentinos en los que se registra una matriz revolucionaria (antiparlamentaria y antiburguesa) que los llevó a simpatizar tanto con el comunismo como con el fascismo. Entre esas figuras se encuentran Roberto Arlt, Brándan Carrafa y Guglielmini. Valiéndose de esa noción y de la de "organizador cultural”, Rodríguez (2010) se detuvo en el itinerario político-intelectual de Brandán Caraffa. Sobre Inicial es interesante revisar las interpretaciones encontradas de Altermann (2005) y Rodríguez (2004).

399 "Protestamos...", Inicial, no 1, septiembre de 1923, p. 66.

${ }^{400}$ Ese fue el apodo que le habían puesto los estudiantes a Brandán Caraffa durante el Primer Congreso de Estudiantes, por las discusiones que mantuvo con el joven antipositivista y entonces presidente del CE de
} 
Inicial, además de algunos jóvenes que se sumaron entre ese quinto número y el décimo primero y último. ${ }^{401}$ La Inicial que perduró hasta 1927 se ligó políticamente al Partido Unión Reformista Centro-Izquierda y a la ULA, dos instituciones fundadas en el mismo año 1925 en que los editores se dividían.

Mientras las heterogéneas intervenciones de Inicial esbozaban una "nueva generación" que se identificaba con la Reforma y con un vanguardismo literario y político que barría con la democracia parlamentaria para simpatizar tanto con el comunismo como con el fascismo y enunciados antisemitas, Valoraciones proponía un antipositivismo de una intensidad mucho más moderada. Esta revista platense fue el órgano del grupo Renovación, surgido al calor de los festivales estudiantiles de la "huelga grande". Si bien sus miembros habían liderado la FULP, para 1922 ya no la hegemonizaban. Por entonces se constituyeron en un grupo estudiantil que probó canales de intervención no ligados a la Federación. Recuerda uno de sus miembros, Guillermo Korn:

La palabra 'Renovación' sintetizó una modalidad propia dentro del vasto movimiento de la Reforma Universitaria [...] El programa fue genuinamente reformista en el sentido político del vocablo: más que arrasar y reconstruir por la revolución, reformar por el método de la renovación. [...] Al resolverse el triunfo estudiantil en la defraudación -lo que se denominó el nazarismo- los núcleos descontentos que se consideraban portadores del verdadero espíritu de la Reforma intentaron seguir luchando, primero en torno al rector Saúl Taborda [...] luego en la supervivencia militante del Grupo Renovación. La Compañía Teatral Estudiantil Renovación y la revista Valoraciones fueron dos de las más representativas empresas de este grupo juvenil (Korn, 1963: 275-276).

El grupo teatral se fundó en 1922, pero ya en 1918 los jóvenes universitarios buscaron reemplazar la tutela "pasatista" de las representaciones estudiantiles por la "poderosa sugestión teatral" llevada a los gremios obreros. Esa experiencia teatral -que Guillermo Korn calificó luego como el antecedente del Teatro del Pueblo y continuó organizando tanto en La Plata como en Caracas- estuvo en su comienzo guiada por el primer líder del Colegio Novecentista, José Gabriel, por el futuro filósofo Luis Juan Guerrero y por quien había

Filosofía y Letras Jacinto Cuccaro. Véase Walter Elena, "Informe del Congreso Nacional de Estudiantes", Themis, $\mathrm{n}^{\circ}$ 70, agosto de 1918, p. 97, cit. en Ciria y Sanguinetti, 1968: 36.

${ }^{401}$ Acompañaron a Brandán Caraffa en ese único número 5: Roberto Ortelli, Luis E. Soto, Roberto Cigini y Raúl González Tuñón. En el otro número 5 de Inicial figuraban Ortelli, Guglielmini, Smith y -ocupando el lugar de Brandán Caraffa- Ruiz de Galarreta. Entre el octavo y el décimo número (agosto de 1925-mayo de 1926), Guglielmini figuró como director y el cuerpo de redactores se amplió para incorporar a Miguel A. Virasoro, Héctor M. Irusta, Armando Levene, Manuel Juan Cruz, Vicente Fatone, H. Ferreyra Díaz, Ricardo E. Molinari y Carlos María Onetti. 
dirigido la revista Atenea, Rafael Alberto Arrieta, -todos por entonces profesores del Colegio Nacional dependiente de la UNLP-. Más precisamente, según el recuerdo de Korn, "José Gabriel, genial e impulsivo, autodidacto de una prodigiosa capacidad de asimilación y de trabajo, tuvo una actuación más prolongada en la Compañía Renovación en la que fue actor, director, escenógrafo y, a veces, feroz polemista interno" (Korn, 1963: 280). ${ }^{402}$ Entre los estudiantes, el más entusiasta parece haber sido Ripa Alberdi, quien, para el acto del día del estudiante de 1922 realizado por Renovación, compuso los poemas "La farsa estudiantil" y“"Epílogo”. ${ }^{403}$

En cuanto a la política universitaria, entre 1921 y 1922 el grupo apoyó desde la FULP la candidatura y la gestión de Taborda como rector del Colegio Nacional y, al año siguiente, la candidatura de Alejandro Korn como decano en la Facultad de Humanidades, elecciones que ganó el socialista cientificista Enrique Mouchet. ${ }^{404}$ Además, Renovación publicó el periódico -hoy inhallable- Bandera Violeta (color que identifica a la FUA).

La revista Valoraciones -calificada por Guillermo Korn como la segunda empresa representativa de Renovación- apareció en septiembre de 1923. Su orientador y financiador fue Alejandro Korn, pero la iniciativa parece haber sido de los jóvenes Ripa Alberdi -fallecido luego de la aparición del primer número- y Carlos Américo Amaya, director de Valoraciones entre el primero y sexto número. Entonces estos jóvenes también fundaban la editorial Renovación, la que anunció como primera publicación La vida de Gandhi de Romain Rolland y en 1924 elegió para continuar la construcción de la biblioteca reformista Fatalidad de Henri Babusse y Relato de un desconocido de Anton Chejov. ${ }^{405}$

Los números de Valoración sugieren como identidad de la "nueva generación" una

\footnotetext{
${ }^{402}$ Para la celebración del Día del Estudiante de 1923 realizada en el Coliseo Podestá de La Plata, Gabriel preparó Estudiantina, una parodia, de los Coros Ukranianos que, en el marco de su gira latinoamericana, se habían presentado ese año en el Teatro Argentino de La Plata. Para esa "parodia sensacional y desopilante", Gabriel convocó a más de cien voces estudiantiles (Korn, 1963: 278). En 1942 Palacios desde su cargo de presidente de la UNLP encargó a una comisión el proyecto del instituto de teatro de la UNLP. Entre los miembros de la comisión -disuelta poco después del golpe de Estado de 1943- se encontraban Monner Sans, José Gabriel y Guillermo Korn (Korn, 1963: 289-230). Para un análisis de estos distintos proyectos, véase Graciano (2008).

${ }^{403}$ Luego de cantar el Himno de los estudiantes y de leer el poema de Ripa Alberdi, el grupo teatral representó dos obras "La cueva se Slamanca" y "La Posadera", a continuación Felipe Bellini recitó el Epílogo y la banda de policía se encargó de la parte musical. Una copia del programa, puede consultarse en ella archivo de la Reforma del CeDInCI. Allí actúan Aznar, Korn y Gabriel, entre otros.

${ }^{404}$ Para un agudo análisis de esa gestión, véase Graciano (2008: 71-79).

${ }^{405}$ Extrajimos los datos de la colección de los anuncios aparecidos en Inicial. Además del artículo, de cierto tono autobiográfico, que citamos de Korn (1963), puede consultarse un abordaje crítico en Graciano (2008: 80-90). Para una caracterización, también de tono autobiográfico, de Valoraciones, véase Aznar (1963). Sobre el lugar ocupado por esta revista en la red del reformismo platense, véase, además de la obra de Graciano, el agudo análisis de Rodríguez y Vásquez (2002).
} 
convergencia del antipositivismo de matriz kantiana y bergsoniana con el socialismo cristiano que Korn había propuesto en 1918, tanto en el manifiesto "Socialismo ético", aparecido en los Cuadernos, como en "Incipit vita nova", con el que se inauguraba la revista Atenea. Seguramente, el gesto más irreverente de Valoraciones haya sido publicar en su primer número un jocoso y célebre relato, luego atribuido a Ripa Alberdi, en el que se ridiculizaba el abordaje experimental de la cátedra de psicología platense que dirigía -siguiendo la psicología ingenieriana- el profesor que acababa de asumir como decano, Enrique Mouchet. ${ }^{406}$ En esta sólida plataforma antipositivista no tendría participación el otro referente indiscutido del antipositivismo argentino, Coriolano Alberini, quien desde 1923 dictaba Gnoseología y Metafísica en la Facultad platense de Humanidades. Su ausencia en Valoraciones no sorprende cuando se tiene en cuenta que, como vimos en el capítulo cuarto, en mayo de 1924 Korn rompió su estrecha amistad con Alberini por las diferencias irreconciliables en torno de las decisiones institucionales en la FFyL. A pesar de que las historias de la filosofía lo han olvidado, desde entonces el antipositivismo argentino se escindió entre los seguidores del socialismo ético de Korn y los alberinianos, afines al nacionalismo y el catolicismo (Ruvituso, 2010).

Mientras que en la FFyL el socialismo de Korn no encontraba un espacio de recepción, en La Plata el grupo Renovación construía una interesante plataforma de difusión. Y esa diversa recepción guardaba cierta consonancia con el perfil de los estudiantes de cada una de las facultades. Sobre esos perfiles traigamos la elocuente descripción que dejó Juan José Arévalo. El guatemalteco recuerda que, como los demás estudiantes platenses de Humanidades, mantenía un enlace fraternal con la FFyL porteña:

Cada vez que allá llegaba algún eminente humanista extranjero, nos movilizábamos en grupo a escuchar clases y conferencias. Era aquel un medio distinto. Los estudiantes varones predominaban. Las alumnas asistían a clase vestidas de gran lujo, como que tenían que atravesar Florida. Las vi, varias veces, con abrigo de piel. Y cuando convocaban público extra para rodear, por ejemplo a Victoria Ocampo, los abrigos de astrakán o de visón se adormecían bajo hisopos de perfumada literatura. La copiosa Biblioteca de esta Facultad porteña era uno de mis refugios habituales, gracias al copioso Director doctor Carbia. (En La Plata no existía mucho material europeo y tampoco bibliografía del siglo pasado) (Arévalo, 1975: 175).

\footnotetext{
${ }^{406}$ La redacción, "El cripto-pedagogismo y las 'memorias del intelectómetro"', Valoraciones, ${ }^{\circ}$ 1, septiembre de 1923, pp. 55-64.
} 
A cierta distancia de los estudiantes porteños, los platenses intentaron constituir un amplio frente cultural antipositivista que se reunía en torno de la tesis de la condición libre -y por ello responsable- del hombre, pero también en torno de la democratización de la universidad y de la sociedad, en general, y de la vinculación de los estudiantes con el pueblo. ${ }^{407}$

Esa convergencia del proyecto antipositivista y socialista de Korn con el grupo estudiantil se advierte en el hecho de que los dos primeros números de Valoraciones fueran remitidos a los posibles suscriptores junto con los ensayos de Korn "La libertad creadora" (1920) y "El pensamiento filosófico actual" (1922). ${ }^{408}$ A ello se sumaron, por un lado, el hecho de que el último número de la revista editara como separata la primera traducción al español -a cargo de uno de los redactores de Inicial, Carlos María Onetti- de Introducción a la metafisica de Henri Bergson y, por el otro, el modo contrastante como eligieron anunciarse Inicial y Valoraciones. En ésta se lee el siguiente anuncio:

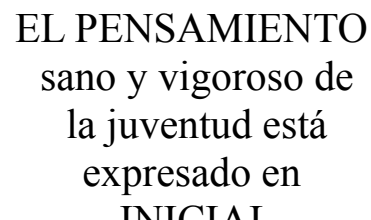

INICIAL

Revista de la nueva generación

Lejos de la intensidad a la que apelan las referencias a la salud y el vigor, Valoraciones hacía primar en su anuncio la reunión en una "amplia" corriente. Se lee en Inicial y en otras revistas de la época:

\section{VALORACIONES \\ REVISTA de Humanidades, Crítica y Polémica \\ Editada por el grupo \\ RENOVACIÓN de La Plata}

\footnotetext{
407 En otros términos, en la apuesta filosófico-política de Valoraciones puede encontrarse desplegada esa "libertad tolerante" que analizó agudamente Terán (1986a) en su ensayo sobre Korn. Para un análisis centrado en las tesis filosóficas de Korn y su implicancia en la "cultura filosófica", véase Ramaglia (2010). Asimismo, otro análisis de la filosofía de Korn puede encontrarse en su discípulo Torchia Estrada (1986).

${ }^{408}$ En la última página de Valoraciones $\mathrm{n}^{\mathrm{o}} 3$ (número dedicado al homenaje de Kant), se reproduce una carta enviada por el profesor González Martínez que confirma la circulación conjunta de los dos primeros números de la revista y los dos ensayos de Korn. Sobre ese número de Valoraciones, Inicial publicó una reseña que explicita la diferente intervención que proponía cada una de las revistas. El autor anónimo saluda a la "revista amiga", "hecha con talento" que "honra en el país y en el extranjero a la juventud argentina" para a continuación desplegar un gesto vanguardista e "intenso", pues le reclama que se aligere "de ese pequeño lastre académico y universitario que desbarata su impulso esencial hacia los vuelos atrevidos", pues "no nos da lo bastante esa impresión de apolínea frescura y de entusiasta belicosidad que debe caracterizar lo joven" ("Valoraciones", Inicial, $\mathrm{n}^{\mathrm{o}}$ 6, septiembre de 1924).
} 


\section{Director: Carlos Américo Amaya}

"La nueva fantasía y los nuevos pensamientos, que nos llegan traídos por una amplia corriente de humanismo, hemos de recoger en estas páginas afirmando así, sobre una sólida base idealista, nuestra posición estética y filosófica", (VALORACIONES Nº 1.)

Desde 1925, la identidad estudiantil de Valoraciones, antipositivista y socialista moderada -ante la que Inicial pedía más "vuelos atrevidos" y "belicosidad"-, entró en una marcada rivalidad con la red antiimperialista de la Reforma Universitaria que se conformó en torno del "cientificista" José Ingenieros. A partir del séptimo número, la dirección de Valoraciones quedó a cargo de Korn, pues Amaya se alejó para fundar, junto a otros dos colaboradores de Valoraciones -y ya destacados reformistas-, Julio González y Carlos Sánchez Viamonte, Sagitario. La nueva revista platense mantuvo la impronta antipositivista y socialista de Valoraciones, pero evitó el cristianismo y formuló un posicionamiento político más preciso ligado a la denuncia del imperialismo yanqui y al obrerismo y complementario de la intervención del boletín porteño Renovación, que se editaba desde 1923. Más precisamente, con la fundación de la ULA en 1925, Renovación se convertía en su órgano informativo, al tiempo que surgía Sagitario como la revista de cultura de la ULA. Antes de abordar las instancias a través de las que se tensó esa red, repasemos brevemente la identidad latinoamericanista que se había insinuado entre 1918 y 1925 y que la ULA venía a consolidar.

De la hora americana al antiimperialismo latinoamericano: el Primer Congreso Internacional de Estudiantes, la revista Claridad de Lima y la gira sudamericana de Vasconcelos

El movimiento universitario argentino (cordobés por la sede geográfica pero argentino por la conjunción de energías en acción) fue a golpear con recia mano los pesados portales de las casas de estudio extranjeras, en trance de enquistamiento; que la onda liberal e idealista realizó en un bello instante, aun no logrado por los juegos de la diplomacia, la fusión en un sólo anhelo de los juveniles corazones de Sud América. Arturo Orgaz, "Lo que fue, lo que es y lo que debe ser nuestra facultad de derecho", 1922.

El "Manifiesto liminar" y otros textos programáticos del reformismo, como los de Taborda e 
Ingenieros, anunciaban una hora americana marcada por la crisis civilizatoria que habían instalado la Primera Guerra Mundial y la Revolución Rusa. También los grupos estudiantiles recogían y difundían ese tópico. Como ejemplo, traigamos el breve anuncio "Huelga", publicado en 1919 por La Gaceta de Córdoba:

Un eco saludable de la revolución del año 18, se ha extendido a toda la América. Ayer fueron las universidades nacionales argentinas y hoy fuera de nuestros compañeros de Santa Fe, son los universitarios de Montevideo (Uruguay) y Lima (Perú) que bregando por los sagrados intereses de la cultura superior y desoídas sus justas reclamaciones apelan al último recurso, el recurso de la justicia por la fuerza: la huelga. [...] Vayan, pues, en esta hora histórica de confraternidad universitaria, nuestros sinceros votos porque todas las antiguas instituciones americanas abran sus puertas a las nuevas orientaciones científicas (La Gaceta universitaria, $\mathrm{n}^{\mathrm{o}} 16,25 / 07 / 1919$, p. 6).

En los primeros años de la Reforma, el americanismo que saludaban los estudiantes cordobeses era recurrente en las declaraciones de apoyo, pero no conseguía una clara traducción doctrinaria ni política. En cambio, como señalan Cattáneo y Rodríguez (2000: 51), hacia mediados de los años veinte ese americanismo encontraría carriles políticos más precisos en torno del pronunciamiento contra el imperialismo estadounidense y del reconocimiento de problemáticas propiamente latinoamericanas. Esos carriles coincidían tanto con la llegada a Buenos Aires y a La Plata de estudiantes bolivianos y peruanos exiliados como con la autocolocación exitosa de Haya de la Torre como el héroe de una nueva generación latinoamericana, construida desde lo que Bergel (2009) identificó como un "nomadismo proselitista".

Como han señalado diversos estudios (Biagini, 2012; Cattáneo y Rodríguez, 2000), ese programa político tuvo al menos tres antecedentes significativos: el Primer Congreso Internacional de Estudiantes celebrado en México, la firma de los primeros "convenios internacionales estudiantiles de nuestra América" y la gira sudamericana de Vasconcelos.

Por un lado, a fines de 1921 la Revolución Mexicana organizó el Primer Congreso Internacional de Estudiantes. Los estudiantes y las figuras de distintos países latinoamericanos y europeos que participaron coincidieron en una serie de resoluciones y fundaron una efímera Federación Internacional de Estudiantes. Si bien las resoluciones no superarían su condición programática, permitirían identificar y construir sensibilidades políticas afines entre figuras y grupos ubicados en distintas ciudades del continente, consiguiendo que tomara "carta de 
ciudadanía mundial el movimiento reformista organizado" (Biagini, 2012: 61).

Entre las seis resoluciones que aprobó el Congreso no sólo se encontraron las referidas a la mejora de la calidad educativa -como la promoción de las cátedras libres y de la participación estudiantil en el gobierno universitario-, sino también definiciones políticas que, a distancia del moderatismo político que primó en las resoluciones del Congreso Nacional de Estudiantes cordobés de 1918, tenían una clara inscripción en las izquierdas. La federación fundada por el Congreso se comprometía a apoyar las distintas luchas antiimperialistas del continente y "los modernos postulados de la justicia social". Esto es, además de adherir a la Revolución Rusa y a la Internacional del Pensamiento -como vimos que entre 1919 y 1921 lo hicieron revistas como Clarín y Bases-, el Congreso colocaba en el centro de sus preocupaciones la denuncia de la presencia económica y política de los Estados Unidos en Latinoamérica. ${ }^{409}$

La "resolución final" consistió en la convocatoria "a la juventud del mundo para el segundo congreso internacional de estudiantes en la ciudad de Buenos Aires, en 1922” (del Mazo, t.VI: 81). La delegación argentina fue, junto con la mexicana, la más numerosa. Llegaron a México, con la financiación del estado argentino, Héctor Ripa Alberdi (como presidente de la delegación y vicepresidente del Congreso), acompañado de Miguel Bonchil, Enrique Dreyzin, Arnaldo Orfila Reynal y Pablo Vrillaud. La invitación al congreso no había sido realizada a través de las federaciones estudiantiles sino a través de los Estados, y eso implicó que las organizaciones estudiantiles de países como Chile -cuyo gobierno no mantenía buenas relaciones con México- no recibieran la invitación. El tono celebratorio de las crónicas del Congreso nada nos dice acerca de las indudables discusiones que antecedieron a la elección de los estudiantes delegados, ni de las tensiones en el momento de votar las resoluciones, pero sabemos que, finalizado el Congreso, muchos jóvenes volvieron a sus países a difundir la nueva "fe americanista". 410

Dado que la proclamada Federación Internacional de Estudiantes realizaría su

\footnotetext{
${ }^{409}$ Las resoluciones pueden consultarse en del Mazo (1927, t.VI: 75-81). Para una reconstrucción tanto de la trama política desde la que el estado mexicano decidió la organización del Congreso como de las distintas reivindicaciones institucionales que tuvo el reformismo en Latinoamérica, véase Moraga Valle (2014). En esa reconstrucción, el autor propone una mirada que difiere de la desplegada en la presente tesis, pues rechaza la vinculación estrecha entre la Reforma y la reforma social, al tiempo que sostiene que el Congreso mexicano pertenece y cierra un ciclo de organización gremial estudiantil de dimensión latinoamericana, que se habría iniciado en 1908 con el Congreso Americano de Estudiantes, evento al que nos referimos brevemente en el primer capítulo.

${ }^{410}$ Para un análisis de los vínculos simbólicos y materiales que trazaron los estudiantes a partir del encuentro, así como del lugar destacado que ocuparon los argentinos, véase Biagini (2012: 80-96).
} 
siguiente congreso en Buenos Aires, se organizaron dos giras compuestas por representantes argentinos y financiadas por el estado mexicano para difundir las resoluciones y comprometer a diversos grupos universitarios en su participar. El santafesino Vrillaud lideró la gira europea, que compartió con Dreyzin y Orfila Reynal, el platense Ripa Alberdi la gira latinoamericana, donde estrechó vínculos con los reformistas peruanos.

La gira europea comenzó en Nueva York, donde los estudiantes no tenían una organización central, continuó en París, ciudad en la que los estudiantes se organizaban en dos federaciones rivales que ajustaban la política estudiantil a los intereses de los países aliados. Luego la delegación recorrió una serie de ciudades italianas (Milán, Venecia, Génova, Florencia y Roma) y terminó su gira en Suiza (del Mazo, 1927, t.VI: 83-84).

A estos vínculos transnacionales les antecedía la prédica antiimperialista que -como mencionamos en el tercer capítulo- venía realizando Manuel Ugarte. Pero esa impronta reformista y antiimperialista parece haber encontrado una revitalización con el paso por sudamérica del joven Haya de la Torre, quien representaba a la perseguida Federación de Estudiantes del Perú y llegaba a la UNC en el mismo momento en que arribaban Nicolai y Goldschmidt. ${ }^{411}$ La presencia de Haya de la Torre era antecedida por la firma, a mediados de 1920, de dos "convenios internacionales estudiantiles de nuestra América". Uno entre la Federación de los Estudiantes del Perú (presidida por Haya de la Torre) y la FUA (presidida por del Mazo), otro entre ésta y la Federación de Estudiantes de Chile (presidida por Alfredo Demaría). Los estudiantes chilenos estaban organizados desde la primera década del siglo XX, pero el conflicto reformista estalló allí a mediados de 1922. Y desde entonces la federación chilena y la peruana publicaron frecuentes declaraciones de apoyo y de paz entre los países, con la intención de contrarrestar la campaña militarista que pretendía iniciar una guerra entre Chile y Perú. ${ }^{412}$

Los cinco puntos de los dos convenios son sumamente similares. En términos generales se sostiene: 1. El intercambio intelectual por medio de libros, estudios de carácter monográfico, etc.; 2. La continuidad de la reforma de la enseñanza; 3. El estudio de los

\footnotetext{
${ }^{411}$ Haya de la Torre regresó a Lima a fines de junio de 1922, su recorrido por los cuatro países duró cuatro meses y once días. El relato de viaje que el joven publicó en el diario La Crónica de Lima puede consultarse en del Mazo (1927, t.VI:147-153). En la estadía argentina se vinculó con los reformistas porteños, cordobeses y santafesinos. Es más Haya de la Torre viajó a la ciudad de Santa Fe para asistir junto a del Mazo, Araujo, Ripa Alberdi, Vrillaud, Korn Villafañe y Boljover, entre otros, a la inauguración de una de las nuevas sedes de la Universidad Nacional del Litoral. Asimismo, en Buenos Aires intercedió entre Araujo y Korn Villafañe en la disputa que mantenían sobre la línea de la FUA que entonces conducía el primero. Véase La Gaceta Universitaria de Santa Fe, 1922.

${ }^{412}$ Tres documentos de la "fraternidad chileno-peruana" son recogidos por del Mazo (1927, t.VI: 185-193).
} 
problemas sociales y el sostenimiento de las universidades populares; 4. El sostenimiento de la propaganda para hacer efectivo el ideal de americanismo; 5. El intercambio de estudiantes y la realización de congresos internacionales (del Mazo, 1927, t.VI: 27-28).

Si bien son conocidos los convenios, no suele recordarse que fue a través de una publicación quincenal que sus cinco puntos encontraron una primera concretización. En efecto, esos puntos fueron el eje de la revista Claridad que, como órgano de la Federación Estudiantil de Lima, fundó Haya de la Torre cuando regresó a Lima y que, al partir este al exilio, fue dirigida por Mariátegui. El primer número de este "órgano de la juventud libre del Perú" esta fechado en la primera quincena mayo de 1923, esto es, poco días antes de los actos multitudinarios -y violentamente reprimidos- que protagonizaron numerosos estudiantes y obreros contra el intento de Leguía de consagrar el Perú al Corazón de Jesús.

La página inaugural de Claridad ofrece una interesante muestra del modo en que desde entonces el ala radicalizada de la Reforma tendió a conciliar el socialismo revolucionario y el latinoamericano antiimperialista. Allí se explicita que la revista está dedicada a Barbusse por su fundación de la Internacional del Pensamiento y al pie de página se vincula el compromiso de los intelectuales al que llama Barbusse con Latinoamérica, pues se denuncia: "En México se ha organizado el Fascismo contra el Gobierno. Un deber de América es ahogar en el Continente todo intento reaccionario". Cada número refuerza esa continuidad entre la Internacional de Barbusse y el antiimperialismo latinoamericano a través de fragmentos de Con el cuchillo bajo los dientes (ensayo en el que Barbusse despliega los principios de su Internacional y que los peruanos tradujeron especialmente), de noticias tanto de las Universidades Populares como del movimiento obrero organizado y de la elogiosa difusión de las iniciativas estudiantiles del continente, sobre todo las argentinas. E incluso la revista no se priva de cuestionar al "socialista nacionalista argentino y notable agitador de la juventud" Alfredo Palacios por haber sucumbido "a las ofrendas" que en forma de un Honoris causa le ofreció la "vieja Universidad". ${ }^{413}$

Además de las iniciativas de educación popular que entonces emprendían los peruanos, fue central para la latinoamericanización de Claridad la trama de relaciones que Haya de la Torre había tejido en su paso por Argentina. En cada portada la revista anunció una

\footnotetext{
${ }^{413}$ De camino a México para inaugurar, en su condición de decano platense, la Escuela de Crimonología, Palacios pasó por Lima. Allí, según Claridad, sucumbió a las ofrendas de las autoridades universitarias, pues "ha sido rodeado por el círculo de hierro oficialista de la Universidad que le ha monopolizado totalmente" y "le ha brindado cenas opíparas"; para seguir manteniendo su condición de maestro, debería rechazar, como lo hizo con la condecoración de la Legión de Honor del gobierno francés, el Honoris Causa que le otorgó la "vieja Universidad de San Marcos" ("La llegada de Alfredo Palacios", Claridad, nº 1, mayo de 1923, p. 24).
} 
lista de "auspiciantes en América" y de "redactores honorarios, encargados de secciones especiales". Entre los auspiciantes el primero era Ingenieros, a él le sucedían trece figuras, cinco de los cuales eran animadores clave de proyectos reformistas radicalizados de Argentina: Nicolai, Goldschmidt, Bermann, Palcos y Korn. La lista de redactores se dividió por países y estuvo compuesta por estudiantes provenientes de Argentina, Uruguay, México, Chile y Ecuador. Entre los uruguayos se encuentran Quijano y otros activos arielistas, al tiempo que la mayoría nuevamente es argentina, en este caso encabezada por del Mazo, con quien Haya de la Torre mantuvo desde 1923 una "correspondencia cordial y al servicio de la integración americana" al punto que para 1954 le había remitido unas dos mil carillas (de Mazo, 1976: 219). ${ }^{414}$

Más allá de las ofrendas que en 1923 aceptó Palacios de la "vieja Universidad de San Marcos”, otros argentinos pusieron de manifiesto su auspicio a Claridad. Entre ellos, Bermann envió una nota de desagravio ante el folleto contra Haya de la Torre que circulaba en Argentina y Nicolai remitió "para los estudiantes de Medicina" la primera parte de las lecciones de Fisiología que impartía en Córdoba, que estaba en prensa. ${ }^{415}$ Asimismo, del Mazo, en su condición de "ex presidente de la Federación Universitaria Argentina", junto a los “ex delegados al Congreso Estudiantil de México" Pablo Vrillaud y Héctor Ripa Alberdi enviaron a la federación peruana, luego de la represión de mayo de 1923, un telegrama de aliento que subrayaba la unidad americana. Para hermanarse con los peruanos, los argentinos elegían los siguientes términos:

Estudiantes del Perú, - Lima

Acabamos conocer publicaciones La Prensa referentes viaje Haya, ese gran espíritu americano. - Son una total impostura. - no nos extraña sean noticias enviadas prensa Buenos Aires. - Prensa grande constituye hermandad real y virtual al servicio fuerzas egoístas Continente, en oposición pensamiento libre justiciero que rendirá América y logrará su verdadera grandeza ("La protesta de

\footnotetext{
${ }^{414}$ Lamentablemente, ninguna de esas cartas se han conservado. Respeto de los otros redactores de Claridad, son anunciados: por Buenos Aires: Horario H. Trejo, Eduardo Araujo y Julio Prebisch; por Córdoba: Sebastián Soler, Jorge Orgaz y Guillermo Ahumada; por Rosario: Gregorio Paz, Luis Di Fillipo y Antonio Benítez; por Tucumán: Marcelino Constenla; por La Plata: Eduardo Lazcano y Héctor Ripa Alberdi; y por Santa Fe: Mauricio Boijover y F. Belfer. Los redactores uruguayos son, además de Carlos Quijano, Héctor González Arreosa (quien, como mencionamos, dirigió Ariel entre 1923 y 1924), Carlos Benvenuto y Julio Lorenzo y Leal.

${ }^{415}$ El texto sería editado a mediados de 1925 por la Editorial de la Revista de la Universidad Nacional de Córdoba como la primera parte de La base biológica del relativismo científico y sus complementos absolutos. Explicitando la trama de figuras reformistas que hicieron posible esa publicación, en el prólogo Nicolai agradeció a "los buenos amigos y discípulos -principalmente el ingeniero Augusto Scmiedecke, los doctores Gregorio Bermann y Sebastián Soler, y los estudiantes Antonio Boher y Antonio Sartori- que me ayudaron, con generosos esfuerzos, a enmendar la dicción y corregir al menos los más molestos errores" (Nicolai, 1925: XIV).
} 
los estudiantes argentinos por las imposturas de la prensa de Lima”, Claridad, $\mathrm{n}^{\circ}$ 2, junio de 1923, p. 20).

Esta revista no sólo buscó hermanarse con el reformismo argentino, sino que también ofreció a éste la primera difusión de Mariátegui. En efecto, en la carta de del Mazo al amauta que rescató Tarcus (2001), se aclara que fue a través de Claridad y del mencionado decenario Córdoba que los argentinos conocieron los primeros artículos del Amauta, revista que fundó Mariátegui en Lima en 1926 y que apareció hasta 1930.

En cuanto a su definición política, Claridad contó con la sección "Página del proletariado organizado", en la que Claridad publicó una serie de noticias sobre los conflictos que mantenían los sectores obreros peruanos. En recuadro declaraba: "Organicemos a los estudiantes sin política y sin intrigas", pero como en el caso de La Gaceta de Córdoba o de Clarín, esa falta de política y de intrigas no implicaba una agremiación estudiantil ajena a los problemas sociales y a las reivindicaciones del movimiento obrero, sino una politización extrapartidaria como la proclamada por la Internacional del Pensamiento. Dando nuevas pruebas de la difícil convivencia en el estudiantado de diferentes representaciones sobre su lugar social, se lee en la misma página el irónico recuadro "Machaca muchacho": "Machaca, sin cesar, muchacho, sin otra aspiración que la de ser doctor y ganar dinero, sí, mucho dinero. [...] que lo demás es nada. Tonterías, ¿qué pueden importarle a tu corazón inflamado de orgullo el dolor ajeno, el enorme y sombrío dolor de los pobres, de los lisiados?". 416

El tercer evento que fue importante para la precisión de una identidad latinoamericanista del movimiento de la Reforma fue la gira por Sudamérica que emprendió en 1922 Vasconcelos junto a Henríquez Ureña y una comitiva de casi cien personas. Bajo el financiamiento del estado mexicano, esta comitiva tenía el encargo de difundir los avances culturales de la Revolución Mexicana y de despertar las simpatías de la región hacia México. ${ }^{417}$ Como ha analizado detenidamente Pita González (2009) y antes Terán (1986b), en su extenso discurso en honor a Vasconcelos, Ingenieros retomó el antipanamericanismo que difundía la gira, así como el que venía predicando Ugarte, para hacer público, por primera vez, su propósito de fundar la ULA. Ingenieros proponía allí el pasaje del "primer antiimperialismo latinoamericano" marcado por la preocupación cultural a otro que se enfrenta a la dependencia económica y política. En efecto, para Ingenieros Estados Unidos

\footnotetext{
416 "Machaca muchacho", Claridad, no 3, julio de 1923, p. 16.

${ }^{417}$ Sobre la gravitación rioplatense de la Revolución Mexicana en los años previos y posteriores a esa gira, véase Yankelevich (2003).
} 
representaba un peligro para Latinoamérica no por la cultura utilitaria que había denunciado Rodó, sino por su "capitalismo expansionista" y su "diplomacia del dólar" que hipoteca progresivamente la independencia nacional, pues "el capitalismo norteamericano quiere captar las fuentes de nuestras riquezas nacionales y asegurarse su contralor, con derecho de intervención para proteger los capitales que radica y garantizar los intereses de los prestamistas". ${ }^{418}$

Para contrarrestar ese imperialismo económico y político, las juventudes universitarias del continente, además de adherir a la "Revolución en los Espíritus, debían organizarse. Sus gritos de alarma y su llamado a una "renovación política, ética y social", que recogiera las enseñanzas de la Revolución Rusa y de la Mexicana, sólo serían oídos por el pueblo si fundaban una institución. En ese sentido, la primera tarea justamente consistía en convencer al pueblo de que había que presionar a los gobiernos para crear "entidades jurídicas, económicas e intelectuales de carácter continental, que sirvan de sólidos cimientos para una ulterior confederación". 419

Si bien recién a mediados de 1925 Ingenieros conseguiría que los intelectuales porteños se reunieran en la ULA, para comenzar esa organización financió, desde enero de 1923, la edición del boletín Renovación. En ese boletín, y sobre todo en las iniciativas de la ULA, puede encontrarse una confirmación y acentuación de un rasgo que descubrimos como constitutivo del movimiento reformista: el establecimiento de las revistas -junto a los actos, las asambleas y las reuniones- como un espacio de militancia. En efecto, la ULA no sólo fue prefigurada por Renovación -revista que en 1925 se convirtió en el órgano de aquella-, sino que además erigió a las revistas en el espacio privilegiado de difusión de sus iniciativas. E incluso surgió a partir de los animadores de un grupo de revistas culturales ligadas al movimiento reformista. Como prueba de ello, recordemos el modo en que la ULA era presentada por La Cureta, la revista vocera de los estudiantes radicalizados de Medicina. Allí se aclara que en las reuniones preparatorias participaron "un grupo de escritores e intelectuales, entre los que se cuentan los directores de Nosotros, Revista de Filosofía, El Universitario e Inicial, el Decano de la Facultad Derecho de La Plata [cargo que, como mencionamos, ocupó Palacios entre 1922 y 1925] y los Consejeros Estudiantiles de la

\footnotetext{
${ }^{418}$ José Ingenieros, "Por la Unión Latino-americana. Discurso pronunciado el 22 de octubre de 1922”, Revista de Filosofia, noviembre de 1922. Para un sugerente análisis del despliegue del discurso antiimperialista a nivel continental en las primeras décadas del siglo XX, en el que se registran la polémica entre apristas y socialistas, véase Funes (2006: 205-258)

${ }^{419}$ Idem.
} 
Facultad de Derecho de Buenos Aires". ${ }^{420}$

Más precisamente, el reflujo del ciclo rioplatense de protestas obreras y la inscripción de la "Revolución en los Espíritus" y de Barbusse en el PC francés habían tornado sumamente difícil el equilibrio -que vimos que propusieron revistas como Ariel de Montevideo o Insurrexit de Buenos Aires- entre la adhesión al comunismo, por un lado, y una intervención que construyera un modelo de intelectual revolucionario -abocado a la instrucción de las masas, la democratización de la universidad y el estudio del problema social a escala nacional-, por el otro. Algunos grupos estudiantiles optaban por conciliar la figura del estudiante con el vanguardismo estético-político, otros con un socialismo antipositivista. ${ }^{421}$ Pero los reformistas rioplatenses que perseveraron en defender la identidad socialista y radicalizada del estudiante pudieron encontrar una interesante intervención en la red y la sensibilidad que, en sintonía con la propuesto en Lima por Haya de la Torre y Claridad, comenzaba a alentar entusiastamente Ingenieros y para la que aprovechaba el prestigio que Palacios había acumulado desde 1918 en su apoyo a los reformistas y que había acrecentado con su decanato en la Facultad platense de Derecho. En ese sentido, la cultura política de la Reforma Universitaria que comienza a trazarse hacia 1923 no tendrá en Rodó, sino en Ingenieros y Palacios a sus principales maestros locales.

\title{
El primer tramado de una red intergeneracional porteña de latinoamericanismo antiimperialista
}

\begin{abstract}
En breve espacio de tiempo ha hecho Ud. en mí un discípulo ferviente, hasta tal punto y en forma tan intensa, que en la actualidad estoy meditando acerca del medio de consagrar todas mis energías a la gran causa revolucionaria. [...] acogeré todo consejo que Ud. juzgara oportuno darme, cual fruto de la experiencia y del saber de quien saludo como el primero y más autorizado guía intelectual de la revolución en nuestra patria.

Carta de Arturo Orzábal Quintana a José Ingenieros, 1920.
\end{abstract}

\footnotetext{
420 “Unión Latino Americana - Fundación y propósitos", La Cureta, n 16, $1^{\circ}$ quincena de abril de 1925, p. 334.

${ }^{421}$ Por su parte, el intelectual católico Antonio Herrera, junto a Adolfo Korn Villafañe, fundaba en 1925 el pequeño grupo platense Diógenes, del que aparecerían entre 1925 y 1928 una pequeña revista y en 1928 el libro firmado por el grupo Ideario Nuclear. Al igual que el grupo que permaneció en el Colegio Novecentista desde mediados de 1918, Diógenes se propuso la revisión de la cultura nacional desde un antiliberalismo organicista y cristiano. Y en esa intervención contó con el saludo de la revista oficial del fascismo italiano. "Nucleo di idee", dentro de "Ressegna del pensiero latino" en Crítica fascista. Revista quindicinale del fascismo, n" 13, 1928, p. 259. Agradezco el dato a Horacio Tarcus.
} 
En 1923, luego de la salida de la gestión de Sáenz, los jóvenes izquierdistas de Derecho realizaron un nuevo intento de instalar en esa facultad las reivindicaciones reformistas. Entonces pudieron contar con un espacio de difusión y apoyo en la publicación porteña que estaría en el centro de la red latinoamericanista, el boletín Renovación (1923-1930). Sobre este boletín y la red de la ULA contamos con la minuciosa reconstrucción y análisis de Pita González (2009). Teniendo en cuenta esa investigación, buscamos iluminar el papel que jugaron, en esa red latinoamericanista, la revista Sagitario y los Consejeros Estudiantiles de la Facultad de Derecho.

Renovación fue diseñada y financiada por Ingenieros. En sus primeros años, tuvo, al igual que la colección "La Cultura Argentina", un tiraje masivo y una distribución a través de los puestos de diarios. Entre 1923 y 1925 (probablemente, durante 1926 no se haya editado), estuvo dirigida por Gabriel Moreau con un comité editor compuesto por Julio Barreda Lynch (seudónimo de Ingenieros) y Luis Campos Aguirre (seudónimo de Aníbal Ponce). Durante 1927 el director fue Fernando Márquez Miranda ${ }^{422}$ mientras que, entre 1928 y su cierre en agosto de 1930, estuvo dirigida por el estudiante peruano, exiliado en La Plata, Manuel Seoane.

En términos ideológicos, Renovación opera una interesante apropiación del "Mensaje a los intelectuales y estudiantes de la América Latina" que había realizado a comienzo de 1921 Barbusse y su grupo, y que -como muestra la correspondencia entre aquel e Ingenierosel argentino se encargó de difundir y alentar en América Latina -e incluso republicó en un número de 1924 de Renovación-. ¿En qué consistió esa “apropiación” latinoamericanista del mensaje de Barbusse? Los primeros números del boletín retoman la gravitación que, luego del congreso mexicano y la gira de Vasconcelos, alcanzó la Revolución Mexicana y su prédica contra el imperialismo estadounidense. Asimismo, difunden información -la mayoría de ella proveniente de Orzábal Quintana- sobre la experiencia civilizatoria que estaba teniendo lugar en Rusia y los peligros de la Liga de las Naciones. Además, dedican una sección -aparecida en la primera página y firmada por Julio Barreda Lynch- a reseñar y saludar cada nuevo proyecto del movimiento estudiantil izquierdista de la Argentina. Este saludo se completa con la publicación de artículos de Haya de la Torre, Bermann, González, Sanguinetti y Sánchez

\footnotetext{
${ }^{422}$ En sus años de estudiante de Derecho en La Plata, participa en el centro de estudiantes. Entre 1918 y 1919 es secretario de redacción junto a Dirval Palomo de la publicación semanal Gaceta universitaria. Órgano del Centro de Estudiantes de Ciencias Jurídicas y Sociales. Cuando en mayo de 1919, cambia la gestión del CE y Manuel Crespo García renuncia, Márquez Miranda asume como "director interino" de número de la segunda semana de mayo para presentar también su renuncia.
} 
Viamonte. Y la cuestión sobre la que vuelven una y otra vez los primeros números es la necesidad -enunciada por Ingenieros en el discurso dedicado a Vasconcelos- de fundar un "partido americano de intelectuales" que, desde las simpatías a la experiencia rusa y a una "Revolución en los Espíritus", se encargue de adaptar la ideología antiimperialista, ligada al socialismo, a las problemáticas latinoamericanas.

Para fundar ese partido, en mayo de 1924 se iniciaron reuniones en el local de la revista Nosotros. Luego de varios encuentros, en marzo de 1925 los participantes pusieron a circular los propósitos de la ULA, institución que tendría en Renovación su vocero y en el prestigioso "maestro" de la Reforma Alfredo Palacios, su presidente. Sobre esa fundación recordaba Sánchez Viamonte:

Nuestra institución revistió un carácter cultural, pero de activa propaganda por la difusión de sus principios, para lo cual contaba con dos publicaciones: Renovación, dirigida por José Ingenieros y Sagitario que aparecía en La Plata bajo la dirección de Julio V. González, Carlos A. Amaya y el autor de estas crónicas. Renovación tenía carácter de periódico y asumía una actitud más combativa que Sagitario. Revista de humanidades, pero esta última recibía el aporte intelectual de escritores de toda la América latina y España (Sánchez Viamonte, 1971: 200).

Además de estas dos publicaciones, las páginas de las olvidadas revistas porteñas Acción Universitaria y Revista de Oriente sugieren que ambas fueron importantes animadoras de la red político-intelectual que nacía. Acción Universitaria fue fundada en agosto de 1924 por Elías Jaskevich y Luis Petraglia -quien se aleja después del tercer número- y se definió en su subtítulo como una "publicación mensual de actualidad y política universitaria" y contó con un diseño gráfico y un formato idénticos al de Renovación, esto es, sus ocho páginas tamaño sábana estaban plegadas en cuatro, con un índice en la cara visible que aparecía como tapa. Esas páginas estaban dedicadas, casi exclusivamente, a difundir, mediante notas breves, los ideales y las iniciativas del ala izquierdista y porteña de la Reforma. Entre sus anuncios profesionales aparecieron los de José Belbey y Ubaldo Isnardi y entre las revistas publicitadas Valoraciones, Renovación e Inicial.

Seguramente, la iniciativa más novedosa de Acción Universitaria fue la organización, entre febrero y abril de 1925, de un "ciclo de disertaciones radiotelefónicas de extensión de cultura y divulgación científica". La primera estuvo a cargo de Sanguinetti y versó sobre la extensión universitaria. A ella le sucedió la del antiguo arielista socialista Ubaldo Isnardi sobre "Le coup de chaleur". Poco después Palacios disertó sobre el "Hispanoamericanismo", 
Belbey sobre "Juventud e idealismo" y Felipe A. Justo (entonces vicedecano de la Facultad de Ciencias Médicas) sobre la "Función social de la Universidad". ${ }^{423}$

Desde su número 13 (correspondiente a agosto de 1925), Acción Universitaria inició una encuesta sobre la Reforma, cuyas primeras respuestas fueron las de Palacios, Del Mazo y Derqui, y publicitó entusiastamente el ciclo de conferencias que -según veremos- organizaron figuras ligadas a la ULA con la intención de consolidar la filial argentina y fundar una en Uruguay. Unos meses después, Acción Universitaria dejó de editarse y resurgió en septiembre de 1926, bajo la dirección de Jaskevich y José Morin, como 1918 (2época de Acción Universitaria). Esta revista parece haber tenido sólo tres números. Ellos mantuvieron el formato de su sucesora y se destacaron por su prosa combativa en la que se fijaba 1918 como el comienzo "revolucionario" de la Reforma frente al año 1919 que proponía la fracción nacionalista.

En junio de 1925 aparecía el primer número de la Revista de Oriente. Ésta se presentaba como el órgano de la Asociación Amigos de Rusia y hasta septiembre de 1926 editaría diez números. ${ }^{424}$ Su director, Arturo Orzábal Quintana (1892-1969), era un joven, proveniente de la elite económica argentina, que había vuelto de París en 1920 con un título de abogado. En vinculación con Ingenieros, emprendió por entonces una intensa campaña periodística de legitimación de la Revolución Rusa, de cuestionamiento de la Liga de las Naciones y de defensa de los recursos naturales nacionales. Para vigorizar esa campaña, además de enviar numerosas colaboraciones a Nosotros, Renovación y Revista de Filosofía, en 1925 asumía las tareas de coordinación de la ULA y fundaba la Revista de Occidente.

Explicitando su vínculo con los animadores de la ULA, el número tres (fechado en agosto de 1925) publicó en la sección "Noticias Universitarias" el manifiesto del Partido Unión Reformista Centro-Izquierda y una presentación que apoyaba la campaña de los Consejeros Estudiantiles y “censores severos” Sánchez Viamonte, Sanguinetti, González y Ocampo. Los consejeros se enfrentaban a la gestión por su negativa a reorientar los estudios jurídicos hacia las cuestiones sociales, y sobre ello sostiene la Revista de Oriente:

El decano [Juan Ramos] manifiesta su posición completamente obscurantista al tratar de orientar la enseñanza en la Facultad hacia la intensificación de las ciencias jurídicas en prejuicio de las sociales. Se explica muy bien la posición del decano: las ciencias sociales, rectamente enseñadas, importan una condenación segura del régimen social imperante. Las jurídicas no, porque están acomodadas

\footnotetext{
423 "Disertaciones de carácter universitario", s/d., 12/02/1925. Fondo personal Florentino Sanguinetti, CeDInCI.

424 Para un análisis de esta revista, véase Bergel (2006).
} 
al interés de las clases dominantes ("Noticias universitarias", Revista de Oriente, $\mathrm{n}^{\mathrm{o}} 3$, agosto de 1925).

A continuación, la revista sugiere que esa resistencia del decano es la que motivó la formación de Centro-Izquierda, partido que deliberadamente "establece que las fuentes del saber no han de cerrarse impidiendo que los labios sedientos calmen en ellas su excelso ser" (idem). Esa nota y la publicación del manifiesto de la FUC (aparecida en el número 5) son los dos únicos abordajes explícitos que realiza la Revista de Oriente respecto de la orientación que debería tener la Reforma. Es que la Revista de Oriente dispuso otros modos más mediados, pero sumamente sólidos, para promover las iniciativas de la fracción antiimperialista de la Reforma. Esos modos consistieron en la elección de largas notas que informaban sobre los estudiantes rusos y chinos, en la reseña de las últimas obras de los líderes de esa fracción, en la publicación de algunas notas y en el ciclo de conferencias que organizó en el salón Unione e Benevolenza.

Específicamente, se descubren las vinculaciones entre esta revista, los consejeros y la ULA en la publicación de varias notas de Palacios y en el anuncio, que realiza el número 4, de la inauguración del ciclo de conferencias de la Asociación Amigos de Rusia. El ciclo era inaugurado con una disertación de Orzábal Quintana sobre la Liga de las Naciones y la diplomacia capitalista que contó con "un público numerosísimo de obreros e intelectuales [que] llenaba el salón y siguió con verdadero entusiasmo al orador", mientras que para el segundo encuentro Sánchez Viamonte, recién vuelto del Perú, se refería a "La juventud peruana ante la tiranía” y “el estudiante desterrado del Perú, Eudocio Ravines”, a "El momento social en América". ${ }^{425}$

los estudiantes en Perú. Asimismo, el breve apartado "Libros recibidos" consigna la recepción de Derechos políticos de Carlos Sánchez Viamonte, Tierra Fragosa de Julio V. González y "el libro últimamente publicado por el señor Gustavo Riccio”, tres obras que "obras serán incluidas en un próximo envío de materiales literarios a la Sociedad de Relaciones Culturales de Moscú". Y entre los anuncios profesionales aparecen los de Sanguinetti, Sánchez Viamonte, Aníbal Ponce, Simón Scheimberg y Eduardo Araujo. De todos modos, una vez fallecido Ingenieros el 31 de octubre de 1925, la relación del director de la Revista de Occidente con la ULA se tornó sumamente tensa, al punto que Orzábal Quintana fundaría en 1927 la Alianza Continental, una institución que coordinó actos con la ULA, pero

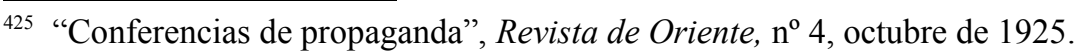


que concentró su prédica en la nacionalización del petróleo.

Sagitario, $\mathrm{n}^{\mathrm{o}}$ 7, "Por el reconocimiento de los soviets. Declaración de un grupo de intelectuales", octubre-noviembre de 1926: 140-141. Firman: Alejandro Catiñeiras, Alfredo L. Palacios, Roberto F. Giusti, Anibal Ponce, Alfredo A. Bianchi, Carlos Camino, Enrique Mouchet, Julio V. González, Arturo Orzábal Quintana, Alfonsina Storni, Florentino V. Sanguinetti, Alberto Palcos, Nicolas Besio Moreno, Mariano A. Barrenechea, Carlos Sánchez Viamonte, Alejandro Korn y Mario Sáenz.

Volviendo a las iniciativas de la ULA, ese año Alejandro Sux publica “... y más lirismo", una breve nota sobre la ULA en la que se reseña un acto y que es interesante porque nos muestra el modo en que se presentaba la Unión, al tiempo que ofrece algunos datos desconocidos. Sux aclara que "el doctor Julio H. Brandán, paisano mío, profesor, abogado y diplomático de la Universidad de Buenos Aires, exconsejero de la de Córdoba, exlíder del movimiento universitario que se llamó 'la Reforma', director de revistas y redactor de periódicos izquierdistas de la Argentina, está en México. Ha sido enviado por LA UNIÓN LATINO AMERICANA de Buenos Aires, con el objetivo de promover en ésta la fundación de una entidad análoga o lograr la adhesión de las que existan". A continuación menciona que la ULA “está compuesta por un grupo altamente representativo de intelectuales y estudiantes abrazados" y que "ya hay secciones en Argentina, Chile y Uruguay". ${ }^{426}$ Además de la "misión” de Brandán en México, la ULA contaría con Sánchez Viamonte como enviado a Brasil, Ingenieros a Francia y México, y Julio B. Barcos a Chile (Pita González, 2009).

Las dos últimas misiones fueron las más productivas. Sobre las iniciativas de Brandán en México y las de Sánchez Viamonte en Brasil, no tenemos prácticamente noticias. Por su parte, Ingenieros organizaba en París, en junio de 1925, la "Comisión de Solidaridad con los pueblos del nuevo continente", comisión que se presentaba a través de un acto y un pronunciamiento contra las amenazas imperialistas del secretario de Estado Kellog contra México. El promotor de la ULA reunía en ese acto, entre otros, a Unamuno, Enrique Ortega y Gasset (hermano mayor del reconocido filósofo), Haya de La Torre y Carlos Quijano. A partir de ese acto, Ingenieros estrechaba una breve y significativa amistad con Quijano: ambos partían poco tiempo después a conocer el México revolucionario y, si a su vuelta a Buenos Aires, Ingenieros fallecía, el itinerario político-intelectual de quien se convertiría en el

\footnotetext{
${ }^{426}$ Fondo de la Reforma Universitaria, Casa de la Reforma, Universidad Nacional de Córdoba.
} 
máximo representante de la izquierda nacional uruguaya estaría desde entonces marcado por la denuncia imperialista en el continente. ${ }^{427}$ Más precisamente, no sólo Quijano encontró en la revista cultural de la ULA, Sagitario, la plataforma de difusión de sus primeros textos antiimperialistas, sino que además, el mismo mes de octubre de 1925 en que Ingenieros fallecía, regresaba a País para fundar una agrupación en la que los estudiantes e intelectuales discutieran y organizaran su denuncia del imperialismo en Latinoamérica, la Asociación General de Estudiantes Latinoamericanos (AGELA; 1925-1933). Una asociación que sin duda debe ser pensada como la sucesora de la Comisión de Solidaridad organizada por Ingenieros y la filial parisina de la ULA. ${ }^{428}$

En cuanto a la misión chilena, Barcos se contactó allí con las organizaciones de maestros y logró organizar, junto a la ULA y publicaciones afines, en Buenos Aires en los primeros días de enero de 1928 la Primera Convención Continental de Maestros. Esta Convención fue fuertemente cuestionada por la gran prensa, que la consideraba como corruptora de los valores educativos y promotora del caos social. Frente a ello, del Mazo, otro de los entusiastas participantes, contestó en la prensa erigiendo la Convención en la reunión internacional más importante de los trabajadores intelectuales después de los congresos de estudiantes celebrados en Argentina en 1918, y en México en 1921. Esa importancia residía en que allí representantes de diversos estamentos educativos debatieron los problemas en la enseñanza desde una perspectiva integral (La vanguardia, 18/01/1928, p. 4, cit. Ascolani, 2010: 85).

Respecto de las filiales chilenas y uruguayas que menciona Sux, veremos en este capítulo que Oscar Cosco Montaldo fue el joven que más persistió en el intento de fundar -aparentemente sin éxito- esa sección uruguaya, mientras que de la sección chilena nada menciona la bibliografía crítica ni el boletín Renovación. Además de la sección porteña, a

\footnotetext{
${ }^{427}$ Respecto de la repentina muerte de Ingenieros, con sólo cuarenta y cuatro años, Pita González (2009) ha reconstruido y analizado los homenajes formulados por la ULA, y con ello ha esbozado el tipo de "ceremonia reformista" que quienes se identificaban con la Reforma disponían ante el fallecimiento de sus compañeros. Por su parte, Castilla (2011) ha realizado un minucioso análisis del tipo de homenaje y recuperación de Ingenieros que propuso Mariátegui en Amauta. Actos y notas -que definían la Reforma y se apropiaban simbólicamente de sus líderes- también fueron dispuestos ante el fallecimiento, a fines de 1923, del joven Héctor Ripa Alberdi y, a mediados de 1925, del líder estudiantil y poeta romántico Pablo Vrillaud.

${ }^{428}$ Un interesante estudio de la AGELA puede consultarse en Taracena (2006). Allí no sólo se reconstruyen las actividades de la asociación, sino que, a partir de la lectura de los archivos policiales parisinos, se repone la repercusión que tenían esas actividades y la preocupación que causaba al gobierno. Taracena recupera también el elocuente retrato de Quijano que realizaba en 1926 otro participante de la AGELA, Miguel Ángel Asturias. Éste lo caracteriza como: "Manager, cabeza y pies de la Asociación General de Estudiantes Latino-Americanos de París. Literatófobo, poetáfobo, viviseccionista y hombre-sandwich de las ideas renovadoras de la América" (cit. en Taracera, 2005).
} 
fines de 1925 se constituía en Córdoba una sección cuyos miembros ofrecen otra prueba de que la ULA nacía para organizar la acción que venía realizando el movimiento reformista de 1918. En efecto, presidía la sección cordobesa Deodoro Roca, y entre los jóvenes que lo acompañaban en la comisión directiva se encontraban Enrique Barros y Gregorio Bermann.

Finalmente, recordemos que la construcción de la red antiimperialista anclada en Buenos Aires ocurría en un momento en que Ingenieros contaba con un alto respeto y prolongado contacto epistolar con la intelectualidad centroamericana y, como muestra Muñíz (2015), especialmente en La Habana, donde no sólo circuló y fue replicado Renovación por el grupo de la revista Juventud, sino que también Ingenieros alentó a los intelectuales con los que mantenía correspondencia para que fundaran una filial de la ULA.

Pero la fundación de la unión argentina era simultánea a la fundación de otros grupos que procuraban la organización de los intelectuales y los sectores populares en torno a la denuncia del fenómeno imperialista y a la definición de la cultura política de la Reforma como antiimperialista y latinoamericanista. En efecto, mientras Ingenieros fundaba la ULA, Haya de la Torre comenzaba su "nomadismo proselitista" y el poeta peruano Edwin Elmore (1890-1925) publicaba notas en las revistas latinoamericanas de cultura y se escribía con diversos intelectuales para la "organización de las fuerzas espirituales en el continente" a través de un Congreso Iberoamericano de Intelectuales, que se realizaría en La Habana y recogía las iniciativas del congreso internacional realizado en México de oponer una prédica organizada al panamericanismo. Para concertar el proyecto Elmore llegaba a principios de 1925 a Buenos Aires e iniciaba diálogo personal con Renovación y la ULA (Pita González, 2009: 110-111). Poco antes Elmore le escribía a Mariátegui una carta en la que le agradecía la difusión que había hecho de la iniciativa para aclararle luego:

Yo creo firmemente que es la falta de unión lo que ha mantenido en una situación subalterna a los hombres, cuyo tipo (bien determinado también, pese a todos los equívocos) se conoce con el nombre de intelectuales. ¿Por qué no ensayar, pues, su acercamiento? [...] no se trata siquiera de proteger la propiedad intelectual de la rapacidad de los editores, se trata de algo mucho más noble y más grande, se trata de conferir a la Inteligencia un poder y una eficacia en la acción de que hasta ahora ha estado despojada (Carta de Edwin Elmore a José Carlos Mariátegui, 09/01/1925, Alta Mar, reprod. en Mariátegui, 1964: 72).

Ese Congreso no se realizaría, entre otras cosas, porque su principal promotor sería asesinado en octubre de 1925 por el poeta José Santos Chocano, con quien Elmore mantenía una 
polémica pública en torno de los festejos del Centenario de la Batalla de Ayacucho y de las proclamas dictatoriales de Chocano y Lugones (Yankelevich, 2003; Funes, 2006). Las otras organizaciones de la "familia antiimperialista" que surgirían a mediados de la década del veinte serían: la LADLA y la UCSAYA en México, la AGELA en París, la Liga Antiimperialista Sección Argentina (LASA) y la Alianza Continental en Argentina, y el APRA en Perú , al que -como muestra Pita González (2009)- en 1928 se sumó la ULA.

\section{Sagitario, la revista estudiantil de cultura de la Unión Latino-Americana}

El primer número de Sagitario apareció en mayo de 1925 en La Plata. Allí se anunció a Amaya, González y Sánchez Viamonte como sus directores y al joven Pedro Verde Tello como su secretario de redacción. Verde Tello había participado de la "huelga grande" platense y del grupo Claridad del PS. Cuando el grupo fue expulsado, ingresó al PC, pero en 1922 salió junto a Palcos y Asimismo, en 1924 había dirigido el periódico estudiantil de la Facultad de Derecho de La Plata, al que bautizó como Bases -con el mismo nombre del periódico de Solari que analizamos-. Al igual que Solari, Verde Tello sería en las décadas siguientes un importante referente intelectual del PS, pero además entre 1927 y 1928 sería Consejero Estudiantil en el Consejo Superior de la UNLP y ocuparía entre 1927 y 1931 el puesto de corresponsal argentino de la revista montevideana Ariel, que -como vimos- Solari había ocupado entre 1919 y $1922 .{ }^{429}$

También Sánchez Viamonte ya se había iniciado como revistero, en una breve -y hacia 1925 ya muy lejana- experiencia. En 1908 había fundado y dirigido la revista platense Coloseum, de la que aparecieron sólo tres números (los dos primeros en 1908 y el tercero al año siguiente). Sánchez Viamonte, además de reconocerse como "hermano intelectual" de Palacios en tanto militantes se una similar renovación del derecho argentino, es quien continuó la prédica latinoamericanista y antiimperialista de Sagitario a través de la refundación de ella tres décadas después. En su segunda época, Sagitario puso en circulación, entre 1955 y 1956, ocho números.

Pero sin duda quien aportó la experticia para armar la revista cultural de la ULA fue Amaya, pues -como vimos- venía dirigiendo desde 1923 Valoraciones. Mientras que Sánchez Viamonte y González asumían importantes cargos en la ULA, Amaya sólo ocupaba una

\footnotetext{
429 Sobre su itinerario político-intelectual, véase las mencionadas reconstrucciones de Tarcus (2007a) y de Graciano (2008).
} 
suplencia para dedicarse

Sobre la trama material que acompañó la intervención latinoamericanista de la revista Sagitario de 1925, recuerda Sánchez Viamonte que "circuló por toda América Latina y España, manteniendo contacto con publicaciones de análoga orientación, como lo fueron Repertorio Americano de Costa Rica dirigido por Joaquín García Monge y Amauta dirigida por José Carlos Mariátegui” (Sánchez Viamonte, 1971: 201). En cuanto a España, las páginas de Sagitario muestran que mantuvo contacto con Alfar y El Estudiante. Y los vínculos con esta última llegaron a ser tan importantes que su "sección latinoamericana" tendió a equiparar la región con las noticias proveniente de la red porteña del latinoamericanismo. ${ }^{430}$

En cuanto al Perú, la correspondencia de Mariátegui prueba que fue Amaya quien se encargó de vincular a Sagitario con Amauta (1926-1930), e incluso de insertar a Mariátegui en la red porteña. En respuesta a una carta del peruano -con la que probablemente se haya iniciado el contacto-, Amaya se comprometió a ayudar a Mariátegui en la publicación y circulación argentina de sus textos. Además de listarle las librerías que podían recibir sus libros en consignación -entre ellas "La Estrella" que había fundado José Gabriel en La Plata-, le prometió "algunas notas para Vanguardia" de Lima y le advirtió -como buen discípulo de Korn- "que mi prosa no es de combate; mis aficiones intelectuales se inclinan hacia la ciencia de Kant". Finalmente, confirmando las revistas porteñas con las que Sagitario se hermanaba en la red antiimperialista, aseguraba Amaya:

En lo sucesivo irán 15 ejemplares de Sagitario a lo de Rego y 10 a la librería de su hermano. Ambas liquidaciones deberá reservarse Ud. Le diré al Director de Renovación que le envíe el periódico; asimismo lo haré mandar Acción Universitaria.

No bien aparezca su libro envíemelo para ocuparnos de él. En la semana próxima va Sagitario. Aparecen dos notas suyas en ese número (Carta de Carlos Amaya a José Carlos Mariátegui, 25/11/1925, La Plata, reprod. en Tarcus, 2001: 229).

No sabemos si Acción Universitaria y su sucesora 1918 llegaron a manos de Mariátegui, pero la correspondencia publicada testimonia que Márquez Miranda, al tomar la dirección de Renovación en febrero de 1927, le envió veinte números al amauta junto a una nota en la que le rogaba que "los distribuya en Perú, entre la gente que nosotros consideramos representativa. [...] es el caso de expandir ideas que le son afines, que Ud. mismo profesa con la noble resolución de que es capaz, y por eso quiero creer que podrá ayudarme a la difusión

${ }^{430}$ Para un análisis de ese vínculo, véase Carreño (2012). 
de Renovación", 431

Volviendo a Sagitario, esta "revista de humanidades" prosiguió desde su primer número la construcción del horizonte filosófico antipositivista que Valoraciones venía desplegando desde 1923, pero -como analizaron Rodríguez y Vásquez (2002)- junto a ese horizonte tramó uno político ligado a las denuncias contra el imperialismo en el continente. Participando de la desconfianza antipositivista ante la ciencia como orientadora de la acción, el manifiesto que inauguraba Sagitario (luego atribuido a González) declaraba que

Poco más de un lustro ha trascurrido desde la hora en que un efebo desnudo, terciado a la espalda el arco inverosímil y erizado de flechas del carcax, se detuvo a las puertas de la historia y llamó con recio aldabonazo.

Era el hombre de la nueva generación que aparecía en el escenario de la América Latina. En actitud resuelta, se allegó a la mesa donde producían su interminable debate los prohombres y dijo con fuerte voz:

- Vosotros ya nada tenéis para decir. Habéis hablado lo bastante. [...] La vida ha tomado un sentido que vuestras disciplinas científicas no podrán interpretar y reanuda su marcha con un ritmo que escapa a la disposición de vuestros registradores. Idos, pues, antes que os devore la esfinge con la primera pregunta ("Las flechas de Carcax", Sagitario, n 1, mayo-junio de 1925, p. 1).

A pesar de que este llamado apelaba al imaginario grecolatino del modernismo, los jóvenes de Sagitario ya no erigían a Rodó como el maestro de la juventud culta, ni formulaban esa confianza en la ciencia que aparecía en el grupo arielista de 1914. En este manifiesto -y en los que publican en los años siguientes-, Rodó tiende a ser relevado por Vasconcelos y Ortega y Gasset. El primero por la confianza que, desde su puesto de gestor cultural de la Revolución Mexicana, depositaba en los estudiantes latinoamericanos. El segundo porque había propuesto la tesis de las generaciones, la que en el citado manifiesto Sagitario hacía suya para anunciar una época de "beligerancia constructiva" y un llamado a volverse "ejecutores del designio histórico e intérpretes de la realidad social". ${ }^{332}$

Si bien en sus sucesivos números Sagitario irá precisando la condición de ejecutora e intérprete pedida a la generación latinoamericana, ya en la primera entrega esa condición quedó asociada a las iniciativas de la ULA. Allí se reproduce el manifiesto de la Unión con un elogioso prólogo en el que se informa que los intelectuales y estudiantes argentinos se habían

\footnotetext{
${ }^{431}$ Carta de Fernando Márquez Miranda a José Carlos Mariátegui, 15/02/1927, Buenos Aires, reprod. en Tarcus (2011: 231).

${ }^{432}$ Este tipo de apropiación "beligerante" de Ortega sería recusada en 1924 por éste en su columna de La Nación, luego de leer los primeros números de Inicial y Valoraciones.
} 
reunido "con el objeto de fomentar por medio de un acercamiento espiritual el desarrollo de una nueva conciencia en armonía con la idiosincrasia y la sensibilidad de los pueblos americanos" y, al igual que la nota de Sux, se anuncia que se han establecido los grupos respectivos en Uruguay, Chile y Perú.

Como mencionamos, la ULA parece haber funcionado únicamente en Buenos Aires y en Córdoba. Ello también es sugerido por Sagitario, pues los números posteriores reseñan los actos y difunden las solicitadas de la sección porteña y cordobesa, sin mencionar actividades organizadas en Chile y Perú, mientras que con respecto a Uruguay sólo se saludan las iniciativas de la Asociación Cultural Universitaria -que dirigía Cosco Montaldo- y su revista Cultura.

El antiimperialismo latinoamericano de Sagitario se construía, entonces, a partir del saludo y la difusión de las iniciativas de la ULA. A las noticias y comunicados antiimperialistas se sumaron ensayos sobre la cultura latinoamericana de Mariátegui y de Henríquez Ureña así como las primeras notas antiimperialistas de Carlos Quijano y la frecuente presencia de Haya de la Torre y de los exiliados peruanos, presencia lograda tanto mediante la publicación de notas firmadas por los peruanos como de solicitadas firmadas por grupos porteños en su apoyo. ${ }^{433}$

Esta puesta del latinoamericano en el centro del movimiento reformista que proponían Sagitario y Renovación tendría también como correlato una serie de "actos latinoamericanos" organizados por los editores de esas mismas revistas. En ellos la condición latinoamericana estaba dada no sólo por el motivo bajo el que se reunían los reformistas porteños (a saber: el homenaje a la independencia boliviana, la oposición a la invasión a Nicaragua o el apoyo a los estudiantes paraguayos), sino también por el lugar que se le asignaba a los discursos de representantes latinoamericanos, esto es, a Cosco Montaldo en nombre de los estudiantiles uruguayos, a los estudiantes desterrados del Perú y de Bolivia, y a las adhesiones enviadas por la Federación Universitaria de Chile.

Como prueba de la novedad que introducía ese "antiimperialismo latinoamericano" en el movimiento estudiantil, traigamos la breve carta de Luisa Luisi que Sagitario publica en su

\footnotetext{
${ }^{433}$ Sobre esa presencia en distintas publicaciones del continente, Bergel (2009) identificó agudamente el despliegue de un "nomadismo proselitista" característico del primer aprismo. En lo relativo a la revista Sagitario, Sessa formuló una acertada caracterización: "Las referencias al APRA, a partir de 1927, demostraban la posibilidad de traducir en términos de una organización política los aires de renovación surgidos en torno del reformismo. A esto se sumaba el contenido antiimperialista de su prédica y la común referencia a la necesidad de que fueran las nuevas generaciones las responsables de encabezar el movimiento de renovación" (Sessa, 2013: 77).
} 
segundo número. Junto a los artículos de "humanidades" y a los documentos de la ULA, aparece esa carta en la que la pedagoga uruguaya identificaba la revista con el proyecto de la ULA y explicaba que no se sumaría por disentir con el tipo de matiz antiiperialista. Y confesaba que, de todos modos, no podía dejar de saludar a la juventud platense, pues Sagitario mostraba que ella "despierta al fin del ensueño griego e intelectualista" producido por el llamado de Rodó, para comenzar a sentirse "urgida por la amenaza de una sojuzgación económica". Esta observación tiende a confirmar que el pasaje que buscaba Ingenieros en 1922 desde un antiimperialismo cultural hacia uno económico, en 1925 se logró, al menos, en una activa fracción del reformismo porteño.

Ese año Quijano formaba parte de la comitiva que, presidida por Ingenieros, viajó a conocer el México revolucionario. Poco después, aparecía el primer artículo suyo en Sagitario: el número 7 de Sagitario publicó “De Poincaré a Poincaré pasando por Herriot”, un artículo en el que el montevideano explica el conflicto político vivido por el parlamento francés. Y el número siguiente (correspondiente a julio-agosto de 1927) ofrece la primera entrega de "Nicaragua. Los procedimientos del imperialismo yanqui", versión escrita de la conferencia que Quijano había pronunciado en un acto parisino de la AGELA y que representa su primer análisis sistemático del imperialismo económico padecido por América Latina. Sagitario acompañó esa publicación con su propia declaración antiimperialista, "Nicaragua”, y anunció que el texto de Quijano aparecería en cinco entregas, pero los jóvenes platenses no pudieron cumplir su promesa, pues luego de la tercera entrega del ensayo, Sagitario dejó de editarse. ${ }^{434}$

Valoraciones, Inicial y Sagitario, revistas reformistas surgidas en un momento de retroceso del ciclo obrero combativo, combinaban la intervención cultural con la política. De ahí que, a diferencia del periodismo estudiantil político que analizamos en el capítulo sexto, en ellas se registre una mayor apertura en sus colaboraciones. Sagitario ofrece un interesante ejemplo de ello al publicar en su sección "Universitarias" las iniciativas de los reformistas de izquierda de la Facultad porteña de Derecho, aunque en su sección de artículos editó uno breve de Adolfo Korn Villafañe, el principal oponente de esos reformistas. En efecto, el primer número de Valoraciones difundió "Matemática de la personalidad", artículo en el que Korn Villafañe exponía un sistema filosófico que pretendía sustentar un nacionalismo que adhería a la ULA por su denuncia del imperialismo, a pesar de no compartir las simpatías con

\footnotetext{
${ }^{434}$ Ese año el ensayo de Quijano también es publicado en entregas por el diario El País de Montevideo. Y al año siguiente es editado como folleto por la AGELA en la Agencia Mundial de Librería de París.
} 
la Revolución Rusa ni el ideal emancipatorio de la cultura de izquierda.

\section{Cultura, la hermana montevideana de Sagitario}

Al partir Quijano a París en 1924, la revista Ariel, que éste había editado de forma regular entre 1919 y 1923 para -como analizamos en el capítulo sexto- que los estudiantes montevideanos impulsaran la "Revolución en los Espíritus", pasaba a estar dirigida por González Areosa, al tiempo que una fracción de arielistas, encabezada por los estudiantes de Derecho Oscar Cosco Montaldo y José P. Cardoso, se desligaba del Centro Ariel para fundar la Asociación Cultural Universitaria (1924-1926) y Cultura. Órgano de la Asociación Cultural Universitaria. Esta revista, de veinte páginas, editó, al menos, siete números entre 1924 y 1926 y, además de mantener una estrecha vinculación con la red estudiantil porteña ligada a los proyectos antiimperialistas de Ingenieros, buscó animosamente fundar una filial montevideana de la ULA.

En junio de 1924 aparecía el primer número de Cultura y un mes después el primero de los tres números de Ariel dirigidos por González Areosa. El editorial de esta última anunciaba la "reiniciación" de la revista proponiendo un interesante relato del despertar político del grupo y con ello de su interpretación izquierdista de la Reforma. Declaraban los arielistas en un relato que guarda importantes afinidades con los que no se cansará de proponer Deodoro Roca:

Esa vaga aspiración de idealidad fue haciéndose, luego, idea organizada y sentimiento imperioso.

Empezábamos, entonces, a adquirir conciencia del momento histórico que vivíamos. La crisis espiritual de la post-guerra removió nuestros corazones. La nueva sensibilidad y los nuevos valores que surgían nos anunciaban el advenimiento incontenible de otra época. $\mathrm{Y}$ entre las incertidumbres y las turbulencias de esa génesis confusa, acogimos con fe el llamado de los hombres que promovían la revolución en los espíritus, la prédica renovadora de los pensadores y el clamor auroral del pueblo ruso. [...] la Universidad vivía tapiada de indiferentismo, ajena a la realidad circundante que pujaba por entrar en los claustros y fecundarlos. [...] [Las Casas de Estudios] en sí mismas se retraen y no buscan al pueblo, tratan de esterilizar todo germen de inquietudes y aspiran a encasillar el espíritu en textos de atiborrado intelectualismo. Las Casas de Estudios preparan profesionales, pero no hombres.

Y así fue que nos lanzamos a redimir la Universidad ("Reiniciación", Ariel, n 36, julio de 1924, p. 1).

Allí se afirmaba también que para 1924 "ya había una conciencia colectiva" que sentía los 
nuevos ideales y "una fuerza juvenil que los imponía". Pero si ellos eran clave en las campañas democratizadoras que impulsaba el grupo al interior de la Universidad de la República, no alcanzaban para que la revista consiguiera reiniciarse. En efecto, más de dos años después, en octubre de 1926, aparecía el primer -y único- número de una nueva publicación del grupo: Ariel. Boletín del Centro de Estudiantes Ariel. Frustrada la iniciativa de un boletín, al año siguiente era editado un nuevo número de la revista que se había interrumpido en 1924: en diciembre de 1927 aparecía Ariel n 37 y, hasta su cierre en 1931, se editarían sólo cuatro números más. ${ }^{435}$

Esta aparición irregular no sólo coincide con el alejamiento de Quijano de Montevideo, sino también con el reflujo del ciclo rioplatense de protestas obreras y la inscripción de la "Revolución en los Espíritus" y de Barbusse en el Partido Comunista francés. En ese nuevo horizonte político, Ingenieros lograba organizar a los estudiantes e intelectuales que venían alentando el movimiento político de la Reforma en torno del antiimperialismo latinoamericanista. Y los montevideanos que se plegaban a esa iniciativa eran los que en 1924 abandonaron el Centro Ariel para fundar la Asociación Universitaria Cultural y la revista Cultura. ${ }^{436}$

El manifiesto que inaugura la revista permite advertir claras afinidades con la red porteña preocupada por el imperialismo en Latinoamérica. La Asociación se presentó como un

núcleo activo de hombres jóvenes que, conscientes, de su misión, han decidido lanzarse atrevidos a la cruzada del ideal [...]. Nuestra bandera es la gran bandera de la colectividad estudiantil: la Reforma, que sostendremos siempre para llegar a la emancipación de nuestra Casa de Estudios y para salvaguardar los fueros inviolables de la cultura nacional [...], para que represente la disciplina de las ideas frente a las vacías alharacas y para que consagre la sensatez de la acción frente a las acometividades de un quijotismo trasnochado.[...] hemos inscrito en

\footnotetext{
${ }^{435}$ En septiembre de 1929 aparece Ariel $n^{\circ}$ 38, también bajo la dirección de González Areosa. Los siguientes números corresponden a mayo de 1930 uno y a diciembre de 1930 el otro. Ambos tienen como redactores responsables a: Arturo Figueredo, Arturo Prünell, Héctor E. Fasenello, Arturo Dubra y Hugo Fernández Artucio. En el último número, fechado en junio de 1931, sólo permanecía de ese grupo Figueredo. Los otros jóvenes fueron Raúl Capurro, Alfredo Aragona, J. Bentencauet S. Fernández Correa y J. Magariño.

${ }^{436}$ Cultura guarda una apariencia muy similar a Ariel, sobre todo porque su información se organiza prácticamente las mismas secciones. Por un manifiesto de 1925 contra el gobierno boliviano difundido en la Revista Jurídica sabemos que entonces su comisión directiva estaba compuesto por: Cosco Montaldo, presidente; José P. Cardoso, vicepresidente; Eminio Bonino y Gabriel Terra (h), secretarios; Juan C. Victorica, prosecretario; Pedro Bezozi, tesorero; Pablo Purriel, protesorero; Juan Llopart, bibliotecario; Homero Cosco Montaldo, Guillermo García Gil, Antonio Laconich, Carlos Mainzteguy, Luis Moura, Severo Marizcurrena, Alberto Pi, Aristeo A. Piaggio, Raúl Previtali, Arturo Prunell, Ángel Uriarte y Cipriano Vitureira, vocales ("Manifiesto de la Asociación Cultural de Montevideo", Revista Jurídica, octubre de 195, p. 165).
} 
nuestro programa de realizaciones el ideal de fomentar la solidaridad estudiantil, que rebasará las fronteras de nuestro ambiente local, para abarcar un amplio programa americanista, inspirado en la ferviente unidad de nuestro continente [...] finalmente, ensanchando aún más el escenario de nuestra acción, haremos de la difusión de la cultura, un verdadero apostolado ("Nuestra idea", Cultura, $\mathrm{n}^{\mathrm{o}} 1$, junio de 1924, p. 1).

Los siguientes números precisaron las tres tareas que se trazó la Asociación. Para "disciplinar las ideas" y lograr "la sensatez de la acción", convocó a los grupos estudiantiles uruguayos a distintas asambleas en las que debería refundarse una federación estudiantil. Para alcanzar "la ferviente unidad del continente", saludó la aparición de la ULA, envió a su presidente como representante en los actos que ésta organizó y promovió la organización de los intelectuales uruguayos en una sección nacional de la ULA. Finalmente, para difundir la cultura dispuso cursos de extensión y ciclos de conferencias. Aunando las últimas dos tareas, a mediados de 1925 la Asociación emprendió junto con el Partido Centro-Izquierda de la Facultad porteña de Derecho un ciclo de intercambio de conferencias entre las ciudades rioplatenses.

EL presidente de la Asociación y estudiante de abogacía Oscar Cosco Montaldo sólo publicó una nota con su firma en Sagitario. En el número seis (fechado en abril-agosto de 1926) apareció “Orientaciones Universitarias”, un largo discurso que Cosco Montaldo había pronunciado en la Facultad de Derecho de Montevideo al inaugurarse la cátedra de "Legislación obrera y previsión social", a cargo del abogado y poeta, fundador del Partido Socialista uruguayo, Emilio Frugoni. A pesar de que es esa única referencia a Cosco Montaldo en los doce números de Sagitario, el repaso de Renovación, Acción Universitaria y 1918 prueba que, a través de la Asociación y de su revista, de los viajes frecuentes a Buenos Aires que realizó Cosco Montaldo para participar de los actos antiimperialistas y de las conferencias de intercambio, una fracción del reformismo montevideano buscó que los jóvenes que estudiaban en la Universidad de la República comenzaran a participar de una identidad estudiantil que incorporaba a la "Revolución en los Espíritus" difundida entre 1921 y 1924 por Ariel un antiimperialismo latinoamericanista, tramado desde Buenos Aires por el grupo que lideraba Ingenieros.

Antes de revisar las iniciativas comunes entre porteños y montevideanos, mencionemos, al menos, que Sagitario tendrá otras dos "hermanas", Estudiantina (19251927) y Don Segundo Sombra (1928-1930). La primera apareció entre mayo de 1925 y 1927 como órgano de los estudiantes del Colegio Nacional de La Plata y fue dirigida por Juan 
Manuel Villarreal. ${ }^{437}$ Cuando éste ingrese a la Facultad de Humanidades comenzará a editar, desde septiembre de 1928, Don Segundo Sombra. Revista de letras, crítica y arte. Ésta se inauguraba como el órgano del CE de Humanidades y reemplazaba a la revista Proteo que editaba ese Centro desde 1924 y que recogía artículos de los profesores y estudiantes ofreciendo ese "canasto de apuntes" que criticaba explícitamente Bermann. El diseño y el tipo de intervención con que Villarreal renovó el órgano del $\mathrm{CE}$ de Humanidades guardó una fuerte similitud con el que, bajo la impronta de Sagitario, había tenido Estudiantina. ${ }^{438}$

\section{El Partido Unión Reformista Centro-Izquierda, la Asociación Cultural Universitaria y la proyección de una filial uruguaya de la ULA}

Al igual que Sanguinetti, los tres directores de la primera Sagitario ocuparon cargos en la comisión directiva de la ULA: González y Sanguinetti fueron parte de los diez consejeros titulares, Amaya fue uno de los consejeros suplentes y Sánchez Viamonte el vicepresidente. Además, colaboraron en las publicaciones vinculadas a la ULA Acción Universitaria, Cultura y la Revista de Oriente.

Además de asumir esos cargos en la ULA, Sanguinetti, González y Sánchez Viamonte ejercían su mandato como consejeros estudiantiles de la Facultad de Derecho y participaban de la fundación de un grupo que buscaba aunar a los reformistas izquierdistas de la Facultad. A mediados de 1925, los tres graduados se unieron a un grupo de estudiantes para transformar el Partido Unión Reformista en el mítico -y poco estudiado- Partido Unión Reformista Centro-Izquierda. Éste surgía bajo la iniciativa de los jóvenes militantes del PC Héctor Raurich y Mariano Calvento y perviviría, al menos, hasta 1933.

El manifiesto inaugural fue difundido tanto por Renovación como por Sagitario, Revista de Oriente y Acción Universitaria. El texto proponía una definición clasista de la Reforma y señalaba una "crisis de la cultura contemporánea" afín a las "inquietudes contemporáneas" -desde las que, como vimos en el capítulo anterior, ya desde 1921

\footnotetext{
${ }^{437}$ Esta revista estudiantil contó con el saludo de Haya de la Torre, a través de del Mazo. Comienza declarando la carta que, desde Londres, envía el exiliado peruano a los estudiantes platenses: "Gabriel del Mazo, nuestro compañero y amigo, a cuyo nombre está en gran parte ligada la gloria de la revolución universitaria argentina y la gloria, -ésta más rara, - de la lealtad absoluta y vigilante a sus principios, me ha enviado un número de Estudiantina y me pide unas líneas para sus páginas. Lo hago sin tardanza porque es mi deber" (Estudiantina, ${ }^{\circ}$ 4, noviembre de 1926). Asimismo, seguramente los jóvenes platenses hayan conseguido "Romain Rolland y la América Latina" por Haya de la Torre (Estudiantina, $\mathrm{n}^{\circ}$ 5-6, febrero de 1927, pp. 82-85) también a través de del Mazo.

${ }^{438}$ Para un análisis de estas revistas, véase los estudios citados de Rodríguez y Vásquez (2002) y Graciano (2008).
} 
Sanguinetti llamaba a reformar el rol de la Facultad de Derecho-. Enuncia el primer apartado del manifiesto:

\section{I. - La crisis de la cultura contemporánea}

1. El problema educacional no es sino una de las fases del problema social; por ello no puede ser solucionado aisladamente.

2. La cultura de toda sociedad es la expresión ideológica de los intereses de la clase dominante. La cultura en la sociedad actual es, por lo tanto, la expresión ideológica de los intereses de la clase capitalista.

3. La última guerra imperialista, rompiendo el equilibrio de la economía burguesa, ha puesto en crisis su cultura correlativa.

4. Esta crisis sólo puede superarse por el advenimiento de una cultura socialista (Partido Unión Reformista Centro-Izquierda, "Definición social de la Reforma Universitaria", Sagitario, nº 2, julio-agosto de 1925, p. 262).

Luego de alejar la Reforma de su definición generacionista para ligarla a la lucha de clases y la revolución socialista, el grupo reivindicaba lo que llamamos la "dimensión institucional” de la Reforma:

9. El movimiento de reforma universitaria responde a necesidades concretas de la masa estudiantil que pueden expresarse en los postulados siguientes:

a) Autonomía universitaria;

b) Participación de todos los factores concurrentes en la dirección y orientación de la misma;

c) Renovación de los métodos pedagógicos;

d) Socialización de la cultura;

e) Solidaridad permanente de la masa estudiantil con el proletariado en su carácter de fuerza reivindicadora (idem).

Junto a esas medidas universitarias los animadores de Centro-Izquierda debía alentarse una “dimensión política" que creara en la Facultad de Derecho una "corriente de izquierda". Para ello los puntos anteriores al citado precisaban:

6. Se ha comprobado que el movimiento reformista ha originado en su desarrollo un gran acercamiento entre los estudiantes y el proletariado -sobre las bases de intereses comunes- hasta llegar a asumir como en Perú una faz netamente antiimperialista.

7. A medida que se agrava la crisis del capitalismo los intereses de la masa estudiantil y de los intelectuales en general tienden a confundirse con el proletariado.

8. Esto hace posible profundizar el movimiento, asignándole una finalidad político-social (idem). 
Semanas después de la difusión este manifiesto, González, en representación de CentroIzquierda, proponía en el Consejo Directivo el proyecto de extensión universitaria anunciado en ese texto. En la presentación, sostenía González que la Universidad debía superar su aislamiento al "medio ambiente formado en la entraña de la sociedad por la clase proletaria, con su vida de labor y sus ideales de reivindicación". Y luego precisaba que a través de la extensión la Universidad:

debe enseñarle la ciencia y las doctrinas surgidas de la lucha de clases, que es lo que interesa al proletariado, para ponerla en condiciones de comprender su problema fundamental, formar su criterio a fin de que pueda saber si su movimiento reivindicatorio responde a una realidad histórica social y económica, o si no entraña más que un error o una función (Julio V. González, "El problema de la extensión universitaria en el Consejo Directivo de la Facultad", Revista Jurídica, año 41 (sin número), octubre de 1925, p. 171).

En las elecciones siguientes, la Revista Jurídica quedaba a cargo de los animadores de la Unión Universitaria -de la que, ya egresados, Adolfo Korn Villafañe y Carlos Cossio eran sus maestros- y desde ella contestaban al reformismo izquierdista que todaba vigor a partir de la formación de Centro Izquierda. El editorial del primero de los números dirigidos por $\mathrm{V}$. E. Márquez Bello defendía los indudables e importantes logros de la Reforma en la Facultad de Derecho, y con ello mostraba lo innecesario de la empresa del nuevo grupo estudiantil: "No hallando justificada la unión del Centro con la Izquierda, dada la posición diametralmente opuesta de ambas tendencias, dejamos al lector curioso esa tarea, ya que detrás de cada gesto o actitud debemos encontrar una posición filosófica que la explique. [...] Como que en opinión suya, hay que rectificar la dirección seguida hasta ahora para adaptarla a las exigencias del credo marxista". ${ }^{439}$ Luego, ese editorial asimilaba la agrupación a un marxismo economicista insostenible, pues al proponerlo Marx habría abandonado su idealismo hegeliano para negar "toda filosofía en homenaje al realismo ingenuo que orienta aún la acción de todos sus continuadores. Pues bien, realismo ingenuo y positivismo son sinónimos". Y se concluía allí: "La convicción de que constituimos en la hora actual los únicos depositarios de la auténtica ideología reformista, nos dará fortaleza necesaria para desinteresarnos de toda incitación al fetichismo exitista". ${ }^{440}$

\footnotetext{
439 "A cuenta de los Nuevos Rumbos. ¿Una segunda etapa?”, Revista Jurídica y de Ciencias Sociales. Órgano del Centro de Derecho y Ciencias Sociales, año 42 (sin número), mayo de 1926. p. 11.

${ }^{440}$ Idem, p. 13.
} 
Los tres números aparecidos de esta segunda época de la Revista Jurídica buscaron asimilar el latinoamericanismo a una preocupación por la identidad del continente en la que la denuncia antiimperialista adquiría una formulación vaga. Esos números contaron con un "enviado extraordinario en Europa", el Dr. Armando Levene, y cuatro representantes en Bolivia (Mariano Clause en Cochabamba, Abraham Valdéz en La Paz, Julio Alvarado en Sucre y el Dr. Carlos Cerrudo Vargas en Potosí. Esos números intercalaron artículos sobre la libertad, la contingencia y otros tópicos antipositivistas, notas sobre cuestiones jurídicas y otras de carácter latinoamericanista, como el llamado a un "nuevo ibero-americanismo", que realizaba Elmore poco antes de ser asesinado, y dos notas breves de Anibal Ponce y de Haya de la Torre.

Centro-Izquierda contrarrestó esa identidad estudiantil desde Sagitario y sobre todo desde Centro Izquierda. Órgano del Partido Reformista Centro Izquierda de la Facultad de Derecho y C. $S$. (1925-1933). Esta revista alentaría y difundiría la acción de los tres Consejeros Estudiantiles y en 1927 -cuando Sanguinetti finalmente se casó y dedicó más tiempo a su vida privada- llevó a González y Sánchez Viamonte como sus candidatos estudiantiles al Consejo Directivo de la Facultad, a los que en 1929 se sumó Emilio Biagosch, un cordobés que había participado activamente en la formación de la FUC -al punto que le fue adjudicada la redacción de la segunda parte del "Manifiesto liminar"- y que, según el informe del Congreso que publicó Walter Elena era apodado "el pragmático". ${ }^{441}$

Como puede suponerse -y prueban algunas de las cartas conservadas en el Fondo personal Florentino Sanguinetti-, esas campañas de los reformistas de izquierda no estuvieron exentas de fricciones, al interior del grupo, entre los egresados representantes del Consejo Directivo y los estudiantes. Específicamente, éstos les reclamaron en cartas privadas a los consejeros que estaban enunciando posiciones más moderadas a las previamente acordadas, o bien que relegaban las iniciativas que los convocaban. Asimismo, otro punto de fricción seguramente haya sido la interpretación de la Reforma, pues, a distancia de la definición clasista que proponía el manifiesto inaugural de Centro-Izquierda, González publicaba por esos años numerosos artículos, tanto en Inicial como en Sagitario, Renovación, Acción Universitaria e incluso en La Nación, en los que sostenía que la Reforma debía asociarse no a una alianza clasista, sino a una nueva generación llamada a completar y profundizar la misión

\footnotetext{
${ }^{441}$ Walter Elena, "Informe del Congreso Nacional de Estudiantes", Themis, $\mathrm{n}^{\circ}$ 70, agosto de 1918, p. 97, cit. en Ciria y Sanguinetti, 1968: 36. Allí también se dice de Biagosch que "se ajustaba en todo al reglamento del Congreso, y su palabra prolija parecía perfumada" (idem).
} 
trazada por la generación del '37. ${ }^{42}$ Seguramente, esta convivencia al interior del grupo de definiciones diversas sobre la Reforma se explique por la decisión de los líderes clasistas de Centro-Izquierda de contar con referentes prestigiosos como los consejeros estudiantiles y de hacer primar el armado político sobre las precisiones conceptuales.

La primera y más visible iniciativa de Centro-Izquierda fue la organización, junto a la Asociación Cultural, de un ciclo de conferencias impartidas por miembros o simpatizantes rioplatenses de la ULA. Según la auspiciosa reseña del boletín Renovación, el ciclo buscaba iniciar una activa corriente de intercambio de estudiantes y profesores entre Buenos Aires y Montevideo. En ella se cruzarían conferencias de los argentinos Ingenieros, Sánchez Viamonte, Palacios, Orzábal Quintana, González, Sanguinetti, Sáenz, Rébora y Levene, y de los uruguayos Vaz Ferreira, Frugoni, Juan Antonio Buero, Santín C. Rossi y Dardo Regules. ${ }^{443}$

El ciclo se inició en 1925 con una conferencia de Sánchez Viamonte del lado uruguayo y una de Frugoni del lado argentino. A ellas le siguieron, ese mismo año, otros tres disertantes que, como los anteriores, viajaban al país vecino acompañados de un grupo de estudiantes que participaban de la Asociación o de Centro-Izquierda. Esos disertantes fueron Palacios (quien como mencionamos presidía la ULA), Sanguinetti y Orzábal Quintana. ${ }^{444}$

Acción Universitaria, que solía difundir los documentos de la ULA e informar sobre la labor de los consejeros estudiantiles de la Facultad porteña de Derecho, reprodujo fragmentos de la conferencia con que Frugoni inauguró el ciclo del lado argentino. Además trascribió la elocuente presentación que realizó el joven Cosco Montaldo. Luego de recordar que la voluntad de democratización del gobierno uruguayo distanciaba a su país del resto de los países de América, al punto que allí no existían “intelectuales de combate”, el joven destacó la importancia de incorporar a la lucha reformista el contacto personal:

La juventud del Uruguay quiere ahora incorporarse a la gran falange.

De ahí el significado trascendente de esta obra de intercambio. Por encima de todo, estos torneos intelectuales, desprovistos de protocolos y estiramientos,

\footnotetext{
${ }^{442}$ En varios de los textos de 1925, González remite a la Declaración de 1923 que citamos y refuerza el paralelismo entre el estallido de la Reforma y el nacimiento de una nueva generación. Como sugerimos, si bien González se apoyó explícitamente en la propuesta de Ortega y Gasset, le imprimió una torsión más política que moral. Aunque esta torsión permanece poco explorada por la bibliografía crítica, ella fue identificada y cuestionada por el mismo Ortega en algunos artículos que publicó entre 1924 y 1925 en su columna de $L a$ Nación.

443 "Crónicas", Renovación, año 3, nº 8, agosto de 1925, p. 3.

${ }^{444}$ Sólo hemos accedido a la conferencia de Sanguinetti. Ésta llevó el título de "Reforma y Contrareforma en la Facultad de Derecho de Buenos Aires" y consistió en una síntesis ejemplatizante de la campaña que por entonces realizaban los Consejeros Estudiantiles de esa facultad (del Mazo, 1941, t.III: 302-313).
} 
provocarán el conocimiento personal entre los estudiantes y entre los intelectuales de ambos países. Los libros son medios imperfectos para la transfusión de ciertas ideologías; en sus páginas se esteriliza el pensamiento y se enfría la pasión. Nuestra obra, de grandes proyecciones internacionales y sociales, no podrá prosperar sino al calor de la amistad, porque ella tiene la prodigiosa virtud de crear la simpatía entre los hombres (Cosco Montaldo, "La juventud universitaria uruguaya", Acción Universitaria, n 13, agosto de 1925, p. 2).

Como señalaba el manifiesto de la Asociación, la obra de la juventud reclamaba mucho más que la amistad latinoamericana. De ahí que el antiguo arielista enunciara a continuación un llamado a los universitarios a ingresar tanto a los partidos políticos como al partido latinoamericano de intelectuales que acababan de fundar Ingenieros y la fracción izquierdista de la Reforma porteña. Prácticamente glosando el discurso de Ingenieros en homenaje a Vasconcelos, declaraba el joven:

\begin{abstract}
Al lado de los partidos políticos nacionales, renovados y transformados, debemos crear partidos ideológicos de intelectuales de carácter continental, para realizar los superiores fines de la colectividad americana. Es por esto que no es aventurado afirmar que la creación de la Unión Latino-Americana es un acierto luminoso, y que está llamada a ejercer una influencia decisiva en el Continente. Los problemas que se plantea hoy la Unión Latino-Americana son precisamente los que ofrecen verdadero interés actual e indiscutible trascendencia, entre ellos la lucha contra las tiranías en América (y he ahí el ejemplo del Perú, de Venezuela y de Bolivia) y la lucha contra el imperialismo yanqui y la diplomacia del dollar, que ha venido a desnaturalizar la doctrina de Monroe, transformando el principio de defensa contra el intervencionismo europeo, en el principio de hegemonía yanqui y de absorción imperialista. [...] Una gran fe nos posee a los universitarios de la nueva generación. Los grupos intelectuales se han buscado y han comenzado a elaborar una conciencia continental que adquiere admirable vigor (Idem).
\end{abstract}

Como enuncia aquí Cosco Montaldo y muestran los documentos compilados por del Mazo (1926-1927), es fundamentalmente hacia 1925 que los grupos formados por intelectuales que hicieron sus primeras intervenciones políticas en torno de la Reforma "se buscan" intensamente. Anticipemos que, si bien numerosos grupos "se encuentran" y se despliega una red de alcance continental, el cambio de coyuntura política hacia la década del treinta hará que ella la red se disuelva y reformule para colocar en el centro de sus denuncias el avance del fascismo $\mathrm{y}$, en el caso argentino y uruguayo, la participación en partidos políticos ya existentes -que reunían no sólo a intelectuales-.

En la misma 
página en que aparecía el llamado de Cosco Montaldo a fundar la filial uruguaya de la ULA, Acción Universitaria publicó "Observaciones sobre la organización de la Unión LatinoAmericana", una carta que del Mazo dirigió a Palacios, en su condición de presidente de la ULA, para explicarle que uno de los puntos que impedían su incorporación era el carácter excluyente de "sociedad de 'intelectuales"” de la institución". Como mencionamos, ese carácter seguramente deba asociarse a la traducción latinoamericanista que propuso Ingenieros del llamado a un partido de intelectuales adherentes a la Revolución Rusa formulado desde 1919 por Barbusse. Pero además, como mostró Pita González (2009), esa fue la misma crítica que hasta 1927 formuló a la ULA Haya de la Torre, quien ya mantenía una fuerte amistad con del Mazo. Del Mazo logra que en 1927 la ULA se incorpore al APRA! El último número de Sagitario reproduce el "acuerdo tomado por el C. D, de la Unión LatinoAmericana" a través del que la ULA se suma al APRA y a su denuncia del imperialismo en Nicaragua. Se comprometen enviar una delegación a ese país integrada por Palacios, Vasconcelos y Haya de la Torre. Firman como comisión directiva de la ULA: Carlos Sánchez Viamonte, Fernando Márquez Miranda, Manuel A. Seoane, Florentino V. Sanguinetti, Euclides E. Jaime, Gabriel del Mazo, Adolfo Korn Villafañe, Carlos A. Amaya, Antonio Herrero, ${ }^{445}$ Andrés D'Onofrio y Agustín Dillón (quien, por una de las cartas de Barros a Bermann que citamos, sabemos que era contacto rosarino para fundar en esa ciudad una sede de la Federación de Asociaciones CUlturales).

La inexplorada Asociación Cultural Universitaria de Montevideo logró algunos de sus propósitos gremiales, ${ }^{446}$ pero no consiguió que se estructurara en el Uruguay esa organización política orientada a elaborar la conciencia continental. En septiembre de 1925, Cosco Montaldo pronunciaba otro largo discurso, "La juventud universitaria del Uruguay, frente a la Reforma Universitaria y a los problemas de América”. En éste citaba pasajes del discurso pronunciado en Buenos Aires y nos da más información sobre el desarrollo del ciclo. ${ }^{447} \mathrm{El}$ presidente de la Asociación declaraba que el grupo surgió en 1923 produciendo una "eficaz sacudida" en un ambiente universitario "indiferente y rutinario": la Asociación sería la encargada de "llenar ese gran vacío" que dejaba la ausencia de una federación universitaria, la indiferencia de la juventud y la falta de estudio de los problemas de la enseñanza en general y

\footnotetext{
445 Escribió la biografía de Almafuerte, luego la primera de Palacios. En 1919 dirigía la Universidad Popular Integralista y su órgano quincenal El integralismo.

${ }^{446}$ El editorial de Cultura $\mathrm{n}^{\circ} 2$ (julio de 1925) discute la orientación del Comité Pro-Reforma y de la Federación que, aunando a doce grupos estudiantiles, se acababa de constituir por la iniciativa de la Asociación.

${ }^{447}$ Hemos consultado el discurso en del Mazo (1927, t.VI: 303-312), pero lamentablemente no encontramos las revistas en las que, sin duda, circuló.
} 
de dirigencia en el campo de las ideas y de la acción (del Mazo, 1927, t.VI: 303). Cuando se revisa la comisión del grupo y su órgano, se advierte que varios venían participando del centro y la revista montevideanas Ariel. Más precisamente, si bien es cierto que los estudiantes montevideanos no lograban refundar una federación, habían organizado grupos pequeños pero activos en torno del Centro Ariel y en la Asociación de Estudiantes de Medicina. En ese sentido, la pesimista descripción de Cosco Montaldo se acerca más a la prosa desmesurada de los discursos y al énfasis en la novedad desde las que suelen construirse las genealogías grupales. A pesar de esa desmesura, Cosco Montaldo formula interesantes precisiones sobre el ciclo de intercambio:

En el curso del corriente año han venido a Montevideo, a decirnos su palabra cálida, entusiasta, henchida de fe, hombres de ideas, predicadores formidables como Alfredo Palacios, Carlos Sánchez Viamonte, Arturo Orzábal Quintana y Florentino Sanguinetti. Delegaciones de estudiantes han ido y venido en el curso de este intercambio, estrechando vínculos de simpatía y consolidando francas e indestructibles amistades entre los estudiantes de ambos países. Por nuestra parte, nosotros hemos enviado a Buenos Aires a nuestros mejores maestros y hombres de acción: Emilio Frugoni, Santín C. Rossi y Dardo Regules. Para el año próximo hemos prometido llevar a Buenos Aires al maestro de maestros, el doctor Carlos Vaz Ferreira y, a su vez, los compañeros argentinos nos enviarán a José Ingenieros, Mario Sáenz, Ricardo Levene, Julio V. González, Mario de Vedia y Mitre y otros prestigiosos representantes de la nueva generación. [...] Necesitamos hombres de acción, predicadores, agitadores de ideas. Es menester mezclarse en la lucha (del Mazo, 1927, t.VI: 306-308).

Junto al intercambio rioplatense, vuelve a recordar Cosco Montaldo la importancia de la ULA como "foco de renovación" en el que deben participar los estudiantes uruguayos y concluye informando que la Asociación "movida de nobles anhelos de acercamiento, estudia en estos momentos la forma práctica de extender su iniciativa de intercambio intelectual a las relaciones con España, y con tales propósitos se ha puesto en comunicación con el compañero presidente de la Federación de Estudiantes de Madrid" (del Mazo, 1927, t.VI: 311-312).

Nada sabemos sobre el destino de esa comunicación, pero las revistas porteñas sí nos informan de nuevos intentos, protagonizados por Cosco Montaldo, de estrechar vínculos rioplatenses y fundar una filial uruguaya de la ULA. El primer número de la revista $1918\left(2^{\circ}\right.$ época de Acción Universitaria) contó con un manifiesto, firmado por Cosco Montaldo, en el que se identifica la "sana doctrina de la Reforma" con los "empeñosos y honestos esfuerzo realizados por un grupo de intelectuales $-\mathrm{y}$ en especial por los consejeros estudiantiles de la 
Facultad de Derecho de Buenos Aires- para salvar tan valioso cuerpo de doctrinas, del caos y la desorientación que sobrevino después del formidable acontecimiento revolucionario del 18" ${ }^{448}$ Además, por esos días, el joven montevidiano volvía a cruzar el Río de la Plata para asistir, como representante de la Asociación, al acto en que, con motivo de la celebración de la independencia de Bolivia, la ULA y Centro-Izquierda denunciaron al gobierno boliviano por su carácter dictatorial y cómplice del imperialismo. ${ }^{449}$

Finalmente, por una carta personal sabemos que a mediados de 1927 el ciclo de intercambio se interrumpió. En la carta que Sanguinetti le redacta a Cosco Montaldo, le informa sobre la marcha de la Reforma en Buenos Aires y antes de concluir intenta un consuelo ante el fracaso del proyecto compartido. No duda el argentino que

volverán otros tiempos mejores, buen amigo, o no volverán pero de todo lo que usted ha hecho, queda a evidencia del justo, queda nuestra amiganza cordial y definitiva, quedan vínculos espirituales entre muchos hombres jóvenes de América. Queda una sembradura de ideas y de sentimientos que servirán como tarea histórica para nuestra generación. Nada importa el filisteísmo. Por sobre todo vive encendida esa solidaridad continental que nos unirá a todos los hombres libres de América, y el aporte que Ud. ha ofrecido, será siempre el mayor galardón de su quijotismo, querido amigo (22/09/1927; Sanguinetti, 2002: 147-148).

El mismo día en que Sanguinetti redactaba la carta, Julio González pronunciaba ante los estudiantes porteños el discurso -difundido en el noveno número de Sagitario (octubre de 1927)- con el que proclamaba la fundación del frustrado Partido Nacional Reformista. Por entonces la Asociación de Cosco entraba en conflicto, pero el Centro Ariel conseguía, después de más de dos años, poner en circulación un nuevo número de su revista, en el que no sólo es notoria la incorporación de la problemática imperialista continental, sino también la vinculación con la red antiimperialista rioplatense, organizada desde el lado argentino precisamente a través del secretario de redacción de Sagitario, Pedro Verde Tello, quien reemplazaba a Solari en la corresponsalía argentina de la revista montevideana.

Ariel n 37 se abre con "La Revisión de Rodó", manifiesto que reconoce la inicial inspiración rodoniana del grupo que fundó Quijano en 1917, pero luego de ese

\footnotetext{
${ }^{448}$ Oscar Cosco Montaldo, “'1918’ y los universitarios uruguayos”, 1918, № 1, junio de 1926, p. 11.

${ }^{449}$ Tanto el número de Renovación como el de Acción Universitaria correspondientes a agosto de 1925 reseñan el acto. Continuando esa visibilización de las problemáticas latinoamericanas, poco tiempo después la ULA presentaba ante el parlamento un proyecto de condonación de la deuda paraguaya con la Argentina (Sánchez Viamonte, 1929).
} 
reconocimiento pronuncia una distancia rotunda: "La dinámica de nuestros gestos no puede ensayar la sonrisa amable y serena en que se expresa el idealismo de Rodó. El maestro ha dejado de ser una presencia activa en nuestra formación espiritual" ${ }^{450}$ La relación de los montevideanos con los reformistas argentinos que también se había desligado de Rodó para formular un antiimperialismo no ya cultural sino económico se refuerza con la adhesión del Centro Ariel a los "principios generales de la Unión Latino-Americana, los cuales tienden a concertar, en amplio programa, las aspiraciones sociales, políticas y culturales que mueven a la juventud latinoamericana" ${ }^{451}$ y la transcripción de la carta que habían recibido de Alfredo Palacios, en calidad de presidente de la ULA, y Fernando Márquez Miranda (1897-1961), en calidad de secretario. $Y$ con esa adhesión los arielistas montevideanos también tomaban partido en las tensiones que atravesaban a la red antiimperialista, pues -como mencionamosen 1927 la disputa por el liderazgo entre Palacios y Arturo Orzábal Quintana al interior de la ULA decidía al último a fundar la breve Alianza Continental, a la que se sumó Cosco Montaldo y seguramente otros miembros de la Asociación.

Y esas disputas al interior de la ULA dificilmente hayan sido una cuestión menor en la fundación del partido reformista que proponía González también en 1927. En las memorias que ya citamos, éste recuerda que por entonces se había convencido de que en el trascurso de esos años "habíamos llegado, si no a concretar un programa de ideas, a cristalizar una sensibilidad política, una tendencia ideológica, un modo de ser propios, frente a los problemas nacionales y universales. Era menester que ese pensamiento penetrase en la masa popular, se infiltrase en la conciencia colectiva" (González, 1931: 47). Allí afirma que, ante de anunciar el Partido Nacional Reformista, había realizado los primeros intentos en esa dirección al interior del grupo de la revista Sagitario y que había sondeado el ambiente con los editoriales "Política" (que abrió el número 7 de Sagitario) y "Pensamiento en acción" (que abrió el número siguiente). Pero luego recuerda: "no pudimos arribar a ninguna decisión, no obstante que se llegó hasta la redacción de un manifiesto. De mis ensayos fue este el más concreto y empeñoso. Llevó por esto mismo al máximo los efectos de la prueba a que, sin advertirlo, venía sometiendo nuestra verdad y las aptitudes de nuestra generación para captar la realidad circundante" (González, 1931: 47-48).

Sin negar las convicciones que recuerda González como el impulso de sus iniciativas, habría que agregar ciertos conflictos que no suelen explicitarse en la retórica celebratoria ${ }^{450}$ Ariel, $\mathrm{n}^{\circ} 37$, diciembre de 1927, p. 2.

${ }^{451}$ Ariel no 37, p. 19. 
característica del género autobiográfico. En efecto, las revistas y las reconstrucciones no dejan dudas de que ya existían proyectos para "penetrar en la masa popular" y que en ellos participaban González y los otros animadores de la fracción antiimperialista del reformismo argentino. Más precisamente, cuando González presenta el Partido, esos proyectos estaban atravesados por fuertes tensiones que una nueva agrupación podía llegar a neutralizar. En 1926 el PC fundaba en Buenos Aires la LASA -en la que participó el mencionado Paulino González Alberdi- (durante ese año parece no haberse editado Renovación). Luego de un primer intento de torcer la decisión de la ULA de mantenerse como "partido de intelectuales", así como de radicalizar su línea política, la LASA iniciaba una fuerte rivalidad con la ULA, que parece haber decidido a ésta a inscribirse en 1927 en el APRA (Pita González, 2010). Pero además ese año, por un lado, los estudiantes peruanos exiliados en Buenos Aires y pertenecientes a la ULA fundaban la célula porteña del APRA y, por el otro, algunos miembros de la ULA se alejaban para fundar la Alianza Continental, que, de todos modos, organizó actividades conjuntas con la ULA y que, como ésta, se disolvió pocos años después (Pita González, 2009).

Tanto los reformistas argentinos como los uruguayos no lograrían inscribir el movimiento de la Reforma en un horizonte político que trascendiera a los universitarios, y en los años próximos se sumaban a los partidos políticos existentes. En cuanto a los uruguayos, mientras que en 1929 Quijano fundaba la “Agrupación Nacionalista Demócrata Social”, ala izquierdista del Partido Nacional, Cosco Montaldo se reconocía a mediados de 1926 como dirigente batllista y, desde esa posición polemizaba, en las páginas de Nosotros, con la mirada del Uruguay propuesta en 1925 por Vasconcelos en una de las obras que construían el latinoamericanismo, la Raza Cósmica. Misión de la raza iberoamericana. Notas de viajes a la América del Sur (Caetano, 2011). Más allá de ello, lamentablemente, nada sabemos del itinerario político-cultural de Cosco Montaldo luego de que en 1927 conociera, junto a Orzábal Quintana, las ciudades de Europa Central y la Rusia comunista. En cuanto a los argentinos, la mayoría de los miembros de la ULA ingresaba en el PS, desde el que alentarían durante las décadas siguientes numerosas iniciativas. ${ }^{452}$

\section{La circulación latinoamericana de las fuentes reformistas}

Como mencionamos al comienzo de este capítulo, en diciembre de 1926 del Mazo y el CE de

$\overline{452}$ Esas iniciativas han sido objeto de una detenida reconstrucción en Graciano (2008: 139-330). 
Medicina de Buenos Aires ponían a circular el primero de los seis tomos de las fuentes sobre la Reforma. Estos eran el resultado de una metódica revisión de publicaciones periódicas y folletos editados por grupos de estudiantes, sobre todo argentinos. En términos de del Mazo, la colección aspiraba

a poseer elementos adecuados para la iniciación seria de las nuevas promociones de jóvenes; a disponer de una fuente bibliográfica, útil para la divulgación y el mejor estudio, que contenga en forma sistematizada los papeles de más importancia producidos por los estudiantes que promovieran y realizaran la cruzada, y salvar de esta manera de la dispersión o pérdida definitiva, buena parte de los instrumentos escritos (del Mazo, 1926, t.I: 7).

Del Mazo aclaraba en esa "Nota al lector" que para lograr esos objetivos se editarían cinco volúmenes organizados temáticamente, el primero de exégesis y los demás documentales, más un sexto volumen -que apareció en mayo de 1927- "destinado a ser profusamente distribuido, reunirá los escritos más expresivos de los demás libros y traerá un trabajo de revista general que habrá de ser vertido en varios idiomas" (del Mazo, 1926, t.I: 8). Efectivamente, a partir de la circulación nacional y continental de los seis volúmenes -y de las ediciones abreviadas posteriores-, la Reforma encontró un relato relativamente sistemático sobre su origen y definición. Respecto del origen, desde entonces quedaron pocas dudas de que el "Manifiesto liminar" -que del Mazo elegía para abrir tanto el primer tomo como el último- era el documento inaugural de la Reforma.

Respecto de la definición, el primer volumen se compone de trece textos -redactados por jóvenes reformistas argentinos entre 1918 y 1926- que no coinciden en su definición de la Reforma ni en las proyecciones políticas del movimiento, pero sí identifican todos ellos la Reforma como un movimiento político-cultural con reivindicaciones que exceden las aulas. ${ }^{453}$

En ese primer tomo, del Mazo recupera las distintas corrientes argentinas -entre las que se destaca la discusión sobre el carácter clasista de la Reforma (sostenido por Palcos, Lanuza y Hurtado Mendoza) o su asociación con el nacimiento de una nueva generación (propuesta por González y Ripa Alberdi)-. Pero esa recuperación no le impide a del Mazo dejar en claro su intención de estabilizar las disputas sobre la definición de la Reforma a partir de la interpretación y proyección del reformismo como un movimiento latinoamericanista y antiimperialista ligado a la propuesta que entonces realizaba el APRA. La intención de del

${ }^{453}$ Los textos del primer tomo pertenecen a los siguientes reformistas: Deodoro Roca, Guillermo J. Watson, Saúl A. Taborda, Héctor Ripa Alberdi, Alberto Palcos, Pedro Verde Tello, Carlos Cossio, Julio V. González José Luis Lanuza, Mariano Hurtado de Mendoza y Florentino V. Sanguinetti. 
Mazo se advierte tanto en la cantidad de textos ligados al APRA y a la denuncia antiimperialista de los años 1924-1927 reproducidos en los últimos tomos, como en la "Nota al lector" que citamos. La afirmación que elige para concluirla es que la Reforma es la "precursora de otra gran cruzada, que ya se inicia: por la unión de los pueblos para la liberación económica de nuestra América; por su autonomía espiritual; por las nuevas formas de su derecho público" (del Mazo, 1926, t.I: 9). ${ }^{454}$

Como era esperable, esa interpretación de la Reforma fue cuestionada por la fracción nacionalista de la Facultad de Derecho de Buenos Aires. Para ello Cossio amplió su ensayo sobre el problema universitario que había presentado en 1923 para doctorarse en Jurisprudencia y, bajo el sello del CE de Derecho, publicó a fines de 1927 La Reforma Universitaria o el problema de la Nueva Generación, un largo ensayo que -como mencionamos en la Introducción a esta tesis- sintetizaba y evaluaba bajo un prisma nacionalista las distintas interpretaciones de la Reforma que habían propuesto los líderes argentinos. Y esa evaluación llegaba a la conclusión de que la "teoría auténtica para crear una Nueva Universidad" era el "nacionalismo ético" modelado por el kantismo que proponía Aldolfo Korn Villafañe. Poco después, éste publicaba una nueva compilación de sus discursos y artículos en un libro, también difundido por el sello del CE de Derecho -pero además prologado por el entonces presidente de ese centro-, que ya desde su provocador título de 1919 perseveraba en su propuesta, formulada en 1920, de que la auténtica Reforma se había iniciado en 1919, luego de que los disturbios cordobeses fueran reemplazados por la meditación nacional.

Ante la afrenta que significaban esas publicaciones, del Mazo sabía, a partir del recorrido que había realizado desde su temprana participación en el Ateneo de Estudiantes Universitarios hasta su condición de líder reformista y primer compilador de sus fuentes, que su intento de estabilizar la identidad latinoamericanista y antiimperialista de la Reforma era una tarea colectiva y que debía apoyarse en prácticas que no se acotaran al espacio porteño. En sus memorias recuerda que lo primero que hizo "fue conseguir [que la compilación] fuese enviada a todas las Federaciones de Estudiantes de nuestra América" (del Mazo, 1976: 225). Una carta conservada en el Fondo personal Florentino Sanguinetti muestra que algunos de

\footnotetext{
${ }^{454}$ En cuanto a la estabilización de los documentos reformistas, es la edición en tres tomos de 1941 -con menos documentos pero actualizada hasta 1940- la que estará accesible a los estudiosos y militantes. Una prueba de la cristalización de fuentes que produce la compilación de 1941 es que de allí seleccionan los textos tanto Cúneo (1978) como Portantiero (1978). Los tomos llevan por título: I. El Movimiento Argentino; II. Propagación americana, III. Ensayos Críticos. En 1957 del Mazo publica otra compilación. Como la de 1941, éste incorpora nuevas fuentes y extrae de la primera compilación los textos anteriores a 1926.
} 
esos tomos circularon acompañados de una comunicación firmada por el presidente del CE de Medicina, en la que pedía colaboración "en la tarea de divulgación y afianzamiento de los principios reformistas". Carta a la que Sanguinetti se apuraba a contestar celebrando la publicación “como uno de los esfuerzos más serios para dar base permanente al movimiento de emancipación espiritual, iniciado en 1918". ${ }^{455}$

En ese mismo intento de nutrir la fracción latinoamericanista y antiimperialista que en Perú estaba pronta a escindirse entre socialistas y apristas, del Mazo le remitía los tomos a Mariátegui -de quien, como vimos, obtenía una pronta reseña en Amauta-, al tiempo que colaboraba con los exiliados peruanos para la publicación del primer libro de Haya de la Torre. En cuanto a Mariátegui, el 3 de marzo de 1928 del Mazo le envío los tomos de La Reforma Universitaria "para que quede constancia de su sumario en su revista y para que los destine luego a la biblioteca pública donde según su juicio pueda ser más útil” (Tarcus, 2001: 237). Allí también le aclaraba que el sexto tomo llevaba una nota sobre la "singular y valiosa" Amauta $^{456}$ y que le adjuntaba documentos del Convención de Educadores, en la que había pronunciado una declaración a favor de Nicaragua redactada "teniendo a la vista la que produjo nuestra Apra en París". Con esa carta, del Mazo y Mariátegui iniciaban una comunicación epistolar fraternal, pero sumamente accidentada, pues cuatro de los seis tomos, así como algunas cartas de del Mazo, se perdieron o fueron confiscadas. Luego de reenviar los tomos perdidos, escribía el argentino:

Me dice usted en su tarjetita que no tiene noticias mías. Sin embargo le he escrito, y repetidamente -a su dirección de Casilla. ¿De nuevo la censura para usted? Las listas que le envié no son de suscrptores sino de presuntos suscriptores. [...] Nunca me dijo usted si había recibido la cartulina que firmamos aquí cuando su prisión del 27. ¿Se ha perdido también? ¿Recibió la colección completa de $L a$ Reforma Universitaria? (Carta de Gabriel del Mazo a José Carlos Mariátegui, 11/01/1929, Buenos Aires, reprod. en Tarcus, 2001: 240).

Además, a pesar de sus reiterados pedidos, el argentino no recibió de Mariátegui la autorización para que el $\mathrm{CE}$ de Ciencias Económicas de Buenos Aires publicara -como finalmente lo hizo- un folleto con las dos notas aparecidas en Amauta, revista que del Mazo

\footnotetext{
${ }^{455}$ Carta de Florentino Sanguinetti a Eduardo Carasa, presidente del Centro de Estudiantes de Medicina, Buenos Aires, 14/05/1928. Fondo personal Florentino Sanguinetti, CeDInCI.

${ }^{456}$ Bajo el título "Aparición de la revista Amauta en Lima (1926)", el tomo reproduce el primer editorial de Amauta y una carta de felicitación y apoyo enviada a Mariátegui por la Federación de Estudiantes del Perú el 20 de enero de 1927 (del Mazo, 1927, t.VI: 178-181).
} 
recibía en Buenos Aires a través de Oscar Herrera, uno de los exiliados peruanos y futuros líderes apristas.

Sobre la circulación porteña de Amauta se ha conservado una carta sumamente elocuente, pues en ella se sugiere que era en 1925 que el latinoamericanismo comenzaba a ser una práctica y una idea central de la Reforma. Herrera le escribe desde Buenos Aires a Mariátegui para avisarle que ha recibido los paquetes del $n^{0} 10$ de Amauta. Allí le propone que la revista coloque al pie de cada artículo el lugar de procedencia: "así se podría apreciar más fácilmente que Amauta es tribuna de toda la vanguardia latinoamericana", y también le informa:

He distribuido ya 10 números entre personas que me han prometido hacerse suscriptores y 4 entre del Mazo que quería interesar a dos muchachos de Córdoba y Julio R. Barcos, que tenía interés en hacerle más propaganda en Chile entre los maestros. A un muchacho paraguayo Creidt, presidente de la Federación de los Estudiantes de Asunción, y ya abogado, a pesar de sus ventitrés años, le acabo de escribir remitiéndole Amauta y pidiéndole colaboración. Este joven vino a Buenos Aires hace poco como delegado a la Convención Internacional de Maestros y pude oírle decir cosas muy acertadas e interesantes sobre temas sociales (Carta de Oscar Herrera a José Carlos Mariátegui, 07/02/1928, Buenos Aires, Mariátegui, 1984: 349).

En cuanto a la relación de del Mazo con Haya de la Torre, aquel no sólo tomaba del líder aprista la inspiración de sus discursos y mantenía una prolífica correspondencia, sino que además ayudaba en 1927 a los jóvenes exiliados peruanos a editar en Buenos Aires Por la emancipación de América Latina. Artículos, mensajes y discursos (1923-1927), el primer libro de Haya de la Torre Haya, pero que funcionaba en Argentina como la carta de presentación de la célula aprista de Buenos Aires y de la imbricación de ésta con del Mazo.

Haya de la Torre dedicaba su "literatura de acción, de lucha, de ataque"

a un amigo de juventud, Gabriel del Mazo, presidente de la Federación Universitaria Argentina en los días memorables de la precursora revolución estudiantil, amigo y compañero de nuestra causa, en la que lucha silenciosa pero efectivamente. Yo y mis compañeros desterrados por la tiranía 'yanqui' del Perú, que están en Buenos Aires, hemos encontrado en él un amigo y camarada irremplazable" (Haya de la Torre, 1927: 18).

Esta dedicatoria junto a la "noticia biográfica sobre el autor", que firmaban los estudiantes peruanos y miembros de la ULA Oscar Herrera, Eudocio Ravines, Enrique Cornejo Koster, 
Luis E. Heysen, Manuel A. Seoane y Francisco Acero, dejaban pocas dudas de que el libro presentaba a la célula aprista de Buenos Aires ${ }^{457}$ y que -como también sugiere la citada "Nota al lector" de La Reforma Universitaria- del Mazo era partidario de un tipo de organización similar en Argentina. A ello agrega del Mazo, cuando recuerda y reivindica su ayuda en esa publicación, que esa participación no fue suficiente y que como "hacía falta más, particularmente cuando Haya sufrió prisión y tortura en 1932, publiqué entonces Construyendo el Aprismo, tal como antes había publicado Ideario y Acción Aprista" (del Mazo, 1976: 219).

Volviendo a la compilación de 1927, ella se cerraba con “¿Qué es el APRA?”, manifiesto programático que, como mencionamos, había sido duramente criticado por Mella cuando se publicó originariamente en The Labour Monthly y que -por lo que hemos rastreadocon la ayuda de del Mazo encontraba su primera circulación argentina.

\section{EI balance de los primeros diez años de la Reforma Universitaria}

En julio de 1928 se cumplía el décimo aniversario de la Reforma y nuevamente entre los actos institucionales y los grupos reformistas aparecía en primer plano la disputa por la definición del movimiento. Coriolano Alberini, en su condición de decano de la FFyL, era invitado como orador en el acto que organizaba el CE de esa facultad. Su discurso, sumamente crítico de lo que llamamos la "dimensión política" de la Reforma, comenzaba advirtiendo:

La Reforma Universitaria cuenta con una densa legión de hermeneutas, entre los cuales, a veces, se encuentra, siquiera por vía de feliz accidente, algún auténtico universitario. Es de lamentar que los que han puesto toda su alma en la ciencia y en la cátedra hayan dejado el tema a los doctores de la exégesis sonora y de la retórica melodramática. Los verdaderos universitarios nada o muy poco han hecho para clarificar el ánimo estudiantil, siempre pronto al ímpetu, pero también a comprensión cuando se les habla con perspicacia y con genuino amor de las cosas de la inteligencia. [...] no menos nefasta resulta la confusa hermenéutica frangollada por los profesionales de la Reforma [...] La prole intelectual de esa generación ha dado no pocos expositores, grandes y pequeños maestros de la juventud, fecundos en peroratas donde se habla de todo, y de cuanto en cuando, también de la Universidad (Alberini, 1973: 75-76).

Esos verdaderos universitarios "con genuino amor de las cosas de la inteligencia" a los que se

\footnotetext{
${ }^{457}$ Para un análisis de la intervención que realizó esa célula y su correlativa platense en los años inmediatamente posteriores, véase Sessa (2013).
} 
refiere Alberini no eran otros que los animadores del Colegio Novecentista y los que, en sintonía con éste y la Unión Universitaria, propusieron una versión nacionalista y antipositivista de la Reforma. Asimismo, con su crítica a las "peroratas" reformistas que intentaban extender las preocupaciones de la juventud más allá de lo universitario, el decano de la FFyL -y con él el CE que lo había invitado al acto- se definía en contra de proyectos como la ULA o la edición de documentos de la Reforma que, entre 1926 y 1927, preparó del Mazo y luego continuó revisando, recolectando y publicando. Más precisamente, Alberini se refería al "positivista" Ingenieros como quien había sentido "la voluptuosidad de cultivar apostolados referentes a ideales inconclusos" (Alberini, 1973: 80).

Lejos de asentir el balance de Alberini, Sánchez Viamonte, del Mazo y otros tempranos líderes reformistas no renegaron de su condición de "profesional de la reforma". En carta a Mariátegui, Sánchez Viamonte le contaba que en octubre de 1927 se encontraba absorbido por la campaña electoral en la Facultad de Derecho, que era inminente la publicación de dos nuevas obras, La cultura frente a la Universidad (con prólogo del boedista y comunista Álvaro Yunque) y Jornadas, y le confesaba: “como Ud. ve, no estoy con los brazos cruzados y sin embargo todo me parece poco para las exigencias del momento histórico que vivimos. Cumpla su promesa de tenerme al corriente de todo" ${ }^{458}$ Al igual que los libros que Sánchez Viamonte había editado en la editorial Sagitario en 1926 y 1927, los dos nuevos recogían su intervención como líder reformista, pues se componían de breves artículos, de discursos y de versiones taquigráficas de intervenciones en el Consejo Directivo de la Facultad de Derecho.

Mientras Sánchez Viamonte preparaba esos libros y continuaba junto a González su campaña reformista en el Partido Unión Reformista Centro-Izquierda, del Mazo reconocía a éste como una "interesante agrupación", pero apostaba por los jóvenes que liderados por Pablo Lejarraga, presidía el CE de la Facultad porteña de Ciencias Económicas. ${ }^{459}$ En efecto, en la carta con que iniciaba contacto con Mariátegui, del Mazo le confesaba, con ese orgullo que descalificaba Alberini ante los estudiantes de la FFyL, que para el noveno aniversario "del movimiento continental de la nueva generación latinoamericana me fue dedicada la comida de

\footnotetext{
${ }^{458}$ Carta de Carlos Sánchez Viamonte a José Carlos Mariátegui, 25/10/1927, La Plata, reprod. en Tarcus (2001: 236). Sánchez Viamonte publica esas obras en 1928 y 1929. Y dando nuevas muestras de que no se "quedaba de brazos cruzados", luego del golpe de estado de 1930 se apuraba a editar, ese mismo año, un libro sobre Yrigoyen con prólogo de Deodoro Roca, El último caudillo. Para un análisis de esa intervención, véase Martínez Mazzola (2010).

${ }^{459}$ Sólo sabemos sobre este joven que en la década del treinta fue clave en la fundación de la filial bahiense del Colegio Libre de Estudios Superiores y que en los sesenta participó del Partido Socialista Argentino, grupo que iniciaba las discusiones que serían características de la "nueva izquierda" (Tortti, 2007).
} 
celebración" ${ }^{460}$ y que aprovechó la ocasión para que se firmara un saludo para Mariátegui en el momento en que estaba perseguido y enfermo -una cartulina que luego le envía y en la carta citada le preguntaba si le había llegado-. Y en sus cartas posteriores, además de referir que Centro-Izquierda era una agrupación interesante, del Mazo le pide autorización a Mariátegui para publicar, por "el Centro de Estudiantes de Ciencias Económicas (la vanguardia, este año, en la federación universitaria)", los dos textos sobre la Reforma aparecidos en Amauta. ${ }^{461}$

Si bien la autorización no llegó, los textos aparecían, antecedidos de un fragmento de “No conocen a José Carlos Mariátegui?” de Blanca Luz Brum que funcionaba como prólogo, en la colección de folletos "De orientación reformista" del mencionado CE. Entre 1927 y 1928, el CE publicó dos colecciones de folletos. En "De orientación reformista" se editaron seis folletos, sin duda, seleccionados bajo la orientación de del Mazo. El primer folleto se compuso de "La juventud argentina de Córdoba a los hombres libres de Sud América. (Manifiesto, junio de 1918)" junto a "El movimiento continental de los jóvenes (en el aniversario de su iniciación)" por Gabriel del Mazo. El segundo reprodujo "La Universidad del porvenir ("La filosofía científica en la organización de las Universidades")" por José Ingenieros. El tercero se compuso de "Realización integral de la Reforma" junto a "El partido nacional reformista” por Julio V. González. En el cuarto folleto se editó “José Ingenieros: En el II aniversario de su muerte. Homenaje del Centro Estudiantes de Ciencias Económicas. Resolución de la C. D. Discursos de Fernando Márquez Miranda y Juan Antonio Solari”. El quinto contenía "Teoría y táctica de la campaña renovadora y antimperialista de la juventud en América Latina. Páginas de J. Ingenieros y R. V. Haya de la Torre”. El último folleto es el citado "La Reforma Universitaria” por José Carlos Mariátegui.

En la colección de "La comisión de extensión universitaria" aparecían "El problema del petróleo y la capacidad del Estado para su explotación” por Javier López Zavaleta y “E1 imperialismo como fenómeno económico" por Paulino González Alberdi, quien había egresado de la Facultad en 1926 con el título de contador público y ya era un activo militante del PC. Por su parte, el CE también renovaba su órgano, la Revista de Ciencias Económicas. Publicación de la Facultad de Ciencias Económicas, Centro de Estudiantes y Colegio de Graduados, y editaba unos pocos números de Comentarios. Periódico mensual de información y orientación reformista.

\footnotetext{
${ }^{460}$ Carta de Gabriel del Mazo a José Carlos Mariátegui, 03/03/1928, Buenos Aires, reprod. en Tarcus (2001: 237).

${ }^{461}$ Carta de Gabriel del Mazo a José Carlos Mariátegui, 09/04/1928, Buenos Aires, reprod. en Tarcus (2001: 238).
} 
Además de apoyar a los estudiantes de economía, para el decenario de la Reforma del Mazo emprendía una ambiciosa iniciativa. En su calidad de reconocido reformista, buscó reactivar, entre quienes habían sido líderes iniciales de la Reforma y entonces eran profesores universitarios y no se sentían identificados con la ULA, la reflexión y la acción colectiva sobre la relación de la universidad con los problemas sociales. En octubre de 1928, Sanguinetti recibía la siguiente carta:

\section{Estimado amigo:}

A raíz de la conversación que un grupo de graduados partidarios de la Reforma Universitaria, realizamos hace algo más de dos meses en el Restaurant Conte, quedé comisionado para promover una nueva reunión, una vez que el Dr. Taborda hubiera conversado con los amigos de Córdoba y el Dr. Guerrero hubiera hecho lo propio con los de La Plata. [...] Siendo la reunión de carácter preliminar, sólo han sido invitadas aquellas personas que desde un comienzo participaron o estuvieron enteradas de nuestro propósito. Son los doctores Biagosch, González, Guerrero, Lascano, May Zuviría, Romano, Sanguinetti, Trejo, Uslenghi y Watson. ${ }^{462}$ Por ofrecimiento del primero de los nombrados, la reunión tendrá lugar en su escritorio Bartolomé Mitre $836,2^{\circ}$ piso.

Dentro del motivo que nos mueve a concertarnos (el problema de la escuela argentina en general, y en particular el problema de nuestra Universidad), esperamos en esa reunión presentar aquellos temas que fueren motivo de nuestro especial interés y dar cuenta de los que han sido objeto de las conversaciones en La Plata y Córdoba (Carta de Gabriel del Mazo a Florentino Sanguinetti, 07/10/1928, Buenos Aires, Fondo personal Florentino Sanguinetti, CeDInCI).

Por otras cartas conservadas en el mismo fondo, sabemos que las reuniones comenzaron a realizarse y que se formaron "comisiones especiales" que elaborarían informes para discutir en los encuentros. Pero seguramente la iniciativa no traspasó la órbita de esas reuniones y quedó interrumpida a mediados del año siguiente, cuando del Mazo partió a la ciudad de Santa Fe como Delegado interventor de la Facultad de Química Industrial y Agrícola de la Universidad del Litoral, en la que, junto a José Barreiro (el joven que había dirigido la primera revista Claridad porteña), dirigió un innovador proyecto de extensión universitaria a través del que los obreros podían perfeccionar sus oficios en la universidad y participó de la fundación del Instituto Social, bajo el que se desarrollaría una universidad popular, la extensión universitaria y un museo social (Universidad Nacional del Litoral, 2009b).

Poco después del aniversario de la Reforma, la red porteña antiimperialista se disgregaba. Como muestra Graciano (2008), luego del golpe de estado, muchos de sus

\footnotetext{
${ }^{462}$ Lascano había sido presidente en 1922 del CE de la Facultad de Ciencias Jurídicas de La Plata. Taborda acababa de volver de Europa, donde había permanecido desde mediados de 1923.
} 
miembros se convencen de que deben entrar a los partidos políticos existentes para enfrentar más sistemáticamente el fascismo, encarnado a escala nacional en el presidente Uriburu. Pero ello no implicó que la Reforma dejara de estar ligada al antiimperialismo latinoamericano. Más precisamente, la iniciativa de del Mazo de repensar el lugar social de la universidad junto a los graduados reformistas quedaba trunca. Lo mismo le ocurría a la interpretación nacionalista que proponía Cossio y su grupo de Derecho. En cambio, la extensa compilación con la que del Mazo procuraba ligar la Reforma a un movimiento latinoamericano antiimperialista sería actualizada y varias veces reeditada -no sólo en Buenos Aires-, logrando orientar durante décadas -en un comienzo, ayudada por la campaña de los apristas y de las ligas antiimperialistas de los comunistas- la cultura política de los estudiantes de las diversas ciudades del Latinoamérica que se preguntaban por su función social.

Antes de concluir recordemos que, aún no contamos con investigaciones detalladas al respecto, del Mazo fue sin duda la figura que, en el escenario argentino, más persistió en la difusión de el ideario latinoamericanista y antiimperialista de la Reforma, pero también en el señalamiento de que su expresión más lograda se encontraba en el APRA y en la construcción de un partido de masas -y no sólo de estudiantes e intelectuales como el propuesto por ULAen la Argentina.

En 1938 del Mazo viajaba a Córdoba para asistir al veinte aniversario de la Reforma organizado por la FUC. En su discurso afirma ese había sido un pionero líder estudiantil que

nuestros intelectuales, nuestros maestros, nos habían enseñado a resolver nuestros problemas según las maneras y dictados de los últimos compendios y figurines exóticos. Éramos repetidores de gestos extraños; actores de una civilización de copia. La Reforma Universitaria es en cambio el nombre, uno de los nombres, de una actitud profunda, de una amplia transformación que responde a una crisis general del mundo y una crisis particular del desarrollo nacional. No es una proposición intelectual, artificiosa, extranjera, ni anacrónica, sino que surge de las entrañas de nuestro país y de nuestra América, de la juventud y del pueblo. Un afán por ser, no por imitar; la segura fe en el destino humano, cuando un Hombre, un Pueblo, "sea él y no otro" (del Mazo, 1956: 8).

Luego del extenso recorrido propuesto por nuestra tesis, es fácil descubrir la operación de selección que, entre las múltiples iniciativas ligadas al movimiento reformista, decidía realizar del Mazo para homenajear la Reforma. Una similar selección -que nuestra tesis pretende abrir como una nueva línea de investigación- se descubre en la apuesta política que realizó del Mazo con la fundación de FORJA, al interior de la UCR, y, dos décadas después, con la 
organización de la UCRI y la difusión del pensamiento reformista y aprista a partir de la colección "Nuestro América” que dirigió entre 1955 y 1956 para la editorial Raigal y en la que republicó el discurso que citamos arriba, además de una compilación de José Martí y otra del líder aprista Luis Alberto Sánchez. ${ }^{463} \mathrm{Y}$ una futura investigación que se pregunte por las operaciones de selección y definición de la Reforma que realizaron los líderes reformistas argentinos a partir de la década del treinta debería comparar esa apuesta aprista de del Mazo tanto con el itinerario de algunos miembros del primer grupo Insurrexit que reconstruyó Tarcus (2000) como con el de los socialistas platenses que analizó Graciano (2008). Pero también esa futura investigación no podría dajar de trazar la comparación y vinculación con la apuesta que realizaron en Buenos Aires quienes -bajo el liderazgo primero de Ponce y luego de Agosti- se reconocieron reformistas, comunistas y activos antifascista, y la que realizaron en Córdoba quienes -liderados por Roca, Bermann y Barros- participaron, primero, en el Partido Socialista y, luego, en los grupos antifascistas tanto socialistas como comunistas.

\footnotetext{
${ }^{463}$ La colección se compuso de los siguientes cinco tomos: Ensayos en busca de nuestra expresión de Pedro Henríquez Ureña, Ensayos americanos (con Introducción de Luis Alberto Sánchez) de José Martí, ¿Tuvimos maestros en nuestra América? Balance y liquidación del Novecientos y Reforma universitaria y cultura nacional (con prólogo de Luis Alberto Sánchez).
} 


\section{CONCLUSIONES FINALES}

\section{Las publicaciones estudiantiles como campo de estudio del movimiento estudiantil}

A lo largo de las páginas que componen esta investigación, intentamos mostrar que el análisis detenido de los diversos y efímeros grupos y revistas estudiantiles que surgieron en la ciudad de Buenos Aires durante las primeras décadas del siglo XX es central para comprender las características de la Reforma Universitaria en la Argentina, así como los peculiares rasgos que el reformismo asumió en la FFyL y en la Facultad porteña de Derecho.

En el estallido y la prolongación de la Reforma convergieron tres dimensiones asociadas a debates diversos, esto es, la dimensión institucional ligada al reclamo -en parte logrado- de democratización de la universidad, de renovación de la planta docente, de revisión del perfil de egresado y de la fundación de nuevas universidades; la dimensión cultural, que nos llevó a revisar la disputa en torno a la relación de la filosofía con la ciencia o con la dimensión ética y estética del hombre; y finalmente, la dimensión política asociada a la construcción del estudiante como un tipo de actor social vinculado al nacionalismo o a distintas vertientes del socialismo. Para comprender esas dimensiones retomamos la atención -característica de la historia intelectual y la historia de los intelectuales- a los itinerarios político-intelectuales, los grupos y las prácticas, y emprendimos el análisis de los grupos estudiantiles y sus revistas -junto a todo un conjunto de prácticas que posibilitaron, acompañaron y excedieron a esas revistas, como la redacción de manifiestos, la organización de ciclos de conferencias y el establecimiento de contactos epistolares-. Específicamente, nos propusimos revisar y ampliar el corpus de documentos de la Reforma que quedó estabilizado con reconstrucciones como las de González (1922 y 1927) y del Mazo (1955) y fundamentalmente con las compilaciones del Mazo (1926-1927 y 1941) -que fueron las fuentes a partir de las que Ciria y Sanguinetti (1968), Cúneo (1978) y Portantiero (1976) construyeron sus importantes análisis de la Reforma-.

Para revisar y ampliar ese corpus nos resultaron fundamentales cuatro tareas: el rescate y el análisis de las distintas revistas estudiantiles -de carácter cultural y/o de carácter político-; la reinscripción de muchos de los "documentos reformistas" compilados por del Mazo (1926-1927) en su espacio original de circulación; el trazado de los itinerarios políticointelectuales de líderes estudiantiles y de sus contactos con otros líderes; y la reconstrucción de la llegada de Eugenio d'Ors, Georg Nicolai y Alfons Goldschmidt. 
El estudio de ese corpus ampliado nos permitió iluminar tanto las diversas y numerosas iniciativas de los estudiantes porteños como las diferentes matrices culturales y políticas asociadas a esas iniciativas y a la condición del estudiante. Cuestiones sumamente importantes cuando se atiende a que, si bien muchas de esas iniciativas estudiantiles y matrices político-culturales no habían recibido de parte de la bibliografía crítica un análisis sistemático como el que propusimos, de todos modos ellas operaron activamente en la conformación de una cultura política estudiantil que se inscribió en el campo de las izquierdas argentinas e introdujo en ese campo una significativa renovación. En efecto, desde el estallido y la prolongación de la Reforma resultó indudable que el campo de las izquierdas contaba con un nuevo y animado -aunque por mucho tiempo nada numeroso- actor social, el estudiante organizado.

Para concluir subrayemos, entonces, algunos rasgos de la cultura política de la Reforma que aparecen más claros luego de nuestra interrogación desde la historia intelectual y la historia de los intelectuales. Las publicaciones periódicas de los estudiantes que relevamos pertenecen a tres tipos diversos: los órganos de los Centros de Estudiantes, las revistas culturales y las revistas políticas. Los primeros están marcados por el cambio anual de sus directores (elegidos por votación junto al presidente del CE), así sólo en algunos pocos casos -como en los números de Verbum dirigidos por Bermann y en los posteriores dirigidos por Probst y Cuccaro, por un lado, y en la aparición del órgano de la Facultad porteña de Derecho como Themis, primero, y como Revista Jurídica, bajo la dirección de Sanguinettiencontramos una línea editorial que exprese un proyecto estudiantil. Más bien, como señalaba Bermann, los órganos de los Centros de Estudiantes tendían a asimilarse a "canastos" que reunían los apuntes a estudiar por los alumnos para cada materia. Sin embargo, la perduración en el tiempo que -a diferencia de los otros dos tipos de publicaciones- tuvieron estas revistas nos permite registrar el persistente envío de colaboraciones de algunos estudiantes y profesores, así como la variación o permanencia de los temas abordados en las materias, pero sobre todo ese tipo de publicaciones nos permite recuperar la politización de los Centros de Estudiantes o bien la resistencia a esa politización.

Las revistas estudiantiles de cultura -entre las que Ideas fue pionera en el ambiente argentino- y las de política -que permanecían muy poco exploradas- son seguramente las fuentes más importantes para recuperar los itinerarios iniciales de intelectuales que luego realizaron una prolongada y activa intervención político-cultural, muchas veces lejana a esos 
inicios. En cuanto al arco de las derechas, nuestra investigación permite recuperar la intervención estudiantil de Korn Villafañe, Irazusta, Probst y Casares; en cuanto a las izquierdas, la de Palcos, Bermann, Gabriel, Solari, Scheimberg, Monner Sans, Del Mazo, Muñoz Montoro y Sanguinetti. Asimismo, esas revistas precisan la condición de "organizadores culturales" que asumieron entre los jóvenes figuras de una generación mayor, como Sáenz, Ingenieros, Palacios, Ugarte y Giusti, cuando aceptaron impartir conferencias organizadas por los grupos estudiantiles y redactaron saludos a las nuevas iniciativas juveniles, pero seguramente también cuando mantuvieron charlas informales -de las que, aunque son difíciles de recuperar, encontramos algunas referencias-.

A su vez, el análisis de las revistas estudiantiles que proyectaron una intervención claramente política nos permite dar cuenta de dos cuestiones diversas: por un lado, el papel señero que ejerció el periodismo político del semanario madrileño España y, por el otro, la diversa recepción de Barbusse que alentaron los grupos estudiantiles entre 1919 y 1922 en relación con los posteriores -recepción a la que debería sumarse el rol que en las décadas siguientes jugó Barbusse en la organización del antifascismo argentino-.

En cuanto a la dimensión política de la Reforma, el recorrido de nuestra investigación muestra que desde las huelgas estudiantiles de 1903 y 1905 hasta el partido americano de intelectuales y estudiantes que, entre 1925 y 1930, representó la ULA, pasando por los grupos nacionalistas del Centenario y los periódicos estudiantiles bolcheviques de 1919 y 1922, una fracción de jóvenes que estudiaba en la UBA -ayudados por intelectuales de la generación anterior- dispusieron diversas e innovadoras prácticas y representaciones que lograron señalar al estudiante como un tipo de intelectual con una cultura política particular, cultura que pronto se inscribiría en el campo de las izquierdas y lo reformularía.

Según vimos en el primer capítulo, la bibliografía crítica y algunas fuentes de época evidencian que la construcción de ese "estudiante" se inició en los primeros años del siglo $\mathrm{XX}$, cuando los jóvenes -en su mayoría hijos de la elite político-económica- acusaban a sus profesores de falta de autoridad moral por sus decisiones sobre la validez de los exámenes, los cupos de aprobación y el costo de los aranceles, y a partir de esa acusación se agruparon gremialmente y se vincularon con los estudiantes de otros países latinoamericanos y de países europeos desde rasgos aristocráticos que pronto serían cuestionados por las minorías reformistas.

Como estudiamos en el capítulo segundo, la aparición de grupos y revistas culturales 
en la década del diez traía importantes novedades en esa primera forma de socialización de los estudiantes porteños ligada al momento corporativo de la organización estudiantil. En efecto, con la conformación del Centro y de la revista Ariel de 1914, encontramos a un activo grupo de estudiantes, perteneciente a los sectores medios, que no conseguía que sus iniciativas, marcadas por el socialismo científico, interesaran a un gran número de jóvenes porteños. Pero, sin saberlo, esos peculiares arielistas hacían aprendizajes relativos a la intervención político-cultural que se revelarían significativos a partir de 1918, cuando varios de esos jóvenes se convertían en los promotores de la fracción porteña más radicalizada de la Reforma.

En efecto, con el horizonte político abierto por la Revolución Rusa y los conflictos estudiantiles en Córdoba, La Plata y Santa Fe, la organización estudiantil entraba en un momento político, pues un número mayor de jóvenes -que continuaba siendo pequeño en comparación con el número total de estudiantes- empezaba a interesarse por definir la posición de los estudiantes respecto de las cuestiones políticas y sociales. Y los arielistas de 1914, como Bermann, Isnardi, Scheimberg y Palcos, ya disponían -a través de su participación en ese grupo juvenil, pero también en el PS y en una sociabilidad que involucraba a intelectuales como Palacios, Ugarte, Giusti y sobre todo Ingenieros- de una mirada crítica sobre la universidad y la sociedad y de un conjunto de saberes prácticos acerca de cómo organizar instancias de discusión y difusión de esa mirada. Entre esas instancias se destacaron los manifiestos, los ciclos de conferencias, la edición de revistas y folletos, y la participación en asambleas y movilizaciones.

A su vez, encontramos que, en esos años previos a la Reforma, el poblado Ateneo de Estudiantes Universitarios realizaba un recorrido distinto al de esos arielistas socialistas, pues conformaba un grupo que para atraer a un número importante de estudiantes suspendía su acuerdo sobre la relación de los estudiantes con el socialismo. Sin embargo, este grupo "apolítico" centrado en la "formación integral" del estudiante, también sería clave en la inscripción de la Reforma en el campo de las izquierdas, pues varios de sus principales animadores -Monner Sans, del Mazo y Muñoz Montoro, fundamentalmente- se contarían entre los primeros líderes de la fracción porteña radicalizada de la Reforma.

La adhesión que realizaba el Ateneo a fines de 1918 a la izquierda estaba, además, marcada por el alejamiento de los ateneístas que habían fundado, a mediados de 1917, el Colegio Novecentista. Es que, aunque en un comienzo el Colegio promovió las filosofías 
antipositivistas y simpatizó con el socialismo ético propuesto por Alejandro Korn, desde fines de 1918 reunió a los jóvenes identificados con un nacionalismo aristocratizante y antisocialista. Así, junto al grupo editor de la Revista Nacional y de la Unión Universitaria, el Colegio Novecentista devino un promotor de la restricción de la Reforma a una renovación de los planes de estudio y de la asociación de la figura del estudiante al nacionalismo político. Y esta corriente, minoritaria pero activa, promoverá, durante las décadas siguientes, intensas disputas al interior de esa cultura política de la Reforma que se había inscrito en las izquierdas.

Junto a este fraccionamiento de los grupos estudiantiles en dos definiciones divergentes de la Reforma y de la figura del estudiante se generaron interesantes debates e iniciativas en el campo de los estudios filosóficos y en el de los estudios jurídicos. Según estudiamos en el capítulo cuarto, en rivalidad con la filosofía cientificista y social -que proponía Bermann desde Verbum y el CE de Filosofía y Letras, e Ingenieros desde la Revista de Filosofia-, el Colegio organizaba una "reacción antipositivista" preocupada por la recepción de la filosofía de Eugenio d'Ors y de corrientes neokantianas, y por la vinculación del discurso filosófico con una ética y una estética alejadas de los problemas sociales. Por su parte, analizamos en el capítulo séptimo que, en el campo del derecho, los grupos reformistas rivalizaron en su definición de la relación de las leyes con problemas sociales: mientras que para los nacionalistas una nueva legislación debía superar el individualismo para atender a las características nacionales y corporativas, para los izquierdistas la revisión legal no tenía marcas nacionales sino internacionales, pues debía recoger las innovaciones realizadas por la Revolución Rusa ante los problemas sociales propios de las sociedades capitalistas.

En el marco de este claro momento corporativo, las redefiniciones de los grupos estudiantiles generaron debates en torno de la dimensión cultural y política de la Reforma, pero también alentaron a otros jóvenes a fundar nuevos grupos y revistas que asumieron una posición radicalizada. En ese sentido, el análisis de ese olvidado periodismo político estudiantil que emprendimos en el capítulo sexto sugiere que, si bien los estudiantes argentinos -a distancia del caso peruano, chileno y boliviano- no tuvieron necesidad de enfrentarse violentamente al gobierno para conseguir la democratización de la universidad, de todos modos, entre ellos hubo una minoría que asumió posiciones revolucionarias en las que la Reforma Universitaria buscó definirse como un movimiento político ligado a la Revolución Rusa y a la convicción de que los estudiantes debían organizarse y agruparse junto al 
movimiento obrero para aportar la formación cultural necesaria para la emancipación. Más específicamente, la circulación de Clarín, Bases, Insurrexit, Hoy y Ariel de Montevideo, así como las iniciativas que esas revistas promovieron o saludaron, señalan una activa recepción de la Internacional del Pensamiento que Barbusse llamaba a formar para organizar una "Revolución en los Espíritus" que antecedía a la revolución socialista.

Esas intervenciones estudiantiles radicalizadas tendieron a desaparecer hacia 1922, esto es, cuando con la recuperación de la economía argentina y el reroceso del ciclo de protestas obreras rioplatense finalizaba el "trienio rojo". Pero, como mostró el capítulo octavo, entre los estudiantes y quienes comenzaban a ser los líderes reformistas, la recepción de la Internacional del Pensamiento y la adhesión a la Revolución Rusa prosiguió y se fue reelaborando. En efecto, entre 1923 y 1930 una fracción de jóvenes que había participado en las primeras organizaciones estudiantiles ligó la Reforma a un antiimperialismo latinoamericanista que se organizó, como lo proponía la Internacional de Barbusse, en un grupo de estudiantes e intelectuales encargados de las tareas culturales necesarias para la emancipación, lo que entonces era traducido, sobre todo, como la denuncia del imperialismo yanqui a través de la organización de actos, de la puesta en circulación de manifiestos y de la edición de revistas.

Un rasgo significativo, en tanto revela los aprendizajes realizados durante este momento político, es que los animadores de esa definición de la Reforma diversificaron sus intervenciones. Mientras que el boletín Renovación se proponía como una revista de amplia tirada compuesta de notas breves y de coyuntura sobre el antiimperialismo latinoamericano y el movimiento reformista, Sagitario se dirigía a los estudiantes y combinaba la prédica de Renovación con ensayos extensos de cultura y de política. A ello la Revista de Oriente sumó la información y promoción de la Revolución Rusa, Acción Universitaria las noticias breves del movimiento reformista y Cultura el intento de fundar una filial uruguaya de la ULA.

Si bien esta red, con múltiples contactos latinoamericanos, tendió a perder vitalidad hacia 1928 y se disgregó en 1930, sus enunciaciones perdurarán como un núcleo central de la cultura política de la Reforma y de la identificación del estudiante como ese nuevo actor social. Y fue sobre ese actor que a fines de la década del veinte ya se inscribía claramente en el campo de las izquierdas para revitalizarlas y reformularlas que nuestra investigación se propuso precisar -a través de las interrogaciones de la historia intelectual y la historia de los intelectuales- su complejo y conflictivo proceso de constitución. 


\section{ABREVIATURAS}

CE: Centro de Estudiantes

FUA: Federación Universitaria Argentina

FUBA: Federación Universitaria de Buenos Aires

FULP: Federación Universitaria de La Plata

PC: Partido Comunista

PS: Partido Socialista

PSI: Partido Socialista Internacional

UBA: Universidad de Buenos Aires

UCR: Unión Cívica Radical

ULA: Unión Latino-Americana

UNC: Universidad Nacional de Córdoba

UNLP: Universidad Nacional de La Plata

\section{BIBLIOGRAFÍA}

\section{Fuentes primarias}

\section{Revistas}

1918. Órgano de la nueva generación sudamericana (2 época de Acción Universitaria) (1925-1926), Buenos Aires.

Acción Universitaria (1924-1925), Buenos Aires.

Ariel. Revista del Centro de Estudiantes “Ariel” (1919-1931), Montevideo.

Ariel. Revista mensual de ciencias, letras y artes (1914-1915), Buenos Aires.

Bases. Tribuna de la juventud (1919-1920), Buenos Aires.

Boletín de la Federación Universitaria Argentina (1920-1922), Buenos Aires.

Boletín de la Federación Universitaria de Buenos Aires (1917-1918), Buenos Aires.

Centro Izquierda. Órgano del Partido Reformista Centro Izquierda de la Facultad de Derecho y C. S. (1925-1933), Buenos Aires.

Claridad (1923-1924), Lima.

Cuadernos del Colegio Novecentista, (1917-1919), Buenos Aires.

Cultura. Órgano de la Asociación Cultural Universitaria (1924-1926), Montevideo.

Documentos del progreso (1919-1922), Buenos Aires.

Hoy (1921), Buenos Aires.

Ideas. Órgano del Ateneo de Estudiantes Universitarios (1915-1919), Buenos Aires. 
Inicial (1923-1927), Buenos Aires.

Insurrexit. Revista Universitaria (1920-1921), Buenos Aires.

La Cureta. Órgano de la Agrupación de Estudiantes de Medicina "Pro Reformas" (19181925), Buenos Aires.

La Gaceta Universitaria (1918-?), Córdoba.

La Gaceta Universitaria (1919-?), Santa Fe.

La Internacional. Órgano del Partido Socialista Internacional (1919-1920), Buenos Aires.

La Montaña. Publicación de "Córdoba Libre” (1918), Córdoba.

Nosotros. Revista mensual de letras, arte, historia, filosofia y ciencias sociales (1907-1934), Buenos Aires.

Nuestra Época (1917), Lima.

Quaderns d'Estudi (1915-1923), Barcelona.

Renovación. Boletín mensual de ideas, libros y revistas de la América Latina (1923-1930), Buenos Aires.

Revista de Filosofia, Cultura, Ciencia y Educación (1915-1929), Buenos Aires (ed. facs. Ingenieros, José y Ponce, Aníbal (1999), Revista de Filosofía, Cultura, Ciencia y Educación, (1915-1929), Bernal, Universidad Nacional de Quilmes).

Sagitario. Revista de Humanidades (1925-1927), La Plata.

Themis. Órgano del Centro de Estudiantes de Derecho y Ciencias Sociales (1918-1919), Buenos Aires.

Unión Reformista. Órgano oficial del Partido Unión Reformista de la Facultad de Derecho y C. S. (1924), Buenos Aires.

Valoraciones (1923-1928), La Plata.

Verbum. Órgano del Centro de Estudiantes de la Facultad de Filosofía y Letras de Buenos Aires (1912-1948), Buenos Aires.

Via Libre (1919-1922), Buenos Aires.

\section{Fondos documentales}

Fondo documental sobre la Reforma Universitaria, Museo Histórico, Universidad del Litoral.

Fondo documental sobre la Reforma Universitaria, Casa de la Reforma Universitaria, Universidad Nacional de Córdoba.

Fondo personal Eugenio d'Ors, Arxiu Nacional de Catalunya, Barcelona.

Fondo personal Florentino Sanguinetti, CeDInCI, Buenos Aires.

Fondo personal Héctor Agosti, CeDInCI.

Fondo personal José Ingenieros, CeDInCI, Buenos Aires.

Fondo personal Roberto Giusti, CeDInCI. 


\section{Libros y artículos}

Alberini, Coriolano (1973 [1928]), "La reforma universitaria y la Facultad de Filosofía y Letras" en Escritos de Filosofía de la Educación y Pedagogía, Mendoza, Universidad Nacional de Cuyo, Facultad de Filosofía y Letras, Instituto de Filosofía.

Alberini, Coriolano (1981), Epistolario, dos tomos, Mendoza, Universidad Nacional de Cuyo, Facultad de Filosofía y Letras, Instituto de Filosofía.

Arévalo, Juan José (1975), La Argentina que yo viví (1927-1944), México, Carlos Balleza.

Bergson, Henri (1928), Introducción a la metafisica, La Plata, Valoraciones.

Bianchi, Alfredo (1932), "Veinticinco años de vida intelectual argentina", Buenos Aires, Nosotros.

Britos Muñoz, Alberto (1917), Impresiones, Buenos Aires, Publicaciones del Colegio Novecentista.

Caballero Martín, Ángel S. (1931), La Universidad en Santa Fe, Santa Fe, Imprenta de la Universidad.

Capdevila Arturo (1933), Una estudiantina de hacha y tiza, Buenos Aires, Selección, Cuadernos mensuales de cultura.

Carulla, Juan (1964), Al filo del medio siglo, Buenos Aires, Huemul.

Casares, Tomás (1918), La religión y el estado, Buenos Aires, Publicaciones del Colegio Novecentista.

Cossio, Carlos (1923), El problema universitario, Buenos Aires, Caracciolo y Plantié.

Cossio, Carlos (1927), La Reforma Universitaria o el problema de la Nueva Generación, Buenos Aires, Centro de Estudiantes de Derecho.

D'Ors, Eugenio (1920a), Las obras y los días, Buenos Aires, Cuadernos Mensuales de Ciencia y Letras, Ediciones Mínimas.

D'Ors, Eugenio (1920b), Del Glosario de Eugenio d'Ors, América Literaria, Cuadernos Quincenales de Arte, Ciencias y Letras, año I, núm. 2, Buenos Aires, Bayardo,1921.

D'Ors, Eugenio (1921), Introducción a la filosofía. Curso de Eugenio d'Ors sobre la doctrina de la inteligencia I, Buenos Aires, Publicación del Centro universitario, Agencia General de Librerías y Publicaciones.

De Sais, Teófilo (seud. Taborga, Benjamín) (1917), La otra arcadia, Buenos Aires, Publicaciones del Colegio Novecentista.

Del Mazo (comp.) (1926-1927), La Reforma Universitaria, compilación y notas a cargo de Gabriel del Mazo, 6 tomos, Buenos Aires, Círculo Médico Argentino y Centro de Estudiantes de Medicina, Federación Universitaria de Buenos Aires.

Del Mazo, Gabriel (1976), Vida de un político argentino. Convocatoria de recuerdos, Buenos Aires, Plus Ultra.

Del Mazo, Gabriel (comp.) (1941), La Reforma Universitaria, 3 tomos, La Plata, Centro de Estudiantes de Ingeniería.

Gabriel, José (1921), La educación filosófica, Buenos Aires, Ediciones del Centro de Derecho y Ciencias Sociales. 
Gálvez, Manuel (1922 [1916]), El Mal Metafísico, Buenos Aires, s/d.

Gálvez, Manuel (1961), En el mundo de los seres ficticios, Buenos Aires, Hachette.

García Morente, Manuel (1917), La filosofía de Henri Bergson, Madrid, Publicaciones de la Residencia Universitaria.

Giusti, Roberto (1965), Visto y vivido, Buenos Aires, Losada.

Haya de la Torre (1927), Por la emancipación de América Latina. Artículos, Mensajes, Discursos (1923-1927), Buenos Ares, Gleizer.

Ingenieros, José (1962 [1928]), Obras completas, ocho tomos, Buenos Aires, Mar Océano.

Irazusta, Julio (1975), Memorias (historia de un historiador a la fuerza), Buenos Aires, Ediciones Culturales Argentinas.

Korn Villafañe, Adolfo (1918), El irredimido, Buenos Aires, Publicaciones del Colegio Novecentista.

Korn Villafañe, Adolfo (1920), Incipit vita nova!, Alberdi, La nueva Argentona y La nueva Universidad, Buenos Aires, Edición de Revista Nacional y de la Unión Universitaria de Buenos Aires.

Korn Villafañe, Adolfo (1922), Disciplinas de la nueva generación. Cuaderno III: Los derechos proletarios (ensayo novecentista), La Plata (edición propia),

Korn Villafañe, Adolfo (1928), 1919 (Primera Parte), Buenos Aires, Publicaciones de la Editorial Reformista del Centro de Estudiantes de Derecho y Ciencias Sociales.

Korn Villafañe, Adolfo (1953), Paginas Novecentistas, La Plata, s/n.

Korn, Alejandro (1949), Obras completas, Buenos Aires, Claridad.

Korn, Alejandro (2012), Lecciones inéditas 1925, La Plata, Edulp.

Laferrère, Alfonso (1928), Literatura y política, Buenos Aires, Gleizer.

Mariátegui, José Carlos (1927), La Reforma Universitaria, Buenos Aires, Centro de Estudiantes de Ciencias Económicas, Federación Universitaria de Buenos Aires.

Mariátegui, Juan Carlos (1984), Correspondencia: 1915-1930, Lima, Amauta.

Martínez, Raúl (1920), Xenius. Una comedia satírica en 4 actor y 5 cuadros en verso, Buenos Aires, Coni.

Monner Sans, José María (1930), Historia del Ateneo Universitario (1914-1920), Buenos Aires, Mercatali (originalmente en Nosotros $\mathrm{n}^{\circ}$ 252, mayo de 1930),

Monner Sans, José María (1976), Breves recuerdos de un largo pretérito, Buenos Aires, Emecé.

Nalé Roxlo, Conrado (1978), Borrador de memorias, Buenos Aires, Plus Ultra, 1978.

Nicolai, Jorge (1925), La base biológica del relativismo científico y sus complementos absolutos, Córdoba, Editorial de la Revista de la Universidad Nacional de Córdoba.

Noé, Julio (1993), Escritos de un lector, Buenos Aires, Facultad de Filosofía y Letras.

Ortega y Gasset, José (1996), Meditación de nuestro tiempo, México, Fondo de Cultura Económica. 
Palacios, Alfredo (1920), El Nuevo Derecho: legislación del trabajo, Buenos Aires, Claridad.

Palacios, Alfredo (1922), La fatiga y sus proyecciones sociales, Buenos Aires, Rosso.

Palacios, Alfredo (1925), La Universidad Nueva, Buenos Aires, Gleizer.

Palacios, Alfredo (1961), Nuestra América y el imperialismo, Buenos Aires, Palestra.

Partido Socialista (1945), La Reforma Universitaria y el Partido Socialista, Buenos Aires, Partido Socialista.

Partido Socialista Internacional (1919), Historia del socialismo marxista en la República Argentina. Origen del Partido Socialista Internacional (Informe dirigido a la Internacional Socialista y a todos los Partidos Socialistas), Buenos Aires, Partido Socialista Internacional.

Ripa Alberdi, Héctor (1925), Obras completas, 2 tomos, La Plata, Grupo de estudiantes Renovación.

Roca, Deodoro (1956), El dificil tiempo nuevo, Buenos Aires, Lautaro.

Rohde, José Max, Cantos, Buenos Aires, Publicaciones del Colegio Novecentista.

Rojas Ricardo (1919), Alianza de la nueva generación. Profesión de fe, Buenos Aires, Imprenta Rinaldi.

S/d (2009), Pablo Vrillaud. Huellas de un líder estudiantil, Santa Fe, Universidad Nacional del litoral.

Sáenz, Mario (1917), La misión social de la juventud, Buenos Aires, Publicaciones del Ateneo de Estudiantes Universitarios.

Sánchez Viamonte, Carlos (1925), Derecho político, La Plata, Sagitario.

Sánchez Viamonte, Carlos (1926), Del taller universitario, La Plata, Sagitario.

Sánchez Viamonte, Carlos (1928), La cultura frante a la Universidad, Buenos Aires, Samet.

Sánchez Viamonte, Carlos (1929), Jornadas, Buenos Aires, Samet.

Sánchez Viamonte, Carlos (1971), Crónicas de ayer y de hoy, Buenos Aires, Carija.

Sanguinetti, Florentino (2002), Epistolario. 1921-1975, Buenos Aires, Colegio Nacional de Buenos Aires.

Solari, Juan Antonio (1976), Iniciación, Buenos Aires (edición privada),

Taborda, Saúl (2009), Escritos políticos. 1918-1934, Córdoba, Universidad Nacional de Córdoba.

Taborga, Benjamín (1924), Obras completas, 2 tomos, Buenos Aires, Calpe.

Toro, Gervasio (seud. Gonzalo Muñoz Montoro) (1919), Cosecha politica, Buenos Aires, s/d.

\section{Fuentes secundarias}

\section{Estudios metodológicos}

Altamirano, Carlos (2005), Para un programa de historia intelectual y otros ensayos. Buenos Aires, Siglo XXI.

Altamirano, Carlos (2007), Intelectuales. Notas de Investigación, Buenos Aires, Norma. 
Angenot, Marc (2010), El discurso social. Los límites históricos de lo pensable y lo decible, Buenos Aires, Siglo XXI.

Beigel, Fernanda (2003), "Las revistas culturales como documentos de la historia latinoamericana", Utopía y praxis latinoamericana, $\mathrm{n}^{\mathrm{o}} 20$.

Berstein, Serge (1999), "La cultura política", Rioux, Jean-Pierre y Sirinelli, Jean-Francois, Para una historia intelectual, México, Taurus.

Bourdieu, Pierre (2009), "Las condiciones sociales de la circulación de las ideas", Intelectuales, politica y poder, Buenos Aires, Eudeba.

Ciriza, Alejandra (2008), "Genealogías femeninas y memoria: a propósito de la cuestión de la ciudadanía de las mujeres", Ciriza (comp.), Intervenciones sobre ciudadanía de mujeres, politica y memoria. Perspectivas subalternas, Mendoza, Feminaria.

Collini, Stefan (2007), "Escuchar a escondidas entre los arbustos. Historia intelectual y crítica literaria", en Prismas, no 11. pp. 165-169.

Dosse, François (2006), "El modelo del caso Dreyfus en acción entre los historiadores franceses" en La marcha de las ideas. Historia de los intelectuales, historia intelectual, Universitat de Valencia. pp. 43-97.

Graciarena, Jorge (1971), "Clases medias y movimiento estudiantil. El Reformismo Argentino: 1918-1966”, Revista Mexicana de Sociología, n 1, UNAM, México. pp. 61100 .

Gramsci, Antonio (1973), "Los intelectuales y la organización de la cultura", Cultura y literatura, Barcelona, Península.

Jay, Martin (1990), “Debería la historia intelectual tomar un giro lingüístico”, Socialismofin-de-siècle, Buenos Aires, Nueva Visión.

Jay, Martin (2007), "Pretensiones desvergonzadas. La historia intelectual como juicio del pasado", en Prisma, n 1 . pp. 153-157.

Ory, Pascal y Jean François Sirinelli (1992), Les intellectuels in France. De l'affaire Dreyfus à nos jours, París, Armand Colin.

Palti, Elías (2007), "Lugares y no lugares de las ideas en América Latina”, El tiempo de la política, Buenos Aires, Siglo XXI.

Pluet-Despatin, Jacqueline (1999), "Une contribution a l'histoire des intellectuals: les revues" en Les Cahiers de L' IHTP, $\mathrm{n}^{\circ}$ 20, marzo de 1999, número especial "Sociabilites intellectuels : lieux, milieux, reseaux". pp. 125-136.

Sarlo, Beatriz (1992), "Intelectuales y revistas: razones de una práctica", América. Cahiers du CRICCAL n 9-10: Le discourse culturel dans le revue latino-americaines de 1940 à 1970, París, Presses de la Sorbonne Nouvelle- París III. pp. 9-16.

Tarcus, Horacio (2007b), "Introducción. La historia intelectual y la problemática de la recepción", Marx en la Argentina. Sus primeros lectores obreros, intelectuales y cientificos, Buenos Aires, Siglo XXI.

Williams, Raymond (1982), “The Bloomsbury Fraction”, Problems in Materialism in Culture, London, Verso.

Williams, Raymond (1997), Marxismo y literatura, Barcelona, Península. 


\section{Estudios sobre revistas culturales}

Alterman, Daniel (2004), "Inicial: del reformismo al protofascismo en el período de entreguerras (1923-1927)", El Matadero, no 3 (2 época). pp. 55-81.

Aznar, Luis (1963): “Valoraciones': órgano del grupo de estudiantes 'Renovación”", en AAVV, Universidad nueva y ámbitos culturales platenses, La Plata, Departamento de Letras.

Beigel, Fernanda (2005), La epopeya de una generación y una revista. Las redes editoriales de José Carlos Mariátegui en América Latina, Buenos Aires, Biblos.

Bergel, Martín, "Un caso de orientalismo invertido. La Revista de Oriente (1925-1926) y los modelos de relevo de la civilización occidental", Prismas, no 10, pp. pp-117.

Biagini, Hugo (1984), “Introducción”, La Revista de Filosofía. Cultura, Ciencia y Educación (1915-1929), Índices, Buenos Aires, Academia Nacional de Ciencias.

Bischoff, Efraín (s/d), "Periodismo cordobés de 1915 y...". Disponíble en línea: http://www.nosotroscordobeses.com.ar/xml/comments.aspx?art=829. Fecha de consulta: 06/10/2014.

Bontempo, María Paula (2012), Editorial Atlántida. Un continente de publicaciones, 19181936, Tesis de Doctorado en Historia, Universidad de San Andrés. Disponible en línea: http://hdl.handle.net/10908/879. Fecha de consulta: 05/05/2014.

Bustelo, Natalia (2013), "La construcción de la familia estudiantil de la Reforma Universitaria. El Ateneo de Estudiantes Universitarios (1914-1920) de Buenos Aires y sus publicaciones periódicas Ideas y Clarín”, Políticas de la memoria, n 14. pp. 63-78.

Carreño, Luciana (2012), "Relaciones culturales hispanoargentinas en la década del veinte. Universitarios, intelectuales y maestros, un diálogo a través de revistas estudiantiles", Circunstancia, $\mathrm{n}^{\mathrm{o}} 28$. s/d.

Castilla, Martín (2012), "Mariátegui ante la muerte de Ingenieros: apropiación simbólica y construcción de un paradigma intelectual", Políticas de la memoria, n 13. pp. 110-118.

De Diego, José Luis (comp.) (2006), Editores y políticas editoriales en Argentina, 1880-2000, Buenos Aires, Fondo de Cultura Económica.

Delgado, Verónica (2005), "Reconfiguraciones de debates y posiciones del campo literario en el semanario La Nota 1915-1920", Anclajes. Revista del Instituto de análisis semiótico del discurso, $\mathrm{n}^{\circ}$ 8. pp. 81-99.

Delgado, Verónica (2008), "España en Nosotros", $1^{\circ}$ Congreso Internacional de Literatura y Cultura Españolas Contemporáneas, 1 al 3 de octubre de 2008, La Plata. Disponible en: http://www.fuentesmemoria.fahce.unlp.edu.ar/trab eventos/ev.374/ev.374.pdf. Fecha de consulta: 01/07/2014.

Delgado, Verónica (2010), El nacimiento de la literatura argentina en las revistas literarias: 1896-1913, La Plata, Edulp.

Domínguez Rubio, Lucas (2012), "Las publicacioes periódicas libertarias argentinas en el acerco del CeDInCI: 'una hemerografía local esmerada"', Políticas de la memoria, $\mathrm{n}^{\mathrm{o}} 13$, pp. 23-48. 
Eujanian, Alejandro (1999), Historia de las revistas argentinas. La conquista del público (1900-1950), Buenos Aires, Asociación Argentina de Editores de Revistas.

Eujanian, Alejandro (2001), "El novecentismo argentino: reformismo y decadentismo. La revista CUADERNO del Colegio Novecentista, 1917-1919", Estudios Sociales, no 21. pp. 83-105.

Eujanián, Alejandro y Giordano, Alberto (2002), "Las revistas de izquierda y la función de la literatura: enseñanza y propaganda", Gramuglio, María Teresa (dir.), El imperio realista. Historia crítica de la literatura argentina, vol. 6, Buenos Aires, Emecé.

Fernández, Cristina Beatriz (2012), Ingenieros y los saberes modernos, Córdoba, Alción.

Gallasi, Gisela y López, Julieta (2011), "No hay día sin palabras. Estanislao Zeballos y la Revista de Derecho, Historia y Letras", Fernández, Sandra y Navarro, Fernando (comp.), Scribere est agere. Estanislao Zeballos en la vorágine de la modernidad argentina, Buenos Aires, La Quinta Pata.

Girbal-Blacha, Noemí y Quatrocchi-Woisson, Diana (1999), Cuando opinar es actuar. Revistas argentinas del siglo XX, Buenos Aires, Academia Nacional de ciencias.

Lafleur, Héctor R., Provenzano, Sergio D.,yAlonso, Fernando P. (con prólogo de Marcela Croce) (2006), Las revistas literarias argentinas.1893-1967, Buenos Aires, El 8vo loco.

Lobato, Mirta Zaida (2009), La prensa obrera. Buenos Aires y Montevideo, 1890-1958, Buenos Aires, Edhasa.

Longoni, Ana y Tarcus, Horacio (2001), "Crónica de un temprano e inusual encuentro entre la vanguardia artística y vanguardia política”, Ramona, $\mathrm{n}^{\circ} 16$. pp. 34-35.

Mailhe, Alejandra (2014), "El archivo de Archivos. Un latinoamericanismo eurocéntrico en la psiquiatría y la criminología de principios del siglo XX", Vária História (en prensa),

Pita González, Alexandra (2009), La Unión Latino Americana y el Boletín Renovación. Redes intelectuales y revistas culturales en la década de 1920, México, Colegio de México.

Prislei, Leticia (1992), "Itinerario intelectual y político de los maestros-ciudadanos (del fin de siglo a la década del '20)", Entrepasados, n 2. pp. 41-62.

Prislei, Leticia (1994), "Nosotros y la Reforma Universitaria”, Pensamiento Universitario, no 2. pp. 69-71.

Prislei, Leticia (1999a), "Nosotros y la Nueva Generación: una lectura sobre la tramitación de las diferencias entre los 20 y los 30”, Entrepasados, n 16. pp. 43-54.

Rivera, Jorge (1998), El escritor y la industria cultural, Buenos Aires, Atuel.

Rivera, Jorge y Romano, Eduardo (comp.) (1985), Medios de comunicación y cultura popular, Buenos Aires, Legasa.

Rodríguez, Fernando (1999), "Inicial, Sagitario y Valoraciones. Una aproximación a las letras y la política de la nueva generación”, Sosnowsky, Raúl (comp.), La cultura de un siglo. América Latina en sus revistas, Buenos Aires, Alianza.

Rodríguez, Fernando (2004), "INICIAL. El frente estético-ideológico de la nueva generación" en Inicial. Revista de la nueva generación (1923-1927), Bernal, Universidad Nacional de Quilmes. 
Rodríguez, Fernando y Vásquez, Karina (2002) "Gritos y susurros en el Jardín de Akademos. El movimiento estudiantil reformista en La Plata a través de sus revistas (1923-1927)", Intellèctus. Revista Eletrônica, $\mathrm{n}^{\mathrm{o}}$ 2. pp. 1-22. Disponible en línea: http://www.intellectus.uerj.br/Textos/Ano1n2/Texto\%20de\%20Fernando\%20Diego \%20Rodriguez $\% 20 \mathrm{y} \% 20$ Karina $\% 20$ Vasquez $\% 20$.pdf.

Romano, Eduardo (2004), Revolución en la Lectura. El discurso periodístico-literario de las primeras revistas ilustradas rioplatenses, Buenos Aires, Catálogos.

Romano, Eduardo (1984), "Las revistas argentinas de vanguardia en la década del '20" en Cuadernos Hispanoamericanos, $\mathrm{n}^{\circ}$ 411. pp. 177-200.

Romero, Luis (1995), "Una empresa cultural: los libros baratos", Gutiérrez, Leandro y Romero Luis (comp.), Sectores populares. Cultura y politica. Buenos Aires en la entreguerra, Buenos Aires, Sudamericana.

Rossi, Luis (1999), "Los proyectos intelectuales de José Ingenieros desde 1915 a 1925: la crisis del positivismo y la filosofía en la Argentina". Prólogo a la edición fascimilar de Revista de Filosofia, Cultura, Ciencia y Educación. Bernal, Universidad Nacional de Quilmes.

Saítta, Sylvia (1998), Regueros de tinta. El diario Crítica en la década del 1920, Buenos Aires, Sudamericana.

Sanguinetti, Horacio (2003), Trayectoria de una flecha. Las obras y los días de Deodoro Roca, Buenos Aires, Librería Histórica.

Sarlo, Beatriz (1983), "Vanguardia y criollismo: La Aventura de Martín Fierro", Altamirano, Carlos y Sarlo, Beatriz, Ensayos Argentinos. De Sarmiento a la Vanguardia, Buenos Aires, Centro Editor de América Latina/Colección Capítulo.

Shuway, Nicolás (1999), “Nosotros y el 'nosotros' de Nosotros", Sosnowsky, Raúl (comp.), La cultura de un siglo. América Latina en sus revistas, Buenos Aires, Alianza. pp. 165180.

Tarcus, Horacio (1997), “Insurrexit. Revista Universitaria (1920-1921)", Lote $\mathrm{n}^{\mathrm{o}} 8$. Disponible en línea: http://www.fernandopeirone.com.ar/Lote/nro008/rcinsurre.htm. Fecha de consulta: 01/07/2014.

Tarcus, Horacio (2004), "Revistas, intelectuales y formaciones culturales izquierdistas en la Argentina de los veinte", Revista Iberoamericana, no 208-209. pp. 749-772.

Tauro, Alberto (1994), "Sobre la aparición y proyección de NUESTRA ÉPOCA”, Nuestra época, ed. facsimilar, Lima, Amauta.

Torchia Estrada, Juan Carlos (1986), Alejandro Korn: profesión y vocación, México, UNAM.

Vásquez, Karina (2003), "De la modernidad y sus mapas. Revista de Occidente y la "nueva generación" en la Argentina- de los años veinte", Estudios interdisciplinarios de América Latina y el Caribe, $\mathrm{n}^{\circ} 1$. pp. 167-188.

Vásquez, Karina (2005), "Redes Intelectuais hispano-americanas na Argentina de 1920" en Tempo Social. Revista de Sociologia da USP, n 1. pp. 55-79.

\section{Estudios sobre la universidad y la Reforma Universitaria}


Ascolani, Adrián (2010), "Las Convenios Internacionales del Magisterio Americano de 1928 y 1930. Circulación de ideas sindicales y controversias político-ideológicas", Revista Basileira de Hisória da Educação, no 23. pp. 71-96.

Beigel, Fernanda (2003), El itinerario y la brújula. El vanguardismo estético-politico de José Carlos Mariátegui, Buenos Aires, Biblos.

Bergel, Martín (2009), "Nomadismo proselitista y revolución: notas para una caracterización del primer exilio aprista (1923-1931)", Estudios Interdisciplinarios de América Latina y el Caribe, $\mathrm{n}^{\mathrm{o}}$ 1. Disponible en línea: http://www1.tau.ac.il/eial/index.php? option $=$ com_content\&task $=$ blogcategory\&id=66\&Itemid=178. Fecha de Consulta: 24/04/2014.

Bergel, Martín (2012), "Flecha, o las animosas obsesiones de Deodoro Roca", Prefacio a Deodoro Roca. Obra Reunida. Tomo IV. Escritos Políticos, Córdoba, Editorial de la Universidad de Córdoba.

Bergel, Martín (2013), “Con el ojo izquierdo. Mirando a Bolivia, de Manuel Seoane. Viaje y deriva latinoamericana en la génesis del antiimperialismo APRISTA", Pita González, Alexandra (comp.), Intelectuales y antiimperialismo: entre la teoría y la practica, Colima, Universidad de Colima.

Bergel, Martín y Martínez Mazzola, Ricardo (2010), “América Latina como práctica. Modos de sociabilidad intelectual de los reformistas", Altamirano Carlos (comp.), Historia de los intelectuales en América Latina, tomo II, Buenos Aires, Katz.

Bermann, Gregorio (1946), Juventud de América, México, Cuadernos Americanos.

Biagini, Hugo (2001), "El movimiento estudiantil-reformista y sus mentores", en Biagini (comp.), La Universidad de La Plata y el movimiento estudiantil. Desde sus orígenes hasta 1930, La Plata, Edulp.

Biagini, Hugo (2012), La contracultura juvenil. De la emancipación a los indignados, Capital Cultural, Buenos Aires.

Bravo, María Celia (2008), "La ardua empresa de institucionalización de la Reforma en la Universidad Nacional de Tucumán. Huelgas y conclictors universitarios", La Gaceta Universitaria 1918-1919. Una mirada sobre el movimiento reformista en las universidades naconales, Buenos Aires, Eudeba.

Bravo, María Celia (comp.), Docentes, cientificos, artistas e intelectuales en la creación de la Universidad Nacional de Tucumán (1910-1060), Tucumán, Edunt.

Buchbinder, Pablo (1997), Historia de la Facultad de Filosofia y Letras. Universidad de Buenos Aires. Buenos Aires, Eudeba.

Buchbinder, Pablo (2000), "El movimiento reformista de 1918. una perspectiva desde la historia interna de la Universidad de Buenos Aires", Estudios Sociales, n 19. pp. 37-63.

Buchbinder, Pablo (2005), Historia de las universidades argentinas, Sudamericana, Buenos Aires.

Buchbinder, Pablo (2006), "De la impugnación al profesionalismo a la crítica de la Reforma: perspectivas de la universidad", Roldán, Darío (comp.), Crear la democracia. La Revista de Ciencias Políticas y el debate en torno de la República Verdadera, Buenos Aires, Fondo de Cultura Económica. 
Buchbinder, Pablo (2008), ¿Revolución en los claustros? La Reforma universitaria de 1918, Buenos Aires, Buenos Aires, Sudamericana.

Bustelo, Natalia (2012), "La juventud universitaria de Buenos Aires y su vínculo con las izquierdas en los inicios de la Reforma Universitaria (1914-1922)", Izquierdas, ${ }^{\circ} 16$. pp. 1-30.

Bustelo, Natalia (2014a), "Eugenio d'Ors en la Argentina. La recepción de la filosofía noucentista en la emergencia de la Reforma Universitaria (1916-1923): el Colegio Novecentista y la agrupación Córdoba Libre", Hispanismo Filosófico, no 19. pp. 33-54.

Bustelo, Natalia (2014b), "Las naves renovadoras españolas en el puerto de la Reforma Universitaria $\mathrm{La}$ recepción argentina de la Residencia Universitaria y del novecentismo", Actas de las Jornadas Interescuelas y Departamentos de Historia, Universidad Nacional de Cuyo, Mendoza, del 2 al 5 de octubre de 2013 (e. p.),

Bustelo, Natalia (2014c), "Enrique Barros", Proyecto Culturas Interiores. Un archivo de la cultura de Córdoba, http://culturasinteriores.ffyh.unc.edu.ar/inicio.jsp.

Bustelo, Natalia y Grisendi, Ezequiel (2014), "Alfons Goldschmidt", Proyecto Culturas Interiores. Un archivo de la cultura de Córdoba, http://culturasinteriores.ffyh.unc.edu.ar/ifi002.jsp. Fecha de consulta: 12/10/2914.

Caldelari, María y Funes, Patricia (1996), "La Reforma Universitaria (1918-1939), algunas proposiciones", Taller, no 2, Buenos Aires. pp. 87-99.

Castiñeiras, Julio (1940), Historia de la Universidad de La Plata, La Plata, Universidad Nacional de La Plata.

Cattáneo, Liliana y Rodrígez, Fernando (2000), "Ariel exasperado. Avatares de la Reforma Universitaria en la década del veinte", Prismas, no 4. pp. 47-58.

Caturelli, Alberto (1992), Historia de la filosofía en Córdoba, 1610-1983, 3 tomos, Córdoba, Buffignandi.

Chiroleu, Adriana (2000), "La reforma universitaria", Falcón, Ricardo (dir), Nueva historia argentina. Democracia, conflicto social y renovación de ideas (1916-1930), tomo VI, Buenos Aires, Sudamericana.

Ciria, Alberto y Sanguinetti, Horacio (1968), Los reformistas, Buenos Aires, Jorge Álvarez.

Compilación histórica de la Universidad Nacional de Tucumán. Desde su fundación hasta el 31.12.1936 (1964), Tucumán, Edunt.

Croce, Marcela (2010), "La Reforma Universitaria: de Córdoba a Lima y La Habana”, Croce, Marcela (comp.), Latinoamericanismo. Historia intelectual de una geografía inestable, Buenos Aires, Simurg. pp. 175-219.

Cúneo, Dardo (comp.) (1978), Reforma Universitaria, Caracas, Biblioteca Ayacucho.

Del Mazo, Gabriel (1955), El radicalismo. Notas sobre su historia y doctrina (1922-1952), Buenos Aires, Raigal.

Del Mazo, Gabriel (1955), Reforma Universitaria y cultura nacional, Buenos Aires, Raigal.

Del Mazo, Gabriel (1956[1938]), La Reforma Universitaria. Una conciencia de emancipación en desarrollo, Buenos Aires, Centro de Estudios Reforma Universitaria.

Del Mazo, Gabriel (1967), El movimiento de la Reforma Universitaria en América Latina. 
Sintesis explicatoria, Lima, Universidad Nacional Federico Villarreal.

Denot, Sol (2007), "La emergencia de las mujeres en la UBA. Transformaciones del campo intelectual y nuevos sujetos" en Actas del V Encuentro Nacional y II Latinoamericano "La Universidad como objeto de estudio", Tandil.

Devoto, Fernando (2002), Nacionalismo, fascismo y tradicionalismo en la Argentina moderna. Una historia, Buenos Aires, Siglo XXI.

Devoto, Fernando (2009), "Los proyectos de un grupo de intelectuales católicos argentinos entre las dos guerras" en Altamirano Carlos (comp.), Historia de los intelectuales en América latina, tomo II, Buenos Aires, Katz.

Dujovne, Alejandro (2004), "El partido Socialista de Córdoba y la Reforma Universitaria, 1917-1948”, González, Marcela (ed.), Poder político y estrategias sociales. Córdoba 1900-1950, Córdoba, EDUCC.

Ferrero, Roberto (1988), Saúl Taborda. De la Reforma Universitaria a la Revolución Nacional, Córdoba, Alción.

Finocchio, Silvia (comp.) (2001), Facultad de Humanidades y Ciencias de la Educación. Documentos y notas para su historia, La Plata, Al Margen-Edulp.

García, Susana (2006), “Ni solas ni resignadas: la participación femenina en las actividades científico-acadéicas de la Argentina en los inicios del siglo XX”, Cadernos Pagu, n 27. pp. 133-172.

Gómez, Alejandra (1995), No nos han vencido... Historia del Centro de Estudiantes de Derecho, UBA, Buenos Aires, Eudeba.

González Alberdi, Paulino (1968), Los estudiantes en el movimiento revolucionario a 50 años de la Reforma Universitaria, Buenos Aires, Medio Siglo.

González, Julio V. (1922), La Revolución Universitaria, Buenos Aires, Jesús Menéndez e hijos.

González, Julio V. (1927), La Reforma Universitaria, tomo I, Buenos Aires, Sagitario.

González, Julio V. (1931), Reflexiones de un argentino de la nueva generación, Buenos Aires, Editorial Buenos Aires.

Graciano, Osvaldo (2008), Entre la torre de Marfil y el compromiso político. Intelectuales de la izquierda argentina 1918- 1955, Bernal, Universidad Nacional de Quilmes.

Graciano, Osvaldo (2005), "Los proyectos científicos y las propuestas legislativas de los intelectuales socialistas para la renovación de la universidad argentina", Camarero, Hernán y Herrera, Carlos, El Partido Socialista en la Argentina, Buenos Aires, Prometeo.

Grisendi, Ezequiel (2012), "Un momento reformista. Emprendimientos de renovación intelectual en el espacio académico cordobés de los primeros años veintes", Actas de las VI Jornadas de Política y Cultura. Los intelectuales de la nación argentina, Córdoba, 5 y 6 de noviembre de 2012. Disponible en línea: http://www.eci.unc.edu.ar/archivos/politicaycultura/grisendie.pdf, fecha de consulta 26/09/2014.

Grisendi, Ezequiel (2013), "Carlos Astrada", Proyecto Culturas Interiores. Un archivo de la cultura de Córdoba, http://culturasinteriores.ffyh.unc.edu.ar/inicio.jsp. Fecha de 
consulta: 04/10/2014.

Grisendi, Ezequiel y Requena, Pablo (2009), "Dos eventos de recepción densa en la Universidad de Córdoba: los homenajes a Oswald Spengler (1924) y Henri Bergson (1936)", Actas de las V Jornadas de Historia de las Izquierdas ¿Las ideas fuera de lugar?, Buenos Aires, noviembre 2009. Disponible en línea: www.cedinci.org/VJornadas.htm. Fecha de consulta: 10/12/2012.

Halperín Donghi, Tulio (1962), La Universidad de Buenos Aires, Buenos Aires, Eudeba.

Hurtado, Gustavo (1990), Estudiantes: Reforma y revolución. Proyección y límites del movimiento estudiantil reformista (1918-1966), Buenos Aires, Cartago.

Justo, Liborio (2007), "La dimensión americanista del movimiento de la Reforma Universitaria", Los estados socialistas de América Latina, Buenos Aires, Grupo Editor Universitario.

Kerffeld, Daniel (2007), "La Liga Antiimperialista de las Américas: una construcción política entre el marxismo y el latinoamericanismo", Políticas de la memoria, n 6-7. pp. 143148 .

Lazarte, Juan (1935), Líneas y trayectorias de la Reforma Universitaria, Córdoba, Librería Ruiz.

Marcó del Pont, Luis (2005), Historia del movimiento estudiantil reformista, Córdoba, Universitas.

Mariátegui, José Carlos (2012), 7 ensayo de interpretación de la realidad peruana, Buenos Aires, Gorla.

Martínez Mazzola, Ricardo (2010), “¿El último manifiesto reformista? Democracia y socialismo en 'El último caudillo' de Carlos Sánchez Viamonte", Agüero, Ana Clarisa y García, Diego, Culturas interiores. Córdoba en la geografía nacional e internacional de la cultura, Córdoba, Al margen.

Melgar Bao, Ricardo (2010), "Las universidades populares en América Latina 1910-1925", Pacarina del sur, $\mathrm{n}^{\circ}$ 5. Disponible en línea: http://pacarinadelsur.com/home/amautas-yhorizontes/149-las-universidades-populares-en-america-latina-1910-1925. Fecha de consulta: 20/10/2014.

Moraga Valle, Fabio (2007), Muchachos casi silvestre: la Federación de Estudiantes y el movimiento estudiantil chileno, 1906-1936, Santiago de Chile, Ediciones de la Universidad de Chile.

Moraga Valle, Fabio (2014), "Reforma desde el sur, revolución desde el norte. El primer Congreso Internacional de Estudiantes de 1921", Estudios de Historia Moderna y Contemporánea, $\mathrm{n}^{\circ}$ 47. pp. 155-195.

Muñiz, Manuel (2015), "Del Caribe al Plata, del Plata al Caribe. Sobre la recepción en Cuba de José Ingenieros a partir de la correspondencia (1915-1925)", Políticas de la memoria, no 15. pp. 37-46.

Navarro, Mina (2009), Los jóvenes de la “Córdoba Libre”!, México, Nostromo.

Oddone Juan y Paris de Oddone, M. Blanca (2010), Historia de la Universidad de la República, Tomo II: La Universidad del militarismo a la crisis, Montevideo, Ediciones Universitarias. 
Ortíz, Tulio (2004), Historia de la Facultad de Derecho, Buenos Aires, Facultad de Derecho de la Universidad de Buenos Aires.

Portantiero, Juan Carlos (1978), Estudiantes y política en América Latina (1918-1938), El proceso de la Reforma Universitaria, México, Siglo XXI.

Puiggrós, Adriana (2006), ¿Qué pasó en la educación argentina. Breve historia desde la conquista hasta el presente?, Buenos Aires, Galerna.

Richard, Walter (1968), Students politics in Argentine, The universitri Reform and ist effects, 1918-1964, Nueva York, Basic Book.

Rimoldi, Marcelo (2010), La Reforma Universitaria en La Plata, La Plata, Institución Cultural de la Provincia de Buenos Aires.

Rodríguez, Fernando (2010), “Alfredo Brandán Caraffa. Un moderno intenso en la escena cultural reformista”, Agüero, Ana Clarisa y García, Diego, Culturas interiores. Córdoba en la geografía nacional e internacional de la cultura, Córdoba, Al margen.

Ruvituso, Clara (2010), "Pensamiento filosófico, inserción universitaria e idearios políticos en Alejandro Korn y Coriolano Alberini”, Soprano, Germán, Graciano, Osvaldo y Federic, Sabina (comp.), El Estado argentino y las profesiones liberales, académicas y armadas, Buenos Aires, Porhistoria.

Sanguinetti, Horacio (2013), "La verdad acerca de la creación del Instituto de Enseñanza Práctica", Academia. Revista sobre enseñanza del derecho, $\mathrm{n}^{\circ} 21$, disponible en línea: http://www.derecho.uba.ar/publicaciones/rev academia/revistas/21/la-verdad-acerca-dela-creacion-del-instituto-de-ensenanza-practica.pdf),

Schenone, Gabriela (2009), "La Reforma Universitaria en sus estatutos. Avances y retrocesos 1918-1925", Actas del VI Encuentro Interdisciplinario de ciencias sociales y humanas, Facultad de Filosofía y Humanidades, Universidad Nacional de Córdoba.

Sessa, Leandro (2013), "Aprismo y apristas en Argentina: derivas de una experiencia antiimperialista en la 'encrucijada' ideológica y pol'ítica de los años treinta", Tesis doctoral en Historia, Universidad Nacional de La Plata. Disponible en línea: www.memoria.fahce.unlp.edu.ar/tesis/te.824/te.824.pdf. Fecha de consulta: 06/10/2014.

Tarcus, Horacio (2000), "Hipólito Etchebéhère y Mika Feldman, de la reforma universitaria a la guerra civil española", Rodaballo, $\mathrm{n}^{\mathrm{o}}$ 11-12. Disponible en línea: http://www.fundanin.org/tarcus2.htm. Fecha de consulta: 12/09/2013.

Tarcus, Horacio (2001), Mariátegui en la Argentina o las políticas culturales de Samuel Glusberg, Buenos Aires, El cielo por asalto.

Terán, Oscar (1997), “Modernos intensos en los veintes”, Prismas, n 1. pp. 91-103.

Terán, Oscar (1998a), "La Reforma Universitaria en el clima de ideas de 'la nueva sensibilidad"', Espacios, n 24. pp. 3-7.

Universidad Nacional del Litoral (2009a), La Universidad Nacional del Litoral. Antecedentes de su creación, Santa Fe, Universidad Nacional del Litoral.

Universidad Nacional del Litoral (2009b), Creación de la Universidad Nacional del Litoral (crónica retrospectiva). Apéndice documental complementario, Santa Fe, Universidad Nacional del Litoral.

Vallejo, Gustavo (2007), Escenarios de la cultura científica argentina. Ciudad y universidad 
(1882-1955), Madrid, Consejo superior de Investigaciones científicas.

Vallejos, Gustavo (2001), "El culto de lo bello", Biagini (comp.), La Universidad de La Plata y el movimiento estudiantil. Desde sus orígenes hasta 1930, La Plata, Edulp.

Van Aken, Mark (1990), Los militantes: una historia del movimiento estudiantil universitario uruguayo, Fundación de Cultura Universitaria, Montevideo.

Vera de Flachs, María Cristina (2006b), "Un precedente de la Reforma del '18. El I Congreso Internacional de Estudiantes Americanos. Montevideo 1908", Vera de Flachs, María Cristina (comp.), Movimientos estudiantiles en América y Europa, Tomo II, Córdoba, Junta Provincial de Historia de Córdoba.

Vidal, Gardenia (s/f), "La Reforma Universitaria de 1918 y la Unión Cívica Radical”. Disponible en línea: http://historiapolitica.com/datos/biblioteca/Vidal.pdf.

Villavicencio, Susana (1998), "José Ingenieros: una filosofía de la Reforma", Espacios, n 24. pp. 33-39.

\section{Estudios sobre historia intelectual y política en Latinoamérica}

Acri, Martín Alberto y Cácerez, María del Carmen (2011), La educación libertaria en la Argentina y en México (1861-1945), Buenos Aires, Utopía Libertaria.

Agüero, Ana Clarisa (2010), Local / nacional. Córdoba: cultura urbana, contacto con Buenos Aires y lugares relativos en el mapa cultural argentino (1880-1918), Tesis de doctorado en Historia, mímeo.

Alberini, Coriolano (1981), Precisiones sobre la evolución del pensamiento argentino. Buenos Aires, Editorial Docencia.

Altamirano, Carlos (1983), "La fundación de la literatura argentina", Altamirano, Carlos y Sarlo, Beatriz, Ensayos argentinos. De Sarmiento a la Vanguardia, Buenos Aires, Centro Editor de América Latina/Colección Capítulo.

Aricó, José (1999), La hipótesis de Justo. Escritos sobre el socialismo en América Larina, Buenos Aires, Sudamericana.

Asociación "Universitarias Argentinas" (2010), Centenario del Primer Congreso Femenino Internacional de la República Argentina: mayo de 1910, Buenos Aires, Comité Organizador del II Congreso Feminista Internacional de la República Argentina

Barrancos, Dora (1991), Educación, cultura y trabajadores (1890-1930), Buenos Aires, CEAL.

Barrancos, Dora (1996), La escena iluminada. Ciencia para trabajadores, 1890-1930, Buenos Aires, Plus Ultra.

Barrancos, Dora (2007), Las mujeres en la sociedad argentina. Una historia de cinco siglo, Buenos Aires, Sudamericana.

Benedetti, Mario (1966), Genio y figura de José Enrique Rodó, Buenos Aires, Eudeba.

Biagini, Hugo (1995), Intelectuales y políticos españoles a comienzos de la inmigración masiva, Buenos Aires, CEAL.

Bilsky, Edgardo (1984), La Semana Trágica. Buenos Aires, CEAL. 
Bisso, Andrés (2007), El antifascismo argentino. Selección documental y estudio preliminar, Buenos Aires, CeDInCI.

Burkart, Mara (2007), "La prensa de humor político en Argentina. De El Mosquito a Tía Vicenta", Revista electrónica Question. $\mathrm{n}^{\mathrm{o}}$ 15. Disponible en línea: www.perio.unlp.edu.ar/question. Fecha de consulta: 20/10/2013.

Bustelo, Natalia y Celentano, Adrián (2012), “'Estudiantes y populismo' de Juan Carlos Portantiero. Presentación", en coautoría con Adrián Celentano, en Los trabajos y los días. Revista de la cátedra de Historia Socioeconómica de América Latina y Argentina de la Facultad de Trabajo Social de la UNLP n 3. pp. 87-94.

Caetano, Gerardo (2011), “José Vasconcelos y su paso por el Uruguay de los años veinte”, Secuencia, $\mathrm{n}^{\circ} 80$, pp. 109-113.

Caetano, Gerardo y Rilla, Jorge (1986), El joven Quijano, 1900-1933: izquierda nacional y conciencia crítica, Montevideo, Ediciones de la Banda Oriental.

Campione, Daniel (2005), "La fundación del Partido Socialista Internacional", Camarero, Hernán y Herrera, Carlos, El Partido Socialista en la Argentina, Buenos Aires, Prometeo.

Campione, Daniel (2007), "El Partido Comunista de la Argentina. Apuntes sobre su trayectoria", Cocheiro, Elvira, Modonesi, Massimo y Crespo, Horacio (comp.), El comunismo: otras miradas desde América Latina, México, UNAM.

Campomar, Marta (2009), Ortega y Gasset en la curva histórica de la Institución Cultural Española, Madrid, Biblioteca Nueva.

Castillo, Horacio (1999), Ricardo Rojas, Buenos Aires, Academia Argentina de letras.

Celentano, Adrián (2005), "Determinismo y psiquiatría: una lectura de la tesis de Gregorio Bermann", Darwinismo social y eugenesia en el mundo latino, Buenos Aires, Biblos.

Celentano, Adrián (2006a), "Psiquiatría, psicología y política de izquierdas en Argentina del siglo XX: la historia intelectual de Gregorio Bermann", História Unisinos, n ${ }^{\circ} 10$. pp. 53-64.

Celentano, Adrián (2006b), "Ideas e intelectuales en la formación de una red sudamericana antifascista”, Literatura y Lingüística, n 17. pp. 195-218.

Cobière, Emilio (1984), Orígenes del comunismo argentino: el Partido Socialista Internacional, Buenos Aires, CEAL.

Cossio del Pomar, Felipe (1961), Víctor Raúl, México, Cultura.

Crespo, Horacio (2010), “La Internacional Comunista”, Pita González, Alexandra (comp.), Intelectuales y antiimperialismo: entre la teoría y la practica, Colima, Universidad de Colima.

De Giovanni, Fernando (2007), Los textos de la patria. Nacionalismo, politicas culturales y canon en la Argentina. Rosario, Viterbo.

De la Cruz Agañaraz, Juan (2007), El freudismo reformista 1926-1979. en la literatura, la medicina, la política y la psicología, Córdoba, Brujas.

De Lucía, Daniel (2004), “¡Ni capitalismo rentista ni socialismo! Los liberales georgistas”, Biagini, Hugo y Roig. Arturo (comp.), El pensamiento alternativo en la Argentina del 
siglo XX. tomo I, Buenos Aires, Biblos.

De Lucía, Daniel (2012), “Liberalismo y revolución: los georgistas argentinos y la revolución rusa", Pacarina del Sur, $\mathrm{n}^{\mathrm{o}}$ 10. Disponible en línea: http://www.pacarinadelsur.com/home/oleajes/385-liberalismo-y-revolucion-losgeorgistas-argentinos-y-la-revolucion-rusa. Fecha de consulta: 18/09/2014.

Devés Valdés, Eduardo (2007), Redes intelectuales en América Latina. Hacia la constitución de una comunidad intelectual, Santiago de Chile, Colección Idea, Instituto de estudios avanzados, Universidad de Santiago de Chile.

Doeswijk, Andreas (2013), Los anarco-bolcheviques rioplatenses, Buenos Aires, CeDInCI Editores.

Dotti, Eugenio (1900), "Las hermanas-enemigas. Ciencia y ética en el positivismo del Centenario", Las vetas del texto. Una lectura filosófica de Alberdi, los positivistas, Juan B. Justo, Buenos Aires, Puntosur.

Dotti, Eugenio (1992), La Letra gótica. Recepción de Kant en Argentina desde el romanticismo hasta el treinta, Buenos Aires, FFyL.

Farré, Luis (1958), Cincuenta años de filosofía en Argentina. Buenos Aires, Ediciones Peuser.

Fernández Cordero, Laura (2014), "The anarchist wager of sexual emancipation in Argentina, 1900-1930", de Loforcade, Geoffroy y Shaffer, Kirwin (comp.), In defiance of boundaries: anarchism in Latin American History (en prensa),

Funes, Patricia (2006), Salvar la nación. Intelectuales, cultura y política en los años veinte latinoamericanos, Buenos Aires, Prometeo.

Gasquet, Alex (2007), Oriente al sur. El orientalismo literario argentino de Esteban Echeverría a Roberto Arlt. Buenos Aires, Eudeba.

Gilbal-Blacha, Noemí y Ospital, María Silvia (1986), "Elite, cuestión social y apertura política en la Argentina (1910-1930): La propuesta del Museo Social Argentino", Revista de Indias, $\mathrm{n}^{\circ} 178$. pp. 609-625.

Grisendi, Ezequiel (2014), "Contra nuestro feudalismo: debates políticos y redes intelectuales del liberalismo georgista (Córdoba, 1914-1923)", II Congreso de Historia Intelectual de América Latina, Buenos Aires, 12 al 14 de noviembre de 2014 (mímeo).

Godio, Julio (1986), La Semana Trágica. Buenos Aires, Hyspamérica.

Halperín Donghi, Tulio (2007), Vida y Muerte de la Republica Verdadera (1910-1930), Biblioteca del pensamiento argentino, tomo IV, Buenos Aires, Ariel.

Herrera, Carlos (2001), "Socialismo jurídico y reformismo político en Carlos Sánchez Viamonte", Revista de Estudios políticos (Nueva época), no 113. pp. 295-324.

Jasinski, Alejandro (2013), Revuelta obrera y masacre en La Foresta. Sindicalización y violencia en tiempos de Yrigoyen, Buenos Aires, Biblos.

Jeifets, Lazar, Víctor Jeifets y Meter Huber (2004), La Internacional comunista y América Latina, 1919-1943. Diccionario biográfico, Moscú.

Kohan, Néstor (2000), De Ingenieros al Che, Buenos Aires Biblos.

Korn, Guillermo (1963), "El teatro de grupo 'Renovación"”, AAVV, Universidad nueva y ámbitos culturales platenses, La Plata, Universidad Nacional de La Plata. 
Lértora Mendoza, Celina (s/d), "Carlos Cossio ante la condición humana". Disponible en línea: http://www.ensayistas.org/critica/generales/C-H/argentina/cossio.htm. Fecha de consulta: 08/10/2914.

List Avner, Mara (2006), La Semana Trágica de enero 1919 y los judíos: mitos y realidades. Disponible en línea: http://www.raoulwallenberg.net/wpcontent/files flutter/1293026680lasemanatragica.pdf. Fecha de consulta: 24/07/2014.

Losada, Leandro (2008), La alta sociedad en la Buenos Aires de la Belle Époque, Buenos Aires, Siglo XXI.

Lucena, Daniela (2007), "Por el hambre en Rusia. Una ofrenda de los artistas argentinos al pueblo de los soviets", Sociedad, $\mathrm{n}^{\mathrm{o}} 26$. Disponible en línea: http://www.sociales.uba.ar/wp-content/uploads/6.-Por-el-hambre-en-Rusia-N \%C2\%B026.pdf. Fecha de consulta: 24/07/2014.

Daniel Lvovich, Nacionalismo y antisemitismo en la Argentina, Buenos Aires, Vergara, 2003.

Mailhe, Alejandra (2013), "'El laberinto de la soledad' del genio, o las paradojas de El hombre mediocre", Varia historia, $\mathrm{n}^{\mathrm{o}}$ 49. pp. 197-216 . Disponible en: http://www.scielo.br/scielo.php?script=sci_arttext\&pid=S010487752013000100010\&lng=pt\&nrm=iso. Fecha de consulta: 24/07/2014.

Medin, Tzin (1994), Ortega y Gasset en la cultura hispanoamericana, México, Fondo de Cultura Economica.

Melgar Bao, Ricardo (2007), "Un neobolivarianismo antiimperialista: La Unión Centro Sud Americana y de las Antillas (UCSAYA)", Políticas de la memoria, nº 6-7. pp. 149-163.

Melgar Bao, Ricardo (2012) "Trotskistas y apristas exiliados en ciudad de México: Afinidades y rupturas", Pacarina del Sur, $\mathrm{n}^{\mathrm{o}}$ 10. Disponible en línea: http://www.pacarinadelsur.com/home/mallas/382-trotskistas-y-apristas-afinidades-yrupturas?ml=1. Fecha de consulta: 12/10/2014.

Merbilhaá, Margarita (2009), Trayectoria intelectual y literaria de Manuel Ugarte (18951924), Tesis presentada para la obtención del grado de Doctora en Letras, Universidad Nacional de La Plata. Disponible en línea: http://www.memoria.fahce.unlp.edu.ar/tesis/te.462/te.462.pdf. Fecha de consulta: $16 / 07 / 2014$.

Newton, Jorge (1968), Historia del Club Universitario de Buenos Aires.1918-1968, Buenos Aires, CUBA.

Pasolini, Ricardo (2005), "El nacimiento de una sensibilidad política. Cultura antifascista, comunismo y nación en la Argentina: entre la AIAPE y el Congreso Argentino de la Cultura, 1935-1955", Desarrollo económico, no 179, pp. 403-433.

Pasolini, Ricardo (2007), "Crítica erudita y exaltacion antifascista. Acerca de la obra de José Ingenieros 'historiador'”, Prismas, $\mathrm{n}^{\mathrm{o}}$ 11. pp. 87-107.

Penco, Wilfredo (2010), "La revisión de Ariel en el Uruguay de los años veintes", Penco, Wilfredo et al., Los cien años de "Ariel", Biblioteca Virtual Miguel de Cervantes, Alicante.

Persello, Ana Virginia (2004), El partido radical. Gobierno y oposición, 1916-1943, Buenos Aires, Siglo XXI. 
Petra, Adriana (2013), "Revolução e guerra. Formas de comrpomisso e trajetórias intelectuais na conformação de um espaço cultural comunista na Argentina (1920-1935)", Perseu. História, memória e política, $\mathrm{n}^{\circ}$ 9, 11-45.

Pita González, Alexandra (2010), "La LASA: opiniones y representaciones a través de la prensa periódica (1926-1929)", Pita González, Alexandra (comp.), Intelectuales y antiimperialismo: entre la teoría y la practica, Colima, Universidad de Colima.

Pita González, Alexandra (2012), "De la Liga Racionalista a cómo educa el Estado asu hijo: el itinerario de Julio Barcos", Revista Historia, no 65-66. pp. 123-141.

Pita, Alexandra y Brumo, Paula (2009), "Defendiendo su propia emoción. Una relectura de $E l$ hombre mediocre de José Ingenieros", Weinberg, Liliana (comp.), Estrategias del pensar I, México, UNAM. pp. 189-229.

Prieto, Adolfo (comp.) (1968), El periódico Martín Fierro, Buenos Aires, Galerna.

Prieto, Osvaldo (2003), Arielismo y socialismo en Río Cuarto, Universidad Nacional de Río Cuarto, Río Cuarto.

Prislei, Leticia (1999b), “Tres ensayos y una encuesta en busca de la nación”, Prismas, no 3. pp. 165-189.

Pucciarelli, Alfredo y Tortti, María Cristina (1995), "La construcción de la hegemonía compartida: el enfrentamiento entre neutralistas, rupturistas e yrigoyenistas", Ansaldi, Waldo y Pucciarelli Alfredo y Villarruel, José (comp.), Representaciones inconclusas. Las clases, los actores y los discursos de la memoria, 1912-1946, Buenos Aires, Biblos.

Quintanilla, Susana (2008), "Nosotros". La juventud del Ateneo de México, México, Tusquets.

Rama, Ángel (1985), "La canción de oro de la clase media emergente". Las máscaras democráticas del modernismo, Montevideo, Arca.

Rama, Ángel (2008), Transculturación narrativa en América Latina, Buenos Aires, El Andariego.

Ramaglia, Dante (2010), "Condiciones y límites del proceso de institucionalización de la cultura filosófica argentina a comienzos del siglo XX", Solar, no 6. pp. 13-39.

Ramos, Julio (2003), Desencuentros de la mdoernidad en América Latina: literatura y política en el siglo XIX, Buenos Aires, Siglo XXI.

Real de Azúa, Carlos (1975), "Ariel, libro porteño", Historia visible e historia esotérica, Montevideo, Arca-Calicanto.

Real de Azúa, Carlos (1986), "Modernismo e ideologías", Punto de vista, no 28, separata.

Real de Azúa, Carlos (2010), Significación y trascendencia literario-filosófica de "Ariel” en América entre 1900 y 1950, Biblioteca virtual Miguel de Cervantes, Alicante.

Rock, David (1992), El radicalismo argentin,. Buenos Aires, Amorurtu.

Roig, Arturo (2006), Los krausistas argentino, Buenos Aires, El Andariego.

Romero, José Luis (1965), El desarrollo de las ideas en la sociedad argentina del siglo XX, Buenos Aires, Fondo de Cultura Económica.

Sarlo, Beatriz (1988), Una modernidad periférica: Buenos Aires 1920 y 1930, Buenos Aires, 
Nueva Visión.

Sosa de Newton, Lily (1986), Diccionario biográfico de mujeres argentinas, Buenos Aires, Plus Ultra.

Suriano, Juan (2004), Anarquistas. Cultura y política libertaria en Buenos Aires, 1890-1910. Buenos Aires, Manantial.

Taracena, Arriola (2006), "La Asociación General de Estudiantes", Calvo, Thomas y Musset, Alain (comp.) Le travail et l'argent, México, Centro de estudios mexicanos y centroamericanos.

Tarcus, Horacio (dir.) (2007a), Diccionario biográfico de la izquierda argentina. De los anarquistas a la "nueva izquierda" (1870-1976), Buenos Aires, Emecé.

Tarcus, Horacio (2007b), Marx en la Argentina. Sus primeros lectores obreros, intelectuales y cientificos, Buenos Aires, Siglo XXI.

Tarcus, Horacio (2009) (ed.), Cartas de una hermandad. Leopoldo Lugones, Horacio Quiroga, Ezequiel Martinez Estrada, Luis Franco, Samuel Glusberg. Buenos Aires, Emecé.

Tarcus, Horacio (2011), Biografía de Ingenieros. José Ingenieros. Guía y catálogo, Buenos Aires, Fondo de Archivo, CeDInCI.

Tarcus, Horacio (2012), "Espigando la correspondencia de José Ingenieros. Modernismo y socialismo fin-de-siècle", Políticas de la memoria, no 10/11/12. pp. 97-122.

Tato, María Inés (2007), "Ciudadanos en movimiento: la sociedad porteña y la Primera Guerra Mundial”, $2^{\circ}$ Jornadas sobre la política en Buenos Aires en el siglo XX, Tandil. Disponible en línea: www.historiapolítica.com. Fecha de consulta: 04/04/2014.

Terán, Oscar (1986a), En busca de la ideología argentina, Buenos Aires, Catálogo.

Terán, Oscar (1986b), José Ingenieros: Pensar la nación, Buenos Aires, Alianza.

Terán, Oscar (1998b), “Carlos Octavio Bunge: entre el científico y el político”, Prismas, n 2. pp. 95-110.

Terán, Oscar (2008), Historia de las ideas en la Argentina. Diez lecciones iniciales, 18101980, Buenos Aires, Siglo XXI.

Terán, Oscar (2009), "El Ariel de Rodó o cómo entrar en la modernidad sin perder el alma", Weinberg, Liliana (comp.), Estrategias del pensar I, México, UNAM.

Tortti, Cristina (2009), El “viejo" Partido Socialista y los orígenes de la "nueva” izquierda (1955-1965), Buenos Aires, Prometeo.

Van Aken, Mark (1990), Los militantes: una historia del movimiento estudiantil universitario uruguayo, Fundación de Cultura Universitaria, Montevideo.

Vásquez, Karina (2000), “Intelectuales y política: la 'nueva generación' en los primeros años de la Reforma Universitaria” en Prismas, no 4. pp. 59-75.

Viñas, David (1964), Literatura argentina y realidad politica, Buenos Aires, Jorge Álvarez.

Yankelevich, Pablo (1999), "En la retaguardia de la revolución mexicana. Propaganda y propagandistas mexicanos en América Latina. 1914-1920”, Boletín americanista, no 49. pp. $245-278$. 
Yankelevich, Pablo (2003), La revolución mexicana en América Latina. Intereses políticos e itinerarios intelectuales, Instituto Mora, México.

Yukelson, Ana (2005), "Raúl V. Martínez. Idealismo y realismo en una comedia de intriga: Xenius" en Pelletieri, Osvaldo y Burgos, Nidia (comp.), Historia del teatro en las provincias, tomo I, Buenos Aires, Galerna.

Zimmerman, Eduardo (1994), Los liberales reformistas. La cuestión social en la Argentina 1890-1916, Buenos Aires, Sudamericana.

\section{Estudios sobre pensamiento europeo}

Barrio, Ángeles (2001), "Estudio preliminar”, Araquistain, Luis, La revista España y la crisis del estado liberal, Santander, Cantabria 4 estaciones.

Cacho Viu, Vicente (1997), Revisión de Eugenio d'Ors, Madrid, Quaderns crema.

Fisher, David James (2012), "La internacional de los intelectuales", Politicas de la memoria, $\mathrm{n}^{\circ} 10 / 11 / 12$. pp. 179-192.

García Queipo de Llanos (1988), Los intelectuales y la dictadura de Primo Rivera, Madrid, Alianza.

Presas, Mario (1986), "La fenomenología inicial de Ortega y su superación en el sistema de la razón vital”. Revista de Filosofia y Teoría Política, no 26-27. pp. 145-150.

Ribagorda, Álvaro (2011), El coro de Babel. Las actividades culturales de la Residencia de Estudiantes, Madrid, Publicaciones de la Residencia de Estudiantes. 